\title{
Projected Benefits of Federal Energy Efficiency and Renewable Energy Programs FY 2008 Budget Request
}

Bringing you a prosperous future where energy is clean, abundant, reliable, and affordable

\section{Prepared by the}

NPEE National Renewable Energy Laboratory 


\section{Projected Benefits of Federal Energy Efficiency and Renewable Energy Programs: FY 2008 Budget Request}

Prepared under Task No. SA07.2300

\section{Technical Report} NREL/TP-640-41347

March 2007

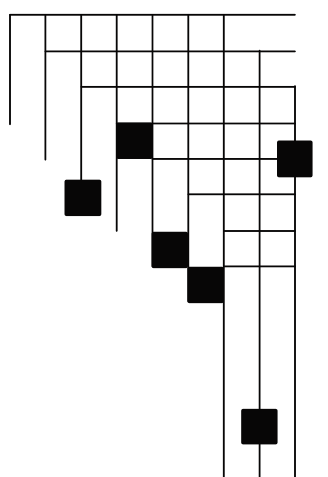




\section{NOTICE}

This report was prepared as an account of work sponsored by an agency of the United States government. Neither the United States government nor any agency thereof, nor any of their employees, makes any warranty, express or implied, or assumes any legal liability or responsibility for the accuracy, completeness, or usefulness of any information, apparatus, product, or process disclosed, or represents that its use would not infringe privately owned rights. Reference herein to any specific commercial product, process, or service by trade name, trademark, manufacturer, or otherwise does not necessarily constitute or imply its endorsement, recommendation, or favoring by the United States government or any agency thereof. The views and opinions of authors expressed herein do not necessarily state or reflect those of the United States government or any agency thereof.

Available electronically at http://www.osti.gov/bridge

Available for a processing fee to U.S. Department of Energy and its contractors, in paper, from:

U.S. Department of Energy

Office of Scientific and Technical Information

P.O. Box 62

Oak Ridge, TN 37831-0062

phone: 865.576 .8401

fax: 865.576 .5728

email: mailto:reports@adonis.osti.gov

Available for sale to the public, in paper, from:

U.S. Department of Commerce

National Technical Information Service

5285 Port Royal Road

Springfield, VA 22161

phone: 800.553.6847

fax: 703.605.6900

email: orders@ntis.fedworld.gov

online ordering: http://www.ntis.gov/ordering.htm 


\section{ACKNOWLEDGMENTS}

This report summarizes program benefits analysis undertaken by experts in energy technology programs, energy markets, and energy-economic modeling. The primary team members and their areas of responsibility are listed below.

Report Managers, Writers, and Editors

- EERE

- Report Coordinator: Michael Leifman

○ Biomass: Zia Haq, Tien Nguyen

○ Buildings: Jerry Dion, David Boomsma

- Federal Energy Management: David Boomsma

○ Hydrogen, Fuel Cells, and Infrastructure Technologies: Fred Joseck, Jeff Dowd

○ Industry: Peggy Podolak

○ Solar: Glenn Strahs

○ Vehicle Technologies: Lee Slezak, Phil Patterson

○ Weatherization and Intergovernmental: Mark Bailey, Cathy Short

- Wind: Jack Cadogan, Linda Silverman

- Contractors

- Project Manager: John Sheehan, National Renewable Energy Laboratory (NREL)

- Guidance and Review: Thomas Jenkin (NREL), Gian Porro (NREL), Lynn McLarty (TMS), David Shen (TMS)

- Editorial: Michelle Kubik (NREL)

- $\quad$ Chapter Authors

○ Chapter 1 - Estimating Benefits: John Sheehan (NREL)

- Chapter 2 - The Value of EERE's Portfolio: John Sheehan (NREL), Frances Wood (OnLocation, Inc.), Chip Friley, Brookhaven National Laboratory (BNL)

- Chapter 3 - The Value of Individual Programs: John Sheehan (NREL), Frances Wood (OnLocation Inc.), Chip Friley (BNL)

- Energy-Economic Integration - NEMS: Frances Wood (OnLocation Inc).

- Energy-Economic Integration - MARKAL: Chip Friley (BNL)

- Biomass: David Andress, David Andress and Associates (DAA)

○ Buildings: Donna Hostick, Pacific Northwest National Laboratory (PNNL)

○ Federal Energy Management: Donna Hostick (PNNL)

○ Hydrogen and Fuel Cells: Fred Joseck (EERE), Margaret Singh, Argonne National Laboratory (ANL)

- Industry: Jim Reed (Energetics)

- Solar: Robert Margolis (NREL)

○ Vehicle Technologies: Margaret Singh (ANL), Phil Patterson (EERE), Jim Moore (TA Engineering)

- Weatherization and Intergovernmental: Donna Hostick (PNNL)

$\circ \quad$ Wind: Joe Cohen, Princeton Energy Resources International (PERI)

In all cases, these lead analysts drew from the studies and expertise of many others. Other members of the Benefits Analysis Team include:

EERE: Darrell Beschen, Scott Hassell, Joan Glickman, Quonnie Laughlin, John Ryan, Randy Steer

ANL: Don Hillebrand, Steve Plotkin

Navigant Consulting: Ed Barbour

NREL: Ian Baring-Gould, Kelly Ibsen, John Jechura, Cindy Riley, Laura Vimmerstedt

OnLocation: John Holte, Laura Train, Mark Ditmer

PERI: Jim McVeigh

PNNL: Dave Anderson, Dave Belzer, Katie Allen Cort, Jesse Dean, Jim Dirks, Doug Elliott, Emily Rauch, Joe Roop Sentech; Bill Zwack

TMS: Brian Lavoie 


\section{EXECUTIVE SUMMARY}

The U.S. Department of Energy's (DOE) Office of Energy Efficiency and Renewable Energy (EERE) sponsors research, development, demonstration, and deployment (RD3) activities aimed at transforming the future of U.S. energy through improved efficiency of energy use and the development of new renewable energy resources. EERE invests in high-risk, high-value research and development (R\&D) that - conducted in partnership with the private sector and other government agencies-accelerates the development and facilitates the deployment of advanced energy technologies and practices.

\section{Highlights}

EERE annually assesses the contribution of its work to DOE's goals of providing affordable, clean, and reliable energy. Two energy market models are used in this assessment-one that looks in detail at the midterm (through 2030) and one that looks more generally at trends in the long term (through 2050).

The midterm model is a variant of the tool used by DOE's Energy Information Administration (EIA) to report annually on the U.S. energy outlook. A snapshot of midterm benefits associated with technical and market success of EERE's programs includes the following:

- Providing affordable energy. More than \$630 billion of consumer savings from 2008 to 2030.

- Delivering clean energy. Two billion tons of avoided carbon emissions from 2008 to 2030.

- Ensuring reliable energy. Savings of more than 6 billion barrels of imported oil from 2008 to 2030 .

- Hedging our bets. High energy prices and the need to reduce greenhouse gas emissions are scenarios that could threaten our economy. Under each of these scenarios, EERE's portfolio saves consumers more than \$1 trillion from 2008 to 2030.

The full set of both mid- and long-term benefits estimates are shown in Tables ES-1, ES-2, and ES-3.

\section{What's new this year?}

Expanded Metrics. This year's analysis includes new metrics intended to more fully understand the energy, environmental, and economic impacts of EERE's portfolio. For details on the definitions of the metrics, see Chapter 1.

The Impact of Alternative Futures. In previous years, projected benefits of EERE's portfolio have been estimated for a single "Business-as-Usual" view of the future. This ignores the possibility of other adverse potential futures. So, this year, projected benefits are evaluated for three different scenarios:

- Business-as-Usual (BAU)—based on DOE's forecast in Annual Energy Outlook 2006 (AEO2006).

- High Fuel Price (HFP) - based on DOE's high oil price forecast in AEO2006, with additional assumptions leading to higher natural gas prices.

- Carbon Constraint (CC)—based on a future policy requiring steady reductions in emissions of carbon dioxide from energy consumption.

This allows for evaluation of the ability of EERE's portfolio to mitigate adverse impacts of a carbonconstrained future and a high fuel price future. 


\section{Economic security—-benefits to the consumer}

Under a Business-as-Usual future, EERE's portfolio enables consumers to reduce overall energy consumption and to access cost-effective renewable energy resources, both of which translate directly to reduced consumer spending for energy. The largest source of savings occur in the transportation sector, where improved vehicle technologies lead to less spending for fuel, and bioethanol and hydrogen fuel cell technologies ultimately lead to reductions in oil consumption. Consumer savings under the High Fuel Price scenario are nearly double those seen for the BAU scenario, demonstrating that success in EERE's portfolio can help protect consumers from high fuel prices. Similarly, EERE's portfolio offers consumers even greater protection from impacts of market costs for carbon emissions in a carbon-constrained world. These results illustrate that success in EERE's RD3 portfolio can lead to clean and secure energy supplies while actually providing cost savings to consumers.

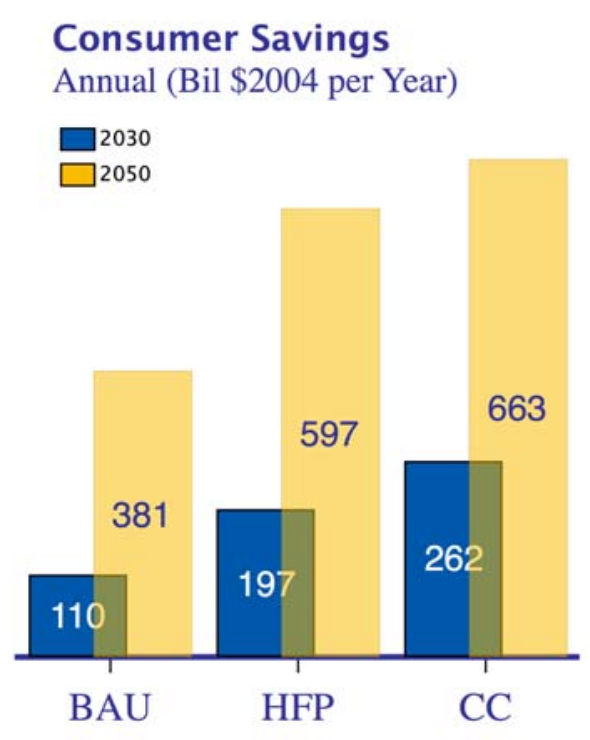

Consumer Savings

\section{Energy security—reducing our dependence on oil}

Reducing oil imports is key to increasing the energy security of the Nation. Oil savings associated with EERE's portfolio are substantial. In 2030, oil savings are about 2 million barrels per day for all scenarios. By 2040, these savings climb to between 6 million and 9 million barrels per day, depending on the scenario. By 2050, EERE's portfolio could reduce oil imports to levels not seen since the 1990s.

Oil savings through 2030 are actually lower in the High Fuel Price scenario than in the Business-asUsual scenario. The impact of EERE's portfolio is less because the private sector is more motivated early on (when energy costs are high) to make progress on energy efficiency and renewable fuels technologies on their own. Even though the private sector would make more progress on its own in a High Fuel Price future, success in EERE's

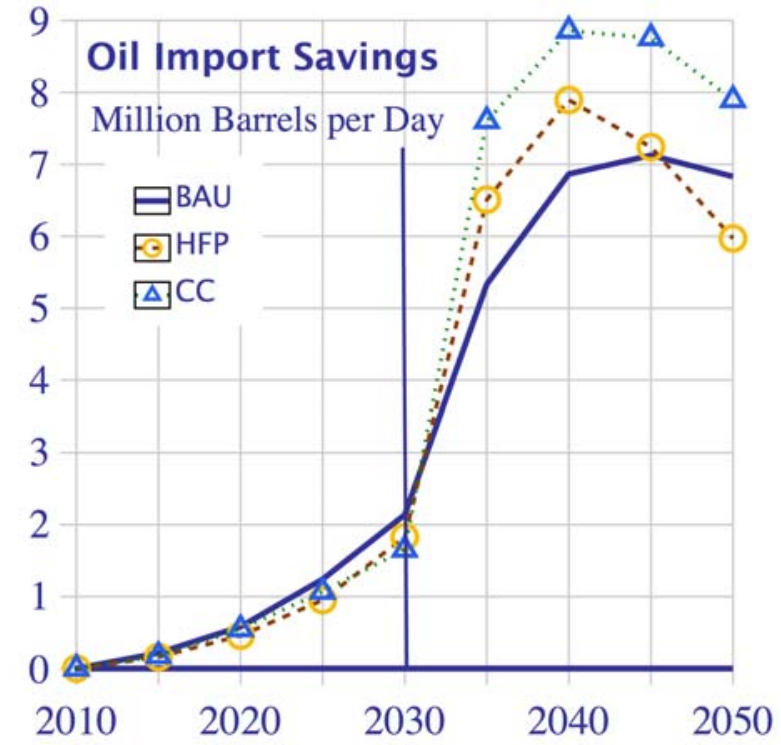
portfolio adds substantially more to the Nation's oil savings. 


\section{Environmental security_energy and climate change}

Success in EERE's RD3 portfolio leads to more than 200 million metric tons of carbon savings per year in 2030, with savings leveling off by 2040 at about 500 million metric tons per year in both the Business-as-Usual and High Fuel Price scenarios. The technologies made available by EERE's portfolio eliminate the often-assumed (but false) choice between economic and environmental benefits.

EERE's portfolio has no carbon savings under the Carbon Constraint scenario. Because we only take credit for benefits directly attributable to the outcomes of EERE's research, a scenario in which regulation drives savings means that we cannot take any credit. But, as the economic benefits described above suggest, EERE helps society meet such a requirement with less impact on consumers.

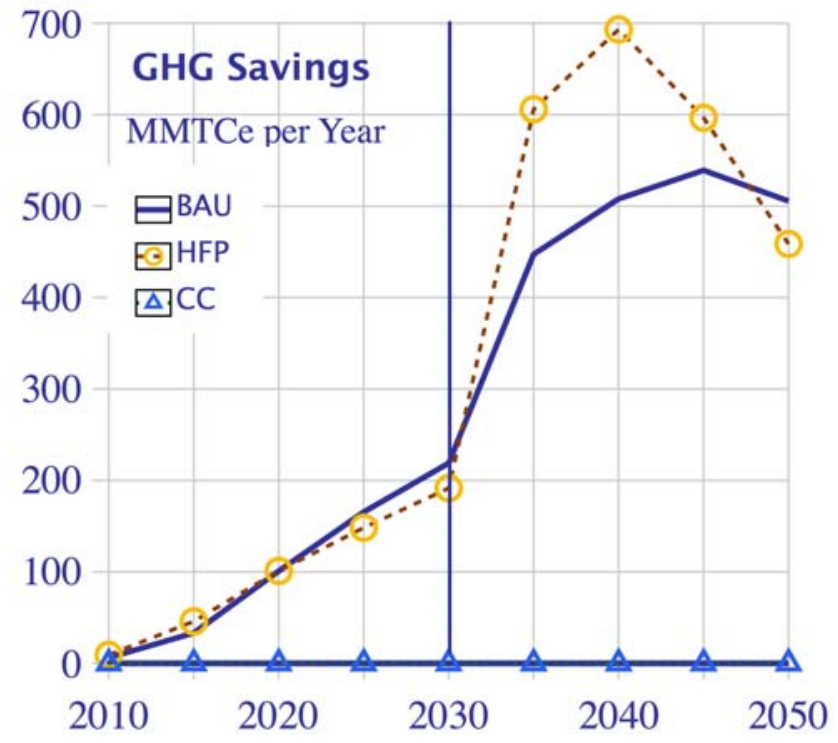

\section{Summary of projected benefits}

Tables ES-1, ES-2, and ES-3 summarize all of the metrics for EERE's portfolio from 2010 to 2050.

Table ES-1. The Benefits of EERE's Portfolio Under the Business-as-Usual Scenario

\begin{tabular}{|c|c|c|c|c|c|c|c|c|c|}
\hline & \multicolumn{5}{|c|}{ MIDTERM BENEFITS } & \multicolumn{4}{|c|}{ LONG-TERM BENEFITS } \\
\hline Metric & 2010 & 2015 & 2020 & 2025 & 2030 & 2035 & 2040 & 2045 & 2050 \\
\hline \multicolumn{10}{|l|}{ ECONOMIC BENEFITS ("AFFORDABLE") } \\
\hline Reduction in Average Delivered Natural Gas Price & $1 \%$ & $0 \%$ & $3 \%$ & $5 \%$ & $2 \%$ & $5 \%$ & $10 \%$ & $16 \%$ & $12 \%$ \\
\hline Energy System Cost Savings (bil \$2004) & $\mathrm{nr}$ & $\mathrm{nr}$ & $\mathrm{nr}$ & $\mathrm{nr}$ & $\mathrm{nr}$ & 120 & 146 & 173 & 203 \\
\hline Consumer Savings, Annual (bil \$2004) & 4 & 12 & 43 & 86 & 110 & 232 & 322 & 385 & 381 \\
\hline Consumer Savings, NPV (bil \$2004) & 6 & 46 & 148 & 359 & 632 & 1,518 & 2,088 & 2,707 & 3,278 \\
\hline Electric Power Industry Savings, Annual (bil \$2004) & 1 & 5 & 13 & 21 & 26 & 51 & 63 & 77 & 69 \\
\hline Electric Power Industry Savings, NPV (bil \$2004) & 2 & 18 & 54 & 110 & 174 & 419 & 536 & 658 & 766 \\
\hline $\begin{array}{l}\text { Reduction in Fraction of Household Income Spent on } \\
\text { Energy }\end{array}$ & $0.3 \%$ & $0.7 \%$ & $2.0 \%$ & $3.6 \%$ & $4.8 \%$ & $8 \%$ & $9 \%$ & $10 \%$ & $10 \%$ \\
\hline Reduced Energy Intensity of Economy & $0.3 \%$ & $1.7 \%$ & $3.9 \%$ & $6.1 \%$ & $7.8 \%$ & $10 \%$ & $13 \%$ & $15 \%$ & $17 \%$ \\
\hline \multicolumn{10}{|l|}{ ENVIRONMENTAL BENEFITS ("CLEAN") } \\
\hline $\begin{array}{l}\text { Avoided Greenhouse Gas Emissions, Annual } \\
\text { (MMTCE/year) }\end{array}$ & 6 & 33 & 101 & 165 & 219 & 447 & 508 & 539 & 505 \\
\hline $\begin{array}{l}\text { Avoided Greenhouse Gas Emissions, Cumulative } \\
\text { (MMTCE) }\end{array}$ & 12 & 116 & 470 & 1,158 & 2,136 & 4,630 & 7,047 & 9,680 & 12,276 \\
\hline $\begin{array}{l}\text { Reduced Cost of Criteria Pollutant Control, NPV (bil } \\
\$ 2004 \text { ) }\end{array}$ & 0 & 1 & 3 & 9 & 13 & $\mathrm{nr}$ & $\mathrm{nr}$ & $\mathrm{nr}$ & $\mathrm{nr}$ \\
\hline \multicolumn{10}{|l|}{ SECURITY BENEFITS ("RELIABLE") } \\
\hline Avoided Oil Imports, Annual (mbpd) & ns & 0.2 & 0.6 & 1.2 & 2.1 & 5.3 & 6.9 & 7.1 & 6.8 \\
\hline Avoided Oil imports, Cumulative (bil barrels) & ns & 0.3 & 1.0 & 2.8 & 6.1 & 17 & 28 & 41 & 54 \\
\hline $\begin{array}{l}\text { Security Fuel Economy Improvement (MPG of Crude } \\
\text { Oil) }\end{array}$ & 0.1 & 0.5 & 1.3 & 2.8 & 5.3 & 23 & 38 & 51 & 64 \\
\hline Improved Transportation Fuel Diversity & ns & ns & $4 \%$ & $10 \%$ & $24 \%$ & $82 \%$ & $86 \%$ & $67 \%$ & $42 \%$ \\
\hline Reduced Oil Intensity of the Economy & $0.2 \%$ & $1 \%$ & $3 \%$ & $6 \%$ & $9 \%$ & $26 \%$ & $32 \%$ & $33 \%$ & $33 \%$ \\
\hline
\end{tabular}


Table ES-2. The Benefits of EERE's Portfolio Under the High Fuel Price Scenario

\begin{tabular}{|c|c|c|c|c|c|c|c|c|c|}
\hline & \multicolumn{5}{|c|}{ MIDTERM BENEFITS } & \multicolumn{4}{|c|}{ LONG-TERM BENEFITS } \\
\hline Metric & 2010 & 2015 & 2020 & 2025 & 2030 & 2035 & 2040 & 2045 & 2050 \\
\hline ECONOMIC BENEFITS ("AFFORDABLE") & & & & & & & & & \\
\hline Reduction in Average Delivered Natural Gas Price & $1 \%$ & $4 \%$ & $4 \%$ & $8 \%$ & $7 \%$ & $14 \%$ & $15 \%$ & $22 \%$ & $15 \%$ \\
\hline Energy System Cost Savings (bil \$2004) & $\mathrm{nr}$ & $\mathrm{nr}$ & $\mathrm{nr}$ & $\mathrm{nr}$ & $\mathrm{nr}$ & 258 & 303 & 325 & 341 \\
\hline Consumer Savings, Annual (bil \$2004) & 4.3 & 28 & 66 & 133 & 197 & 510 & 558 & 629 & 597 \\
\hline Consumer Savings, NPV (bil \$2004) & 10 & 85 & 246 & 553 & 1,012 & 2,681 & 3,758 & 4,794 & 5,703 \\
\hline $\begin{array}{l}\text { Electric Power Industry Savings, Annual (bil } \\
\$ 2004 \text { ) }\end{array}$ & 2 & 9 & 14 & 21 & 25 & 99 & 103 & 97 & 73 \\
\hline Electric Power Industry Savings, NPV (bil \$2004) & 5 & 28 & 68 & 123 & 185 & 532 & 735 & 907 & 1,031 \\
\hline $\begin{array}{l}\text { Reduction in Fraction of Household Income Spent } \\
\text { on Energy }\end{array}$ & $0.21 \%$ & $1.1 \%$ & $2.9 \%$ & $5.0 \%$ & $6.7 \%$ & $14 \%$ & $15 \%$ & $16 \%$ & $14 \%$ \\
\hline Reduced Energy Intensity of Economy (Percent) & $0.42 \%$ & $2.0 \%$ & $3.8 \%$ & $6.0 \%$ & $7.4 \%$ & $15 \%$ & $18 \%$ & $18 \%$ & $16 \%$ \\
\hline ENVIRONMENTAL BENEFITS ("CLEAN") & & & & & & & & & \\
\hline $\begin{array}{l}\text { Annual Avoided Greenhouse Gas Emissions } \\
\text { (MMTCE/year) }\end{array}$ & 9 & 46 & 101 & 148 & 192 & 606 & 693 & 597 & 459 \\
\hline $\begin{array}{l}\text { Cumulative Avoided Greenhouse Gas Emissions } \\
\text { (MMTCE) }\end{array}$ & 14 & 158 & 562 & 1,204 & 2,072 & 5,628 & 8,918 & 12,095 & 14,665 \\
\hline $\begin{array}{l}\text { Reduced Cost of Criteria Pollutant Control, NPV } \\
\text { (bil \$2004) }\end{array}$ & 0.5 & 1.2 & 5.0 & 8.7 & 15 & $\mathrm{nr}$ & $\mathrm{nr}$ & $\mathrm{nr}$ & $\mathrm{nr}$ \\
\hline SECURITY BENEFITS ("RELIABLE") & & & & & & & & & \\
\hline Avoided Oil Imports, Annual (mbpd) & ns & 0.2 & 0.5 & 1.0 & 1.8 & 6.5 & 7.9 & 7.2 & 6.0 \\
\hline Avoided Oil imports, Cumulative (bil barrels) & ns & 0.2 & 0.8 & 2.2 & 4.8 & 18.5 & 32.0 & 45.7 & 57.5 \\
\hline $\begin{array}{l}\text { Security Fuel Economy Improvement (MPG of } \\
\text { Crude Oil) }\end{array}$ & 0.1 & 0.5 & 1.3 & 2.8 & 5.8 & 63 & 136 & 223 & 285 \\
\hline Transportation Fuel Diversity Improvement & ns & ns & $6.2 \%$ & $6.0 \%$ & $16 \%$ & $94 \%$ & $91 \%$ & $66 \%$ & $48 \%$ \\
\hline Reduced Oil Intensity & ns & $1.0 \%$ & $2.8 \%$ & $5.3 \%$ & $9.5 \%$ & $36 \%$ & $43 \%$ & $42 \%$ & $39 \%$ \\
\hline
\end{tabular}

Table ES-3. The Benefits of EERE's Portfolio Under the Carbon Constraint Scenario

\begin{tabular}{|c|c|c|c|c|c|c|c|c|c|}
\hline & \multicolumn{5}{|c|}{ MIDTERM BENEFITS } & \multicolumn{4}{|c|}{ LONG-TERM BENEFITS } \\
\hline Metric & 2010 & 2015 & 2020 & 2025 & 2030 & 2035 & 2040 & 2045 & 2050 \\
\hline ECONOMIC BENEFITS ("AFFORDABLE") & & & & & & & & & \\
\hline Reduction in Average Delivered Natural Gas Price & $0 \%$ & $1 \%$ & $9 \%$ & $11 \%$ & $13 \%$ & $40 \%$ & $42 \%$ & $35 \%$ & $28 \%$ \\
\hline Energy System Cost Savings (bil \$2004) & $\mathrm{nr}$ & $\mathrm{nr}$ & $\mathrm{nr}$ & $\mathrm{nr}$ & $\mathrm{nr}$ & 177 & 221 & 247 & 271 \\
\hline Consumer Savings, Annual (bil \$2004) & 2.1 & 21 & 104 & 179 & 262 & 641 & 751 & 750 & 663 \\
\hline Consumer Savings, NPV (bil \$2004) & 4.4 & 53 & 302 & 749 & 1,359 & 4,106 & 5,519 & 6,814 & 7,856 \\
\hline Electric Power Industry Savings, Annual (bil \$2004) & 1.9 & 12 & 37 & 45 & 52 & 113 & 104 & 103 & 92 \\
\hline Electric Power Industry Savings, NPV (bil \$2004) & 4.3 & 34 & 137 & 269 & 405 & 887 & 1103 & 1282 & 1425 \\
\hline $\begin{array}{l}\text { Reduction in Fraction of Household Income Spent on } \\
\text { Energy }\end{array}$ & $0.17 \%$ & $1.0 \%$ & $3.8 \%$ & $5.9 \%$ & $8.2 \%$ & $15 \%$ & $16 \%$ & $15 \%$ & $12 \%$ \\
\hline Reduced Energy Intensity of Economy (Percent) & $0.20 \%$ & $1.5 \%$ & $2.6 \%$ & $4.7 \%$ & $8.0 \%$ & $9.2 \%$ & $13 \%$ & $14 \%$ & $14 \%$ \\
\hline ENVIRONMENTAL BENEFITS ("CLEAN") & & & & & & & & & \\
\hline $\begin{array}{l}\text { Annual Avoided Greenhouse Gas Emissions } \\
\text { (MMTCE/year) }\end{array}$ & ns & ns & ns & ns & ns & 10 & 0 & 0 & 0 \\
\hline $\begin{array}{l}\text { Cumulative Avoided Greenhouse Gas Emissions } \\
\text { (MMTCE) }\end{array}$ & ns & ns & ns & ns & ns & 28 & 28 & 28 & 28 \\
\hline Reduced Cost of CO2 Allowances, (bil \$2004) & 0.0 & 11 & 59 & 80 & 97 & $\mathrm{nr}$ & $\mathrm{nr}$ & $\mathrm{nr}$ & $\mathrm{nr}$ \\
\hline Reduced Cost of CO2 Allowances, NPV (bil \$2004) & 0.0 & 15 & 167 & 382 & 624 & $\mathrm{nr}$ & $\mathrm{nr}$ & $\mathrm{nr}$ & $\mathrm{nr}$ \\
\hline $\begin{array}{l}\text { Reduced Cost of Criteria Pollutant Control, NPV (bil } \\
\$ 2004)\end{array}$ & 0.8 & 0 & -1 & -3 & -4 & $\mathrm{nr}$ & $\mathrm{nr}$ & $\mathrm{nr}$ & $\mathrm{nr}$ \\
\hline SECURITY BENEFITS ("RELIABLE") & & & & & & & & & \\
\hline Avoided Oil Imports, Annual (mbpd) & ns & 0.18 & 0.55 & 1.1 & 1.7 & 7.6 & 8.9 & 8.8 & 7.9 \\
\hline Avoided Oil imports, Cumulative (bil barrels) & ns & 0.17 & 0.85 & 2.4 & 5.0 & 24 & 40 & 56 & 71 \\
\hline $\begin{array}{l}\text { Security Fuel Economy Improvement (MPG of Crude } \\
\text { Oil) }\end{array}$ & 0.1 & 0.5 & 1.4 & 2.7 & 4.9 & 41 & 71 & 106 & 128 \\
\hline Transportation Fuel Diversity Improvement & ns & ns & $10 \%$ & $14 \%$ & $23 \%$ & $191 \%$ & $184 \%$ & $139 \%$ & $111 \%$ \\
\hline Reduced Oil Intensity & ns & $0.9 \%$ & $2.7 \%$ & $5.3 \%$ & $7.7 \%$ & $35 \%$ & $40 \%$ & $41 \%$ & $39 \%$ \\
\hline
\end{tabular}


Notes for Tables ES-1, ES-2, and ES-3

1. Midterm benefits modeled using NEMS-GPRA08

2. Long-term benefits modeled using MARKAL-GPRA08

3. NPV is "net present value" of cumulative savings beginning in 2008

4. nr is "not reported"

5. ns is "not significant"

\section{The benefits of individual programs}

In addition to assessing the benefits of $100 \%$ success across the EERE portfolio, this report includes assessments of the individual programs in the portfolio. The benefits reflect the impact of success in only one program at a time. The FY 2008 budget request for each of EERE's nine programs is shown below:

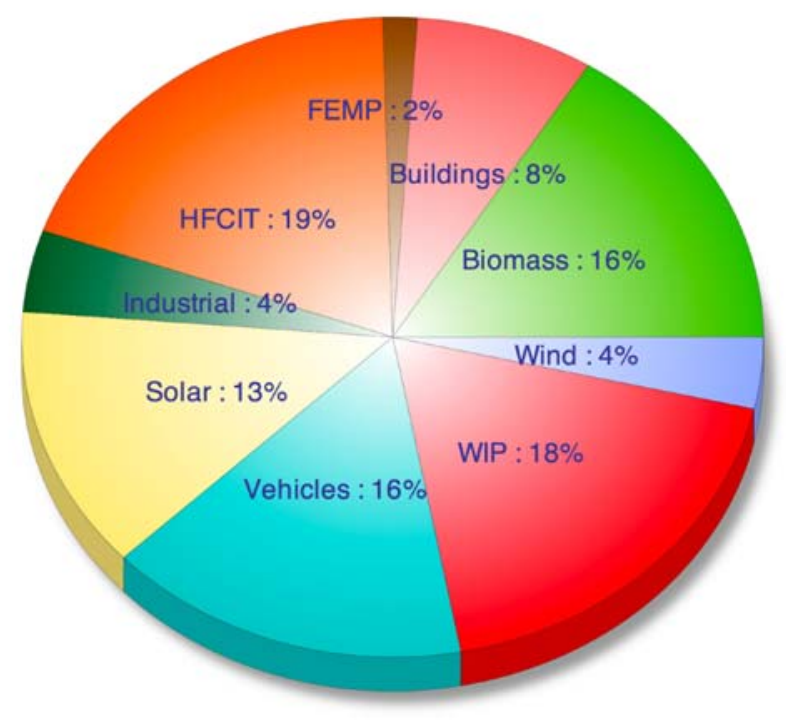

\begin{tabular}{|r|r|}
\hline Federal Energy Management & $\$ 16,791$ \\
\hline Wind & $\$ 40,069$ \\
\hline Industry & $\$ 45,998$ \\
\hline Buildings & $\$ 86,456$ \\
\hline Solar & $\$ 148,304$ \\
\hline Vehicles & $\$ 176,138$ \\
\hline Biomass & $\$ 179,263$ \\
\hline $\mathrm{Weatherization/Intergovt}_{2}$ Fuel Cell Infrastructure & $\$ 204,904$ \\
\hline $\mathrm{H}_{2}$ & $\$ 213,000$ \\
\hline
\end{tabular}

The two largest program budgets are \$213 million for the Hydrogen, Fuel Cell, and Infrastructure Technologies (HFCIT) Program, and \$205 million for the Weatherization and Intergovernmental Program (WIP). The latter includes $\$ 144$ million for Low-Income Weatherization Assistance.

\section{Impact of individual programs on consumer savings}

The sum of the individual programs' consumer savings is generally greater than the EERE portfolio's savings - due to some overlap in markets served by each program. The biggest contributors to consumer savings are the FreedomCAR and Vehicle Technologies Program and the Building Technologies Program. Both of these programs reduce energy consumption through efficiency improvements. Less energy consumption translates directly into savings for consumers. By 2050, the Biomass Program, the Solar Technologies Program, and the Hydrogen, Fuel Cells, and Infrastructure Technologies Program offer significant savings.

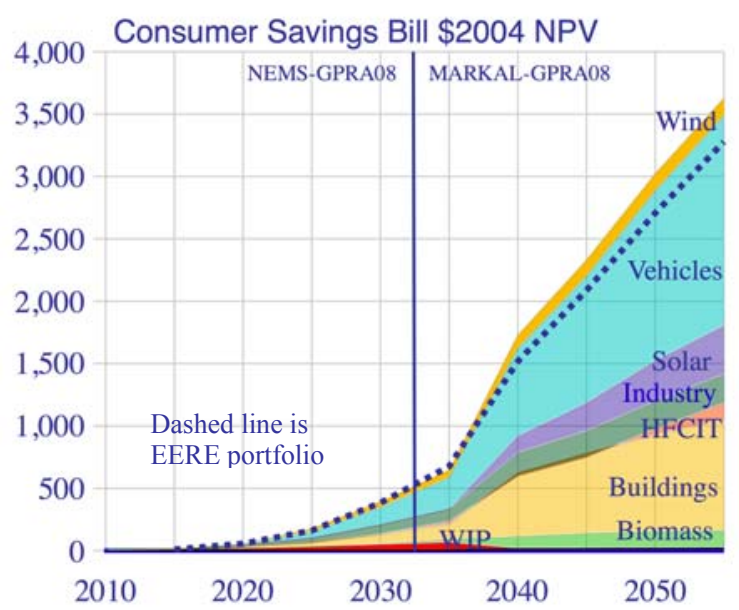




\section{Impact of individual programs on carbon savings}

By 2030, the Buildings Technologies Program, the Industrial Technologies Program, and the Wind Technologies Program all contribute significantly to carbon savings. While the Weatherization and Intergovernmental Program has a relatively small impact, it provides other social benefits. It also plays a role in accelerating early adoption of efficiency and renewable energy technologies, which is not readily captured in the energy market models. By 2050, savings from all of these programs continues to grow, along with savings from the Biomass Program, the Solar Technologies Program, and the FreedomCAR and Vehicle Technologies Program.

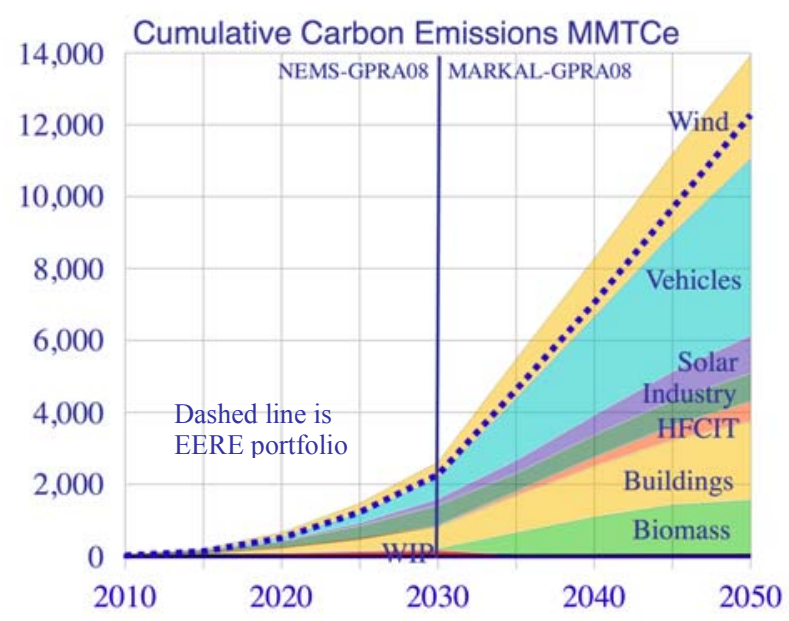

\section{Impact of individual programs on oil savings}

The transportation-related programs - the FreedomCAR and Vehicle Technologies Program; the Hydrogen, Fuel Cells, and Infrastructure Technologies Program; and the Biomass Program - dominate oil import savings among the individual programs in EERE's portfolio under the Business-as-Usual scenario. The Building Technologies and Industrial Technologies programs provide small savings. In the long run, Vehicle Technologies and the Hydrogen, Fuel Cells, and Infrastructure Technologies programs take over as the largest potential contributors to oil savings.

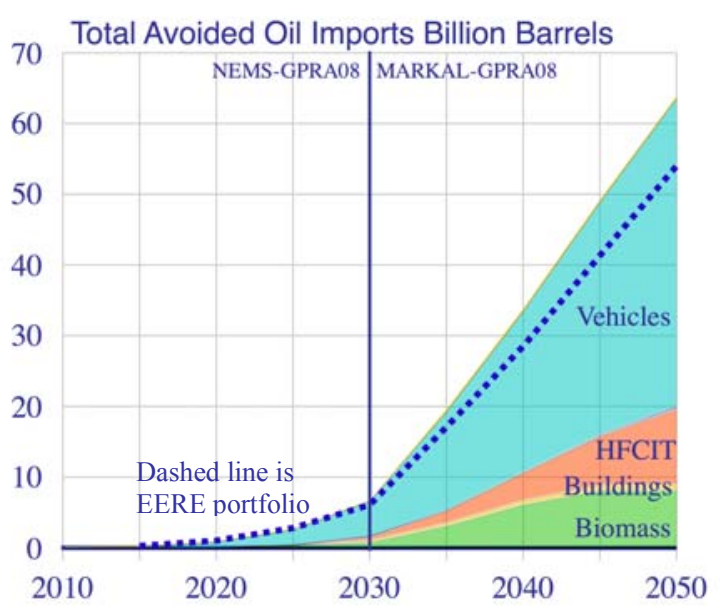

\section{Summary of Individual Program Benefits}

Table ES-4 summarizes FY 2008 budgets and selected benefits results for each of the individual programs, along with the benefits estimates of the full portfolio, under the Business-as-Usual scenario. 
Table ES-4. Selected Benefits for Individual Programs and the EERE Portfolio Under the Business-as-Usual Scenario

\begin{tabular}{|c|c|c|c|c|c|c|c|}
\hline & \multirow[t]{2}{*}{$\begin{array}{l}\text { FY } 2008 \text { Budget } \\
\text { Request }\end{array}$} & \multicolumn{2}{|c|}{$\begin{array}{l}\text { Oil Import Savings } \\
\text { (mbpd) }\end{array}$} & \multicolumn{2}{|c|}{$\begin{array}{l}\text { Consumer Savings } \\
\text { (\$2004/yr) }\end{array}$} & \multicolumn{2}{|c|}{$\begin{array}{l}\text { Carbon Savings } \\
\text { (MMTCe/yr) }\end{array}$} \\
\hline & & 2030 & 2050 & 2030 & 2050 & 2030 & 2050 \\
\hline Biomass & 179,263 & 0.3 & ns & 3.3 & -1.8 & 8.7 & 3.3 \\
\hline Building Technologies & 86,456 & 0.1 & 0.1 & 27 & 78 & 57 & 77 \\
\hline Federal Energy Management & 16,791 & ns & ns & 1.0 & 0.89 & 0.80 & 0.90 \\
\hline $\begin{array}{l}\text { Hydrogen, Fuels and } \\
\text { Infrastructure }\end{array}$ & 213,000 & 0.25 & 2.1 & 7.3 & 55 & 14 & 31 \\
\hline Industrial Technologies & 45,998 & ns & ns & 11 & 6 & 40 & 18 \\
\hline Solar Energy Technologies & 148,304 & ns & 0.13 & ns & 33 & 23 & 50 \\
\hline Vehicle Technologies & 176,138 & 1.8 & 5.9 & 46 & 220 & 69 & 210 \\
\hline Weatherization Intergovernmental & 204,904 & 2.1 & $\mathrm{nr}$ & 7.8 & $\mathrm{nr}$ & 6.64 & $\mathrm{nr}$ \\
\hline Wind Technologies & 40,069 & ns & ns & 7.8 & 0.85 & 69 & 139 \\
\hline Facilities and Infrastructure & 26,052 & na & na & na & na & na & na \\
\hline Program Direction & 101,868 & na & na & na & na & na & na \\
\hline Program Support & 13,321 & na & na & na & na & na & na \\
\hline Total EERE Integrated Portfolio & $1,252,164$ & 2.1 & 6.8 & 119 & 381 & 233 & 505 \\
\hline
\end{tabular}

Notes for Table ES-4

6. 2030 benefits modeled using NEMS-GPRA08

7. 2050 benefits modeled using MARKAL-GPRA08

8. NPV is "net present value" of cumulative savings beginning in 2008

9. $\mathrm{nr}$ is "not reported"

10. ns is "not significant" 


\section{CHAPTER 1 - ESTIMATING PROSPECTIVE BENEFITS OF EERE'S PORTFOLIO}

\section{Table of Contents}

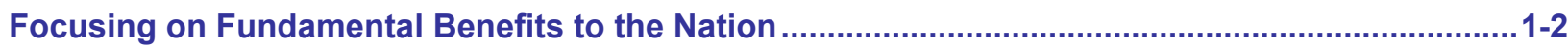

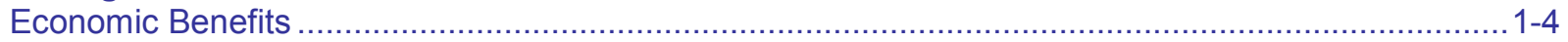

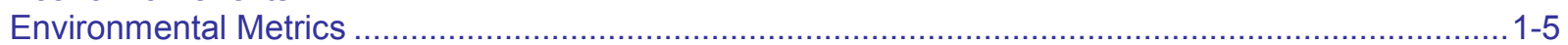

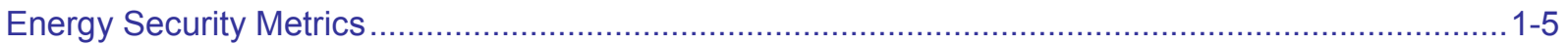

Meeting Congressional and Presidential Demand for Accountability ...............................................1-8

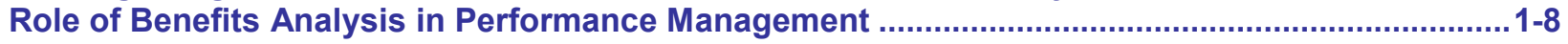

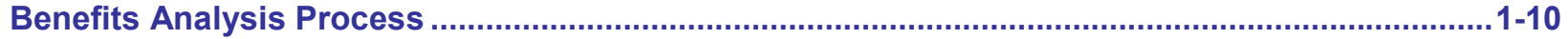

\section{List of Figures}

Figure 1.1. Evolution of an Evaluation Matrix - DOE RD3 Programs …............................................ 1-3

Figure 1.2. Generalized EERE Logic Model ............................................................................ 1-9

Figure 1.3. Holistic View of the Role of Benefits Analysis in EERE Performance Management.............1-10

\section{List of Tables}

Table 1.1. EERE Metrics for the NRC Category of Economic Benefits .............................................1-6

Table 1.2. EERE Metrics for the NRC Category of Environmental Benefits...................................... 1-7

Table 1.3. EERE Metrics for the NRC Category of Security Benefits ............................................... 1-7

\section{Text Boxes}

Box 1.1. DOE's Strategic Goals 
The Office of Energy Efficiency and Renewable Energy (EERE) estimates expected benefits for its overall portfolio and for each of its nine Research, Development, Demonstration, and Deployment (RD3) programs. Benefits for the FY 2008 budget request $^{1}$ are estimated for the midterm (2008-2030) and long term (2030-2050). Two separate models suited to these periods are employed-NEMS-GPRA08 for the midterm and MARKAL-GPRA08 for the long term. [The first is a modified version of the National Energy Modeling System (NEMS) for the Government Performance and Results Act (GPRA); and the second is a modified version of the MARKet ALlocation (MARKAL) model for GPRA.] Estimated benefits reflect the value of program activities from 2008 forward. They do not include the impacts of past program success, nor technology development or deployment efforts outside EERE's programs.

\section{Focusing on Fundamental Benefits to the Nation}

The direct outcome of EERE's energy efficiency improvements and renewable energy technology developments is a reduction in the use of traditional energy resources such as coal, oil, and natural gas. For this reason, EERE has, in the past, relied on projections of nonrenewable energy displacement as a key indicator of both RD3 progress and value to the Nation. While reducing the use of nonrenewable energy may result in benefits to the Nation, it is not an intrinsically valuable benefit. For example, reducing coal use can reduce greenhouse gas emissions from the burning of coal for heat and powersomething of potential value to the Nation. But it is not the only means of reducing greenhouse gas emissions from coal. Clean coal technology can both improve the efficiency of converting coal to energy and reduce greenhouse gas emissions via carbon sequestration.

This distinction became very clear when EERE joined the broader effort this year among all of the DOE offices of Energy, Science, and Environment (ESE) to understand the value of DOE's entire RD3 energy portfolio. ESE's RD3 portfolio includes projects within the Office of Fossil Energy (FE), Nuclear Energy (NE), Electricity Delivery and Energy Reliability (OE), and Science $(\mathrm{Sc})$. A more rigorous valuation of the programs involves - an ESE-wide working group has concluded - metrics that reflect intrinsic or fundamental benefits to the Nation. As a result, this year's assessment of the EERE portfolio is based on a new set of metrics.

The choice of metrics has been influenced not only by the collaborative effort within ESE, but also by collaborative efforts with the National Research Council (NRC) during the past few years.

"DOE funding of energy R\&D is not," the NRC concluded in a 2001 analysis of the value of DOE's energy efficiency and fossil energy research programs, "necessarily associated with the most obviously attractive advances. Rather, as basic economic principles suggest, DOE research should also, and even mostly, be associated with public policy objectives." 2

In that 2001 study, the NRC proposed a matrix for evaluating the benefits of DOE's research, as shown in Figure 1.1. The public good identified by NRC fell into the three categories of economic, environmental, and security benefits. The emphasis of the NRC assessment was retrospective in nature. NRC focused on three areas of public good from DOE research, which were purposely aligned with the strategic goals of the DOE. Within the context of the three classes of public good they saw from DOE energy research, NRC identified benefits associated with DOE outcomes that ranged from technology "ready to go" to technology that was very high risk or that had even "failed."

\footnotetext{
${ }^{1}$ EERE budget-request materials may be accessed at http://www1.eere.energy.gov/ba/pba/budget formulation.html ${ }^{2}$ Committee on Benefits of DOE R\&D on Energy Efficiency and Fossil Energy, Board on Energy and Environmental Systems, Division on Engineering and Physical Sciences, National Research Council. Energy Research at DOE: Was It Worth It? Energy Efficiency and Fossil Energy Research 1978 to 2000. ISBN: 0-309-07448-7 (2001). Free PDF available at http://www.nap.edu/catalog/10165.html
} 


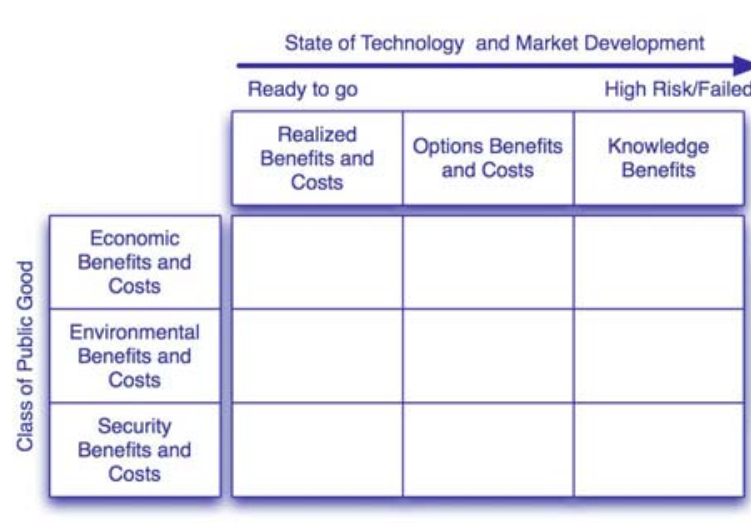

NRC RETROSPECTIVE EVALUATION MATRIX

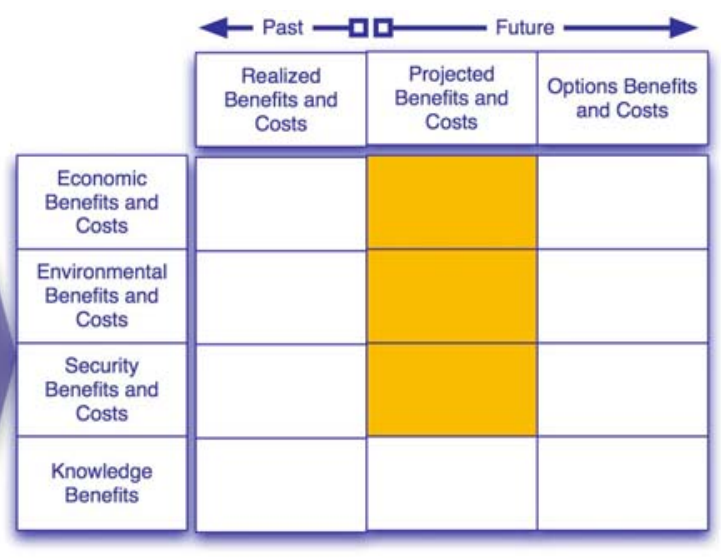

EERE EVALUATION MATRIX

Figure 1.1. Evolution of an Evaluation Matrix - DOE RD3 Programs

Technologies from DOE programs that were fully developed in markets that were ready to accept them had "realized" benefits and costs. Technologies that were still in the development stage offered "options benefits." Technologies that remained very high risk or had experienced market failure were seen as still offering "knowledge benefits."

In 2003, DOE's ESE offices brought together experts to discuss how to extend the NRC framework to the kind of prospective benefits analysis reported here. ${ }^{3}$ DOE's RD3 activities fit into all three categories of public good and all three categories of risk reflected in the NRC's original retrospective framework. The modified evaluation matrix that came out of the 2003 discussions is also shown in Figure 1.1. Note that knowledge benefits in this scheme are now a class of public good (i.e., a row in the matrix rather than a column). This is a logical extension of the NRC's original view that knowledge benefits exist regardless of the commercial failure or success of the technology being developed. EERE is working with DOE's Office of Science and other offices within ESE to develop indicators that reflect the value of "knowledge."

The matrix elements highlighted in yellow represent benefits categories for which EERE has adopted specific indicators. This year (as in prior years), EERE's prospective benefits are - effectively - built on an assumption of $100 \%$ probability of success, falling under the category of "projected benefits" perhaps better described as "projected realized benefits." As part of the FY 2009 budget process, EERE will expand the projections to reflect differences in relative risk among the RD3 activities, allowing for estimation of "options" benefits for technologies that face some risk of failure.

DOE has recently revised its strategic plan. ${ }^{4}$ The new plan is organized along five themes, two of which are particularly relevant to understanding the value of EERE's results. Box 1.1 shows the themes and goals that are relevant to benefits analysis for RD3 programs.

\footnotetext{
${ }^{3}$ Lee, R. et al. Estimating the Benefits of Government-Sponsored Energy R\&D: Synthesis of Conference Discussions. Oak Ridge National Laboratory, Oak Ridge, Tennessee (2003)

${ }^{4}$ U.S. DOE Office of the Chief Financial Officer. U.S. Department of Energy Strategic Plan 2006. DOE/CF-0010, Washington, D.C. (2006). Available at www.energy.gov.
} 
Theme 1: Energy Security-Promoting America's energy security through reliable, clean, and affordable energy.

Goal 1.1 Energy Diversity: Increase our energy options and reduce dependence on unstable foreign fuel supplies, thereby reducing vulnerability to disruption and increasing the flexibility of the market to meet U.S. needs.

Goal 1.2 Environmental Impacts of Energy: Reduce greenhouse gas emissions and other environmental impacts (water use, land use, criteria pollutants) from our energy production and use.

Goal 1.3 Energy Infrastructure: Create a more flexible, secure, reliable, and higher capacity U.S. energy infrastructure by improving energy services throughout the economy, enabling use of diverse sources, and improving robustness against, as well as recovery from, disruptions.

Goal 1.4 Energy Use: Cost effectively improve the energy efficiency of the U.S. economy

\section{Theme 3: Scientific Discovery and Innovation-Strengthening U.S. scientific discovery, economic competitiveness, and improving quality of life through innovations in science and technology.}

Goal 3.1 Scientific Discovery: Achieve the major scientific discoveries that will drive U.S. competitiveness; inspire America; and revolutionize our approaches to the Nation's energy, national security, and environmental quality challenges.

Goal 3.2 Foundations of Science: Deliver the scientific facilities, train the next generation of scientists and engineers, and provide the laboratory infrastructure required for U.S. scientific primacy.

Goal 3.3 Research Integration: Integrate basic and applied research to accelerate innovation and to create transformational solutions for U.S. energy needs.

\section{Economic Benefits}

The economic metrics used in this report are summarized in Table 1.1. These metrics are aligned with the modified NRC categories described in Figure 1.1 as well as with DOE's recently revised strategic goals described in Box 1.1. In its deliberation on how to assess the economic benefits of DOE's RD3 programs, the NRC strongly recommended the adoption of "consumer and producer surplus" as a rigorous measure of net benefit to the economy. The energy system cost as measured in MARKAL-GPRA08 (see metric No. 2 in Table 1.1) can be used as an approximate measure of the change in consumer and producer surplus. In NEMS-GPRA08, there is currently no simple way to measure energy system cost or consumer and producer surplus.

While consumer and producer surplus may represent a more comprehensive method of measuring economic benefit, it is a metric that is both difficult to quantify and difficult for many people to understand. For that reason, this year's benefits analysis includes a variety of different metrics or indicators that shed light on different elements of the economic impacts of EERE's RD3 activities- 
including impacts on natural gas prices (a particularly acute issue in the past few years), consumer and household spending on energy, electric-sector costs, and energy intensity of the economy. Detailed descriptions of these metrics are provided in Table 1.1. Where net present values are computed, a 3\% discount rate is used following NRC guidance as well as guidance from the White House Office of Management and Budget (OMB).

\section{Environmental Metrics}

The environmental metrics used in this report are summarized in Table 1.2. These metrics are aligned with the modified NRC categories described in Figure 1.1, as well as with DOE's recently revised strategic goals. Defining environmental metrics for EERE's RD3 programs is difficult. In the past, the only environmental metric that has been tracked is reductions in greenhouse gas emissions - because it is both measurable and directly attributable to energy impacts. The problem of attribution for other regulated emissions is that EERE's programs cannot take credit for emission reductions that are required by policies or regulations that exist independent of the emissions savings of the technologies being developed by EERE.

This year, a new metric has been introduced that estimates the reduced cost of meeting existing and known future regulations for air emissions. The concept is that, given a level of reduction or control mandated by policy, EERE's technologies that lead to lower generation rates of regulated air pollutants will lower costs for air pollution control. This savings is measured as reduction in emissions of $\mathrm{NO}_{\mathrm{x}}$ and $\mathrm{SO}_{\mathrm{x}}$, times the value of the allowance permit for these pollutants. In future years, we anticipate developing metrics that more comprehensively address the broad range of air-, water-, and land-related environmental impacts related to energy production and use.

\section{Energy Security Metrics}

The energy security metrics used in this report are summarized in Table 1.3. These metrics are aligned with the modified NRC categories described in Figure 1.1, as well as with DOE's recently revised strategic goals. Defining energy security metrics for EERE's RD3 programs is even more difficult than for economic or environmental benefits. The obvious focus for energy security is the Nation's dependence on oil and the increasing levels of foreign imports. Thus, four out of the five metrics reported here are oil-related-including year-to-year and cumulative estimates of avoided foreign oil imports and oil intensity of the economy.

Because U.S. transportation demand for energy is almost exclusively reliant on petroleum, two of the energy security metrics are specific to transportation. One is a twist on the commonly recognized measure of fuel economy reported by the Environmental Protection Agency (EPA) in miles per gallon. This new metric is referred to as a "security fuel economy" measured as miles per gallon of crude oil consumed. The details of how this metric is calculated are in Table 1.3.

The second transportation-related metric - the transportation fuel diversity index - requires a little more explanation. As DOE goals 1.1 and 1.3 suggest (see Box 1.1), diversifying the Nation's sources of energy is seen as an important strategy for improving the reliability of energy supply. Diversification is a common-sense notion applied by many individuals as a means of reducing risk and vulnerability in financial investment decisions and in many other situations. Diversity indices have been used to measure the "health" of market, ecosystems, and other systems. 
Table 1.1. EERE Metrics for the NRC Category of Economic Benefits

\begin{tabular}{l|l} 
DOE Theme Key Word: & "Affordable" \\
Relevant DOE Goal & Goal 1.4 Energy Use \\
DOE Key Phrases & "Cost Effective," "Energy Efficiency of the U.S. Economy"
\end{tabular}

1. Reduction in Average Delivered Natural Gas Price (Percent). The percent change in the average natural gas prices measured in constant 2004 dollars. Average natural gas price in NEMS mid-term benefits projections is a rolling three-year average. Average natural gas price in MARKAL long-term benefits projections is the value reported for each five-year increment.

2. Energy System Cost Savings, Annual Billion \$2004. Energy system costs include the annualized capital costs for all capital stock (residual and new), as well as O\&M and fuel costs. Annualized capital costs are calculated using MARKAL hurdle rates, which include both a financial and behavioral components.

3. Consumer Savings, Annual Billion \$2004. Total energy expenditures for all consumers (residential, commercial, industry, and transportation energy prices times energy quantities, same as reported in the Annual Energy Outlook (AEO2006 ${ }^{5}$ ) plus consumer capital expenditures (post-processor computed for selected end-use energy-using equipment investments expressed in annuities calculated using a 3\% discount rate and the average lifetime of the equipment).

4. Consumer Savings, NPV, Billion \$2004. Net present value (NPV) of annual net consumer expenditures beginning in year 2008, discounted at 3\%.

5. Electric Power Industry Savings, Annual Billion \$2004. Total annual expenses and capital payments (fuel, O\&M, and capital for retrofits, new generation capacity, and transmission upgrades). Capital costs are levelized using a 3\% discount rate over 30 years. Currently, distribution costs and existing transmission costs are not included. In addition, only the power industry costs are included, not distributed generation installed by consumers.

6. Electric Power Industry Savings, NPV Billion \$2004. Net present value of electric power industry costs beginning in year 2008 , discounted at $3 \%$.

7. Reduction in Fraction of Household Income Spent on Energy. Fraction of household income spent is defined as residential fuel bill expenditures, plus light-duty vehicle (LDV) fuel bill expenditures, plus capital investments for residential end uses and LDVs divided by real disposable personal income.

8. Reduced Energy Intensity of Economy (Percent). Primary energy is computed with renewable generation counted as 3,412 Btu/kWh except for biomass or other energy sources where Btus are consumed. This is computed as the sum of 1) all primary nonrenewable energy consumption, plus 2) non-biomass generation times 3,412, plus biomass, plus 3 ) other nonelectric renewable fuels divided by the chain-weighted $\$ 2000$ value for gross domestic product (GDP), as reported in the $A E O 2006$ ).

\footnotetext{
${ }^{5}$ U.S. Department of Energy, Energy Information Administration, Annual Energy Outlook 2006: With Projections to 2030.
} Washington, D.C. February 2007. See http://www.eia.doe.gov/oiaf/aeo/index.html 
Table 1.2. EERE Metrics for the NRC Category of Environmental Benefits

DOE Theme Key Word

Relevant DOE Goal

DOE Key Phrases
"Clean"

Goal 1.2 Environmental Impacts of Energy "Reduce greenhouse gas emissions and other environmental impacts"

1. Avoided Greenhouse Gas Emissions, Annual (MMTCE/year). Total million metric tons of carbon equivalent per year from all energy sectors (same as reported in the AEO2006, but as carbon instead of carbon dioxide).

2. Avoided Greenhouse Gas Emissions, Cumulative (MMTCE). Total cumulative carbon emissions beginning in 2008, in million metric tons of carbon equivalent.

3. Reduced Cost of Criteria Pollutant Control, NPV (bil \$2004). Net present value in 2008 of allowance permits for $\mathrm{NO}_{\mathrm{x}}, \mathrm{SO}_{\mathrm{x}}$, and mercury in billions of $\$ 2004$, discounted at $3 \%$.

Table 1.3. EERE Metrics for the NRC Category of Security Benefits

$\begin{array}{ll}\text { DOE Theme Key Word } & \text { "Reliable" } \\ \text { Relevant DOE Goals } & \text { Goal 1.1 Energy Diversity } \\ & \text { Goal 1.3 Energy Infrastructure } \\ \text { DOE Key Phrases } & \text { "Flexibility," "Reduced Foreign Oil" }\end{array}$

1. Avoided Oil Imports, Annual (mbpd). Net crude oil imports and petroleum product savings each year, measured in millions of barrels per day.

2. Avoided Oil imports, Cumulative (bil barrels). Cumulative oil import savings beginning in 2008.

3. Security Fuel Economy Improvement (MPG of Crude Oil). Light-duty vehicle miles traveled divided by light-duty vehicle oil (gasoline, diesel, and LPG) consumption converted to gallons.

4. Transportation Fuel Diversity Improvement (percent). Percent change in the Shannon-Wiener diversity index for the transportation sector, calculated based on estimates of the pro rata share of primary energy sources contributing to U.S. energy supply. (See detailed discussion in the text of this chapter). ${ }^{6}$

5. Oil Intensity Reduction (percent). Measured as percent change in annual oil consumption per GDP. Oil intensity is billion barrels of oil consumed per dollar of annual GDP.

\footnotetext{
${ }^{6}$ In ecology, a diversity index is a statistic that measures the biodiversity of an ecosystem. The Shannon index (also called the Shannon-Wiener index), $H^{\prime}$, is one of several diversity indices used to measure biodiversity. It is estimated as follows:

$H^{\prime}=\sum_{i=1}^{S} p_{i} \ln p_{i}$

where $p_{i}$ is the fraction of each proportion of individuals in a given species " $i$ " relative to the total population, and $\mathrm{S}$ is the total number of species. This index takes into account both the number of species and the "evenness" of distribution of the species. In fact, $H^{\prime}$ always has a maximum value when all species are present in equal numbers. When few species exist or when a small number of species dominate, the value of $H^{\prime}$ is lower. We apply this index to transportation energy diversity by substituting types of primary energy sources for species.
} 


\section{Meeting Congressional and Presidential Demand for Accountability}

This benefits analysis helps EERE meet the provisions of the Government Performance and Results Act (GPRA) of 1993 and the President's Management Agenda (PMA). GPRA requires Federal Government agencies to develop and report on output and outcome measures for each program. ${ }^{7}$ The analyses reported here support these GPRA requirements by providing a quantitative assessment of the benefits that may accrue to the Nation if the performance goals of EERE's programs are realized.

The analysis summarized in this report also supports the President's Management Agenda by linking funding and performance goals to real benefits to the Nation. EERE's programs develop these goals based on the following key assumptions: ${ }^{8}$

- Programs will be funded at levels consistent with DOE's FY 2008 Budget Request.

- Funding levels will remain constant in inflation-adjusted dollars or increase to accommodate key initiatives in particular cases, as indicated.

- Funding is assumed to be in place until goals are achieved.

\section{Role of Benefits Analysis in Performance Management}

EERE employs a widely used logic model ${ }^{9}$ as the foundation for managing its portfolio of efficiency and renewable investments, and for ensuring that these investments provide energy benefits to the Nation. In its simplest form, a logic model identifies the relationship between budget and other inputs to a program, activities conducted by the program, and the resulting outputs and outcomes of those activities. The logic model employed by EERE (Figure 1.2) provides an integrated approach that explicitly links requested budget levels to performance goals and estimated benefits - and helps ensure that estimated benefits reflect the funding levels requested. The elements of the logic model, which are specified in GPRA, are included in the annual budget request.

Multiyear Program Plans (MYPPs), developed by each of EERE's nine programs, identify available inputs, the activities that will be undertaken with their budget, the performance milestones they expect to achieve as they pursue these activities, and the resulting products or outputs of the RD3 effort. ${ }^{10}$ Inputs may include cost-shared or leveraged funds, as well as EERE program dollars - and may also include advances by others on which the program builds. Performance milestones capture intermediate points of discernable progress toward outputs and are used by program managers, DOE, the White House OMB, and others to track program progress toward their outputs. Outputs, often referred to as "program goals" or "program performance goals," 11 are the resulting products or achievements of an overall area of

\footnotetext{
${ }^{7}$ See the Government Performance and Results Act (GPRA) of 1993 at http://www.whitehouse.gov/omb/mgmtgpra/gplaw2m.html and http://www.whitehouse.gov/omb/circulars/a11/02toc.html

${ }_{8}$ Achieving program goals is generally not dependent on a single technical pathway, but instead encompasses a number of alternative approaches, of which some may fall short without jeopardizing realization of the final goal. The pursuit of multiple pathways can increase the likelihood of achieving program goals, thereby reducing the risk of the program. Risk is being addressed in a separate EERE effort to develop a standard approach to risk assessment.

${ }^{9}$ The logic model is a fundamental program planning-and-evaluation tool. For more on logic models, see: Wholey, J. S. (1987). Evaluability assessment: developing program theory. Using Program Theory in Evaluation. L. Bickman. San Francisco, Calif., Jossey-Bass. 33. Jordan, G. B. and J. Mortensen (1997). "Measuring the performance of research and technology programs: a balanced scorecard approach." Journal of Technology Transfer 22(2). McLaughlin, J. A. and G. B. Jordan (1999). "Logic models: a tool for telling your program's performance story." Evaluation and Program Planning 22(1): 65-72.

${ }^{10}$ Appendices B through J provide more information on each program's multiyear program plan and the inputs, activities, milestones, and outputs that are included.

${ }^{11}$ Some programs derive their outputs through technology-cost simulation models to develop the specific requirements to meet overall program cost and performance goals. Specific details of the representation of the program outputs in NEMS-GPRA08, MARKAL-GPRA08, and the underlying program analysis and documentation are found in Chapters 2 and 3 of this report and Appendices B through J.
}

Projected Benefits of Federal Energy Efficiency and Renewable Energy Programs (FY 2008-FY 2050) Estimating Prospective Benefits of EERE's Portfolio (Chapter 1) - Page 1-8 
activity. EERE's RD3 programs typically specify their outputs in terms of technology advances (e.g., reduced costs, improved efficiency), while deployment programs develop outputs related to their immediate market impacts (e.g., number of homes weatherized). Outputs evolve over time as the program pursues increasing levels of technology performance or market penetration. ${ }^{12}$

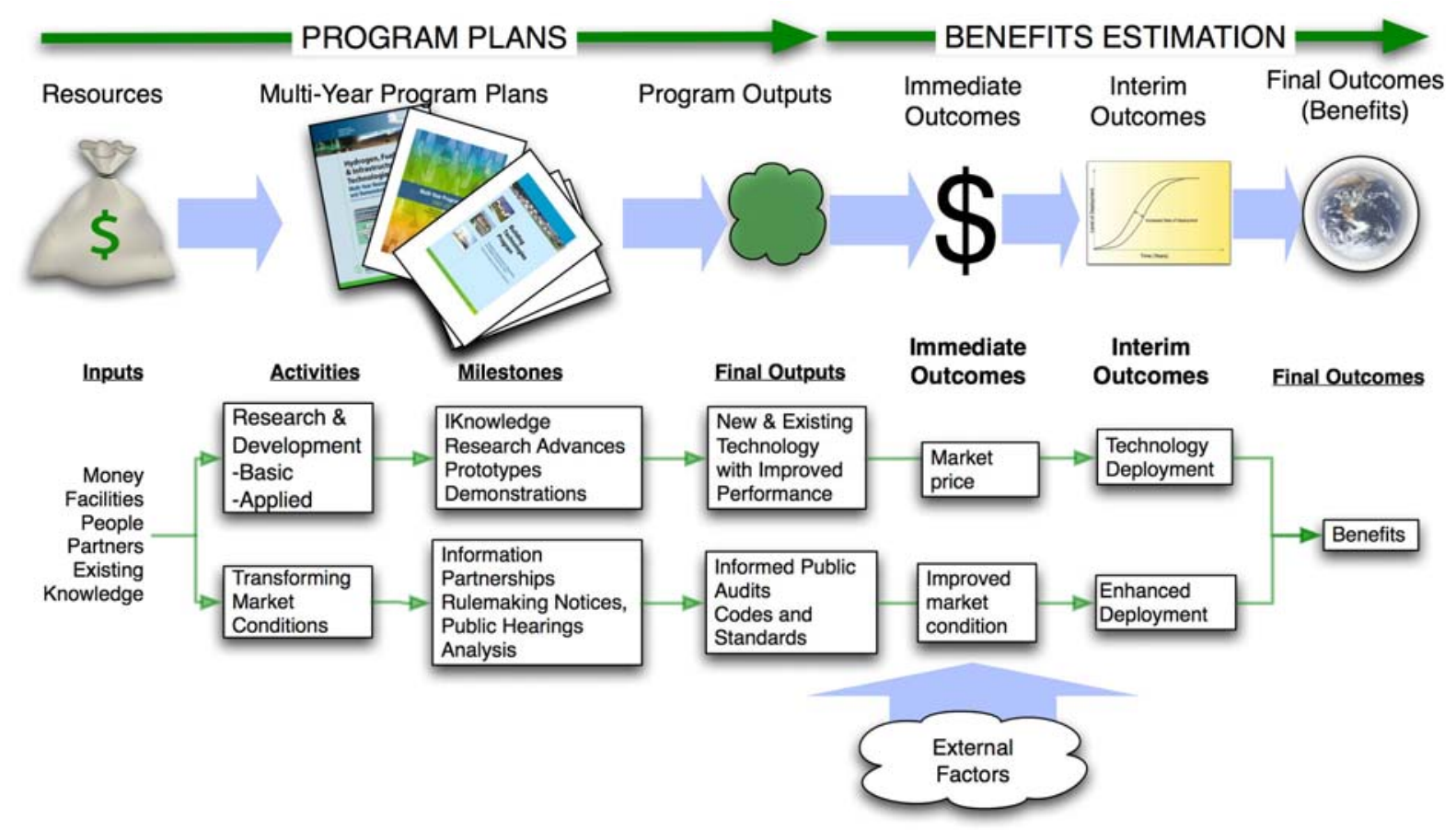

Figure 1.2. Generalized EERE Logic Model

This benefits analysis links these program outputs to their market impacts or outcomes using integrated energy market models. EERE's programs have discernable effects on energy markets, both by reducing the level of energy demand (through efficiency improvements) and by changing the mix of our energy supplies (through increased renewable and distributed energy production).

These changes in energy use provide the basis for the economic, environmental, and security benefits estimated here. The extent to which a new technology or a deployment effort changes energy markets will depend on a variety of external factors. The future demand for energy, its price, the development of competing technologies, and other market features (such as consumer preferences) all will contribute to the marketability and total sales of a new technology.

While the logic model discussed here shows the linkage between resources and benefits for each program, it does not show the full scope of how benefits analysis fits in the overall process of performance management. Figure 1.3 shows a more holistic perspective on the role of benefits analysis in performance management. When used appropriately, benefits analysis serves as an important feedback loop at two levels: 1) individual program planning, and 2) EERE management assessment of its technology development and deployment portfolio. In the first case, this analysis can help individual program managers make better choices about the suite of activities and technology options that will maximize their program's benefits to the Nation. Looking at the benefits available from the entire suite of EERE

\footnotetext{
${ }^{12}$ The level of risk for the programs is assessed qualitatively as part of the Office of Management and Budget (OMB) R\&D Investment Criteria. EERE is developing a standard approach to assessing technology and program risk. 
programs in an integrated portfolio can help decision-makers maximize the overall return on government investment in energy efficiency and renewable energy technologies. Results of benefits analyses represent just one of many important criteria that must be weighed in prioritizing spending across the portfolio.

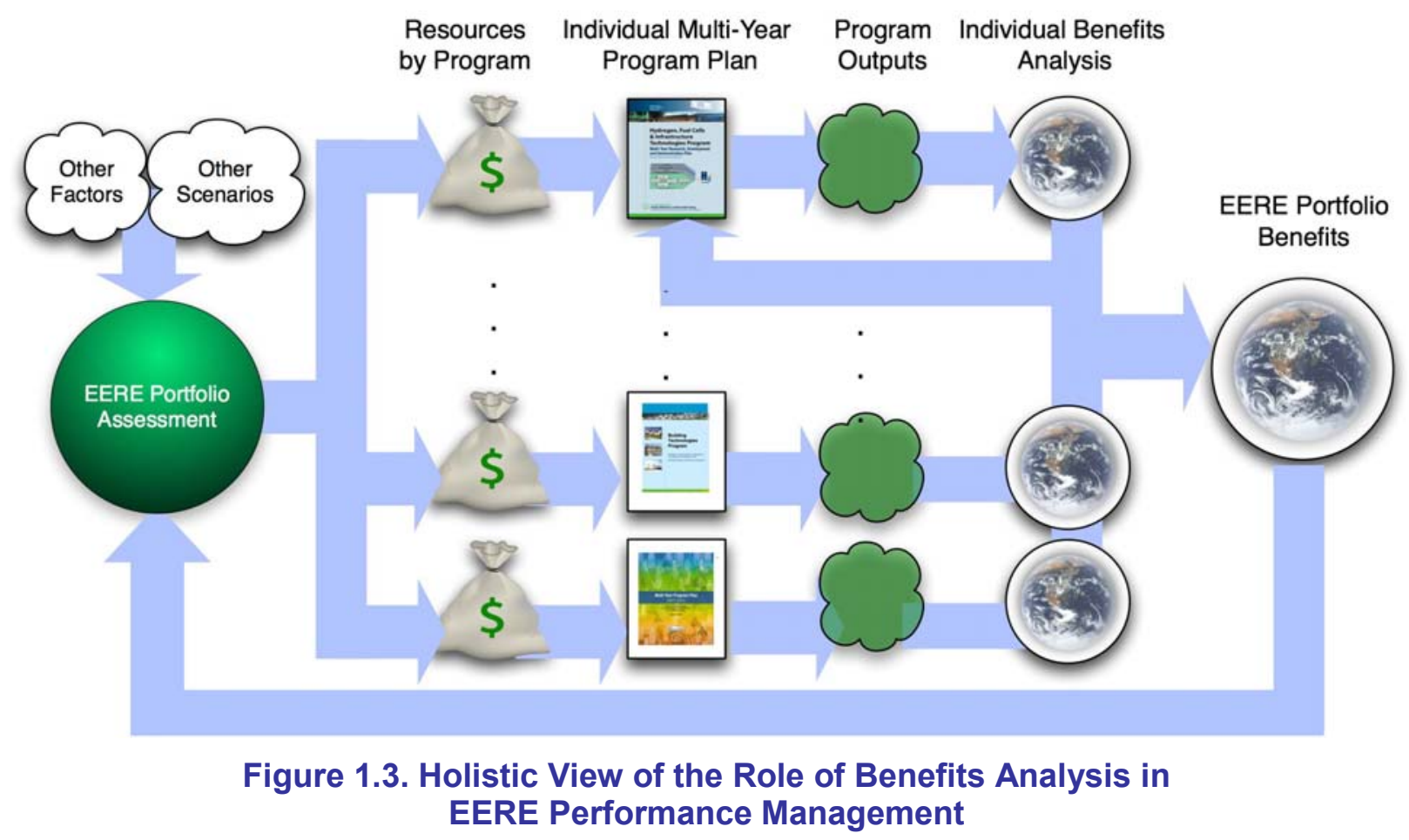

\section{Benefits Analysis Process}

EERE's benefits analysis process involves three major steps. In Step 1, EERE's Office of Planning, Budget, and Analysis (PBA) develops a standard baseline and methodological approach (guidance) to help ensure consistency in estimates across programs. In Step 2, EERE's programs develop specific technology and market information, which is necessary to understanding the potential roles of each program in its target markets. In Step 3, PBA uses this program and market information to assess the impacts of each EERE program (as well as the overall EERE portfolio) on energy markets in the United States using integrated energy-economic models.

The first step in the benefits analysis process is to establish an appropriate Baseline Case. The EERE Baseline Case is a projection intended to represent the future U.S. energy system without the effect of EERE and other DOE RD3 energy, science, and environment (ESE) programs. The most recent ${ }^{13}$ Annual Energy Outlook Reference Case is used as the starting point for developing the Baseline Case. The Energy Information Administration (EIA) Annual Energy Outlook (AEO2006) Reference Case provides an independent representation of the likely evolution of energy markets. Neither the EIA Reference Case nor the EERE Baseline Case includes any changes in future energy policies.

In establishing its Baseline Case, EERE makes a number of modifications to the AEO2006 Reference Case. Modifications are made to the same model — the National Energy Modeling System (NEMS) — used by EIA in developing the Annual Energy Outlook. To distinguish it from EIA's version, the model is referred to as NEMS-GPRA08. The AEO2006 Reference Case is also the starting point for the long-term

\footnotetext{
${ }^{13}$ See http://www.eia.doe.gov/oiaf/aeo/index.html
} 
(to 2050) benefits modeling using MARKAL-GPRA08. The Baseline Cases for both NEMS-GPRA08 and MARKAL-GPRA08 are aligned as closely as possible, but the two models are different in their internal design.

In Step 2, program goals and salient target-market characteristics are developed as inputs to modeling the benefits estimation in Step 3. The effort required under Step 2 varies, depending on the form in which programs specify their output or performance goals and how NEMS-GPRA08 and MARKAL-GPRA08 utilize this information. It ranges from the compilation of technology goals to detailed market analyses that produce technology-penetration rates - and, in some cases, delivered energy savings.

For much of EERE's portfolio, "off-line" analyses are needed to translate information about program technology and market characteristics into usable modeling inputs. In general, analysts perform the most detailed off-line analyses for the Industrial Technologies Program, Weatherization and Intergovernmental Program (WIP), Federal Energy Management Program (FEMP), and portions of the Building Technologies Program. Analysts tailor these off-line analytical approaches to the characteristics of the program and target market being analyzed; but, in all cases, they are conducted within the overall guidance provided through the GPRA benefits-estimation process. 


\section{ERRATUM \\ CHAPTER 2 - THE VALUE OF EERE'S PORTFOLIO}

Last-minute changes in the budget and direction for the Weatherization and Intergovernmental Program (WIP) were not incorporated in the portfolio benefits shown in Chapter 2. Revised midterm benefits reflecting the changes in WIP are shown below.

\begin{tabular}{|c|c|c|c|c|c|}
\hline & \multicolumn{5}{|c|}{ MIDTERM BENEFITS } \\
\hline Metric & 2010 & 2015 & 2020 & 2025 & 2030 \\
\hline \multicolumn{6}{|l|}{ ECONOMIC BENEFITS ("AFFORDABLE") } \\
\hline $\begin{array}{l}\text { Reduction in Average Delivered Natural Gas Price } \\
\text { (Percent) }\end{array}$ & $1 \%$ & $1 \%$ & $3 \%$ & $6 \%$ & $3 \%$ \\
\hline Energy System Cost Savings (bil \$2004) 1/ & $\$ 6$ & $\$ 23$ & $\$ 39$ & $\$ 67$ & $\$ 95$ \\
\hline Consumer Savings, Annual (bil \$2004) & 6 & 15 & 46 & 91 & 119 \\
\hline Consumer Savings, NPV (bil \$2004) 2/ & 10 & 56 & 162 & 384 & 676 \\
\hline Electric Power Industry Savings, Annual (bil \$2004) 3/ & 2 & 6 & 14 & 23 & 30 \\
\hline Electric Power Industry Savings, NPV (bil \$2004) 2/ 3/ & 4 & 23 & 61 & 122 & 195 \\
\hline $\begin{array}{l}\text { Reduction in Fraction of Household Income Spent on } \\
\text { Energy }\end{array}$ & $0.1 \%$ & $0.5 \%$ & $1.8 \%$ & $3.5 \%$ & $4.9 \%$ \\
\hline Reduced Energy Intensity of Economy (Percent) & $0.4 \%$ & $1.8 \%$ & $4.1 \%$ & $6.4 \%$ & $8.3 \%$ \\
\hline \multicolumn{6}{|l|}{ ENVIRONMENTAL BENEFITS ("CLEAN") } \\
\hline $\begin{array}{l}\text { Avoided Greenhouse Gas Emissions, Annual } \\
\text { (MMTCE/year) }\end{array}$ & 8 & 35 & 105 & 173 & 233 \\
\hline $\begin{array}{l}\text { Avoided Greenhouse Gas Emissions, Cumulative } \\
\text { (MMTCE) 5/ }\end{array}$ & 16 & 134 & 503 & 1223 & 2262 \\
\hline $\begin{array}{l}\text { Reduced Cost of Criteria Pollutant Control, NPV (bil \$2004) } \\
2 /\end{array}$ & 1 & 2 & 4 & 10 & 14 \\
\hline \multicolumn{6}{|l|}{ SECURITY BENEFITS ("RELIABLE") } \\
\hline Avoided Oil Imports, Annual (mbpd) & ns & 0.2 & 0.6 & 1.3 & 2.1 \\
\hline Avoided Oil imports, Cumulative (bil barrels) 4/ 5/ & ns & 0.3 & 1.0 & 2.8 & 6.1 \\
\hline Security Fuel Economy Improvement (MPG of Crude Oil) & 0.1 & 0.5 & 1.3 & 2.7 & 5.2 \\
\hline Improved Transportation Fuel Diversity (percent) 6/ & ns & ns & $3 \%$ & $10 \%$ & $22 \%$ \\
\hline Reduced Oil Intensity of the Economy (percent) & ns & $1.2 \%$ & $2.9 \%$ & $5.9 \%$ & $9.2 \%$ \\
\hline
\end{tabular}

Table notes:

1/ Energy system costs include the annualized capital costs for all capital stock (residual and new), as well as O\&M and fuel costs. Annualized capital costs are calculated using MARKAL hurdle rates, which include both financial and behavioral components.

2/ NPV (net present value) calculations done using 3\% real discount rate back to 2008.

3/ Electric power industry cost does not include demand-side distributed generation.

4/ Renewable generation values at output value (3412 Btu/kWh) except for biomass and geothermal where energy content is used.

5/ All cumulative values are from 2008.

6/ Diversity index change is Case minus Base (opposite of others).

7/ Midterm benefits based on NEMS-GPRA08 model.

8/ Long-term benefits based on MARKAL-GPRA08 model.

$\mathrm{nr}=$ not reported or calculated by model

$\mathrm{ns}=$ not significant relative to model error 


\section{CHAPTER 2 - THE VALUE OF EERE'S PORTFOLIO}

\section{Table of Contents}

The Benefits of EERE's RD3 Portfolio Under a Business-As-Usual Future ....................................2-3

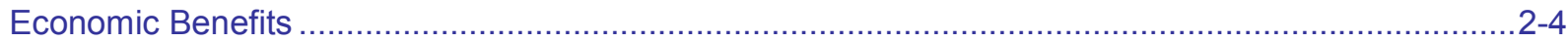

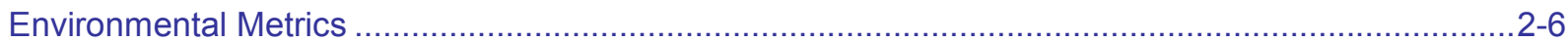

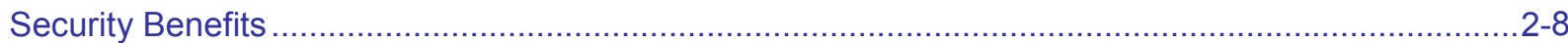

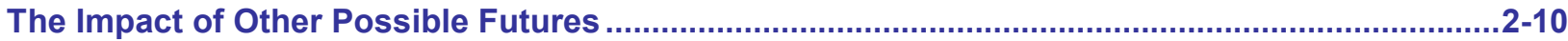

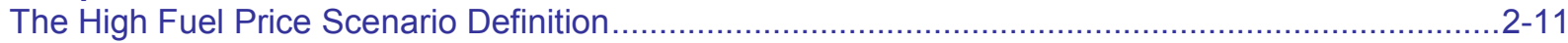

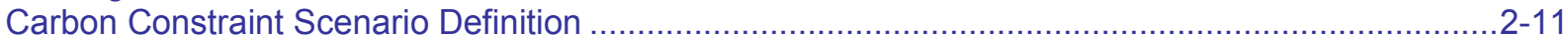

Summary of Benefits Metrics Under Alternative Scenarios......................................................... $2-13$

Economic Benefits Under Alternative Scenarios .................................................................... -15

Environmental Benefits of EERE's Portfolio Under Alternative Scenarios ....................................2-19

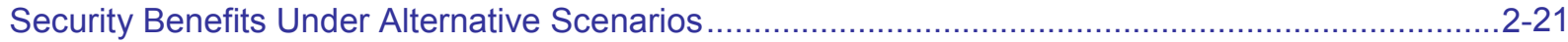

A Closer Look at the Energy Picture .........................................................................................2

Changes in Primary Energy Demand Under Alternative Scenarios ...........................................2-23

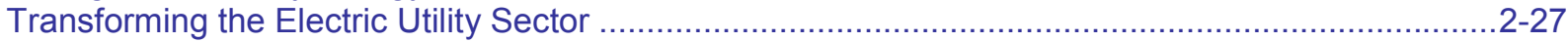

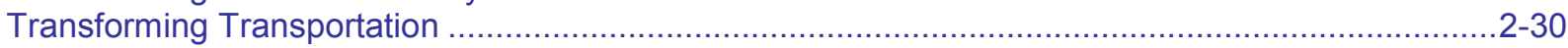

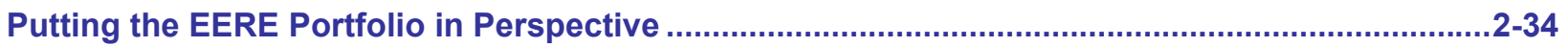

\section{List of Figures}

Figure 2.1. Projected Economic Benefits Metrics for EERE's RD3 Portfolio ......................................2-5

Figure 2.2. Historical and Projected Trends for Consumer Spending and Energy Intensity of the Economy

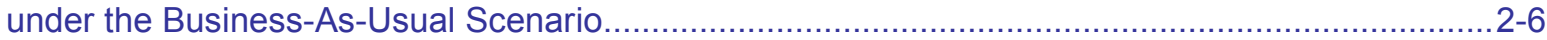

Figure 2.3. Environmental Metrics for the Business-As-Usual Scenario ...........................................2-7

Figure 2.4. Historical and Projected Greenhouse Gas Emissions under the Business-As-Usual Scenario

Figure 2.5. Security Metrics for EERE's Portfolio Under the Business-As-Usual Scenario..........................2-8

Figure 2.6. Historical and Projected Oil Trends for the Business-As-Usual Scenario ...........................2-9

Figure 2.7. Historical and Projected Oil and Gas Prices Under Business-As-Usual and High Fuel Price

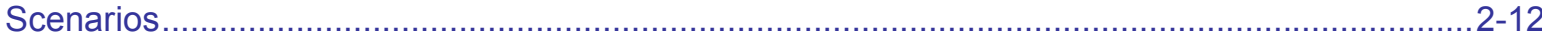

Figure 2.8. Carbon Emissions Under a Carbon Cap Policy ............................................................ $2-12$

Figure 2.9. Carbon Allowance Price ................................................................................... $2-13$

Figure 2.10. Consumer, Energy System, and Electric Power-Sector Cost Savings Under Alternative

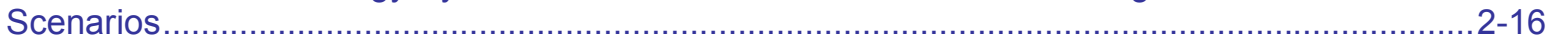

Figure 2.11. Consumer Spending for Energy Under Alternative Scenarios ....................................2-17

Figure 2.12. Reduction in Household Spending and Energy Intensity Under Alternative Scenarios ......2-18

Figure 2.13. Energy Intensity Trends Under Alternative Scenarios ....................................................2-19

Figure 2.14. Environmental Benefits Under Alternative Scenarios .................................................2-19

Figure 2.15. Carbon Emissions and Carbon Intensity Trends Under Alternative Scenarios ...................2-20

Figure 2.16. Security Benefits Under Alternative Scenarios ..........................................................2-21

Figure 2.17. Oil Import and Oil Intensity Trends Under Alternative Scenarios ..................................2-22

Figure 2.18. Primary Energy Consumption Baselines Under Alternative Scenarios ...........................2-24

Figure 2.19. Effect of EERE's Portfolio on Primary Energy Consumption Under Alternative Scenarios.2-24

Figure 2.20. Shifts in Midterm Energy Growth by Sector Under Alternative Scenarios ........................2-25

Figure 2.21. Shifts in Long-Term Energy Growth by Sector Under Alternative Scenarios ....................2-26

Figure 2.22. Growth in Building-Sector Energy Demand Under Alternative Scenarios .........................2-26

Figure 2.23. Electricity Generation Capacity in 2030 Under Alternative Scenarios.............................2-27

Figure 2.24. Changes in Electricity Generation Capacity Distribution Under Alternative Scenarios .......2-28

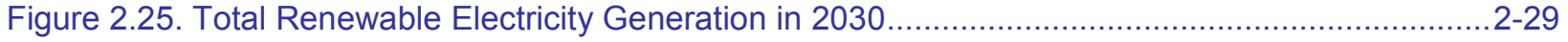


Figure 2.26. Total Renewable Electricity Generation in 2050 ......................................................2-30

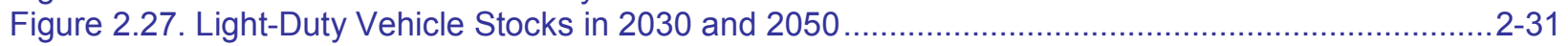

Figure 2.28. Changes in Transportation Fuel Demand Under Alternative Scenarios............................2-33

Figure 2.29. Overall Impact of EERE's Portfolio Under Alternative Scenarios ......................................2-35

\section{List of Tables}

Table 2.1. EERE Portfolio Benefits for FY 2008 Budget Request-Business-As-Usual Scenario............2-3

Table 2.2. EERE Portfolio Benefits for FY 2008 Budget Request-High Fuels Price Scenario...............2-14

Table 2.3. EERE Portfolio Benefits for FY 2008 Budget Request-Carbon Constraint Scenario...........2-15 


\section{The Benefits of EERE's RD3 Portfolio Under a Business-As-Usual Future}

Benefits analysis under the business-as usual (BAU) case reflects the effect of EERE's RD3 portfolio on a baseline case built on the AEO2006 Reference Oil Price Case. Table 2.1 shows the estimated economic, environmental, and security benefits of EERE's overall portfolio of investments in improved energyefficient technologies, renewable energy technologies, and assistance to consumers in adopting these technologies. Results by five-year increments from 2010 to 2030 are shown for NEMS-GPRA08 and by five-year increments from 2035 to 2050 for MARKAL-GPRA08. The benefits reported here do not reflect last-minute changes in budget and direction for the Weatherization and Intergovernmental Program (WIP). An erratum is included at the end of this report showing revised midterm benefits estimates that reflect the changes in WIP. These revised estimates are roughly $10 \%$ higher than the estimates shown in

Table 2.1.

Table 2.1. EERE Portfolio Benefits for FY 2008 Budget RequestBusiness-As-Usual Scenario

\begin{tabular}{|c|c|c|c|c|c|c|c|c|c|}
\hline & \multicolumn{5}{|c|}{ MIDTERM BENEFITS 7/ } & \multicolumn{4}{|c|}{ LONG-TERM BENEFITS 8/ } \\
\hline Metric & 2010 & 2015 & 2020 & 2025 & 2030 & 2035 & 2040 & 2045 & 2050 \\
\hline \multicolumn{10}{|l|}{ ECONOMIC BENEFITS ("AFFORDABLE") } \\
\hline $\begin{array}{l}\text { Reduction in Average Delivered Natural Gas Price } \\
\text { (Percent) }\end{array}$ & $1 \%$ & $0 \%$ & $3 \%$ & $5 \%$ & $2 \%$ & $5 \%$ & $10 \%$ & $16 \%$ & $12 \%$ \\
\hline Energy System Cost Savings (bil \$2004) 1/ & $\mathrm{nr}$ & $\mathrm{nr}$ & $\mathrm{nr}$ & $\mathrm{nr}$ & $\mathrm{nr}$ & 120 & 146 & 173 & 203 \\
\hline Consumer Savings, Annual (bil \$2004) & 4 & 12 & 43 & 86 & 110 & 232 & 322 & 385 & 381 \\
\hline Consumer Savings, NPV (bil \$2004) 2/ & 6 & 46 & 148 & 359 & 632 & 1,518 & 2,088 & 2,707 & 3,278 \\
\hline Electric Power Industry Savings, Annual (bil \$2004) 3/ & 1 & 5 & 13 & 21 & 26 & 51 & 63 & 77 & 69 \\
\hline Electric Power Industry Savings, NPV (bil \$2004) 2/ 3/ & & 18 & 54 & 110 & 174 & 419 & 536 & 658 & 766 \\
\hline $\begin{array}{l}\text { Reduction in Fraction of Household Income Spent on } \\
\text { Energy }\end{array}$ & $0.3 \%$ & $0.7 \%$ & $2.0 \%$ & $3.6 \%$ & $4.8 \%$ & $8 \%$ & $9 \%$ & $10 \%$ & $10 \%$ \\
\hline Reduced Energy Intensity of Economy (Percent) & $0.3 \%$ & $1.7 \%$ & $3.9 \%$ & $6.1 \%$ & $7.8 \%$ & $10 \%$ & $13 \%$ & $15 \%$ & $17 \%$ \\
\hline \multicolumn{10}{|l|}{ ENVIRONMENTAL BENEFITS ("CLEAN") } \\
\hline $\begin{array}{l}\text { Avoided Greenhouse Gas Emissions, Annual } \\
\text { (MMTCE/year) }\end{array}$ & 6 & 33 & 101 & 165 & 219 & 447 & 508 & 539 & 505 \\
\hline $\begin{array}{l}\text { Avoided Greenhouse Gas Emissions, Cumulative } \\
\text { (MMTCE) 5/ }\end{array}$ & 12 & 116 & 470 & 1158 & 2136 & 4630 & 7047 & 9680 & 12276 \\
\hline $\begin{array}{l}\text { Reduced Cost of Criteria Pollutant Control, NPV (bil } \\
\$ 2004) 2 /\end{array}$ & 0 & 1 & 3 & 9 & 13 & $\mathrm{nr}$ & $\mathrm{nr}$ & $\mathrm{nr}$ & $\mathrm{nr}$ \\
\hline \multicolumn{10}{|l|}{ SECURITY BENEFITS ("RELIABLE") } \\
\hline Avoided Oil Imports, Annual (mbpd) & ns & 0.2 & 0.6 & 1.2 & 2.1 & 5.3 & 6.9 & 7.1 & 6.8 \\
\hline Avoided Oil imports, Cumulative (bil barrels) 4/ 5/ & $\mathrm{ns}$ & 0.3 & 1.0 & 2.8 & 6.1 & 17 & 28 & 41 & 54 \\
\hline $\begin{array}{l}\text { Security Fuel Economy Improvement (MPG of Crude } \\
\text { Oil) }\end{array}$ & 0.1 & 0.5 & 1.3 & 2.8 & 5.3 & 23 & 38 & 51 & 64 \\
\hline Improved Transportation Fuel Diversity (Percent) 6/ & ns & ns & $4 \%$ & $10 \%$ & $24 \%$ & $82 \%$ & $86 \%$ & $67 \%$ & $42 \%$ \\
\hline Reduced Oil Intensity of the Economy (Percent) & $0.2 \%$ & $1 \%$ & $3 \%$ & $6 \%$ & $9 \%$ & $26 \%$ & $32 \%$ & $33 \%$ & $33 \%$ \\
\hline
\end{tabular}

Table notes:

$1 /$ Energy system costs include the annualized capital costs for all capital stock (residual and new), as well as O\&M and fuel costs. Annualized capital costs are calculated using MARKAL hurdle rates, which include both financial and behavioral components.

2/ NPV (net present value) calculations done using 3\% real discount rate back to 2008

3/ Electric power industry cost does not include demand-side distributed generation.

4/ Renewable generation values at output value (3412 Btu/kWh) except for biomass and geothermal where energy content is used.

5/ All cumulative values are from 2008.

6/ Diversity index change is Case minus Base (opposite of others).

7/ Midterm benefits based on NEMS-GPRA08 model.

8/ Long-term benefits based on MARKAL-GPRA08 model.

$\mathrm{nr}=$ not reported or calculated by model

$\mathrm{ns}=$ not significant relative to model error 


\section{Economic Benefits}

Figure 2.1 shows projected economic benefits associated with EERE's portfolio. The top row of charts shows net consumer cost savings, net energy system cost savings, and electric power-sector cost savings through 2050. EERE's portfolio has its greatest impact on the consumer side of the economy. Consumer savings reach $\$ 100$ billion annually in 2030 , and level off at almost $\$ 400$ billion annually by 2045 . The apparent jump in consumer savings from 2030 to 2035 is an artifact related to switching from NEMSGPRA08 to MARKAL-GPRA08. The net present value of these savings is almost $\$ 700$ billion by 2030 , and more than $\$ 3$ trillion by 2050 .

From an economist's perspective, consumer savings do not necessarily represent the net impact of EERE's portfolio on the economy. Net annual energy system cost savings - a proxy for the consumer and producer surplus that takes into account the net gains on both the consumer and producer side of the economy - are lower than the benefits projected for consumers. Nevertheless, it doubles from $\$ 100$ billion annually in 2030 to $\$ 200$ billion annually in 2050 . The results shown here are all based on MARKAL-GPRA08 over the entire projection because NEMS-GPRA08 cannot estimate net energy system cost.

The electric power industry - a major component of the energy producer side of the economy - shows savings that reach almost $\$ 30$ billion annually by 2030 , peak at almost $\$ 80$ billion annually in 2045 , and decline to $\$ 70$ billion annually in 2050 . Total electric power industry expenses were about $\$ 235$ billion in 2005. ${ }^{1}$ As with the consumer savings estimates, there is a slight discontinuity from 2030 to 2035 due to the change from NEMS-GPRA08 to MARKAL-GPRA08 models. The net present value of these savings to the electric power sector is more than $\$ 170$ billion and more than $\$ 600$ billion, respectively, in 2030 and 2050 .

The bottom row of charts in Figure 2.1 shows trends for other relevant economic benefits of EERE's portfolio. The relative spending of household income on energy is 5\% lower in 2030 for the EERE portfolio case, with the reductions leveling off to about $10 \%$ by 2050 . Reductions in energy intensity of the economy grow steadily throughout the period of 2010 through 2050 , reaching $8 \%$ and $17 \%$, respectively, in 2030 and 2050 . Trends for natural gas price reductions are more volatile, showing two peaks in reductions of $5 \%$ in 2025 and $16 \%$ in 2045.

Figure 2.2 provides a historical perspective on the projected absolute trends in consumer spending on energy and the energy intensity of the U.S. economy. ${ }^{2}$ In the absence of EERE's portfolio, consumer spending continues its historical increase through 2045. EERE's portfolio slows and ultimately reverses the historical and projected growth in consumer spending for energy. Consumer expenditures on fuel purchases are $10 \%$ lower than they would be in 2030 without EERE's portfolio, and $30 \%$ lower than projected 2050 spending without EERE's portfolio.

Energy intensity of the U.S. economy has been declining dramatically since data on this metric have been available starting in 1949. This decline is due to both structural changes in the economy - a shift from an industrial to a service-oriented economy - and to significant improvements in energy efficiency, especially since the 1970s. This historical and projected decline in energy intensity overwhelms the impact of EERE's portfolio, which provides additional $8 \%$ and $18 \%$ reductions in energy intensity in 2030 and 2050, respectively.

\footnotetext{
${ }^{1}$ Revenue and expense statistics reported in Electric Power Annual 2005. Energy Information Administration, U.S. Department of Energy, DOE/EIA-0348(2005. Washington, D.C. November 2006.

${ }^{2}$ Note that the consumer spending trends presented here differ from the consumer expenditures data used to calculate the metric of net consumer savings. Projected net consumer savings includes both expenses for purchasing energy and investment costs associated with purchasing end-use energy technologies. Because EIA's historical data does not include investment costs, the trend data reported for both historical and projected consumer spending excludes consumer investment costs (and therefore overstates the EERE impact). The trends are nevertheless instructive.
} 

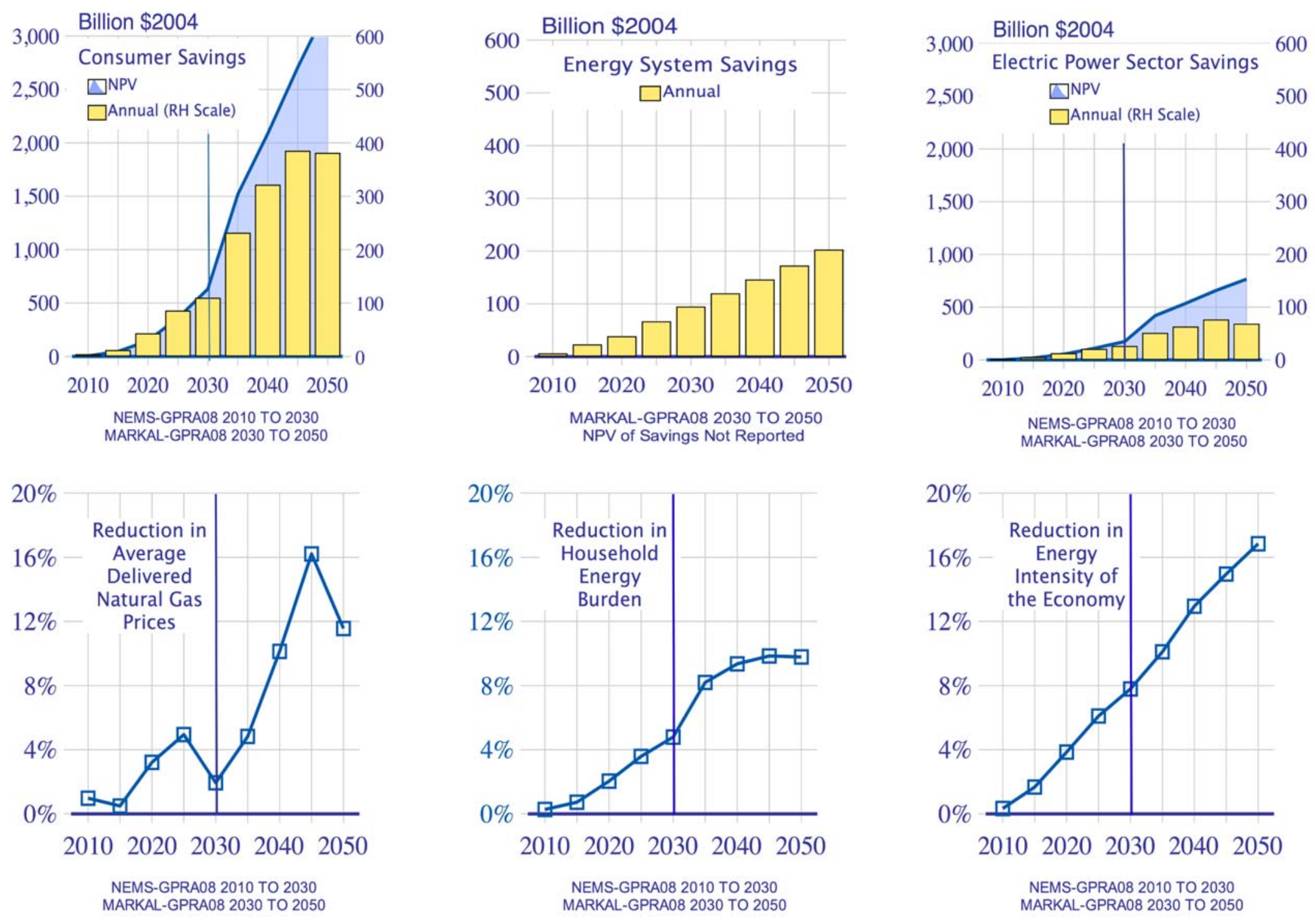

Figure 2.1. Projected Economic Benefits Metrics for EERE's RD3 Portfolio 


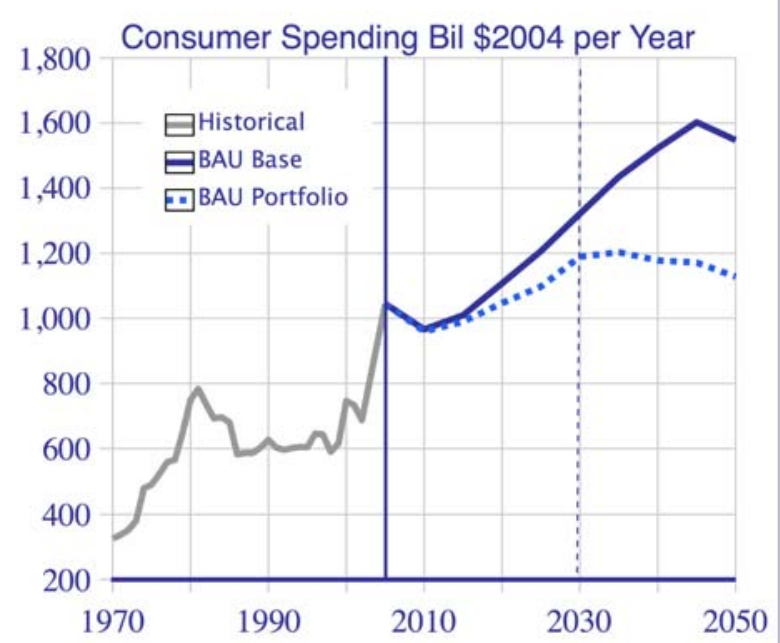

Solid line represents historical and projected trend without future funding of the EERE portfolo. Dashed line represents projected trend assuming continued funding of the EERE portfolio.

NEMS-GPRA08 2010 to 2030 MARKAL-GPRA08 2035 to 2050. Historical data to 2002 from U.S. Department of Energy, Energy Information Administration. Annual Energy Review 2005 DOE/ EIA-0384 (2005) (Washington, D.C., July 2006) Consumer Expenditure Estimates for Energy by Source. (http:/l www.eia.doe.gov/emeu/aer/contents.html)

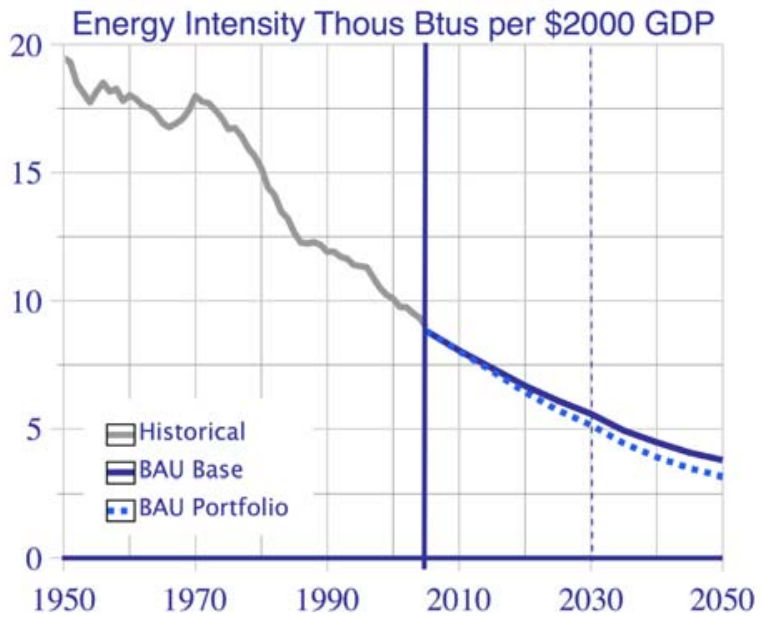

Solid line represents historical and projected trend without future funding of the EERE portfolo. Dashed line represents projected trend assuming continued funding of the EERE portfolio.

NEMS-GPRA0 2010 to 2030 MARKAL-GPRA08 2035 to 2050 Historical data to 2005 from U.S. Department of Energy, Energy Information Administration. Annual Energy Review $2005 \mathrm{DOE} /$ ElA-0384 (2005) (Washington, D.C., July 2006) Table 1.5 Energy Consumption, Expenditures, and Emissions Indicators, 1949 -2005. (http://www.eia.doe.gov/emeu/aer/contents.html)

\section{Figure 2.2. Historical and Projected Trends for Consumer Spending and Energy Intensity of the Economy under the Business-As-Usual Scenario}

\section{Environmental Metrics}

Figure 2.3 shows the projected environmental benefits associated with continued funding of EERE's portfolio under the "Business-As-Usual" (BAU) scenario. Approximately 200 million metric tons of carbon per year are avoided by 2030, with savings leveling off to about 500 million metric tons per year by about 2040. The slowing in the rate of growth in carbon emissions savings in the out-years reflects assumptions about technological progress that would eventually result in many of the same outcomes as EERE's portfolio produces, but not as quickly as they can occur with continued funding of EERE's portfolio. The doubling of carbon emissions savings from 2030 to 2035 is an artifact related to the switch from NEMS-GPRA08 to MARKAL-GPRA08. Cumulative carbon savings are 2 billion and 12 billion metric tons in 2030 and 2050. The net present value of projected reduced costs of air pollution control associated with EERE's portfolio is $\$ 13$ billion in 2030. These savings represent the allowance value for avoided emissions of nitrogen oxides, sulfur oxides, and mercury in the electric power sector. Pollution control cost savings are not estimated beyond 2030 because MARKAL-GPRA08 cannot estimate these savings.

Figure 2.4 provides a historical perspective on the projected absolute emissions of greenhouse gases and the greenhouse gas intensity of the U.S. economy. EERE's portfolio effectively returns emissions of greenhouse gases in 2050 to 2010 levels. Greenhouse gas emissions in a future with continued support for EERE's portfolio (measured as carbon equivalent emissions per year) are $10 \%$ and $20 \%$ lower in 2030 and 2050, respectively, than they would be without the portfolio.

As with the U.S. economy's energy intensity, greenhouse gas intensity of the U.S. economy has declined dramatically over the past half century - for structural reasons and as a result of efficiency improvements. The effect of EERE's portfolio on greenhouse gas-intensity tracks closely with the effects on energy intensity. The portfolio adds $10 \%$ and 20\% more reductions in carbon intensity in 2030 and 2050, respectively. 


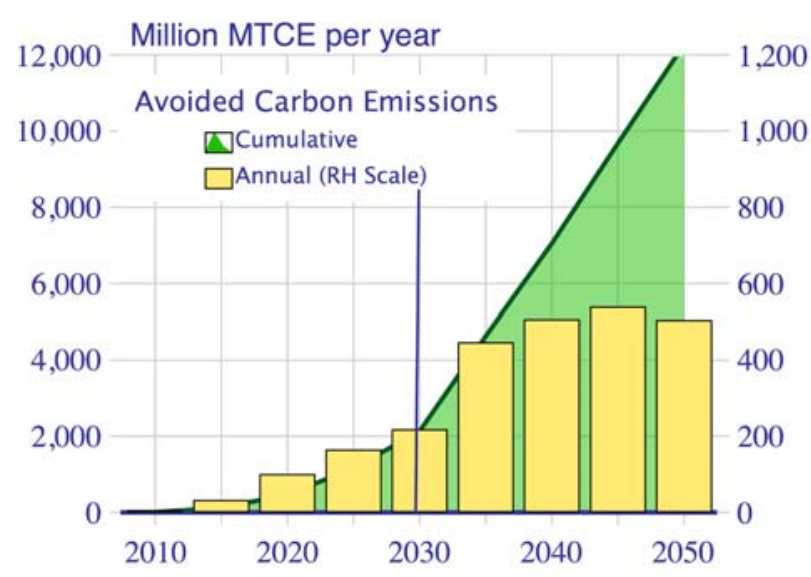

NEMS-GPRA8 2010 TO 2030 MARKAL-GPRA08 2030 TO 2050

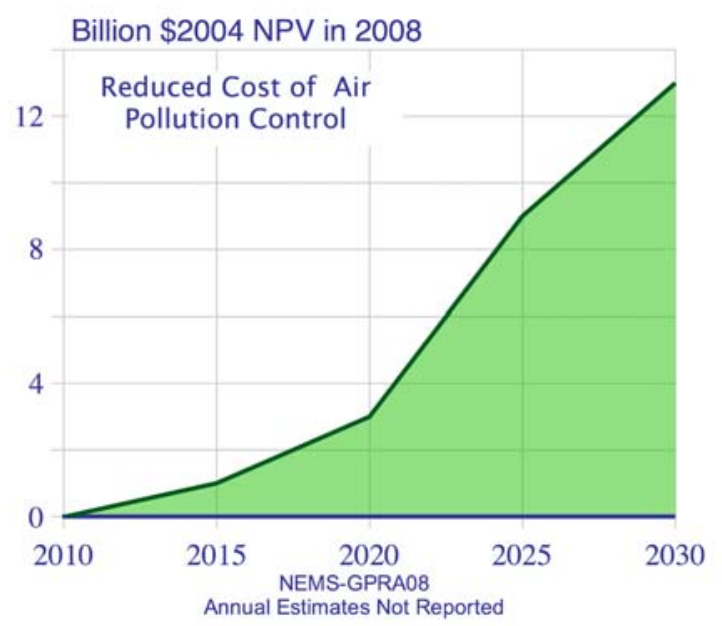

Figure 2.3. Environmental Metrics for the Business-As-Usual Scenario

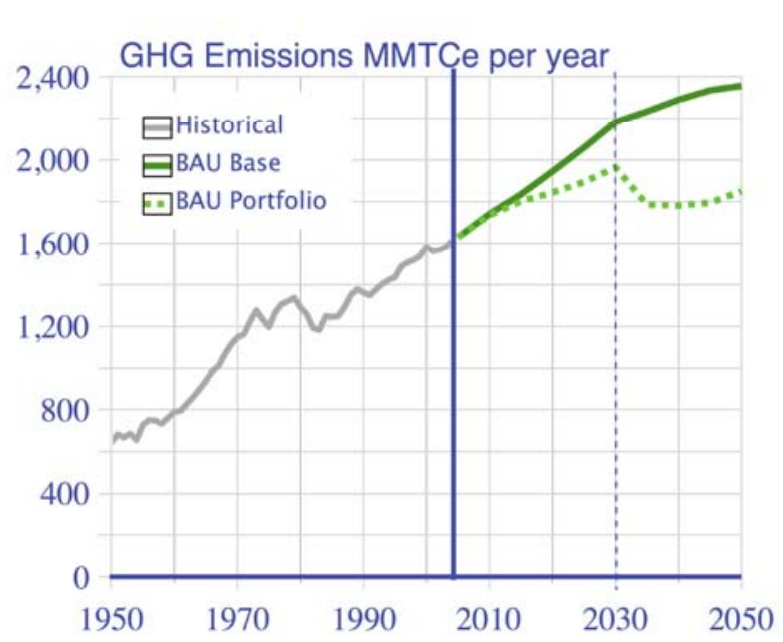

Solid line represents historical and projected trend without future funding of the EERE portfolo. Dashed line represents projected trend assuming continued funding of the EERE portfolio.

NEMS-GPRA08 2010 to 2030 MARKAL-GPRA08 2035 to 2050 Historical data to 2004 from U.S. Department of Energy, Energy Information Administration. Emissions of Greenhouse Gas Emissions in the United States 2005. DOE/EIA-0573(2005) (Washington, D.C., July 2006) Table B3 Total Energy-Related Carbon Dioxide Emissions by End-Use Sector, and the Electric Power Sector, by Fuel Type, 1949-2004.Table available at http:// www.eia.doe.gov/emeu/aer/contents.html)

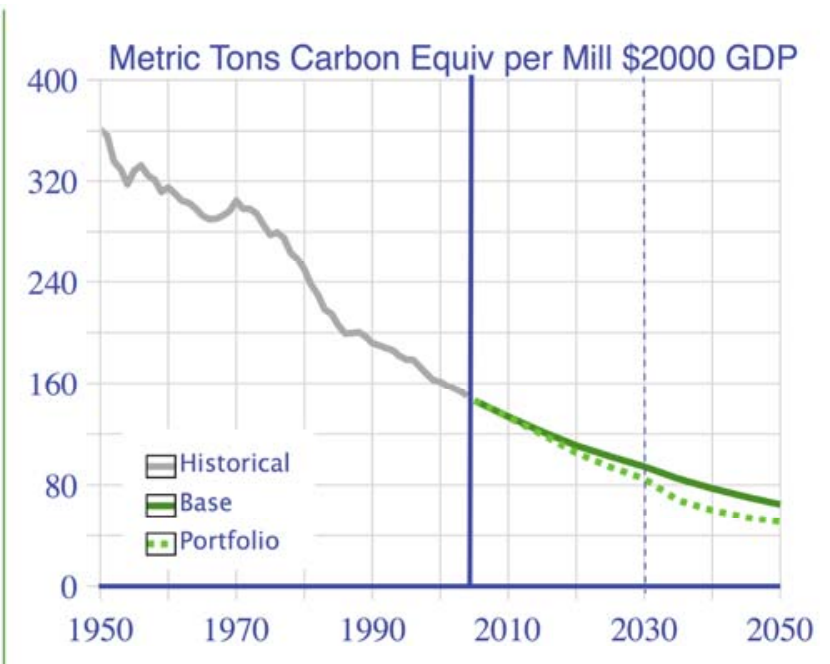

Solid line represents historical and projected trend without future funding of the EERE portfolo. Dashed line represents projected trend assuming continued funding of the EERE portfolio.

NEMS-GPRA08 2010 to 2030 MARKAL-GPRA08 2035 to 2050 Historical carbon emissions data to 2004 from U.S. Department of Energy, Energy Information Administration. Emissions of Greenhouse Gas Emissions in the United States 2005. DOE/ EIA-0573(2005) (Washington, D.C., November 2006) Table B3 Total Energy-Related Carbon Dioxide Emissions by End-Use Sector, and the Electric Power Sector, by Fuel Type, 1949-2004. Table available at http://www.eia.doe.gov/emeu/aer/contents.html). Historical GDP data from U.S. Department of Energy, Energy Information Administration. Annual Energy Review 2005 DOE/EIA-0384 (2005),

(Washington, D.C., July 2006 ). Table 1.5

Energy Consumption, Expenditures, and Emissions Indicators, 194 9-2005. (http://www.eia.doe.gov/emeu/aer/contents.html)

\section{Figure 2.4. Historical and Projected Greenhouse Gas Emissions Under the Business-As-Usual Scenario}

The environmental benefits of EERE's portfolio are all the more impressive given that they occur in conjunction with real economic gains, as described in the previous section. 


\section{Security Benefits}

Figure 2.5 summarizes the projected security benefits associated with EERE's portfolio of RD3 programs. The two charts in the left-hand column show overall security benefits to the U.S. economy. The two charts in the right-hand column show security benefits specific to the transportation sector.

By 2030, avoided imports of foreign oil reach 2 million barrels per day. From 2040 to 2050, avoided imports level out at about 7 million barrels per day. The apparent increase in oil import savings in 2035 is related to the switch from NEMS-GPRA08 to MARKAL-GPRA08. As with the benefits reported for the economy and the environment, the leveling off and decline in security benefits seen in the out-years is attributable to the assumption that many of the foreign oil-reducing technologies coming out of EERE's portfolio will eventually be developed in the marketplace even without the future funding of EERE's programs. The cumulative amount of avoided foreign oil reaches 6 billion barrels in 2030, climbing to 54 billion barrels by 2050 .
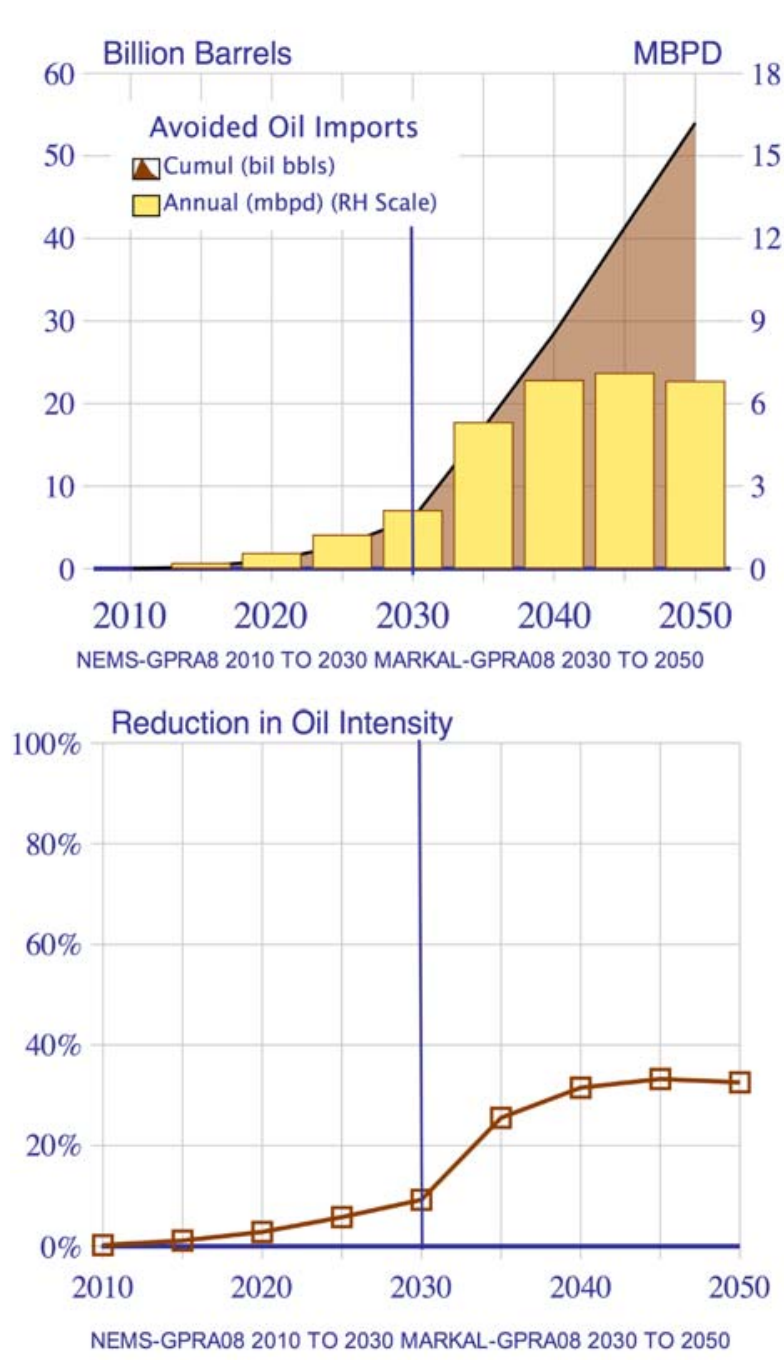

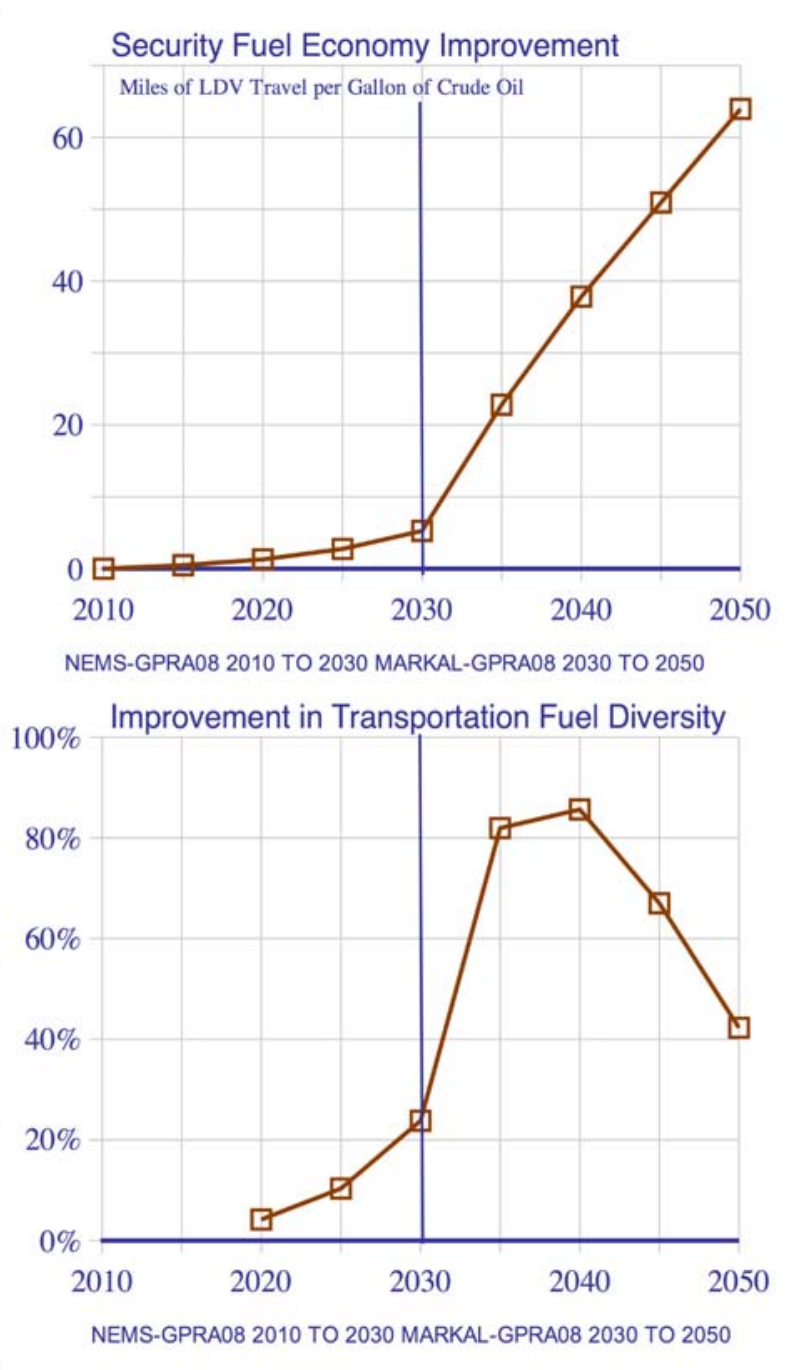

Figure 2.5. Security Metrics for EERE's Portfolio Under the Business-As-Usual Scenario 
EERE's portfolio reduces the oil intensity of the overall U.S. economy by $10 \%$ in 2030 . The effect of the portfolio on oil intensity levels off at a reduction of about $35 \%$ in 2050 . Again, these reductions are measured relative to the projected oil intensity of the economy in the absence of EERE's RD3 efforts.

Figure 2.6 provides a historical perspective on oil imports and oil intensity. The late 1960s through the late 1970s saw an intense - and even exponential - growth in the U.S. demand for foreign oil. This trend was reversed briefly in the late 1970s and the first half of the 1980s in response to the oil price and supply shocks that occurred in that period. Since then, oil imports have returned to a steady rate of growth. Although the base case projection suggests that oil import growth will slow somewhat as a result of the step-change increase in oil prices experienced in recent years, demand for imported oil is expected to increase $50 \%$ from its current level—from about 12 million barrels per day up to 18 million barrels per day by 2030 in the base case - without continued support for EERE's RD3 programs.

EERE's portfolio stabilizes oil imports, and even leads to imports that are about 1 million barrels per day lower than today's level. With EERE's portfolio, oil imports peak in 2030 at 15 million barrels per day, a $12 \%$ reduction from the base case; and fall to 11 million barrels per day in 2050 , a $40 \%$ reduction from the base case. A comparison of the individual program benefits results (see Chapter 3 in this report) suggests that the largest source of savings (about two-thirds) comes from vehicle efficiency improvements, with the remaining savings coming from ethanol fuel and hydrogen fuel cells.

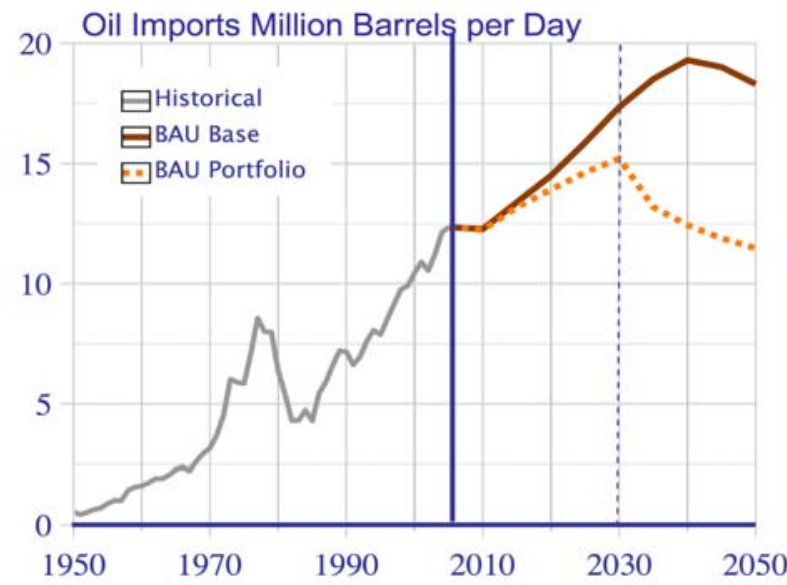

Solid line represents historical and projected trend without future funding of the EERE portfolo. Dashed line represents projected trend assuming continued funding of the EERE portfolio.

NEMS-GPRA0 2010 to 2030 MARKAL-GPRA08 2035 to 2050 Historical data to 2005 from U.S. Department of Energy, Energy Information Administration. Annual Energy Review 2005 DOE/ EIA-0384 (2005) (Washington, D.C., July 2006) Table 5.1 Petroleum Overview, 1949-2005 (http://www.eia.doe.gov/ emeu/aer/contents.html)

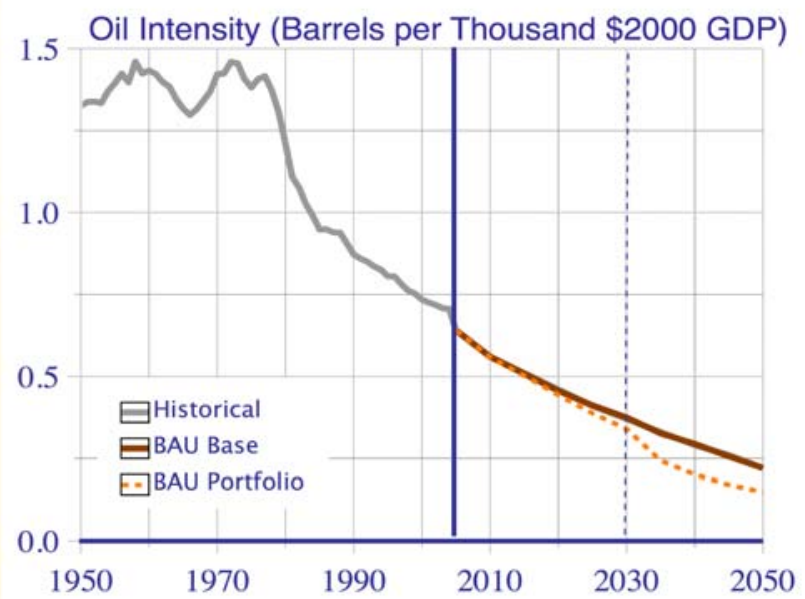

Solid line represents historical and projected trend without future funding of the EERE portfolo. Dashed line represents projected trend assuming continued funding of the EERE portfolio.

NEMS-GPRA08 2010 to 2030 MARKAL-GPRA08 2035 to 2050 Historical data to 2005 from U.S. Department of Energy, Energy Information Administration. Annual Energy Review 2005 DOE/ EIA-0384 (2005) (Washington. D.C., July 2006) Table 1.5 Energy Consumption, Expenditures, and Emissions Ind icators, 1949-2005 and Table 5.1 Petroleum Overview, 1949-2005 (http://www.eia.doe.gov/emeu/aer/contents.html)

\section{Figure 2.6. Historical and Projected Oil Trends for the Business-As-Usual Scenario}

Oil intensity of the economy — as measured in barrels of oil per thousand \$2000 of GDP — was more or less flat from 1949 through 1978; but, it has fallen steadily since then (again in response to oil supply and price shocks in the second half of the 1970s). Today, oil intensity is 0.7 barrels per thousand $\$ 2000$ of GDP, roughly half of its 1978 level. Even without EERE's RD3 programs, oil intensity is projected to continue its decline, falling to 0.4 and 0.2 barrels per thousand \$2000 of GDP in 2030 and 2050, respectively. With EERE's programs, oil intensity drops even further. By 2030, oil intensity reaches 0.3 in 2030 (9\% lower than the base case) and 0.15 in 2050 (33\% lower than the base case). 
This year, EERE introduced two security metrics specifically related to the transportation sector-the most vulnerable part of our economy to foreign energy supply disruptions (see the charts on the righthand side of Figure 2.5). The first - measured as miles traveled per gallon of crude oil consumed by light-duty vehicles - is a security-oriented variant of fuel economy for cars, sport utility vehicles (SUVs), and other small trucks. EERE's portfolio enables the U.S. light-duty vehicle fleet to gain an additional 5 miles of travel for each gallon of crude oil it consumes in 2030. By 2050, EERE's portfolio adds more than 60 miles of travel for each gallon of crude oil consumed. This improvement is due mostly to introduction of hydrogen fuel cells and improvements in vehicle efficiency.

The lack of diversity in fuel supply for transportation is another important source of vulnerability (see Chapter 1 for more detail on how fuel diversity is calculated). As Figure 2.5 shows, EERE's portfolio improves the diversity of the fuel supply for light-duty vehicles by more than $20 \%$ in 2030 and by more than $80 \%$ in 2040 . The impact of the portfolio on fuel diversity declines rapidly after that point, as the base case market begins to catch up with the alternative fuel developments in the EERE portfolio case.

\section{The Impact of Other Possible Futures}

There is considerable uncertainty in long-term energy projections. In fact, uncertainty about future energy demand, supplies, and prices is one of the motivations for Federal investment in R\&D, which can provide options for the Nation in the face of potentially adverse world energy markets. Under such circumstances, EERE's portfolio may have much greater value than under the reference or business-as-usual (BAU) projections described previously. The prospective benefits framework developed by the National Research Council (NRC) recognizes this in their recommendation of assessing benefits for several "global scenarios."

EERE - in collaboration with the other DOE R\&D Offices in the Office of Energy, Science, and the Environment (ESE) - has developed alternative scenarios to capture two of the key uncertainties impacting future energy: prices and climate policy. The use of alternative scenarios that project other possible futures addresses just one type of uncertainty. Modeling bias, error, and uncertainty are still embedded in all of the scenarios. Programmatic success is another major source of uncertainty that is not addressed through these scenarios.

The two alternative market scenarios that were developed for GPRA08 are a high fuel price case and a case with a constraint on national energy-related carbon emissions. Baseline cases (without EERE programs) and EERE portfolio cases have been analyzed under each of the alternative scenarios. The benefits of the portfolio are then evaluated as the difference between each pair of portfolio and base case, using a similar methodology as for the BAU GPRA08 benefits.

The differences in the benefits seen in the scenario and BAU cases can be subtle and difficult to interpret. For the high fuel price case, the alternative scenarios have different underlying macroeconomic assumptions and demands for energy services (such as light, travel, industrial steam, etc.) due to the higher energy prices. For the carbon-constrained scenario, the definition of the climate policy as a cap on energy-related carbon emissions leads to reduced emissions to the cap level in both the baseline and EERE portfolio cases. Hence, there are no carbon emission reductions attributable to the EERE portfolio of programs. The primary benefit is that the EERE programs help reach that cap at lower cost. ${ }^{4}$

\footnotetext{
${ }^{3}$ National Research Council (2005). Prospective Evaluation of Applied Energy Research and Development At DOE (Phase One): A First Look Forward. The National Academies Press, Washington, D.C.

${ }^{4}$ One might argue that the presence of EERE technologies that allows for more rapid adoption of technologies that reduce carbon emissions might influence climate policy; however, carbon caps, including the one modeled here, usually specify a time-path for reductions. The level of emissions reductions and the timing of the reductions are thus dictated by the scenario, and not influenced by the technologies in this construct.
} 
The off-line analyses that support the benefits analysis were revised for the alternative scenarios, although it was a challenge to do so in a comprehensive manner. For example, without multiple iterations, it is difficult to account for the impact of changes in the carbon value in the carbon scenario program cases. Thus, for programs whose inputs to the integrating models are "outcomes" (such as market penetration rates or energy savings), this potentially leads to an overstatement of benefits, especially in the carbon constraint scenario, where the value of carbon varies by case. For most programs, the baseline assumptions were not modified, except to the extent that the models will endogenously project reactions to the scenarios. In other words, the baseline technology characteristics for EERE technologies for the most part remain the same under all the scenarios.

As in the benefits analysis for the Business-As-Usual scenario, two integrated energy models were used: NEMS-GPRA08 and MARKAL-GPRA08. The former provides the midterm projections (to 2030), while the latter is used to extend them out to 2050 .

\section{The High Fuel Price Scenario Definition}

The High Fuel Price (HFP) scenario is predicated on a future in which the supply of natural gas and oil, relative to demand, are more limited. As a result, significantly higher fuel prices occur (see Figure 2.7 for comparison of oil and gas prices under the High Fuel Price and Business-As-Usual scenarios). The world oil price follows the trajectory of the AEO 2006 High Oil Price case. Oil prices start off higher than the reference case in 2006 and increase to $\$ 90$ per barrel by 2030. Beyond 2030 (outside the projections in the AEO 2006 High Oil Price), oil prices increase more slowly, reaching \$100 per barrel by 2050.

Natural gas supply in the High Fuel Price case was restricted in order to cause natural gas prices to increase to roughly $\$ 11$ by 2030 . The restrictions on gas supply included limiting the ability of new LNG terminals to be constructed, delaying the Alaska gas pipeline until after 2030, and reducing assumed Canadian resources. Coal price assumptions were not explicitly changed, but mine mouth coal prices increase by up to $8 \%$ through 2030 in NEMS-GPRA08 due to the increases in the other prices. Beyond 2030, these restrictions result in continued higher natural gas prices according to MARKAL-GPRA08, though not quite as high as the prices projected by NEMS-GPRA08 in 2030.

\section{Carbon Constraint Scenario Definition}

The Carbon Constraint (CC) scenario was designed to examine the implications of a cap on energyrelated carbon emissions for EERE benefits. The carbon cap was set to meet the Administration's "Global Climate Change Initiative" goal of an 18\% reduction in national GHG intensity (below the 2002 level) by 2012, along with assumptions for continued emission reductions through $2050 .^{5}$ Figure 2.8 compares projected allowable emissions under this carbon cap scenario with "Business-As-Usual" baseline emissions of energy-related $\mathrm{CO}_{2}$ emissions.

Between 2012 and 2020, the U.S. carbon cap decreases at a constant rate, reaching 1,600 MMTCE per year in 2020 - representing a return to year 2000 carbon emission levels. Between 2020 and 2050, carbon emissions are constrained to decrease at a constant rate resulting in an ultimate emissions level of 1,200 MMTCE per year in 2050 - representing a return to mid-1970s and early 1980s carbon emission levels. An economy-wide trading system is assumed where the lowest cost reductions will occur first.

By definition, carbon emissions are at the specified cap in the carbon cases and take place on a specified schedule, with or without EERE technologies. Therefore, no carbon emission reductions are expected that would be attributable to the EERE programs, unless the cap becomes non-binding. ${ }^{6}$ Nevertheless, there is a significant reduction in the cost required to meet that cap when the EERE advanced technologies are

\footnotetext{
${ }^{5}$ Global Climate Change Policy Book. The White House, February 2002.

http://www.whitehouse.gov/news/releases/2002/02/climatechange.html

${ }^{6}$ No banking of allowances was included in the scenario.
} 
available. An economy-wide trading system is assumed where the lowest cost reductions will occur first. The price of the carbon allowances indicates the marginal cost of compliance.

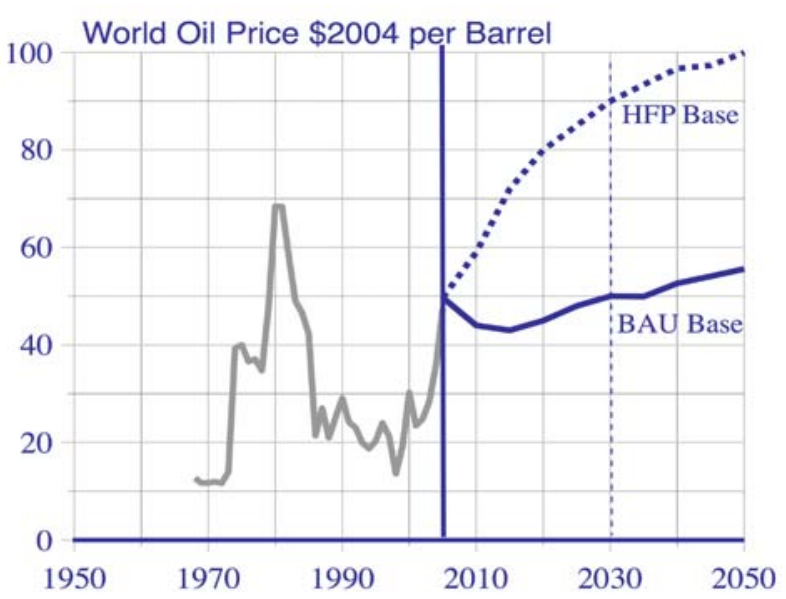

Dashed line represents world oil price under "High Fuel Price" (HFP) scenario. Solid line represents world oil price under "Business-AsUsual" (BAU) or AEO 2006 reference oil price case. NEMS-GPRA08 2010 to 2030 MARKAL-GPRA08 2035 to 2050

Historical data to 2005 from U.S. Department of Energy, Energy Information Administration. Annual Energy Review 2005 DOE/ EIA-0384 (2005) (Washington, D.C., July 2006) Table 5.21 Crude Oil Refiner Acquisition Costs, 1968-2005. (http:// www.eia.doe.gov/emeu/aer/contents.html)

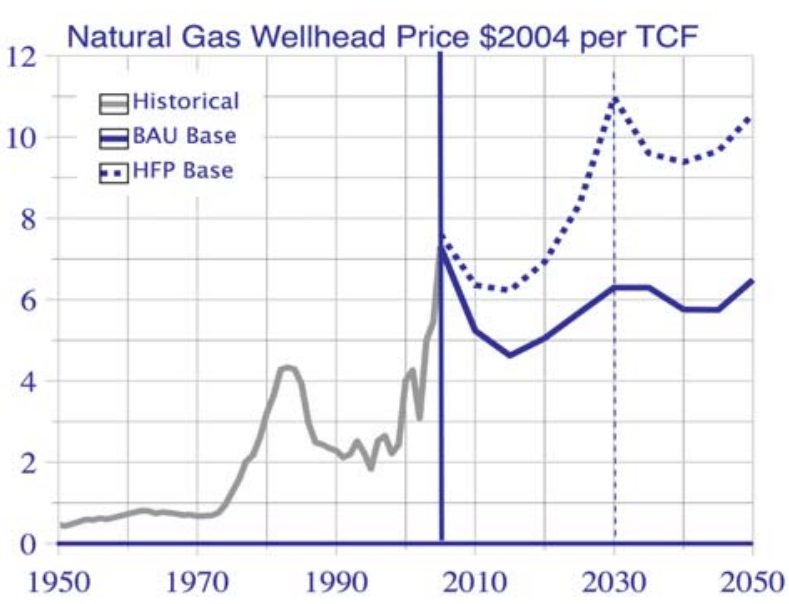

Dashed line represents natural gas price under "High Fuel Price" (HFP) scenario. Solid line represents natural gas price under "Business-As-Usual" (BAU) or AEO 2006 reference oil price case. NEMS-GPRA08 2010 to 2030 MARKAL-GPRA08 2035 to 2050

NEMS-GPRA08 2010 to 2030 MARKAL-GPRA08 2035 to 2050 Historical data to 2005 from U.S. Department of Energy, Energy Information Administration. Annual Energy Review 2005 DOE EIA-0384 (2005) (Washington, D.C., July 2006 Table 6.7 Natural Gas Wellhead, City Gate, and Imports Prices, 194 9-2005. (http://www.eia.doe.gov/emeu/aer/contents.html)

\section{Figure 2.7. Historical and Projected Oil and Gas Prices Under Business-As-Usual and High Fuel Price Scenarios}

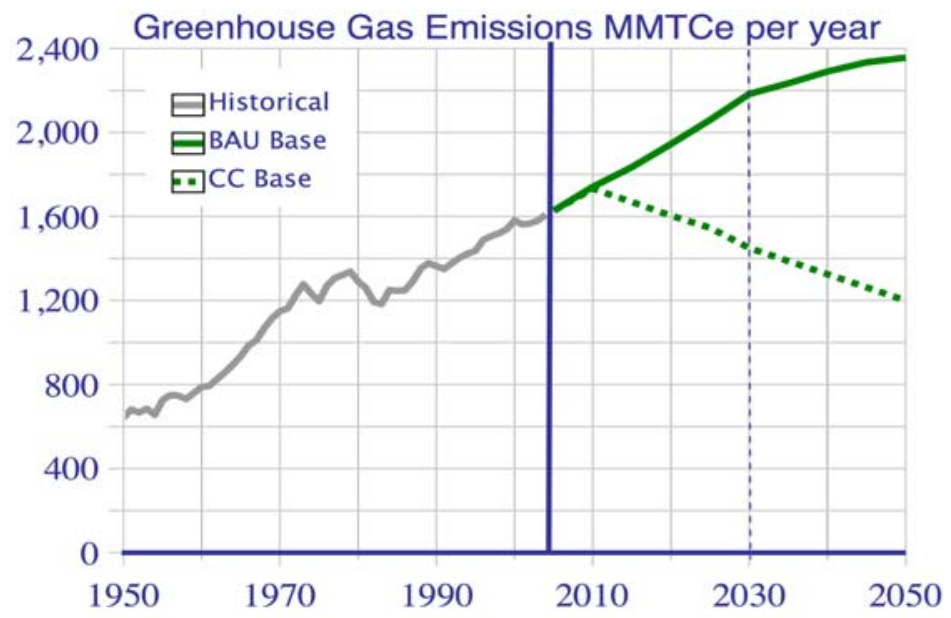

Solid line represents energy-related $\mathrm{CO} 2$ emissions for the Business as Usual baseline (without EERE's portfolio). Dashed line represents allowed emissions of $\mathrm{CO} 2$ under a carbon cap policy. Note that EERE's portfolio has no effect on carbon emissions under a carbon cap since the allowable levels of $\mathrm{CO} 2$ are dictated by policy.

Historical data to 2004 from U.S. Department of Energy, Energy Information Administration. Emissions of Greenhouse Gas Emissions in the United States 2005. DOE/EIA-0573(2005) (Washington, D.C., July 2006) Table B3 Total Energy-Related Carbon Dioxide Emissions by End-Use Sector, and the Electric Power Sector, by Fuel Type, 1949-2004. Table available at http://www.eia.doe.gov/emeu/aer/contents.html)

Figure 2.8. Carbon Emissions Under a Carbon Cap Policy

Figure 2.9 shows projected carbon allowance prices for the NEMS-GPRA08 and MARKAL-GPRA08 models. The two integrated energy models project very different carbon allowance prices. NEMSGPRA08 projects a carbon allowance price in the base case that increases steadily through 2030 to about 
\$230 per metric ton in response to the increasingly more stringent carbon cap. The increase is less rapid in the EERE portfolio case relative to the base case, due to the development and market adoption of advanced technologies that provide opportunities for lower-cost energy efficiency or carbon-free generation. By 2030, the price increases to $\$ 165$ per metric ton with the EERE portfolio.

MARKAL-GPRA08 shows a much more rapid price response to the carbon cap, with the carbon allowance price climbing to almost $\$ 250$ per metric ton by 2020 . Long-term allowance prices approach $\$ 300$ per metric ton in the base case. The EERE portfolio reduces carbon prices significantly, eventually resulting in carbon prices that are $\$ 200$ to $\$ 270$ per metric ton lower than the base case- even dropping temporarily to zero in 2035 .

The more aggressive response in MARKAL-GPRA08 is an example of the kinds of inherent differences in various models' structure and assumptions on consumer behavior that can lead to different extrapolations of the future. MARKAL-GPRA08 optimizes more aggressively for a future cost minimization of the energy system, resulting in more dramatic carbon price swings. In this case, MARKAL-GPRA08 achieves significant carbon savings in the transportation sector with the addition of the EERE portfolio technologies (particularly, new vehicle technologies, hydrogen fuel cells, and cellulosic ethanol), while NEMS-GPRA08 shows a much more modest response for the transportation sector.

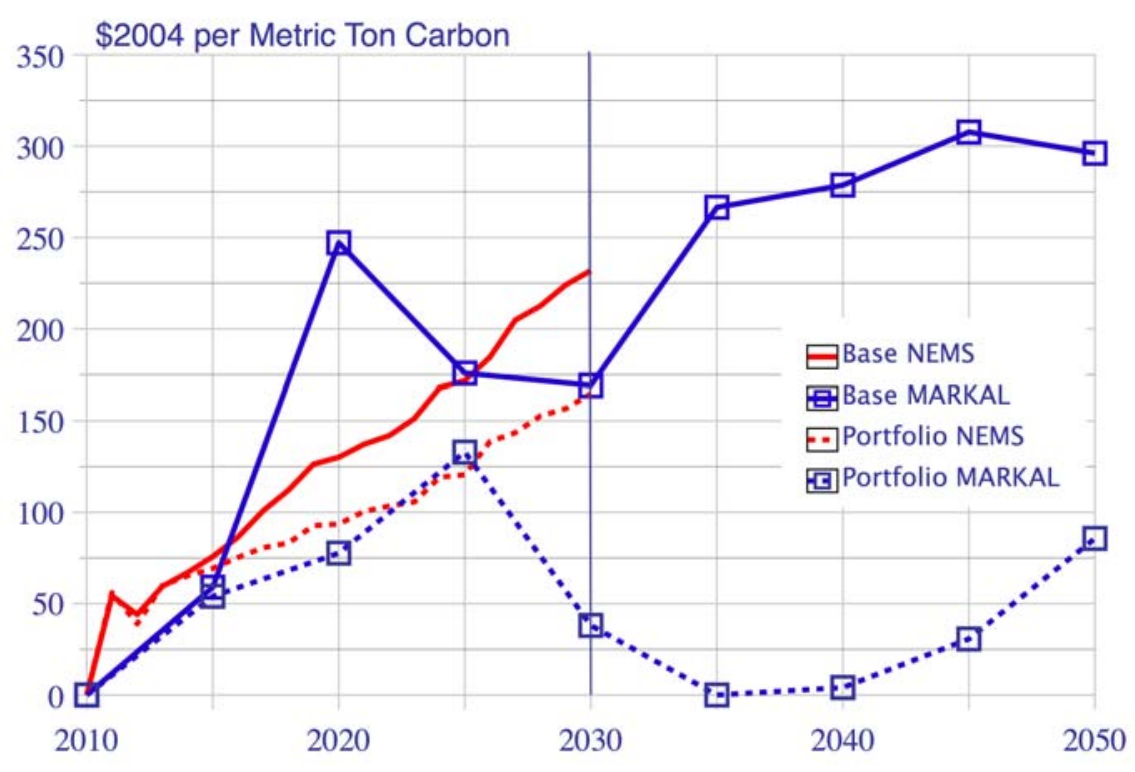

Figure 2.9. Carbon Allowance Price

\section{Summary of Benefits Metrics Under Alternative Scenarios}

Table 2.2 and Table 2.3 summarize the benefits for EERE's RD3 portfolio under the High Fuels Price and Carbon Constraint scenarios. Subsequent sections discuss these findings in more detail. 


\section{Table 2.2. EERE Portfolio Benefits for FY 2008 Budget Request- High Fuel Price Scenario}

\begin{tabular}{|c|c|c|c|c|c|c|c|c|c|}
\hline & \multicolumn{5}{|c|}{ MIDTERM BENEFITS 7/ } & \multicolumn{4}{|c|}{ LONG-TERM BENEFITS 8/ } \\
\hline Metric & 2010 & 2015 & 2020 & 2025 & 2030 & 2035 & 2040 & 2045 & 2050 \\
\hline $\begin{array}{l}\text { ECONOMIC BENEFITS ("AFFORDABLE") } \\
\text { Reduction in Average Delivered Natural Gas Price } \\
\text { (Percent) }\end{array}$ & $1 \%$ & $4 \%$ & $4 \%$ & $8 \%$ & $7 \%$ & $14 \%$ & $15 \%$ & $22 \%$ & $15 \%$ \\
\hline Energy System Cost Savings (bil \$2004) 1/ & $\mathrm{nr}$ & $\mathrm{nr}$ & $\mathrm{nr}$ & $\mathrm{nr}$ & $\mathrm{nr}$ & 258 & 303 & 325 & 341 \\
\hline Consumer Savings, Annual (bil \$2004) & 4.3 & 28 & 66 & 133 & 197 & 510 & 558 & 629 & 597 \\
\hline Consumer Savings, NPV (bil \$2004) $2 /$ & 10 & 85 & 246 & 553 & 1012 & 2,681 & 3,758 & 4,794 & 5,703 \\
\hline $\begin{array}{l}\text { Electric Power Industry Savings, Annual (bil } \\
\$ 2004) 3 /\end{array}$ & 2 & 9 & 14 & 21 & 25 & 99 & 103 & 97 & 73 \\
\hline $\begin{array}{l}\text { Electric Power Industry Savings, NPV (bil \$2004) } \\
2 / 3 /\end{array}$ & 5 & 28 & 68 & 123 & 185 & 532 & 735 & 907 & 1,031 \\
\hline $\begin{array}{l}\text { Reduction in Fraction of Household Income Spent } \\
\text { on Energy }\end{array}$ & $0.21 \%$ & $1.1 \%$ & $2.9 \%$ & $5.0 \%$ & $6.7 \%$ & $14 \%$ & $15 \%$ & $16 \%$ & $14 \%$ \\
\hline Reduced Energy Intensity of Economy (Percent) & $0.42 \%$ & $2.0 \%$ & $3.8 \%$ & $6.0 \%$ & $7.4 \%$ & $15 \%$ & $18 \%$ & $18 \%$ & $16 \%$ \\
\hline ENVIRONMENTAL BENEFITS ("CLEAN") & & & & & & & & & \\
\hline $\begin{array}{l}\text { Annual Avoided Greenhouse Gas Emissions } \\
\text { (MMTCE/year) }\end{array}$ & 9 & 46 & 101 & 148 & 192 & 606 & 693 & 597 & 459 \\
\hline $\begin{array}{l}\text { Cumulative Avoided Greenhouse Gas Emissions } \\
\text { (MMTCE) } 5 /\end{array}$ & 14 & 158 & 562 & 1,204 & 2,072 & 5,628 & 8,918 & 12,095 & 14,665 \\
\hline $\begin{array}{l}\text { Reduced Cost of Criteria Pollutant Control, NPV } \\
\text { (bil \$2004) } 2 /\end{array}$ & 0.5 & 1.2 & 5.0 & 8.7 & 15 & $\mathrm{nr}$ & $\mathrm{nr}$ & $\mathrm{nr}$ & $\mathrm{nr}$ \\
\hline SECURITY BENEFITS ("RELIABLE") & & & & & & & & & \\
\hline Avoided Oil Imports, Annual (mbpd) & ns & 0.2 & 0.5 & 1.0 & 1.8 & 6.5 & 7.9 & 7.2 & 6.0 \\
\hline Avoided Oil imports, Cumulative (bil barrels) 4/ 5/ & ns & 0.2 & 0.8 & 2.2 & 4.8 & 18.5 & 32.0 & 45.7 & 57.5 \\
\hline Security Fuel Economy Improvement (MPG) & 0.1 & 0.5 & 1.3 & 2.8 & 5.8 & 63 & 136 & 223 & 285 \\
\hline $\begin{array}{l}\text { Transportation Fuel Diversity Improvement } \\
\text { (Percent) 6/ }\end{array}$ & ns & ns & $6.2 \%$ & $6.0 \%$ & $16 \%$ & $94 \%$ & $91 \%$ & $66 \%$ & $48 \%$ \\
\hline Reduced Oil Intensity (Percent) & ns & $1.0 \%$ & $2.8 \%$ & $5.3 \%$ & $9.5 \%$ & $36 \%$ & $43 \%$ & $42 \%$ & $39 \%$ \\
\hline
\end{tabular}

Table notes

$1 /$ Energy system costs include the annualized capital costs for all capital stock (residual and new), as well as O\&M and fuel costs. Annualized capital costs are calculated using MARKAL hurdle rates, which include both financial and behavioral components.

2/ NPV (net present value) calculations done using 3\% real discount rate back to 2008

3/ Electric power industry cost does not include demand-side distributed generation.

4/ Renewable generation values at output value (3412 Btu/kWh) except for biomass and geothermal where energy content is used.

5/ All cumulative values are from 2008.

6/ Diversity index change is Case minus Base (opposite of others).

7/ Midterm benefits based on NEMS-GPRA08 model.

8/ Long-term benefits based on MARKAL-GPRA08 model.

$\mathrm{nr}=$ not reported or calculated by model 


\section{Table 2.3. EERE Portfolio Benefits for FY 2008 Budget Request- Carbon Constraint Scenario}

\begin{tabular}{|c|c|c|c|c|c|c|c|c|c|}
\hline & \multicolumn{5}{|c|}{ MIDTERM BENEFITS 7/ } & \multicolumn{4}{|c|}{ LONG-TERM BENEFITS 8/ } \\
\hline Metric & 2010 & 2015 & 2020 & 2025 & 2030 & 2035 & 2040 & 2045 & 2050 \\
\hline ECONOMIC BENEFITS ("AFFORDABLE") & & & & & & & & & \\
\hline $\begin{array}{l}\text { Reduction in Average Delivered Natural Gas Price } \\
\text { (Percent) }\end{array}$ & $0 \%$ & $1 \%$ & $9 \%$ & $11 \%$ & $13 \%$ & $40 \%$ & $42 \%$ & $35 \%$ & $28 \%$ \\
\hline Energy System Cost Savings (bil \$2004) 1/ & $\mathrm{nr}$ & $\mathrm{nr}$ & $\mathrm{nr}$ & $\mathrm{nr}$ & $\mathrm{nr}$ & 177 & 221 & 247 & 271 \\
\hline Consumer Savings, Annual (bil \$2004) & 2.1 & 21 & 104 & 179 & 262 & 641 & 751 & 750 & 663 \\
\hline Consumer Savings, NPV (bil \$2004) 2/ & 4.4 & 53 & 302 & 749 & 1,359 & 4,106 & 5,519 & 6,814 & 7,856 \\
\hline $\begin{array}{l}\text { Electric Power Industry Savings, Annual (bil \$2004) } \\
\text { 3/ }\end{array}$ & 1.9 & 12 & 37 & 45 & 52 & 113 & 104 & 103 & 92 \\
\hline $\begin{array}{l}\text { Electric Power Industry Savings, NPV (bil \$2004) 2/ } \\
3 /\end{array}$ & 4.3 & 34 & 137 & 269 & 405 & 887 & 1103 & 1282 & 1425 \\
\hline $\begin{array}{l}\text { Reduction in Fraction of Household Income Spent on } \\
\text { Energy }\end{array}$ & $0.17 \%$ & $1.0 \%$ & $3.8 \%$ & $5.9 \%$ & $8.2 \%$ & $15 \%$ & $16 \%$ & $15 \%$ & $12 \%$ \\
\hline Reduced Energy Intensity of Economy (Percent) & $0.20 \%$ & $1.5 \%$ & $2.6 \%$ & $4.7 \%$ & $8.0 \%$ & $9.2 \%$ & $13 \%$ & $14 \%$ & $14 \%$ \\
\hline ENVIRONMENTAL BENEFITS ("CLEAN") & & & & & & & & & \\
\hline $\begin{array}{l}\text { Annual Avoided Greenhouse Gas Emissions } \\
\text { (MMTCE/year) }\end{array}$ & ns & ns & ns & ns & ns & 10 & 0 & 0 & 0 \\
\hline $\begin{array}{l}\text { Cumulative Avoided Greenhouse Gas Emissions } \\
\text { (MMTCE) } 5 /\end{array}$ & ns & ns & ns & ns & ns & 28 & 28 & 28 & 28 \\
\hline Reduced Cost of CO2 Allowances, (bil \$2004) & 0.0 & 11 & 59 & 80 & 97 & $\mathrm{nr}$ & $\mathrm{nr}$ & $\mathrm{nr}$ & $\mathrm{nr}$ \\
\hline $\begin{array}{l}\text { Reduced Cost of CO2 Allowances, NPV (bil \$2004) } \\
\text { 2/ }\end{array}$ & 0.0 & 15 & 167 & 382 & 624 & $\mathrm{nr}$ & $\mathrm{nr}$ & $\mathrm{nr}$ & $\mathrm{nr}$ \\
\hline $\begin{array}{l}\text { Reduced Cost of Criteria Pollutant Control, NPV (bil } \\
\$ 2004) 2 /\end{array}$ & 0.8 & 0 & -1 & -3 & -4 & $\mathrm{nr}$ & $\mathrm{nr}$ & $\mathrm{nr}$ & $\mathrm{nr}$ \\
\hline SECURITY BENEFITS ("RELIABLE") & & & & & & & & & \\
\hline Avoided Oil Imports, Annual (mbpd) & ns & 0.18 & 0.55 & 1.1 & 1.7 & 7.6 & 8.9 & 8.8 & 7.9 \\
\hline Avoided Oil imports, Cumulative (bil barrels) 4/ 5/ & ns & 0.17 & 0.85 & 2.4 & 5.0 & 24 & 40 & 56 & 71 \\
\hline Security Fuel Economy Improvement (MPG) & 0.1 & 0.5 & 1.4 & 2.7 & 4.9 & 41 & 71 & 106 & 128 \\
\hline $\begin{array}{l}\text { Transportation Fuel Diversity Improvement (Percent) } \\
6 /\end{array}$ & ns & ns & $10 \%$ & $14 \%$ & $23 \%$ & $191 \%$ & $184 \%$ & $139 \%$ & $111 \%$ \\
\hline Reduced Oil Intensity (Percent) & ns & $0.9 \%$ & $2.7 \%$ & $5.3 \%$ & $7.7 \%$ & $35 \%$ & $40 \%$ & $41 \%$ & $39 \%$ \\
\hline
\end{tabular}

Table notes

1/ Energy system costs include the annualized capital costs for all capital stock (residual and new), as well as O\&M and fuel costs. Annualized capital costs are calculated using MARKAL hurdle rates, which include both financial and behavioral components.

2/ NPV (net present value) calculations done using 3\% real discount rate back to 2008

3/ Electric power industry cost does not include demand-side distributed generation.

4/ Renewable generation values at output value (3412 Btu/kWh) except for biomass and geothermal where energy content is used.

5/ All cumulative values are from 2008.

6/ Diversity index change is Case minus Base (opposite of others).

7/ Midterm benefits based on NEMS-GPRA08 model.

8/ Long-term benefits based on MARKAL-GPRA08 model.

$\mathrm{nr}=$ not reported or calculated by model

\section{Economic Benefits Under Alternative Scenarios}

Consumer savings due to EERE's portfolio are significantly greater under the two alternative scenarios of High Fuel Prices (HFP) and Carbon Constraints (CC) than they are under the Business-As-Usual (BAU) case, as shown in Figure 2.10. For the High Fuel Price (HFP) scenario, annual consumer savings by 2030 are roughly double those projected under the BAU scenario. For the Carbon Constraint (CC) scenario, annual consumer savings by 2030 are 2.3 times higher than those projected under the BAU scenario. Annual consumer savings in 2030 climb to $\$ 200$ billion and \$260 billion, respectively, under the HFP and $\mathrm{CC}$ scenarios. The cumulative savings to the consumer over the period of 2008 to 2030 are $\$ 1.1$ trillion and \$1.4 trillion, respectively, for the HFP and CC scenarios. 
In 2050, consumer savings under the HFP scenario reach $\$ 600$ billion annually, 1.6 times greater than under the BAU scenario. In the carbon-constrained scenario, annual consumer savings reach $\$ 670$ billion in 2050. Cumulative savings to consumers under the HFP and CC scenarios are about $\$ 6$ and $\$ 8$ trillion, respectively, by 2050 .
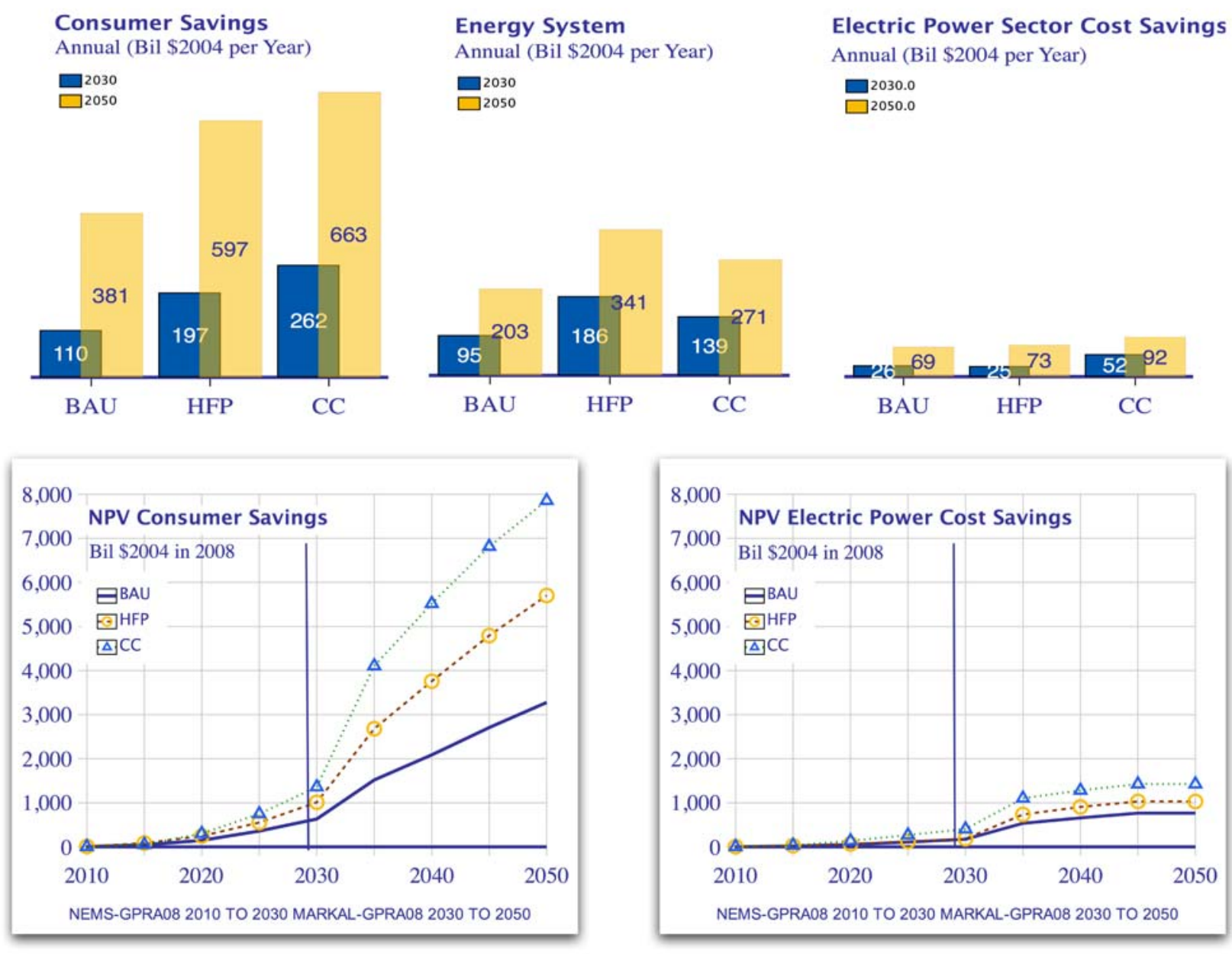

\section{Figure 2.10. Consumer, Energy System, and Electric Power-Sector Cost Savings Under Alternative Scenarios}

As noted in the discussion of the BAU scenario results, the estimated economic benefits of EERE's portfolio decreases as more producer-side economic impacts are considered in the calculation of savings. Thus, consumer savings are greater than estimated energy system savings, which are, in turn, greater than the producer-side cost savings seen in the electric power sector. Cost savings in the electric power sector vary significantly between the high fuel price (HFP) and the carbon constraint (CC) scenarios. Under the HFP scenario, EERE's portfolio generates relatively small additional savings over the BAU scenario. By 2025, the HFP and CC scenarios are essentially identical. This is due, in part, to the fact that the electric power sector can turn to coal as a cost-effective alternative to the high-priced oil and gas marketsmaking this sector less vulnerable to oil and gas prices.

The carbon constraint scenario has significant impacts on cost to the electric power sector, making EERE's renewable energy technologies more valuable. As a result, savings to the electric power sector, 
due to EERE's portfolio, are nearly double the savings projected under the BAU scenario in 2030. Annual savings in the electric power sector increase to almost $\$ 50$ billion per year in 2030 under the carbon constraint scenario, compared to a little more than $\$ 25$ billion per year under the BAU scenario. In 2050, annual electric power savings are $\$ 92$ billion per year, as compared to $\$ 70$ billion per year in the BAU scenario.

Historical and projected consumer spending on energy under each of the alternative scenarios is shown in Figure 2.11. Both base cases under the HFP and CC scenarios show significantly higher spending for energy by consumers - in both scenarios, around $\$ 300$ billion per year higher in 2030 than the BAU baseline. By 2050, base case spending by consumers is $\$ 600$ and $\$ 700$ billion per year higher, respectively, under the HFP and CC scenarios, compared to the BAU scenario.

In the case of the HFP scenario, higher spending is directly related to higher fuel prices. In the CC scenario, higher spending is due to the added cost of carbon emissions associated with fossil fuels. A corollary to the higher cost of conventional fossil fuels under these scenarios is that the fossil fuel savings associated with EERE's portfolio is worth more, resulting in greater economic benefits to consumers and producers.
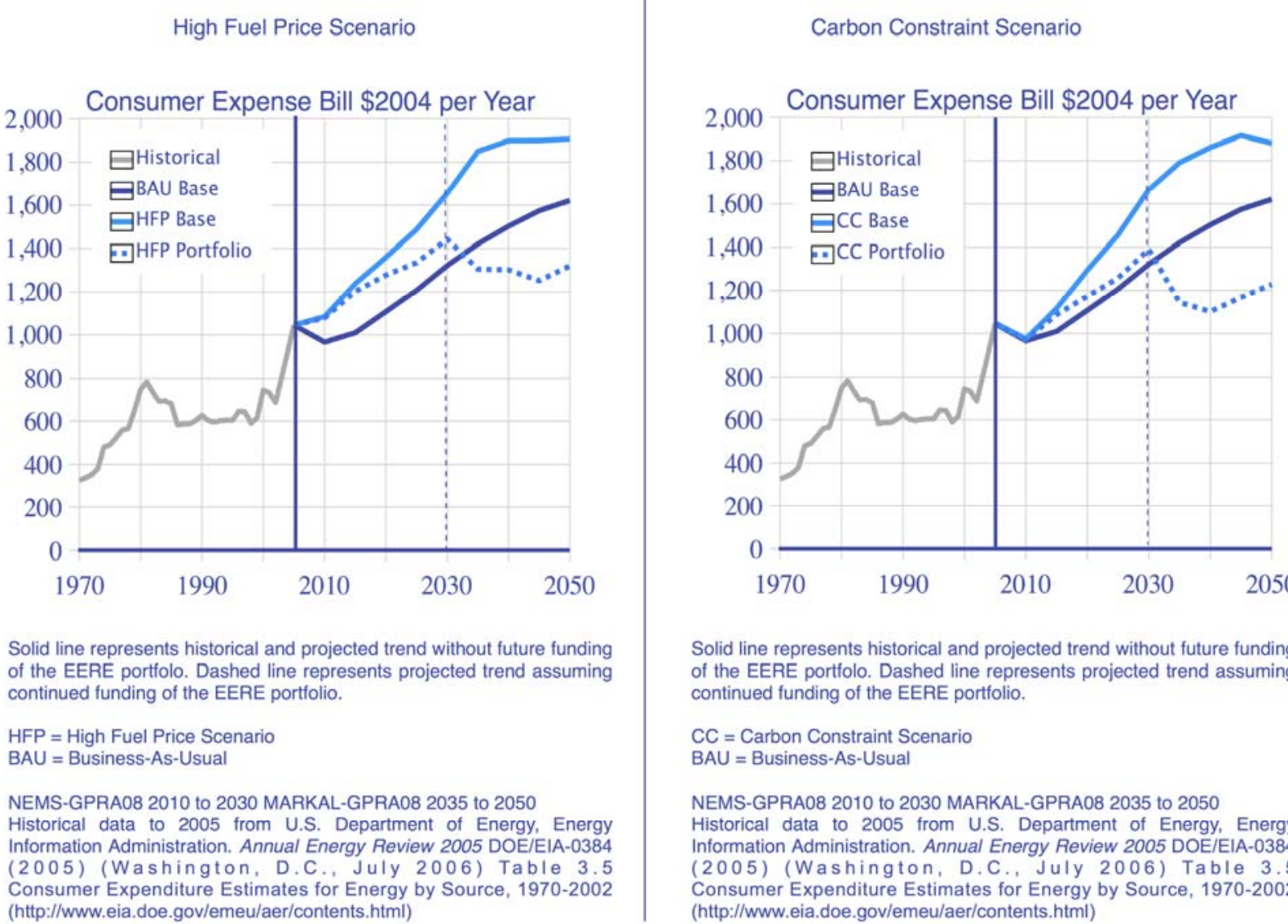

Solid line represents historical and projected trend without future funding of the EERE portfolo. Dashed line represents projected trend assuming continued funding of the EERE portfolio.

$\mathrm{CC}=$ Carbon Constraint Scenario $\mathrm{BAU}=$ Business-As-Usual

NEMS-GPRA08 2010 to 2030 MARKAL-GPRA08 2035 to 2050 Historical data to 2005 from U.S. Department of Energy, Energy Information Administration. Annual Energy Review 2005 DOE/EIA-0384 (2005) (Washington, D.C., July 2006) Table 3.5 Consumer Expenditure Estimates for Energy by Source, 1970-2002 (http://www.eia.doe.gov/emeu/aer/contents.html)

\section{Figure 2.11. Consumer Spending for Energy Under Alternative Scenarios}

The EERE portfolio eliminates $65 \%$ of the increased annual energy cost to consumers in 2030 associated with the high fuel price baseline case. In 2050, the EERE portfolio actually reduces consumer spending on energy under the HFP scenario by $\$ 300$ billion per year relative to the BAU baseline. The portfolio is even more effective under the carbon constraint scenario. It eliminates $80 \%$ of the added cost to consumers in 2030 associated with the carbon constraint baseline case. In 2050, the EERE portfolio 
reduces consumer spending on energy by $\$ 400$ billion per year, compared to the baseline case under the BAU scenario. Note that the discontinuity in projected spending trends between NEMS-GPRA08 and MARKAL-GPRA08 is more pronounced in the carbon constraint, due to the significant differences in how each model handles carbon pricing under the carbon constraint.

EERE's portfolio also reduces the impact of high fuel prices and a carbon constraint on household energy spending (see Figure 2.10). By 2030, relative spending of household income drops $7 \%$ and $8 \%$, respectively, in the HFP and CC scenarios - compared to a 5\% reduction in the BAU scenario. EERE's portfolio has its peak impact on household spending for energy at about 2040 to 2045 in the HFP and CC scenarios, with reductions of about $16 \%$, compared to reductions in the BAU scenario that level off at $10 \%$.

These results demonstrate an important element of the value of Federal funding of energy efficiency and renewable energy. Government support of high-risk technology development aimed at addressing important issues that have the potential to cause harm to society and the economy is a strategy that mitigates - in this case - possible economic hardships brought on by circumstances such as unanticipated growth in fuel prices or the need for strong measures to reduce carbon emissions.
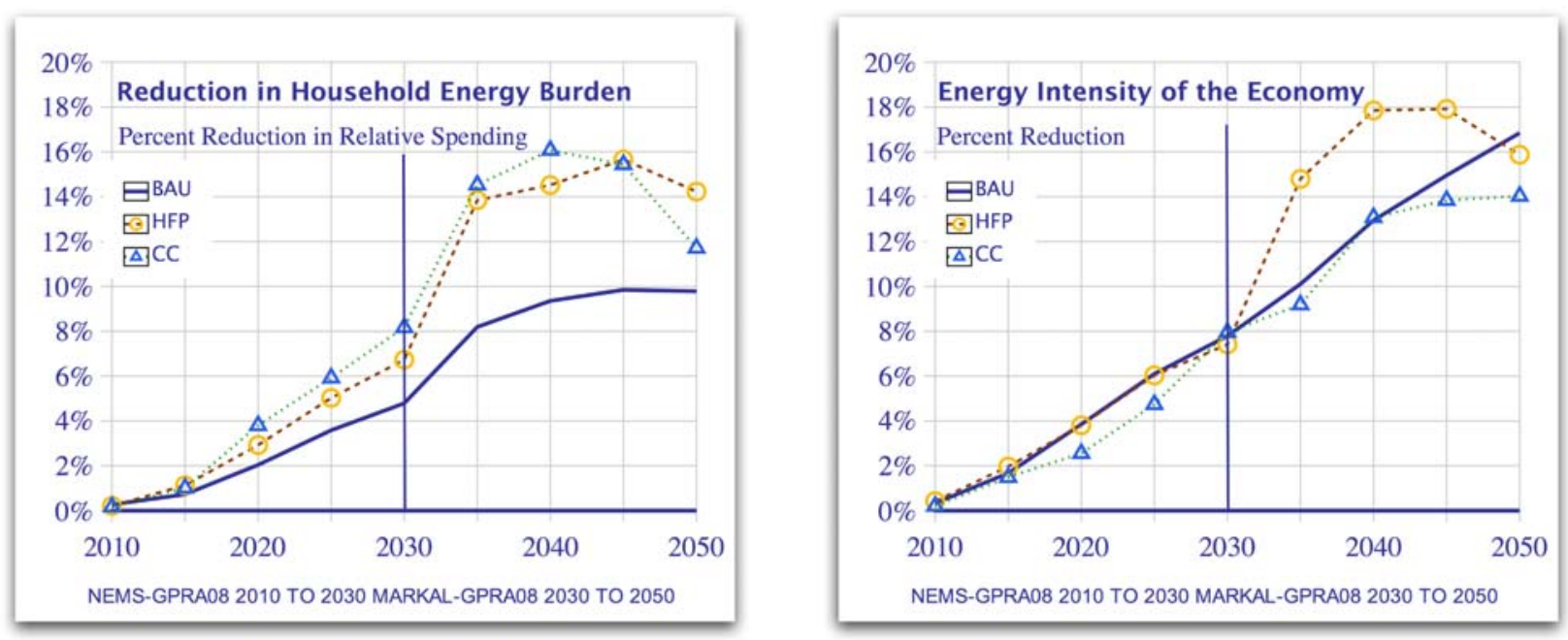

\section{Figure 2.12. Reduction in Household Spending and Energy Intensity Under Alternative Scenarios}

As Figure 2.12 shows, energy intensity of the economy sees a reduction in all scenarios due to the introduction of technologies promoted or developed by EERE under all three scenarios (BAU, HFP, and CC). In the midterm (2010 through 2030), EERE's portfolio has slightly less impact on energy intensity under the alternative scenarios than it does under the BAU scenario. EERE's portfolio seems to peak in its impact on energy intensity around 2040 to 2045, with somewhat higher impacts seen for the HFP scenario.

Figure 2.13 shows historical and projected trends for energy intensity under all three scenarios. Longterm trends for energy intensity are only slightly impacted by changing scenarios. Energy intensity trends under the HFP Base case are almost identical to the BAU base case; while the carbon constraint base case shows somewhat lower energy intensity than the BAU scenario through 2030 . The combined effect of higher fuel prices and EERE's portfolio reduces energy intensity by $11 \%$ and $20 \%$ in 2030 and 2050, respectively, compared to the BAU baseline. The combined effect of a carbon cap and EERE's portfolio reduces energy intensity by $16 \%$ compared to the BAU baseline in the midterm (2030) and long-term (2050) time frames. 
High Fuel Price Scenario

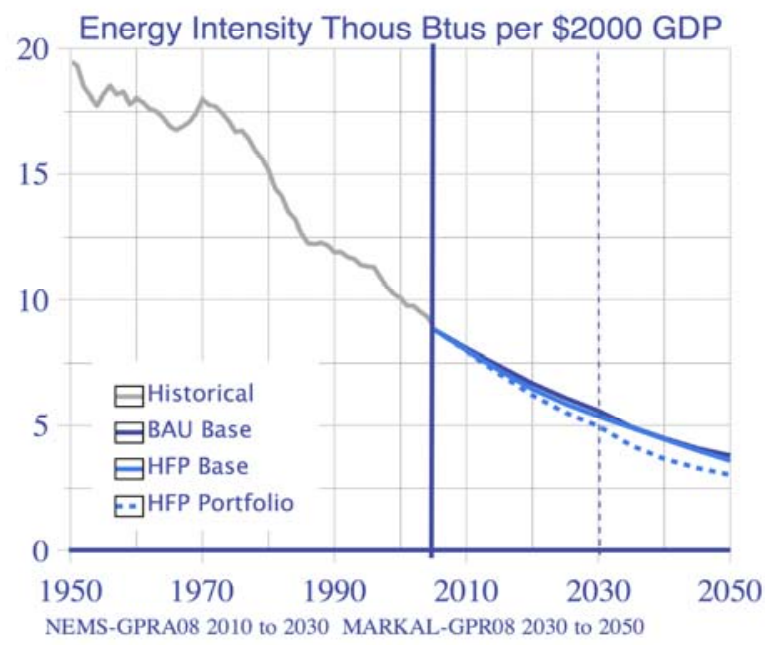

Solid line represents historical and projected trend without future funding of the EERE portfolo. Dashed line represents projected trend assuming continued funding of the EERE portfolio.

HFP $=$ High Fuel Price Scenario

BAU - Business-As-Usual Scenario

NEMS-GPRA08 2010 to 2030 MARKAL-GPRA08 2035 to 2050

Historical data to 2005 from U.S. Department of Energy, Energy Information Administration. Annual Energy Review 2005 DOE/EIA-0384

(2005) (Washington, D.C. July 2006) Table 1.5

Energy Consumption, Expenditures, and Emissions Indicators, 1949-2005

(http://www.eia.doe.gov/emeu/aer/contents.html)
Carbon Constraint Scenario

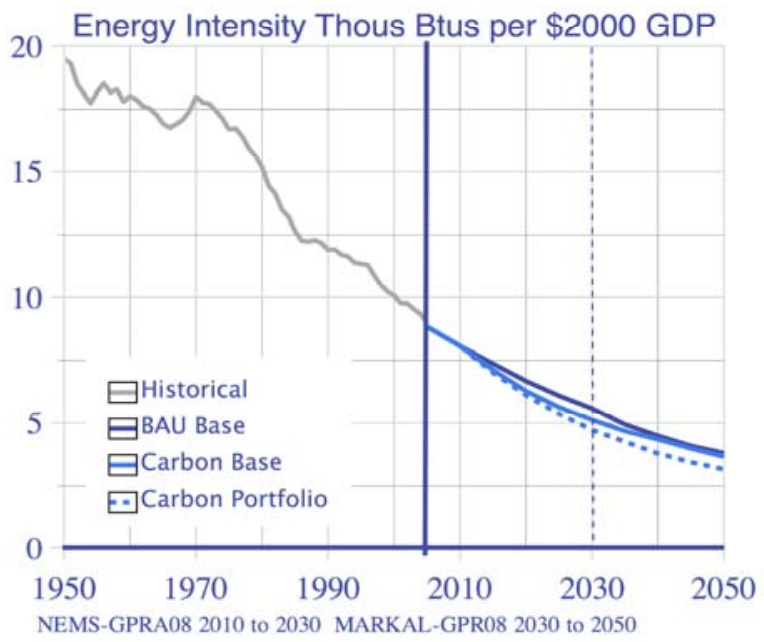

Solid line represents historical and projected trend without future funding of the EERE portfolo. Dashed line represents projected trend assuming continued funding of the EERE portfolio.

$\mathrm{CC}=$ Carbon Constraint Scenario

$\mathrm{BAU}=$ Business-As-Usual Scenario

NEMS-GPRA08 2010 to 2030 MARKAL-GPRA08 2035 to 2050

Historical data to 2005 from U.S. Department of Energy, Energy Information Administration. Annual Energy Review 2005 DOE/EIA-0384 (2005) (Washington, D.C., July 2006 ) Table 1.5 Energy Consumption, Expenditures, and Emissions Indicators, 1949-2005 . (http://www.eia.doe.gov/emeu/aer/contents.html)

\section{Figure 2.13. Energy Intensity Trends Under Alternative Scenarios}

\section{Environmental Benefits of EERE's Portfolio Under Alternative Scenarios}

Figure 2.14 summarizes environmental benefits of EERE's portfolio under all of the scenarios. In the midterm, carbon emission savings under the High Fuel Price scenario and under the Business-As-Usual scenario are comparable.

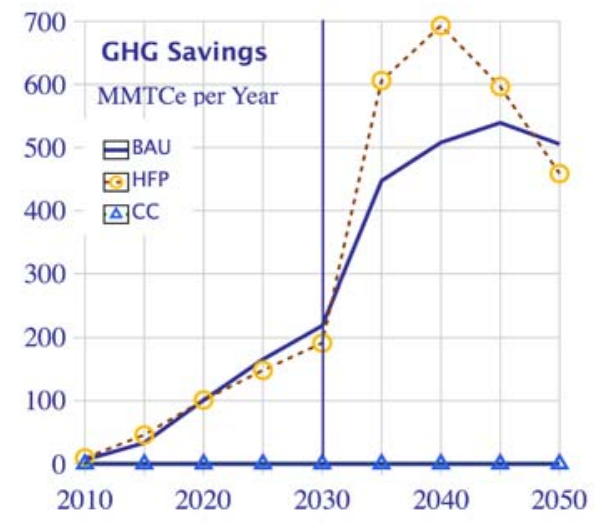

NEMS-GPRA08 2010 TO 2030 MARKAL-GPRA08 2030 TO 2050

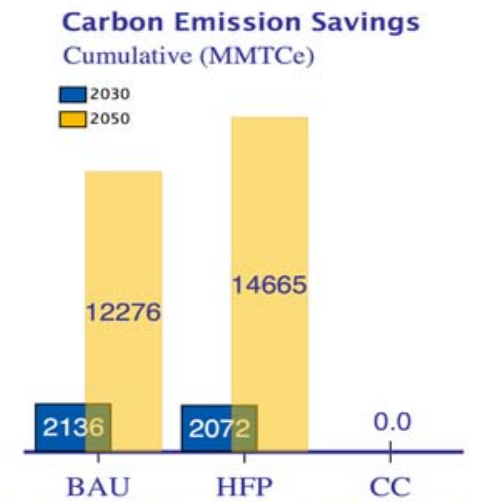

NEMS-GPRA08 2030 MARKAL-GPRA08 2050
Criterion Pollutant Control NPV in 2008 (Billion \$2004)

$\square 2030$

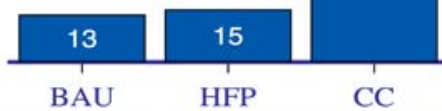

NEMS-GPRA08 2030 MARKAL-GPRA08 2050

Figure 2.14. Environmental Benefits Under Alternative Scenarios 
After 2020, carbon savings under the HFP are somewhat lower than under the BAU, because the electric power sector shifts more to coal use as oil and gas prices increase. GHG savings reach 180 MMTCe per year in 2030 under the HFP scenario, compared with 230 MMTCe per year under the BAU scenario. Cumulative carbon savings in 2030 are roughly the same in both scenarios-more than 2,000 MMTCe.

Long-term projections from MARKAL-GPRA08 show a peak in carbon emission savings of 700 MMTCe per year under the HFP scenario in 2040 that is significantly higher than savings under the BAU scenario. By 2050, savings due to EERE's portfolio under the HFP scenario are similar to the savings expected for the BAU scenario.

Carbon savings for the carbon constraint scenario are zero because - with or without EERE's portfoliothe carbon cap mandates the same level of carbon emission reductions.

Historical and projected annual carbon emissions and carbon intensity under the BAU and HFP scenarios are shown in Figure 2.15. Base carbon emissions and carbon intensity are very similar under both scenarios. Likewise, the EERE portfolio cases achieve similar reductions in annual carbon emissions and carbon intensity. The carbon constraint scenario results in reductions of annual carbon emissions and carbon intensity that are twice as great as those achieved by the portfolio under either the BAU or HFP scenario.

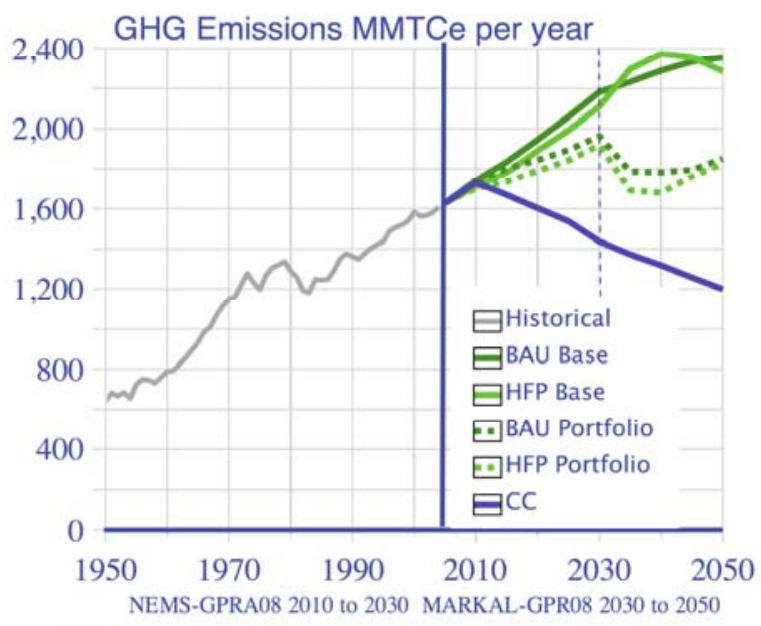

Solid line represents historical and projected trend without future funding of the EERE portfolo. Dashed line represents projected trend assuming continued funding of the EERE portfolio.

HFP $=$ High Fuel Price Scenario

$\mathrm{BAU}=$ Business-As-Usual Scenario

$\mathrm{CC}=$ Carbon Constraint Scenario

NEMS-GPRA08 2010 to 2030 MARKAL-GPRA08 2035 to 2050 Historical data to 2004 from U.S. Department of Energy, Energy Information Administration. Emissions of Greenhouse Gas Emissions in the United States 2005. DOE/EIA-0573(2005) (Washington, D.C., July 2006) Table B3 Total Energy-Related Carbon Dioxide Emissions by End-Use Sector, and the Electric Power Sector, by Fuel Type, 1949-2004. Table available at http:// www.eia.doe.gov/emeu/aer/contents.html)

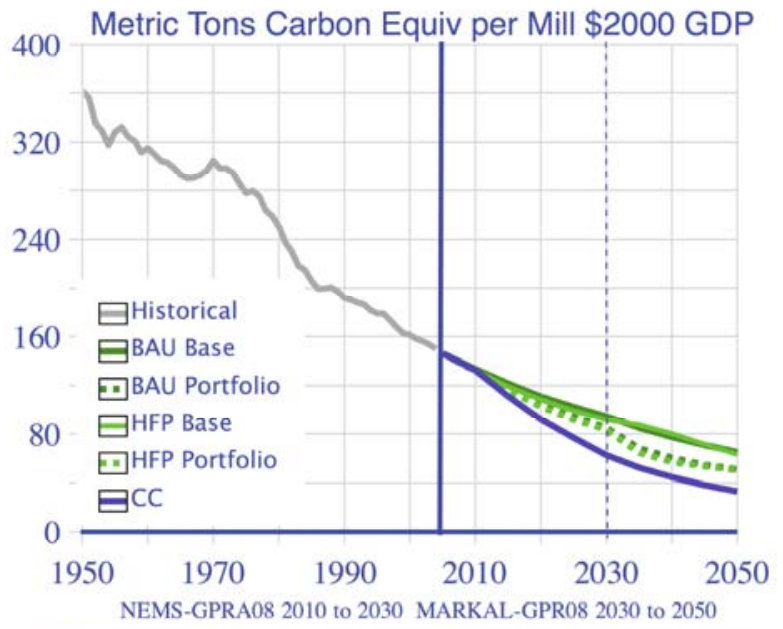

Solid line represents historical and projected trend without future funding of the EERE portfolo. Dashed line represents projected trend assuming continued funding of the EERE portfolio.

HFP $=$ High Fuel Price Scenario

$\mathrm{BAU}=$ Business-As-Usual Scenario

$\mathrm{CC}=$ Carbon Constraint Scenario

NEMS-GPRA08 2010 to 2030 MARKAL-GPRA08 2035 to 2050 Historical carbon emissions data to 2004 from U.S. Department of Energy, Energy Information Administration. Emissions of Greenhouse Gas Emissions in the United States 2005. DOE/EIA-0573(2005) (Washington, D.C., November 2006) Table B3 Total Energy-Related Carbon Dioxide Emissions by End-Use Sector, and the Electric Power Sector, by Fuel Type, 1949-2004.Table available at http://www.eia.doe.gov/emeu/aer/ contents.html). Historical GDP data from U.S. Department of Energy, Energy Information Administration. Annual Energy Review 2005 DOE/ EIA-0384 (2005), (Washington, D.C., July 2006). Table 1.5 Energy Consumption, Expenditures, and Emissions Indicators, 1949-2005 (http://www.eia.doe.gov/emeu/aer/contents.html)

Figure 2.15. Carbon Emissions and Carbon Intensity Trends Under Alternative Scenarios

Reduced cost of air pollution control due to EERE's portfolio in the HFP and BAU scenarios are similar (see Figure 2.14). In 2030, reduced air pollution control costs $\$ 13$ billion and $\$ 15$ billion per year, 
respectively, for the HFP and BAU cases. Under the carbon constraint case, air pollution cost savings jump to almost $\$ 100$ billion per year due to the inclusion of carbon allowance prices along with $\mathrm{NO}_{\mathrm{x}}, \mathrm{SO}_{\mathrm{x}}$, and mercury allowance prices.

\section{Security Benefits Under Alternative Scenarios}

Avoided oil imports due to EERE's portfolio are substantial under all scenarios (see Figure 2.16).

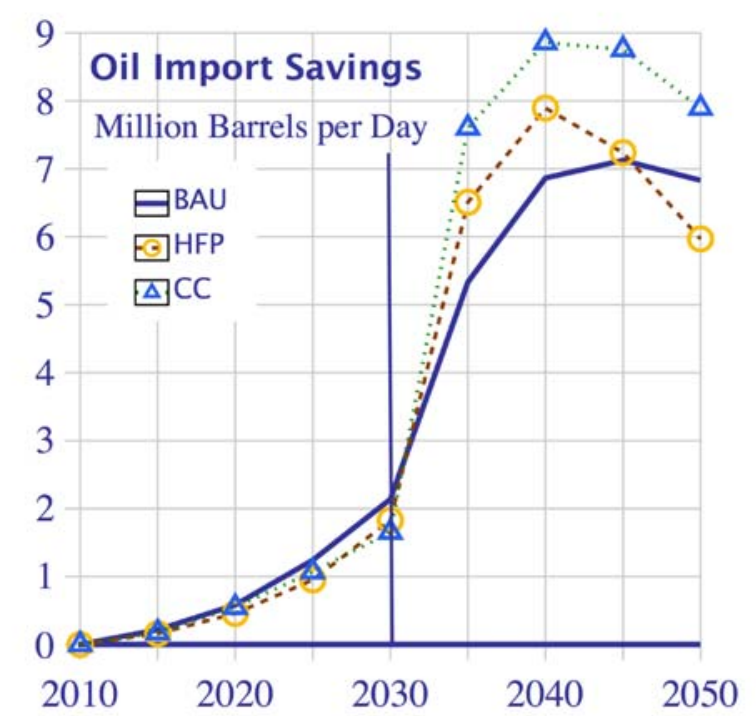

NEMS-GPRA08 2010 TO 2030 MARKAL-GPRA08 2030 TO 2050

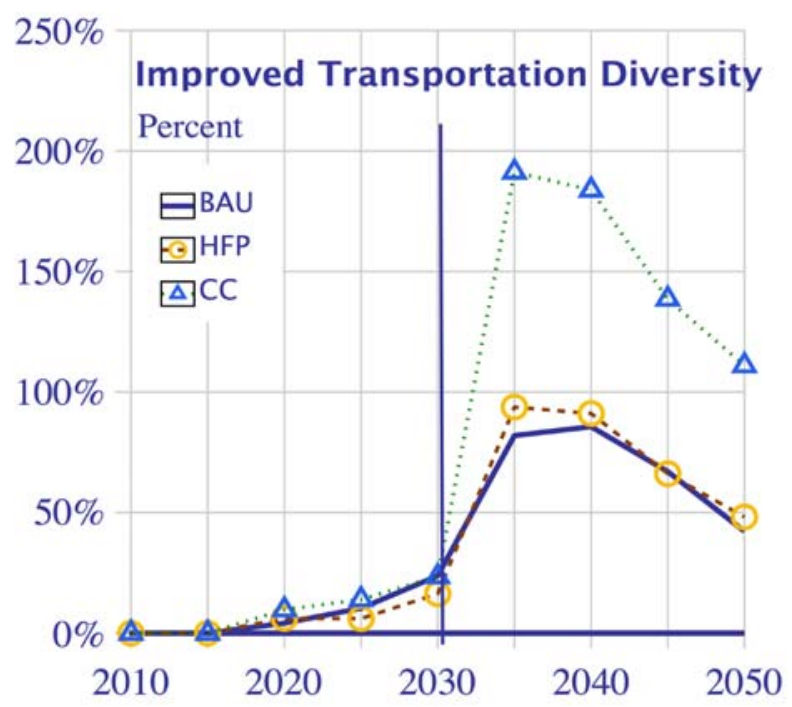

NEMS-GPRA08 2010 TO 2030 MARKAL-GPRA08 2030 TO 2050

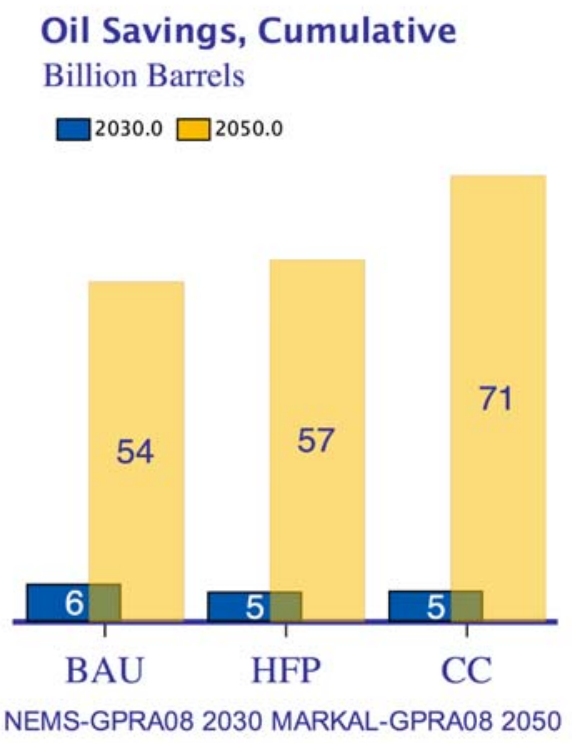

Security MPG Improvement Gallons of Oil per LDV

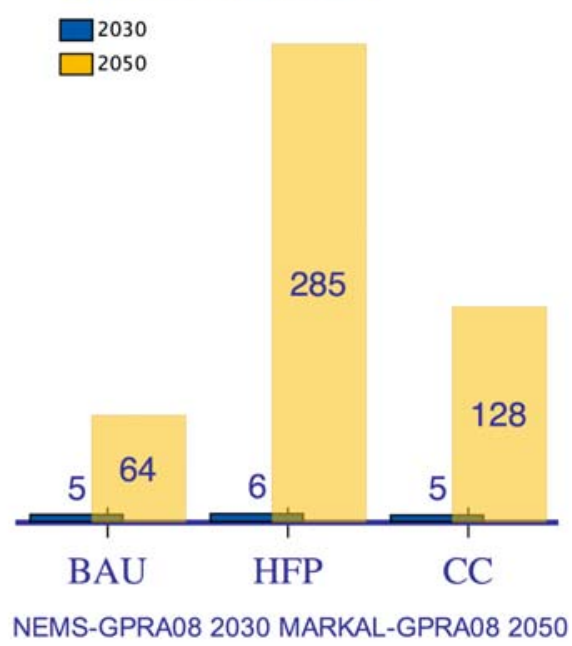

Figure 2.16. Security Benefits Under Alternative Scenarios

However, in both the HFP and the CC scenarios, the midterm impact of EERE's portfolio is somewhat less than under the BAU scenario. In 2030, EERE portfolio leads to oil import reductions of 1.8 and 1.7 million barrels per day, respectively, for the HFP and CC scenarios, compared to $2.1 \mathrm{mbpd}$ under BAU 
conditions. Cumulative oil savings under both alternative scenarios are 5 billion barrels of oil, compared to 6 billion barrels for the BAU scenario.

In the long term (2030 through 2050), the HFP and CC scenarios see a peak in EERE's impact that occurs sooner than in the BAU scenario, reaching savings of 8 and 9 mbpd, respectively, in the HFP and CC scenarios.

Historical and projected oil import trends under all three scenarios (BAU, HFP, and CC) are shown in Figure 2.17.

High Fuels Price Scenario
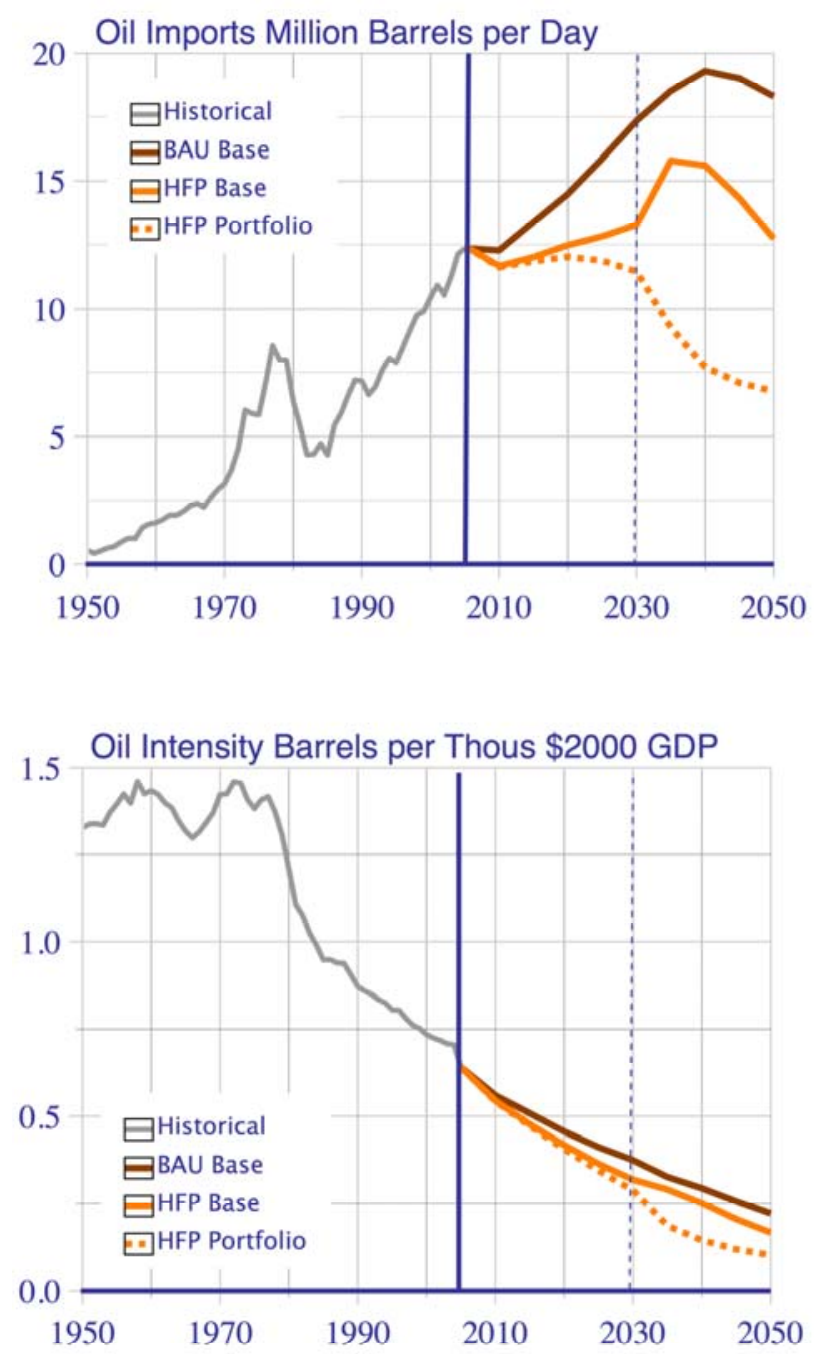

Carbon Constraint Scenario
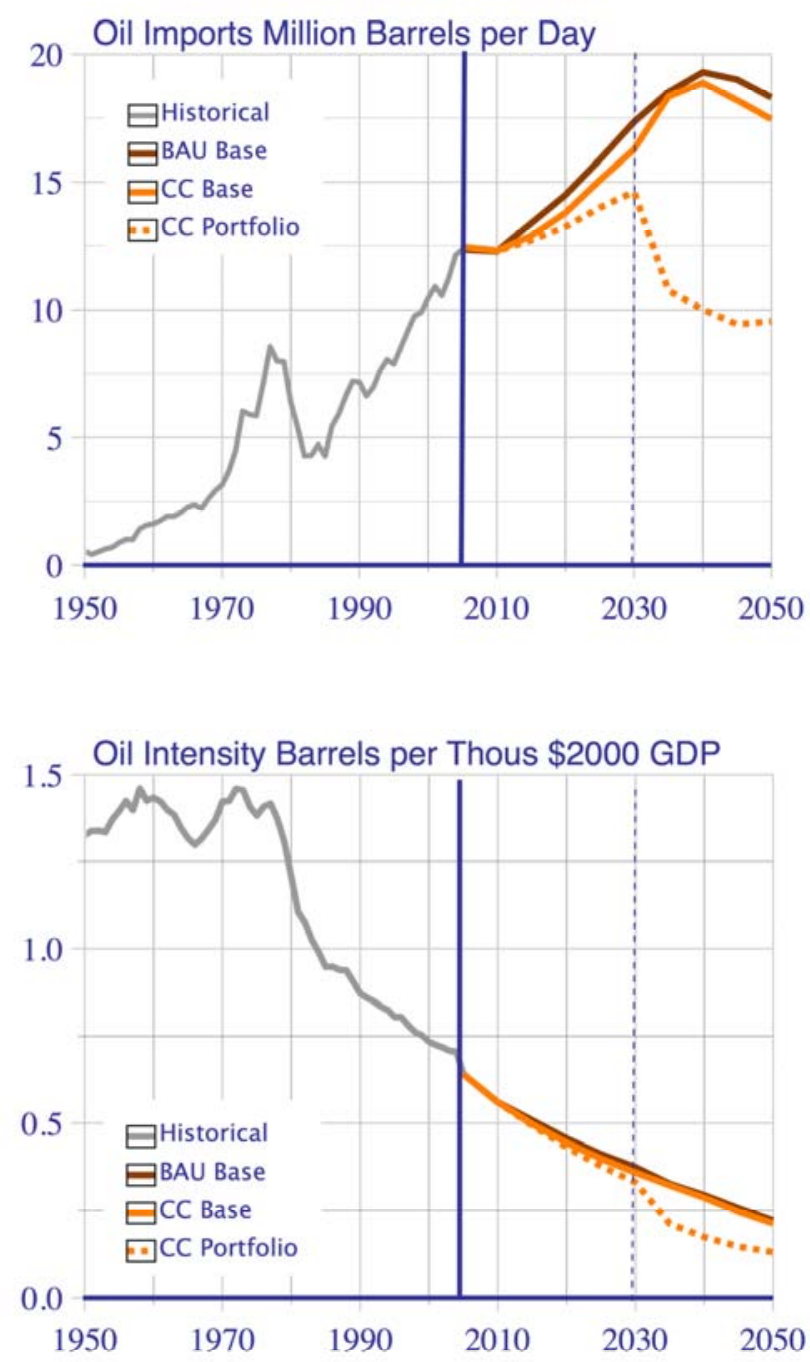

Solid line represents historical and projected trend without future funding of the EERE portfolo. Dashed line represents projected trend assuming continued funding of the EERE portfolio. NEMS-GPRA08 2010 to 2030 MARKAL-GPRA08 2035 to 2050

Historical data to 2005 from U.S. Department of Energy, Energy Information Administration. Annual Energy Review 2005 DOE/EIA-0384 (2005)

(Washington, D.C., July 2006) Table 1.5 Energy Consumption, Expenditures, and Emissions Indicators, $1949-2005$ and

Table 5.1 Petroleum Overview, 1949-2005 (http://www.eia.doe.gov/emeu/aer/contents.html)

HFP = High Fuel Price Scenario

$\mathrm{CC}=$ Carbon Constraint Scenario

$\mathrm{BAU}=$ Business-As-Usual Scenario

Figure 2.17. Oil Import and Oil Intensity Trends Under Alternative Scenarios 
The NEMS-GPRA08 model projects a HFP baseline that has 4 million barrels per day lower import levels compared to the BAU Baseline by 2030 - a $26 \%$ reduction. The combination of high oil prices and the impact of EERE's portfolio reduces projected 2030 import levels by more than 6 million barrels per day-a 34\% reduction.

As the trends in Figure 2.17 suggest, some of the differences in the midterm (2030) and long-term (2050) impacts are due to differences in the models used. In the case of oil imports, baseline imports under high fuel prices do not decline as rapidly in the MARKAL-GPRA08 projections as they do in the NEMSGPRA08 projections. Oil imports in the EERE portfolio case under the HFP scenario, on the other hand, decline more dramatically in the MARKAL-GPRA08 projections than they do in the midterm NEMSGPRA08 projections. By 2050, the combination of high oil prices and EERE's portfolio bring oil imports down to $7 \mathrm{mbpd}$ - a level not seen in the United States since the late 1980s. This represents a reduction of $11 \mathrm{mbpd}$ in oil imports over the projected baseline level in 2050 - or $63 \%$.

A carbon constraint scenario has less-but still significant - impact on oil imports. The CC baseline shows lower import levels ( 1 million barrels per day) compared to the BAU baseline by 2030 - a $6 \%$ reduction. The combination of a carbon constraint and the impact of EERE's portfolio reduces projected 2030 import levels by 3 million barrels per day - a 16\% reduction. The dramatic drop in oil imports from 2030 to 2035 reflects the more aggressive impacts of EERE's portfolio projected by MARKAL-GPRA08. The combined effect of a carbon constraint and EERE's portfolio reduces oil imports to $9.6 \mathrm{mbpd}$ in 2050 .

Energy security in the transportation sector improves in all scenarios, as measured by security MPG and transportation fuel diversity (see Figure 2.16). In the midterm (2010 through 2030), the effect of EERE's portfolio is essentially the same across all scenarios. In all three scenarios, the effect of EERE's portfolio is to improve fuel diversity in light-duty vehicles by about $25 \%$ relative to the base cases in each scenario. In the long term, EERE's portfolio has a much greater impact on transportation diversity under the carbon constraint scenario than it does under the BAU or HFP scenarios. Fuel diversity is improved by almost $200 \%$ under the HFP in the 2035 to 2040 time frame. Security MPG, meanwhile, is impacted much more by EERE's portfolio under the HFP scenario than it is under the BAU and CC scenarios. By 2050, security fuel economy increases by 285 miles of travel per gallon of crude oil consumed by light-duty vehicles under the HFP scenario, compared to 128 miles per gallon and 64 miles per gallon under the CC and BAU scenarios, respectively.

\section{A Closer Look at the Energy Picture}

\section{Changes in Primary Energy Demand Under Alternative Scenarios}

One of the key determinants of how the benefits change under the alternative scenarios is the shift in the baseline projections, given that benefits are defined as the difference between the baseline and the portfolio cases. Higher prices - seen in both the HFP and CC scenarios - shrink the demand for energy. This is due, in part, to lower demand for energy services as a result of slightly lower incomes and economic output, and behavioral responses to higher prices such as turning down thermostats and driving less. Higher energy prices also stimulate greater investment in energy efficient and renewable technologies, even in the absence of technology improvements resulting from the EERE RD3 programs.

The impacts of the alternative scenarios for high fuel prices and carbon constraints on baseline primary energy demand are shown in Figure 2.18. High fuel prices reduce primary energy demand by $4 \%$ in 2030 - from 129 to 124 quadrillion Btus per year. The carbon constraint scenario has the strongest effect, reducing demand for primary energy by $9 \%$ in 2030 - from 129 to 118 quadrillion Btus per year. By 2045, primary energy demand under the HFP and CC scenario baselines plateaus at the 2040 level of energy demand projected for the Business-as-Usual scenario baseline. 
The imposition of the carbon cap has a profound impact on the energy system. Carbon emission reductions are achieved through a combination of energy service demand reductions, increased efficiency, and fuel switching to less carbon-intensive energy sources. In meeting the carbon cap, energy consumption falls in the Baseline below the level in the BAU EERE Portfolio case.

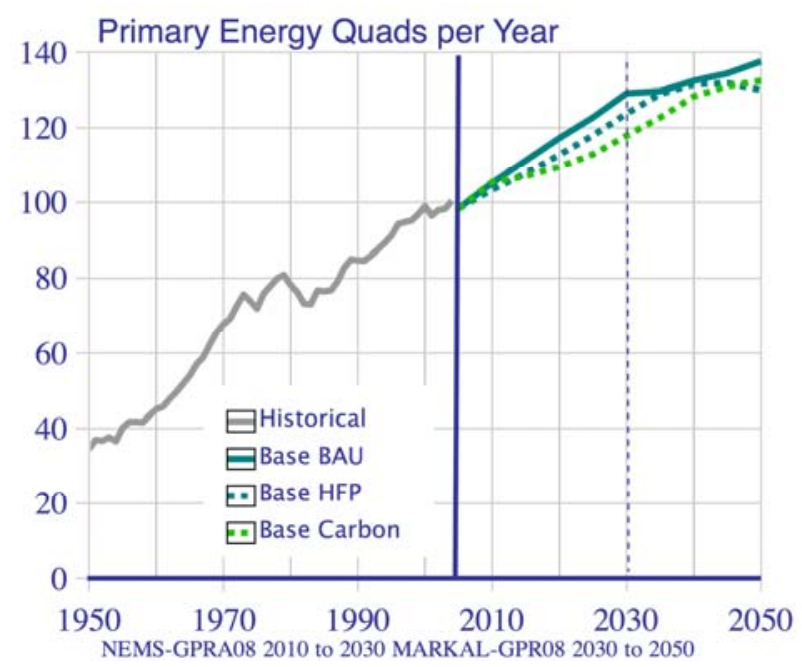

Solid lines represents total primary energy consumption (both renewable and nonrenewable) under the Business-As-Usual scenario. The dashed lines represent primary energy consumption under alternative future scenarios.

HFP = High Fuel Price Scenario

$\mathrm{BAU}=$ Business-As-Usual Scenario

$\mathrm{CC}=$ Carbon Constraint Scenario

Historical data (1949 to 2005) on primary energy use from U.S. Department of Energy, Energy Information Administration. Annual Energy Review 2005 DOE/EIA-0384 (2005) (Washington, D.C., July 2006) Table 1.1 Energy Overview, 1949-2005 (http:// www.eia.doe.gov/emeu/aer/contents.html).

Figure 2.18. Primary Energy Consumption Baselines Under Alternative Scenarios

The combined effect of the alternative scenarios and EERE's portfolio leads to even greater reductions in primary energy consumption (see Figure 2.19).
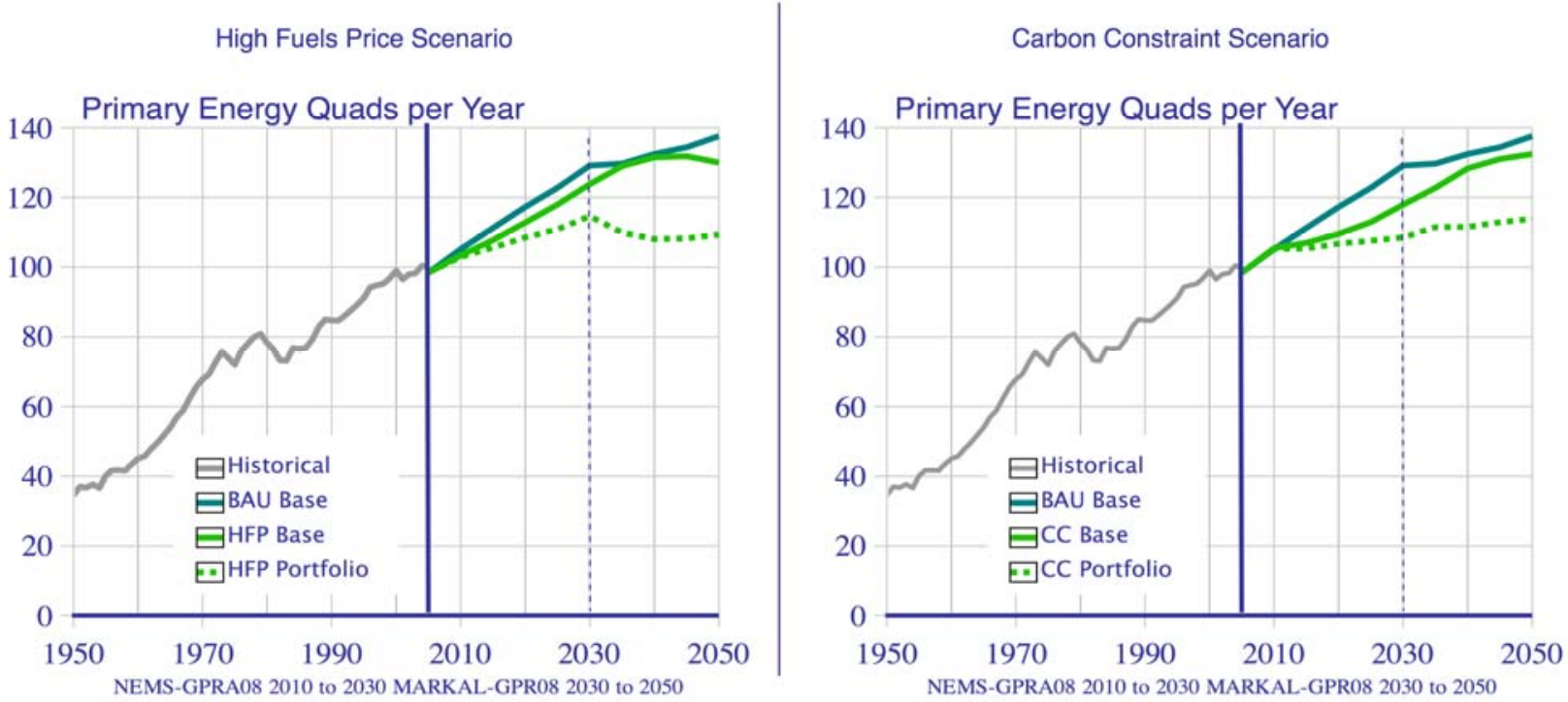

Solid lines represents total primary energy consumption (both renewable and nonrenewable) under the baseline cases (without EERE's portfolio) scenario. The dashed lines represent primary energy consumption under alternative future scenarios. Historical data (1949 to 2005) on primary energy use from U.S. Department of Energy, Energy Information Administration. Annual Energy Review 2005 DOE/EIA-0384 (2005) (Washington, D.C., July 2006) Table 1.1 Energy Overview, 1949-2005 (http://www.eia.doe.gov/emeu/aer/contents.html).

HFP $=$ High Fuel Price Scenario

$\mathrm{CC}=$ Carbon Constraint Scenario

$\mathrm{BAU}=$ Business-As-Usual Scenario

\section{Figure 2.19. Effect of EERE's Portfolio on Primary Energy Consumption Under Alternative Scenarios}

Projected Benefits of Federal Energy Efficiency and Renewable Energy Programs (FY 2008-FY 2050)

The Value of EERE's Portfolio (Chapter 2) - Page 2-24 
By 2030, the EERE portfolio under the HFP scenario reduces primary energy consumption by $11 \%$ compared to the BAU baseline case - reducing primary energy consumption from 129 quadrillion Btus per year under the BAU baseline to 115 quadrillion Btus per year under the HFP portfolio case. The EERE portfolio under the carbon constraint scenario results in primary energy consumption that is $16 \%$ lower than the BAU baseline case in 2030 - reducing primary energy consumption from 129 quadrillion Btus per year under the BAU baseline to 109 quadrillion Btus per year under the CC portfolio case. By 2050, the combined effect of high fuel prices and EERE's portfolio reduces primary energy consumption from 138 to 109 quadrillion Btus per year - a 21\% reduction. The combined effect of the carbon cap and EERE's portfolio reduces primary energy consumption to 114 quadrillion Btus per year in 2050 -a $17 \%$ reduction over BAU baseline of 138 quadrillion Btus per year.

The relative growth of energy demand within each of the four sectors of the U.S. energy market (transportation, residential, commercial, and industrial) is shown for two time frames - midterm (2010 to 2030) and long term (2030 to 2050) - in Figure 2.20 and Figure 2.21, respectively. High fuel prices have the greatest effect, in the midterm, on transportation - reducing baseline growth in the transportation sector by about one-third and by about $20 \%$ each in the three remaining sectors. The carbon cap puts much more downward pressure on industrial- and residential-sector baseline consumption, where each sees $54 \%$ and $37 \%$ less growth in 2030 . These scenario-driven reductions effectively reduce the opportunity for EERE's portfolio to impact each sector. This helps to explain why NEMS-GPRA08 shows lower oil import and carbon emission benefits in the HFP and CC scenarios, compared to the BAU scenario (see Figure 2.14 and Figure 2.15).

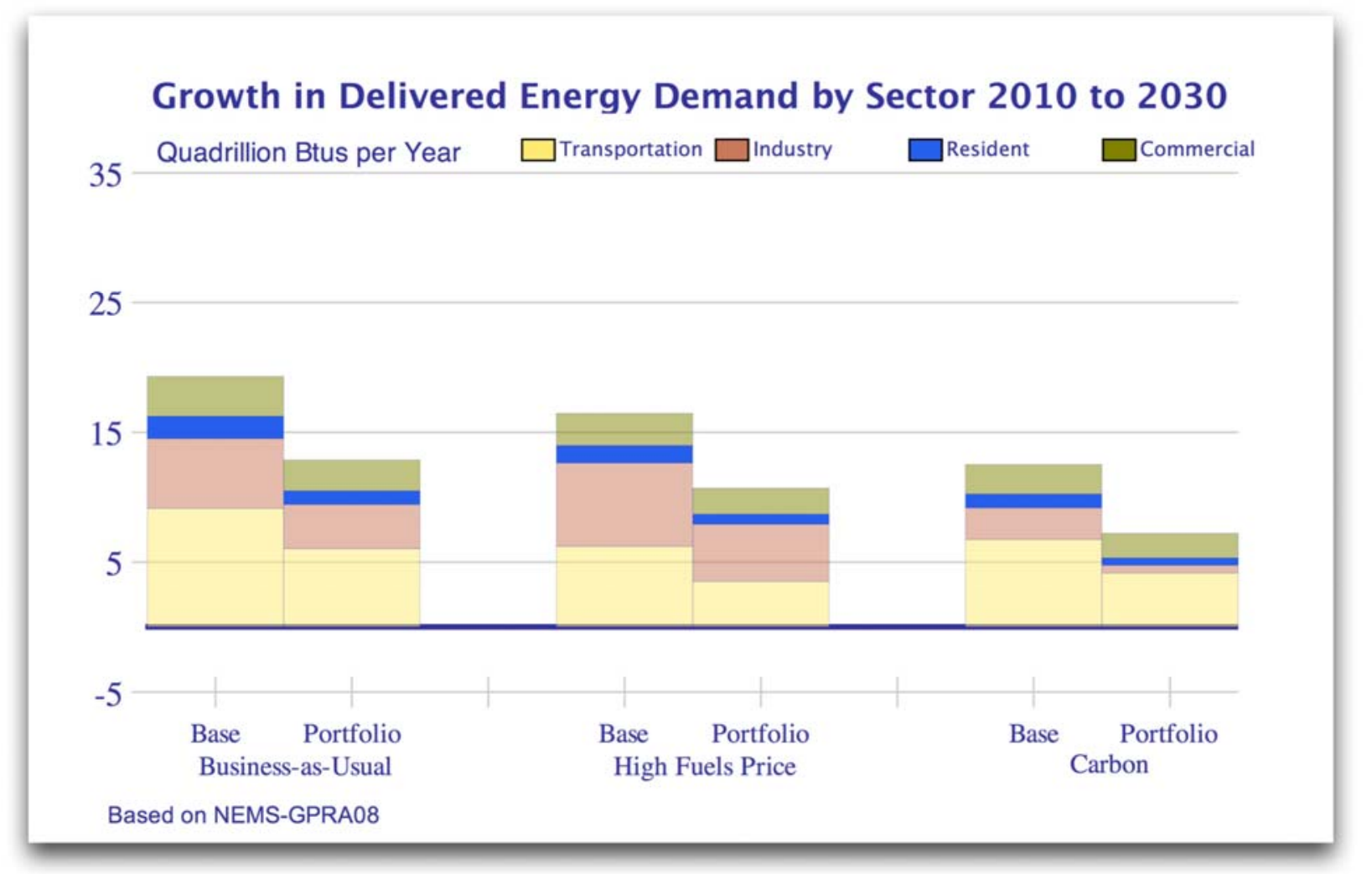

Figure 2.20. Shifts in Midterm Energy Growth by Sector Under Alternative Scenarios

The long-term picture of energy growth is shown in Figure 2.21. Energy growth still declines in the HFP and CC scenarios relative to the BAU scenario. In 2050, vehicle technologies have a much larger impact on energy demand overall — and on the transportation sector, in particular - in all three scenarios. Under 
the BAU, EERE's portfolio eliminates new growth in energy demand for the transportation sector. Under the HFP and CC scenarios, energy demand in transportation actually shrinks from 2010 to 2050.

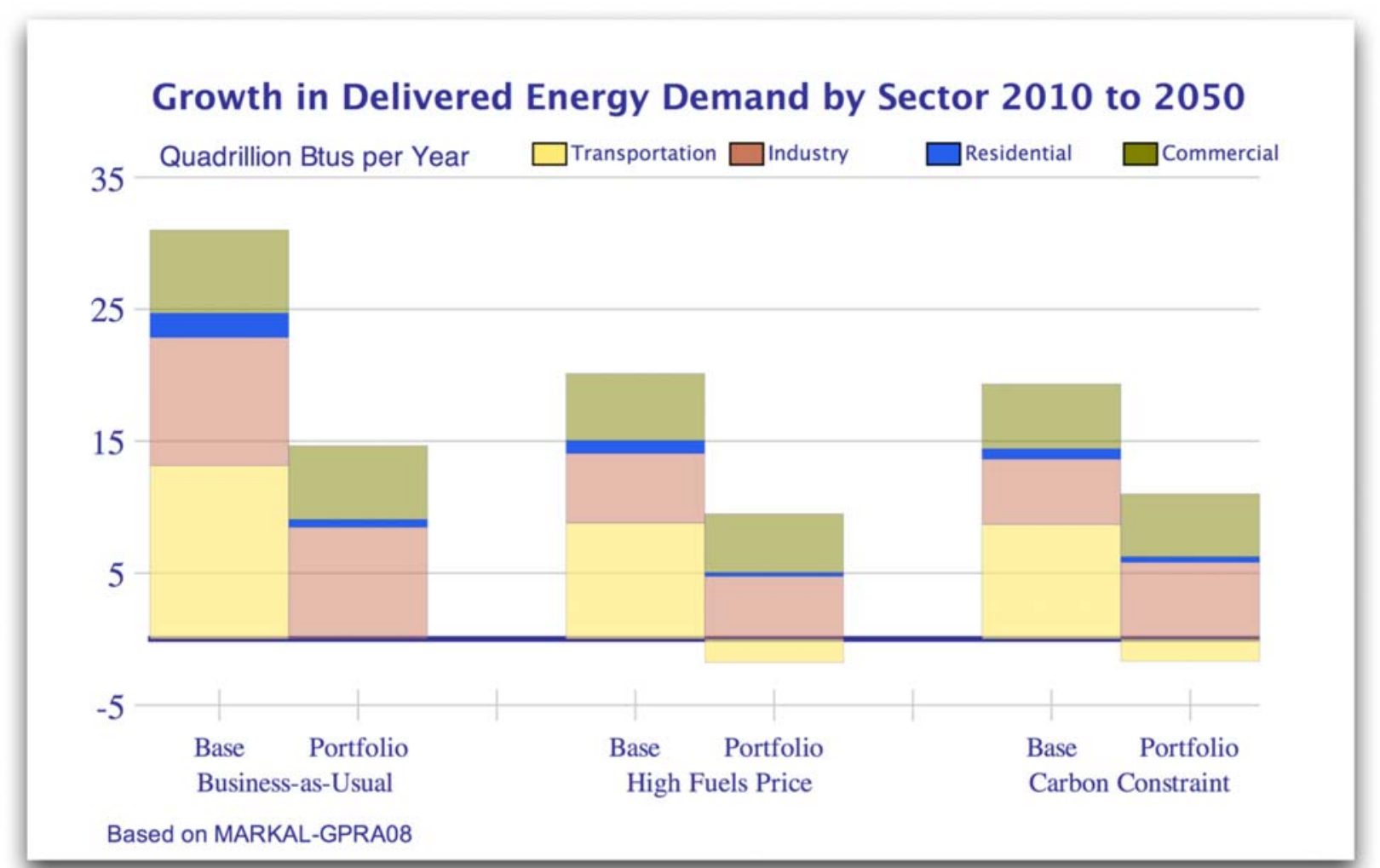

\section{Figure 2.21. Shifts in Long-Term Energy Growth by Sector Under Alternative Scenarios}

Growth in energy demand for the buildings sector is shown Figure 2.22. Energy growth under the alternative scenarios declines around $20 \%$ in the midterm and $25 \%$ in the long term. Relative energy savings in the buildings sector due to EERE's portfolio is somewhat lower under the alternative scenarios, compared to the BAU scenario.
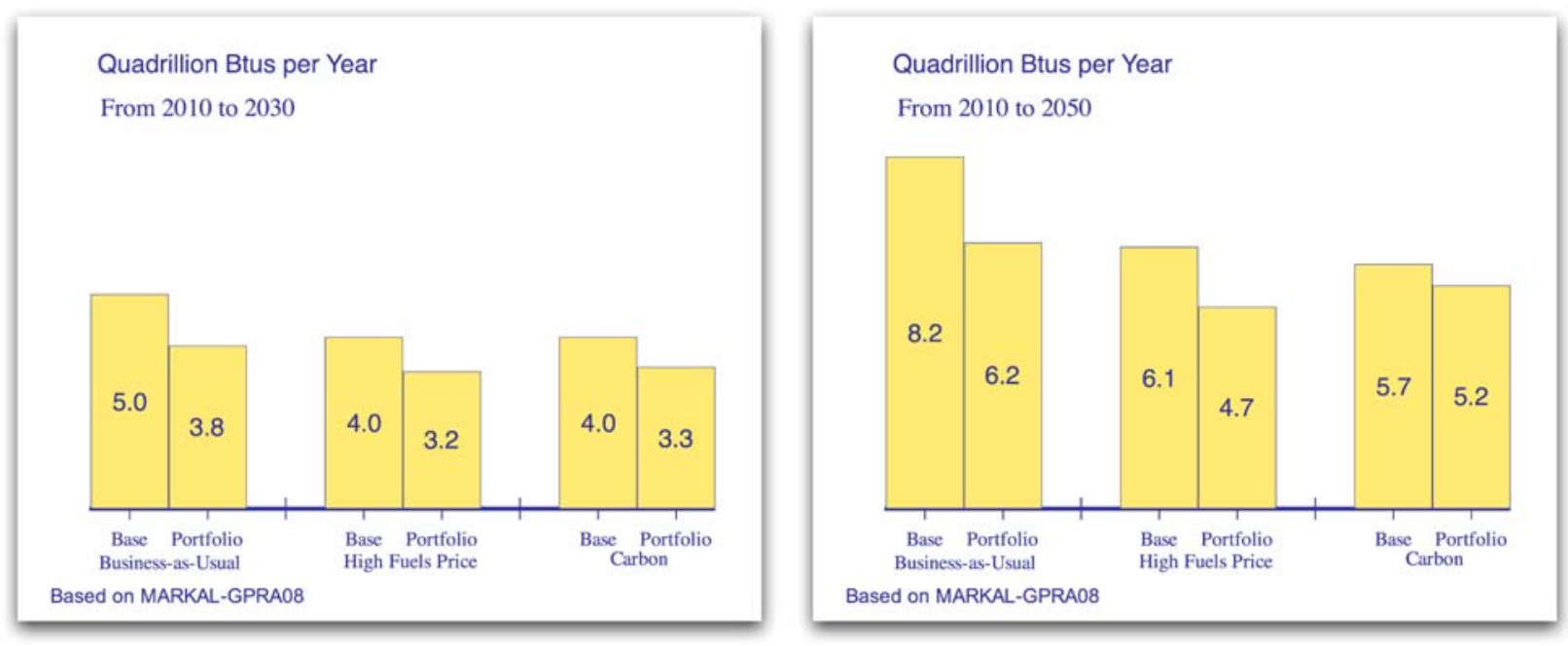

Figure 2.22. Growth in Building-Sector Energy Demand Under Alternative Scenarios 


\section{Transforming the Electric Utility Sector}

Midterm shifts in electric generation capacity (based on NEMS-GPRA08) are shown in Figure 2.23. Baseline generation capacity in 2030 shifts away from natural gas-oriented technology (items in shades of blue in Figure 2.23) under the high fuels price scenario, and moves toward coal-oriented technologies (steam coal and coal-based integrated gasification combined cycle - IGCC). Renewable power generation also sees a modest increase in the HFP baseline. Under the carbon constraint scenario, baseline coal power generation capacity declines substantially, while low- and no-carbon renewable power generation and nuclear power generation capacity both grow substantially.

The EERE portfolio cases in the alternative scenarios lead to increased displacement of fossil fuel technology with renewable power generation technology, especially under the carbon constraint case, in which nearly 500 gigawatts of the 1,300 gigawatts of total installed capacity in 2030 is renewable energybased. Note that the relative impact of the EERE portfolio on growth in renewable power generation capacity is less for the HFP and CC scenarios, because of the larger baseline levels of renewable power generation capacity that occur in these scenarios.

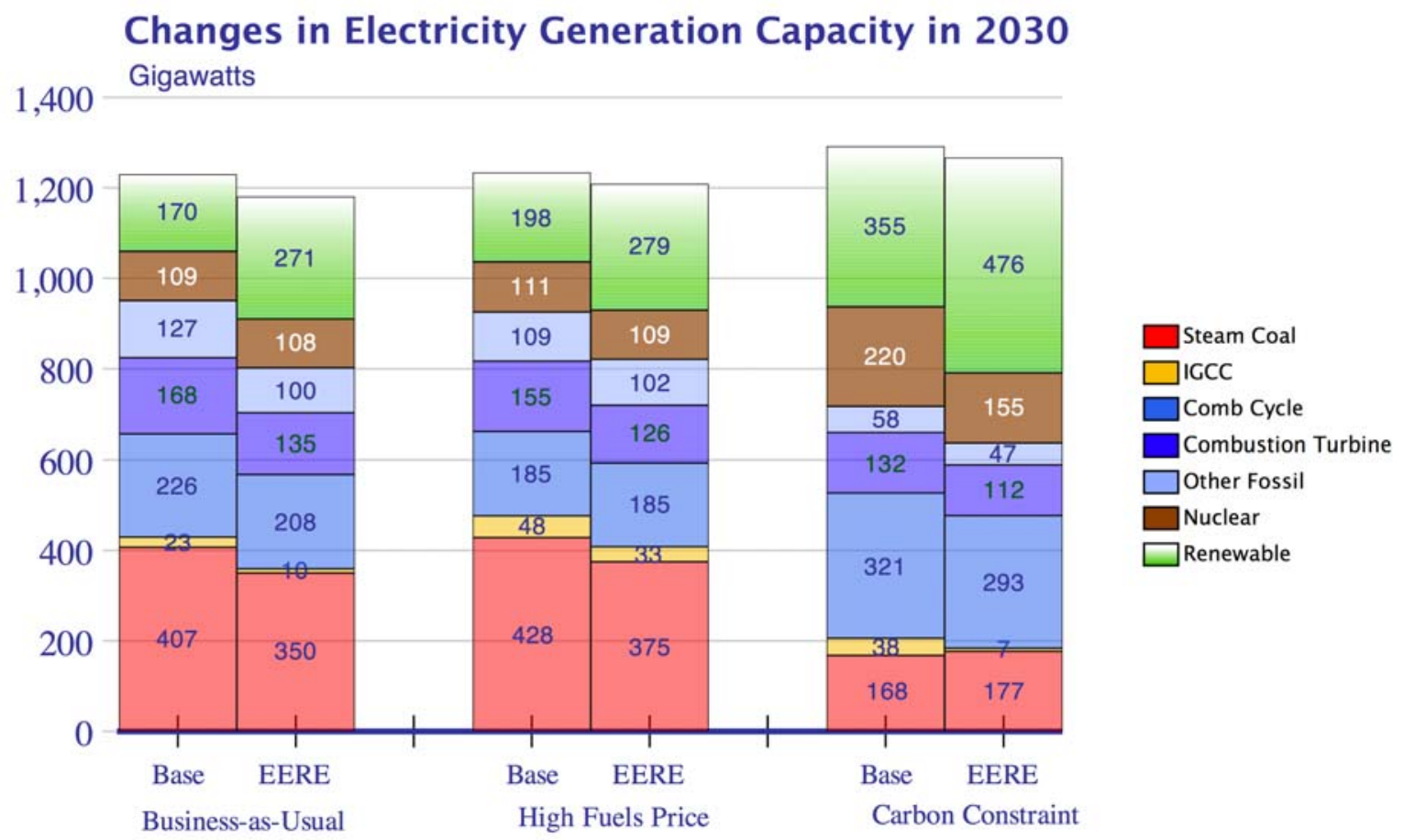

Figure 2.23. Electricity Generation Capacity in 2030 Under Alternative Scenarios

Figure 2.24 shows the relative distribution of electric power-generation capacity from 2010 to 2050 as estimated by MARKAL-GPRA08 for baseline and EERE portfolio cases under the three BAU, HFP, and CC scenarios. An inspection of distribution patterns from top to bottom in the left-hand column shows how trends in technology distribution change for the baselines as a function of scenario. The BAU baseline shows coal technologies maintaining a solid $40 \%$ of the capacity through 2050 . In 2025 , IGCC technology begins to displace traditional steam coal technology, growing to $50 \%$ of the total coal capacity in 2050. Natural gas technologies maintain a similarly high fraction (roughly 40\%) of the total generating capacity throughout this time period. In the BAU baseline, nuclear power's share of the capacity gradually disappears. Renewable energy shows modest growth, from $11 \%$ of the total generating capacity in 1010 to $18 \%$ by 2050 . 


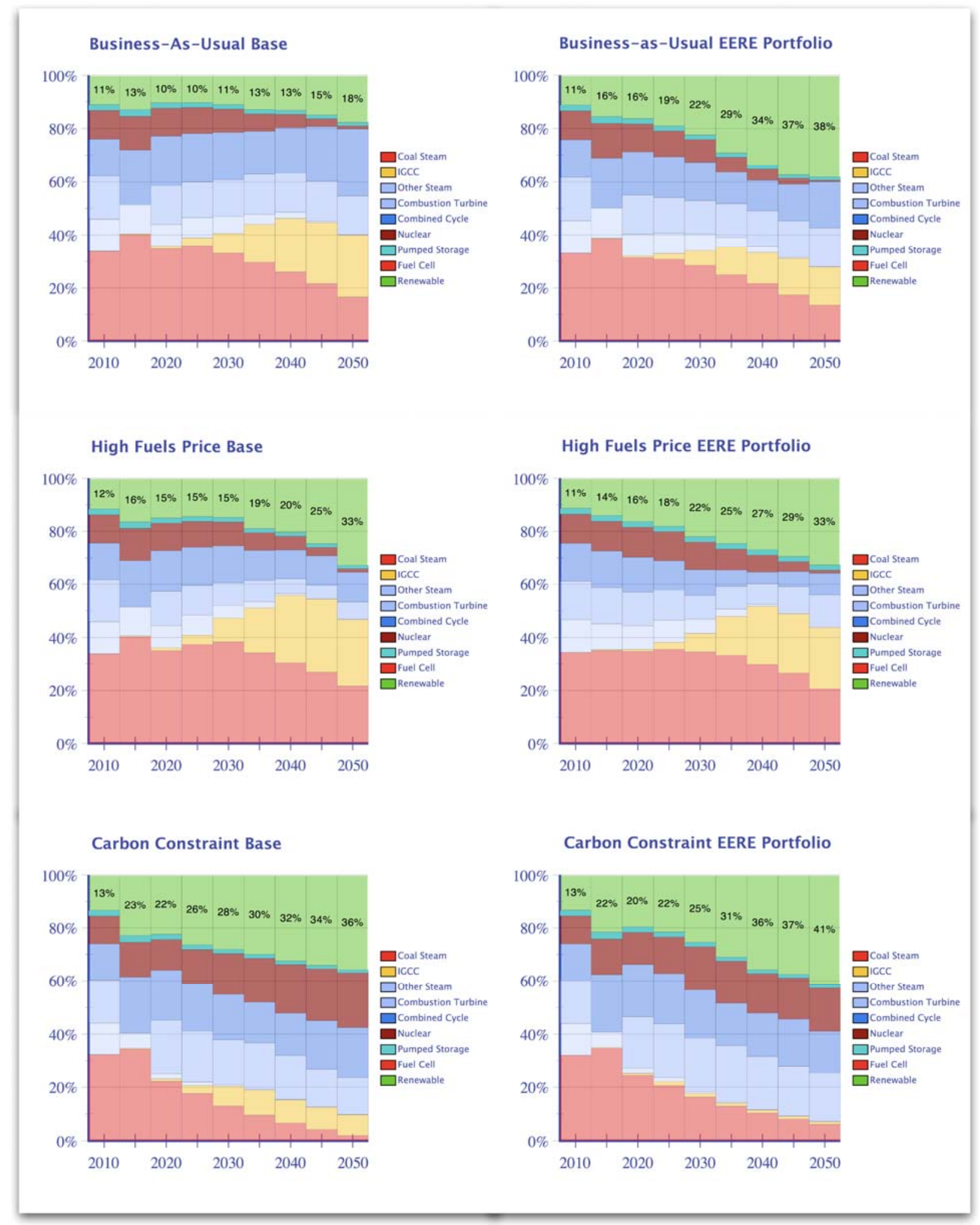

Figure 2.24. Changes in Electricity Generation Capacity Distribution Under Alternative Scenarios 
High fuel prices cause a significant shift away from natural gas technologies in the base case (see the middle chart in the left column). Much of the decline in natural gas-generating capacity is made up by growth in renewable energy technologies, which represents one-third of the total capacity by 2050. Coal's share of the total generating capacity also grows under the high fuels price base case to a level of about $50 \%$ in 2050 , because coal prices remain relatively low under this scenario. Under the carbon-constrained scenario, the baseline share of coal technology declines steadily, with traditional steam coal technology almost completely displaced by 2050 .

The portfolio cases (charts on the right-hand side of Figure 2.24) vary significantly across the scenarios. EERE's renewable energy technologies have their greatest impact in the BAU scenario. The portfolio case sees nearly a doubling in the relative contribution of renewable power generation capacity over the baseline - $18 \%$ versus $38 \%$ of total capacity in 2050 . In the HFP and CC scenarios, the portfolio does not significantly increase renewable power generation capacity. Nevertheless, there are some impacts worth noting. In the HFP, renewable energy technology builds up earlier in the portfolio case than it does in the BAU scenario. In the carbon cap scenario, renewable energy technology seems to push out coal-based IGCC technology.

While EERE's portfolio does not necessarily influence the relative contribution of renewable energy technology capacity in the electric power sector under the HFP and CC scenarios, it does-in all scenarios - lead to significantly greater total generation of renewable electricity. ${ }^{7}$ In 2030 , the greatest amount of renewable generation occurs in the EERE portfolio case under a carbon constraint scenario (see Figure 2.25).

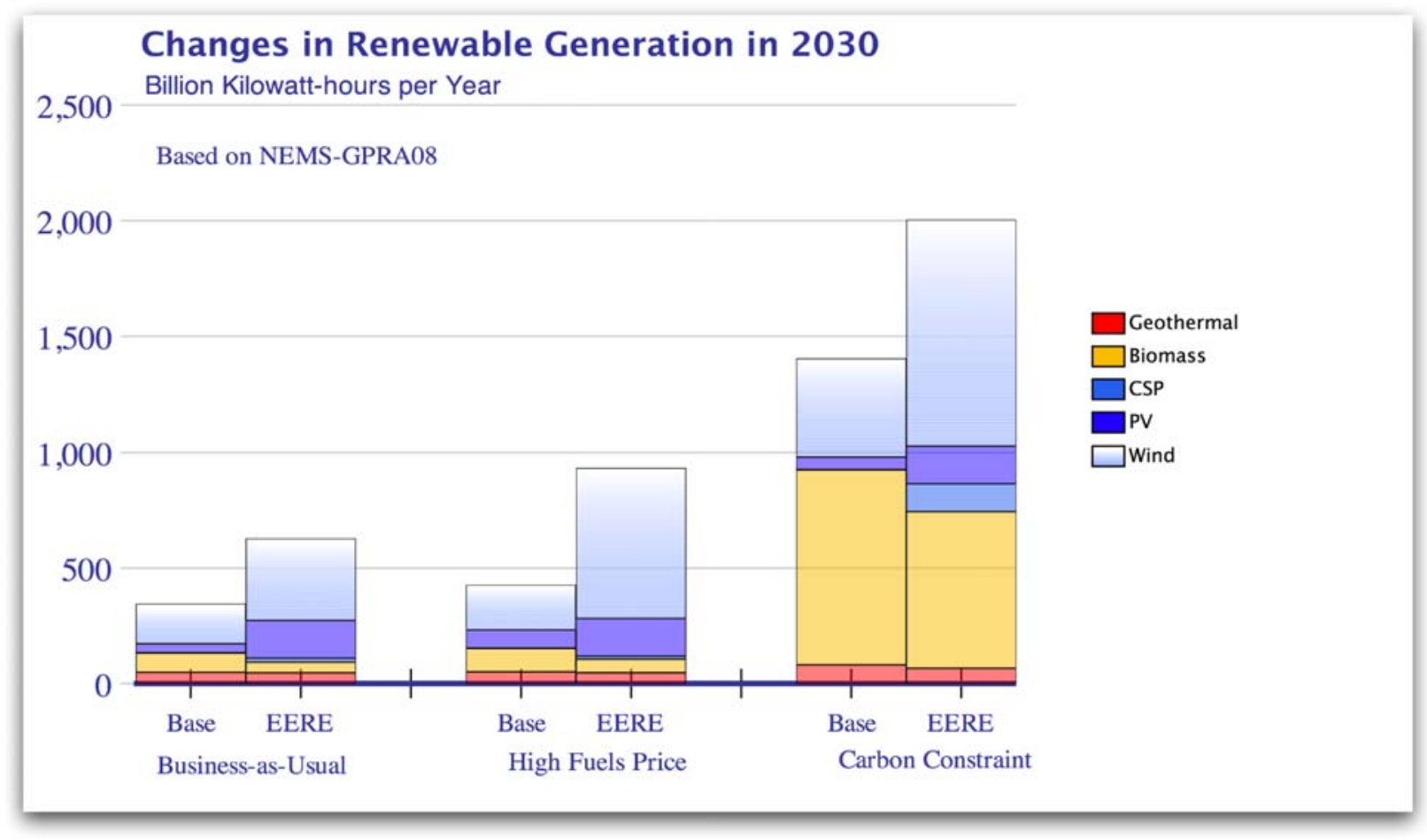

Figure 2.25. Total Renewable Electricity Generation in 2030

EERE's portfolio results in an increase from 1,300 billion to 2,000 billion kilowatt-hours per year of total generation under the carbon scenario (a 50\% increase). In both the BAU and HFP scenarios, the effect of EERE's portfolio is a doubling of total renewable electricity generation-300 billion to 600 billion

\footnotetext{
${ }^{7}$ Note that we are referring to actual generation of electricity from renewables, not capacity for renewable generation. This is an important distinction, particularly for intermittent power sources such as wind and solar, which have lower capacity factors.
} 
kilowatt-hours under the BAU scenario and 400 billion to 900 billion kilowatt-hours in the HFP scenario. Most of the EERE portfolio-related growth is from wind generation, which dominates both the BAU and HFP scenarios. In the carbon constraint scenario, biomass power really comes into its own, representing almost half of the renewable electricity generation in the EERE portfolio case.

In 2050, the greatest growth in renewable electricity generation occurs in the EERE portfolio case under the high fuels price scenario-reaching 2,400 billion kilowatt-hours per year. The technologies that come into play are significantly different in this time frame. By this time, solar truly comes into its own. Eighty percent of the renewable electricity generated in this case comes from equal shares of wind and solar PV. In all three scenarios, EERE's portfolio dramatically expands the contribution of wind. Under the BAU scenario, EERE's portfolio more than doubles solar's contribution, and has more modest impacts on solar generation under the HFP and CC scenarios.

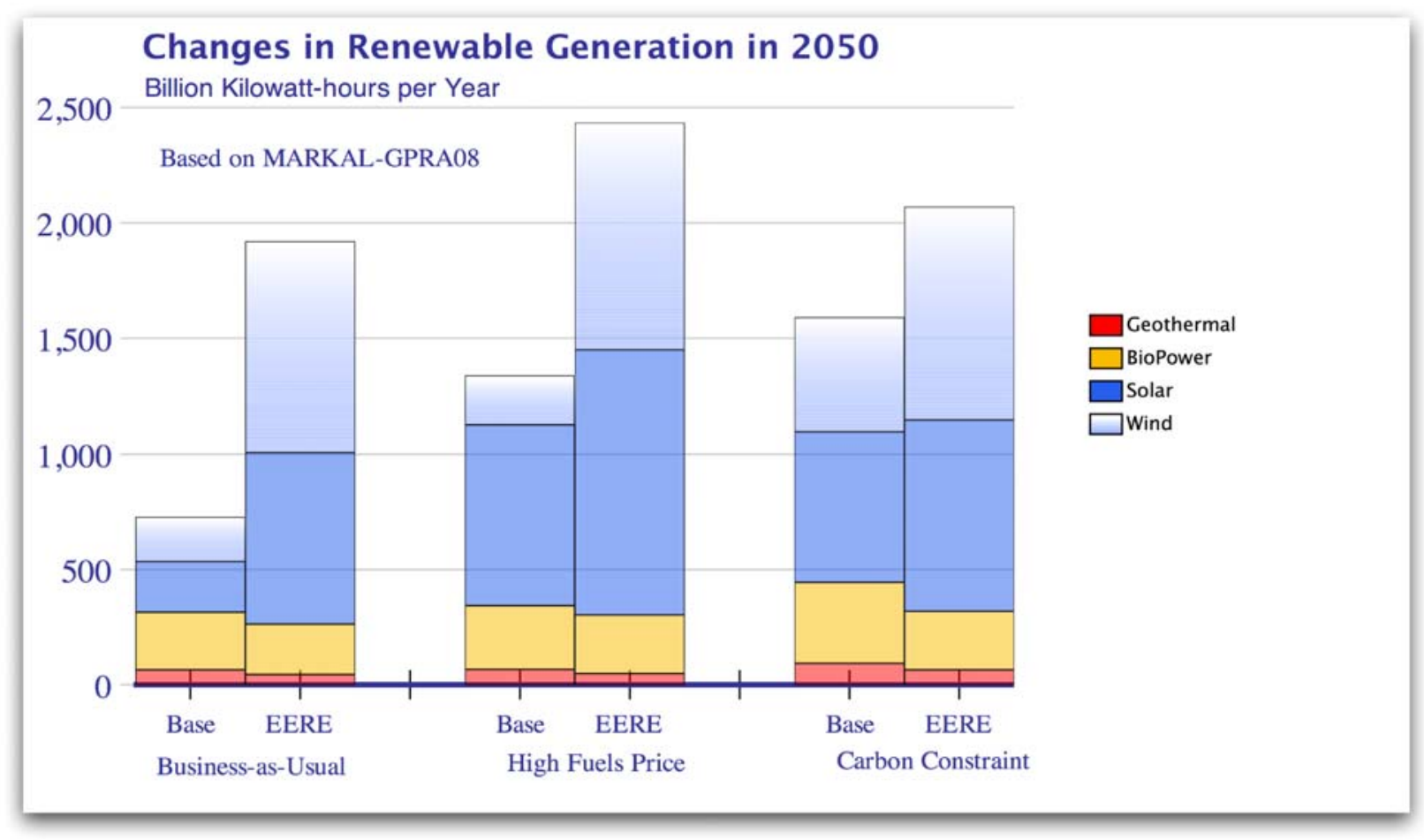

Figure 2.26. Total Renewable Electricity Generation in 2050

\section{Transforming Transportation}

The transportation sector looks very different, depending on which scenario of the future is considered. Figure 2.27 shows the distribution of light-duty vehicle technologies in the mid- and long term, for both baseline and portfolio cases under all three scenarios. In 2030, the baseline cases under all three scenarios for light-duty vehicle fleet are dominated by gasoline internal combustion engines (ICE). This is a case where EERE's portfolio has greater impacts on the future mix of vehicle technologies under the high fuels price and carbon constraint scenarios. Under the BAU scenario, new vehicle technologies in the portfolio case displace about one-third of the gasoline fleets. The biggest impact is seen under the high fuel price scenario, where conventional gasoline vehicles drop from $92 \%$ in the base case to $44 \%$ of the total vehicle stock in the portfolio case. The largest share of the new technologies is in hybrid and plug-in hybrid vehicles.

In 2050, EERE's portfolio catalyzes a dramatic shift away from conventional gasoline vehicles to new vehicle technologies. In all scenarios, the portfolio case has $10 \%$ or less of the fleet in conventional gasoline. The baseline cases under the HFP and CC scenarios also see significant declines in conventional 
gasoline vehicles - with gasoline internal combustion engines (ICEs) maintaining only $34 \%$ and $46 \%$ share of the fleet in the HFP and CC scenarios, respectively.
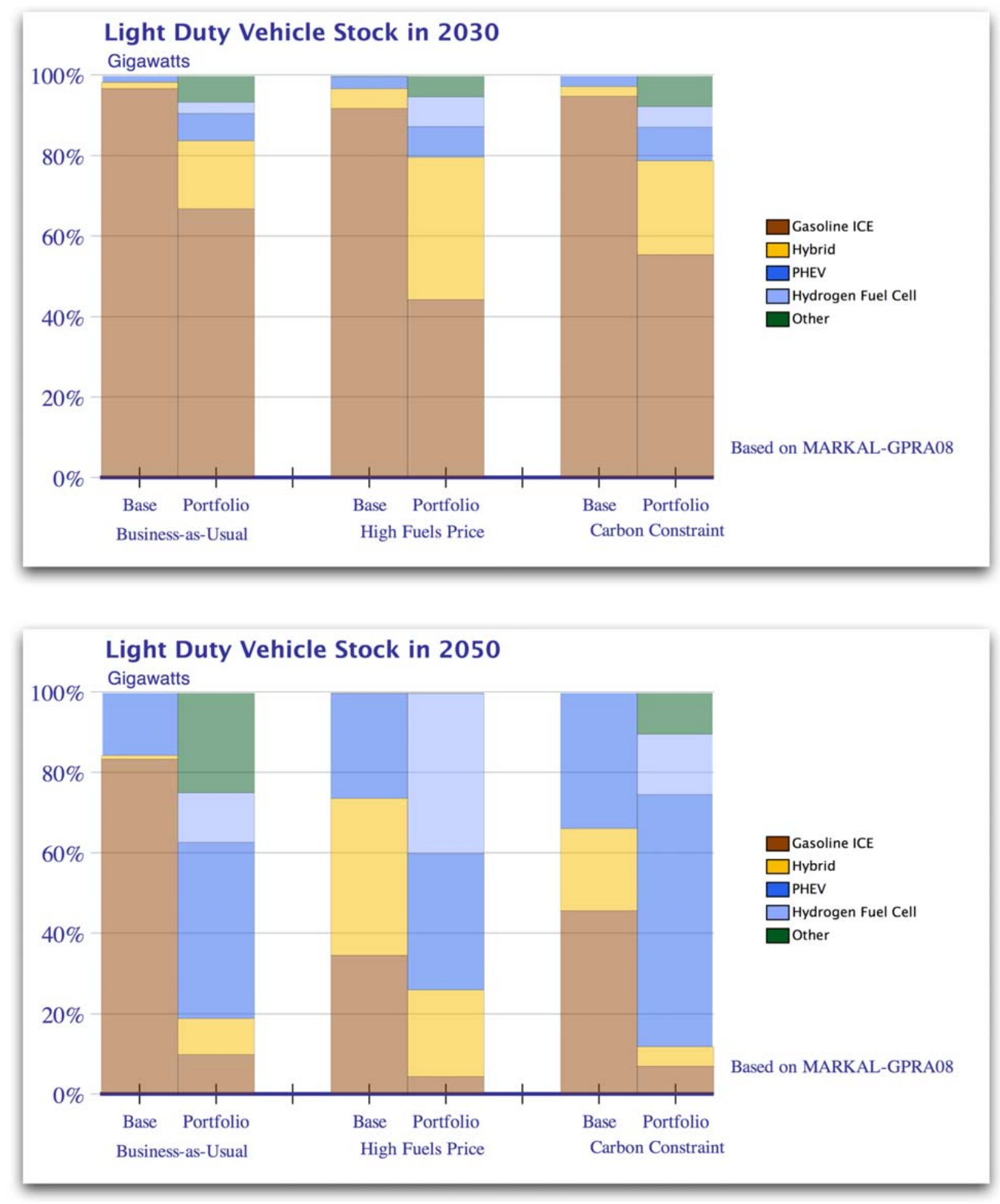

Figure 2.27. Light-Duty Vehicle Stocks in 2030 and 2050 
The mix of new vehicle technologies varies among the three scenarios. The biggest difference is in the relative contribution of hydrogen fuel cell vehicles. In a high fuels price environment, hydrogen fuel cells garner $40 \%$ of the market share; while, under the BAU and carbon-constrained futures, hydrogen fuel cell vehicles capture only $12 \%$ and $15 \%$ of the fleet, respectively. This is because hydrogen fuel cells can use hydrogen made from fossil fuels as well as from renewable low- or no-carbon containing fuels.

Figure 2.28 shows the changes in fuel demand in the U.S. transportation sector for baseline and portfolio cases under all three scenarios.

The high fuels price scenario puts some downward pressure on baseline crude oil use in transportation, resulting in somewhat lower oil consumption in 2050 than in 2010. This reduced oil consumption is due primarily to introduction of ethanol and coal-to-liquids technology. Overall energy consumption in the HFP baseline is also lower, reflecting adoption of more efficient vehicle technology. Under the carbon constraint scenario, the baseline introduction of ethanol in the fuel mix is the dominant change, with some efficiency gains in vehicles as well. In all three scenarios, EERE's portfolio reduces oil consumption by roughly $50 \%$ relative to the baseline projections in 2050 . The mix of fuels changes depending on the scenario, but the effect of EERE's portfolio is the same. 

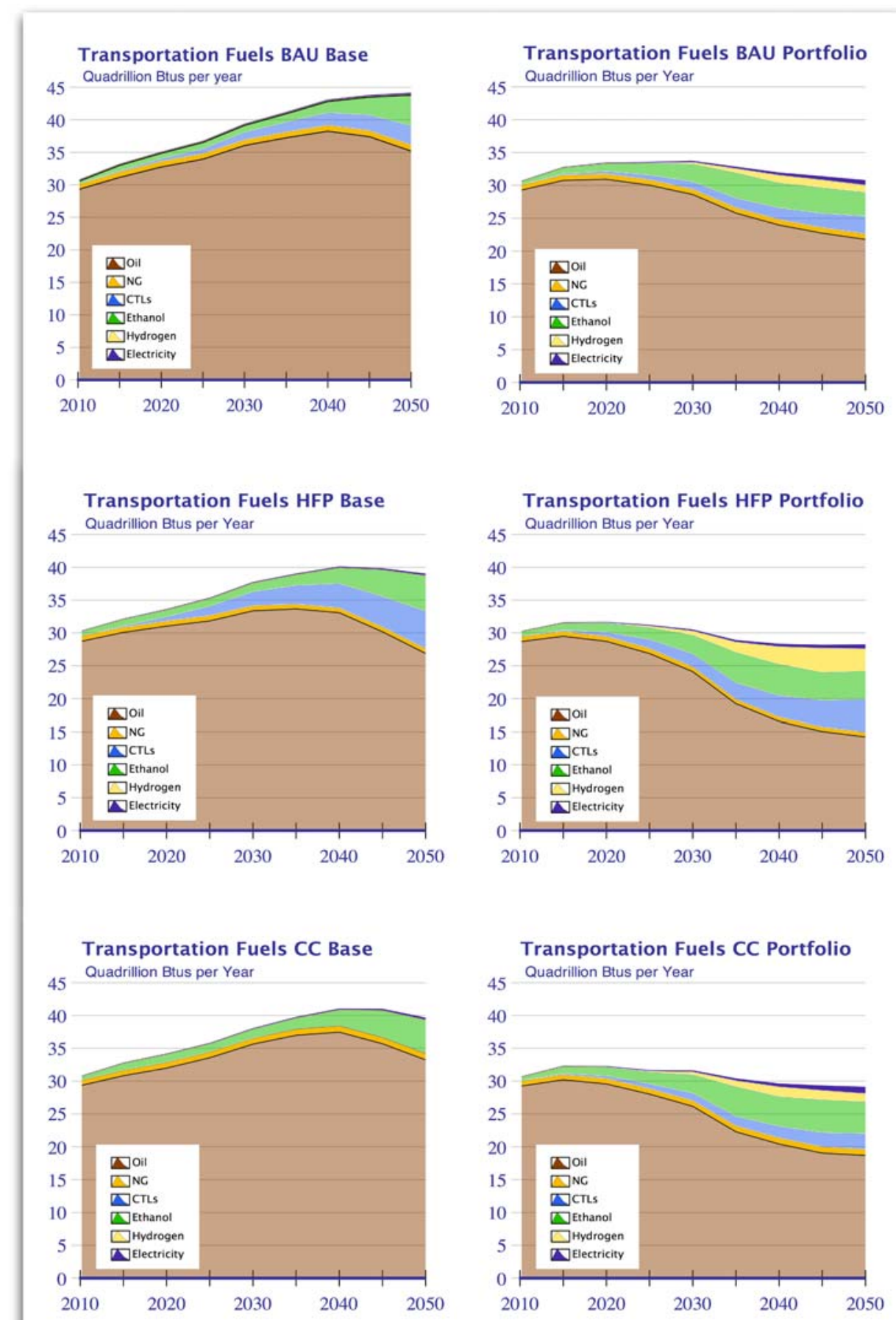

Based on MARKAL-GPRA08

Figure 2.28. Changes in Transportation Fuel Demand Under Alternative Scenarios 


\section{Putting the EERE Portfolio in Perspective}

Figure 2.29 summarizes the overall impact of EERE's portfolio under three different futures-Businessas-Usual, High Fuel Prices and a Carbon Constraint. Each chart shows the percent improvement of selected benefits metrics for the EERE portfolio case relative to the baseline case under each scenario. The metric most impacted by EERE's portfolio is imported oil, which is reduced by $37 \%, 47 \%$ and $45 \%$ under the BAU, HFP, and CC scenarios. The next biggest impact is on consumer savings, which actually increases under the more adverse conditions of high fuel prices and a carbon constraint. Consumer savings are $25 \%, 31 \%$ and $35 \%$ higher under the BAU, HFP, and CC scenarios. EERE's portfolio reduces carbon emissions in the BAU and HFP scenarios by $20 \%$ over the respective baselines. Carbon savings under the carbon constraint scenario are, by definition, zero. But the higher results for consumer savings under the carbon constraint case suggest that EERE's portfolio mitigates the impact of the carbon constraint on consumers. Finally, energy intensity of the economy sees around $8 \%$ improvement due to EERE's portfolio in 2030. In 2050, energy intensity reductions are $17 \%, 16 \%$ and $14 \%$ under the BAU, HFP, and CC scenarios. Overall, the portfolio is robust in its impact across three markedly different possible futures, with the greatest gains seen for energy security. 


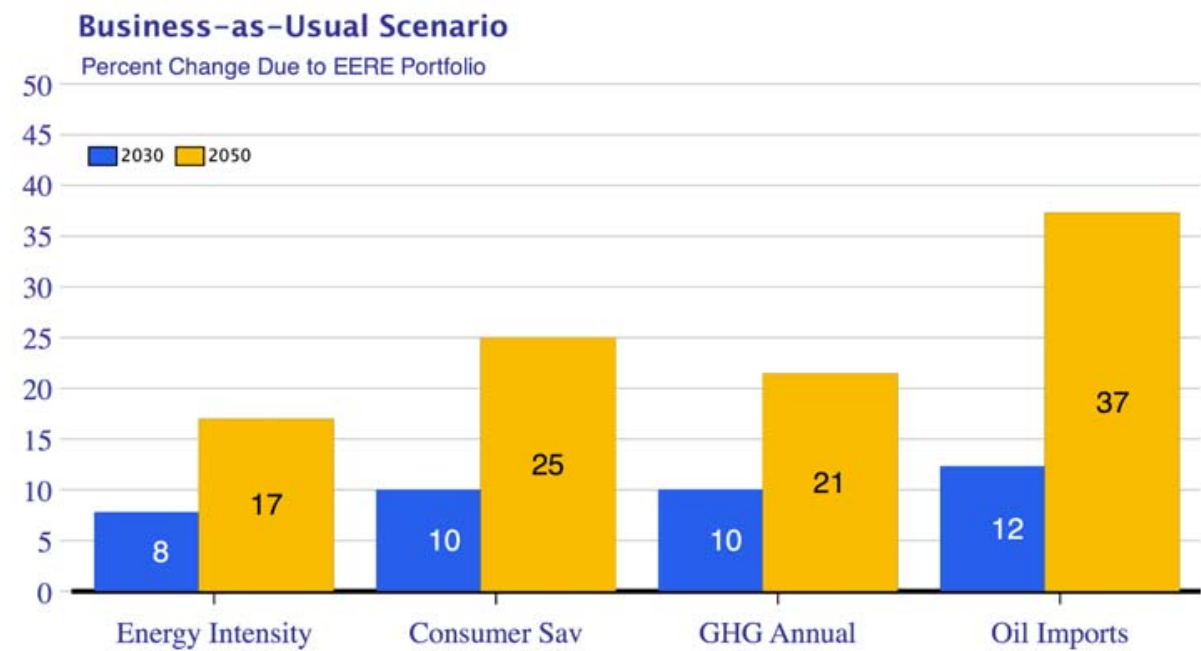

High Fuels Price Scenario

50 Percent Change Due to EERE Portfolio

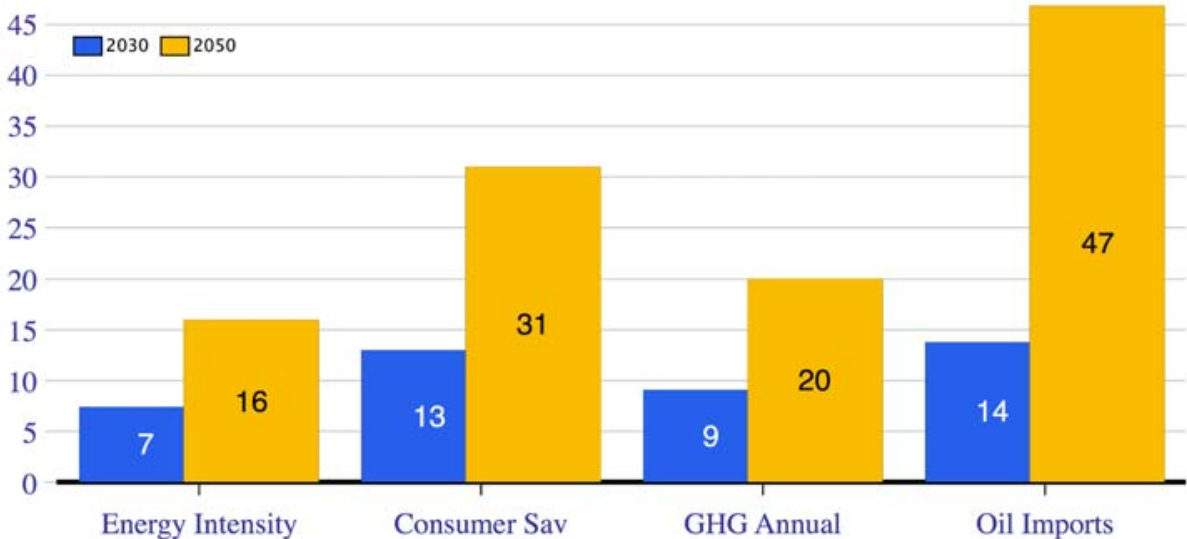

Carbon Constraint Scenario

50 Percent Change Due to EERE Portfolio

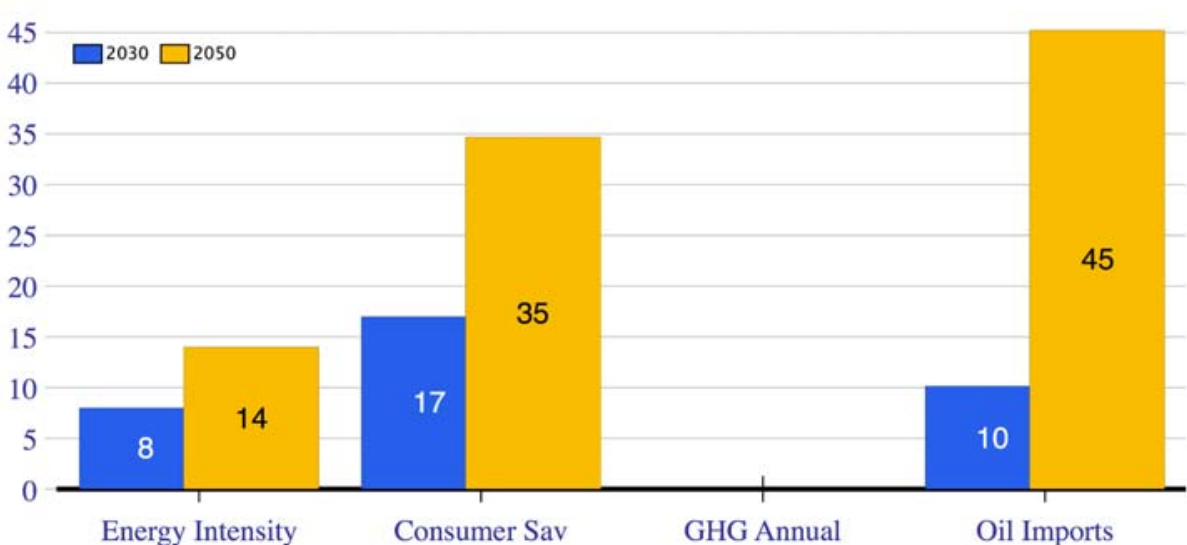

Figure 2.29. Overall Impact of EERE's Portfolio Under Alternative Scenarios

Projected Benefits of Federal Energy Efficiency and Renewable Energy Programs (FY 2008-FY 2050) The Value of EERE's Portfolio (Chapter 2) - Page 2-35 


\section{CHAPTER 3 - THE VALUE OF INDIVIDUAL EERE PROGRAMS}

\section{Table of Contents}

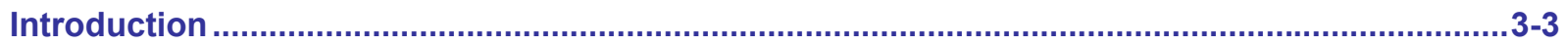

Overview of Individual Program and Portfolio Benefits ................................................................3-3

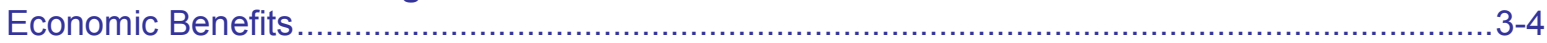

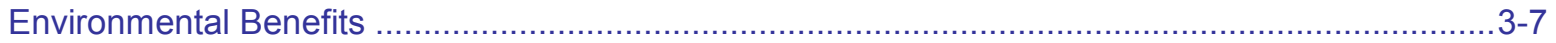

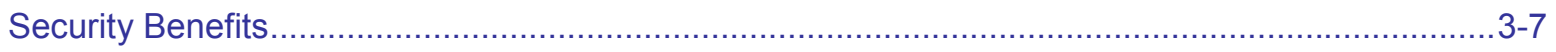

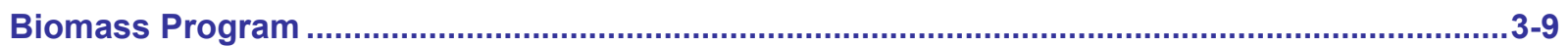

Translating Biomass Program Goals into Energy Model Parameters ............................................

Individual Program Case Results for Biomass ........................................................................

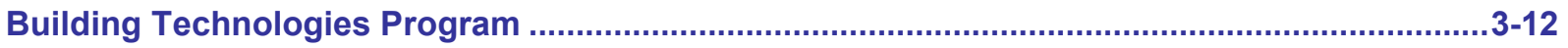

Translating Building Technologies Program Goals into Market Outcomes.................................. $3-13$

Individual Program Case Results for Building Technologies Program ....................................... $3-13$

Federal Energy Management Program (FEMP) .....................................................................

Translating FEMP Goals and Program Outcomes into Energy Model Parameters .......................3-16

Individual Program Case Results for the FEMP Program .......................................................

Hydrogen, Fuel Cells, and Infrastructure Technologies Program (HFCIT).................................3-17

Translating HFCIT Goals into Energy Model Parameters..........................................................

Individual Program Case Results for HFCIT Program ............................................................ $3-20$

Industrial Technologies Program...................................................................................................23

Translating Industrial Technologies Program Goals into Energy Model Parameters ....................3-23

Individual Program Case Results for the Industrial Technologies Program ................................ $3-23$

Solar Energy Technologies Program (SETP)............................................................................25

Translating SETP Goals into Energy Model Parameters ..........................................................

Individual Program Case Results for Solar Energy Technologies Program ................................ 3-27

FreedomCAR and Vehicle Technologies Program (FCVT)......................................................3-29

Translating FCVT Goals into Energy Model Parameters ..........................................................29

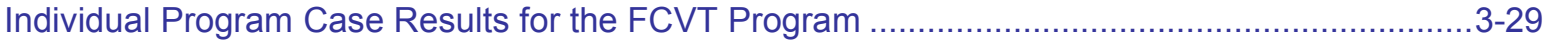

Weatherization and Intergovernmental Program (WIP) ............................................................3-34

Translating WIP Goals and Program Outcomes into Energy Model Parameters .........................3-35

Individual Program Case Results for Weatherization and Intergovernmental Program .................3-35

Wind Technologies Program ..........................................................................................................37

Translating the Wind Technologies Program Goals into Energy Model Parameters.....................3-37

Individual Program Case Results for the Wind Technologies Program .......................................3-38 


\section{List of Figures}

Figure 3.1. FY 2008 Budget Request for EERE Programs........................................................ $3-3$

Figure 3.2. Illustration of Individual Program Benefits Charts...................................................... $3-4$

Figure 3.3. Consumer and Electric Power-Sector Savings for EERE Portfolio and Individual

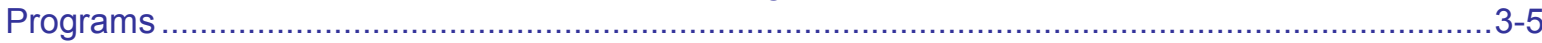

Figure 3.4. Household Spending, Natural Gas Prices, Energy Intensity, and Energy System Cost

Savings for EERE Portfolio and Individual Programs .......................................................... $3-6$

Figure 3.5. Avoided Greenhouse Gas Emissions for the EERE Portfolio and Individual Program

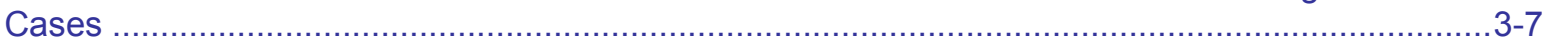

Figure 3.6. Avoided Criteria Pollutant Control Costs for the EERE Portfolio and Individual

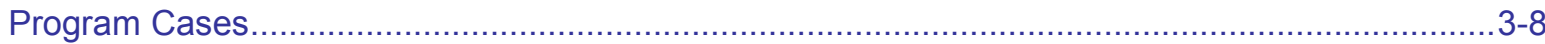

Figure 3.7. Security Benefits for the EERE Portfolio and Individual Program Cases ............................. 3-8

Figure 3.8. Selected Biomass Technology Input Parameters for Integrated Benefits Modeling .............3-10

Figure 3.9. Projected Ethanol Growth for the Biomass Program under the BAU Scenario.....................3-11

Figure 3.10. Delivered Energy Use in Commercial and Residential Buildings by Type .......................3-14

Figure 3.11. Cumulative Energy Savings Associated with FEMP …............................................ $3-16$

Figure 3.12. Projected Capital Cost of Stationary Fuel Cell Systems for the AEO2006 Reference,

GPRA Base, and GPRA HFCIT Program Cases .................................................................

Figure 3.13. Projected Hydrogen Fuel Cell Vehicle Market Penetration ............................................3-21

Figure 3.14. Projected Capital Cost of PV Systems for the AEO2006 Reference, GPRA Base, and GPRA

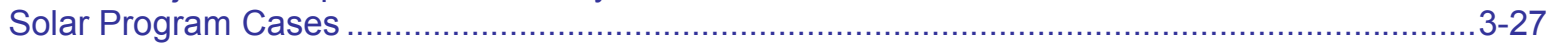

Figure 3.15. Projected Solar Capacity for Base Case and Individual Solar Program Case ...................3-28

Figure 3.16. Midterm Vehicle Technology Sales and Fleet Stock Shares........................................3-30

Figure 3.17. Long-Term Light-Duty Vehicle Stocks in BAU Baseline and Vehicle Program Cases........3-31

Figure 3.18. Fuel Consumption for the Baseline Case and the Vehicle Program Case........................3-32

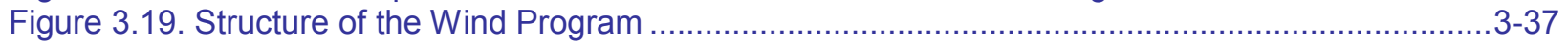

Figure 3.20. Comparison of Selected AEO2006 Reference, Baseline Case, and Program Case

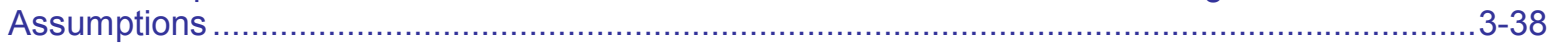

Figure 3.21. Projected Wind Capacity for the Base Case and the Wind Program Case........................3-39

\section{List of Tables}

Table 3.1. Key Biomass Program Outputs and Milestones ............................................................

Table 3.2. FY08 Annual Benefits Estimates for the Biomass Program ............................................. $3-11$

Table 3.3. FY08 Benefits Estimates for the Building Technologies Program .................................... $3-15$

Table 3.4. Anticipated FEMP Annual Outputs, Activities, and Milestones.......................................... $3-16$

Table 3.5. FY08 Benefits for the Federal Energy Management Program .......................................... $3-17$

Table 3.6. Light-Duty Vehicle Miles Traveled (billion VMTs/year) .................................................... $3-19$

Table 3.7. FY08 Benefits for the Hydrogen, Fuel Cell, and Infrastructure Technologies Program ..........3-22

Table 3.8. FY08 Benefits for the Industrial Technologies Program ................................................... $3-24$

Table 3.9. Cost Targets for Grid-Connected PV Systems in Key Market Sectors................................3-25

Table 3.10. Technology Cost Inputs to NEMS-GPRA08 and MARKAL-GPRA08 for PV Systems

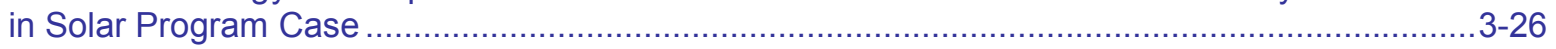

Table 3.11. Technology Cost Inputs to NEMS-GPRA08 and MARKAL-GPRA08 for CSP Systems

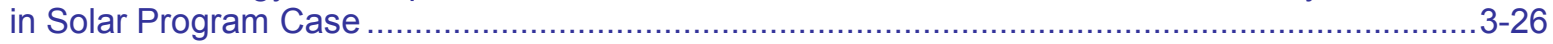

Table 3.12. FY08 Benefits for the Solar Energy Technologies Program ........................................... $3-28$

Table 3.13. FY08 Benefits for the FreedomCAR and Vehicle Technologies Program...........................3-34

Table 3.14. FY08 Benefits for the Weatherization and Intergovernmental Program ............................3-36

Table 3.15. FY08 Benefits for the Wind Program .............................................................................. 


\section{Introduction}

The Office of Energy Efficiency and Renewable Energy (EERE) funds nine Research, Development, Demonstration, and Deployment (RD3) programs. Figure 3.1 displays the EERE program budget requests for FY 2007. The top two largest program budgets are \$213 million for the Hydrogen, Fuel Cell, and Infrastructure Technologies (HFCIT) Program, and \$205 million for the Weatherization and Intergovernmental Program (WIP). The latter includes \$144 million for Low-Income Weatherization Assistance.

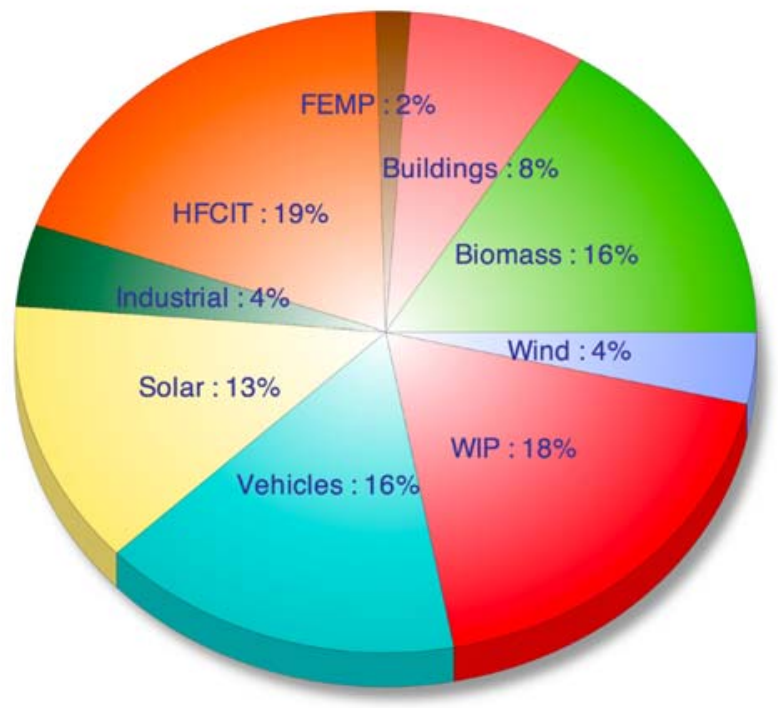

\begin{tabular}{|r|r|}
\hline Federal Energy Management & $\$ 16,791$ \\
\hline Wind & $\$ 40,069$ \\
\hline Industry & $\$ 45,998$ \\
\hline Buildings & $\$ 86,456$ \\
\hline Solar & $\$ 148,304$ \\
\hline Vehicles & $\$ 176,138$ \\
\hline Biomass & $\$ 179,263$ \\
\hline $\mathrm{H}_{2}$ Fuel Cell Infrastructure & $\$ 213,000$ \\
\hline
\end{tabular}

Figure 3.1. FY 2008 Budget Request for EERE Programs

Source: Budget request from FY 2008 Budget-in-Brief, U.S. Department of Energy Office of Energy Efficiency and Renewable Energy, http://www1.eere.energy.gov/ba/pba/budget 08.html

\section{Overview of Individual Program and Portfolio Benefits}

This chapter focuses on the estimated benefits of the individual programs under the "Business-as-Usual" (BAU) scenario, and how they compare with the benefits of EERE's overall portfolio under the BAU scenario. Individual program benefits are not - in sum - equal to the total benefits of the integrated EERE portfolio. That is because individual programs can compete or be synergistic with other programs in the portfolio. ${ }^{1}$ The individual program benefits presented here represent how each program's technologies can compete in the U.S. energy market by themselves, without the presence of any other programs in the EERE portfolio and ESE programs.

Still, the individual program benefits presented here serve as a proxy for understanding the relative strengths of each program's activities. To highlight the relative impacts of the programs, this section provides graphs depicting each program's metrics as stacked "slices" on an area chart of a given metric vs. time, so that the upper edge of the stack represents the sum of the individual program metric values (see Figure 3.2 for illustration). For comparison, a dashed line representing the value of each metric over time for the integrated EERE portfolio is also provided. In most cases, the dashed line does not correspond with the top of the stacked individual program slices, reflecting the fact that - when all of the

\footnotetext{
${ }^{1}$ The individual program benefits are computed as the difference between the Baseline and the Individual Program Goal Case, which includes only the impacts of the one program.
} 
programs' outcomes are modeled together - there is competition that will lower the portfolio value, or synergy that will raise the portfolio value relative to the sum of the individual programs. In general, the values projected for the portfolio range within $+/-10 \%$ of the sum of the individual program values for all of the metrics. The discontinuity shown here between 2030 and 2035 reflects the fact that there are two different models used in the midterm (through 2030) and the long term (2030 to 2050).

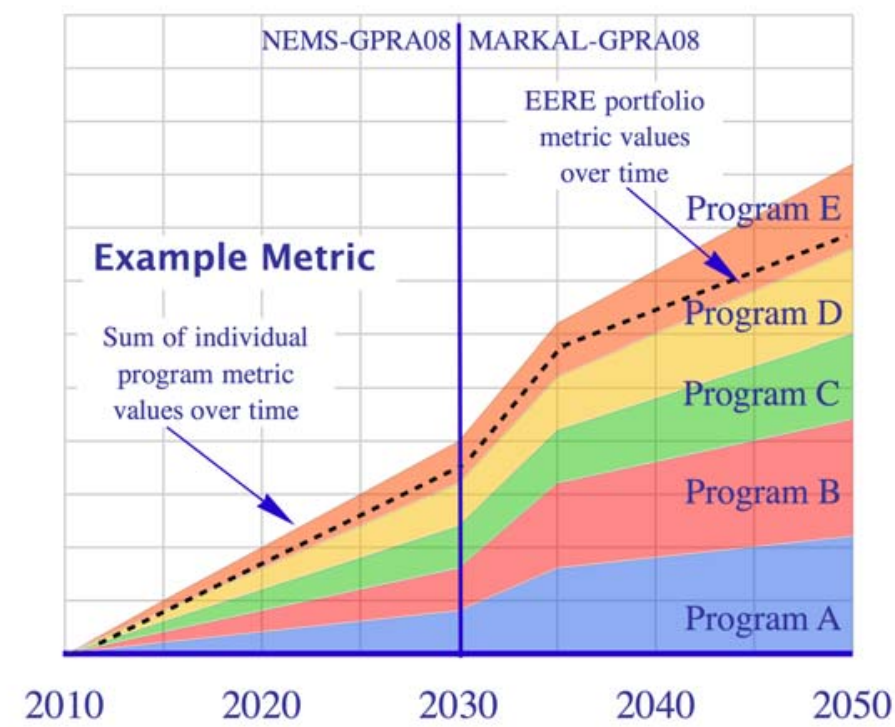

Figure 3.2. Illustration of Individual Program Benefits Charts

Note that the Federal Energy Management Program (FEMP) and the Weatherization and Intergovernmental Program (WIP) values are typically too small to show up on the charts. This is indicative of the problem that the metrics selected for DOE's RD3 programs do not measure the societal values associated with these programs. In the case of WIP, the programs provide energy savings for lowincome households and provide opportunities for Native American tribes. FEMP provides opportunities to showcase or prove new energy technologies within the Federal government, and also assures Federal leadership in adopting advanced energy technologies.

The variety of metrics included in this year's report sheds light on the differing roles that each of the programs potentially have in EERE's portfolio. ${ }^{2}$ Some programs, for example, show greater potential impact on consumer savings, while others show greater potential impact on electric power costs and overall energy system savings. For greenhouse gas reductions, different programs show greater or less impact in the midterm vs. the long term. The three programs related to transportation dominate security benefits. $^{3}$

\section{Economic Benefits}

Figure 3.3 shows projected consumer and electric power industry savings associated with EERE's portfolio and each of its individual programs. The biggest contributors to consumer savings are the FreedomCAR and Vehicle Technologies, and Building Technologies programs - most likely attributable to less spending on energy because of the availability of more energy-efficient vehicles and buildings.

\footnotetext{
${ }^{2}$ For a more detailed explanation of the metrics, see Chapter 1.

${ }^{3}$ Note that these comparisons do not include the effect of differences in the relative risk associated with meeting the programs' goals.
} 
Vehicle Technologies and Building Technologies represent $64 \%$ and $71 \%$ of the sum of individual programs' cumulative consumer savings in 2030 and 2050, respectively.
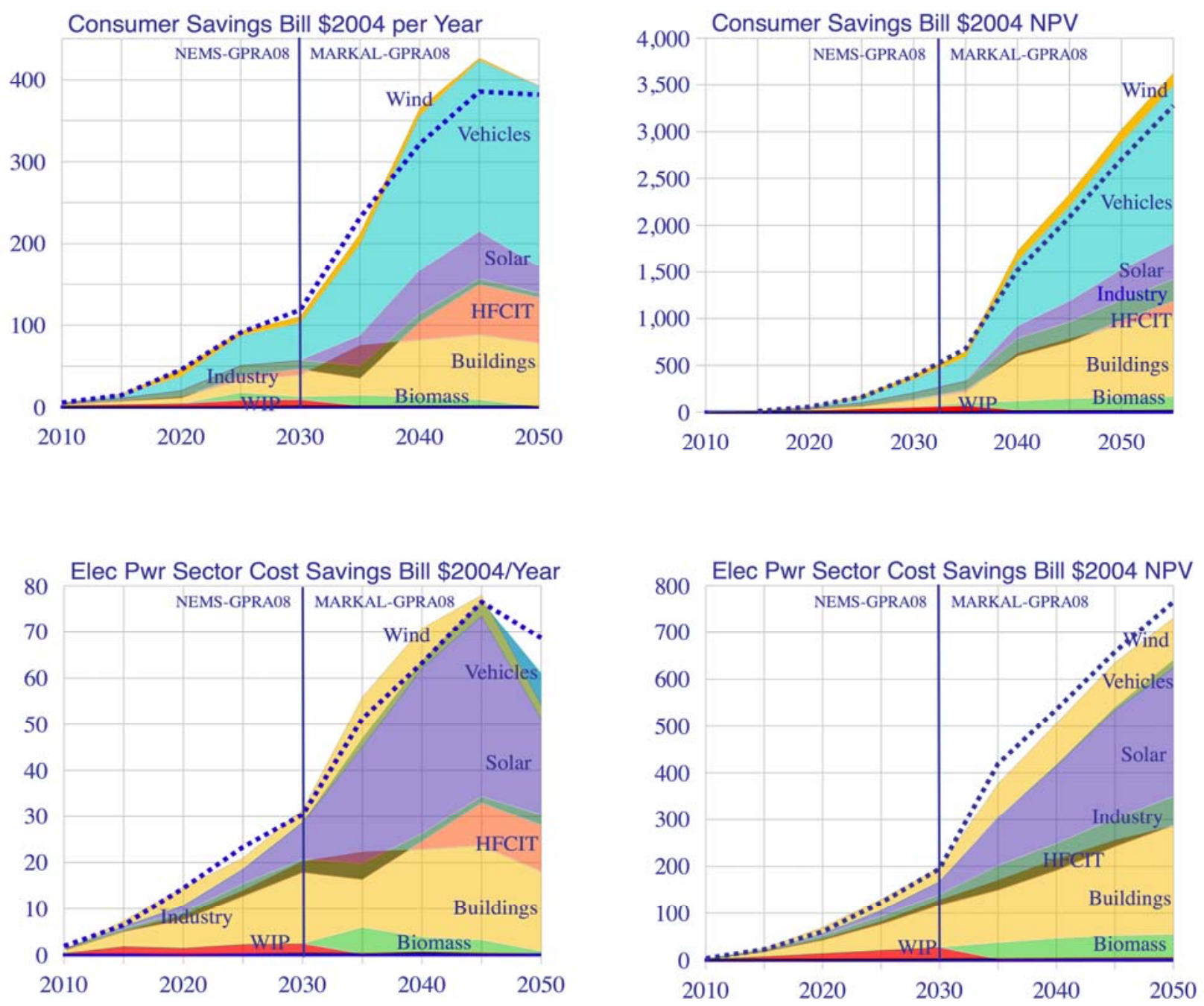

Dashed line represents total integrated EERE portfolio. Results for midterm (through 2030) from NEMSGPRA08 model. Results for long term (2030 through 2050) from MARKAL-GPRA08 model

\section{Figure 3.3. Consumer and Electric Power-Sector Savings for EERE Portfolio and Individual Programs ${ }^{4}$}

By 2050, the Solar Energy Technologies, and Hydrogen, Fuel Cell, and Infrastructure Technologies programs contribute significantly to annual consumer savings. For the electric power sector, on the other hand, Solar Technologies and Building Technologies show the greatest individual potential for savings. Together, they represent more than $70 \%$ of the sum of individual programs' cumulative electric power sector savings in 2050. Wind Technologies has much more impact on electric power savings than it does on overall consumer savings.

The remaining economic metrics are shown in Figure 3.4. The Vehicles Technologies Program shows the greatest potential for reducing the relative amount of household income spent on energy-roughly twothirds of the sum of individual program effects. It also has the greatest potential for reducing energy

${ }^{4}$ Benefits for Weatherization and Intergovernmental Programs (WIP) are not estimated beyond 2030. 
intensity of the economy $-60 \%$ of the sum of the individual program reductions in 2050 . Biomass actually increases energy intensity, ${ }^{5}$ while the Solar, Wind, HFCIT, and Buildings programs almost equally contribute to the remaining $40 \%$ of reduced energy intensity in 2050 . In the near to midterm, the Industrial Technologies Program shows its greatest potential impact on energy intensity-especially in the early years.
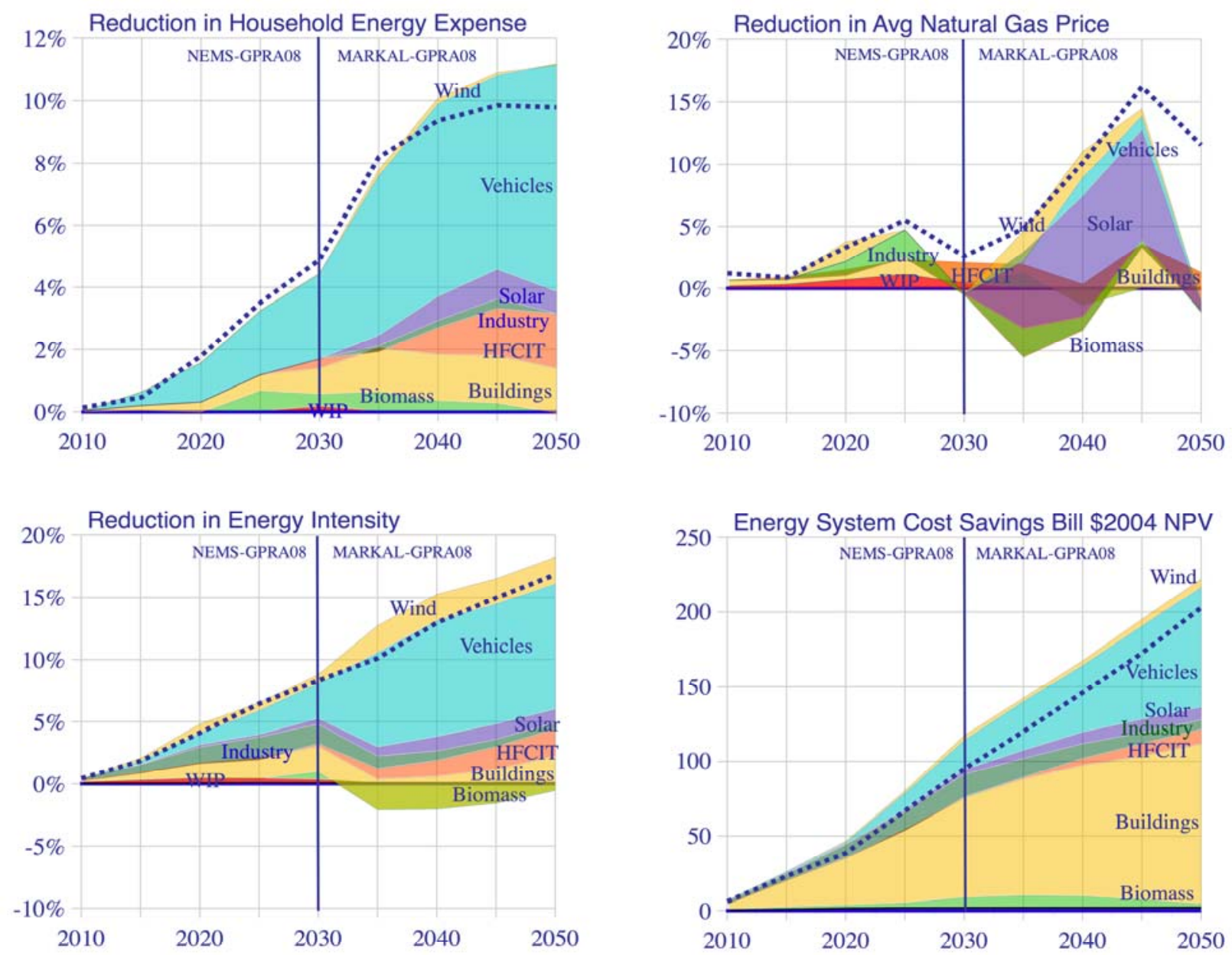

Dashed line represents total integrated EERE portfolio. Results for midterm (through 2030) from NEMS-GPRA08 model. Results for long term (2030 through 2050) from MARKAL-GPRA08 model

Figure 3.4. Household Spending, Natural Gas Prices, Energy Intensity, and Energy System Cost Savings for EERE Portfolio and Individual Programs ${ }^{6}$

Energy system savings - an approximate measure of the impact of EERE's RD3 programs on the consumer and producer surplus - appear to be dominated by Vehicles Technologies and Buildings Technologies in the individual program results. The combined potential savings of these two programs is more than $80 \%$ of the sum of the individual program energy system savings in 2050 . The Industrial Technologies and Biomass programs have their greatest relative potential impact in the midterm, with their combined potential savings representing almost $20 \%$ of the total individual program savings.

\footnotetext{
${ }^{5}$ The overall efficiency of converting the primary energy in biomass into fuels is lower than that of converting petroleum to fuels. Use of biofuels therefore increases energy intensity of the economy even though it decreases oil intensity of the economy.

${ }^{6}$ Benefits for Weatherization and Intergovernmental Programs (WIP) are not estimated beyond 2030.
} 
Effects on average natural gas prices are much more mixed, with higher demand from Biomass and HFCIT programs resulting in potential increases in natural gas prices in the 2030 to 2040 time frame. From 2020 to 2030, the Industrial Technologies Program shows the greatest potential for reducing natural gas prices; while, in the long term, the Solar Program leads to the greatest price reduction.

\section{Environmental Benefits}

Figure 3.5 shows the avoided emissions of greenhouse gases associated with energy production and use for the individual program cases and the EERE portfolio case. In 2030, the Buildings Technologies, Vehicles Technologies, Industry, Wind, and Solar programs all show roughly the same potential for avoiding greenhouse gas emissions cumulatively by 2030 , with these five programs totaling about $90 \%$ of the 4.5 billion metric tons of greenhouse gas savings achieved. By 2050, Vehicles Technologies account for $30 \%$ of the sum of the cumulative savings of the individual programs, followed by the Wind and Buildings programs, which together account for another $30 \%$ of the sum of the cumulative savings of the individual programs.

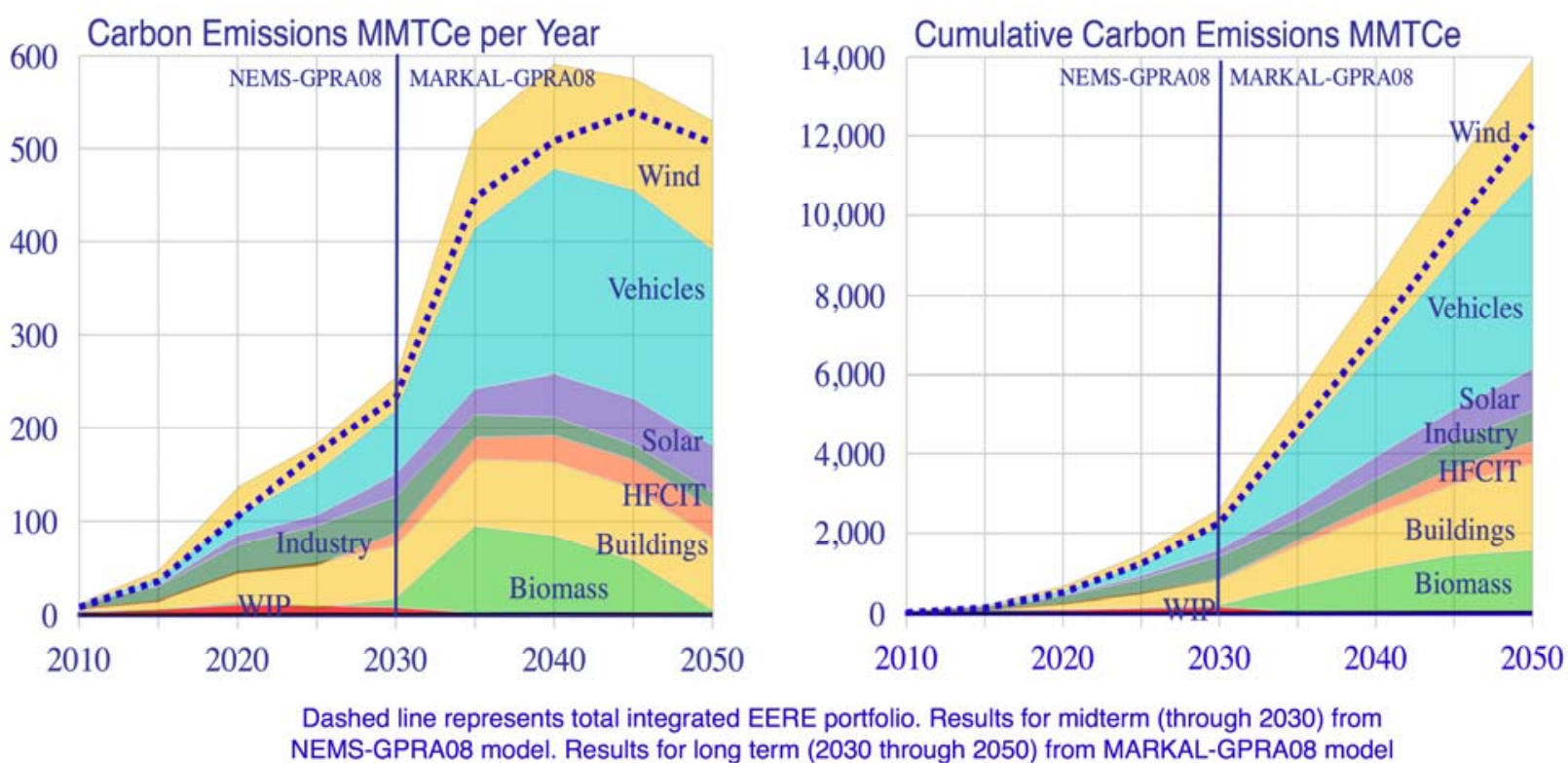

Figure 3.5. Avoided Greenhouse Gas Emissions for the EERE Portfolio and Individual Program Cases

Figure 3.6 shows the avoided criteria pollutant costs for the individual programs and the EERE portfolio cases under the BAU scenario through 2030. Because this cost is based on pollutant emissions trading values, only those programs affecting electricity production and use show value. Of these, only the Buildings Technologies and Wind programs show any measurable reductions by $2030{ }^{7}$

\section{Security Benefits}

Figure 3.7 shows security benefits for the EERE portfolio and individual program cases under the BAU scenario. The transportation-related programs of Vehicles, HFCIT, and Biomass dominate these benefits. Together, the Vehicles and HFCIT programs represent more than $80 \%$ of the sum of the individual program's cumulative oil savings in 2050.

\footnotetext{
${ }^{7}$ Pollution control cost savings are not estimated beyond 2030 because they are not modeled in MARKAL-GPRA08. 


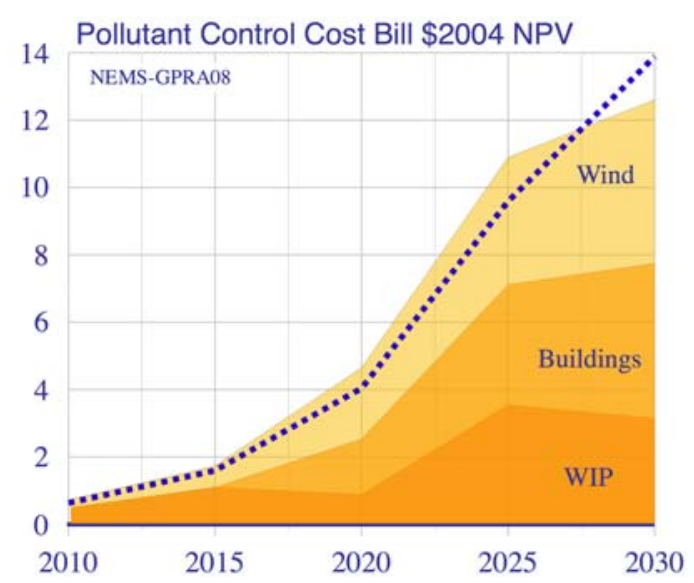

Figure 3.6. Avoided Criteria Pollutant Control Costs for the EERE Portfolio and Individual Program Cases
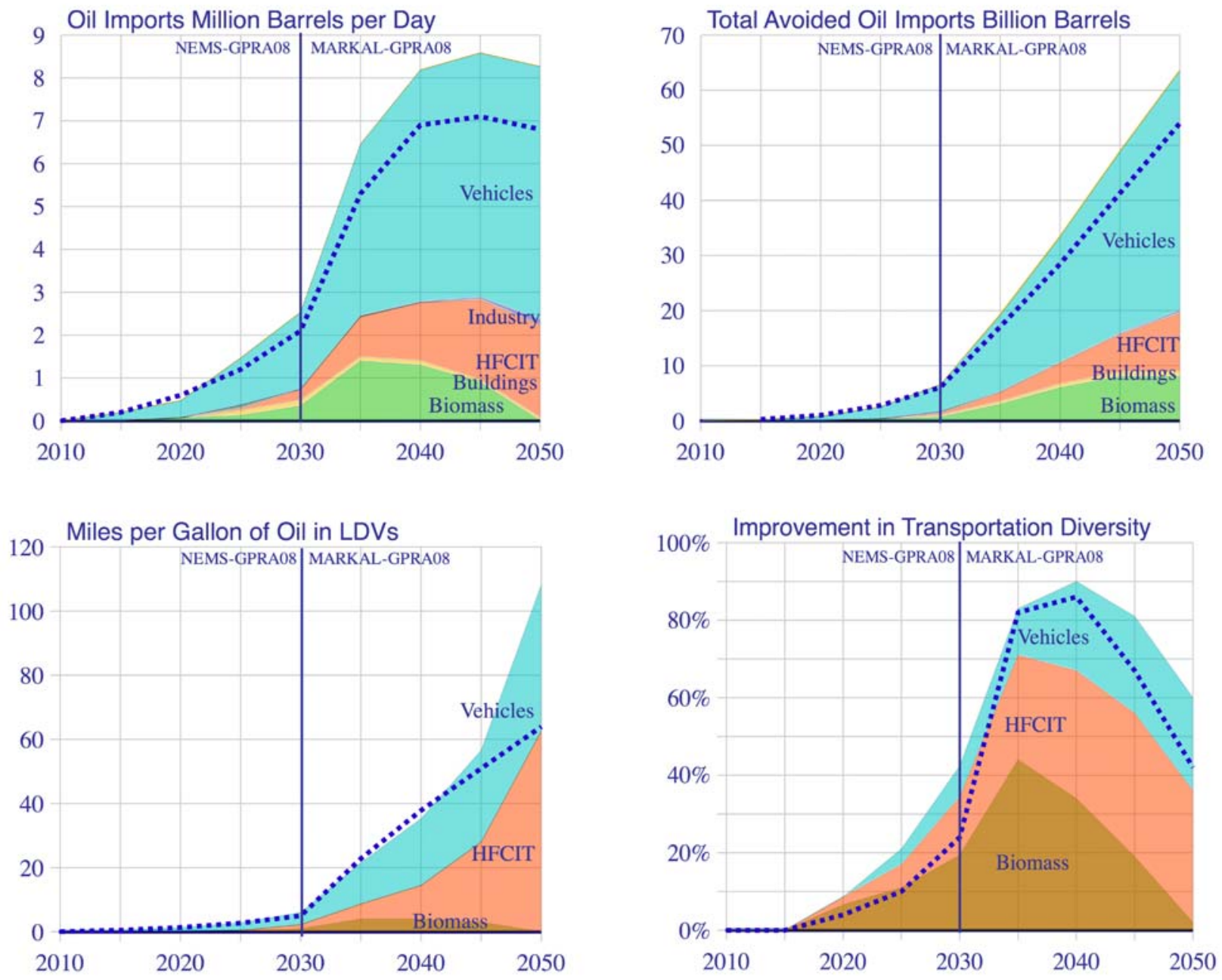

Dashed line represents total integrated EERE portfolio. Results for midterm (through 2030) from NEMS-GPRA08 model. Results for long term (2030 through 2050) from MARKAL-GPRA08 model

Figure 3.7. Security Benefits for the EERE Portfolio and Individual Program Cases

Projected Benefits of Federal Energy Efficiency and Renewable Energy Programs (FY 2008-FY 2050)

The Value of Individual EERE Programs (Chapter 3) - Page 3-8 


\section{Biomass Program}

On February 20, 2006, in his State of the Union Speech, President Bush announced the Advanced Energy Initiative (AEI). The Biofuels Initiative, a key component of the AEI, is designed "to foster the breakthrough technologies needed to make cellulosic ethanol cost-competitive with corn-based ethanol by 2012, enabling greater use of this alternative fuel to help reduce future U.S. oil consumption." DOE's Biomass Program is working to meet these goals by displacing a significant volume of gasoline.

The Biomass Program is currently revising its multiyear plan to reflect the budget, activities, and outputs required to achieve its revised goals. Key outputs of the Biomass Program are summarized in Table 3.1.

Table 3.1. Key Biomass Program Outputs and Milestones

\begin{tabular}{|c|c|}
\hline Outputs & Key Milestones \\
\hline $\begin{array}{l}\text { Enable first corn biorefinery with corn fiber and residual } \\
\text { starch }\end{array}$ & $\begin{array}{l}\text { - Conclude commercial demo with industry partner to increase ethanol } \\
\text { output by at least 4\% for each biorefinery by } 2009\end{array}$ \\
\hline Enable first pilot-scale project with corn stover & $\begin{array}{l}\text { Cost and performance evaluated at pilot scale against target selling } \\
\text { price of } \$ 1.07 \text { per gallon of ethanol with a } \$ 35 / \text { ton feedstock cost or } \\
\$ 1.22 \text { per gallon with a } \$ 45 / \text { ton feedstock cost by } 2012\end{array}$ \\
\hline Enable first demonstration-scale project with corn stover & $\begin{array}{l}\text { Deliver technology for stover collection and storage to demonstration } \\
\text { scale project at costs of } \$ 35 \text { to } \$ 45 \text { per dry ton by } 2013\end{array}$ \\
\hline Enable switchgrass commercialization & $\begin{array}{l}\text { - Increase switchgrass yield per acre by } 10 \% \text { at test sites by } 2015 \text { (from } \\
\text { current regional levels) } \\
\text { Increase switchgrass yield per acre by an additional } 5 \% \text { at test sites by } \\
2019 \\
\text { - Deliver technology for switchgrass collection and storage to demo-scale } \\
\text { ethanol conversion project for } \$ 45 \text { per ton by } 2019\end{array}$ \\
\hline Enable first pilot-scale project with switchgrass and residues & $\begin{array}{l}\text { - Cost and performance evaluated at pilot scale against target yield of } 90 \\
\text { gallons per ton by } 2017\end{array}$ \\
\hline $\begin{array}{l}\text { Enable first demonstration-scale project with switchgrass or } \\
\text { forest residues }\end{array}$ & $\begin{array}{l}\text { - Cost and performance evaluated at demonstration-scale against target } \\
\text { yield of } 90 \text { gallons per ton of feedstock by } 2020\end{array}$ \\
\hline $\begin{array}{l}\text { Enable next-generation cellulosic biorefineries for ethanol } \\
\text { production }\end{array}$ & $\begin{array}{l}\text { Deliver faster growing switchgrass and more competitive technologies } \\
\text { for biomass production, collection, and storage to demonstration } \\
\text { facilities } \\
\text { Industry partners construct, operate, and evaluate subsequent } \\
\text { demonstration-scale projects }\end{array}$ \\
\hline
\end{tabular}

\section{Translating Biomass Program Goals into Energy Model Parameters}

The outputs of the Biomass Program are translated into input parameters for a Biomass Program Case under the BAU scenario. In addition, some adjustments are made to the $A E O 2006^{8}$ reference case to best reflect the base case for the future of biomass technologies in the absence of continued Biomass Program RD3 activities. Figure 3.8 highlights some (but not all) of the key parameters adjusted in both the base case and program case. The projected cost reductions for corn and cellulosic ethanol in the program case are anchored in the outputs listed in Table 3.1. The base case for biofuels technology is significantly different from the AEO2006 reference case. The Biomass Program believes that projected costs for corn and cellulose ethanol technology are lower than AEO2006's assumptions. Furthermore, while the $A E O 2006$ reference case assumes that technology costs for corn and ethanol will not change over time, the program posits continued cost reductions for corn ethanol, identical to those associated with Biomass Program case projections, but delayed by seven years without the program's RD3 activities. Similarly, the program assumes eventual technology development for cellulose technology in the baseline case that lags

\footnotetext{
${ }^{8}$ Annual Energy Outlook 2006: With Projections to 2030. Energy Information Administration, U.S. Department of Energy,
} Washington, D.C. (February 2006). DOE/EIA-0383(2006). 
15 years behind the program's targets. More details on how inputs to the energy models were developed for the Biomass Program are available in the appendices of this report.
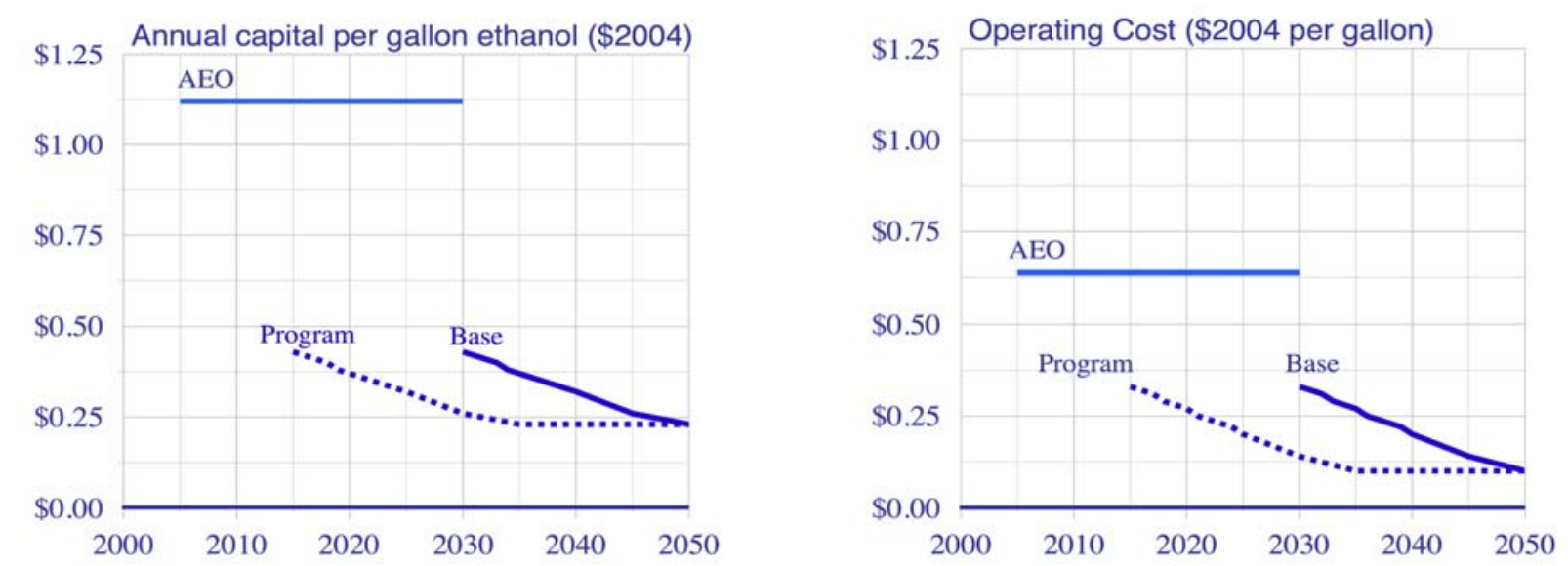

Figure 3.8. Selected Biomass Technology Input Parameters for Integrated Benefits Modeling

\section{Individual Program Case Results for Biomass}

Figure 3.9 shows projected ethanol market penetration for the base case and program case under the BAU scenario. The yellow- and green-area plots represent total corn and cellulosic ethanol production, respectively. The blue bars show the difference in ethanol production between the base case and the program case.

Midterm NEMS-GPRA08 results show that success in Biomass Program RD3 leads to 23 billion gallons of ethanol by 2030 with 14 billion gallons supplied through the cellulosic process, compared to 12 billion gallons of almost all corn-based ethanol in the base case. Corn ethanol production declines slightly after 2020, due to the increasing competitiveness of cellulosic-based ethanol, saturation of the gasoline blending market, and still somewhat limited use of E85 in vehicles.

Long-term MARKAL-GPRA08 results show more than 60 billion gallons per year of ethanol production for the program case by 2050, with corn ethanol production topping out at 12 billion gallons per year. The jump in ethanol between 2030 and 2035 reflects differences between the two modeling systems rather than a real jump in ethanol production. The NEMS-GPRA08 model limits ethanol demand in the midterm much more than MARKAL-GPRA08. This appears to be related to constraints in NEMS-GPRA08 on market penetration of E85 fuel and vehicles.

The impact of the program on ethanol production peaks in 2035 , and declines dramatically by 2050 - due to the assumption that the industry in the base case catches up with progress in cellulosic ethanol technology under the program case in 15 years.

Table 3.2 summarizes the benefits for the individual Biomass Program case under the BAU scenario. The Biomass Program benefits reflect the differences between the Individual Program Goal Case compared with the Baseline Case. 

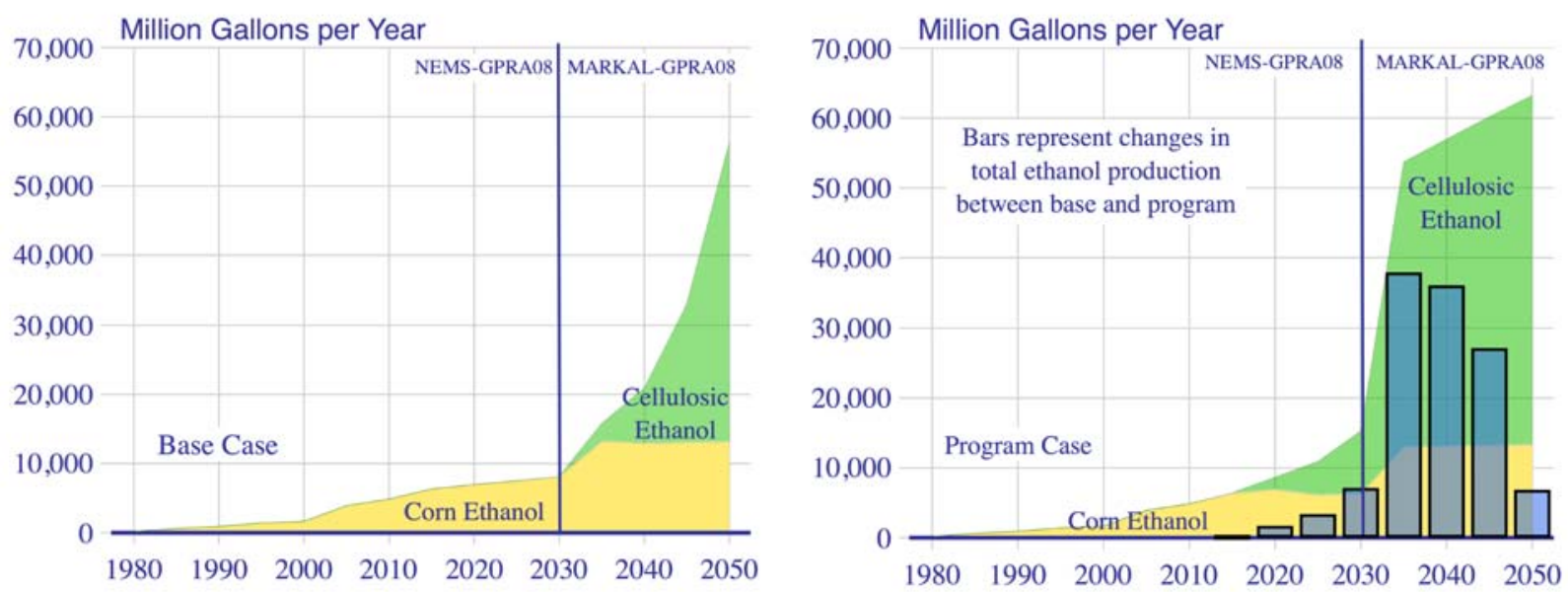

Figure 3.9. Projected Ethanol Growth for the Biomass Program under the BAU Scenario Table 3.2. FY08 Annual Benefits Estimates for the Biomass Program

\begin{tabular}{|c|c|c|c|c|c|c|c|c|c|}
\hline & \multicolumn{5}{|c|}{ MIDTERM BENEFITS 7/ } & \multicolumn{4}{|c|}{ LONG-TERM BENEFITS $8 /$} \\
\hline Metric & 2010 & 2015 & 2020 & 2025 & 2030 & 2035 & 2040 & 2045 & 2050 \\
\hline ECONOMIC BENEFITS ("AFFORDABLE") & & & & & & & & & \\
\hline $\begin{array}{l}\text { Reduction in Average Delivered Natural Gas } \\
\text { Price (Percent) }\end{array}$ & ns & ns & ns & ns & ns & $1 \%$ & $-1 \%$ & $0 \%$ & $0 \%$ \\
\hline Energy System Cost Savings (bil \$2004) 1/ & $\mathrm{nr}$ & $\mathrm{nr}$ & $\mathrm{nr}$ & $\mathrm{nr}$ & $\mathrm{nr}$ & 8 & 7 & 5 & 2 \\
\hline Consumer Savings, Annual (bil \$2004) & ns & ns & ns & 9 & 3 & 14 & 13 & 15 & 0 \\
\hline Consumer Savings, NPV (bil \$2004) 2/ & ns & ns & ns & 7 & 25 & 67 & 94 & 119 & 128 \\
\hline $\begin{array}{l}\text { Electric Power Industry Savings, Annual (bil } \\
\text { \$2004) 3/ }\end{array}$ & ns & ns & ns & ns & ns & 6 & 3 & 3 & 0 \\
\hline $\begin{array}{l}\text { Electric Power Industry Savings, NPV (bil \$2004) } \\
\text { 2/3/ }\end{array}$ & ns & ns & ns & ns & ns & 35 & 43 & 48 & 51 \\
\hline $\begin{array}{l}\text { Reduction in Fraction of Household Income Spent } \\
\text { on Energy }\end{array}$ & $0.0 \%$ & $0.0 \%$ & $0 \%$ & $1 \%$ & $0 \%$ & $1 \%$ & $0 \%$ & $0 \%$ & $0 \%$ \\
\hline Reduced Energy Intensity of Economy (Percent) & $0 \%$ & $0 \%$ & $0 \%$ & $0 \%$ & $1 \%$ & $-2 \%$ & $-2 \%$ & $-2 \%$ & $-1 \%$ \\
\hline ENVIRONMENTAL BENEFITS ("CLEAN") & & & & & & & & & \\
\hline $\begin{array}{l}\text { Avoided Greenhouse Gas Emissions, Annual } \\
\text { (MMTCE/year) }\end{array}$ & ns & ns & 3 & -2 & 9 & 93 & 81 & 55 & 3 \\
\hline $\begin{array}{l}\text { Avoided Greenhouse Gas Emissions, Cumulative } \\
\text { (MMTCE) } 5 /\end{array}$ & ns & ns & 20 & 26 & 46 & 624 & 1,052 & 1,380 & 1,502 \\
\hline $\begin{array}{l}\text { Reduced Cost of Criteria Pollutant Control, NPV } \\
\text { (bil \$2004) } 2 /\end{array}$ & ns & ns & ns & ns & ns & $\mathrm{nr}$ & $\mathrm{nr}$ & $\mathrm{nr}$ & $\mathrm{nr}$ \\
\hline SECURITY BENEFITS ("RELIABLE") & & & & & & & & & \\
\hline Avoided Oil Imports, Annual (mbpd) & ns & ns & 0.1 & 0.1 & 0.3 & 1.4 & 1.3 & 0.9 & 0.0 \\
\hline Avoided Oil imports, Cumulative (bil barrels) 4/ 5/ & ns & ns & ns & 0 & 1 & 3 & 6 & 8 & 8 \\
\hline Security Fuel Economy Improvement (MPG) & ns & ns & 0 & 0 & 1 & 4 & 4 & 3 & 0 \\
\hline $\begin{array}{l}\text { Transportation Fuel Diversity Improvement } \\
\text { (percent) 6/ }\end{array}$ & ns & ns & $7 \%$ & $11 \%$ & $19 \%$ & $44 \%$ & $34 \%$ & $19 \%$ & $2 \%$ \\
\hline Reduced Oil Intensity (Percent) & ns & ns & $0 \%$ & $1 \%$ & $1.5 \%$ & $7 \%$ & $6 \%$ & $4 \%$ & $0 \%$ \\
\hline
\end{tabular}

Table notes:

1/ Energy system costs include the annualized capital costs for all capital stock (residual and new), as well as O\&M and fuel costs. Annualized capital costs are calculated using MARKAL hurdle rates, which include both a financial and behavioral component.

2/ NPV (net present value) calculations done using 3\% real discount rate back to 2008 .

$3 /$ Electric power industry cost does not include demand-side distributed generation.

4/ Renewable generation values at output value (3412 Btu/kWh), except for biomass where energy content is used.

5/ All cumulative values are from 2008.

6/ Diversity index change is Case minus Base (opposite of others).

7/ Midterm benefits based on NEMS-GPRA08 model.

8/ Long-term benefits based on MARKAL-GPRA08 model.

$\mathrm{nr}=$ not reported or calculated by model

ns $=$ not significant relative to model error 
The most significant benefits in the midterm NEMS-GPRA08 results (though 2030) are a reduction in oil imports and an increase in fuel diversity in the transportation sector. Increased use of ethanol (blended with gasoline and as E85) reduces oil imports by 0.3 million barrels per day (or 2\%) in 2030. The security MPG increases by 1.0 MPG relative to the base case or 4\%, and the diversity index for transportation increases by $19 \%$. Consumer savings, resulting from lower blended gasoline and ethanol prices, are relatively modest $(0.4 \%$ of overall annual household energy costs and a total of $\$ 4$ billion on a net present value basis through 2030). Carbon emission reductions are small with corn ethanol displacement of gasoline, but increase once cellulosic ethanol is introduced.

In the long-term MARKAL-GPRA08 results, avoided oil imports peak in 2035 at 1.4 million barrels per day, falling to zero by 2050 when the baseline case presumably catches up with the program case. At their peak in 2035, the security MPG is improved by 4 MPG and the diversity index for transportation fuel is improved by $44 \%$, relative to the base case. Consumer savings remain modest, peaking at $\$ 14$ billion per year in 2035. Carbon emission reductions are substantial in the long term, peaking at 93 million metric tons of carbon equivalent per year in 2035, due partly to the greater incremental ethanol demand - most of which is met with less carbon-intensive cellulosic ethanol. Furthermore, cellulosic ethanol's associated cogeneration component displaces coal-fired generation, which further increases carbon savings.

\section{Building Technologies Program}

The mission of the Building Technologies Program (BT) is to develop technologies, techniques, and tools for making residential and commercial buildings more energy efficient, productive, and affordable. The program has defined its strategic goal more specifically as:

To create technologies and design approaches that enable net-zero energy buildings at low incremental cost by 2025. A net-zero energy building is a residential or commercial building with greatly reduced needs for energy through efficiency gains (60\% to $70 \%$ less than conventional practice), with the balance of energy needs supplied by renewable technologies. These efficiency gains will have application to buildings constructed before 2025 resulting in a substantial reduction in energy use throughout the sector.

This involves research, development, demonstration, and technology transfer activities in partnership with industry, government agencies, universities, and national laboratories.

BT has identified a three-strategy approach to overcome barriers and achieve the goal of Zero Energy Buildings (ZEB) by 2025.

1. Research and Development

2. Regulatory Activities

3. Technology Validation and Market Introduction

Key outputs for the next five years under each strategy are listed below:

Research and Development:

- For residential buildings, five technology packages that can reduce energy consumption in new buildings by at least $40 \%$.

- In commercial buildings, key technology pathways to achieve $30 \%$ to $50 \%$ reduction in purchased energy in new, small commercial buildings relative to the American Society of Heating, Refrigerating, and Air-Conditioning Engineers (ASHRAE) 90.1-2004.

- Continued development of white-light, solid-state lighting, reaching a commercial efficacy of 100 lumens per watt by 2011. 
- An improved EnergyPlus, which can evaluate $90 \%$ of the state-of-the-art technologies under development by BT R\&D.

Regulatory Activities:

- Test procedures - which can include procedures for measuring energy efficiency and/or water-use efficiency, definitions, and/or test sampling, compliance certification, and enforcement requirements - for torchieres, ceiling fans, commercial reach-in refrigerators, vending machines and beverage merchandisers, and incandescent reflector lamps

- Final rules for performance standards for distribution transformers, commercial unitary AC/HP, furnaces and boilers, and ASHRAE products

- Upgraded 2009 International Energy Conservation Code to include improved lighting, envelope, and mechanical requirements

Technology Validation and Market Introduction:

- New criteria for clothes washers and dishwashers, and the expansion of the program to include water heaters, solid-state lighting, and other emerging products

\section{Translating Building Technologies Program Goals into Market Outcomes}

The details of how the outputs of the Building Technologies Program are translated into market outcomes - many of which are determined offline (outside) the integrated energy market models - are summarized in the appendices of this report.

\section{Individual Program Case Results for Building Technologies Program}

The Building Technologies Program's array of R\&D and deployment activities are projected to result in energy savings primarily in four end-use categories: space heating, space cooling, water heating, and lighting. Figure 3.10 demonstrates the level of delivered energy savings (excluding losses from electricity generation) from each category. The stacked area plots show delivered energy use for each end-use category under the base and program cases for the BAU scenario. The yellow bars show the difference in delivered energy use between the base case and the program case. 


\section{Residential Buildings}
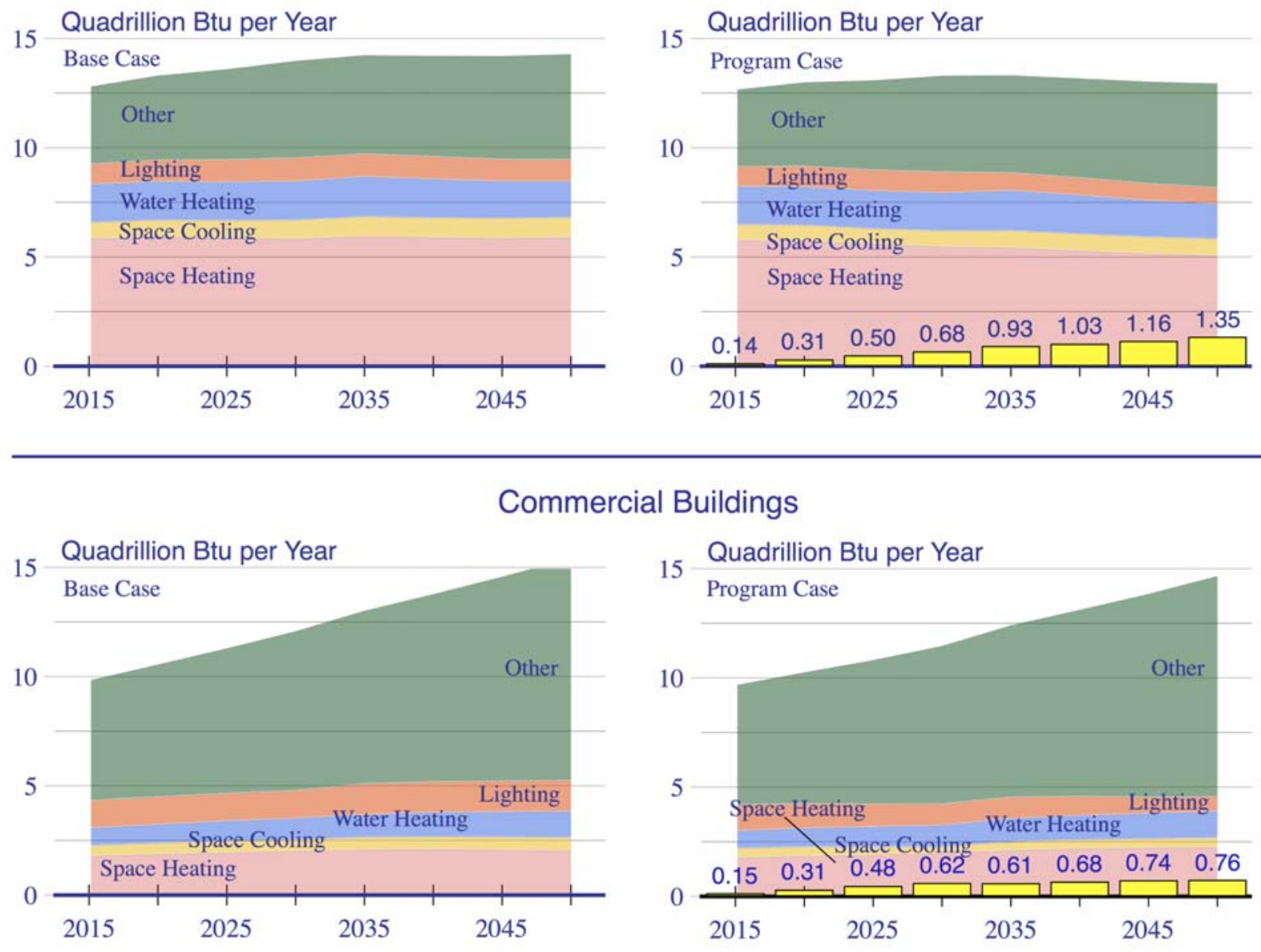

cial Buildings

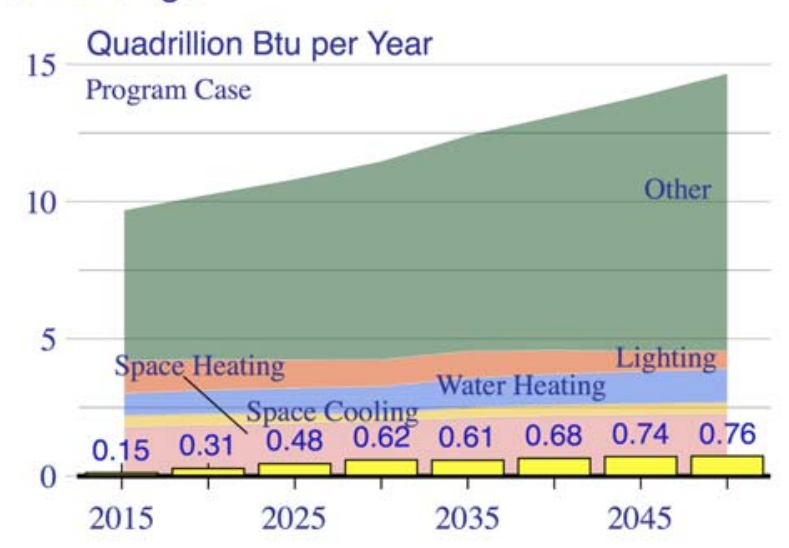

Figure 3.10. Delivered Energy Use in Commercial and Residential Buildings by Type

Table 3.3 summarizes the benefits for the individual Building Technologies Program case under the BAU scenario. The Building Technologies Program benefits are estimated within the integrated energy models, even for those elements where market impacts are estimated offline, so that the electricity-generation primary energy savings are directly computed. In addition, the integrated results include any feedbacks in the buildings or other sectors resulting from changes in energy prices that result from the reduced energy consumption. Cumulative consumer savings (on a net present value basis in the year 2008) are \$120 billion by 2030 , and reach $\$ 900$ billion by 2050 . Consumer savings result from lower energy bills due to efficiency improvements that exceed the investment costs of those improvements. A secondary effect of lower natural gas prices also contributes to savings. Energy system cost savings reach $\$ 107$ billion by 2050. Reduced energy consumption leads to reductions in carbon emissions and reduces the cost for meeting criteria pollutant caps applicable to power generation. By 2030, cumulative carbon emission reductions are more than 600 million metric tons of carbon, and reach more than 2 billion metric tons in 2050 . 
Table 3.3. FY08 Benefits Estimates for the Building Technologies Program

\begin{tabular}{|c|c|c|c|c|c|c|c|c|c|}
\hline & \multicolumn{5}{|c|}{ MIDTERM BENEFITS 7/ } & \multicolumn{4}{|c|}{ LONG-TERM BENEFITS 8/ } \\
\hline Metric & 2010 & 2015 & 2020 & 2025 & 2030 & 2035 & 2040 & 2045 & 2050 \\
\hline \multicolumn{10}{|l|}{ ECONOMIC BENEFITS ("AFFORDABLE") } \\
\hline Reduction in Average Delivered Natural Gas Price (Percent) & $0 \%$ & $1 \%$ & $1 \%$ & $1 \%$ & $2 \%$ & $1 \%$ & $2 \%$ & $4 \%$ & $1 \%$ \\
\hline Energy System Cost Savings (bil \$2004) 1/ & $\mathrm{nr}$ & $\mathrm{nr}$ & $\mathrm{nr}$ & $\mathrm{nr}$ & $\mathrm{nr}$ & 78 & 88 & 96 & 107 \\
\hline Consumer Savings, Annual (bil \$2004) & 2 & 5 & 8 & 16 & 27 & 60 & 72 & 84 & 71 \\
\hline Consumer Savings, NPV (bil \$2004) $2 /$ & 2 & 16 & 36 & 72 & 121 & 514 & 648 & 785 & 899 \\
\hline Electric Power Industry Savings, Annual (bil \$2004) 3/ & 1 & 3 & 7 & 12 & 18 & 16 & 19 & 20 & 17 \\
\hline Electric Power Industry Savings, NPV (bil \$2004) 2/3/ & & 10 & 30 & 61 & 101 & 134 & 169 & 204 & 232 \\
\hline Reduction in Fraction of Household Income Spent on Energy & $0.1 \%$ & $0.2 \%$ & $0 \%$ & $1 \%$ & $1 \%$ & $1 \%$ & $1 \%$ & $2 \%$ & $1 \%$ \\
\hline Reduced Energy Intensity of Economy (Percent) & $0 \%$ & $1 \%$ & $1 \%$ & $2 \%$ & $2 \%$ & $2 \%$ & $3 \%$ & $3 \%$ & $3 \%$ \\
\hline \multicolumn{10}{|l|}{ ENVIRONMENTAL BENEFITS ("CLEAN") } \\
\hline $\begin{array}{l}\text { Avoided Greenhouse Gas Emissions, Annual } \\
\text { (MMTCE/year) }\end{array}$ & 3 & 10 & 32 & 47 & 57 & 72 & 79 & 78 & 77 \\
\hline $\begin{array}{l}\text { Avoided Greenhouse Gas Emissions, Cumulative (MMTCE) } \\
5 /\end{array}$ & 7 & 44 & 150 & 348 & 621 & 1023 & 1404 & 1795 & 2181 \\
\hline $\begin{array}{l}\text { Reduced Cost of Criteria Pollutant Control, NPV (bil \$2004) } \\
\text { 2/ }\end{array}$ & ns & ns & 2 & 4 & 5 & $\mathrm{nr}$ & $\mathrm{nr}$ & $\mathrm{nr}$ & $\mathrm{nr}$ \\
\hline \multicolumn{10}{|l|}{ SECURITY BENEFITS ("RELIABLE") } \\
\hline Avoided Oil Imports, Annual (mbpd) & ns & ns & ns & 0.1 & 0.1 & 0.1 & 0.1 & 0.1 & 0.1 \\
\hline Avoided Oil imports, Cumulative (bil barrels) 4/ 5/ & ns & ns & ns & ns & 0 & 0 & 1 & 1 & 1 \\
\hline Security Fuel Economy Improvement (MPG) & ns & ns & ns & ns & ns & ns & ns & ns & ns \\
\hline Transportation Fuel Diversity Improvement (percent) 6/ & ns & ns & ns & ns & ns & ns & ns & ns & ns \\
\hline Reduced Oil Intensity (Percent) & ns & ns & ns & $0.6 \%$ & $0.6 \%$ & $0.5 \%$ & $0.5 \%$ & $0.4 \%$ & $0.4 \%$ \\
\hline
\end{tabular}

Table notes:

1/ Energy system costs include the annualized capital costs for all capital stock (residual and new), as well as O\&M and fuel costs. Annualized capital costs are calculated using MARKAL hurdle rates, which include both a financial and behavioral component.

2/ NPV (net present value) calculations done using 3\% real discount rate back to 2008.

3/ Electric power industry cost does not include demand-side distributed generation.

4/ Renewable generation values at output value (3412 Btu/kWh), except for biomass where energy content is used.

5/ All cumulative values are from 2008.

6/ Diversity index change is Case minus Base (opposite of others).

7/ Midterm benefits based on NEMS-GPRA08 model.

8/ Long-term benefits based on MARKAL-GPRA08 model.

$\mathrm{nr}=$ not reported or calculated by model

ns $=$ not significant relative to model error

\section{Federal Energy Management Program}

The Federal Energy Management Program (FEMP) strives to enhance energy security, environmental stewardship, and cost reduction within the Federal Government by advancing energy efficiency and water conservation; promoting the use of renewable energy, alternative fuels in Federal vehicle fleets, sustainable building design, and distributed energy resources; and improving utility management decisions at Federal facilities.

FEMP pursues its mission through integrated activities to improve the energy efficiency of, and renewable energy use by, the Federal Government. These improvements reduce the energy intensity at Federal facilities, lower their energy bills, and provide environmental benefits. Additionally, building energy efficiency technologies provide less easily quantifiable benefits, such as improved lighting quality and building occupant productivity. The benefits estimates reported exclude any expected acceleration in the deployment of the technologies that may result from "spillover" to state or local office buildings.

In addition to the benefits quantified, improved Federal energy management increases the ability of the Federal Government to manage its energy loads during emergencies, and facilitates coordination of Federal energy use with local authorities in the event of local energy supply constraints or emergencies.

Annual outputs of the program are summarized in Table 3.4. 
Table 3.4. Anticipated FEMP Annual Outputs, Activities, and Milestones

\begin{tabular}{|c|c|c|}
\hline Outputs & Associated Activities & Associated Milestones \\
\hline Project Financing Activities (Annual) & $\begin{aligned} & \text { Key activities } \\
& \text { 1. } \text { Energy Savings Performance } \\
& \text { Contracts (ESPC) } \\
& \text { 2. } \text { Utility Energy Savings } \\
& \text { Contracts (UESC) } \\
& \text { 3. } \text { Energy Markets/Shared } \\
& \text { Energy Savings Support }\end{aligned}$ & $\begin{array}{l}\text { Complete project financing activities that } \\
\text { will result in life-cycle Btu savings of } 14.9 \\
\text { trillion annually. }\end{array}$ \\
\hline Technical Assistance Activities (Annual) & $\begin{array}{l}\text { Key activities } \\
\begin{aligned} \text { 1. Technical Assistance Projects } \\
\text { (TA) } \\
\text { 2. Renewable Energy Purchases }\end{aligned}\end{array}$ & $\begin{array}{l}\text { Complete technical assistance activities } \\
\text { that will result in life-cycle Btu savings of } \\
4.7 \text { trillion and support renewable energy } \\
\text { purchases of } 0.6 \text { trillion Btu annually. }\end{array}$ \\
\hline
\end{tabular}

\section{Translating FEMP Goals and Program Outcomes into Energy Model Parameters}

Projected annual energy savings for FEMP are estimated offline, and provided directly as inputs to the integrated energy models (see Figure 3.11).

\section{Individual Program Case Results for the FEMP Program}

Benefits of the Federal Energy Management Program (FEMP) are summarized in Table 3.5. It is an implementation program to increase the energy efficiency of Federal Government buildings, which account for about $5 \%$ of U.S. commercial-building energy consumption. Because the program is targeted to a small segment of the energy system, the savings are modest relative to other EERE programs. By 2030, cumulative carbon emission reductions are 11 MMTCE, and the consumer savings (primarily commercial-building energy users) are $\$ 7$ billion on a net present value basis. By 2050 , cumulative carbon emission reductions and cumulative consumer savings reach levels of 35 MMTCE and \$19 billion, respectively.

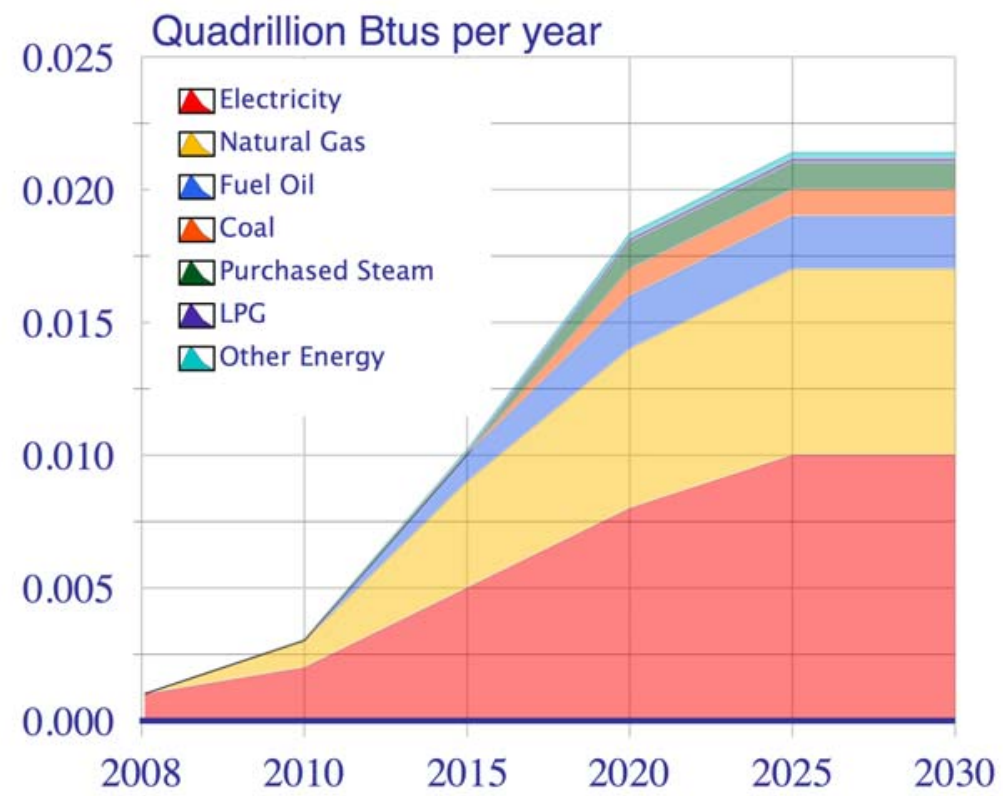

Figure 3.11. Cumulative Energy Savings Associated with FEMP 
Table 3.5. FY08 Benefits for the Federal Energy Management Program

\begin{tabular}{|c|c|c|c|c|c|c|c|c|c|}
\hline & \multicolumn{5}{|c|}{ MIDTERM BENEFITS 7/ } & \multicolumn{4}{|c|}{ LONG-TERM BENEFITS 8/ } \\
\hline Metric & 2010 & 2015 & 2020 & 2025 & 2030 & 2035 & 2040 & 2045 & 2050 \\
\hline \multicolumn{10}{|l|}{ ECONOMIC BENEFITS ("AFFORDABLE") } \\
\hline Reduction in Average Delivered Natural Gas Price (Percent) & ns & ns & ns & ns & ns & $0 \%$ & $0 \%$ & $0 \%$ & $0 \%$ \\
\hline Energy System Cost Savings (bil \$2004) 1/ & $\mathrm{nr}$ & $\mathrm{nr}$ & $\mathrm{nr}$ & $\mathrm{nr}$ & $\mathrm{nr}$ & 2 & 2 & 2 & 2 \\
\hline Consumer Savings, Annual (bil \$2004) & 0 & 0 & 0 & 0 & 1 & 1 & 1 & 1 & 1 \\
\hline Consumer Savings, NPV (bil \$2004) 2/ & 0 & 1 & 2 & 2 & 4 & 13 & 15 & 17 & 19 \\
\hline Electric Power Industry Savings, Annual (bil \$2004) 3/ & 0 & 0 & 0 & 0 & 0 & 0 & 0 & 0 & 0 \\
\hline Electric Power Industry Savings, NPV (bil \$2004) 2/3/ & 0 & 0 & 1 & 1 & 2 & 3 & 4 & 4 & 5 \\
\hline Reduction in Fraction of Household Income Spent on Energy & $0 \%$ & $0 \%$ & $0 \%$ & $0 \%$ & $0 \%$ & $0 \%$ & $0 \%$ & $0 \%$ & $0 \%$ \\
\hline Reduced Energy Intensity of Economy (Percent) & $0 \%$ & $0 \%$ & $0 \%$ & $0 \%$ & $0 \%$ & $0 \%$ & $0 \%$ & $0 \%$ & $0 \%$ \\
\hline \multicolumn{10}{|l|}{ ENVIRONMENTAL BENEFITS ("CLEAN") } \\
\hline Avoided Greenhouse Gas Emissions, Annual (MMTCE/year) & 0 & 0 & 1 & 1 & 1 & 1 & 2 & 1 & 1 \\
\hline Avoided Greenhouse Gas Emissions, Cumulative (MMTCE) 5/ & 0 & 1 & 3 & 7 & 11 & 17 & 23 & 30 & 35 \\
\hline Reduced Cost of Criteria Pollutant Control, NPV (bil \$2004) 2/ & ns & ns & ns & ns & ns & $\mathrm{nr}$ & $\mathrm{nr}$ & $\mathrm{nr}$ & $\mathrm{nr}$ \\
\hline \multicolumn{10}{|l|}{ SECURITY BENEFITS ("RELIABLE") } \\
\hline Avoided Oil Imports, Annual (mbpd) & ns & ns & ns & ns & ns & ns & ns & ns & ns \\
\hline Avoided Oil imports, Cumulative (bil barrels) 4/ 5/ & ns & ns & ns & ns & ns & ns & ns & ns & ns \\
\hline Security Fuel Economy Improvement (MPG) & ns & ns & ns & ns & ns & ns & ns & ns & ns \\
\hline Transportation Fuel Diversity Improvement (percent) 6/ & ns & ns & ns & ns & ns & ns & ns & ns & ns \\
\hline Reduced Oil Intensity (percent) & ns & ns & ns & ns & ns & ns & ns & ns & ns \\
\hline
\end{tabular}

Table notes:

1/ Energy system costs include the annualized capital costs for all capital stock (residual and new), as well as O\&M and fuel costs. Annualized capital costs are calculated using MARKAL hurdle rates, which include both a financial and behavioral component.

2/ NPV (net present value) calculations done using 3\% real discount rate back to 2008

$3 /$ Electric power industry cost does not include demand-side distributed generation.

4/ Renewable generation values at output value (3412 Btu/kWh), except for biomass where energy content is used.

5/ All cumulative values are from 2008.

6/ Diversity index change is Case minus Base (opposite of others).

7/ Midterm benefits based on NEMS-GPRA08 model.

8/ Long-term benefits based on MARKAL-GPRA08 model.

$\mathrm{nr}=$ not reported or calculated by model

ns $=$ not significant relative to model error

\section{Hydrogen, Fuel Cells, and Infrastructure Technologies Program}

The Hydrogen, Fuel Cells, and Infrastructure Technologies (HFCIT) Program conducts research and development activities in hydrogen production, storage, and delivery; and transportation and stationary fuel cells. On the demand side, the program's activities focus on the introduction of fuel cells for both stationary and mobile applications. On the supply side, the program goal is to lower the production cost of hydrogen to a competitive level against petroleum products.

Success for the HFCIT Program is defined as validation, by 2015, of technology for:

- Hydrogen storage systems enabling greater than 300-mile vehicle range, while meeting identified packaging, cost, and performance requirements.

- Hydrogen production from diverse pathways to safely and efficiently deliver hydrogen to lightduty hydrogen fuel cell vehicles, cost-competitively on a per-mile basis without adverse environmental impacts.

- Fuel cells to enable engine costs of less than $\$ 50 / \mathrm{kW}$ (in high-volume production) and stationary power production at $\$ 400-\$ 700 / \mathrm{kW}$, while meeting performance and durability requirements.

Details of the program's activities, milestones, and outputs are described in various source documents, such as the program's multiyear plan and in the appendices to this report. If these indicators are met, there 
is a high probability of success that customer requirements can be met, and that industry will begin to realize a business case for proceeding with the implementation of the hydrogen infrastructure and fuel cell vehicles. While the full extent of life-cycle cost and energy and environmental impacts will not be achieved for decades, meeting the Technology Readiness Milestone in 2015 will begin to yield national benefits as early as 2025 .

\section{Translating HFCIT Goals into Energy Model Parameters}

No individual benefits for the Hydrogen, Fuel Cells, and Infrastructure Technologies Program were computed in NEMS-GPRA08 for the midterm. NEMS-GPRA08 currently does not have a full representation of hydrogen supply (although under development by EERE). A simplified representation was included as part of the EERE Portfolio.

The representation of the Hydrogen, Fuel Cells, and Infrastructure Technologies Program in MARKALGPRA08 requires representation of fuel cell vehicles and transportation markets, hydrogen production and distribution infrastructure, and stationary fuel cell applications. The following sections highlight a few examples of inputs that were developed. A more comprehensive discussion of how baseline and program case assumptions were developed is available in the appendices of this report.

Stationary Fuel Cells: A review of the AEO2006 assumptions and the HFCIT Program goals revealed differences in installed costs and the unit efficiencies. After adjusting for installation costs, there remains a difference in the view of current (or nearly current) technology that might reflect different trade-offs of efficiency and costs, or may reflect differences in development. A recent status review of the stationary fuel cell goals by the Hydrogen Program Fuel Cell team identified current technology information for the efficiencies and costs, which have been used for this analysis. Figure 3.12 compares the AEO2006 and HFCIT Program assumptions about base case projections for capital costs of residential and commercial building stationary fuel cells. While the rates of progress in the base case are similar between the AEO2006 and program assumptions, the HFCIT Program estimates significantly lower current capital costs. Success in the HFCIT program brings capital costs down much more rapidly.
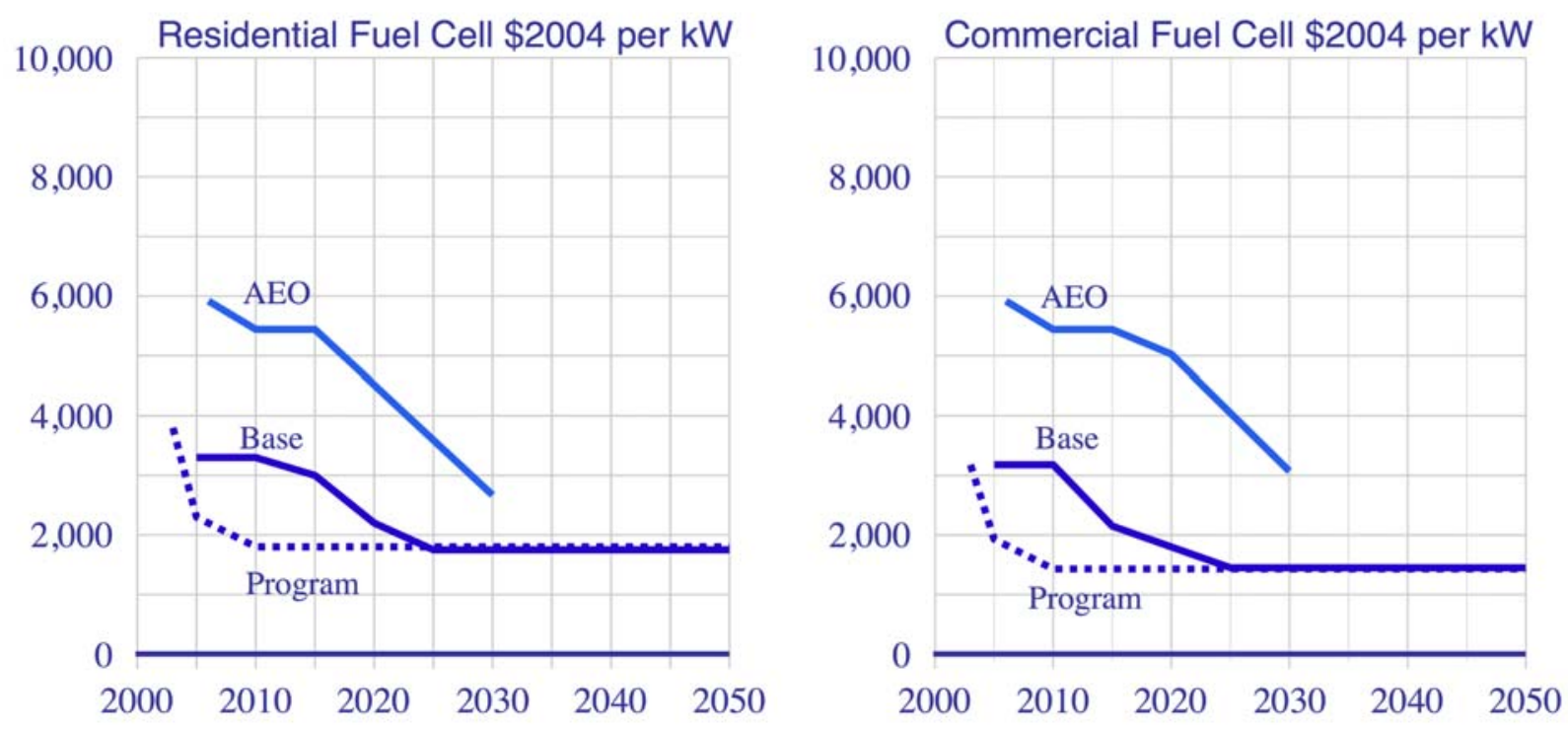

Figure 3.12. Projected Capital Cost of Stationary Fuel Cell Systems for the AEO2006 Reference, GPRA Base, and GPRA HFCIT Program Cases 
Fuel cell vehicles and transportation markets: Fuel cell vehicles are projected to compete with traditional petroleum and hybrid-electric vehicles for market share in the light-duty vehicle (LDV) and commercial light-truck markets. In MARKAL-GPRA08, analysts measure energy service demands for road transportation in vehicle miles traveled (VMT). Projected VMTs are taken directly from the AEO2006 and extended past 2030, based on historical relationships between passenger car and light-truck VMTs and population. LDV VMTs are further disaggregated into three market segments based on population data for Core Based Statistical Areas (CBSAs). The market segments are defined as follows:

- $\quad$ Large City - Population greater than 250,000

- Medium City - Population between 25,000 and 250,000

- $\quad$ Rural - Population under 25,000

Projected VMTs for light-duty vehicles are shown in Table 3.6.

Table 3.6. Light-Duty Vehicle Miles Traveled (billion VMTs/year)

\begin{tabular}{rrrrrrrr}
\hline & 2020 & 2025 & 2030 & 2035 & 2040 & 2045 & 2050 \\
\hline Large City & 2,329 & 2,542 & 2,770 & 2,957 & 3,156 & 3,265 & 3,376 \\
Medium City & 713 & 779 & 849 & 906 & 967 & 1,000 & 1,034 \\
Rural & 439 & 479 & 523 & 558 & 595 & 616 & 637 \\
\hline
\end{tabular}

The Hydrogen Program Case was constructed assuming both HFCIT and modified advanced conventional and hybrid vehicle assumptions; and is compared to a baseline with the advanced conventional vehicles and hybrids. The rationale for this approach is that the hydrogen fuel cell vehicle assumptions provided by the HFCIT Program assume that the Vehicle Technologies Program's hybrid systems and materials technologies R\&D activities are successful. Note that these "modified" advanced conventional and hybrid vehicles are not as efficient as those modeled in the Vehicle Technologies Program, because they are not assumed to use other Vehicle Technologies Program R\&D goals for fuel combustion or deep discharge battery improvements.

Hydrogen production and distribution infrastructure: The HFCIT Program conducts research on developing cost-effective hydrogen production technologies from distributed natural gas reformers, as well as a variety of renewable sources, including biomass. For the EERE Hydrogen Case, analysts modeled nine hydrogen production technologies: distributed natural gas reformers, central natural gas reformers, central coal gasification (with and without cogeneration), central biomass gasification, distributed ethanol reformers, central electrolytic production (both grid electricity and wind-dedicated electrolysis), and distributed electrolytic production. Other renewable hydrogen-production technologies were not modeled, due to a greater degree of uncertainty in their costs. Nuclear hydrogen production technologies were not modeled as part of the EERE HFCIT Program, but were represented in the Office of Nuclear Energy (NE) GPRA analysis. We expect that more hydrogen production technologies will be modeled in future GPRA analyses, as the data becomes available.

Carbon sequestration pathways were available for central coal and natural gas hydrogen production. However, because no carbon policies were assumed in the business-as-usual (BAU) scenario, producers would not have an economic incentive to incur the incremental cost to sequester carbon generated from hydrogen production activities; and, thus, no carbon was sequestered in the BAU Program Case.

HFCIT Program goals were used to estimate capital and O\&M costs and production efficiencies for distributed natural gas reformers, central biomass gasifiers, distributed ethanol reformers, and central and distributed electrolytic production technologies. Assumptions for central coal and natural gas production 
technologies were adapted from $\mathrm{H} 2 \mathrm{~A}$ analysis results. The infrastructure requirements and operating costs for the widespread distribution of hydrogen vary widely by distance and method. The program provided estimated hydrogen distribution costs by market size and market penetration. The HFCIT Program's goal is to reduce the cost of distributing hydrogen from central production facilities to consumers to $\$ 1$ per kilogram. However, the program does not expect the required infrastructure to be in place until 2030, at the earliest. For GPRA08, analysts assumed that distribution costs would fall to program goals in large and medium cities by 2030 and 2035, respectively. Rural markets were assumed to be served only by distributed hydrogen production technologies.

\section{Individual Program Case Results for HFCIT Program}

Figure 3.13 shows the projected distribution of light-duty vehicle (LDV) technologies resulting from success in the HFCIT Program under the Business-as-Usual (BAU) scenario, as well as success in developing advanced conventional and hybrid vehicle technologies (see discussion in previous section). The first hydrogen fuel cell vehicles begin to appear after 2020. By 2030, hydrogen fuel cell vehicles are $5 \%$ of the LDV fleet - reaching a level of $36 \%$ by 2050 . Figure 3.13 also shows the advanced vehicle technologies case without the HFCIT Program. This case is used as the baseline for calculating benefits of the HFCIT. A comparison of the two charts shows that the HFCIT Program case takes away substantial LDV fleet share from the advanced gasoline hybrids, with fewer-but still significant - effects on advanced conventional vehicles and plug-in hybrid vehicles. In both cases, conventional gasoline vehicles in the fleet are gone by 2050 . 

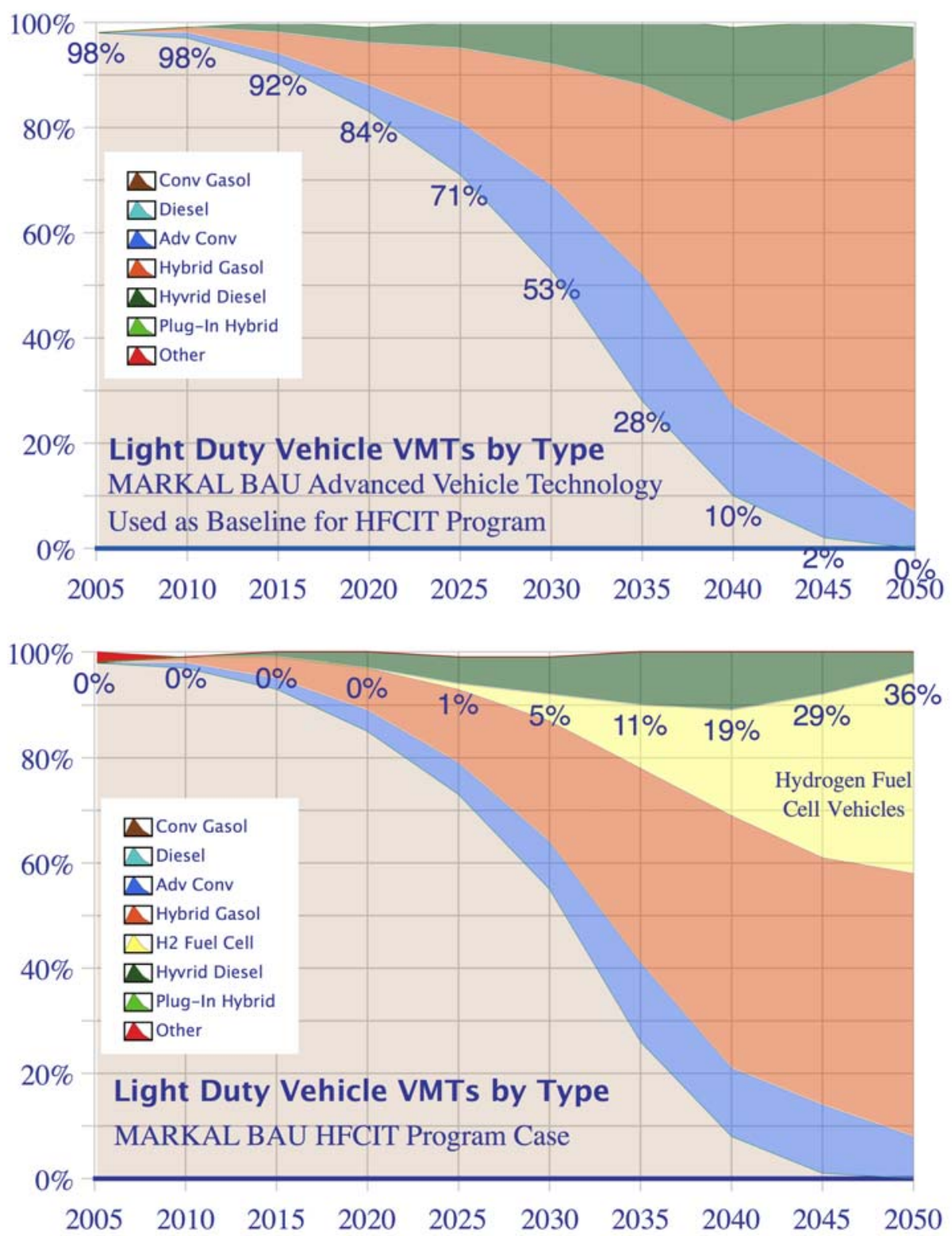

Figure 3.13. Projected Hydrogen Fuel Cell Vehicle Market Penetration

Table 3.7 summarizes the benefits of the HFCIT program through 2050. The impacts of the HFCIT Program are not seen until after 2025. During certain periods at the beginning, or shortly after deployment of HFCIT technology, costs to consumers and the electric power sector and natural gas prices actually increase. Energy system cost savings - a proxy for consumer and producer surplus - is always positive. After 2030, the HFCIT Program results in substantial environmental benefits in the form of avoided greenhouse gas emissions. Security benefits are also substantial throughout this period. Avoided oil imports increase from 0.3 million to 2 million barrels per day between 2030 and 2050. In the transportation sector, the security fuel economy of light-duty vehicles improves by 63 miles per gallon of oil consumed by 2050 . Diversity of the fuel supply for transportation improves by almost $40 \%$ at its peak in 2045. 
Table 3.7. FY08 Benefits for the Hydrogen, Fuel Cell, and Infrastructure Technologies Program

\begin{tabular}{|c|c|c|c|c|c|c|c|c|c|}
\hline \multirow[b]{2}{*}{ Metric } & \multicolumn{5}{|c|}{ MIDTERM BENEFITS 7/ } & \multicolumn{4}{|c|}{ LONG-TERM BENEFITS 7I } \\
\hline & 2010 & 2015 & 2020 & 2025 & 2030 & 2035 & 2040 & 2045 & 2050 \\
\hline $\begin{array}{l}\text { ECONOMIC BENEFITS ("AFFORDABLE") } \\
\text { Reduction in Average Delivered Natural } \\
\text { Gas Price (Percent) }\end{array}$ & $0 \%$ & $0 \%$ & $0 \%$ & $0 \%$ & $-3 \%$ & $-7 \%$ & $-4 \%$ & $0 \%$ & $-3 \%$ \\
\hline $\begin{array}{l}\text { Energy System Cost Savings (bil \$2004) } \\
1 /\end{array}$ & ns & ns & ns & ns & $\$ 0$ & $\$ 1$ & $\$ 5$ & $\$ 8$ & $\$ 10$ \\
\hline Consumer Savings, Annual (bil \$2004) & ns & ns & ns & 3 & 5 & -48 & 10 & 51 & 80 \\
\hline Consumer Savings, NPV (bil \$2004) $2 /$ & ns & ns & ns & 8 & 19 & -41 & -69 & -10 & 92 \\
\hline $\begin{array}{l}\text { Electric Power Industry Savings, Annual } \\
\text { (bil \$2004) 3/ }\end{array}$ & ns & ns & ns & -2 & -3 & -6 & 1 & 9 & 10 \\
\hline $\begin{array}{l}\text { Electric Power Industry Savings, NPV } \\
\text { (bil \$2004) 2/3/ }\end{array}$ & ns & ns & ns & -8 & -14 & -25 & -28 & -18 & -4 \\
\hline $\begin{array}{l}\text { Reduction in Fraction of Household } \\
\text { Income Spent on Energy }\end{array}$ & $0 \%$ & $0 \%$ & $0 \%$ & $0 \%$ & $0 \%$ & $0 \%$ & $1 \%$ & $1 \%$ & $2 \%$ \\
\hline $\begin{array}{l}\text { Reduced Energy Intensity of Economy } \\
\text { (Percent) }\end{array}$ & $0 \%$ & $0 \%$ & $0 \%$ & $0 \%$ & $0 \%$ & $1 \%$ & $1 \%$ & $2 \%$ & $2 \%$ \\
\hline $\begin{array}{l}\text { ENVIRONMENTAL BENEFITS ("CLEAN") } \\
\text { Avoided Greenhouse Gas Emissions, } \\
\text { Annual (MMTCE/year) }\end{array}$ & ns & ns & ns & -3 & 14 & 24 & 29 & 30 & 31 \\
\hline $\begin{array}{l}\text { Avoided Greenhouse Gas Emissions, } \\
\text { Cumulative (MMTCE) } 5 /\end{array}$ & ns & ns & ns & -20 & 16 & 114 & 248 & 396 & 551 \\
\hline $\begin{array}{l}\text { Reduced Cost of Criteria Pollutant } \\
\text { Control, NPV (bil \$2004) 2/ }\end{array}$ & $\mathrm{nr}$ & $\mathrm{nr}$ & $\mathrm{nr}$ & $\mathrm{nr}$ & $\mathrm{nr}$ & $\mathrm{nr}$ & $\mathrm{nr}$ & $\mathrm{nr}$ & $\mathrm{nr}$ \\
\hline $\begin{array}{l}\text { SECURITY BENEFITS ("RELIABLE") } \\
\text { Avoided Oil Imports, Annual (mbpd) }\end{array}$ & ns & ns & 0.0 & 0.0 & 0.3 & 0.9 & 1.4 & 1.9 & 2.1 \\
\hline $\begin{array}{l}\text { Avoided Oil imports, Cumulative (bil } \\
\text { barrels) } 4 / 5 /\end{array}$ & ns & ns & 0 & 0 & 0 & 2 & 4 & 7 & 11 \\
\hline $\begin{array}{l}\text { Security Fuel Economy Improvement } \\
\text { (MPG) }\end{array}$ & ns & ns & 0 & 0 & 1 & 5 & 10 & 25 & 63 \\
\hline $\begin{array}{l}\text { Transportation Fuel Diversity } \\
\text { Improvement (percent) } 6 /\end{array}$ & $0 \%$ & $0 \%$ & $2 \%$ & $6 \%$ & $15 \%$ & $27 \%$ & $33 \%$ & $37 \%$ & $34 \%$ \\
\hline Reduced Oil Intensity (Percent) & ns & ns & ns & ns & $2 \%$ & $5 \%$ & $7 \%$ & $10 \%$ & $13 \%$ \\
\hline
\end{tabular}

Table notes:

1/ Energy system costs include the annualized capital costs for all capital stock (residual and new), as well as O\&M and fuel costs. Annualized capital costs are calculated using MARKAL hurdle rates, which include both a financial and behavioral component.

2/ NPV (net present value) calculations done using 3\% real discount rate back to 2008

3/ Electric power industry cost does not include demand-side distributed generation.

4/ Renewable generation values at output value (3412 Btu/kWh), except for biomass where energy content is used.

5/ All cumulative values are from 2008.

6/ Diversity index change is Case minus Base (opposite of others).

7/ Midterm and long-term benefits based on MARKAL-GPRA08 model. No detailed modeling was done in NEMS-GPRA08.

$\mathrm{nr}=$ not reported or calculated by model

ns $=$ not significant relative to model error 


\section{Industrial Technologies Program}

The Industrial Technologies Program (ITP) will continue its mission of supporting the development of energy-efficient, clean manufacturing technologies by partnering with the industrial sector. ITP has embraced leaner and more agile operating practices to lower industrial energy intensity with reduced resources. By analyzing opportunities, coordinating with other EERE programs, and dynamically refocusing activities, ITP will leverage the current FY 2008 budget request to boost energy efficiency in a sector whose current energy use is approximately 33 quadrillion Btu, one-third of the U.S. total.

In view of the existing challenges, trends, opportunities, and resources, ITP plans to re-examine some aspects of its technology R\&D portfolio such as:

- Research alternatives for natural gas to reduce vulnerability to critical supply and price volatilities, with a focus on energy-intensive industries such as chemicals and steel.

- Identification of crosscutting research opportunities for melting, high-temperature processing, fabrication, and forming of ferrous and nonferrous metals and glass.

- Expansion of current research to address technical challenges in energy conversion systems (e.g., Super Boiler, waste heat recovery), separations (e.g., advanced drying), and alternative chemical reactions.

- Exploring next-generation manufacturing concepts to respond to strategic needs and to produce transformational outcomes that enhance U.S. technological leadership.

The budget request calls for a transition in ITP's program planning unit structure beginning in FY 2008 from one focused on R\&D addressing (1) specific vision industries of the future, (2) crosscutting R\&D, and (3) technical assistance [including Industrial Assessment Centers (IAC) and Best Practices] to a more explicitly crosscutting structure with three new R\&D program components:

- Energy-Intensive Process R\&D

- Fuel and Feedstock Flexibility

- Interagency Manufacturing R\&D

ITP will allocate new FY 2008 projects among these program components, and will phase out funding for the industry-specific planning unit projects as each project is completed. It is expected that transition to the new crosscutting planning structure will be completed within two to three years. However, GPRA08 benefits are necessarily based on analysis of the FY 2007 program portfolio, because the specific content of the FY 2008 portfolio is as yet unknown.

\section{Translating Industrial Technologies Program Goals into Energy Model Parameters}

Because of the level of complexity in the range of technologies and industries covered by ITP, the estimation of market outcomes associated with the program's outputs is done offline. Details of the analysis are available in the appendices to this report.

\section{Individual Program Case Results for the Industrial Technologies Program}

Table 3.8 summarizes the benefits of the ITP through 2050. The Industrial Technologies Program accelerates the development and adoption of efficient technologies. Because the private sector would likely eventually adopt the same or similar technologies at a later time, even in the absence of the program, the benefits that accrue to the program begin to shrink in the later years as the private-sector savings "catch up" in the baseline. Energy savings from the Industrial Technologies Program, relative to the baseline, peak in 2025, this reduces the energy intensity of the economy by $2 \%$. As a result of lower energy use, carbon emissions are reduced by 43 MMTCE per year in 2025. Cumulative carbon emission reductions are almost $600 \mathrm{MMTCE}$ in 2030 and $800 \mathrm{MMTCE}$ in 2050. The cost of energy to industry and 
all other energy consumers is reduced by $\$ 97$ billion on an NPV basis by 2030 and $\$ 243$ billion by 2050 , due to lower energy consumption and slightly lower energy prices. Oil import reductions are not very significant.

Table 3.8. FY08 Benefits for the Industrial Technologies Program

\begin{tabular}{|c|c|c|c|c|c|c|c|c|c|}
\hline & \multicolumn{5}{|c|}{ MIDTERM BENEFITS 7/ } & \multicolumn{4}{|c|}{ LONG-TERM BENEFITS 8/ } \\
\hline Metric & 2010 & 2015 & 2020 & 2025 & 2030 & 2035 & 2040 & 2045 & 2050 \\
\hline \multicolumn{10}{|l|}{ ECONOMIC BENEFITS ("AFFORDABLE") } \\
\hline Reduction in Average Delivered Natural Gas Price (Percent) & ns & ns & $1 \%$ & $2 \%$ & $0 \%$ & $2 \%$ & $1 \%$ & $1 \%$ & $0 \%$ \\
\hline Energy System Cost Savings (bil \$2004) 1/ & $\mathrm{nr}$ & $\mathrm{nr}$ & $\mathrm{nr}$ & $\mathrm{nr}$ & $\mathrm{nr}$ & 13 & 10 & 7 & 6 \\
\hline Consumer Savings, Annual (bil \$2004) & 1 & 4 & 9 & 14 & 11 & 14 & 10 & 7 & 7 \\
\hline Consumer Savings, NPV (bil \$2004) 2/ & 2 & 12 & 37 & 73 & 97 & 195 & 219 & 233 & 243 \\
\hline Electric Power Industry Savings, Annual (bil \$2004) 3/ & 0 & 1 & 2 & 3 & 3 & 3 & 2 & 1 & 2 \\
\hline Electric Power Industry Savings, NPV (bil \$2004) 2/ 3/ & 0 & 3 & 9 & 17 & 22 & 52 & 57 & 59 & 62 \\
\hline Reduction in Fraction of Household Income Spent on Energy & ns & ns & ns & ns & ns & $0 \%$ & $0 \%$ & $0 \%$ & $0 \%$ \\
\hline Reduced Energy Intensity of Economy (Percent) & $0 \%$ & $1 \%$ & $1 \%$ & $2 \%$ & $2 \%$ & $1 \%$ & $1 \%$ & $1 \%$ & $1 \%$ \\
\hline \multicolumn{10}{|l|}{ ENVIRONMENTAL BENEFITS ("CLEAN") } \\
\hline Avoided Greenhouse Gas Emissions, Annual (MMTCE/year) & 4 & 15 & 31 & 43 & 40 & 25 & 20 & 17 & 18 \\
\hline Avoided Greenhouse Gas Emissions, Cumulative (MMTCE) 5/ & 8 & 59 & 174 & 362 & 567 & 503 & 614 & 705 & 791 \\
\hline Reduced Cost of Criteria Pollutant Control, NPV (bil \$2004) 2/ & ns & ns & ns & ns & ns & $\mathrm{nr}$ & $\mathrm{nr}$ & $\mathrm{nr}$ & $\mathrm{nr}$ \\
\hline \multicolumn{10}{|l|}{ SECURITY BENEFITS ("RELIABLE") } \\
\hline Avoided Oil Imports, Annual (mbpd) & ns & ns & ns & ns & ns & ns & ns & ns & ns \\
\hline Avoided Oil imports, Cumulative (bil barrels) 4/ 5/ & ns & ns & ns & ns & ns & ns & ns & ns & ns \\
\hline Security Fuel Economy Improvement (MPG) & ns & ns & ns & ns & ns & ns & ns & ns & ns \\
\hline Transportation Fuel Diversity Improvement (percent) 6/ & ns & ns & ns & ns & ns & ns & ns & ns & ns \\
\hline Reduced Oil Intensity (percent) & ns & ns & ns & ns & ns & ns & ns & ns & ns \\
\hline
\end{tabular}

Table notes:

1/ Energy system costs include the annualized capital costs for all capital stock (residual and new), as well as O\&M and fuel costs. Annualized capital costs are calculated using MARKAL hurdle rates, which include both a financial and behavioral component.

2/ NPV (net present value) calculations done using 3\% real discount rate back to 2008

3/ Electric power industry cost does not include demand-side distributed generation.

4/ Renewable generation values at output value (3412 Btu/kWh), except for biomass where energy content is used.

5/ All cumulative values are from 2008.

6/ Diversity index change is Case minus Base (opposite of others).

7/ Midterm benefits based on NEMS-GPRA08 model.

8/ Long-term benefits based on MARKAL-GPRA08 model.

$\mathrm{nr}=$ not reported or calculated by model

$\mathrm{ns}=$ not significant relative to model error 


\section{Solar Energy Technologies Program}

The Solar Energy Technologies Program develops two electric-solar technologies. Photovoltaics (PVs) are being improved for both distributed and central electricity generation applications. The concentrated solar power (CSP) R\&D activity develops better technology for large-scale central electricity generation facilities that concentrate solar energy to produce electricity through a thermal process.

The President's Solar America Initiative (SAI) was launched January 2006, as part of the Administration's Advanced Energy Initiative, and is being led by the U.S. Department of Energy (DOE) Solar Energy Technologies Program (SETP). The primary mission of the SAI is to reduce the cost of photovoltaic (PV) technologies so PV-generated electricity is cost-competitive with conventional electricity sources by 2015. An analysis of projected market prices for electricity was used to establish technology targets consistent with this goal (see Table 3.9). These targets are based on Energy Information Administration (EIA) projections of relatively flat electricity prices (in real terms) over this time period, based on current conventional fuels. The 2005 Benchmark levelized cost-of-energy (LCOE) of PV systems and target projections are based on SETP internal analyses and the U.S. PV Industry Roadmap. With the ultimate goal for SAI being cost parity with grid-generated electricity, SETP will revise these targets over time as new information warrants.

Table 3.9. Cost Targets for Grid-Connected PV Systems in Key Market Sectors

\begin{tabular}{|c|c|c|c|c|}
\hline \multirow[t]{3}{*}{ Market Sector } & \multirow{3}{*}{$\begin{array}{l}\text { Current U.S. } \\
\text { Market Range } \\
\text { (c/kWh) }\end{array}$} & \multicolumn{3}{|c|}{$\begin{array}{l}\text { Solar Electricity Cost - Current and Projected } \\
\text { (c/kWh) }\end{array}$} \\
\hline & & \multirow{2}{*}{$\begin{array}{c}\text { Benchmark } \\
2005\end{array}$} & \multicolumn{2}{|c|}{ Target } \\
\hline & & & 2010 & 2015 \\
\hline Residential & $5.8-16.7$ & $23-32$ & $13-18$ & $8-10$ \\
\hline Commercial & $5.4-15.0$ & $18-22$ & $9-12$ & $6-8$ \\
\hline Utility & $4.0-7.6$ & $15-22$ & $10-15$ & $5-7$ \\
\hline
\end{tabular}

The SAI enhances DOE's business strategy of partnering with U.S. industry to accelerate commercialization of improved PV systems that can meet aggressive cost and installed-capacity goals. Complementing the core R\&D and engineering activity of the SAI are technology acceptance activities aimed at reducing market barriers and promoting market expansion of solar energy technologies through non-R\&D activities.

The SAI will drive toward accelerated commercialization of solar photovoltaic systems to a milestone in 2015, at which time they will be competitive with conventional sources of electricity in all domestic gridtied market sectors: residential, commercial, and utility-scale markets. The main goals of this nine-year mission are:

- Substantively accelerate development of U.S.-produced PV systems, so that PV-produced electricity reaches parity with the cost of electricity in select grid-tied target markets across the nation.

- Expand the U.S.-installed domestic capacity of PV systems to 5-10 gigawatts (GW) by 2015 .

To implement the SAI, the SETP will pursue an R\&D strategy that is segmented into three manageable three-year phases. These phases will progressively reduce the cost of commercially available PV systems and components, and will ultimately yield commercial products and production processes that achieve the LCOE targets and support installed-capacity targets by 2015. The first three-year phase is scheduled to run from early calendar year (CY) 2007 through early CY 2010; the second three-year phase is expected 
to run from early CY 2010 through early CY 2013; and the third three-year phase is expected to run from early CY 2013 through the end of CY 2015.

\section{Translating SETP Goals into Energy Model Parameters}

The Solar Program Case assumptions for the cost of PV systems are shown in Table 3.10. They are consistent with the market targets shown in Table 3.9.

Table 3.10. Technology Cost Inputs to NEMS-GPRA08 and MARKAL-GPRA08 for PV Systems in Solar Program Case

\begin{tabular}{|c|c|c|c|c|c|c|}
\hline & \multicolumn{2}{|c|}{ Central Generation } & \multicolumn{2}{|c|}{ Residential Buildings } & \multicolumn{2}{|c|}{ Commercial Buildings } \\
\hline Year & $\begin{array}{c}\text { Installed } \\
\text { Price } \\
(2003 \$ / k W)\end{array}$ & $\begin{array}{c}\text { O\&M } \\
(2003 \$ / \mathrm{kW})\end{array}$ & $\begin{array}{l}\text { Installed } \\
\text { Price } \\
(2003 \$ / k W)\end{array}$ & $\begin{array}{c}\text { O\&M } \\
(2003 \$ / k W)\end{array}$ & $\begin{array}{c}\text { Installed } \\
\text { Price } \\
(2003 \$ / k W)\end{array}$ & $\begin{array}{c}\text { O\&M } \\
(2003 \$ / \mathrm{kW})\end{array}$ \\
\hline 2005 & 5,500 & 20 & 8,500 & 100 & 6,290 & 40 \\
\hline 2010 & 3,900 & 10 & 5,000 & 40 & 4,000 & 20 \\
\hline 2015 & 2,580 & 6 & 3,300 & 20 & 2,210 & 10 \\
\hline 2020 & 2,193 & 5 & 2,805 & 17 & 1,879 & 9 \\
\hline 2025 & 1,974 & 5 & 2,525 & 15 & 1,691 & 8 \\
\hline 2030 & 1,875 & 4 & 2,398 & 15 & 1,606 & 7 \\
\hline 2050 & 1,781 & 4 & 2,278 & 14 & 1,526 & 7 \\
\hline
\end{tabular}

Note: These characteristics are for California plants and will vary by region within the integrated energy models.

The cost targets for CSP technology in the Solar Program case are shown in Table 3.11. These targets are based on a funding level consistent with the FY07 budget request for FY07, and a funding level commensurate with those outlined in the Draft CSP Technology Transition Plan for years beyond FY07.

\section{Table 3.11. Technology Cost Inputs to NEMS-GPRA08 and MARKAL-GPRA08 for CSP Systems in Solar Program Case}

\begin{tabular}{|l|l|l|l|}
\hline & $\begin{array}{l}\text { Installed } \\
\text { Price } \\
\text { Year }\end{array}$ & $\begin{array}{l}\text { O\&M } \\
(2003 \$ / \mathrm{kW})\end{array}$ & $\begin{array}{l}\text { Capacity } \\
\text { Factor }\end{array}$ \\
\hline 2010 & 3,510 & 7.8 & $65 \%$ \\
2020 & 2,462 & 4.0 & $72 \%$ \\
2025 & 2,199 & 3.6 & $72 \%$ \\
2030 & 1,993 & 3.2 & $72 \%$ \\
2035 & 1,879 & 3.1 & $72 \%$ \\
2040 & 1,826 & 3.0 & $72 \%$ \\
2050 & 1,797 & 2.9 & $72 \%$ \\
\hline
\end{tabular}

In addition to these program case inputs, analysts for the SETP have developed alternative base case projections for PV system costs. Figure 3.14 compares the AEO2006 reference case, the revised base case, and the program case installed cost projections for residential and commercial PV. For PV technology, the baseline (No DOE RD3 Case) cost projections are very similar to the projections in the AEO2006 reference case, which were based on the baseline scenario in the U.S. PV Industry Roadmap (see the Solar Program appendix for detailed reference information). While the PV industry roadmap 
baseline scenario included the PV program funded at the pre-SAI level, i.e., roughly half the SAI funding level, the U.S. and global PV industry has gained considerable momentum during the past couple of years. Thus, our GPRA08 baseline cost projections take this momentum into account. Based on the program's benchmarked estimates, we assume that the cost of PV in 2005 is higher than in the AEO2006; however, by 2015, the projected GPRA08 baseline costs are roughly equivalent to the AEO2006 projections. The overlap remains relatively close through 2030. Beyond 2030, the costs continue to decline, but at a relatively modest rate through 2050 , ending slightly below the baseline PV industry roadmap projection. Thus, our baseline cost projection is consistent with the AEO2006 reference case and PV industry roadmap baseline scenario. For CSP technology, the Solar Program Baseline simply used the AEO2006 Reference Case projection for CSP systems characteristics and costs. More details on the full set of adjustments made to the $A E O 2006$ reference case are available in the appendices to this report.
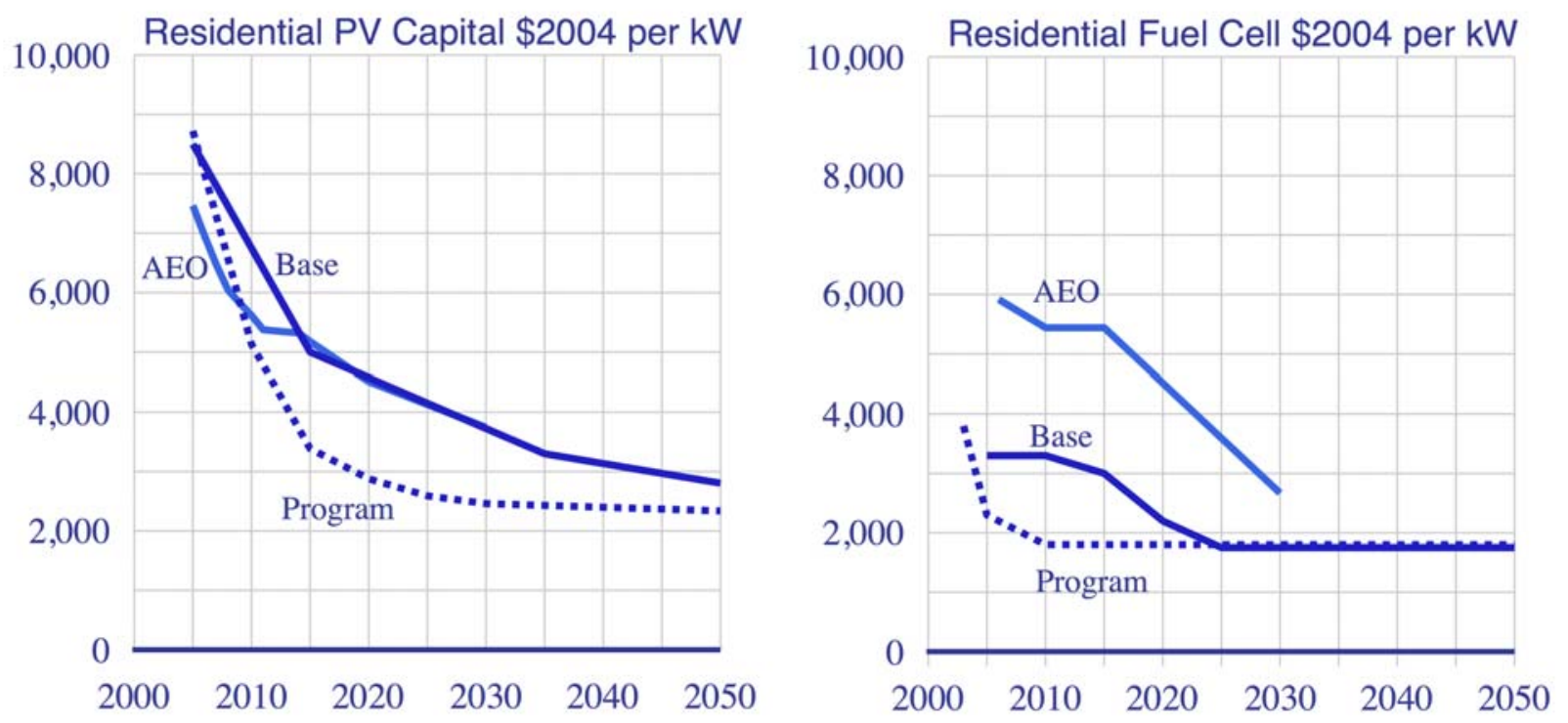

\section{Figure 3.14. Projected Capital Cost of PV Systems for the AEO2006 Reference, GPRA Base, and GPRA Solar Program Cases}

\section{Individual Program Case Results for Solar Energy Technologies Program}

Figure 3.15 summarizes projected solar electricity capacity in the base and program cases. With the success of the EERE's RD3 efforts, PV systems are projected to become much more cost-effectiveespecially in distributed (rooftop) applications - and enjoy more widespread adoption. By 2020, the capacity of installed PV systems is projected to increase from only $1 \mathrm{GW}$ in the Baseline to $17 \mathrm{GW}$ in the Individual Program Goal Case. By 2030, total installed PV is projected to increase to $76 \mathrm{GW}$, or $57 \mathrm{GW}$ above the baseline. By 2030, $4 \mathrm{GW}$ of CSP capacity is anticipated; bringing the total incremental solar power capacity associated with the Solar Program up to $61 \mathrm{GW}$. By 2050, total installed PV is projected to increase to $258 \mathrm{GW}$. CSP capacity in 2050 is $27 \mathrm{GW}$, bringing the total solar capacity in 2050 under the program case to $285 \mathrm{GW}$-almost $190 \mathrm{GW}$ over the baseline case. Incremental benefits of the program peak in 2045, as the baseline case begins to add significant amounts of distributed PV capacity.

Benefits of the Solar Energy Technologies Program are shown in Table 3.12. Economic and environmental benefits result from increased PV and CSP generation. Annual carbon emissions are projected to be reduced by 23 MMTCE by 2030 and by 177 MMTCE on a cumulative basis from 2008 . By 2050, avoided carbon emissions climb to 50 million metric tons of carbon per year, and a cumulative reduction of 1 billion metric tons of carbon. Energy-expenditure savings are measured as the reduction in consumer expenditures for electricity and other fuels offset by increased consumer investments, such as 
distributed PV systems. Net consumer savings are not significant for the program through 2030. The electric system costs savings, on the other hand, indicate that the cost of centrally supplied electricity declines as more electricity demand is met with distributed PV. Cumulative electric power savings are projected to be $\$ 28$ billion and $\$ 291$ billion on a net present value basis in 2030 and 2050, respectively. Energy system cost savings - a proxy for the consumer and producer surplus - are $\$ 6$ billion and $\$ 9$ billion (net present value) in 2035 and 2050.
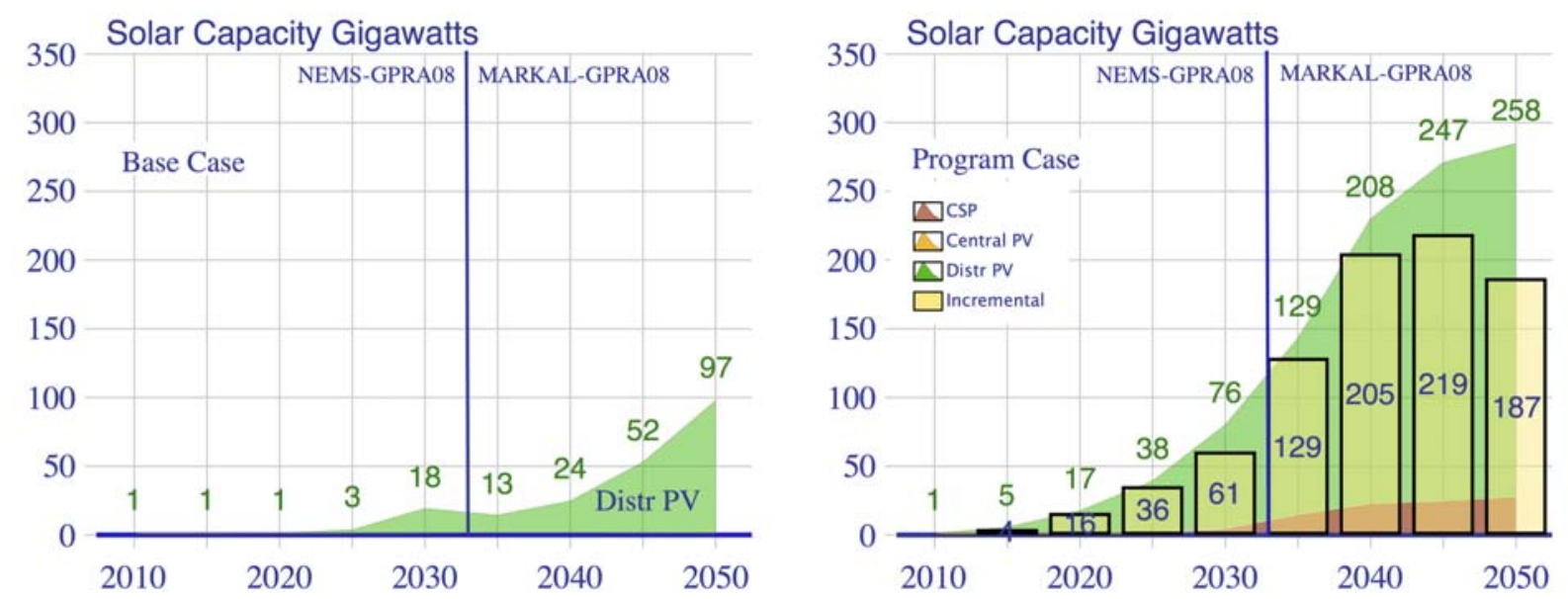

Figure 3.15. Projected Solar Capacity for Base Case and Individual Solar Program Case

Table 3.12. FY08 Benefits for the Solar Energy Technologies Program

\begin{tabular}{|c|c|c|c|c|c|c|c|c|c|}
\hline & \multicolumn{5}{|c|}{ MIDTERM BENEFITS 7/ } & \multicolumn{4}{|c|}{ LONG-TERM BENEFITS 8/ } \\
\hline Metric & 2010 & 2015 & 2020 & 2025 & 2030 & 2035 & 2040 & 2045 & 2050 \\
\hline \multicolumn{10}{|l|}{ ECONOMIC BENEFITS ("AFFORDABLE") } \\
\hline Reduction in Average Delivered Natural Gas Price (Percent) & ns & ns & ns & ns & ns & $6 \%$ & $10 \%$ & $9 \%$ & $1 \%$ \\
\hline Energy System Cost Savings (bil \$2004) 1/ & $\mathrm{nr}$ & $\mathrm{nr}$ & $\mathrm{nr}$ & $\mathrm{nr}$ & $\mathrm{nr}$ & 6 & 8 & 9 & 9 \\
\hline Consumer Savings, Annual (bil \$2004) & ns & ns & ns & ns & ns & 23 & 52 & 67 & 50 \\
\hline Consumer Savings, NPV (bil \$2004) $2 /$ & ns & ns & ns & ns & ns & 58 & 138 & 243 & 328 \\
\hline Electric Power Industry Savings, Annual (bil \$2004) 3/ & 0 & 0 & 1 & 3 & 8 & 27 & 37 & 42 & 31 \\
\hline Electric Power Industry Savings, NPV (bil \$2004) 2/ 3/ & 0 & 0 & 4 & 12 & 28 & 102 & 168 & 238 & 291 \\
\hline Reduction in Fraction of Household Income Spent on Energy & ns & ns & ns & ns & ns & $0 \%$ & $1 \%$ & $1 \%$ & $1 \%$ \\
\hline Reduced Energy Intensity of Economy (Percent) & $0 \%$ & $0 \%$ & $0 \%$ & $0 \%$ & $0 \%$ & $1 \%$ & $1 \%$ & $1 \%$ & $1 \%$ \\
\hline \multicolumn{10}{|l|}{ ENVIRONMENTAL BENEFITS ("CLEAN") } \\
\hline Avoided Greenhouse Gas Emissions, Annual (MMTCE/year) & 0 & 1 & 10 & 12 & 23 & 28 & 47 & 50 & 50 \\
\hline Avoided Greenhouse Gas Emissions, Cumulative (MMTCE) 5/ & 2 & 8 & 33 & 82 & 177 & 359 & 554 & 797 & 1047 \\
\hline Reduced Cost of Criteria Pollutant Control, NPV (bil \$2004) 2/ & ns & ns & ns & ns & ns & $\mathrm{nr}$ & $\mathrm{nr}$ & $\mathrm{nr}$ & $\mathrm{nr}$ \\
\hline \multicolumn{10}{|l|}{ SECURITY BENEFITS ("RELIABLE") } \\
\hline Avoided Oil Imports, Annual (mbpd) & ns & ns & ns & ns & ns & 0 & 0 & 0 & 0 \\
\hline Avoided Oil imports, Cumulative (bil barrels) 4/ 5/ & ns & ns & ns & ns & ns & 0 & 0 & 0 & 0 \\
\hline Security Fuel Economy Improvement (MPG) & ns & ns & ns & ns & ns & ns & ns & ns & ns \\
\hline Transportation Fuel Diversity Improvement (percent) 6/ & ns & ns & ns & ns & ns & ns & ns & ns & ns \\
\hline
\end{tabular}

Table notes:

$1 /$ Energy system costs include the annualized capital costs for all capital stock (residual and new), as well as O\&M and fuel costs. Annualized capital costs are calculated using MARKAL hurdle rates, which include both a financial and behavioral component.

2/ NPV (net present value) calculations done using 3\% real discount rate back to 2008.

3/ Electric power industry cost does not include demand-side distributed generation.

4/ Renewable generation values at output value (3412 Btu/kWh), except for biomass where energy content is used.

5/ All cumulative values are from 2008.

6/ Diversity index change is Case minus Base (opposite of others).

7/ Midterm benefits based on NEMS-GPRA08 model.

8/ Long-term benefits based on MARKAL-GPRA08 model.

$\mathrm{nr}=$ not reported or calculated by model

$\mathrm{ns}=$ not significant relative to model error 


\section{FreedomCAR and Vehicle Technologies Program}

The FreedomCAR and Vehicle Technologies Program (FCVT) provides technology-focused research and development activities for 1) improving the energy efficiency of current automobiles and light trucks; and, 2) developing technologies that will transition automobile technology to use no petroleum fuels. These activities could have dramatic effects over the next 30 years as more hybrid-electric vehicles, lightweight materials, low-temperature combustion regimes, and alternative fuels including hydrogen are used. FCVT technology is aimed at light vehicles (cars and light trucks [pickups, SUVs, minivans, and vans]) and at heavy vehicles (medium and heavy trucks and buses).

The activities of the FCVT program fall into four areas, with key outputs that include the following:

Vehicle Systems and Materials Technologies

- $24 \%$ heavy truck parasitic losses by 2006

- 18,000 lb. tractor trailer by 2010

Hybrid and Electric Technologies

- $\$ 50025 \mathrm{~kW}$ battery by 2010

Advanced Combustion Technologies

- $45 \%$ engine efficiency for light duty applications by 2010

- $55 \%$ engine efficiency for heavy duty applications by 2012

Materials Technologies

- Lightweight vehicle materials and processes by $50 \%$ by 2010

\section{Translating FCVT Goals into Energy Model Parameters}

See the appendices of this report for a detailed discussion of the development of inputs to the integrated energy models. Vehicle attributes are developed (including cost, efficiency, range, acceleration, and others) for each vehicle type, and then competed within the integrated energy models.

\section{Individual Program Case Results for the FCVT Program}

In the midterm, the development of cost-effective, highly efficient light-duty vehicles is projected to lead to a shift over time from conventional gasoline vehicles to hybrids, advanced diesels, and advanced conventional gasoline (includes lightweight materials). As shown in the charts on the left side of Figure 3.16, the overall sales share for conventional gasoline light-duty vehicles in 2030 falls from $65 \%$ in the Baseline Case to $33 \%$ in the Individual Program Goal Case. Among the advanced technology vehicles, the overall share in 2030 for advanced combustion diesel increases from $7 \%$ to $16 \%$; for advanced conventional, from $1 \%$ to $11 \%$; for gasoline hybrids, from $20 \%$ to $17 \%$ (in the program case, gasoline hybrid sales share peaks in 2025 at $21 \%$ ); for diesel hybrids, from $0 \%$ to $11 \%$; and for PHEVs, from $1 \%$ to $8 \%$.

The distribution of vehicles in the stock of vehicles in the U.S. fleet lags behind the changes in the distribution of vehicles in annual vehicle sales, because purchased vehicles remains in the fleet for years after their initial purchase. The total stock of conventional gasoline vehicles in 2030 falls from 236 million vehicles to 166 million (from $74 \%$ to just more than $50 \%$ of the total stock) between the two cases. The total stock for advanced-combustion diesel in 2030 increases from 16 million to 33 million vehicles ( $5 \%$ to $10 \%$ of the total stock) between the baseline and program case; for advanced conventional gasoline vehicles in 2030 from 9 million to 18 million vehicles (3\% to $6 \%$ of the total 
vehicle fleet stock); for gasoline hybrids in 2030, from 33 million to 53 million vehicles (from $10 \%$ to $17 \%$ of the total stock); for diesel hybrids, from 0.1 million to 24 million vehicles (from less than $0.1 \%$ to almost 8\%); and, for plug-in hybrids, from 2 million to 8 million vehicles (from $0.7 \%$ to almost $3 \%$ of the total vehicle fleet stock).
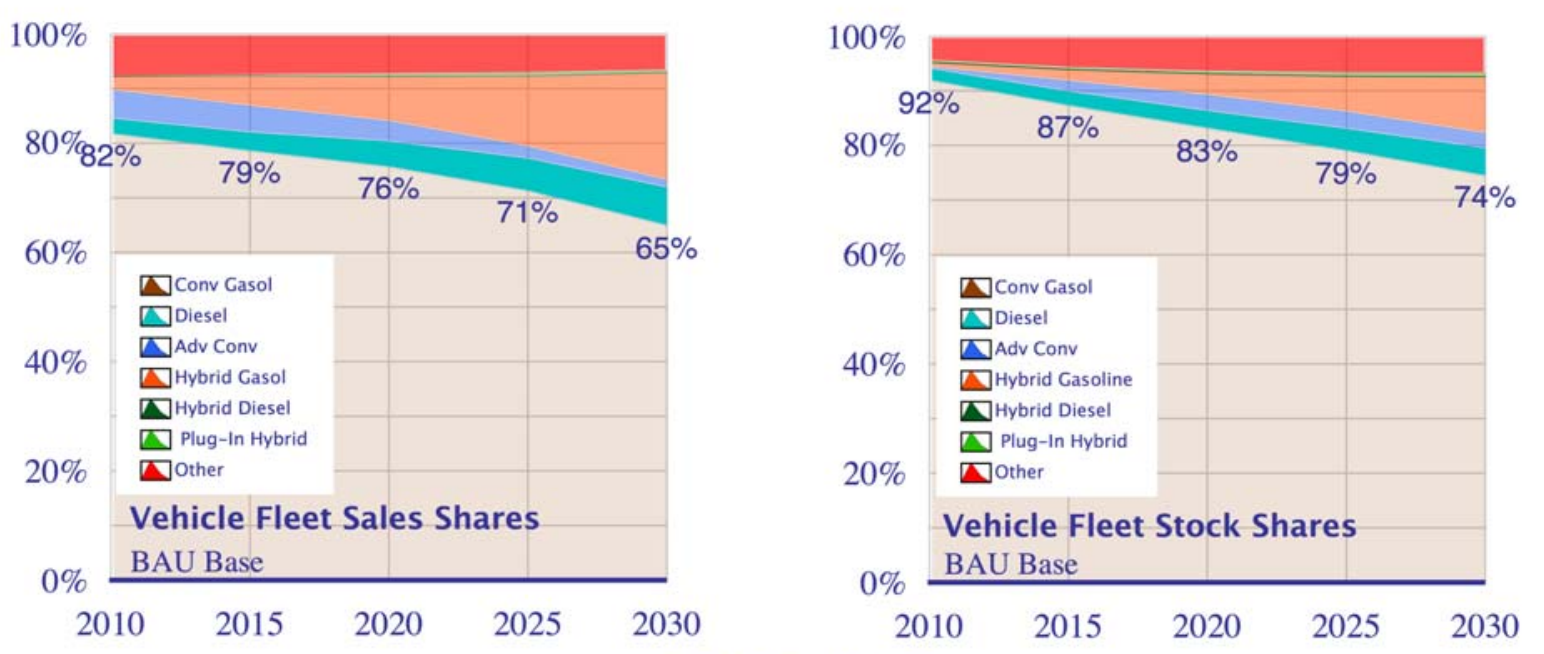

BAU Baseline Case
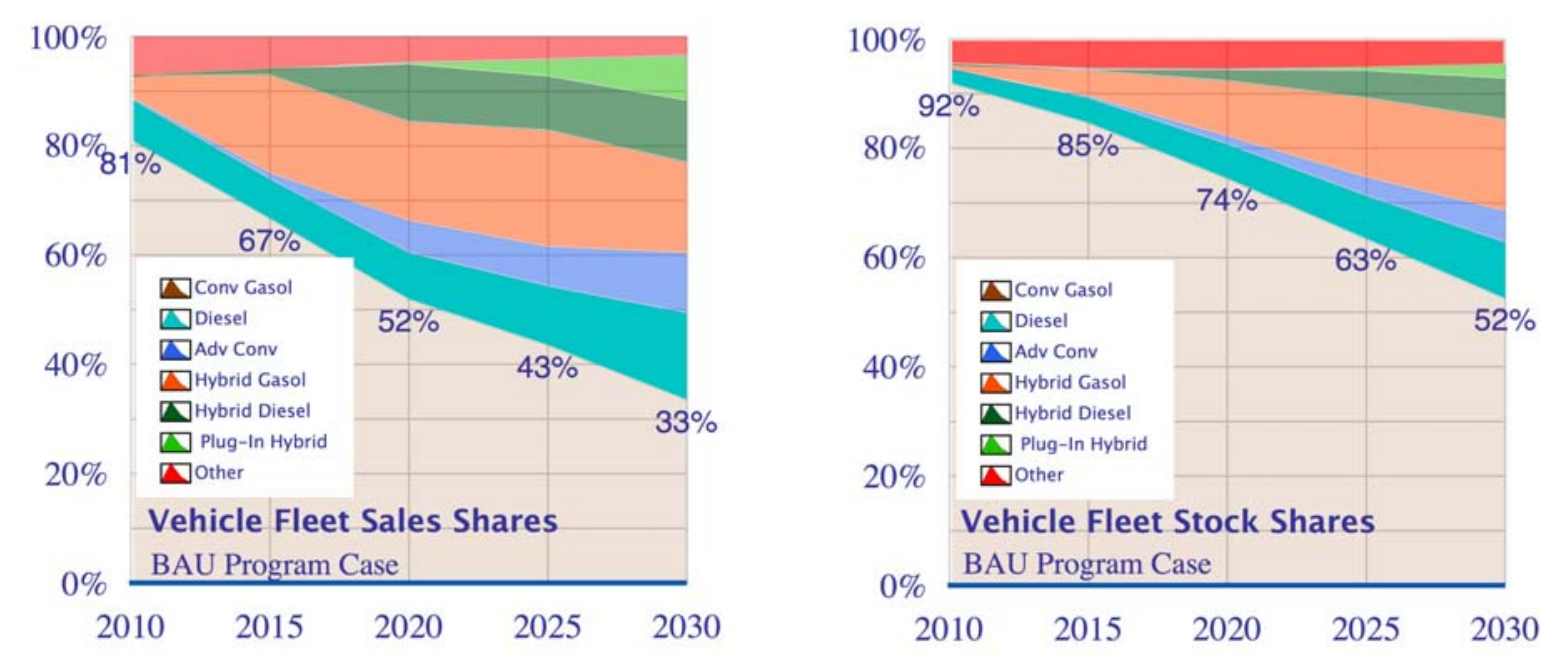

BAU Vehicle Technologies Program Case

Figure 3.16. Midterm Vehicle Technology Sales and Fleet Stock Shares

NEMS-GPRA08 Model Results

In the long term, conventional gasoline vehicle stock drops dramatically by 2050 - from about $80 \%$ of the vehicle stock to $5 \%$ of the vehicle stock between the baseline and program cases. Advanced diesel engine vehicles increase to about $25 \%$ of the total vehicle fleet stock in 2050 between the baseline and program cases. Advanced conventional gasoline vehicles are 5\% of the total vehicle fleet stock in 2050 under the 
program case. Gasoline and diesel hybrids reach peak levels of $31 \%$ and $12 \%$ in 2045 in the program case. Plug-in hybrid market penetration is significant - achieving more than $50 \%$ of the total vehicle fleet stock by 2050 .
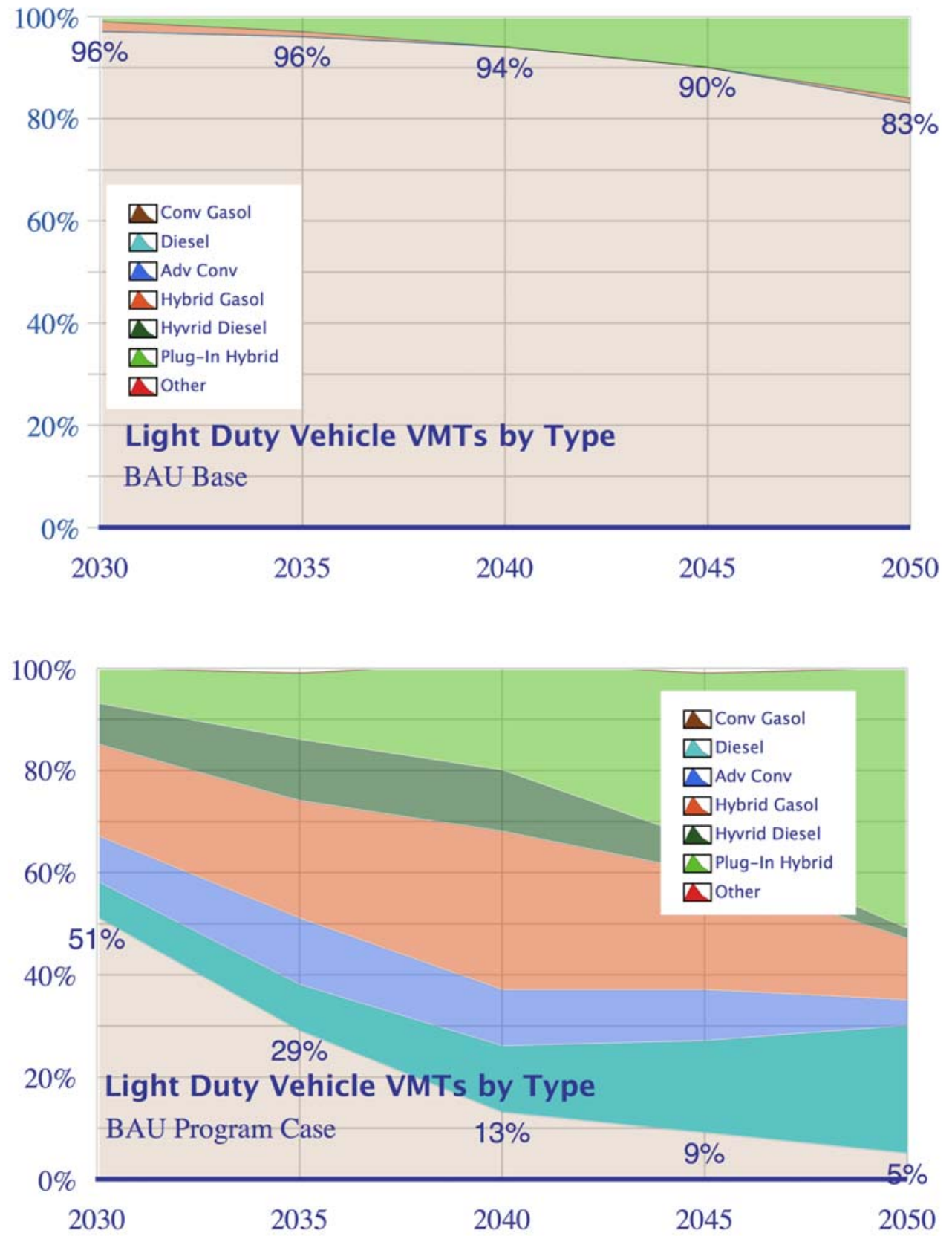

Figure 3.17. Long-Term Light-Duty Vehicle Stocks in BAU Baseline and Vehicle Program Cases

MARKAL-GPRA08 Model Results 
Figure 3.18 shows the projected annual fuel consumption for light-duty vehicles, commercial light trucks, and heavy trucks in the Baseline Case and the Individual Program Case. The efficiency for advancedtechnology vehicles is greater than the efficiency for conventional gasoline vehicles. As a consequence of the advanced-technology vehicles substitution for the conventional gasoline vehicles, fuel savings are 2.2 quads relative to the baseline in 2030. Commercial light-duty and heavy-duty truck efficiency improvements lead to an additional 1.1 quads of reduced oil consumption in 2030. Projected light-duty vehicle fuel savings in 2050 are 11 quads relative to the baseline, and commercial light and heavy truck savings are 2 quads relative to the baseline. Total fuel consumption savings associated with the Vehicles Program are 3 and 13 quads per year, respectively, in the midterm (2030) and long term (2050).
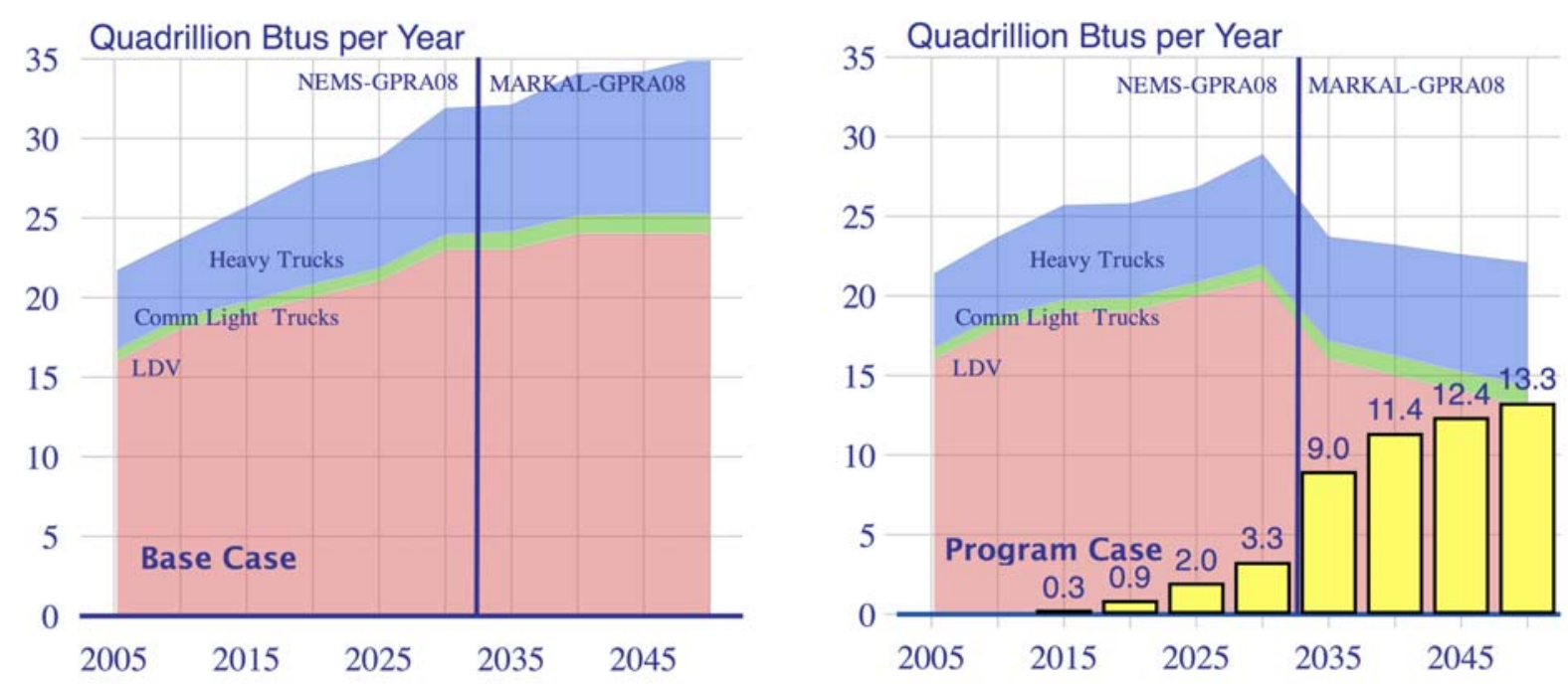

Figure 3.18. Fuel Consumption for the Baseline Case and the Vehicle Program Case

Yellow bars represent the savings in fuel consumption between the base and program cases 
Table 3.13 summarizes the benefits of the Individual Program Case for the Vehicles Technologies Program. Among the economic benefits, the reduced fuel consumption in the transportation sector leads to significant consumer savings and energy system cost savings, as well as a reduced energy intensity of the economy. Cumulative consumer savings (reported as a net present value in 2008) are \$260 billion and $\$ 1.6$ trillion, respectively, by 2030 and 2050. Cumulative energy system cost savings - a proxy for consumer and producer surplus - is $\$ 81$ billion. Energy intensity declines 3\% and 10\%, respectively, in 2030 and 2050. In the long term, the FCVT leads to increased costs to the electric sector, due to the high market penetration of plug-in hybrids.

Among the environmental benefits, reduced fuel consumption translates into avoided carbon emissions of 600 million and 5 billion metric tons of carbon equivalent, cumulatively, in 2030 and 2050 relative to the baseline. No significant effect is seen on pollution control costs - due to the fact that this metric applies only to the electric sector, and the fact that this program has little impact on electricity use in the midterm.

The FCVT program has the greatest impact on security benefits to the Nation, relative to all of the programs in EERE's portfolio. That is because almost all of the energy demand in the transportation sector is for petroleum. Oil imports are reduced by the FCVT program by 2 million and 6 million barrels per day in 2030 and 2050, relative to the Baseline Case. The improvement in "security MPG" is almost 4 miles per gallon of oil in 2030 and 64 miles per gallon of oil in 2050. Oil intensity of the economy is reduced by $7 \%$ and $28 \%$, respectively, in 2030 and 2050. In addition to improving security by reducing fuel demand in the transportation sector, the Vehicles Program also improves transportation fuel diversity - by $8 \%$ and $24 \%$ in 2030 and 2050 - as a result of increased use of electricity in plug-in hybrid vehicles.

In these integrated energy model runs, the savings are typically somewhat less than what they would be if they were estimated in a transportation-only model, because of feedback effects that come through the integration with other energy sectors. The primary feedback effect occurs through lower fuel prices. In this case, reduced gasoline demand causes lower gasoline prices, which leads to an increase in travel and less-efficient vehicle purchases than would otherwise have occurred absent the price change. In addition, the "rebound" effect is influenced by the fact that vehicles are more efficient, thereby reducing the cost to drive, causing more miles to be driven. The total effect is that light-duty VMT in 2030 is roughly 4\% higher in the Individual Program Goal Case than in the Baseline Case. The rebound of gasoline consumption reduces the program savings. At the same time, consumer expenditure savings are greater. The small decreases in gasoline price apply to the total amount of fuel consumed and contribute significant additional expenditure savings. The net result of these lower fuel costs, combined with somewhat more expensive vehicles, yields consumer savings of \$46 billion per year in 2030 or $\$ 255$ billion on a cumulative net present value basis (evaluated at a 3\% discount rate) from 2008 through 2030. 
Table 3.13. FY08 Benefits for the FreedomCAR and Vehicle Technologies Program

\begin{tabular}{|c|c|c|c|c|c|c|c|c|c|}
\hline & \multicolumn{5}{|c|}{ MIDTERM BENEFITS $7 /$} & \multicolumn{4}{|c|}{ LONG-TERM BENEFITS 8/ } \\
\hline Metric & 2010 & 2015 & 2020 & 2025 & 2030 & 2035 & 2040 & 2045 & 2050 \\
\hline ECONOMIC BENEFITS ("AFFORDABLE") & & & & & & & & & \\
\hline $\begin{array}{l}\text { Reduction in Average Delivered Natural Gas } \\
\text { Price (Percent) }\end{array}$ & ns & ns & ns & ns & ns & $-1 \%$ & $2 \%$ & $1 \%$ & $0 \%$ \\
\hline Energy System Cost Savings (bil \$2004) 1/ & $\mathrm{nr}$ & $\mathrm{nr}$ & $\mathrm{nr}$ & $\mathrm{nr}$ & $\mathrm{nr}$ & 33 & 45 & 63 & 81 \\
\hline Consumer Savings, Annual (bil \$2004) & ns & 3 & 17 & 36 & 46 & 112 & 181 & 193 & 218 \\
\hline Consumer Savings, NPV (bil \$2004) 2/ & ns & 10 & 49 & 139 & 255 & 702 & 1007 & 1332 & 1642 \\
\hline $\begin{array}{l}\text { Electric Power Industry Savings, Annual (bil } \\
\$ 2004) 3 /\end{array}$ & ns & ns & ns & ns & ns & -2 & -2 & -3 & -10 \\
\hline $\begin{array}{l}\text { Electric Power Industry Savings, NPV (bil } \\
\$ 2004 \text { ) } 2 / 3 /\end{array}$ & ns & ns & ns & ns & ns & 2 & -1 & -6 & -16 \\
\hline $\begin{array}{l}\text { Reduction in Fraction of Household Income } \\
\text { Spent on Energy }\end{array}$ & ns & $0 \%$ & $1 \%$ & $2 \%$ & $3 \%$ & $5 \%$ & $6 \%$ & $6 \%$ & $7 \%$ \\
\hline $\begin{array}{l}\text { Reduced Energy Intensity of Economy } \\
\text { (Percent) }\end{array}$ & $0 \%$ & $0 \%$ & $1 \%$ & $2 \%$ & $3 \%$ & $8 \%$ & $9 \%$ & $10 \%$ & $10 \%$ \\
\hline ENVIRONMENTAL BENEFITS ("CLEAN") & & & & & & & & & \\
\hline $\begin{array}{l}\text { Avoided Greenhouse Gas Emissions, Annual } \\
\text { (MMTCE/year) }\end{array}$ & 1 & 6 & 22 & 45 & 69 & 172 & 220 & 224 & 210 \\
\hline $\begin{array}{l}\text { Avoided Greenhouse Gas Emissions, } \\
\text { Cumulative (MMTCE) } 5 /\end{array}$ & 3 & 22 & 90 & 275 & 580 & 1741 & 2744 & 3854 & 4932 \\
\hline $\begin{array}{l}\text { Reduced Cost of Criteria Pollutant Control, } \\
\text { NPV (bil \$2004) 2/ }\end{array}$ & ns & ns & ns & ns & ns & $\mathrm{nr}$ & $\mathrm{nr}$ & $\mathrm{nr}$ & $\mathrm{nr}$ \\
\hline SECURITY BENEFITS ("RELIABLE") & & & & & & & & & \\
\hline Avoided Oil Imports, Annual (mbpd) & ns & 0.2 & 0.4 & 1.1 & 1.8 & 4 & 5 & 6 & 6 \\
\hline $\begin{array}{l}\text { Avoided Oil imports, Cumulative (bil barrels) } \\
4 / 5 /\end{array}$ & ns & 0.2 & 1 & 2 & 5 & 14 & 23 & 33 & 44 \\
\hline Security Fuel Economy Improvement (MPG) & 0.1 & 0.5 & 1 & 2 & 4 & 13 & 21 & 29 & 46 \\
\hline $\begin{array}{l}\text { Transportation Fuel Diversity Improvement } \\
\text { (percent) 6/ }\end{array}$ & ns & ns & ns & $4 \%$ & $8 \%$ & $12 \%$ & $23 \%$ & $25 \%$ & $24 \%$ \\
\hline Reduced Oil Intensity (Percent) & $0 \%$ & $1 \%$ & $2 \%$ & $5 \%$ & $7 \%$ & $19 \%$ & $24 \%$ & $26 \%$ & $28 \%$ \\
\hline
\end{tabular}

Table notes:

1/ Energy system costs include the annualized capital costs for all capital stock (residual and new), as well as O\&M and fuel costs. Annualized capital costs are calculated using MARKAL hurdle rates, which include both a financial and behavioral component.

2/ NPV (net present value) calculations done using 3\% real discount rate back to 2008.

$3 /$ Electric power industry cost does not include demand-side distributed generation.

4/ Renewable generation values at output value (3412 Btu/kWh), except for biomass where energy content is used.

5/ All cumulative values are from 2008.

6/ Diversity index change is Case minus Base (opposite of others).

7/ Midterm benefits based on NEMS-GPRA08 model.

8/ Long-term benefits based on MARKAL-GPRA08 model.

$\mathrm{nr}=$ not reported or calculated by model

ns $=$ not significant relative to model error

\section{Weatherization and Intergovernmental Program}

The Weatherization and Intergovernmental Program (WIP) provides funding and technical assistance to its partners in state and local governments, Indian tribes, and international agencies to facilitate the adoption of renewable energy and energy efficiency technologies. WIP activities speed the adoption of new technologies and help transfer technologies that are developed by Department of Energy (DOE)funded research to the private sector.

WIP activities are different from those of most DOE research and development programs that focus on basic science and hardware development. WIP projects are more likely to focus on issues such as economic development in rural areas or how renewable energy and energy efficiency projects can 
improve air quality. For this reason, it is difficult to characterize the benefits resulting from WIP activities by measuring their energy impact.

In general, WIP activities are characterized by:

- Multiple Technologies

- WIP facilitates adoption of a range of technologies that are developed by the DOE Office of Energy Efficiency and Renewable Energy (EERE).

- Work across All Energy Market Sectors

- WIP sponsors activities in the major energy market sectors - buildings, electric power, industry, and transportation - and works to educate the public, teachers, and students about the benefits of renewable energy and energy efficiency technologies. WIP also helps state and local agencies improve their energy efficiencies by upgrading public facilities.

- Partnerships

- WIP is involved with a broad range of energy stakeholders that cover the breadth of the U.S. economy. WIP staff members consult regularly with the National Governors' Association, the National Association of State Energy Officials, the National Council of State Legislatures, the National Association of Counties, the U.S. Conference of Mayors, the National Association of State and Community Service Programs, and many others.

- Leverage of Federal Resources

- Almost every WIP project involves substantial participation and investment by state and local agencies, Indian tribes, and the private sector.

\section{Translating WIP Goals and Program Outcomes into Energy Model Parameters}

For FY2008, the State Energy Program (SEP) within WIP added three new grant areas to the analysis: Tax Credits, Procurement, and Renewable Energy. Additionally, SEP plans to revamp its Special Projects to focus on competitive grants that promote market transformation. In 2008, the State Energy Program will allocate approximately $78 \%$ of its funding to the traditional grant programs, and $22 \%$ of its funding to competitive grants. With a projected budget of $\$ 45$ million, the traditional SEP grants will receive $\$ 35$ million, and the new SEP Market Transformation program will receive \$10 million. The SEP Special Projects: Competitive Grants program was developed to strategically realign the SEP program by transforming energy markets at the state level, to promote an integrated portfolio of energy efficiency and renewable energy options, and to strengthen the traditional state energy grant programs.

These new directions were introduced at the very end of the budget and benefits analysis process. As a result, at the time of the final FY 2008 budget submission to the Office of Management and Budget, only preliminary estimates of the benefits reflecting these changes were available for a limited set of metrics. In the meantime, a full set of benefits estimates have been done for the midterm only (through 2030). Projected annual energy savings for WIP are estimated offline, and provided directly as inputs to the integrated energy models.

\section{Individual Program Case Results for Weatherization and Intergovernmental Program}

Benefits of the Weatherization and Intergovernmental Program are summarized in Table 3.14. By 2030, cumulative carbon emission reductions are $138 \mathrm{MMTCE}$ and the consumer savings are $\$ 62$ billion on a net present value basis. Long-term benefits estimates were not done. 
Table 3.14. FY08 Benefits for the Weatherization and Intergovernmental Program ${ }^{9}$

\begin{tabular}{|c|c|c|c|c|c|c|c|c|c|}
\hline \multirow[b]{2}{*}{ Metric } & \multicolumn{5}{|c|}{ MIDTERM BENEFITS 7/ } & \multicolumn{4}{|c|}{ LONG-TERM BENEFITS 8/ } \\
\hline & 2010 & 2015 & 2020 & 2025 & 2030 & 2035 & 2040 & 2045 & 2050 \\
\hline ECONOMIC BENEFITS ("AFFORDABLE") & & & & & & & & & \\
\hline $\begin{array}{l}\text { Reduction in Average Delivered Natural Gas Price } \\
\text { (Percent) }\end{array}$ & $0.18 \%$ & $0.31 \%$ & $0.70 \%$ & $1.11 \%$ & $0.43 \%$ & $\mathrm{nr}$ & $\mathrm{nr}$ & $\mathrm{nr}$ & $\mathrm{nr}$ \\
\hline Energy System Cost Savings (bil \$2004) 1/ & $\mathrm{nr}$ & $\mathrm{nr}$ & $\mathrm{nr}$ & $\mathrm{nr}$ & $\mathrm{nr}$ & $\mathrm{nr}$ & $\mathrm{nr}$ & $\mathrm{nr}$ & $\mathrm{nr}$ \\
\hline Consumer Savings, Annual (bil \$2004) & 1.7 & 2.8 & 3.9 & 8.1 & 7.8 & $\mathrm{nr}$ & $\mathrm{nr}$ & $\mathrm{nr}$ & $\mathrm{nr}$ \\
\hline Consumer Savings, NPV (bil \$2004) $2 /$ & 3.9 & 13 & 26 & 46 & 62 & $\mathrm{nr}$ & $\mathrm{nr}$ & $\mathrm{nr}$ & $\mathrm{nr}$ \\
\hline $\begin{array}{l}\text { Electric Power Industry Savings, Annual (bil \$2004) } \\
3 /\end{array}$ & 0.25 & 1.7 & 1.5 & 2.1 & 2.1 & $\mathrm{nr}$ & $\mathrm{nr}$ & $\mathrm{nr}$ & $\mathrm{nr}$ \\
\hline $\begin{array}{l}\text { Electric Power Industry Savings, NPV (bil \$2004) 2/ } \\
3 /\end{array}$ & 1.0 & 6.6 & 13 & 19 & 24 & $\mathrm{nr}$ & $\mathrm{nr}$ & $\mathrm{nr}$ & $\mathrm{nr}$ \\
\hline $\begin{array}{l}\text { Reduction in Fraction of Household Income Spent } \\
\text { on Energy }\end{array}$ & ns & ns & ns & ns & $0.14 \%$ & $\mathrm{nr}$ & $\mathrm{nr}$ & $\mathrm{nr}$ & $\mathrm{nr}$ \\
\hline Reduced Energy Intensity of Economy (Percent) & $0.11 \%$ & $0.26 \%$ & $0.39 \%$ & $0.35 \%$ & $0.28 \%$ & $\mathrm{nr}$ & $\mathrm{nr}$ & $\mathrm{nr}$ & $\mathrm{nr}$ \\
\hline ENVIRONMENTAL BENEFITS ("CLEAN") & & & & & & & & & \\
\hline $\begin{array}{l}\text { Avoided Greenhouse Gas Emissions, Annual } \\
\text { (MMTCE/year) }\end{array}$ & 1.8 & 4.5 & 9.7 & 8.3 & 6.6 & $\mathrm{nr}$ & $\mathrm{nr}$ & $\mathrm{nr}$ & $\mathrm{nr}$ \\
\hline $\begin{array}{l}\text { Avoided Greenhouse Gas Emissions, Cumulative } \\
\text { (MMTCE) 5/ }\end{array}$ & 4.0 & 22 & 57 & 101 & 138 & $\mathrm{nr}$ & $\mathrm{nr}$ & $\mathrm{nr}$ & $\mathrm{nr}$ \\
\hline $\begin{array}{l}\text { Reduced Cost of Criteria Pollutant Control, NPV (bil } \\
\$ 2004) 2 /\end{array}$ & 0.49 & 1.1 & 0.89 & 3.6 & 3.2 & $\mathrm{nr}$ & $\mathrm{nr}$ & $\mathrm{nr}$ & $\mathrm{nr}$ \\
\hline SECURITY BENEFITS ("RELIABLE") & & & & & & & & & \\
\hline Avoided Oil Imports, Annual (mbpd) & ns & ns & ns & ns & ns & $\mathrm{nr}$ & $\mathrm{nr}$ & $\mathrm{nr}$ & $\mathrm{nr}$ \\
\hline Avoided Oil imports, Cumulative (bil barrels) 4/ 5/ & ns & ns & ns & ns & ns & $\mathrm{nr}$ & $\mathrm{nr}$ & $\mathrm{nr}$ & $\mathrm{nr}$ \\
\hline Security Fuel Economy Improvement (MPG) & ns & ns & ns & ns & ns & $\mathrm{nr}$ & $\mathrm{nr}$ & $\mathrm{nr}$ & $\mathrm{nr}$ \\
\hline $\begin{array}{l}\text { Transportation Fuel Diversity Improvement (percent) } \\
6 /\end{array}$ & ns & ns & ns & ns & ns & $\mathrm{nr}$ & $\mathrm{nr}$ & $\mathrm{nr}$ & $\mathrm{nr}$ \\
\hline Reduced Oil Intensity (Percent) & ns & ns & ns & ns & ns & $\mathrm{nr}$ & $\mathrm{nr}$ & $\mathrm{nr}$ & $\mathrm{nr}$ \\
\hline
\end{tabular}

Table notes:

1/ Energy system costs include the annualized capital costs for all capital stock (residual and new), as well as O\&M and fuel costs. Annualized capital costs are calculated using MARKAL hurdle rates, which include both a financial and behavioral component.

2/ NPV (net present value) calculations done using 3\% real discount rate back to 2008.

$3 /$ Electric power industry cost does not include demand-side distributed generation.

4/ Renewable generation values at output value (3412 Btu/kWh), except for biomass where energy content is used.

5/ All cumulative values are from 2008.

6/ Diversity index change is Case minus Base (opposite of others).

7/ Midterm benefits based on NEMS-GPRA08 model.

8/ Long-term benefits based on MARKAL-GPRA08 model.

$\mathrm{nr}=$ not reported or calculated by model

ns $=$ not significant relative to model error

\footnotetext{
${ }^{9}$ Last-minute changes in funding for WIP have resulted in changes to the benefits associated with this program. An erratum will be released later showing final results for benefits of WIP and will be available online.
} 


\section{Wind Technologies Program}

The Wind Technologies Program is one component of the Wind and Hydropower Technologies Program under the Office of Energy Efficiency and Renewable Energy (EERE) within the U.S. Department of Energy. The Wind Program focuses on two key areas for its mission - increasing the Technical Viability of wind systems through support of research and development, and increasing wind energy deployment in the emerging marketplace through Technology Application activities. Figure 3.19 depicts the five projects within the two key areas that comprise the Wind Program.

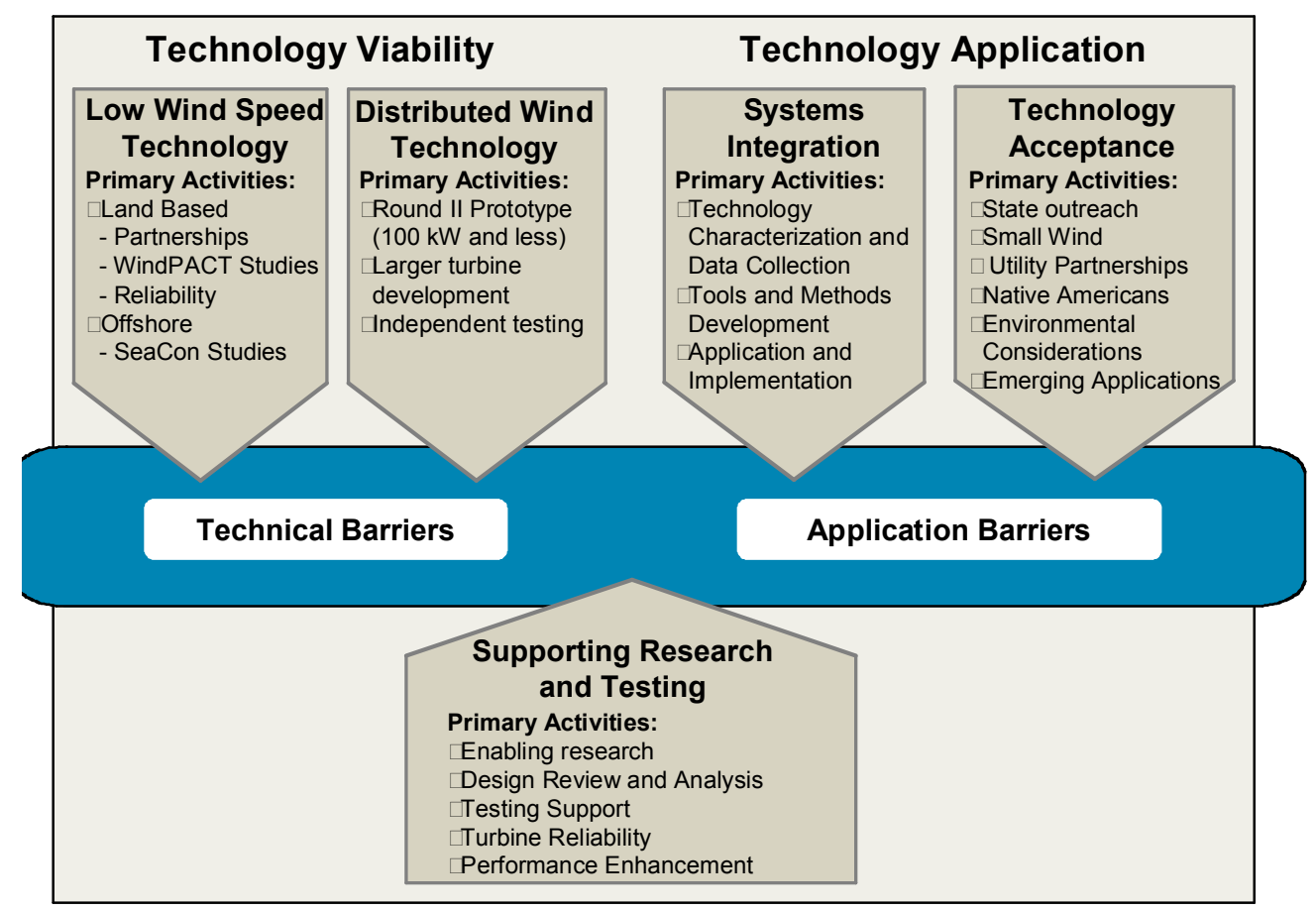

Figure 3.19. Structure of the Wind Program

For a detailed description of the Wind Technologies Program goals and activities, see the appendices to this report and the program's current multiyear technical plan.

\section{Translating the Wind Technologies Program Goals into Energy Model Parameters}

Analysts for the Wind Program have modified the AEO2006 reference case to generate a Baseline (no DOE RD3 effort) Case, in addition to translating the program's goals and outputs into inputs to the integrated energy models (see the appendices for details.) The AEO2006 projections show almost no improvement in cost or performance in future wind power technology from R\&D. The program's Program Case projections for future wind plant capacity factors and capital costs both reflect larger improvements, compared to those in the AEO2006, i.e., capacity factors are higher and costs are lower.

To calculate the benefits from the DOE Wind Program, the GPRA 08 Baseline Case, unlike the AEO2006 Reference Case, must reflect the absence of DOE-sponsored R\&D. For the GPRA 08 Baseline Case, the AEO2006 Reference Case capital cost is assumed for 2005 as the starting point. The 2005 capacity factor is the midpoint between the AEO2006 value and the program value, as in past GPRA analyses. To remove the impacts of Wind Program activities from the Program Case, a projected cost/performance trajectory was estimated whereby industry is assumed to achieve $60 \%$ of the COE reduction projected by the program at each five-year interval for all wind classes. This COE reduction level is supported by a preliminary analysis conducted by NREL staff that projected physical characteristics and performance 
levels of wind turbines likely to result if Federal research investment is discontinued. That analysis builds off of the extensive analysis underlying the Program Case. While the program focus is on low wind speed technology, much of the research is transferable to higher wind speed designs. Also, over the long term, industry is assumed to invest in higher wind-speed R\&D, if needed. Therefore, as a first-order approximation, the $60 \%$ value is assumed for turbines designed for all wind power classes.

Figure 3.20 highlights a few examples of baseline and program case inputs. For class 4 winds, it compares the baseline assumptions used in this report with the assumptions currently used in the AEO2006 reference case.
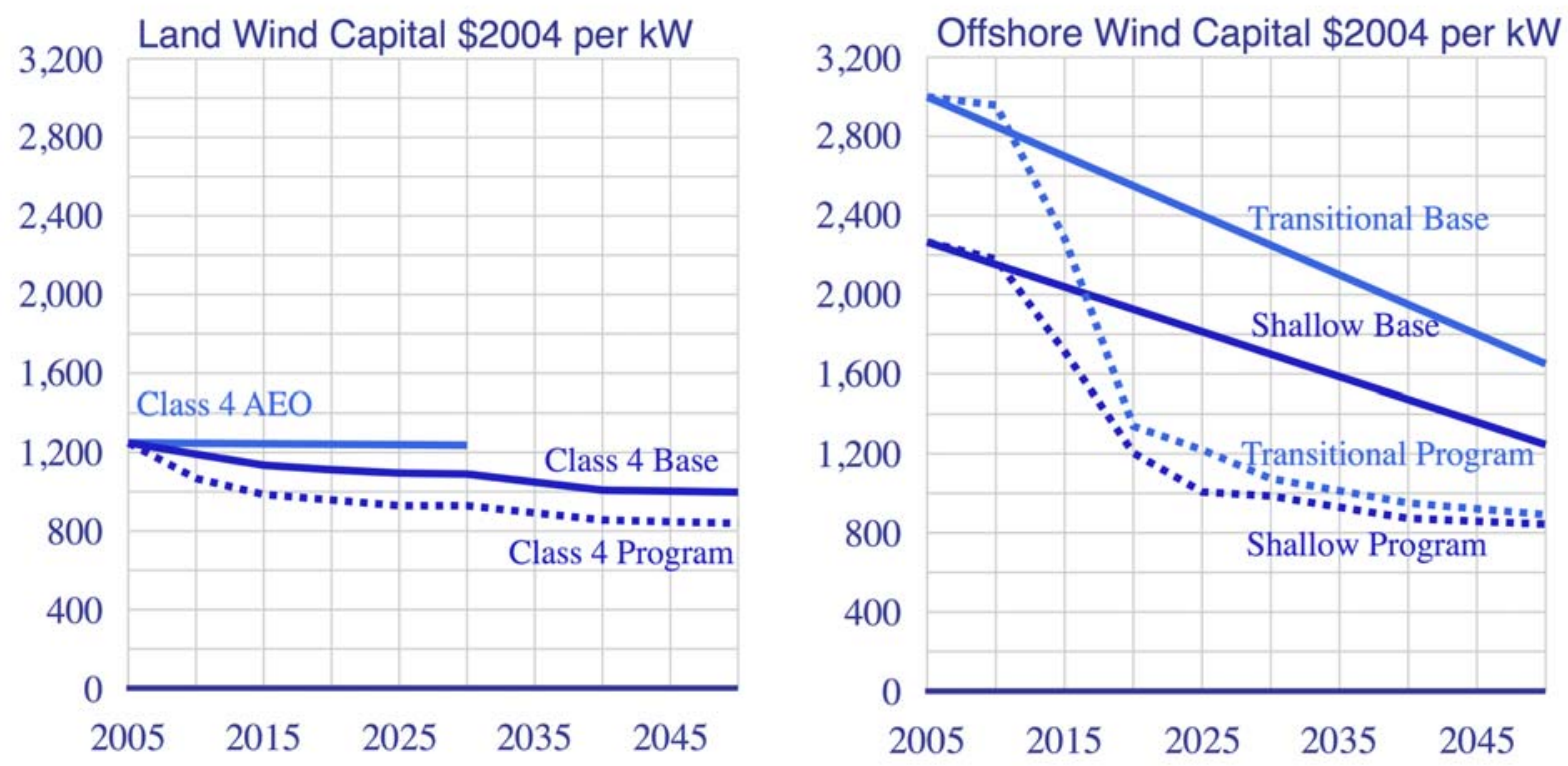

Figure 3.20. Comparison of Selected AEO2006 Reference, Baseline Case, and Program Case Assumptions

\section{Individual Program Case Results for the Wind Technologies Program}

The Wind Technologies Program seeks to reduce the cost—and improve the performance — of wind generation. The result is more cost-effective wind power and greater deployment. As shown in Figure 3.21, in the midterm, wind capacity in the Program Case is projected to be roughly twice that of the baseline as the result of the Wind Program's RD3 efforts. In 2030, land-based wind capacity increases from $50 \mathrm{GW}$ in the Baseline to $90 \mathrm{GW}$ in the Individual Program Goal Case, relative to the Baseline Case. Offshore wind shows little growth in the baseline without R\&D, and increases to more than $10 \mathrm{GW}$ in 2030 as its costs and performance improves. Incremental wind capacity associated with the Wind Program is $52 \mathrm{GW}$ in 2030. In the long term, land-based wind capacity levels off in 2035 at $127 \mathrm{GW}$ (2.5 times greater than the baseline). Offshore wind capacity reaches almost $120 \mathrm{GW}$ by 2050, bringing the total wind capacity in the Program Case to more than $240 \mathrm{GW}$-almost five times greater than the Baseline Case. Incremental wind capacity associated with the Wind Program is more than $190 \mathrm{GW}$ in 2050. 

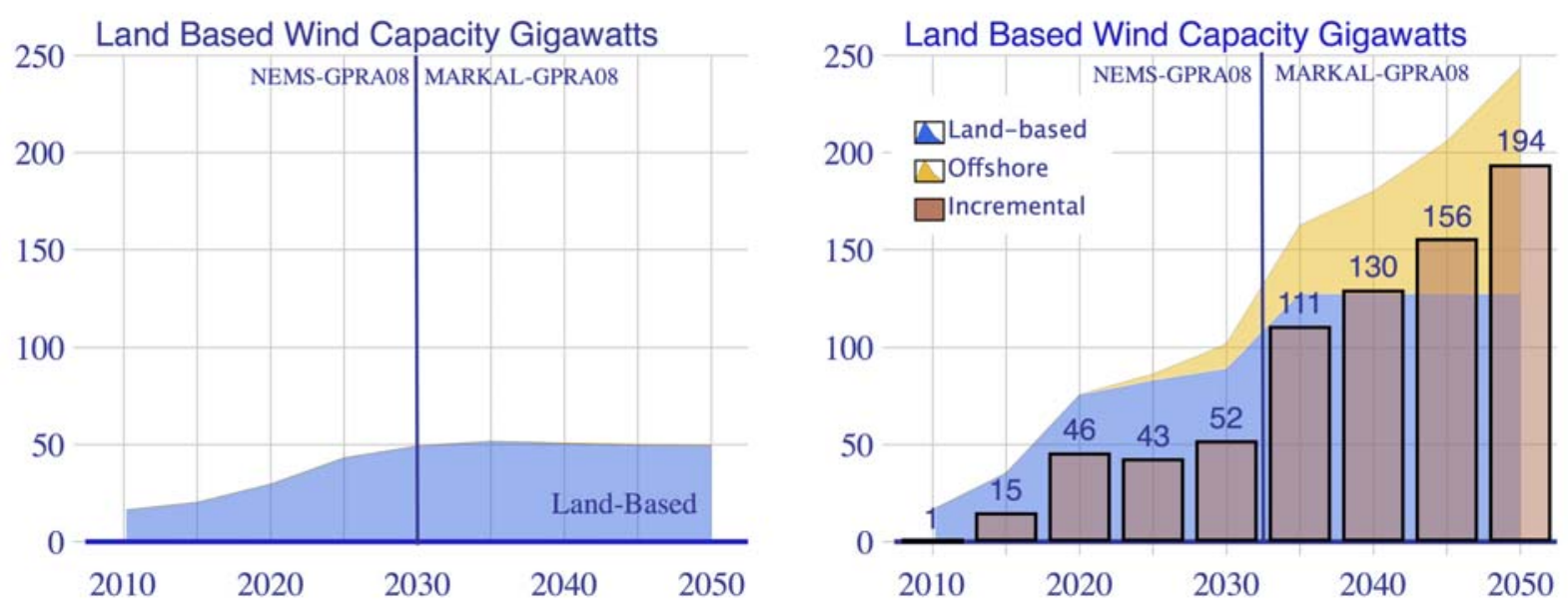

Figure 3.21. Projected Wind Capacity for the Base Case and the Wind Program Case

Table 3.15 provides estimates of the economic and environmental benefits stemming from wind energy displacing fossil-fueled generation sources. Because very little oil is used in power generation, the wind program has little impact on oil-based security benefit metrics. Lower-cost renewable generation options reduce the price of electricity directly and reduce the pressure on natural gas supply, both of which benefit end-use consumers by a cumulative total of $\$ 61$ billion by 2030 and $\$ 150$ billion by 2050 . Similarly, cumulative electricity system cost savings are \$31 billion in 2030 and \$107 billion in 2050. Energy system cost savings reach $\$ 6$ billion in 2050. Carbon emissions reductions total 36 MMTCE in 2030 or almost 460 MMTCE cumulatively from 2008 to 2030. By 2050, annual carbon emission reductions reach 140 MMTCE or almost 3 billion MTCE cumulatively from 2008 to 2050. 
Table 3.15. FY08 Benefits for the Wind Program

\begin{tabular}{|c|c|c|c|c|c|c|c|c|c|}
\hline & \multicolumn{5}{|c|}{ MIDTERM BENEFITS 7/ } & \multicolumn{4}{|c|}{ LONG-TERM BENEFITS 8/ } \\
\hline Metric & 2010 & 2015 & 2020 & 2025 & 2030 & 2035 & 2040 & 2045 & 2050 \\
\hline \multicolumn{10}{|l|}{ ECONOMIC BENEFITS ("AFFORDABLE") } \\
\hline Reduction in Average Delivered Natural Gas Price (Percent) & ns & ns & $2 \%$ & ns & ns & $2 \%$ & $2 \%$ & $1 \%$ & $0 \%$ \\
\hline Energy System Cost Savings (bil \$2004) 1/ & $\mathrm{nr}$ & $\mathrm{nr}$ & $\mathrm{nr}$ & $\mathrm{nr}$ & $\mathrm{nr}$ & 2 & 3 & 5 & 6 \\
\hline Consumer Savings, Annual (bil \$2004) & ns & 2 & 9 & 6 & 8 & 12 & 12 & 5 & -4 \\
\hline Consumer Savings, NPV (bil \$2004) 2/ & ns & 5 & 26 & 49 & 61 & 112 & 136 & 150 & 150 \\
\hline Electric Power Industry Savings, Annual (bil \$2004) 3/ & 0 & 1 & 4 & 2 & 3 & 11 & 9 & 5 & 3 \\
\hline Electric Power Industry Savings, NPV (bil \$2004) 2/ 3/ & 0 & 4 & 14 & 24 & 31 & 71 & 90 & 101 & 107 \\
\hline Reduction in Fraction of Household Income Spent on Energy & ns & ns & ns & ns & ns & $0 \%$ & $0 \%$ & $0 \%$ & $0 \%$ \\
\hline Reduced Energy Intensity of Economy (Percent) & $0 \%$ & $0 \%$ & $1 \%$ & $1 \%$ & $1 \%$ & $2 \%$ & $2 \%$ & $2 \%$ & $2 \%$ \\
\hline \multicolumn{10}{|l|}{ ENVIRONMENTAL BENEFITS ("CLEAN") } \\
\hline Avoided Greenhouse Gas Emissions, Annual (MMTCE/year) & 1 & 10 & 30 & 31 & 36 & 104 & 113 & 121 & 139 \\
\hline Avoided Greenhouse Gas Emissions, Cumulative (MMTCE) 5/ & 2 & 33 & 139 & 286 & 457 & 1083 & 1631 & 2218 & 2877 \\
\hline Reduced Cost of Criteria Pollutant Control, NPV (bil \$2004) 2/ & 0 & 1 & 2 & 4 & 5 & $\mathrm{nr}$ & $\mathrm{nr}$ & $\mathrm{nr}$ & $\mathrm{nr}$ \\
\hline \multicolumn{10}{|l|}{ SECURITY BENEFITS ("RELIABLE") } \\
\hline Avoided Oil Imports, Annual (mbpd) & ns & ns & ns & ns & ns & 0 & 0 & 0 & 0 \\
\hline Avoided Oil imports, Cumulative (bil barrels) 4/ 5/ & ns & ns & ns & ns & ns & 0 & 0 & 0 & 0 \\
\hline Security Fuel Economy Improvement (MPG) & ns & ns & ns & ns & ns & ns & ns & ns & ns \\
\hline Transportation Fuel Diversity Improvement (percent) 6/ & ns & ns & ns & ns & ns & ns & ns & ns & ns \\
\hline
\end{tabular}

Table notes:

1/ Energy system costs include the annualized capital costs for all capital stock (residual and new), as well as O\&M and fuel costs. Annualized capital costs are calculated using MARKAL hurdle rates, which include both a financial and behavioral component.

2/ NPV (net present value) calculations done using 3\% real discount rate back to 2008.

3/ Electric power industry cost does not include demand-side distributed generation.

4/ Renewable generation values at output value (3412 Btu/kWh), except for biomass where energy content is used.

5/ All cumulative values are from 2008.

6/ Diversity index change is Case minus Base (opposite of others).

7/ Midterm benefits based on NEMS-GPRA08 model.

8/ Long-term benefits based on MARKAL-GPRA08 model.

$\mathrm{nr}=$ not reported or calculated by model

ns $=$ not significant relative to model error 


\section{APPENDIX A - GPRA08 BENEFITS ESTIMATES: NEMS AND MARKAL MODEL BASELINE CASES}

\section{Table of contents}

The NEMS-GPRA08 Baseline Case Assumptions and Projections ................................... A-2

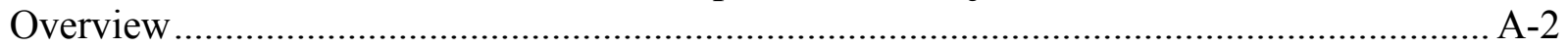

Changes in Assumptions for GPRA08 Baseline........................................................... A-2

GPRA08 Baseline Projections .......................................................................... A-5

The MARKAL-GPRA08 Baseline Assumptions and Projections .................................... A-15

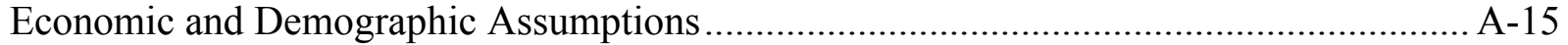

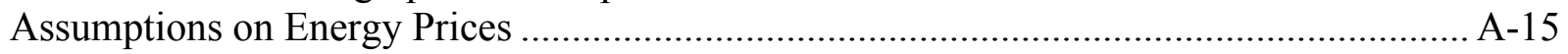

Primary Energy Consumption................................................................................ A-16

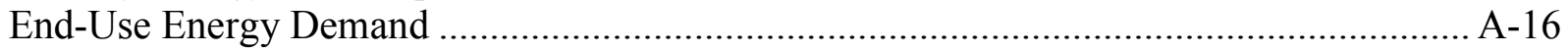

\section{List of tables}

Table 1. Summary of Baseline Changes from the AEO2006 …........................................... A-3

Table 2. Reference Case Macroeconomic and Demographic Assumptions ......................... A-15

Table 3. Reference Case Energy Prices ............................................................................. A-16

Table 4. Primary Energy Consumption, Energy Intensity and Carbon Emissions .................. A-16

\section{List of figures}

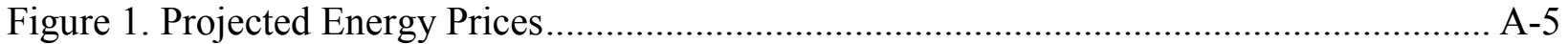

Figure 2. Projected Conventional Energy Demand and Energy Intensity .............................. A-6

Figure 3. Energy Consumption by Sector............................................................. A-17

Figure 4. Relative Energy Intensity by Sector ..................................................... A-17

Figure 5. Electricity Generation by Type .................................................................... A-19 


\section{The NEMS-GPRA08 Baseline Case Assumptions and Projections}

\section{Overview}

The Office of Energy Efficiency and Renewable Energy (EERE) programs use integrated energy models to analyze the benefits expected from successful implementation of individual programs and the EERE portfolio as a whole. The use of integrated models provides a consistent economic framework and incorporates the interactive effects among the various programs. Feedback and interactive effects result from (1) changes in energy prices resulting from lower energy consumption, (2) the interaction between supply programs affecting the mix of generation sources and the end-use sector programs affecting the demand for electricity, and (3) additional savings from reduced energy production and delivery.

A modified version of the National Energy Modeling System (NEMS) ${ }^{1}$ was one of the models used for this benefits analysis. NEMS is an integrated energy model of the U.S. energy system that was developed by the Energy Information Administration (EIA) for forecasting and policy analysis purposes. NEMS provides projection capability to the year 2030, so it is used for the midterm benefits analysis. The latest version of NEMS available at the time of the benefits analysis was used as the starting point. This is a slightly updated version from the Annual Energy Outlook 2006 ( $A E O 2006$ ) that was set up by EIA at the request of the DOE R\&D offices for use in GPRA scenarios. ${ }^{2}$ Several modifications were subsequently made to the model by EERE to enhance its ability to represent the EERE programs. The modified version of the model is referred to as NEMS-GPRA08.

\section{Changes in Assumptions for GPRA08 Baseline}

The first step in the benefits analysis process is to establish an appropriate Baseline Case. The EERE Baseline Case is a projection intended to represent the future U.S. energy system without the effect of EERE programs. This Baseline Case ensures that program benefits are estimated based on the same initial forecasts for economic growth, energy prices, and levels of energy demand. It also ensures that these initial assumptions are consistent with each other; e.g., that the level of electricity demand expected under the economic growth assumptions could be met at the electricity price assumed. It provides a basis for assessing how well renewable and efficiency technologies might be able to compete against future, rather than current, conventional energy technologies (e.g., more efficient central power generation). Finally, it helps ensure that underlying improvements in efficiency and renewable energy are not counted as part of the benefits of the EERE programs. This year, for GPRA08, a coordinated Baseline was constructed by all the Energy, Science, and Environment (ESE) offices that represent a projection without any of the DOE RD3 programs.

The most recent Annual Energy Outlook Reference Case is used as the starting point for developing the base case. ${ }^{3}$ The Energy Information Administration (EIA) Annual Energy

\footnotetext{
${ }^{1}$ The National Energy Modeling System: An Overview 2003, March 2003, DOE/EIA-0581(2003).

${ }^{2}$ The request for the slightly modified base case was made under an initiative to coordinate and integrate the GPRA analyses undertaken by the various offices within DOE's Office of Energy, Science, and Environment. Formally, the request was transmitted to EIA through the Office of Fossil Energy and the National Energy Technology Laboratory's NEMS modelers.

${ }^{3}$ The updated NEMS produces similar reference case projections as the Annual Energy Outlook 2006 with Projections to 2030, February 2006, DOE/EIA-0383 (2006). See http://www.eia.doe.gov/oiaf/archive/aeo06/pdf/0383(2006).pdf.
} 
Outlook (AEO) Reference Case provides an independent representation of the likely evolution of energy markets. This forecast reflects expected changes in the demand for energy (e.g., to reflect the availability of new appliances), technology improvements that might improve the efficiency of energy use, and changes in energy resource production costs, including renewable energy. Current energy market policies, such as state renewable portfolio standards (RPS) and tax policies, which facilitate the development and adoption of these technologies, are included in the Base Case. This approach ensures that EERE's benefits estimates do not include expected impacts of such policies. Neither the EIA Reference Case nor the EERE Base Case includes any changes in future energy policies.

Removal of EERE programs. Several adjustments are made to remove EERE programs from the EIA Reference Case. For example, the most efficient shell improvement packages for new residential buildings were removed, although the impact was minimal because they received small market share in the AEO. Cellulosic ethanol production was assumed to not become available until 2030 without EERE's R\&D efforts, although with improved characteristics compared to the AEO2006.

Table 1. Summary of Baseline Changes from the AEO2006

\begin{tabular}{|c|c|c|}
\hline & AEO2006 & GPRA08 Baseline Case \\
\hline \multicolumn{3}{|l|}{ Removal of EERE Programs } \\
\hline $\begin{array}{l}\text { Residential highest efficiency shell } \\
\text { packages }\end{array}$ & Small penetration & Removed \\
\hline Cellulosic ethanol production & Commercially available by 2015 & Not commercially available until 2030 \\
\hline \multicolumn{3}{|c|}{ Greater Technology Improvement in Base } \\
\hline Photovoltaic system costs & Some improvement & $\begin{array}{l}\text { Slightly more improvement for commercial } \\
\text { systems after } 2020\end{array}$ \\
\hline Solid-state lighting & Small improvement & Much greater improvement \\
\hline Onshore wind performance & $\begin{array}{l}35 \text { to } 44 \text { percent capacity factors } \\
\text { depending on wind class and year ( } 2010 \text { to } \\
\text { 2030) }\end{array}$ & $\begin{array}{l}40 \text { to } 49 \text { percent capacity factors } \\
\text { depending on wind class and year (2010 to } \\
2030 \text { ) }\end{array}$ \\
\hline Onshore wind capital costs & 0.3 percent reduction from 2010 to 2030 & $\begin{array}{l}6 \text { to } 8 \text { percent reduction (depending on } \\
\text { wind class) from } 2010 \text { to } 2030\end{array}$ \\
\hline Conventional corn ethanol production & $\begin{array}{l}\text { Constant costs (excluding fuel and } \\
\text { feedstocks) }\end{array}$ & $\begin{array}{l}\text { Improving costs over time, based on } 7 \text { - } \\
\text { year lag from program goals }\end{array}$ \\
\hline Cellulosic ethanol production & Constant costs (excluding feedstocks) & $\begin{array}{l}\text { Improving costs over time, based on 15- } \\
\text { year lag from program goals }\end{array}$ \\
\hline Hybrid-electric vehicles & Stock share at 6 percent by 2030 & Stock share at 11 percent by 2030 \\
\hline \multicolumn{3}{|l|}{ Energy Market Updates } \\
\hline PV system size & $\begin{array}{l}2 \text { to } 4 \mathrm{~kW} \text { residential, } 25 \text { to } 45 \mathrm{~kW} \\
\text { commercial }\end{array}$ & $\begin{array}{l}4 \mathrm{~kW} \text { residential, } 100 \text { to } 200 \mathrm{~kW} \\
\text { commercial }\end{array}$ \\
\hline PV maximum market share & $\begin{array}{l}30 \text { percent for both residential and } \\
\text { commercial }\end{array}$ & $\begin{array}{l}60 \text { percent for residential and } 55 \text { percent } \\
\text { for commercial }\end{array}$ \\
\hline California PV subsidy & Not included & Included for residential systems \\
\hline Biomass supply & & Updated supply curves \\
\hline Cellulosic maximum production & $\begin{array}{l}50 \text { to } 280 \text { million gallons per year growth } \\
\text { limit }\end{array}$ & $\begin{array}{l}200 \text { million gallons per year increasing to } \\
20 \% \text { to } 25 \% \text { of previous year }\end{array}$ \\
\hline \multicolumn{3}{|l|}{ Structural Changes } \\
\hline Offshore wind capacity & Not included & Included \\
\hline Commercial DG algorithms & & $\begin{array}{l}\text { Market share and stock accounting } \\
\text { modified; growth limit imposed for solar PV }\end{array}$ \\
\hline Plug-in hybrid vehicles & Not included & Included \\
\hline Light-duty vehicle attributes & & Ability to specify attributes over time \\
\hline
\end{tabular}


Greater Technology Improvement in Base. There are a few EERE technologies that are either not represented in the AEO2006, or their improvement is less than anticipated by the program in the absence of EERE programs. These technology assumptions were also modified for the GPRA08 Baseline.

- The improvement in distributed photovoltaic system costs was modified with slightly greater improvement in the commercial systems

- In commercial lighting, solid-state lighting characteristics were assumed to improve significantly more than the very minimal improvement in the AEO2006.

- Offshore wind technology characteristics were added, and the onshore wind characteristics were modified. The onshore capital costs were assumed to decline more rapidly over time. In addition, the capacity factors for each wind class were assumed to be higher than in the $A E O 2006$, although lower than the program goals. Both of these changes for onshore wind increase the projected market penetration of wind in the Baseline and shrink the benefits attributed to the EERE R\&D.

- The representation of hybrid-electric vehicles was modified by gradually increasing the consumer preference for hybrids, leading to greater adoption of hybrids in the base.

- Corn ethanol production costs, excluding fuel and feedstock costs, were assumed to start somewhat lower and improve over time based on a seven-year lag of the program goals. When commercialized in 2030, cellulosic ethanol production costs are lower than the AEO2006 costs.

Energy Market Updates. A few other modifications were made to reflect EERE program assumptions or updated information about energy markets. These changes affect both the Baseline and the Benefits Cases.

- The size of typical PV systems was increased to $4 \mathrm{~kW}$ in residential buildings, and 100 $\mathrm{kW}$ increasing to $200 \mathrm{~kW}$ in commercial buildings to reflect recent PV installation experience and trends.

- The maximum market for PV systems was increased from $30 \%$ to $55 \%$ in the commercial sector and to $60 \%$ for residential PVs.

- California PV credits were incorporated in the Pacific region.

- The biomass supply curves were updated based on data from researchers at the University of Tennessee (UT). The new curves have generally less biomass available at low cost, but significantly more total resources at higher-cost levels.

- Because the technology is very new, cellulosic production capacity is assumed to be able to expand only at a rate of 500 million gallons per year initially, and then by $25 \%$ per year through 2025 and $20 \%$ thereafter. This has no impact on the Baseline, but affects the Program goal case. 
Structural Changes. In a few cases, we made structural changes to improve the model's representation of markets important to EERE technologies.

- Offshore wind was added as another technology option with resources available in the coastal regions and the regions around the Great Lakes.

- Alterations to the distributed generation algorithm in the building modules were made to reflect market adoption data gathered by Lawrence Berkeley National Laboratory, ${ }^{4}$ to account for buildings that have already installed a DG technology in prior years, and to allow greater than an annual $0.5 \%$ adoption rate in existing buildings. In addition, a limit on the expansion rate of PV installations was imposed to reflect time needed to expand manufacturing capability.

- In the light-duty vehicle module, plug-in hybrid vehicles were added as an additional technology. Also, the input data file was modified to allow the direct modification of vehicle attributes.

A summary of these modifications is provided in Table 1. Greater detail can be found in the individual program appendices.

\section{GPRA08 Baseline Projections}

In the Baseline projections, oil prices are projected to fall after 2006 and then gradually increase again after 2015, as shown in Figure A-1. Natural gas prices follow a similar pattern. Electricity prices also drop from a near-term high then stay relatively constant. Coal prices, on the other hand, are projected to be relatively constant in real terms for the entire period.

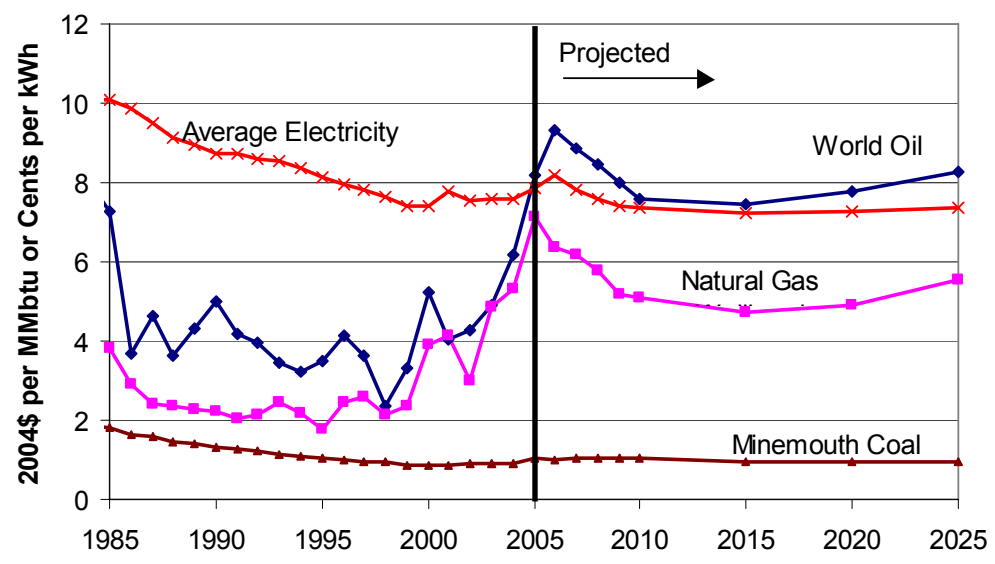

Figure A-1. Projected Energy Prices

The resulting Baseline Case projects a 22\% increase in conventional energy demand from 2010 to $2030 .^{5}$ Energy efficiency and renewable energy improvements, however, contribute toward a

\footnotetext{
${ }^{4}$ See modeling methodology section for more detail.

${ }^{5}$ Very similar to the $A E O 2006$. 
$31 \%$ reduction in conventional energy intensity (energy used per dollar of GDP produced) during the same period (Figure A-2). ${ }^{6}$ Between 2010 and 2025, renewable energy technology improvements result in increases in renewable electric generation in central and distributed applications of roughly 240 billion of $\mathrm{kWh}$, which is an almost $50 \%$ increase in nonhydroelectric generation.

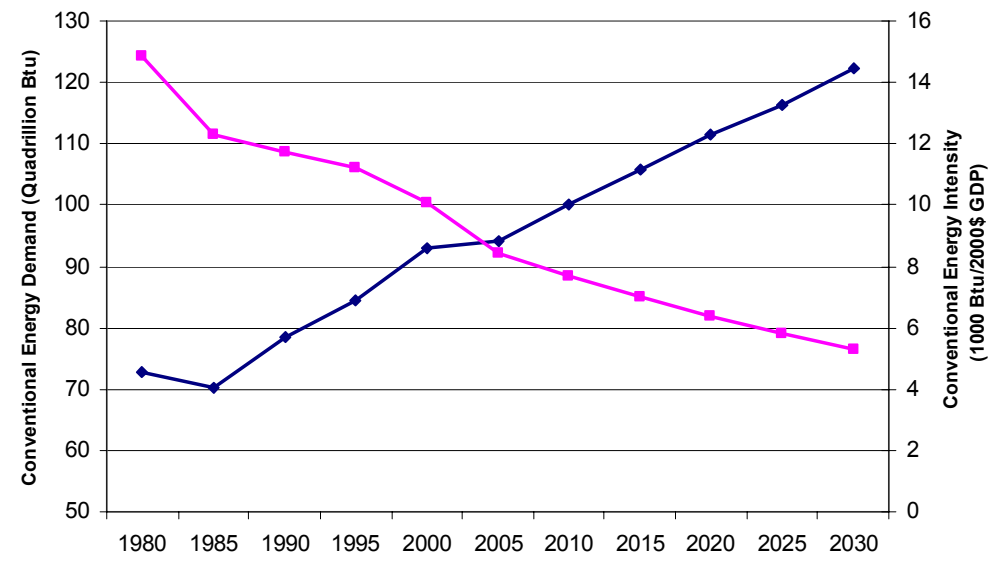

Figure A-2. Projected Conventional Energy Demand and Energy Intensity

The following tables (A-1 through A-6) are a few of the key output tables generated by NEMSGPRA08.

\footnotetext{
${ }^{6}$ Energy intensity changes result from a mix of structural changes in the economy (e.g., growing service sector) and efficiency improvements. Two recent EERE-sponsored studies provide additional background on understanding the sources of changes to our energy intensity: Ortiz and Sollinger, Shaping Our Future by Reducing Energy Intensity in the U.S. Economy; Volume 1:

Proceedings of the Conference (2003, Rand Corporation); and Bernstein, Fonkych, Loeb, and Loughran, "State-Level Changes in Energy Intensity and their National Implications" (2003, Rand Corporation).
} 
Table A-1. Total Energy Supply and Disposition Summary (Quadrillion Btu per Year, Unless Otherwise Noted)

\begin{tabular}{|c|c|c|c|c|c|}
\hline & 2010 & 2015 & 2020 & 2025 & 2030 \\
\hline \multicolumn{6}{|l|}{ Production } \\
\hline Crude Oil \& Lease Condensate & 12.69 & 12.24 & 11.79 & 10.64 & 9.81 \\
\hline Natural Gas Plant Liquids & 2.36 & 2.49 & 2.54 & 2.44 & 2.36 \\
\hline Dry Natural Gas & 18.90 & 20.27 & 20.87 & 20.11 & 19.52 \\
\hline Coal & 25.97 & 26.02 & 27.77 & 30.85 & 33.45 \\
\hline Nuclear Power & 8.44 & 8.66 & 9.09 & 9.09 & 9.09 \\
\hline Renewable Energy 1/ & 6.87 & 7.51 & 8.34 & 9.35 & 9.98 \\
\hline Other 2/ & 2.15 & 2.82 & 3.12 & 3.39 & 3.69 \\
\hline Total & 77.38 & 80.01 & 83.53 & 85.86 & 87.89 \\
\hline \multicolumn{6}{|l|}{ Imports } \\
\hline Crude Oil 3/ & 21.93 & 23.11 & 24.70 & 27.14 & 29.78 \\
\hline Petroleum Products 4/ & 6.30 & 7.42 & 8.08 & 8.64 & 9.29 \\
\hline Natural Gas & 5.18 & 6.09 & 6.14 & 6.72 & 7.94 \\
\hline Other Imports 5/ & 0.45 & 0.74 & 1.56 & 2.00 & 2.21 \\
\hline Total & 33.86 & 37.35 & 40.47 & 44.50 & 49.23 \\
\hline \multicolumn{6}{|l|}{ Exports } \\
\hline Petroleum 6/ & 2.15 & 2.18 & 2.24 & 2.27 & 2.33 \\
\hline Natural Gas & 0.55 & 0.57 & 0.66 & 0.83 & 0.94 \\
\hline Coal & 1.03 & 0.54 & 0.46 & 0.48 & 0.39 \\
\hline Total & 3.74 & 3.29 & 3.37 & 3.58 & 3.66 \\
\hline Discrepancy $7 /$ & -0.32 & -0.12 & -0.11 & -0.08 & 0.00 \\
\hline \multicolumn{6}{|l|}{ Consumption } \\
\hline Petroleum Products 8/ & 43.20 & 45.79 & 48.30 & 50.83 & 53.83 \\
\hline Natural Gas & 23.96 & 26.21 & 26.78 & 26.43 & 26.95 \\
\hline Coal & 25.28 & 25.94 & 28.19 & 31.11 & 33.57 \\
\hline Nuclear Power & 8.44 & 8.66 & 9.09 & 9.09 & 9.09 \\
\hline Renewable Energy 1/ & 6.87 & 7.51 & 8.34 & 9.35 & 9.98 \\
\hline Other $9 /$ & 0.08 & 0.08 & 0.05 & 0.05 & 0.05 \\
\hline Total & 107.82 & 114.19 & 120.74 & 126.85 & 133.46 \\
\hline Net Imports - Petroleum & 26.07 & 28.35 & 30.54 & 33.51 & 36.74 \\
\hline \multicolumn{6}{|l|}{ Prices (2004 dollars per unit) } \\
\hline World Oil Price (\$ per bbl) 10/ & 43.99 & 43.00 & 44.99 & 47.99 & 49.99 \\
\hline Gas Wellhead Price (\$ / Mcf) 11/ & 5.24 & 4.62 & 5.05 & 5.68 & 6.30 \\
\hline Coal Minemouth Price ( $\$$ / ton) & 22.13 & 20.37 & 20.07 & 20.50 & 21.20 \\
\hline Electricity (cents / Kwh) & 7.37 & 7.14 & 7.26 & 7.35 & 7.54 \\
\hline
\end{tabular}

1/ Includes grid-connected electricity from conventional hydroelectric; wood and wood waste; landfill gas; municipal solid waste; other biomass; wind; photovoltaic and solar thermal sources; non-electric energy from renewable sources, such as active and passive solar systems, and wood; and both the ethanol and gasoline components of E85, but not the ethanol components of blends less than 85 percent. Excludes electricity imports using renewable sources and nonmarketed renewable energy. See Table A18 for selected nonmarketed residential and commercial renewable energy.

2/ Includes liquid hydrogen, methanol, supplemental natural gas, and some domestic inputs to refineries.

$3 /$ Includes imports of crude oil for the Strategic Petroleum Reserve.

4/ Includes imports of finished petroleum products, unfinished oils, alcohols, ethers, and blending components.

$5 /$ Includes coal, coal coke (net), and electricity (net).

$6 /$ Includes crude oil and petroleum products.

7/ Balancing item. Includes unaccounted for supply, losses, gains, net storage withdrawals,

heat loss when natural gas is converted to liquid fuel, and heat loss when coal is converted to liquid fuel.

8/ Includes natural gas plant liquids, crude oil consumed as a fuel, and nonpetroleum-based liquids for blending, such as ethanol.

9/ Includes net electricity imports, methanol, and liquid hydrogen.

$10 /$ Average refiner acquisition cost for imported crude oil.

11/ Represents lower 48 onshore and offshore supplies. 
Table A-2. Energy Consumption by Sector and Source (Quadrillion Btu per Year, Unless Otherwise Noted)

\begin{tabular}{|c|c|c|c|c|c|}
\hline & 2010 & 2015 & 2020 & 2025 & 2030 \\
\hline \multicolumn{6}{|l|}{ Residential } \\
\hline Distillate Fuel & 0.83 & 0.78 & 0.72 & 0.65 & 0.59 \\
\hline Kerosene & 0.09 & 0.09 & 0.08 & 0.07 & 0.07 \\
\hline Liquefied Petroleum Gas & 0.56 & 0.58 & 0.61 & 0.63 & 0.64 \\
\hline Petroleum Subtotal & 1.48 & 1.45 & 1.41 & 1.35 & 1.30 \\
\hline Natural Gas & 5.33 & 5.52 & 5.67 & 5.73 & 5.79 \\
\hline Coal & 0.01 & 0.01 & 0.01 & 0.01 & 0.01 \\
\hline Renewable Energy 1/ & 0.44 & 0.43 & 0.43 & 0.42 & 0.41 \\
\hline Electricity & 4.98 & 5.38 & 5.76 & 6.07 & 6.43 \\
\hline Delivered Energy & 12.23 & 12.79 & 13.29 & 13.58 & 13.95 \\
\hline Electricity Related Losses & 10.74 & 11.30 & 11.96 & 12.40 & 12.81 \\
\hline Total & 22.98 & 24.09 & 25.25 & 25.98 & 26.76 \\
\hline \multicolumn{6}{|l|}{ Commercial } \\
\hline Distillate Fuel & 0.48 & 0.49 & 0.50 & 0.50 & 0.51 \\
\hline Residual Fuel & 0.12 & 0.12 & 0.12 & 0.12 & 0.12 \\
\hline Kerosene & 0.02 & 0.02 & 0.02 & 0.03 & 0.03 \\
\hline Liquefied Petroleum Gas & 0.10 & 0.10 & 0.10 & 0.10 & 0.10 \\
\hline Motor Gasoline 2/ & 0.05 & 0.05 & 0.05 & 0.05 & 0.05 \\
\hline Petroleum Subtotal & 0.77 & 0.78 & 0.79 & 0.80 & 0.81 \\
\hline Natural Gas & 3.17 & 3.45 & 3.67 & 3.86 & 4.08 \\
\hline Coal & 0.09 & 0.09 & 0.09 & 0.09 & 0.09 \\
\hline Renewable Energy 3/ & 0.09 & 0.09 & 0.09 & 0.09 & 0.09 \\
\hline Electricity & 4.88 & 5.42 & 5.91 & 6.45 & 7.00 \\
\hline Delivered Energy & 8.98 & 9.82 & 10.55 & 11.28 & 12.06 \\
\hline Electricity Related Losses & 10.51 & 11.39 & 12.28 & 13.18 & 13.95 \\
\hline Total & 19.49 & 21.22 & 22.83 & 24.46 & 26.01 \\
\hline \multicolumn{6}{|l|}{ Industrial 4/ } \\
\hline Distillate Fuel & 1.20 & 1.20 & 1.23 & 1.26 & 1.33 \\
\hline Liquefied Petroleum Gas & 2.21 & 2.27 & 2.35 & 2.44 & 2.51 \\
\hline Petrochemical Feedstocks & 1.48 & 1.49 & 1.51 & 1.52 & 1.55 \\
\hline Residual Fuel & 0.20 & 0.19 & 0.20 & 0.21 & 0.22 \\
\hline Motor Gasoline 2/ & 0.32 & 0.32 & 0.32 & 0.33 & 0.34 \\
\hline Other Petroleum 5/ & 4.62 & 4.85 & 5.07 & 5.37 & 5.73 \\
\hline Petroleum Subtotal & 10.04 & 10.32 & 10.68 & 11.13 & 11.68 \\
\hline Natural Gas & 8.03 & 8.27 & 8.43 & 8.63 & 8.89 \\
\hline Lease and Plant Fuel 6/ & 1.12 & 1.20 & 1.25 & 1.18 & 1.14 \\
\hline Natural Gas Subtotal & 9.15 & 9.47 & 9.68 & 9.82 & 10.03 \\
\hline Metallurgical Coal & 0.62 & 0.61 & 0.59 & 0.58 & 0.58 \\
\hline Other Industrial Coal & 1.43 & 1.43 & 1.43 & 1.44 & 1.45 \\
\hline Coal-to-Liquids Heat and Power & 0.00 & 0.17 & 0.62 & 1.22 & 1.68 \\
\hline Net Coal Coke Imports & 0.02 & 0.02 & 0.02 & 0.01 & 0.02 \\
\hline Coal Subtotal & 2.07 & 2.22 & 2.65 & 3.25 & 3.72 \\
\hline Renewable Energy 7/ & 1.79 & 1.90 & 2.01 & 2.14 & 2.29 \\
\hline Electricity & 3.61 & 3.75 & 3.91 & 4.08 & 4.30 \\
\hline Delivered Energy & 26.65 & 27.66 & 28.94 & 30.42 & 32.02 \\
\hline Electricity Related Losses & 7.78 & 7.89 & 8.12 & 8.34 & 8.58 \\
\hline Total & 34.43 & 35.55 & 37.05 & 38.76 & 40.60 \\
\hline
\end{tabular}

$1 /$ Includes wood used for residential heating.

2/ Includes ethanol (blends of 10 percent or less) and ethers blended into gasoline.

$3 /$ Includes commercial sector consumption of wood and wood waste, landfill gas, municipal solid waste, and other biomass for combined heat and power.

4/ Includes energy for combined heat and power plants, except those whose primary business is to sell electricity, or electricity and heat, to the public.

5/ Includes petroleum coke, asphalt, road oil, lubricants, still gas, and miscellaneous petroleum products.

$6 /$ Represents natural gas used in the field gathering and processing plant machinery.

7/ Includes consumption of energy from hydroelectric, wood and wood waste, municipal solid waste, and other biomass. 
Table A-3. Energy Prices by Sector and Source

(2004 Dollars per Million Btu, Unless Otherwise Noted)

\begin{tabular}{|c|c|c|c|c|c|}
\hline & 2010 & 2015 & 2020 & 2025 & 2030 \\
\hline Residential & 17.15 & 16.74 & 17.30 & 17.96 & 18.75 \\
\hline Primary Energy 1/ & 11.45 & 10.92 & 11.48 & 12.25 & 12.97 \\
\hline Petroleum Products 2/ & 14.75 & 14.79 & 16.06 & 17.34 & 18.57 \\
\hline Distillate Fuel & 12.78 & 12.78 & 13.59 & 14.26 & 14.56 \\
\hline Liquefied Petroleum Gas & 18.19 & 17.98 & 19.53 & 21.17 & 22.91 \\
\hline Natural Gas & 10.56 & 9.92 & 10.36 & 11.06 & 11.72 \\
\hline Electricity & 24.94 & 24.30 & 24.48 & 24.64 & 25.14 \\
\hline Commercial & 16.45 & 15.87 & 16.36 & 16.92 & 17.62 \\
\hline Primary Energy 1/ & 9.12 & 8.53 & 8.89 & 9.44 & 9.97 \\
\hline Petroleum Products 2/ & 10.54 & 10.66 & 11.26 & 11.86 & 12.29 \\
\hline Distillate Fuel & 10.11 & 10.40 & 10.92 & 11.44 & 11.74 \\
\hline Residual Fuel & 6.14 & 6.04 & 6.29 & 6.67 & 6.93 \\
\hline Natural Gas & 8.97 & 8.21 & 8.53 & 9.10 & 9.68 \\
\hline Electricity & 22.50 & 21.71 & 22.10 & 22.44 & 23.05 \\
\hline Industrial 3/ & 8.56 & 8.20 & 8.53 & 8.92 & 9.44 \\
\hline Primary Energy & 7.26 & 6.98 & 7.31 & 7.74 & 8.27 \\
\hline Petroleum Products 2/ & 9.45 & 9.46 & 10.00 & 10.67 & 11.46 \\
\hline Distillate Fuel & 10.71 & 11.40 & 11.86 & 12.48 & 12.89 \\
\hline Liquefied Petroleum Gas & 12.06 & 11.88 & 13.13 & 14.11 & 15.42 \\
\hline Residual Fuel & 6.32 & 6.31 & 6.62 & 7.01 & 7.39 \\
\hline Natural Gas 4/ & 5.87 & 5.25 & 5.63 & 6.22 & 6.83 \\
\hline Metallurgical Coal & 2.36 & 2.19 & 2.23 & 2.28 & 2.28 \\
\hline Steam Coal & 1.86 & 1.80 & 1.81 & 1.85 & 1.90 \\
\hline \multirow[t]{2}{*}{ Electricity } & 0.00 & 0.86 & 1.12 & 1.22 & 1.26 \\
\hline & 15.80 & 14.99 & 15.36 & 15.57 & 16.06 \\
\hline \multicolumn{6}{|l|}{ Transportation } \\
\hline Primary Energy & 14.83 & 14.83 & 15.38 & 15.89 & 16.28 \\
\hline Petroleum Products 2/ & 14.81 & 14.81 & 15.36 & 15.88 & 16.27 \\
\hline Distillate Fuel 5/ & 14.82 & 14.82 & 15.38 & 15.89 & 16.28 \\
\hline Jet Fuel 6/ & 14.27 & 14.54 & 14.82 & 15.30 & 15.62 \\
\hline Motor Gasoline 7/ & 9.62 & 9.89 & 10.49 & 10.93 & 11.50 \\
\hline Residual Fuel & 16.53 & 16.35 & 17.01 & 17.51 & 17.87 \\
\hline Liquefied Petroleum Gas 8/ & 6.40 & 6.32 & 6.55 & 7.05 & 7.66 \\
\hline Natural Gas 9/ & 16.72 & 16.47 & 16.97 & 18.34 & 19.43 \\
\hline Ethanol (E85) 10/ & 11.59 & 10.81 & 11.06 & 11.62 & 12.13 \\
\hline Electricity & 21.30 & 20.52 & 21.30 & 21.73 & 22.11 \\
\hline
\end{tabular}

1/ Weighted average price includes fuels below as well as coal.

2/ This quantity is the weighted average for all petroleum products, not just those listed below.

3 / Includes energy for combined heat and power plants, except those whose primary business is to sell electricity, or electricity and heat, to the public.

4/ Excludes use for lease and plant fuel.

5/ Diesel fuel containing 500 parts per million (ppm) or 15 ppm sulfur. Price includes Federal and

State taxes while excluding county and local taxes.

6/ Kerosene-type jet fuel. Price includes Federal and State taxes while excluding county and local taxes.

7/ Sales weighted-average price for all grades. Includes Federal, State, and local taxes.

8/ Includes Federal and State taxes while excluding county and local taxes.

9/ Compressed natural gas used as a vehicle fuel. Price includes estimated motor vehicle fuel taxes.

10/ E85 refers to a blend of 85 percent ethanol (renewable) and 15 percent motor gasoline (nonrenewable).

To address cold starting issues, the percentage of ethanol actually varies seasonally. The annual average

ethanol content of 74 percent is used for this forecast. 
Table A-4. Electricity Supply, Disposition, Prices, and Emissions (Billion Kilowatthours, Unless Otherwise Noted)

\begin{tabular}{|c|c|c|c|c|c|}
\hline \multicolumn{6}{|l|}{ Generation by Fuel Type } \\
\hline Electric Power Sector 1/ & & & & & \\
\hline Power Only 2/ & & & & & \\
\hline Coal & 2181 & 2235 & 2442 & 2721 & 2980 \\
\hline Petroleum & 92 & 92 & 90 & 99 & 104 \\
\hline Natural Gas 3/ & 528 & 703 & 707 & 636 & 652 \\
\hline Nuclear Power & 809 & 829 & 871 & 871 & 871 \\
\hline Pumped Storage/Other & -9 & -9 & -9 & -9 & -9 \\
\hline Renewable Sources 4/ & 414 & 452 & 500 & 568 & 604 \\
\hline Distributed Generation (Natural Gas) & 0 & 0 & 1 & 1 & 2 \\
\hline Total & 4015 & 4303 & 4601 & 4889 & 5203 \\
\hline \multicolumn{6}{|l|}{ Combined Heat and Power 5/ } \\
\hline Coal & 31 & 31 & 30 & 29 & 28 \\
\hline Petroleum & 2 & 2 & 2 & 2 & 2 \\
\hline Natural Gas & 140 & 155 & 149 & 131 & 124 \\
\hline Renewable Sources & 4 & 4 & 4 & 4 & 4 \\
\hline Other (remove for AEO tables) & 0 & 0 & 0 & 0 & 0 \\
\hline Total & 177 & 192 & 185 & 166 & 158 \\
\hline Total Net Generation & 4192 & 4495 & 4786 & 5054 & 5361 \\
\hline Less Direct Use & 28 & 28 & 28 & 28 & 28 \\
\hline Net Available to the Grid & 4164 & 4467 & 4758 & 5026 & 5333 \\
\hline \multicolumn{6}{|l|}{ Commercial and Industrial Generation 6/ } \\
\hline Coal & 23 & 39 & 81 & 138 & 182 \\
\hline Petroleum & 12 & 13 & 14 & 13 & 13 \\
\hline Natural Gas & 101 & 115 & 132 & 146 & 158 \\
\hline Other Gaseous Fuels 7/ & 4 & 5 & 5 & 5 & 5 \\
\hline Renewable Sources 4/ & 40 & 43 & 46 & 54 & 90 \\
\hline Other $8 /$ & 12 & 12 & 12 & 12 & 12 \\
\hline Total & 192 & 226 & 289 & 368 & 460 \\
\hline Less Direct Use & 149 & 164 & 190 & 226 & 278 \\
\hline Total Sales to the Grid & 43 & 62 & 100 & 143 & 183 \\
\hline Total Electricity Generation & 4385 & 4721 & 5076 & 5423 & 5821 \\
\hline Total Net Generation to the Grid & 4207 & 4529 & 4858 & 5169 & 5516 \\
\hline
\end{tabular}

$1 /$ Includes electricity-only and combined heat and power (CHP) plants whose primary business is to sell electricity, or electricity and heat, to the public.

2/ Includes plants that only produce electricity.

$3 /$ Includes electricity generation from fuel cells.

4/ Includes conventional hydroelectric, geothermal, wood, wood waste, municipal solid waste, landfill gas, other biomass, solar, and wind power.

$5 /$ Includes combined heat and power plants whose primary business is to sell electricity and heat to the public (i.e., those that report NAICS code 22).

6/ Includes combined heat and power plants and electricity-only plants in the commercial and industrial sectors; and small on-site generating systems in the residential, commercial, and industrial sectors used primarily for own-use generation, but which may also sell some power to the grid.

7/ Other gaseous fuels include refinery and still gas.

8/ Other includes batteries, chemicals, hydrogen, pitch, purchased steam, sulfur, and miscellaneous technologies. 
Table A-4. Electricity Supply, Disposition, Prices, and Emissions (Billion Kilowatthours, Unless Otherwise Noted)

\begin{tabular}{|c|c|c|c|c|c|}
\hline \multicolumn{6}{|l|}{ Generation by Fuel Type } \\
\hline \multicolumn{6}{|l|}{ Electric Power Sector 1/ } \\
\hline \multicolumn{6}{|l|}{ Power Only $2 /$} \\
\hline Coal & 2181 & 2235 & 2442 & 2721 & 2980 \\
\hline Petroleum & 92 & 92 & 90 & 99 & 104 \\
\hline Natural Gas 3/ & 528 & 703 & 707 & 636 & 652 \\
\hline Nuclear Power & 809 & 829 & 871 & 871 & 871 \\
\hline Pumped Storage/Other & -9 & -9 & -9 & -9 & -9 \\
\hline Renewable Sources 4/ & 414 & 452 & 500 & 568 & 604 \\
\hline Distributed Generation (Natural Gas) & 0 & 0 & 1 & 1 & 2 \\
\hline Total & 4015 & 4303 & 4601 & 4889 & 5203 \\
\hline \multicolumn{6}{|l|}{ Combined Heat and Power 5/ } \\
\hline Coal & 31 & 31 & 30 & 29 & 28 \\
\hline Petroleum & 2 & 2 & 2 & 2 & 2 \\
\hline Natural Gas & 140 & 155 & 149 & 131 & 124 \\
\hline Renewable Sources & 4 & 4 & 4 & 4 & 4 \\
\hline Other (remove for AEO tables) & 0 & 0 & 0 & 0 & 0 \\
\hline Total & 177 & 192 & 185 & 166 & 158 \\
\hline Total Net Generation & 4192 & 4495 & 4786 & 5054 & 5361 \\
\hline Less Direct Use & 28 & 28 & 28 & 28 & 28 \\
\hline Net Available to the Grid & 4164 & 4467 & 4758 & 5026 & 5333 \\
\hline \multicolumn{6}{|l|}{ Commercial and Industrial Generation 6/ } \\
\hline Coal & 23 & 39 & 81 & 138 & 182 \\
\hline Petroleum & 12 & 13 & 14 & 13 & 13 \\
\hline Natural Gas & 101 & 115 & 132 & 146 & 158 \\
\hline Other Gaseous Fuels 7/ & 4 & 5 & 5 & 5 & 5 \\
\hline Renewable Sources 4/ & 40 & 43 & 46 & 54 & 90 \\
\hline Other $8 /$ & 12 & 12 & 12 & 12 & 12 \\
\hline Total & 192 & 226 & 289 & 368 & 460 \\
\hline Less Direct Use & 149 & 164 & 190 & 226 & 278 \\
\hline Total Sales to the Grid & 43 & 62 & 100 & 143 & 183 \\
\hline Total Electricity Generation & 4385 & 4721 & 5076 & 5423 & 5821 \\
\hline Total Net Generation to the Grid & 4207 & 4529 & 4858 & 5169 & 5516 \\
\hline
\end{tabular}

$1 /$ Includes electricity-only and combined heat and power (CHP) plants whose primary business is to sell electricity, or electricity and heat, to the public.

2/ Includes plants that only produce electricity.

$3 /$ Includes electricity generation from fuel cells.

4/ Includes conventional hydroelectric, geothermal, wood, wood waste, municipal solid waste, landfill gas, other biomass, solar, and wind power.

$5 /$ Includes combined heat and power plants whose primary business is to sell electricity and heat to the public (i.e., those that report NAICS code 22).

6/ Includes combined heat and power plants and electricity-only plants in the commercial and industrial sectors; and small on-site generating systems in the residential, commercial, and industrial sectors used primarily for own-use generation, but which may also sell some power to the grid.

7/ Other gaseous fuels include refinery and still gas.

8/ Other includes batteries, chemicals, hydrogen, pitch, purchased steam, sulfur, and miscellaneous technologies. 
Table A-5. Electricity Generating Capacity (Gigawatts)

\begin{tabular}{|c|c|c|c|c|c|}
\hline & 2010 & 2015 & 2020 & 2025 & 2030 \\
\hline \multicolumn{6}{|l|}{ Electric Power Sector 2/ } \\
\hline Coal Steam & 313.3 & 310.3 & 316.2 & 3324 & 355.3 \\
\hline Other Fossil Steam 4/ & 121.8 & 74.5 & 62.6 & 53.2 & 43.5 \\
\hline Combined Cycle & 151.5 & 153.8 & 162.3 & 168.0 & 175.9 \\
\hline Combustion Turbine/Diesel & 136.2 & 130.0 & 129.6 & 128.6 & 132.0 \\
\hline Nuclear Power 5/ & 100.9 & 101.0 & 108.0 & 108.0 & 108.0 \\
\hline Pumped Storage & 20.8 & 20.8 & 20.8 & 20.8 & 20.8 \\
\hline Fuel Cells & 0.0 & 0.0 & 0.0 & 0.0 & 0.0 \\
\hline Renewable Sources 6/ & 102.7 & 113.3 & 144.8 & 167.3 & 186.1 \\
\hline Distributed Generation (Natural Gas) 7/ & 0.2 & 0.3 & 0.5 & 0.6 & 1.1 \\
\hline Total & 947.4 & 904.2 & 944.6 & 979.0 & 1022.9 \\
\hline Combined Heat and Power 8/ & 0.0 & 0.0 & 0.0 & 0.0 & 0.0 \\
\hline Coal Steam & 4.9 & 4.3 & 4.3 & 4.3 & 4.3 \\
\hline Other Fossil Steam 4/ & 0.5 & 0.5 & 0.5 & 0.5 & 0.5 \\
\hline Combined Cycle & 32.3 & 32.3 & 32.3 & 32.3 & 32.3 \\
\hline Combustion Turbine/Diesel & 2.9 & 2.9 & 2.9 & 2.9 & 2.9 \\
\hline Renewable Sources 6/ & 0.4 & 0.4 & 0.4 & 0.4 & 0.4 \\
\hline Total & 41.0 & 40.5 & 40.5 & 40.5 & 40.5 \\
\hline \multicolumn{6}{|l|}{ Cumulative Planned Additions 9/ } \\
\hline Coal Steam & 8.3 & 9.3 & 9.3 & 9.3 & 9.3 \\
\hline Other Fossil Steam 4/ & 0.1 & 0.1 & 0.1 & 0.1 & 0.1 \\
\hline Combined Cycle & 25.7 & 25.7 & 25.7 & 25.7 & 25.7 \\
\hline Combustion Turbine/Diesel & 5.3 & 5.3 & 5.3 & 5.3 & 5.3 \\
\hline Nuclear Power & 0.0 & 0.0 & 0.0 & 0.0 & 0.0 \\
\hline Pumped Storage & 0.0 & 0.0 & 0.0 & 0.0 & 0.0 \\
\hline Fuel Cells & 0.0 & 0.0 & 0.0 & 0.0 & 0.0 \\
\hline Renewable Sources 6/ & 10.3 & 11.6 & 11.9 & 12.1 & 12.2 \\
\hline Distributed Generation 7/ & 0.0 & 0.0 & 0.0 & 0.0 & 0.0 \\
\hline Total & 49.8 & 52.0 & 52.3 & 52.5 & 52.6 \\
\hline \multicolumn{6}{|l|}{ Cumulative Unplanned Additions 9/ } \\
\hline Coal Steam & 3.0 & 3.0 & 8.9 & 25.1 & 48.0 \\
\hline Other Fossil Steam 4/ & 0.0 & 0.0 & 0.0 & 0.0 & 0.0 \\
\hline Combined Cycle & 0.0 & 2.4 & 10.8 & 16.5 & 24.4 \\
\hline Combustion Turbine/Diesel & 4.8 & 8.6 & 10.4 & 10.5 & 13.9 \\
\hline Nuclear Power & 0.0 & 0.0 & 6.0 & 6.0 & 6.0 \\
\hline Pumped Storage & 0.0 & 0.0 & 0.0 & 0.0 & 0.1 \\
\hline Fuel Cells & 0.0 & 0.0 & 0.0 & 0.0 & 0.0 \\
\hline Renewable Sources 6/ & 0.4 & 9.9 & 41.0 & 63.4 & 82.1 \\
\hline Distributed Generation 7/ & 0.2 & 0.3 & 0.5 & 0.6 & 1.1 \\
\hline Total & 8.4 & 24.2 & 77.6 & 122.2 & 175.7 \\
\hline Cumulative Electric Power Sector Additions & 58.2 & 76.2 & 129.9 & 174.6 & 228.3 \\
\hline
\end{tabular}


Table A-5. Electricity Generating Capacity (Continued)

Cumulative Retirements 10/

Coal Steam

$\begin{array}{rr}3.0 & 5.9 \\ 2.0 & 43.9 \\ 0.6 & 0 . \\ 1.4 & 8.3 \\ 0.0 & 0.0 \\ 0.0 & 0.0 \\ 0.0 & 0.0 \\ 0.1 & 0.1 \\ 7.1 & 58.8\end{array}$

Total Electric Power Sector Capacity

988.4

965.5

5.9
50.6

0.6

Combined Cycle

Combustion Turbine/Diesel

Nuclear Power

Pumped Storage

Fuel Cells

Renewable Sources 6/

Total

Commercial and Industrial Generators 11/
Coal
Petroleum
Natural Gas
Other Gaseous Fuels
Renewable Sources 6/
Other
Total

Cumulative Capacity Additions 9/

\section{9}

0.6

8.3

0.0

0.0
0.1

58.8

$1 /$ Net summer capacity is the steady hourly output that generating equipment is expected to supply to system load (exclusive of auxiliary power), as demonstrated by tests during summer peak demand.

$2 /$ Includes electricity-only and combined heat and power (CHP) plants whose primary business is to sell electricity, or electricity and heat, to the public.

$3 /$ Includes plants that only produce electricity. Includes capacity increases (uprates) at existing units.

4/ Includes oil-, gas-, and dual-fired capacity.

5/ Nuclear capacity reflects operating capacity of existing units, including 3.9 gigawatts of uprates through 2025.

6/ Includes conventional hydroelectric, geothermal, wood, wood waste, municipal solid waste, landfill gas, other biomass, solar and wind power. Facilities co-firing biomass and coal are classified as coal.

7/ Primarily peak-load capacity fueled by natural gas.

$8 /$ Includes combined heat and power plants whose primary business is to sell electricity and heat to the public (i.e., those that report NAICS code 22).

9/ Cumulative additions after December 31, 2004.

10/ Cumulative retirements after December 31, 2004.

11 / Includes combined heat and power plants and electricity-only plants in the commercial and industrial sectors; and small on-site generating systems in the residential, commercial, and industrial sectors used primarily for own-use generation, but which may also sell some power to the grid. 
Table A-6. Carbon Dioxide Emissions by Sector and Source

(Million Metric Tons Carbon Equivalent, Unless Otherwise Noted)

\begin{tabular}{|c|c|c|c|c|c|}
\hline & 2010 & 2015 & 2020 & 2025 & 2030 \\
\hline \multicolumn{6}{|l|}{ Residential } \\
\hline Petroleum & 28 & 27 & 26 & 25 & 24 \\
\hline Natural Gas & 77 & 80 & 82 & 82 & 83 \\
\hline Coal & 0 & 0 & 0 & 0 & 0 \\
\hline Electricity & 256 & 267 & 284 & 299 & 316 \\
\hline Total & 360 & 374 & 392 & 407 & 423 \\
\hline \multicolumn{6}{|l|}{ Commercial } \\
\hline Petroleum & 15 & 15 & 16 & 16 & 16 \\
\hline Natural Gas & 46 & 50 & 53 & 56 & 59 \\
\hline Coal & 2 & 2 & 2 & 2 & 2 \\
\hline Electricity & 250 & 270 & 291 & 318 & 344 \\
\hline Total & 313 & 337 & 362 & 392 & 420 \\
\hline \multicolumn{6}{|l|}{ Industrial 1/ } \\
\hline Petroleum & 121 & 125 & 130 & 136 & 143 \\
\hline Natural Gas 2/ & 130 & 134 & 137 & 139 & 142 \\
\hline Coal & 53 & 56 & 68 & 83 & 95 \\
\hline Electricity & 185 & 187 & 193 & 201 & 211 \\
\hline Total & 488 & 503 & 528 & 560 & 592 \\
\hline \multicolumn{6}{|l|}{ Transportation } \\
\hline Petroleum 3/ & 564 & 605 & 646 & 684 & 729 \\
\hline Natural Gas 4/ & 10 & 11 & 12 & 12 & 12 \\
\hline Electricity & 5 & 5 & 5 & 5 & 5 \\
\hline Total & 579 & 621 & 663 & 701 & 747 \\
\hline \multicolumn{6}{|c|}{ Electric Power Sector 5/ } \\
\hline Petroleum & 21 & 21 & 20 & 22 & 24 \\
\hline Natural Gas & 81 & 100 & 99 & 89 & 89 \\
\hline Coal & 591 & 604 & 650 & 709 & 759 \\
\hline Other 6/ & 4 & 4 & 4 & 4 & 4 \\
\hline Total & 696 & 729 & 773 & 824 & 876 \\
\hline \multicolumn{6}{|c|}{ Total by Primary Fuel 7/ } \\
\hline Petroleum 3/ & 749 & 793 & 838 & 883 & 936 \\
\hline Natural Gas & 343 & 375 & 383 & 378 & 386 \\
\hline Coal & 646 & 663 & 720 & 794 & 857 \\
\hline Other 6/ & 4 & 4 & 4 & 4 & 4 \\
\hline Total & 1741 & 1835 & 1945 & 2060 & 2183 \\
\hline
\end{tabular}

1/ Fuel consumption includes energy for combined heat and power plants, except those plants whose primary business is to sell electricity, or electricity and heat, to the public.

2/ Includes lease and plant fuel.

3/ This includes international bunker fuel, which by convention are excluded from the international accounting of carbon dioxide emissions. In the years from 1990 through 2002, international bunker fuels accounted for 82 to 100 million metric tons carbon dioxide equivalent of carbon dioxide annually.

4 / Includes pipeline fuel natural gas and compressed natural gas used as vehicle fuel.

$5 /$ Includes electricity-only and combined heat and power (CHP) plants whose primary business is to sell electricity, or electricity and heat, to the public.

6/ Includes emissions from geothermal power and nonbiogenic emissions from municipal solid waste.

7/ Emissions from the electric power sector are distributed to the primary fuels. 


\section{The MARKAL-GPRA08 Baseline Assumptions and Projections}

\section{Economic and Demographic Assumptions}

The Baseline Case used to evaluate the impact of the EERE portfolio was benchmarked to EIA's Annual Energy Outlook 2006 (AEO2006) for the period between 2006 and 2030. To the extent possible, the same input data and assumptions were used in MARKAL-GPRA08 as were used to generate the AEO2006 Reference Case. For example, the macroeconomic projections for gross domestic product (GDP), housing stock, commercial square footage, industrial output, and vehicle miles traveled were taken from the AEO2006. At the sector level, both supply-side and demand-side technologies were characterized to reflect the AEO2006 assumptions where the representation of technologies is similar between MARKAL (MARKet ALlocation) and the National Energy Modeling System (NEMS).

The resulting projections track closely with the $A E O 2006$ at the aggregate level, although they do not match exactly at the end-use level. For the period after 2030, various sources were used to compile a set of economic and technical assumptions. For instance, the primary economic drivers of GDP and population were based on the real GDP growth rate from the Congressional Budget Office's Long-Term Budget Outlook and population growth rates from the Social Security Administration's 2005 Annual Report to the Board of Trustees low-cost assumptions. ${ }^{7}$

In the reference case, GDP is projected to increase at an average annual rate of $3 \%$ from 2005 to 2025 , and then slow to an average annual rate of $2.4 \%$ from 2025 to 2050 . The population growth rate is projected to decline from an average annual rate of $0.8 \%$ between 2005 and 2025 to $0.5 \%$ from 2025 to 2050 . The Reference Case macroeconomic assumptions are shown in Table 2.

Table 2. Reference Case Macroeconomic and Demographic Assumptions

\begin{tabular}{|c|c|c|c|c|c|c|c|c|c|c|c|c|c|}
\hline & & & & & & & & & & & \multicolumn{3}{|c|}{ Annual Growth Rates } \\
\hline & 2005 & 2010 & 2015 & 2020 & 2025 & 2030 & 2035 & 2040 & 2045 & 2050 & '05-'25 & $25-' 50$ & '05-'50 \\
\hline GDP (Bill. 2001\$) & $\$ 11,414$ & $\$ 13,356$ & $\$ 15,444$ & $\$ 17,962$ & $\$ 20,606$ & $\$ 23,666$ & $\$ 26,907$ & $\$ 30,295$ & $\$ 33,777$ & $\$ 37,220$ & $3.0 \%$ & $2.4 \%$ & $2.7 \%$ \\
\hline Population (Million) & 296.8 & 310.1 & 323.5 & 337.0 & 350.6 & 364.8 & 375.6 & 384.1 & 390.0 & 395.4 & $0.8 \%$ & $0.5 \%$ & $0.6 \%$ \\
\hline Total Households (Million) & 115.4 & 122.9 & 130.1 & 137.2 & 143.5 & 149.8 & 150.2 & 153.6 & 156.0 & 158.2 & $1.1 \%$ & $0.4 \%$ & $0.7 \%$ \\
\hline Commercial Floorspace (Bill. sq ft) & 76.2 & 82.3 & 88.9 & 96.0 & 103.7 & 112.0 & 119.7 & 127.3 & 134.7 & 141.6 & $1.6 \%$ & $1.3 \%$ & $1.4 \%$ \\
\hline Industrial Production $(2000=100)$ & 101 & 111 & 123 & 136 & 150 & 167 & 188 & 210 & 232 & 254 & $2.0 \%$ & $2.1 \%$ & $2.1 \%$ \\
\hline $\begin{array}{l}\text { Light Duty Vehicle Miles Traveled } \\
\text { (Bill. VMT) }\end{array}$ & 2,619 & 2,890 & 3,171 & 3,474 & 3,791 & 4,132 & 4,418 & 4,653 & 4,820 & 4,978 & $1.9 \%$ & $1.1 \%$ & $1.4 \%$ \\
\hline
\end{tabular}

\section{Assumptions on Energy Prices}

Table 2 shows projected energy prices for the reference case. Real natural gas prices are projected to drop between 2005 and 2015, and then increase at nearly $1.8 \%$ per year from 2015 to 2025 before increasing amounts of arctic gas and LNG imports limit the average annual increase to $0.8 \%$ from 2025 to 2050 . Real crude oil prices are also projected to drop between 2005 and 2015, and increase at average annual rates of $1.4 \%$ between 2010 and 2025, and 1.0\% per year thereafter.

Average real mine mouth coal prices are projected to continue to decline by about $0.3 \%$ a year between 2005 and 2020, due to increasing productivity gains and a continued shift to less labor-

\footnotetext{
7 "The Long-Term Budget Outlook," Congressional Budget Office, December 2003. The 2005 Annual Report of the Board of Trustees of the Federal Old Age and Survivors Insurance and the Federal Disability Insurance Trust Funds, March 2005.
} 
intensive Western coal production. However, coal prices are projected to increase at an average rate of $1.2 \%$ per year after 2020 , due to increased demands, gradually increasing mine depths, and a saturation of labor productivity gains.

Table 3. Reference Case Energy Prices

\begin{tabular}{|c|c|c|c|c|c|c|c|c|c|c|c|c|c|}
\hline \multirow[b]{2}{*}{2001 \$s } & \multirow[b]{2}{*}{2005} & \multirow[b]{2}{*}{2010} & \multirow[b]{2}{*}{2015} & \multirow[b]{2}{*}{2020} & \multirow[b]{2}{*}{2025} & \multirow[b]{2}{*}{2030} & \multirow[b]{2}{*}{2035} & \multirow[b]{2}{*}{2040} & \multirow[b]{2}{*}{2045} & \multirow[b]{2}{*}{2050} & \multicolumn{3}{|c|}{ Annual Growth Rates } \\
\hline & & & & & & & & & & & '05-25 & $25-50$ & '05-'50 - l \\
\hline World Oil Price (\$/bbl) & $\$ 47.10$ & $\$ 41.19$ & $\$ 39.68$ & $\$ 42.57$ & $\$ 45.52$ & $\$ 48.60$ & $\$ 50.62$ & $\$ 52.63$ & $\$ 54.08$ & $\$ 55.58$ & $-0.2 \%$ & $0.8 \%$ & $0.4 \%$ \\
\hline $\begin{array}{l}\text { Natural Gas Wellhead Price } \\
\text { (\$/Mcf) }\end{array}$ & $\$ 7.67$ & $\$ 4.76$ & $\$ 4.01$ & $\$ 4.35$ & $\$ 4.78$ & $\$ 5.42$ & $\$ 5.76$ & $\$ 5.75$ & $\$ 6.49$ & $\$ 6.41$ & $-2.3 \%$ & $1.2 \%$ & $-0.4 \%$ \\
\hline
\end{tabular}

\section{Primary Energy Consumption}

As a result of slightly increasing energy prices relative to technology improvements and shifts within the economy, energy demand is projected to increase more slowly than GDP. As shown in Table 4, total primary energy use is projected to increase at a rate of $1.0 \%$ per year from 2005 to 2025, and at an average annual rate of $0.5 \%$ between 2025 and 2050. By 2050, total primary energy consumption is projected to reach approximately 138 quadrillion Btus (quads). Overall, the energy consumption to GDP ratio is projected to decline by $1.9 \%$ per year from 2005 to 2050 , while total carbon emissions increase by $0.8 \%$ per year during the same period.

Table 4. Primary Energy Consumption, Energy Intensity, and Carbon Emissions

\begin{tabular}{|c|c|c|c|c|c|c|c|c|c|c|c|c|c|c|}
\hline & & & & & & & & & & & \multicolumn{4}{|c|}{ Annual Growth Rates } \\
\hline & 2000 & 2005 & 2010 & 2015 & 2020 & 2025 & 2030 & 2035 & 2040 & 2045 & 2050 & '05-'25 & $25-' 50$ & '05-'50 \\
\hline Petroleum & 39.8 & 40.4 & 42.8 & 44.3 & 45.5 & 46.8 & 48.8 & 49.7 & 50.4 & 49.0 & 46.5 & $0.7 \%$ & $0.0 \%$ & $0.3 \%$ \\
\hline Natural Gas & 22.0 & 23.4 & 25.9 & 28.1 & 29.1 & 29.3 & 29.6 & 30.1 & 31.0 & 31.8 & 32.5 & $1.1 \%$ & $0.4 \%$ & $0.7 \%$ \\
\hline Coal & 22.4 & 22.3 & 23.0 & 24.6 & 27.0 & 30.4 & 33.2 & 34.9 & 36.0 & 38.4 & 40.5 & $1.6 \%$ & $1.2 \%$ & $1.3 \%$ \\
\hline Nuclear & 8.1 & 8.4 & 8.4 & 8.7 & 9.1 & 9.1 & 9.1 & 7.1 & 5.9 & 3.6 & 1.5 & $0.4 \%$ & $-7.1 \%$ & $-3.8 \%$ \\
\hline Renewables & 6.5 & 4.6 & 5.1 & 5.9 & 6.2 & 6.2 & 6.8 & 7.9 & 9.1 & 11.7 & 16.6 & $1.4 \%$ & $4.0 \%$ & $2.9 \%$ \\
\hline Total Primary Energy & 98.8 & 99.1 & 105.1 & 111.6 & 116.9 & 121.8 & 127.5 & 129.7 & 132.5 & 134.4 & 137.6 & $1.0 \%$ & $0.5 \%$ & $0.7 \%$ \\
\hline Energy/GDP (Thos. Btu/ '01\$ GDP) & 10.5 & 8.7 & 7.9 & 7.2 & 6.5 & 5.9 & 5.4 & 4.8 & 4.4 & 4.0 & 3.7 & $-1.9 \%$ & $-1.9 \%$ & $-1.9 \%$ \\
\hline Carbon Emissions (MMT) & 1,594 & 1,627 & 1,725 & 1,834 & 1,934 & 2,052 & 2,167 & 2,234 & 2,290 & 2,334 & 2,356 & $1.2 \%$ & $0.6 \%$ & $0.8 \%$ \\
\hline
\end{tabular}

Petroleum's share of total energy consumption is projected to decline from $41 \%$ in 2005 to about $34 \%$ in 2050 . The natural gas share is projected to remain relatively constant at about $24 \%$. Coal generation is projected to increase from a $22 \%$ share in 2005 to nearly $29 \%$ in 2050 . Almost all existing nuclear generation capacity is assumed to retire between 2025 and $2050{ }^{8}$ However, 19 GW of new nuclear capacity is projected to be added between 2025 and 2050. The share of renewable energy is also projected to increase from $7 \%$ and $9 \%$ throughout the projection period.

\section{End-Use Energy Demand}

The sectoral breakout of energy use, shown in Figure 3, demonstrates that transportation energy demand is projected to increase by $1.0 \%$ per year, while commercial building and industrial energy demand both grow at an average of about $0.8 \%$ annually between 2005 and 2050 . Residential energy consumption increases by about $0.9 \%$, on average, between 2005 and 2025; but this trend reverses as demand contracts in the later years bring net change in the primary energy requirement to zero for this sector. The growth rates in energy consumption are a function

\footnotetext{
${ }^{8}$ The nuclear generation retirement schedule was derived by examining reactor license expiration dates and applying one 20 -year extension where applicable.
} 
of the opposing trends of increasing end-use energy-service demand and improvements in the efficiency of technologies that satisfy this demand, as well as macroeconomic shifts toward less energy-intensive industries. This phenomenon is best illustrated by examining the energy intensity of the economy. Figure 4 shows the relative energy intensity for different end-use and conversion sectors and the economy as a whole.

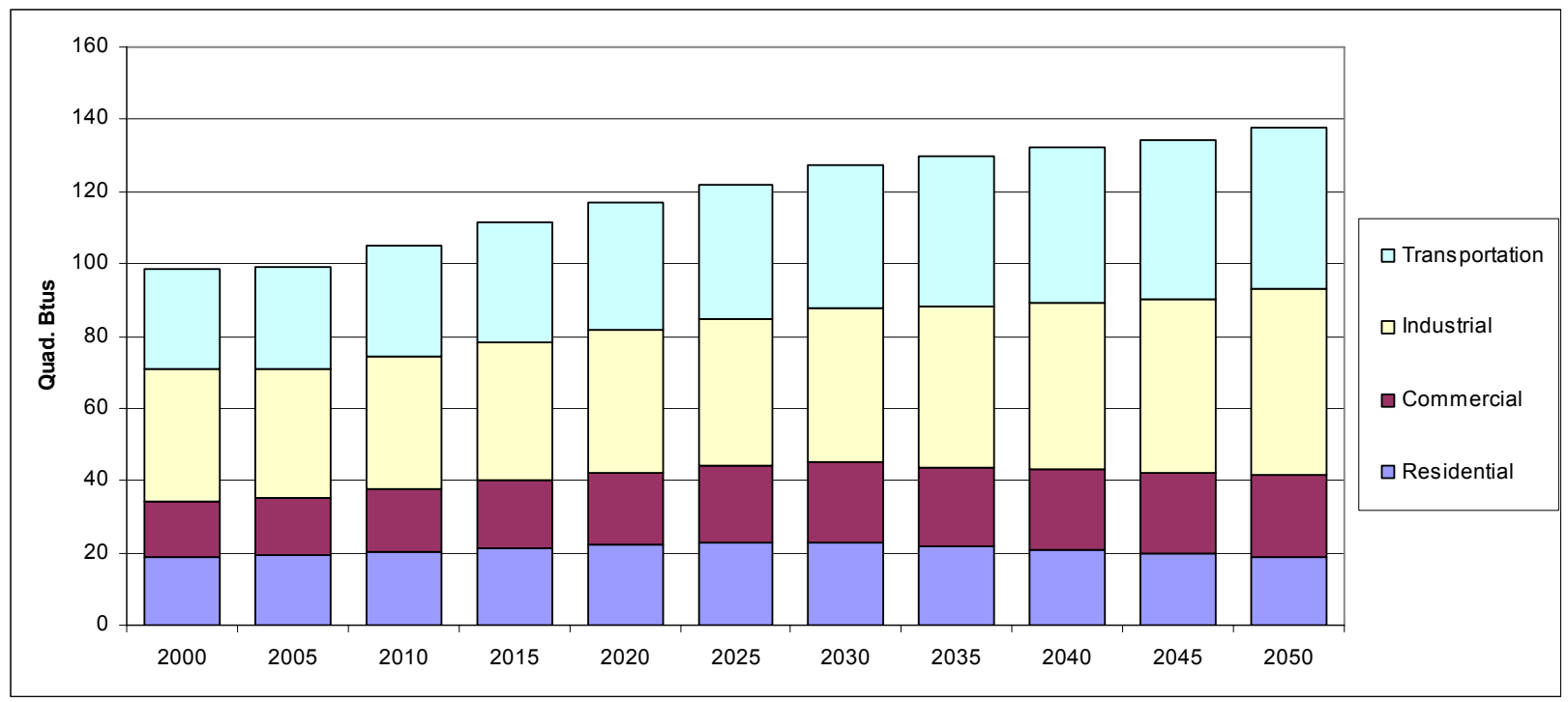

Figure 3. Energy Consumption by Sector

Note: Consumption totals include electric generation and distribution losses.

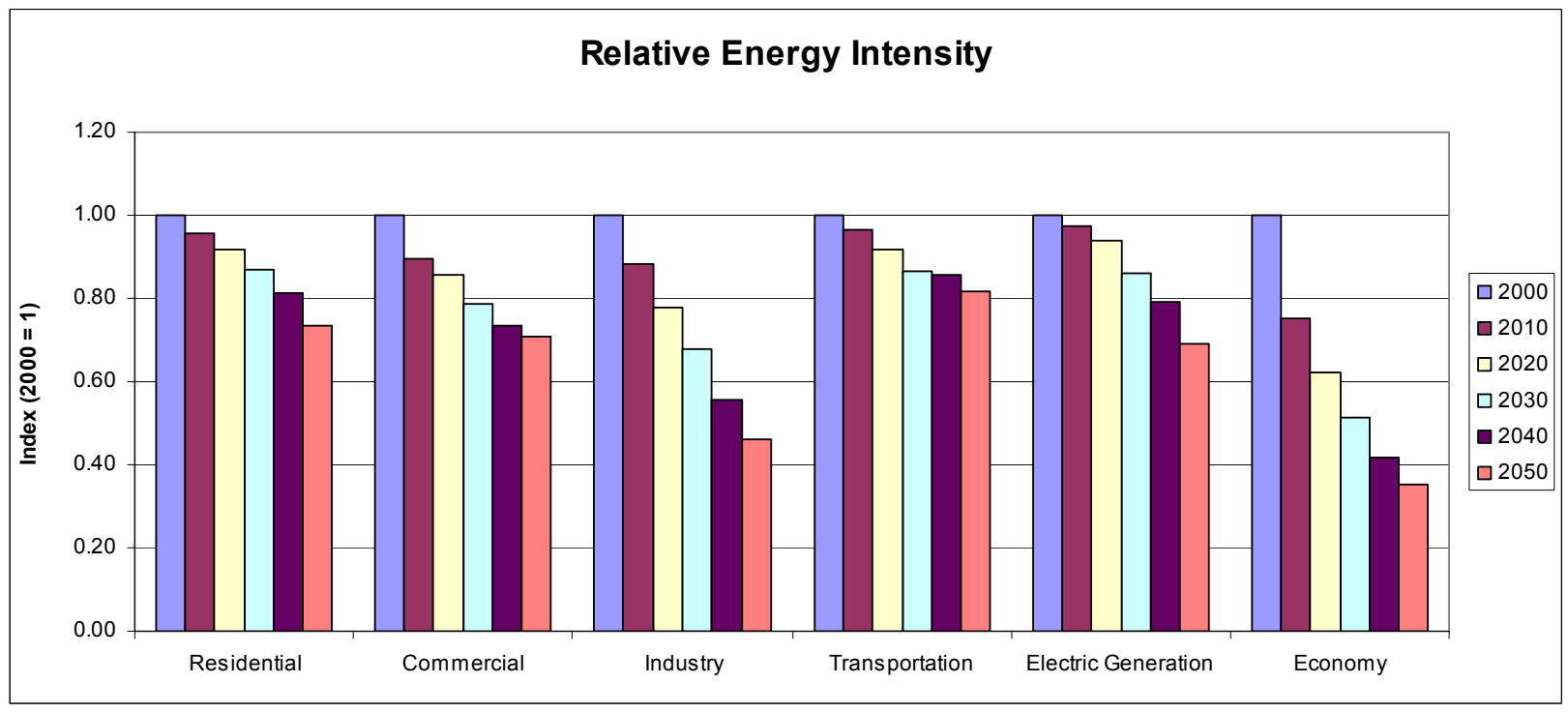

Figure 4. Relative Energy Intensity by Sector

Note: Residential index is primary energy excluding miscellaneous use per household. Commercial index is primary energy use excluding office equipment and miscellaneous appliances per square foot. Industrial index is total primary energy per unit output. Transportation index is light-duty vehicle primary energy per mile traveled. Electricity index is non-renewable average heat rate. Economy index is total primary energy per unit GDP. 
As shown in Figure 4, our Reference Case projection indicates that the energy intensity of the economy (which we've defined as total primary energy consumption per \$ of GDP) is projected to fall by almost two-thirds by 2050. This decrease reflects both a continued shift toward a service-based economy, as well as increases in energy technology efficiency. End-use efficiencies are projected to increase throughout the economy over the projection period as new, more efficient capital stocks are purchased to replace existing equipment and to meet new demand. The Reference Case technology database includes technologies that are expected to become available in the future, as well as those that are currently on the market. For example, more efficient electric heat pumps and light-duty vehicles are assumed to become available throughout the projection period. The technical and economic data associated with these technologies are derived from a variety of sources, but rely most heavily on the NEMS database.

The residential energy intensity index shows significant improvements in energy use per household. However, the residential index excludes "miscellaneous demands," the fastest growing segment of residential energy demand. The miscellaneous demand category includes electric devices such as home computers, TVs, microwave ovens, as well as devices such as gas lamps and swimming pool heaters. Because these service demands are growing faster than the sector as a whole, their energy use per household actually increases over time. Thus, the inclusion of miscellaneous demands in the calculation of residential energy intensity would obscure the efficiency gains being made in other residential service demands. While these miscellaneous demands are excluded from the chart, they are modeled within MARKAL.

The commercial energy intensity index shows significant improvements in energy use per square foot. However, as with the residential sector, this calculation excludes the fastest-growing demand categories: office equipment and miscellaneous commercial appliances. The inclusion of these demand categories would result in relatively constant commercial energy demand per square foot.

The industrial-sector efficiency index shows dramatic declines in energy intensity due to a shift from energy-intensive industries to nonenergy-intensive manufacturing, as well as improvements in process efficiency. Between 2005 and 2050, nonenergy-intensive manufacturing output is expected to grow at twice the rate as energy-intensive industrial output. This shift in output exaggerates the decline in energy intensity. However, in the transportation sector, consumer preferences for more powerful engines and a continued shift from passenger cars to sport utility vehicles (SUVs), limit gains in overall efficiency.

In the power-generation sector, the efficiency of nonrenewable generation is expected to increase as older, less efficient fossil steam units retire and new high efficiency gas combined-cycle and IGCC capacity is built. Electric generation by type is shown in Figure 5; natural gas-fired generation is projected to increase its share of total generation from about $20 \%$ to $26 \%$ over the projection period. Coal-fired generation remains the largest source of electricity at $50 \%$ to $57 \%$ of total generation. Due to significant retirements of existing nuclear capacity, the share of nuclear generation falls from $21 \%$ to $2 \%$ of generation in the projection period. Renewable generation increases from $10 \%$ to $15 \%$ of total generation. 


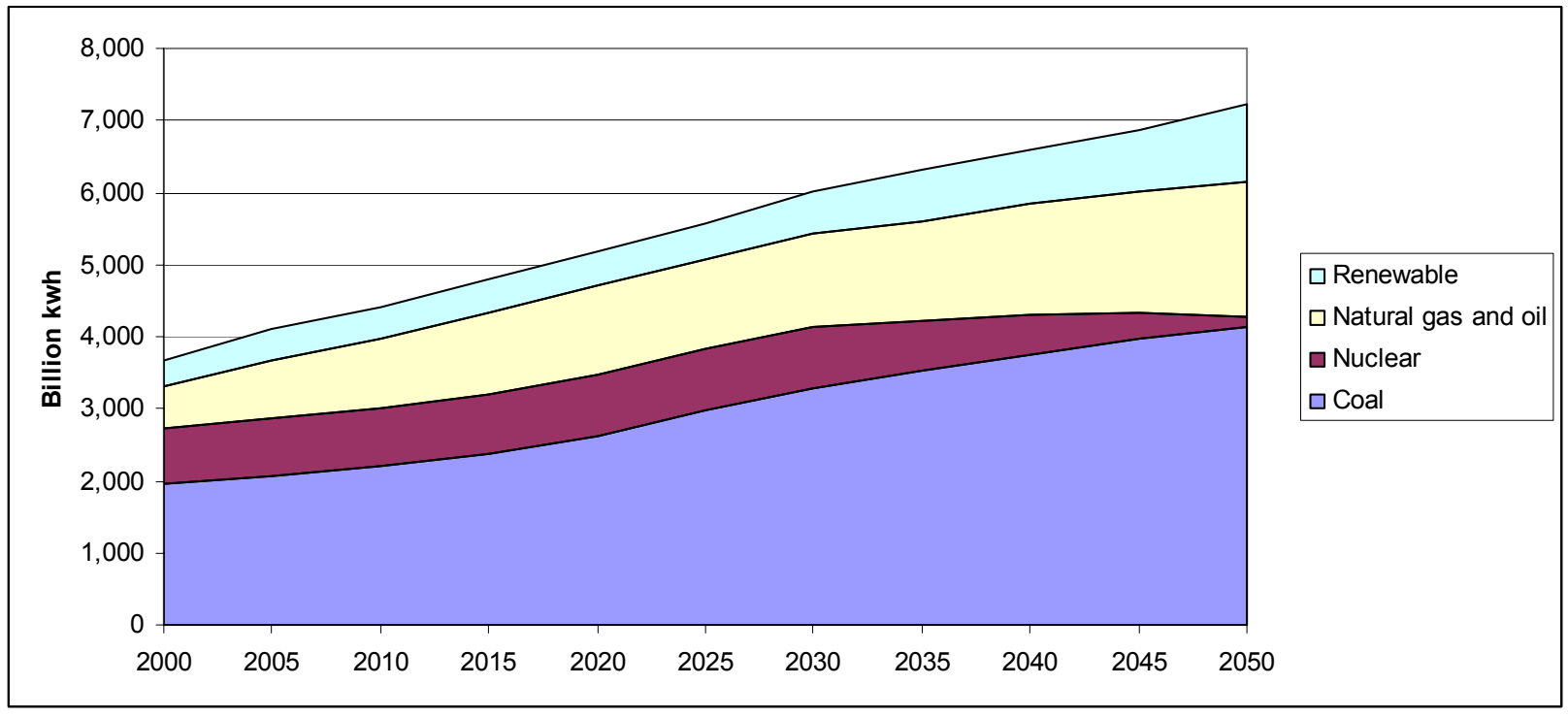

Figure 5. Electricity Generation by Type

While both natural gas and coal-fired generation show increased efficiency, fossil fuel use for electric generation increases by $56 \%$ during the projection period. Such an increase in coal and natural gas demand for power generation is dependent on the availability of these resources. However, potential reduction in supply (such as changes in the outlook in natural gas supply) would necessitate a significant change in fuels used for electric generation. 


\section{APPENDIX B - HYDROGEN, FUEL CELLS, AND INFRASTRUCTURE TECHNOLOGIES PROGRAM INPUTS FOR FY 2008 BENEFITS ESTIMATES}

Table of contents

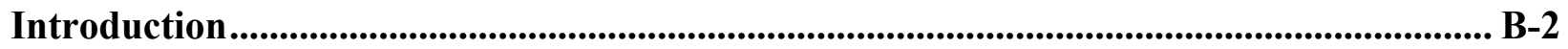

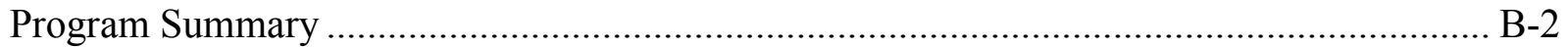

Path Forward: Addressing Barriers to a Hydrogen Fuel/Transportation Option ................... B-3

Defining Success and Measuring Progress for the HFCIT Program .................................. B-7

Significant Changes in HFCIT-Modeled Input Program Goals from Previous GPRA

Analysis ...................................................................................................................................... B-12

The Reference and Baseline ("without DOE RD3" case)................................................ B-13

Target Market Description ........................................................................................... B-14

Target Market: Fuel Cell Vehicle Market........................................................................ B-14

Baseline Assumptions for Fuel Cell Vehicles ........................................................ B-14

Stationary Fuel Cell Market.............................................................................................. B-14

Baseline Assumptions for Stationary Fuel Cells ....................................................... B-15

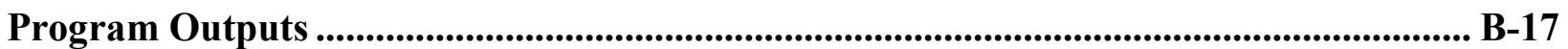

Program Outputs, Activities, and Milestones ................................................................ B-20

Translating Program Outputs to Market Outcomes............................................................. B-23

Key Factors in Shaping Market Adoption of FCVs.................................................... B-23

Interim Outcomes of Fuel Cell Vehicles ......................................................................... B-24

Significant Changes in GPRA08-Modeled HFCIT Program Inputs from GPRA07

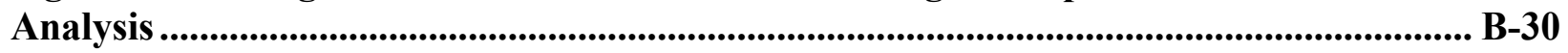

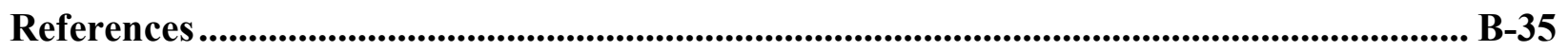




\section{Introduction}

\section{Program Summary}

President George W. Bush launched the Hydrogen Fuel Initiative to ensure our nation's longterm energy security and a clean environment. Using hydrogen to fuel our economy can reduce U.S. dependence on imported petroleum, diversify domestic energy sources, and reduce pollution and greenhouse gas emissions. Fuel cells are an important enabling technology for a future hydrogen fuel/transportation option and have the potential to revolutionize the way we power our nation, offering cleaner, more efficient alternatives to today's technologies.

Energy Security: The United States uses about 20 million barrels of oil per day (60\% of which is imported), at a cost of about $\$ 11$ billion a week (assuming a cost of $\$ 75$ per barrel of oil). Much of this oil is used to power highway vehicles. More than $97 \%$ of our transportation energy is from petroleum. Because hydrogen can be derived from a variety of domestically available primary sources (hydrogen itself is not a primary resource), including fossil fuels, renewable resources, and nuclear power, its use would allow us to diversify our transportation energy supply and make us less reliant on foreign energy sources.

Additionally, fuel cells are significantly more energy efficient than combustion-based power generation technologies. Internal combustion engines in today's automobiles convert less than $30 \%$ of the energy in gasoline into engine power for moving the vehicle. Vehicles using electric motors powered by hydrogen fuel cells have 2-2.5 times the thermal efficiency of internal combustion engines.

Environmental Benefits: Fuel cells powered by pure hydrogen emit no harmful pollutants, only pure water. Hydrogen generation and carbon-management technologies can be developed, which can significantly reduce pollutants and greenhouse gases from fossil-based hydrogen production. As a transportation fuel, it will be much easier to manage and contain greenhouse gas emissions from stationary hydrogen generation sources than from the tailpipe of internal combustion engine vehicles. Using renewable or nuclear-based hydrogen in high efficiency fuel cells to fuel our vehicles and to generate power could virtually eliminate greenhouse gas emissions and air pollution.

Economic Competitiveness: Heavy dependence on imported oil threatens America's economic well-being. Small changes in the price of crude oil or disruptions to oil supplies can have big impacts on our economy, from trade deficits, to industrial investment, to employment levels. Hydrogen's diversity in production and flexibility in use offers opportunities for new technologies and players in energy markets, broadening our energy choices and increasing economic growth both at home and around the world. In addition, developing and leading the way in hydrogen fuel cell technologies for automobiles will help the United States maintain its future economic competitiveness in the worldwide automotive industry. 


\section{Path Forward: Addressing Barriers to a Hydrogen Fuel/Transportation Option}

The changeover of our current energy infrastructure to a clean and secure energy infrastructure based on hydrogen will take decades. The technological, economic, and institutional barriers pose difficult challenges. The "critical path" barriers to a changeover to a hydrogen option are:

\section{Technology Barriers}

- Hydrogen storage systems for vehicles are inadequate to meet customer driving range expectations ( $>300$ miles) without intrusion into vehicle cargo or passenger space.

- Fuel cells are about four times more expensive than internal combustion engines and do not maintain performance over the full useful life of the vehicle.

\section{Economic and Institutional Barriers}

- Investment risk of developing a hydrogen delivery infrastructure is too great given technology status and current hydrogen vehicle demand.

- Uniform model codes and standards to ensure safety, insurability, and fair global competition are lacking.

- Local code officials, policy makers, and the general public lack education on hydrogen benefits and on safe handling and use.

DOE Hydrogen Fuel Initiative:

To realize the goal of the President's Hydrogen Fuel Initiative, the Hydrogen Program supports RD\&D of transportation, stationary, and portable hydrogen fuel cell technologies in parallel with technologies for the hydrogen production and delivery infrastructure. The current focus is on addressing key technical challenges (for fuel cells and hydrogen production, delivery, and storage) and institutional barriers (such as hydrogen codes and standards to maximize safety, and training and public awareness). Once technical and cost targets are close to being met, and the business case can be established by industry, policies and programs with market or end-user incentives may be warranted to facilitate the infrastructure changeover. The Program is partnering with automotive and energy companies to make the technology ready by 2015 , thereby enabling the availability of safe, affordable, and viable hydrogen fuel cell vehicles and hydrogen fuel infrastructure to consumers by 2020.

The Hydrogen Program is currently conducting basic and applied research, technology development, and learning demonstrations, underlying safety research, systems analysis, and public outreach and education activities. These activities include cost-shared, public-private partnerships to address the high-risk, critical technology barriers preventing widespread use of hydrogen as an energy carrier. Public and private partners include automotive and power equipment manufacturers, energy and chemical companies, electric and natural gas utilities, building designers, standards development organizations, other federal agencies, state government agencies, universities, national laboratories, and other national and international stakeholder organizations. The Hydrogen Program encourages the formation of collaborative partnerships to conduct RD\&D and other activities that support program goals. 
These activities address the development of hydrogen energy systems for transportation, stationary power, and portable power applications. Transportation applications include fuel cell vehicles and hydrogen refueling infrastructure. Stationary power applications include use of hydrogen for backup emergency power and residential electric power generation. Portable power applications include consumer electronics such as cellular phones, hand-held computers, radios, and laptop computers. DOE is funding RD\&D efforts that will provide the basis for the near-, mid-, and long-term production, delivery, storage, and use of hydrogen derived from diverse energy sources, including fossil fuel, nuclear energy, and renewable sources. Distributed reforming of natural gas and renewable liquid fuels (e.g., ethanol and methanol) is likely to be the most efficient and economical way to produce hydrogen fuel in the initial fuel infrastructure development, but costs are still too high. However, the Program confirmed in 2006 that the cost of distributed hydrogen production from natural gas achieved the 2005 hydrogen cost goal of $\$ 3$ per gallon of gasoline equivalent (gge) through an independent review. The review panel utilized the $\mathrm{H} 2 \mathrm{~A}$ cost model $^{26}$ to analyze data submitted by DOE industry partners and national laboratories and determined that the calculated hydrogen cost ranged from $\$ 2.75$ to $\$ 3.50$ for units capable of delivering 1,500 kilograms per day when manufactured in quantities of about 500 units per year.

As reflected in the Administration's FutureGen project, technologies will continue to be evaluated and developed to produce low-cost hydrogen from domestic and secure sources of coal with the capture and sequestration of carbon dioxide. With the implementation of carbon management strategies, coal could play a key role in the long term, because of its abundance and low cost. Hydrogen from renewable biomass feedstocks can benefit from gasification, reforming, and separation technologies developed for fossil resources. The production of hydrogen from nonconventional sources such as biological materials will be explored mainly through basic science.

To address the need for diversified energy supplies, DOE is also investigating advanced methods of hydrogen production from renewable and nuclear resources, and more advanced systems for storing and delivering hydrogen in an expanded hydrogen market. The DOE will focus on methods to produce affordable supplies of hydrogen from water using renewable electricity (e.g., solar, wind) and nuclear sources of energy, or using direct solar conversion or biological methods. In a recent report to Congress (prepared in response to section 812(e) of the Energy Policy Act of 2005), the DOE describes options, progress, and plans for developing and demonstrating solar- and wind-based hydrogen production technologies. ${ }^{5}$ A mix of diverse energy feedstocks to produce hydrogen is needed for a secure, affordable, and environmentally safe hydrogen energy system.

The $\$ 1.2$ billion Hydrogen Fuel Initiative proposed by President Bush for FY 2004 through FY 2008 includes $\$ 720$ million in new R\&D funding over FY 2004 DOE baseline budgeting assumptions. ${ }^{7}$ The Initiative reflects an enhanced hydrogen and fuel cell program to accelerate research, technology development, and demonstration activities. This enhanced program will make critical path technologies ready by 2015, potentially enabling market introduction by 2020 and significant oil displacement and environmental benefits for the years 2030 and beyond. The RD\&D for the Hydrogen Fuel Initiative includes the following areas: 
- Basic Research

- Production and Delivery

- Storage

- Conversion (Fuel Cells)

- Technology Validation

- Safety, Codes, and Standards

- Education

- Systems Analysis and Integration

- Manufacturing R\&D

These areas are necessarily interrelated, with developments in one segment relying on corresponding developments in other segments. An integrated approach to RD\&D within the DOE will ensure that, regardless of the pathway, common challenges are efficiently addressed. Table B-1 shows the initiative budget request for FY 2008 and the funding breakout by program office and department. The DOE Hydrogen Program includes R\&D in the other DOE offices and departments.

Table B-1. Hydrogen Technology Funding Profile by Office and Department

(dollars in thousands)

\begin{tabular}{|c|c|c|c|}
\hline $\begin{array}{c}\text { FY 2005 } \\
\text { Appropriation }\end{array}$ & $\begin{array}{c}\text { FY 2006 } \\
\text { Appropriation }\end{array}$ & $\begin{array}{c}\text { FY 2007 } \\
\text { Request }^{\mathrm{a}}\end{array}$ & $\begin{array}{c}\text { FY 2008 } \\
\text { Request }^{\mathrm{b}}\end{array}$ \\
\hline
\end{tabular}

Hydrogen Fuel Initiative

Energy Efficiency and

Renewable Energy (EERE)

Nuclear Energy (NE)

166,772

$155,627 \quad 195,801$

200,000

Fossil Energy (FE)

8,682

24,750

18,665

23,436

Office of Science

16,518

21,635

23,611

20,521

29,183

32,500

50,000

50,000

Subtotal, Department of

Energy

221,155

$234,512 \quad 288,077$

293,957

Department of Transportation (DOT)

\begin{tabular}{rrrr}
549 & 1,411 & 1,420 & 2,350 \\
47,236 & 47,470 & 0 & 0 \\
\hline 268,940 & 283,393 & 289,497 & 296,307 \\
\hline
\end{tabular}

Congressionally Directed

Total, Hydrogen Fuel Initiative

Note:

a The FY 2007 Budget was not approved by Congress at the time of this writing.

The FY 2008 request is confidential until after the budget submission to Congress. 


\section{EERE HFCIT Program:}

The Energy Efficiency and Renewable Energy (EERE) part of the HFI is the HFCIT Program. The fiscal year 2008 budget request for the Hydrogen, Fuel Cells, and Infrastructure Technologies Program is confidential until after the budget submission to Congress. A summary of the recent and requested budgets, by major area, is shown in Table B-2.

\section{Table B-2. Hydrogen Technology Funding Profile by Subprogram}

\begin{tabular}{|c|c|c|c|c|}
\hline & \multicolumn{4}{|c|}{ (dollars in thousands) } \\
\hline & $\begin{array}{c}\text { FY } 2005 \\
\text { Appropriation }\end{array}$ & $\begin{array}{c}\text { FY } 2006 \\
\text { Appropriation }\end{array}$ & $\begin{array}{l}\text { FY } 2007 \\
\text { Request }^{a}\end{array}$ & $\begin{array}{l}\text { FY } 2008 \\
\text { Request }^{\mathrm{b}}\end{array}$ \\
\hline \multicolumn{5}{|l|}{ Hydrogen Technology } \\
\hline $\begin{array}{l}\text { Hydrogen Production and } \\
\text { Delivery R\&D }\end{array}$ & 14,218 & 8,512 & 36,844 & 23,000 \\
\hline Hydrogen Storage R\&D & 23,654 & 26,600 & 34,620 & 43,900 \\
\hline $\begin{array}{l}\text { Fuel Cell Stack Component } \\
\text { R\&D }\end{array}$ & 31,702 & 31,595 & 38,082 & 44,000 \\
\hline Technology Validation $^{6}$ & 26,098 & 33,594 & 39,566 & 45,000 \\
\hline $\begin{array}{l}\text { Transportation Fuel Cell } \\
\text { Systems }\end{array}$ & 7,300 & 1,080 & 7,518 & 7,600 \\
\hline $\begin{array}{l}\text { Distributed Energy Fuel Cell } \\
\text { Systems }\end{array}$ & 6,753 & 962 & 7,419 & 7,500 \\
\hline Fuel Processor R\&D & 9,469 & 617 & 4,056 & 0 \\
\hline $\begin{array}{l}\text { Safety and Codes and } \\
\text { Standards }\end{array}$ & 5,954 & 4,727 & 13,848 & 13,000 \\
\hline Education & 0 & 495 & 1,978 & 2,000 \\
\hline Systems Analysis & 3,404 & 4,925 & 9,892 & 9,000 \\
\hline Manufacturing R\&D & 0 & 0 & 1,978 & 5,000 \\
\hline $\begin{array}{l}\text { Congressionally Directed } \\
\text { Activities }\end{array}$ & 37,292 & 42,520 & 0 & 0 \\
\hline Total, Hydrogen Technology & 165,844 & 155,627 & 195,801 & 200,000 \\
\hline
\end{tabular}

In FY 2009 through FY 2012, the Program will continue to focus R\&D on critical requirements to enable technology readiness in 2015 as exhibited in Table B-3 for the out-year funding projections. Production and delivery will place more emphasis on longer-term central production and delivery pathways such as wind-based electrolysis, biomass, high-temperature solar thermochemical cycles, and photoelectrochemical and biological production. The Hydrogen Storage R\&D will expand the Centers of Excellence to focus on establishing an "engineering center of excellence" for development of promising hydrogen storage systems. The Fuel Cell 
Stack Component R\&D will increase emphasis on stack components that can operate at above $80^{\circ} \mathrm{C}$ and below freezing such as catalysts, catalyst supports, membranes, gas diffusion layers, and innovative concepts.

Table B-3. Hydrogen Technology Funding Profile by Subprogram for the Out Years ${ }^{a}$

\begin{tabular}{|c|c|c|c|c|}
\hline & \multicolumn{4}{|c|}{ (dollars in thousands) } \\
\hline & FY 2009 & FY 2010 & FY 2011 & FY2012 \\
\hline \multicolumn{5}{|l|}{ Hydrogen Technology } \\
\hline $\begin{array}{l}\text { Hydrogen Production and } \\
\text { Delivery R\&D }\end{array}$ & 26,500 & 26,500 & 33,000 & 33,000 \\
\hline Hydrogen Storage R\&D & 53,600 & 63,800 & 71,100 & 71,500 \\
\hline $\begin{array}{l}\text { Fuel Cell Stack Component } \\
\text { R\&D }\end{array}$ & 56,300 & 59,000 & 70,000 & 70,700 \\
\hline Technology Validation $^{6}$ & 50,500 & 51,500 & 51,000 & 50,000 \\
\hline $\begin{array}{l}\text { Transportation Fuel Cell } \\
\text { Systems }\end{array}$ & 7,600 & 7,600 & 7,600 & 7,600 \\
\hline $\begin{array}{l}\text { Distributed Energy Fuel Cell } \\
\text { Systems }\end{array}$ & 8,000 & 4,000 & 0 & 0 \\
\hline Fuel Processor R\&D & 0 & 0 & 0 & 0 \\
\hline $\begin{array}{l}\text { Safety and Codes and } \\
\text { Standards }\end{array}$ & 16,000 & 13,000 & 13,000 & 14,500 \\
\hline Education & 2,500 & 2,500 & 3,000 & 4,000 \\
\hline Systems Analysis & 9,000 & 7,500 & 7,500 & 7,500 \\
\hline Manufacturing R\&D & 8,000 & 9,500 & 15,500 & 16,500 \\
\hline $\begin{array}{l}\text { Congressionally Directed } \\
\text { Activities }\end{array}$ & 0 & 0 & 0 & 0 \\
\hline Total, Hydrogen Technology & 238,000 & 244,900 & 271,700 & 275,300 \\
\hline
\end{tabular}

For funding beyond 2012, it is assumed the Program will continue to exist and have adequate funding until goals are met.

The remainder of this documentation describes the goals, targets, and program input documentation for the GPRA08 analysis of the HFCIT program.

\section{Defining Success and Measuring Progress for the HFCIT Program}

Success for the Hydrogen, Fuel Cells, and Infrastructure Technologies Program is defined as validation, by 2015 , of technology for:

- Hydrogen storage systems enabling greater than 300-mile vehicle range while meeting identified packaging, cost, and performance requirements 
- Hydrogen production from diverse pathways to safely and efficiently deliver hydrogen to light-duty hydrogen fuel cell vehicles, cost competitively on a per-mile basis without adverse environmental impacts.

- Fuel cells to enable engine costs of less than $\$ 30 / \mathrm{kW}$ (in high-volume production) while meeting performance and durability requirements

In addition, the program has a goal for fuel cells to enable stationary power production at $\$ 400$ $\$ 700 / \mathrm{kW}$ while meeting performance and durability requirements by 2011 .

The rationale for these goals is detailed later in this document and in various source documents, such as the Program's multiyear plan. If these indicators are met, there is a high probability that customer requirements can be met, and that industry can begin to realize a business case for proceeding with the implementation of the hydrogen infrastructure and fuel cell vehicles. While the full extent of life-cycle cost and energy and environmental impacts will not be achieved for decades, meeting the Technology Readiness in 2015 will begin to yield national benefits as early as 2025. To assist in measuring interim progress toward the 2015 goal, the following program objectives have been established with industry input. Although the many interrelated program goals are listed and described below, only the goals specific to hydrogen production and fuel cells are directly modeled as program inputs to NEMS and MARKAL. Key milestones will be monitored by the Office of Management and Budget within the Executive Office of the President:

\section{Hydrogen Production ${ }^{32}$}

Lowering hydrogen production cost is a top priority. The National Academies' study requested by DOE and completed in 2004 provides insight into a hydrogen feedstock strategy for the near term and the long term. ${ }^{8}$ The study has helped DOE set priorities for hydrogen production research needs.

Ongoing and planned activities to reduce the cost of hydrogen to $\$ 2-\$ 3 /$ gge $^{1}$ (delivered, untaxed) at the pump by 2015 include the following: ${ }^{2}$

- Reduce the cost of distributed production of hydrogen from natural gas to $\$ 2.50 / \mathrm{gge}$ (delivered, untaxed) at the pump (without carbon sequestration) by 2010; and reduce the cost of distributed hydrogen production from biomass-derived renewable liquids to $\$ 2-\$ 3 /$ gge (delivered, untaxed) at the pump by 2015.

- Verify grid-connected distributed water electrolysis at a projected delivered hydrogen cost of $\$ 2.85 /$ gge by 2010 ; and by 2015 , verify central hydrogen production from renewable energy sources at a projected cost of $\$ 2.75 /$ gge (delivered).

- Reduce the cost of hydrogen produced from biomass to $<\$ 1.60 /$ gge at the plant gate $(\$ 2.60$ delivered) by 2017.

- Research and develop high-temperature thermochemical cycles driven by concentrated solar power processes to produce hydrogen with a projected cost of $\$ 3 /$ gge at the plant gate $(\$ 4$ delivered) by 2015. 


\section{Hydrogen Delivery}

Delivery technologies and economics will heavily influence the level of infrastructure investment and safety assurance required. New concepts will be needed to reduce delivery costs from the point of hydrogen production to the point of use at refueling stations and distributed power facilities. Systems analysis of delivery alternatives will show the life-cycle cost advantages and disadvantages of the alternative approaches for transporting hydrogen over long distances and will identify areas in which R\&D could provide the greatest cost reductions and the greatest value.

Ongoing and planned R\&D activities include the following:

- By 2012, develop technologies to reduce the cost of hydrogen delivery from central and semicentral production facilities to the gate of refueling stations and other end users to $<\$ 0.90 /$ gge of hydrogen and to reduce the cost of compression, storage, and dispensing at refueling stations and stationary power facilities to $<\$ 0.80 /$ gge of hydrogen.

- Develop enabling technologies to reduce the cost of hydrogen delivery from the point of production to the point of use in vehicles or stationary power units to $<\$ 1 /$ gge of hydrogen by 2017 .

\section{Hydrogen Storage}

Lower-cost, lighter-weight, and higher-density hydrogen storage is one of the key technologies needed for the hydrogen option. Advanced storage materials that show promise include complex metal hydrides, chemical hydrides, carbon structures, and metal organic frameworks.

Understanding how to produce and contain these advanced materials will be required as well as how to fill and discharge hydrogen, manage pressure and thermal properties, and integrate the materials into practical systems for stationary and mobile applications. The DOE's "Grand Challenge" solicitation for Hydrogen Storage formed the basis for the National Hydrogen Storage Project, which involves approximately 40 universities, 15 companies, and 10 federal laboratories in conducting R\&D to address these challenges.

Ongoing and planned hydrogen storage R\&D includes the following activities:

- By 2010, develop and verify onboard hydrogen storage systems achieving $2 \mathrm{kWh} / \mathrm{kg}(6$ wt $\%), 1.5 \mathrm{kWh} / \mathrm{L}$, and $\$ 4 / \mathrm{kWh}$. By $2015,3 \mathrm{kWh} / \mathrm{kg}(9 \mathrm{wt} \%), 2.7 \mathrm{kWh} / \mathrm{L}$, and $\$ 2 / \mathrm{kWh} .{ }^{31}$

\section{Fuel Cells}

Reducing fuel cell cost (by a factor of approximately 4) and improving durability and reliability will be required to ensure the commercial viability of fuel cells in both mobile and stationary applications. ${ }^{9}$ Fuel cell research will continue on high-efficiency polymer electrolyte membranes (PEM) and other stack components and systems to meet cost, durability, power density, heat utilization, cycling, load-following, operation and start-up in cold weather, and other key performance targets. In 2004, DOE conducted a go/no-go review of onboard fuel processing activities. The review resulted in a no-go decision, concluding that onboard fuel processing would not improve sufficiently from its current status to compete effectively with gasoline hybrid vehicles. Projects that focus on onboard fuel processing have therefore been terminated or 
redirected to support development of fuel processors for stationary applications or development of catalysts suitable for a variety of fuel processing applications (e.g., auxiliary power units).

Ongoing and planned fuel cell R\&D includes the following activities:

- Develop a $60 \%$ peak-efficient, durable, direct hydrogen fuel cell power system for transportation at a cost of $\$ 45 / \mathrm{kW}$ by 2010 and $\$ 30 / \mathrm{kW}$ by 2015 .

- Develop a distributed generation polymer electrolyte membrane (PEM) fuel cell system operating on natural gas or liquid petroleum gas that achieves $40 \%$ electrical efficiency and 40,000 hours durability at $\$ 400-\$ 750 / \mathrm{kW}$ by $2011^{32}$

Technology Validation

Efforts are needed to demonstrate hydrogen energy systems (including fuel cells, engines, and turbines) in mobile and stationary applications. Learning demonstrations provide technical data on operation in a real world environment to measure progress and to help guide the research program as well as financial data for determining market and investment risks. The National Hydrogen Learning Demonstration Project will support a statistically significant number of hydrogen vehicle and refueling station demonstrations in several locations to achieve the following:

- By 2009, validate hydrogen vehicles that have greater than 250-mile range and 2,000-hour fuel cell durability, with hydrogen infrastructure that results in a hydrogen production cost of less than $\$ 3 /$ gge (delivered, untaxed).

- By 2015, vehicles that have 300+ mile range and 5,000 hours fuel cell durability, with a hydrogen production cost of $\$ 2.50 /$ gge (delivered, untaxed).

- Validate an electrolyzer that is powered by a wind turbine at a capital cost of the electrolyzer of $\$ 400 / \mathrm{kWe}$ and $65 \%$ efficiency, including compression to 5,000 psi, (when built in quantities of 1,000$)$ by 2008 .

- Validate an integrated biomass/wind or geothermal electrolyzer system to produce hydrogen for $\$ 2.85 /$ gge at the plant gate (untaxed) by 2011 .

Demonstration projects will also be conducted through DOT and the Safe, Accountable, Flexible, Transportation Equity Act: A Legacy for Users or SAFETEA-LU.

Codes and Standards

Commercialization of hydrogen technologies cannot proceed unless effective domestic and international codes and standards are in place. DOE and DOT, in collaboration with the Environmental Protection Agency, National Institute of Standards and Technology, Department of Defense, National Aeronautics and Space Administration, and other agencies can play a role in fostering codes and standards development.

Ongoing and planned efforts include the following:

- Support and facilitate development of Global Technical Regulations (GTR) for hydrogen vehicle systems by 2010.

- By 2015, ensure necessary codes and standards are completed that support the commercialization of hydrogen technologies. 


\section{Safety}

- In collaboration with industry, develop a comprehensive hydrogen safety plan by 2005 that establishes Program safety policy and guidelines.

- Integrate safety procedures into new DOE project-funding procurements to ensure that all projects incorporate hydrogen safety requirements.

- Publish a handbook of "Best Management Practices for Safety" by 2007.

- Continuously develop supporting research and development to provide critical hydrogen behavior data and hydrogen sensor and leak-detection technologies to support the establishment of building codes.

- Continuously promote widespread sharing of safety-related information, procedures, and lessons-learned to first responders, jurisdictional authorities, and other stakeholders.

\section{Education}

The President's National Energy Policy and the Energy Policy Act of 2005 recommend that the Secretary of Energy develop an education effort to communicate the benefits of alternative energy, including hydrogen. Effective education is critical to enabling the successful implementation of early hydrogen demonstration projects, as well as the longer-term market adoption and acceptance that is required to realize the benefits of hydrogen fuel. Key audiences include state and local governments (including safety, code, and zoning officials), educators, professional and trade organizations, real estate developers and building owners and operators, public and private fleet operators, and the general public.

Ongoing and planned education efforts include the following:

- By 2010, achieve a fourfold increase (from 2004 baseline) in the number of state and local government representatives, students, and teachers; and a twofold increase in the number of large-scale end users who understand the concept of utilizing hydrogen as a transportation fuel, and how it may affect them.

- Launch a comprehensive and coordinated public education campaign about the hydrogen fuel and fuel cell technology by 2010 .

Systems Analysis

Systems analysis, aided by various modeling tools, will be used in the program management process to establish goals, evaluate tradeoffs, set priorities, and make technology down-selects and go/no-go decisions. Analysis will be required to assess the challenges, evaluate the contribution and interaction of the individual components, and support R\&D efforts to resolve the technical barriers. The changeover from a carbon-based economy to a hydrogen-based fuel will require well-to-wheels analysis of cost, greenhouse gas emissions, energy efficiency, distribution, and nontechnical issues such as policy requirements and consumer preference. Analysis and modeling of components and pathways will be a continual process and directly linked to the Technology Validation activity.

Ongoing and planned activities include the following:

- Through analysis, support the integration of the Program within a balanced, overall DOE national energy $R \& D$ effort addressing the role of hydrogen in context of the overall energy infrastructure. 
- Provide and/or coordinate appropriate and timely analysis of environmental and technoeconomic issues to support decision-making tied to Program schedules, targets, and milestones.

- Develop a macro-system model of the hydrogen fuel infrastructure to support transportation systems. By 2011, enhance the model to include the stationary electrical generation and infrastructure for the option of utilizing hydrogen for power generation.

- Support a spectrum of analyses, including financial and environmental assessments, across and within Program elements - from individual unit/subsystem elements to a fully integrated system and infrastructure.

\section{Systems Integration}

The breadth and complexity of the overall RD\&D effort, as well as the interaction of program elements, requires an integrated Program approach to reduce risk and maximize the potential for technology readiness by 2015. Systems Integration will ensure all requirements are being addressed, track and measure the progress of projects, conduct independent analysis to aid the multiple programmatic decisions that need to be made over the course of the program, support a performance-based management approach, and identify and quantify programmatic and technical risks to ensure the program is proactive in response to issues and challenges.

Ongoing and planned activities include:

- Verify that the system being developed satisfies the Program requirements, projects are meeting performance and milestone objectives, and progress toward technical targets is substantiated.

- Provide analyses and recommend DOE-sponsored activities to enable the commercial sector to deploy a well-integrated hydrogen system that satisfies needs while continually monitoring system performance to identify potential improvements.

\section{Significant Changes in HFCIT-Modeled Input Program Goals from Previous GPRA Analysis}

In FY 2006, the appropriations for Hydrogen, Fuel Cells, and Infrastructure were \$27 million lower than the requested funding. In addition, the appropriations included $\$ 42.5$ million for Congressionally Directed projects, leaving a total of $\$ 69.5$ million less to fund ongoing project work. As a result of funding reductions in FY 2006, several projects for Hydrogen Production and Delivery development projects were re-scoped or delayed. The curtailed funding was intended for development of long-term technologies such as photolytic biological hydrogen production from water, photoelectrochemical hydrogen production, and solar high-temperature thermochemical hydrogen production. Funding in these areas is planned to be restored in FY 2008 , but interruption of the projects will cause delays in the technology development.

The project delays and re-scoping have caused technology milestones to slip for the long-term Hydrogen Production technologies. The laboratory-scale demonstration of solar-driven hightemperature thermochemical hydrogen production milestone was changed from 2010 to 2012 . The other long-term technology milestones for demonstration of laboratory-scale photobiological water-splitting system and demonstration of laboratory-scale photoelectrochemical water splitting system were delayed from 2015 to 2018. 
The costs of hydrogen delivery from central production plant gate to the point of dispensing were revised for the GPRA08 analysis, as a result of model enhancement with the H2A Delivery model. Previously, in the FY 2007 GPRA analysis, the mode of hydrogen delivery from a central plant was assumed to be pipeline at the cost goal of $\$ 1 /$ gge in 2015 . However, the mode and costs were revised to reflect a sequential deployment of the delivery technologies based on DOE R\&D. In the period from 2015 through 2030, the mode of delivery is assumed to be gaseous tube trailer or liquid tanker. The goal of the delivery R\&D is to reduce the cost of delivering hydrogen by pipeline to less than $\$ 1 /$ gge by 2017 . Once the goal is achieved, the pipelines for delivering the hydrogen would begin construction; approximately 13 years are estimated for completion of the pipeline infrastructure. It is expected that hydrogen delivery by pipeline would commence in 2030 after the hydrogen pipelines are built. The costs and delivery modes are discussed further in the "Interim Outcomes" section.

\section{The Reference and Baseline ("without DOE RD3" case)}

The current energy infrastructure and network of the United States, which is fossil-fuel based, is mature and well developed. The conversion of this system to a hydrogen fuel-based system will require a major transformation in technologies, vehicles, infrastructure, and markets of both the supply side (production and delivery) and the demand side (vehicle and stationary applications). Consequently, one will not work without the other. ${ }^{33}$

The transformation of the energy infrastructure will not be straightforward because it is faced with many uncertainties. Many innovations and inventions will be required. As a result, the research and development is relatively high risk. This, coupled with the significant societal benefits offered, warrants a strong government role in supporting the R\&D. The government provides resources, and the role of partnering academics and industry is to overcome these hurdles. DOE's role and need for involvement for developing the hydrogen technologies were clearly identified in the National Academy of Sciences (NAS) report ${ }^{3}$ as follows:

"A hydrogen economy will not come about without significant improvements in technology. This in turn requires that DOE provide significant funding for fundamental, exploratory research supported by organizations and investigators that propose credible, promising, high-risk new concepts for technologies for hydrogen storage, production, transportation, and end-use. The cost reductions (e.g., fuel cell cost per kilowatt) and infrastructure necessary to bring about a hydrogen economy are indeed challenging. While progress will certainly result from further development and demonstrations of existing technologies, some hydrogen system components will require major scientific breakthroughs that development will not address. Such advances will require entirely new approaches and thinking, which can come about only through relatively fundamental, directed exploratory research aimed at identifying technologies that will achieve cost reduction and technology goals (e.g., weight percentage of stored hydrogen)." 


\section{Target Market Description}

The target markets for the Office of Hydrogen, Fuel Cells, and Infrastructure Technologies (HFCIT) Program include transportation (cars and light trucks) and stationary (particularly residential and commercial) applications. More than one-half of the petroleum consumed in the United States is imported, and the percentage is expected to increase to $68 \%$ by 2025 . The Hydrogen Program R\&D is focused on the transportation sector because America's transportation sector relies almost exclusively on refined petroleum products, accounting for more than two-thirds of the oil used. The two main markets will be discussed separately below.

\section{Target Market: Fuel Cell Vehicle Market}

The market for fuel cell vehicles (FCVs) includes all cars and light trucks (including Class $2 \mathrm{~b}$ trucks) sold for both personal and business use. Today, the size of this market is approximately 17 million vehicle sales per year. ${ }^{4}$ Total car and light truck stock is about 230 million vehicles. EIA projects both sales and stock to grow to more than 21 million and 330 million respectively by 2030 . Additional growth in sales and stock will occur post-2030.

Recent studies of market opportunities identified several options for early fuel cell adoption for vehicles. The early-adoption markets would include forklifts and airport towing/support equipment. $^{29}$

The first use of FCVs may occur in those regions of the country in which strong state support exists for hydrogen and FCV research. Specifically, FCVs may first be used in California.

\section{Baseline Assumptions for Fuel Cell Vehicles}

The AEO2006 does not have hydrogen fuel cell vehicles or hydrogen fuel penetrating the market. This is the result of the hydrogen price, the cost of the vehicle, and the cost of the fuel cell. The baseline average hydrogen price of $\$ 2.69 /$ gge is higher than the gasoline price of $\$ 2.18$ in 2015 . The cost of the hydrogen fuel cell vehicles are $\sim \$ 44,000$ more than the conventional gasoline vehicle. Finally, the fuel cell cost is $\$ 307 / \mathrm{kW}$ as compared to the Hydrogen Program fuel cell target of $\$ 30 / \mathrm{kW}$ in 2015 . These factors combine to prevent hydrogen and hydrogen fuel cell vehicles from entering the market in the baseline case.

\section{Stationary Fuel Cell Market}

Stationary fuel cells are one of a variety of distributed electricity-generation technologies. The particular market sectors in which stationary fuel cells are most applicable include residential and commercial applications.

Recent studies of the market opportunities for direct hydrogen PEM fuel cells identified several options for early adoption. Backup power supply for telecommunications would be a near-term market for stationary fuel cells. Other applications for early markets would include emergencyresponse towers and emergency lighting systems. ${ }^{29}$ 


\section{Baseline Assumptions for Stationary Fuel Cells}

The AEO2006 stationary fuel cell costs have been updated and are higher than those of the $A E O 2005$. The differences are attributed to EIA using a new data source from a report by Discovery Insights, LLC, Installed Costs for Small CHP Systems - Estimates and Projections, from April 2005. A review of the AEO2006 assumptions and the HFCIT Program goals reveals differences in installed costs and the unit efficiencies. There remains a difference in the view of current (or nearly current) technology that might reflect different tradeoffs of efficiency and costs or may reflect differences in development. A recent status review of the stationary fuel cell goals by the Hydrogen Program Fuel Cell team identified current technology information for the efficiencies and costs that will be used for this analysis. The GPRA08 baseline will remain consistent with the GPRA07 baseline but will reflect values of the status review.

\section{Residential 10kW PEMFC Baseline}

\begin{tabular}{|c|c|c|c|c|}
\hline \multicolumn{5}{|c|}{ AE02006 Reference Case } \\
\hline & CHP System & Electrical & Installed Cost & Maint. Cost \\
\hline Year & Efficiency $^{28}$ & Efficiency $^{28}$ & $(2003$ \$/kW) & $(2003 \$ / k W-y r)$ \\
\hline 2006 & 0.690 & 0.300 & 5916 & 264 \\
\hline 2010 & 0.700 & 0.320 & 5439 & 184 \\
\hline 2015 & 0.710 & 0.335 & 5439 & 168 \\
\hline 2020 & 0.720 & 0.350 & 4517 & 152 \\
\hline 2025 & 0.725 & 0.355 & 3593 & 140 \\
\hline 2030 & 0.730 & 0.360 & 2669 & 128 \\
\hline \multicolumn{5}{|c|}{ GPRA08 Baseline } \\
\hline & CHP System & Electrical & & \\
\hline & Efficiency $^{28}$ & Efficiency $^{28}$ & & \\
\hline 2006 & 0.72 & 0.288 & 3300 & 264 \\
\hline 2010 & 0.72 & 0.320 & 3300 & 184 \\
\hline 2015 & 0.72 & 0.335 & 3000 & 168 \\
\hline 2020 & 0.72 & 0.350 & 2200 & 152 \\
\hline 2025 to 2050 & 0.72 & 0.355 & 1750 & 140 \\
\hline
\end{tabular}


Commercial 200kW Fuel Cell Baseline

\begin{tabular}{|c|c|c|c|c|}
\hline \multicolumn{5}{|c|}{ AE02006 Reference Case } \\
\hline Year & $\begin{array}{c}\text { CHP System } \\
\text { Efficiency }^{28}\end{array}$ & $\begin{array}{l}\text { Electrical } \\
\text { Efficiency }^{28}\end{array}$ & $\begin{array}{l}\text { Installed Cost } \\
(2003 \$ / \mathrm{kW})\end{array}$ & $\begin{array}{c}\text { Maint. Cost } \\
(2003 \$ / k W-y r)\end{array}$ \\
\hline 2006 & 0.750 & 0.360 & 5916 & 232 \\
\hline 2010 & 0.720 & 0.490 & 5439 & 128 \\
\hline 2015 & 0.720 & 0.500 & 5439 & 124 \\
\hline 2020 & 0.720 & 0.510 & 5025 & 120 \\
\hline 2025 & 0.735 & 0.520 & 4048 & 112 \\
\hline 2030 & 0.750 & 0.530 & 3071 & 104 \\
\hline \multicolumn{5}{|c|}{ GPRA08 Baseline } \\
\hline & $\begin{array}{c}\text { CHP System } \\
\text { Efficiency }^{28}\end{array}$ & $\begin{array}{l}\text { Electrical } \\
\text { Efficiency }^{28}\end{array}$ & Installed Cost & Maint. Cost \\
\hline 2006 & 0.72 & 0.288 & 3180 & 232 \\
\hline 2010 & 0.72 & 0.490 & 3180 & 128 \\
\hline 2015 & 0.72 & 0.500 & 2150 & 124 \\
\hline 2020 & 0.72 & 0.510 & 1800 & 120 \\
\hline 2025 to 2050 & 0.72 & 0.520 & 1450 & 112 \\
\hline
\end{tabular}




\section{Program Outputs}

Program outputs can be linked to the Hydrogen Program milestones. The milestone chart shown in Figure B-1 presents the key activities of the Hydrogen Program through completion of the critical path technology development phase in 2015. The Program is projected to continue beyond 2015 to support basic science and RD\&D on advanced technologies and longer-term, centralized hydrogen production alternatives that are carbon-neutral. The milestones are organized according to the National Hydrogen Energy Roadmap's key elements.

Milestones for each of the timelines specify a delivery date for the given technology development, improvement, or demonstration. Some milestones have slipped due to shortfalls in appropriations or changes in program planning. The values given are compiled mainly from the individual RD\&D Plans for the Office of Energy Efficiency and Renewable, The Office of Fossil Energy, and the Office of Nuclear Energy; but include other sources such as DOE analysis, the FreedomCAR and Fuel Partnership Plan, the National Hydrogen Energy Roadmap, DOT, and ongoing federal laboratory research. As technologies evolve and economic and systems analyses progress, these targets will be refined.

For each milestone, the most appropriate measurement units are provided in the legend. For some technologies, costs are primarily associated with scale (e.g., dollars per megawatt of capacity); for others, costs are associated with delivered hydrogen (e.g., dollars per gallon of gasoline equivalent, or gge). The term "project to" means that the technology demonstrated at the indicated time point would meet the specified cost target if that technology were in full commercial-scale (i.e., high-volume) production.

As technical milestones are achieved, the Administration and Congress may need to consider market or end-user incentives to overcome additional barriers to commercialization and infrastructure development. An increased focus on educating consumers about the safe use of hydrogen and its benefits will be essential to enhance awareness and widespread acceptance of the technology. Detailed analysis of life-cycle costs and benefits and environmental impacts will continue to inform decisions regarding future hydrogen research. 
Figure B-1. Technology Development Timeline: Milestones and Decision Points ${ }^{\mathrm{a}, \mathrm{d}, \mathrm{e}, \mathrm{f}}$

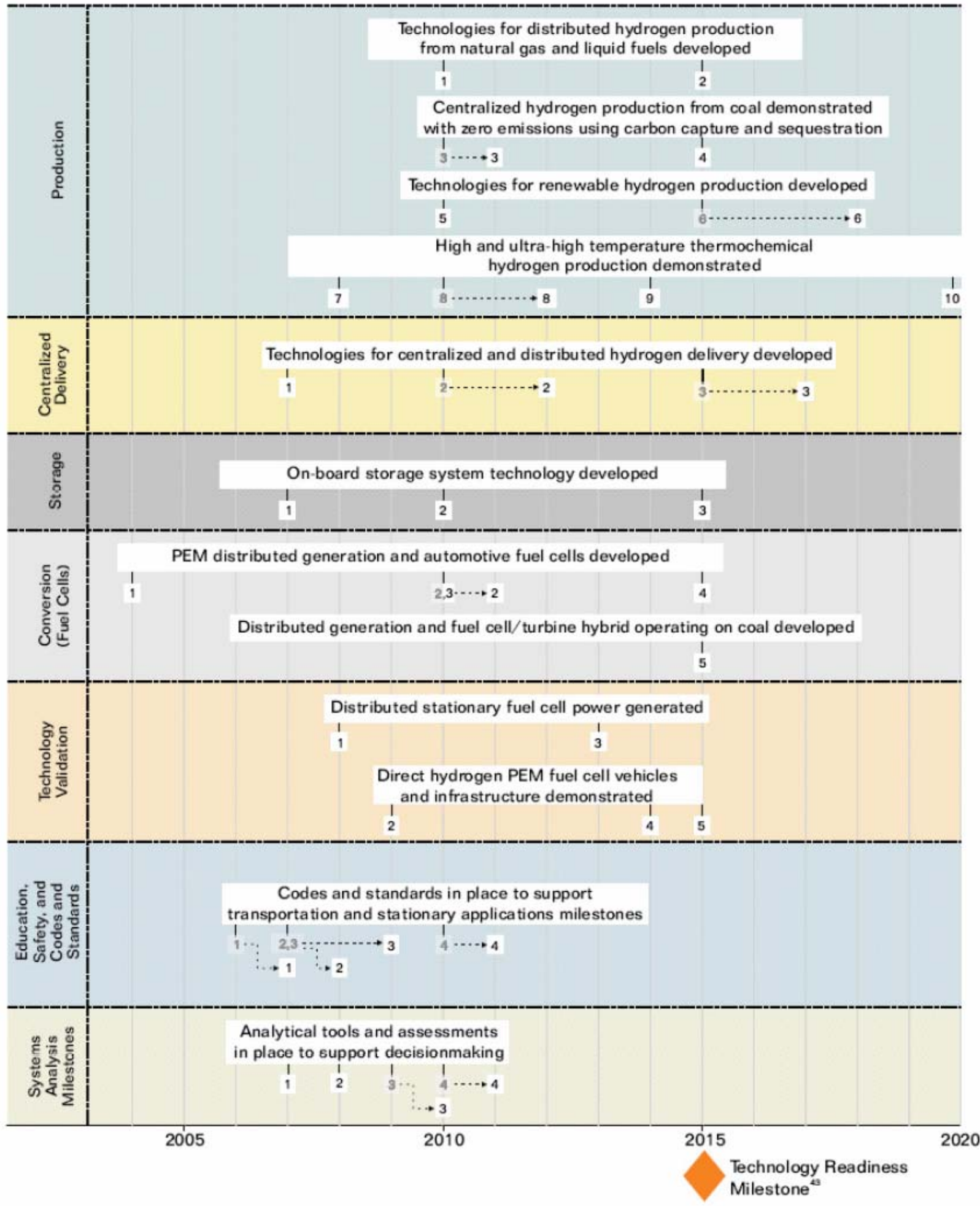

Projected Benefits of Federal Energy Efficiency and Renewable Energy Programs (FY 2008-FY 2050) Appendix B-Hydrogen, Fuel Cells, and Infrastructure Technologies - Page B-18 


\section{Figure B-1 (cont.) Legend for Technology Development Timeline ${ }^{a}$}

\begin{tabular}{|c|}
\hline Production Milestones ${ }^{b}$ \\
\hline Dietrlbuted Natural Gea/Renewable Lquid Fuela \\
\hline $\begin{array}{l}\text { 1. 2010: Develop technology to produce hydrogen from natural } \\
\text { gas at a refueling station that projects to a cost of } \\
\$ 2.50 / \text { gge for hydrogen. [At the pump, untaxed, no carbon } \\
\text { seque stration, at } 5,000 \mathrm{psig} \text { ] }\end{array}$ \\
\hline $\begin{array}{l}\text { 2. 2015: Develop technology to produce distributed hydrogen } \\
\text { from renewable liquid fuels at a refueling station that } \\
\text { projects to a cost of } \$ 2.50 / g \text { ge for hydrogen. [At the pump. } \\
\text { untaxed] }\end{array}$ \\
\hline Central Coal ${ }^{c, d}$ \\
\hline $\begin{array}{l}\text { 3. } 2010 \rightarrow 2011: \text { Develop pre-engineering membrane } \\
\text { separation modules and reactors for hydrogen production } \\
\text { that meet membrane cost target of } \$ 150-200 / \mathrm{ft}^{2}\end{array}$ \\
\hline $\begin{array}{l}\text { 4. 2015: Demonstrate a near-zero atmospheric emission coal } \\
\text { plant producing hydrogen and power with carbon capture } \\
\text { and sequestration at a } 25 \% \text { cost reduction that projects to } \\
\$ 0.80 / g g e \text { at the plant gate (ultimate target: } \$ 1.80 / g g e \\
\text { delivered) }\end{array}$ \\
\hline Renewnable Reeourcee ${ }^{e}$ \\
\hline $\begin{array}{l}\text { 5. 2010: Develop technologies for integrated distributed wind } \\
\text { hydrogen production at } \$ 2.85 / \mathrm{gge} \text { delivered assum ing a } \\
1,500 \mathrm{gge} / \text { day electrolyzer system and } \$ 0.04 / \mathrm{kWh} \text { wind } \\
\text { electricity (2015: } \$ 1.75 / \mathrm{gge} \text { from centralized wind } \\
\text { electrolysis at } \$ 0.03 / \mathrm{kWh} \text {; ultimate target: } \$ 2.75 / \mathrm{gge} \\
\text { delivered) }\end{array}$ \\
\hline $\begin{array}{l}\text { 6. } 2015 \rightarrow 2018 \text { : Demonstrate laboratory-scale } \\
\text { photobiological water splitting system to produce hydrogen } \\
\text { at an energy efficiency of } 5 \% \text { (solar-to-hydrogen). } \\
\text { Demonstrate laboratory-scale photoelectrochemical water } \\
\text { splitting system to produce hydrogen at an energy efficiency } \\
\text { of } 10 \% \text { (solar-to-hydrogen) }\end{array}$ \\
\hline High-Temperature Thermochemical ${ }^{f}$ \\
\hline $\begin{array}{l}\text { 7. } 2007 \rightarrow 2008 \text { : Operate laboratory-scale thermochemical } \\
\text { and electrolytic processes to determine the feasibility of } \\
\text { coupling them with a nuclear reactor }\end{array}$ \\
\hline $\begin{array}{l}\text { 8. } 2010 \rightarrow 2012 \text { : Laboratory-scale demonstration of solar- } \\
\text { driven high-temperature thermochemical hydrogen } \\
\text { production that projects to a cost } \$ 6.00 / g g e \text { (ultimate } \\
\text { target: } \$ 7.00 / g \text { ge delivered) }\end{array}$ \\
\hline $\begin{array}{l}\text { 9. } 2011 \rightarrow 2014: \text { Pilot-scale demonstration of } \\
\text { thermochemical hydrogen production system for use with } \\
\text { nuclear reactors that projects to a cost of } \$ 2.50 / g g e \\
\text { (ultimate target: } \$ 3.50 / \text { gge delivered) }\end{array}$ \\
\hline $\begin{array}{l}\text { 0. } 2017 \rightarrow 2020 \text { : Engineering-scale demonstration of } \\
\text { thermochemical hydrogen production system for use with } \\
\text { nuclear reactors that projects to a cost less than } \$ 2.00 / g g e \\
\text { ( } \$ 3.00 / \text { gge delivered) }\end{array}$ \\
\hline
\end{tabular}

\begin{tabular}{||} 
Storage Milestones \\
1. 2007 : Downselect hydrogen \\
storage options with potential to \\
meet 2010 targets \\
2. 2010 : Develop and verify on- \\
board storage systems achieving: \\
$6 \%$ by weight capacity and 1,500 \\
watt hours/liter energy density at \\
a cost of $\$ 4.00 / \mathrm{kWh}$ of stored \\
energy \\
3. $2015:$ Develop and verify on- \\
board storage systems achieving: \\
$9 \%$ by weight capacity. 2.700 watt \\
hours/liter, and $\$ 2.00 / \mathrm{kWh}$
\end{tabular}

Validation Milestones

1. 2008: Validate stationary fuel cell system that co-produces hydrogen and electricity at 20.000 hours durability with $32 \%$ efficiency at a cost of $\$ 1500 / \mathrm{kW}$ or less

2. 2009: Validate polymer electrolyte membrane fuel cell vehicles at multiple sites. achieving 2,000 hours durability, a 250 -mile range, and $\$ 3.00 / \mathrm{gge}$ of hydrogen

3. 2013: Validate stationary fuel cell system that co-produces hydrogen and electricity at 40,000 hours durability with $40 \%$ efficiency at a cost of $\$ 750 / \mathrm{kW}$ or less

4. 2014: Validate PEM fuel cells on operational vehicles in different climatic conditions that can be produced for $\$ 45 / \mathrm{kW}$ when produce din quantities of 500,000

5. 2015: Validate polymer electrolyte membrane fuel cell vehicles achieving 5,000 hours durability (service life of vehicle) and a 300 -mile range

\section{Conversion Milestones ${ }^{\circ}$}

1. 2004: Decision to discontinue on-board fuel processing based on inability to achieve $78 \%$ efficiency and $<0.5$ minute start time

2. $2010 \rightarrow 2011:$ Distributed stationary generation natural gas/propane 5-250 kW fuel cell go/ no -go decision based on ability to achieve: $40 \%$ electrical to achieve: $40 \%$ electrical
efficiency, 40,000 hours durability (equivalent to service life between major overhauls), at a cost of less than $\$ 400-\$ 750 / \mathrm{kW}$ (depending on application)

3. 2010: Develop direct hydrogen polymer electrolyte membrane aut omotive fuel cell operating at $60 \%$ peak efficiency, $220 \mathrm{~W} / \mathrm{L}$ density, $325 \mathrm{~W} / \mathrm{kg}$ specific power at a cost of $\$ 45 / \mathrm{kW}$ (automotive production quant ity)

4. 2015: Polymer electrolyte membrane automotive fuel cell meets cost of $\$ 30 / \mathrm{kW}$

5. 2015: Fuel cell/turbine hybrid operating on coal developed at a cost of $\$ 400 / \mathrm{kW}$ with a HHV efficiency of $50 \%$ with carbon sequest ration

\section{Education, Safety, and Codes} and Standards Milestones"

1. $2006 \rightarrow 2007$ : Facilitate publishing domestic and international hydrogen quality standards and publish initial set of basic safety training materials

2. $2007 \rightarrow$ 2008: Publish initial Best Practices manual for hydrogen safety

3. $2007 \rightarrow$ 2009: Education program for safety and code officials in place

4. $2010 \rightarrow$ 2012: hitial set of technical codes and standards in place to support demonstrations, commercialization decisions and regulatory standards

\section{Phase 1 Technology Readiness: 2015}

Based on technology development success in meeting customer requirements and establishing a business case

\section{Centralized Delivery Milestones}

1. 2007: Define the criteria for a cost-effective hydrogen fuel delivery infrastructure for supporting the introduction and long-term use of hydrogen for transportation and stationary power

2. $2010 \rightarrow 2012:$ Develop technologies to reduce the cost of hydrogen fuel delivery from the point of production to the point of use in vehicles or stationary power units to $<\$ 1.70 / \mathrm{gge}$ of hydrogen

3. 2015 $\rightarrow$ 2017: Develop technologies to reduce the cost of hydrogen fuel delivery from the point of production to the point of use in vehicles or stationary power units to $<\$ 1.00 / g$ ge of hydrogen

Systems Analysis Milestones
1. $2007:$ Develop transition scenarios for infrastructure and
hydrogen resources for a hydrogen economy
2. $2008:$ Develop a macro- -
infrastructure model of the hydrogen fuel
3. $2009 \rightarrow 2010:$ Complete assessment of hydrogen quality
requirements for production, delivery, storage and fuel cell
pathway
4. $2010 \rightarrow 2011:$ Develop electricity infrastructure module for
the macro-system model

d receiving funding at the Hydrogen Program planning Achieving the milestone

b The hydrogen cost milestones are not yet normalized across the Hydrogen Program. The Program is in the process of normalizing the criteria used to determine the Hydrogen Program cost goals using the recentlydeveloped " $\mathrm{H} 2 \mathrm{~A}$ " modeling tool.

- The assumed feedstock cost for coal is $\$ 29.00 /$ short ton

- Milestone delay due to changes in Fossil Energy program planning.

- Milestone delays are due to shortfalls in congressional appropriations.

Milestone delays are due to changes in the DOE budget planning profile. 
Table B-4 provides the key program outputs and milestones for each of the HFCIT program elements. These outputs are interrelated. The GPRA modeling uses the hydrogen production and stationary fuel cell program outputs as its program inputs.

Table B-4. Program Outputs, Activities, and Milestones

\section{Outputs \\ Fuel Cells}

2010

2015

2011

2010

2010
Associated Activities

Develop durable, direct

hydrogen fuel cell power system

for transportation

Develop durable, direct

hydrogen fuel cell power system

for transportation

Develop a distributed generation PEM fuel cell system operating on natural gas or LPG

Develop a fuel cell system for consumer electronics

Develop a fuel cell system for auxiliary power
Associated Milestones

Cost: $\$ 45 / \mathrm{kW}$

Cost: $\$ 30 / \mathrm{kW}$

Electrical Efficiency: $40 \%$

Durability: 40,000 hrs.

Cost: $\$ 400-750 / \mathrm{kW}$

CHP Efficiency: $80 \%$

Energy density: $1000 \mathrm{Wh} / 1$

Cost: $\$ 3 / \mathrm{W}$

Energy density: $100 \mathrm{~W} / \mathrm{kg}$

Power density: $100 \mathrm{~W} / 1$

Cost: $\$ 400 / \mathrm{kW}$

3-30 kW

\section{Storage}

2010

Develop and verify on-board

storage systems

$2 \mathrm{kWh} / \mathrm{kg}(6 \mathrm{wt} \%)$

$1.5 \mathrm{Kwh} /$ liter

Cost: $\$ 4 / \mathrm{kW}$

Develop and verify on-board

storage systems

$3 \mathrm{kWh} / \mathrm{kg}\left(9 \mathrm{wt}^{0} \%\right)$

$2.0 \mathrm{Kwh} /$ liter

Cost: $\$ 2 / \mathrm{kW}$

\section{Production}

2010

2015

2010

2015

Reduce the cost of distributed production of hydrogen from natural gas

Reduce the cost of distributed production of hydrogen from natural gas

Reduce the cost of distributed hydrogen production from biomass-derived renewable liquids

Reduce the cost of distributed hydrogen production from biomass-derived renewable liquids
Cost: $2.50 /$ gge

Cost: $\$ 2.00 /$ gge

Cost: $\$ 3.60 /$ gge

Cost: $<\$ 3.00 /$ gge 
Develop technologies for distributed electrolysis hydrogen

2015

2015

2012

2017

2012

2017

\section{Delivery}

2012

2012

2017

Technical Validation

2009

2015

2009

2015

2011 production

Develop technologies for

distributed electrolysis hydrogen

production

Develop technology for hydrogen production from central wind electrolysis

Reduce the cost of hydrogen production from biomass gasification

Reduce the cost of hydrogen production from biomass gasification

Develop technologies for solar high temperature thermochemical hydrogen production Develop technologies for solar high temperature thermochemical hydrogen production

Reduce the cost of hydrogen transport from central and semicentral facilities to gate of refueling station Reduce the cost of compression, storage and dispensing

Reduce the cost of hydrogen pipeline delivery from point of production to point of use

Validate hydrogen vehicles

Validate hydrogen vehicles

Validate hydrogen infrastructure for hydrogen production Validate hydrogen infrastructure for hydrogen production

Validate an integrated biomass/wind or geothermal electrolyzer-to-hydrogen system to produce hydrogen
Cost: $\$ 2.85 /$ gge

Cost: $<\$ 3.00 /$ gge

Cost: \$1.75/gge@ plant gate

Cost: \$1.60/gge@ plant gate

Cost: <\$1.60/gge@ @ plant gate

Cost: $\$ 6.00 /$ gge

Cost: $\$ 3.00 /$ gge

Cost: $<\$ 0.80 /$ gge

Cost: $<\$ 1.00 /$ gge

Cost: $<\$ 0.90 /$ gge

Range: 250 miles

Fuel cell durability: 2000 hrs.

Range: 300 miles

Fuel cell durability: 5000 hrs.

Cost: $\$ 3.00 /$ gge

Cost: $\$ 1.50 /$ gge

Cost: $\$ 2.85 /$ gge 
Figure B-2. Summary Program Logic Model for HFCIT

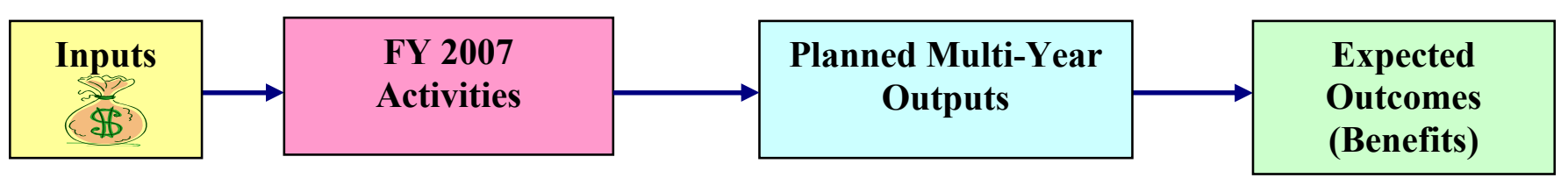

\section{Funding: \\ \$283.4 M FY06 \\ \$289.5 M FY07R \\ \$296.3 M FY08R}

Hydrogen Storage: Increase
storage capacity to 9 wt.\% at
an energy cost of $\$ 2 / \mathrm{kWh}$ of
stored energy
Hydrogen Fuel Cells:
Reduce direct hydrogen
polymer electrolyte membrane
(PEM) automotive fuel cell
operating at $60 \%$ peak
efficiency to a cost of $\$ 30 / \mathrm{kW}$
Hydrogen Production:
Reduce the cost of hydrogen
production from distributed
natural gas reforming to
\$2/gge.
Complete R\&D for hydrogen
production from renewable
resources that could reduce
the hydrogen cost to less than
\$3/gge.
Hydrogen Delivery:
Reduce the cost of hydrogen
fuel delivery from point of
production to the point of use
in vehicles or stationary
power units.
Validate PEM fuel cell
vehicle durability and driving
range.
Validate stationary fuel cell
system for co-production of
hydrogen and electricity.

Hydrogen Storage:
Increase storage capacity to 6
wt.\% at an energy cost of
$\$ 4 / \mathrm{kWh}$ of stored energy by
2010 .
Hydrogen Fuel Cells:
Reduce direct hydrogen polymer
electrolyte membrane (PEM)
automotive fuel cell operating at
$60 \%$ peak efficiency to a cost of
$\$ 45 / \mathrm{kW}$ in 2010 .
Hydrogen Production:
Reduce the cost of hydrogen
production from distributed
natural gas reforming to
$\$ 2.50 /$ gge by 2010.
Complete R\&D for hydrogen
production from renewable
liquid fuels that could reduce the
hydrogen cost to less than
$\$ 3 /$ gge by 2015 .
Hydrogen Delivery:
Reduce the cost of hydrogen fuel
delivery from the point of
production to point of use in
vehicles or stationary power
units to $<\$ 1.00 /$ gge by 2017.
Technology Validation:
Validate PEM fuel cell vehicle
durability of 5,000 hrs. and
driving range of 300 miles by
2015.
Validate stationary fuel cell
system for co-production of
hydrogen and electricity at
40,000 hrs durability with $40 \%$
efficiency at a cost of $\$ 750 / \mathrm{kW}$
by 2013 .

\section{Annual Savings:}

Reduce oil

dependency

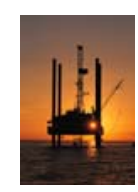

Reduce greenhouse gas emissions.

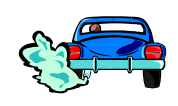




\section{Translating Program Outputs to Market Outcomes}

If these milestones are met, there is a high probability that customer requirements can be met, and that industry can begin to realize a business case for proceeding with the implementation of the hydrogen infrastructure and fuel cell vehicles. While the full extent of life-cycle cost and energy and environmental impacts will not be achieved for decades, meeting the Technology Readiness in 2015 will begin to yield national benefits as early as 2025 . Although the many interrelated program goals and milestones were listed and described above, only the goals specific to hydrogen production and fuel cells are directly modeled as program inputs to NEMS and MARKAL models.

\section{Target Market Description}

The target markets for the Office of Hydrogen, Fuel Cells, and Infrastructure Technologies (HFCIT) program include transportation (cars and light trucks) and stationary (particularly residential and commercial) applications. The two main markets will be discussed separately below.

\section{Target Market: Fuel Cell Vehicle Market}

The market for fuel cell vehicles (FCVs) includes all cars and light trucks sold for both personal and business use. Today, the size of this market is approximately 17 million vehicle sales per year. Total car and light truck stock is about 230 million vehicles. EIA projects both sales and stock to grow to more than 21 million and 330 million respectively by 2030 . Additional growth is expected post-2030.

The early market competition for the hydrogen fuel cell vehicles will be the conventional and hybrid internal combustion engine (ICE) vehicles that operate on gasoline and E85 fuel. Also, the fuel cell vehicle may face competition from other alternative vehicles such as plug-in hybrids as these vehicles develop and enter the market.

\section{Stationary Fuel Cell Market}

Stationary fuel cells are one of a variety of distributed electricity-generation technologies. The particular market sectors in which stationary fuel cells are most applicable include residential and commercial applications.

\section{Key Factors in Shaping the Market Adoption of FCVs}

Key factors associated with the adoption of new vehicle technologies include how the new vehicle technologies compare with the baseline vehicle technologies in terms of the following vehicle attributes:

- Vehicle Price

- Fuel Economy

- Range

- Maintenance Cost

- Acceleration 
- Top Speed

- Passenger and Cargo Space

Of these, vehicle price and fuel economy are the most important.

Non-vehicle attributes that are important factors in a consumer's decision to purchase new vehicle technologies include the following:

- Fuel Price

- Fuel Availability

\section{Interim Outcomes of Fuel Cell Vehicles}

The target market is light vehicles (cars and light trucks). The light vehicles are purchased by buyers who vary from another with respect to driving patterns, number of miles driven each year, and the need for vehicle attributes such as towing, number of seats, and interior volume. These vehicles will be replaced with hydrogen fuel cell vehicles and will require new components for the hydrogen storage and hydrogen fuel cell engines. Also, hydrogen will be needed to fuel the vehicles, which requires production facilities and delivery infrastructure to provide the hydrogen.

The program outputs are hydrogen storage for onboard the vehicle and the fuel cells for the vehicle power plant with their associated efficiencies and costs. These systems will be adopted by industry and placed into new vehicles produced by manufacturers. How well these fuel cell vehicles sell in the marketplace is a function of many variables such as incremental cost when first introduced (which can be affected by company pricing decisions and government incentives and regulations), what models are introduced in first, the overall fuel efficiency of the vehicle (taking into account any performance changes in the vehicle), and fuel prices.

The program outputs for production and delivery of the hydrogen will include the costs, efficiency, and feasibility of construction. The hydrogen must be competitive with the conventional gasoline fuel. Once the program goals are met, industry will utilize the production and delivery technologies to produce the fuel required by the vehicles.

\section{Methodology and Calculations for Fuel Cell Vehicles}

The factors listed above include the factors used in the modeling of new vehicle technology penetration by the NEMS-GPRA08 and MARKAL-GPRA08 models. These models, and their treatment of HFCIT technologies, are described in a separate appendix of this report. Fuel Cell Vehicle (FCV) attributes and other factors are discussed below.

\section{FCV Attributes}

FCV attributes were developed based on the HFCIT program goals, discussions with HFCIT technology development managers, Powertrain Systems Analysis Toolkit (PSAT) modeling, and payback analysis and review of past GPRA characterizations..$^{19,20,21,22,23,24}$ The two most important attributes are vehicle fuel economy and vehicle price. 
FCV fuel economy is estimated using the PSAT model. PSAT is a simulation model used by DOE to evaluate the fuel economy and performance of light vehicles using various technologies. Appendix F (the FCVT program appendix) provides a discussion of how the fuel economies of advanced gasoline and diesel vehicles, hybrids (gasoline and diesel), plug-in hybrids, and FCVs are estimated for use in GPRA.

The incremental vehicle price of FCVs (and other advanced vehicle technologies considered in GPRA) is estimated using payback analysis. The incremental price estimate is based on the assumption that, ultimately, FCVs will become cost-competitive with conventional vehicles, a goal of the program. We assume that FCVs will be cost-competitive when the incremental price of the FCV equals the present value of the energy-cost reduction achieved by FCVs over three years, assuming a hydrogen price seen by the FCV owner of $\$ 2.50$ /gallon (based on the AEO2006 High Oil case in 2030 and expressed in 2004\$) gasoline equivalent plus $\$ 0.392$ in federal and state taxes and 7.5\% discount rate. (This IRS discount rate was selected in 2000 when this payback model was built. If we were to use the 2006 IRS discount rate, it would be $\sim 5.8 \%$.) The hydrogen price is based on the hydrogen cost goal and is an average of the hydrogen cost goal range. In the early years of FCV introduction, incremental prices are assumed to be higher than would be estimated with this simple payback calculation (i.e., 50\% higher). (See the FCVT program appendix for further details on the calculation of incremental prices for GPRA.)

Because the NEMS-GPRA08 and MARKAL-GPRA08 models require different levels of detail for input, two separate vehicle characterizations are developed. In both cases, most of the attributes are provided as ratios to the vehicle attributes of conventional vehicles. (For NEMSGPRA08, the dollar values of the price increments were provided.) The attributes are for new vehicles in the year listed. The conventional vehicles to which the FCVs are compared are the conventional vehicles of the AEO2006 Reference Case extended to 2050 with modest increases in fuel economy.

Table B-5 contains the vehicle attributes for FCVs provided for input to the NEMS-GPRA08 model. Attributes are provided for six car size classes and six light-truck classes. Table B-6 contains vehicle attributes for FCVs provided as input to the MARKAL-GPRA08 model. MARKAL-GPRA08 uses only vehicle price and fuel economy attributes. MARKAL-GPRA08 does not disaggregate cars and light trucks into various classes.

Table B-5. FCV Attributes Input to NEMS-GPRA08

(All units are ratios to the conventional gasoline vehicles of the specific year, except for the incremental price, which is in $2004 \$$. These ratios are described in further detail in the FCVT Program appendix. Additional fuel cell vehicle information is available for 2030 in the attached spreadsheet provided below. This document contains all the detailed information shown below.)

2-SEATER

Fuel Cell (H2)

Incremental Vehicle Price (\$)

Range

Maintenance Cost

\section{2}

2190

0.90

1.05
MINI-COMPACT SUB-COMPACT

2025

1876

0.96

1.02

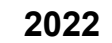

2032

0.90

1.05
2025

1744

0.96

1.02
2022

1850

0.90

1.05
COMPACT

$2025 \quad 2022$

$1583 \quad 1724$

$0.96 \quad 0.90$

$1.02 \quad 1.05$
2025

1482

0.96

1.02 


$\begin{array}{lllllllll}\text { Acceleration } & 1.00 & 1.00 & 1.00 & 1.00 & 1.00 & 1.00 & 1.00 & 1.00 \\ \text { Top Speed } & 0.90 & 0.93 & 0.90 & 0.93 & 0.90 & 0.93 & 0.90 & 0.93 \\ \text { Luggage Space } & 0.80 & 0.86 & 0.80 & 0.86 & 0.80 & 0.86 & 0.80 & 0.86 \\ \text { Fuel Economy (a) } & 2.23 & 2.28 & 2.23 & 2.28 & 2.23 & 2.28 & 2.23 & 2.28\end{array}$

MEDIUM CAR

Fuel Cell (H2)

Incremental Vehicle

Price (\$)

Range

Maintenance Cost

Acceleration

Top Speed

Luggage Space

Fuel Economy (a)

$\begin{array}{ccc}\mathbf{2 0 1 8} & \mathbf{2 0 2 3} & \mathbf{2 0 2 5} \\ & & \\ 1921 & 1450 & 1418 \\ 1.00 & 1.00 & 1.00 \\ 1.05 & 1.00 & 0.97 \\ 1.00 & 1.00 & 1.00 \\ 0.85 & 0.9 & 0.92 \\ 0.90 & 1.00 & 1.00 \\ 2.16 & 2.24 & 2.27\end{array}$

LARGE CAR

$2018 \quad 2023 \quad 2025$

$2061 \quad 1549 \quad 1514$

$\begin{array}{lll}1.00 & 1.00 & 1.00\end{array}$

$\begin{array}{lll}1.05 & 1.00 & 0.97\end{array}$

$\begin{array}{lll}1.00 & 1.00 & 1.00\end{array}$

$\begin{array}{lll}0.85 & 0.9 & 0.92\end{array}$

$\begin{array}{lll}0.90 & 1.00 & 1.00\end{array}$

$\begin{array}{lll}2.16 & 2.24 & 2.27\end{array}$

\begin{tabular}{llllllllll} 
SMALL SUV & \multicolumn{3}{c}{ LARGE SUV } & \multicolumn{2}{c}{ SMALL TRUCK } & \multicolumn{2}{c}{$\begin{array}{c}\text { CARGO (Incl. 2b) } \\
\text { TRUCK }\end{array}$} \\
$\mathbf{2 0 2 0}$ & $\mathbf{2 0 2 5}$ & $\mathbf{2 0 1 8}$ & $\mathbf{2 0 2 3}$ & $\mathbf{2 0 2 5}$ & $\mathbf{2 0 2 0}$ & $\mathbf{2 0 2 5}$ & $\mathbf{2 0 2 4}$ & $\mathbf{2 0 2 5}$ \\
& & & & & & & & \\
2584 & 1833 & 3192 & 2276 & 2170 & 2105 & 1505 & 2665 & 2508 \\
0.90 & 1.00 & 1.00 & 1.00 & 1.00 & 0.90 & 1.00 & 0.90 & 0.93 \\
1.10 & 1.00 & 1.05 & 1.00 & 1.00 & 1.10 & 1.00 & 1.05 & 1.04 \\
1.00 & 1.00 & 1.10 & 1.00 & 1.00 & 1.00 & 1.00 & 1.00 & 1.00 \\
0.90 & 0.95 & 0.90 & 0.95 & 0.95 & 0.90 & 0.95 & 0.90 & 0.90 \\
0.90 & 0.95 & 0.95 & 1.00 & 1.00 & 0.90 & 0.95 & 0.90 & 0.91 \\
2.40 & 2.40 & 2.40 & 2.40 & 2.40 & 2.17 & 2.17 & 2.15 & 2.15
\end{tabular}

Fuel Cell (H2)

Incremental Vehicle Price

(\$)

Range

Maintenance Cost

Acceleration

Top Speed

Luggage Space

Fuel Economy (a)
CARGO (Incl. 2b)
MINIVAN

Fuel Cell (H2)

Incremental Vehicle Price (\$)

Range

Maintenance Cost

Acceleration

Top Speed

Luggage Space

Fuel Economy (a)

$\begin{array}{ll}\mathbf{2 0 2 0} & \mathbf{2 0 2 5} \\ 2521 & 1797 \\ 0.90 & 1.00 \\ 1.10 & 1.00 \\ 1.00 & 1.00 \\ 0.90 & 0.95 \\ 0.90 & 0.95 \\ 2.40 & 2.40\end{array}$

LARGE VAN

$\begin{array}{ccc}\mathbf{2 0 1 8} & \mathbf{2 0 2 3} & \mathbf{2 0 2 5} \\ 2439 & 1749 & 1667 \\ 1.00 & 1.00 & 1.00 \\ 1.05 & 1.00 & 0.97 \\ 1.10 & 1.00 & 1.00 \\ 0.90 & 0.95 & 0.95 \\ 0.95 & 1.00 & 1.00 \\ 2.40 & 2.40 & 2.40\end{array}$

(a) Gasoline gallon equivalent 
Table B-6. FCV Attributes for Input to MARKAL-GPRA08 (2004\$)

All units are ratios to the conventional gasoline vehicles of the specific year, except for the incremental price, which is in $\$ 2004$.

\begin{tabular}{|c|c|c|c|c|c|c|c|}
\hline \multicolumn{8}{|c|}{ Ratios to Conventional Vehicles } \\
\hline & & 2010 & 2020 & 2025 & 2030 & 2035 & 2050 \\
\hline \multirow[t]{2}{*}{ CARS } & MPG & 2.01 & 2.2 & 2.28 & 2.41 & 2.54 & 2.85 \\
\hline & $\begin{array}{l}\text { Incremental } \\
\text { Price }\end{array}$ & & & 1.058 & 1.054 & & \\
\hline \multirow[t]{2}{*}{ LIGHT TRUCKS } & MPG & 2.24 & 2.30 & 2.30 & 2.31 & 2.32 & 2.90 \\
\hline & $\begin{array}{l}\text { Incremental } \\
\text { Price }\end{array}$ & & & 1.066 & 1.056 & & \\
\hline
\end{tabular}

\section{Hydrogen Price}

HFCIT Program goals and the H2A data for the various technologies were used to estimate capital and O\&M costs and production efficiencies for distributed natural gas reformers, central biomass gasifiers, distributed ethanol reformers, and central and distributed electrolytic production technologies. Assumptions for central coal and natural gas production technologies were adapted from $\mathrm{H} 2 \mathrm{~A}$ production analysis results. ${ }^{26}$ The $\mathrm{H} 2 \mathrm{~A}$ model enables analyses to be performed on a well-to-gate basis for the central-plant technologies and a well-to-pump basis for the forecourt technologies. The results - which are based on the economic factors, technology performance and process factors of process efficiency, yield, energy and feedstock inputs, size of the plant and hydrogen product conditions - provide information on the plant-gate hydrogen selling price, technology cost contributions, and total fuel and feedstock consumption.

The infrastructure requirements and operating costs for the widespread distribution of hydrogen from central hydrogen production facilities vary widely by distance and method. The infrastructure representation for hydrogen delivered by truck via gaseous tube trailer and liquid tank truck were obtained from the $\mathrm{H} 2 \mathrm{~A}$ delivery ${ }^{27}$ scenario models. The cost of delivery for various vehicle penetration levels is provided in Figures B-3 and B-4. 
Figure B-3. Hydrogen Delivery Cost for Gaseous Tube Trailer

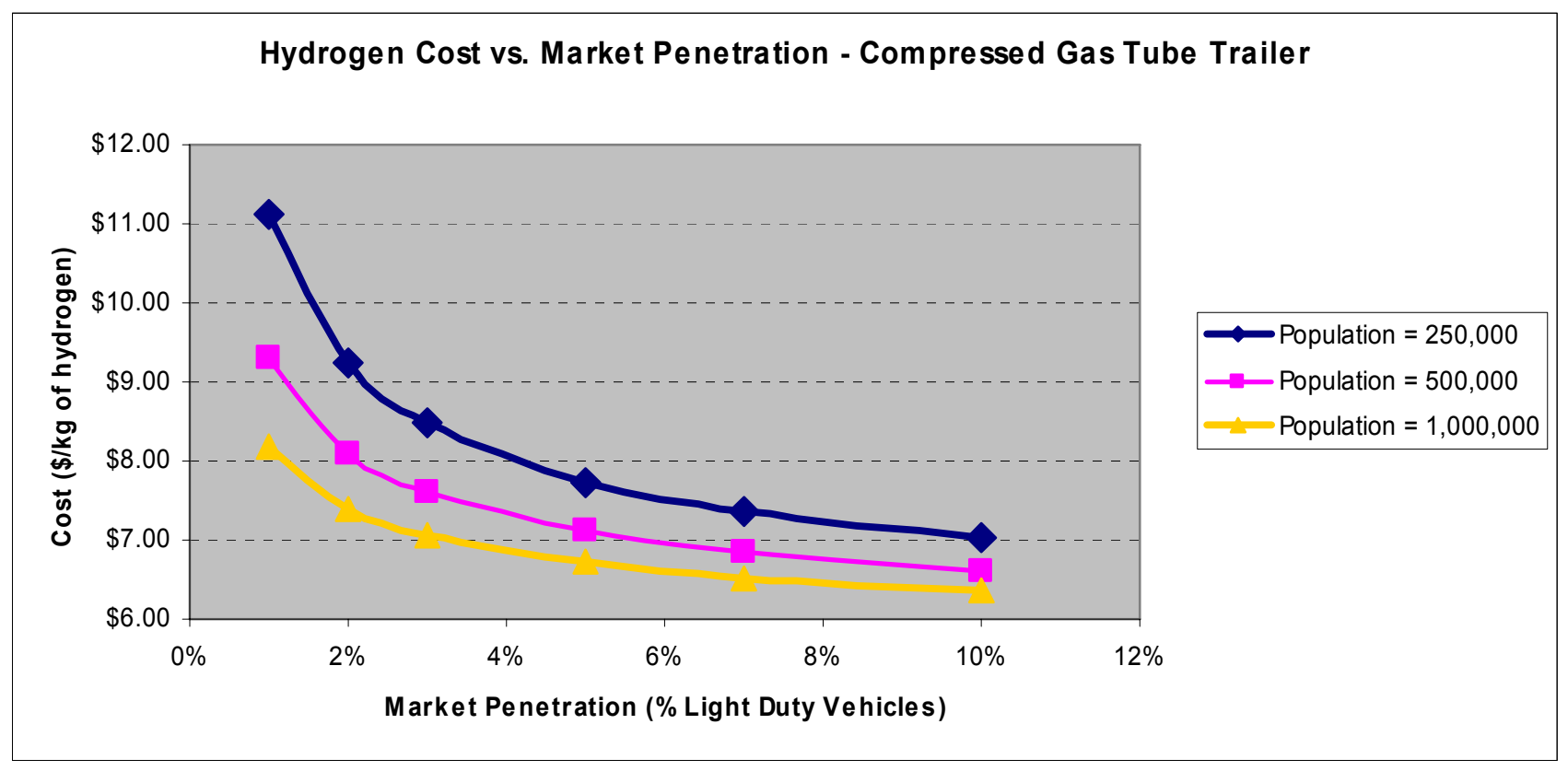

Figure B-4. Hydrogen Delivery Cost for Liquid Tank Truck (cost includes the cost of liquefaction)

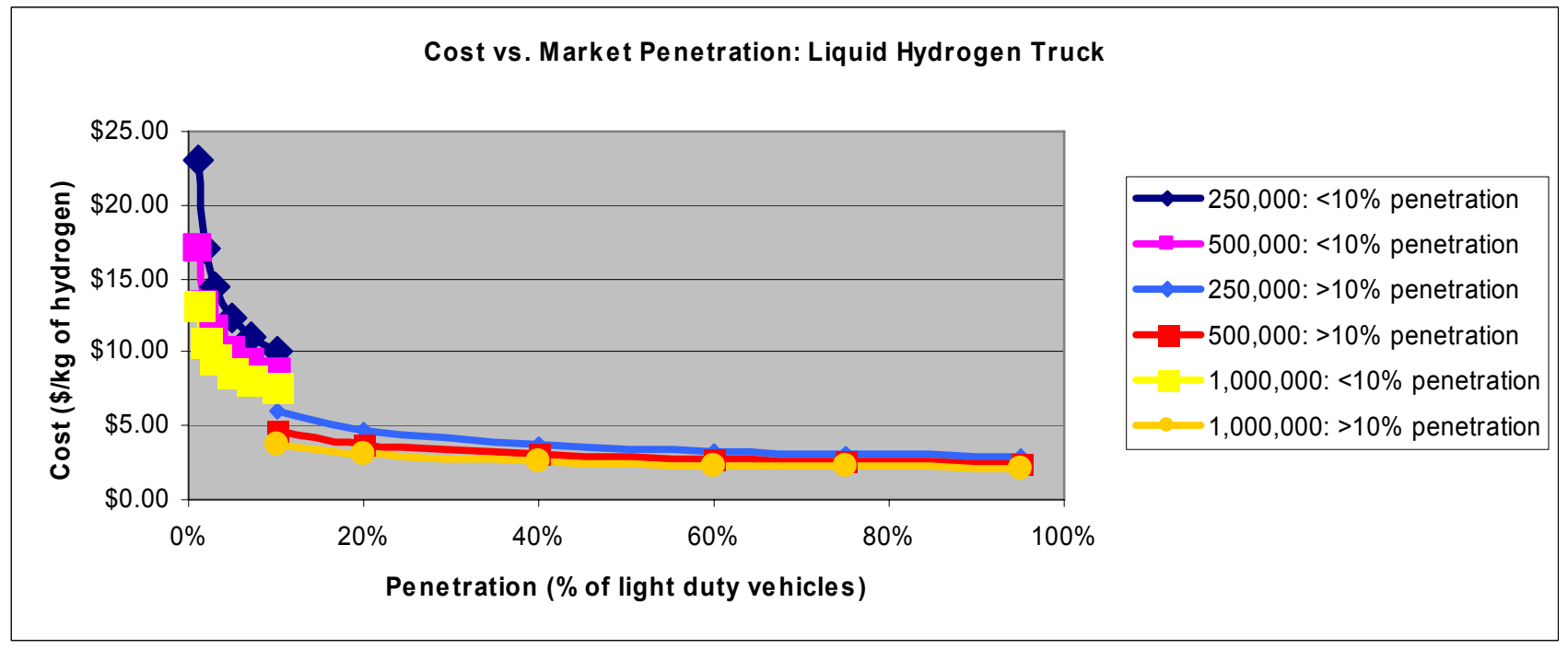


The Hydrogen Program goal (based on the HFCIT MYPP) for hydrogen delivery by pipeline is $\$ 1 /$ gge in 2017. Once the R\&D is completed to achieve this goal for pipeline delivery, the technology will be available for adaptation by industry for commercial use. It is assumed industry will require until 2030 to install the pipeline infrastructure that will be able to deliver hydrogen at $\$ 1 /$ gge.

The hydrogen component costs for production technologies were developed from the technology goals and the use of the H2A cost analysis tool. The Hydrogen Program goals and targets were inputs for each technology in the H2A model. These inputs, combined with basic economic parameters, were used to generate the costs for capital, feedstock, and O\&M (operating and maintenance), which are expressed in terms of gge (gallon of gasoline equivalent) of produced hydrogen. Table B-7 exhibits the projected hydrogen costs by cost component for the Hydrogen Program Cases.

Table B-7. Hydrogen Production Costs by Technology and Component (2005\$/gge) (a)

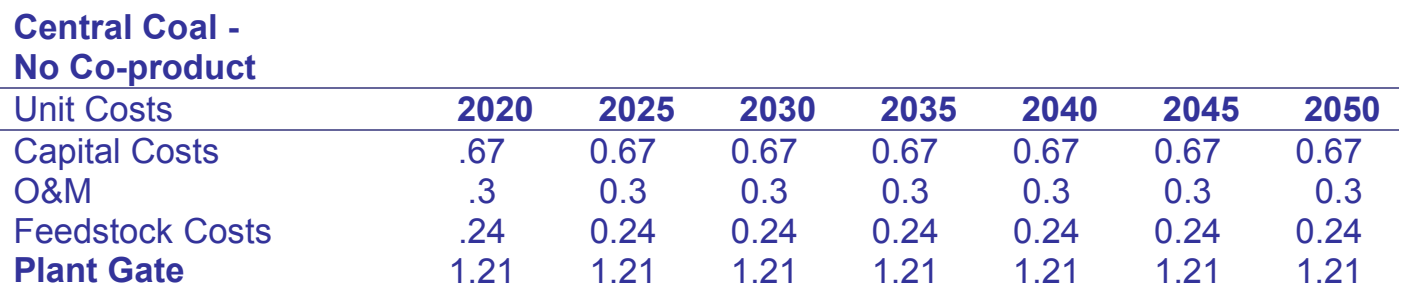

\begin{tabular}{|c|c|c|c|c|c|c|c|}
\hline $\begin{array}{l}\text { Central Coal - with } \\
\text { Elec Co-product }\end{array}$ & & & & & & & \\
\hline Unit Costs & 2020 & 2025 & 2030 & 2035 & 2040 & 2045 & 2050 \\
\hline Capital Costs & & & 1.21 & 1.21 & 1.21 & 1.21 & 1.21 \\
\hline O\&M & & & .01 & .01 & .01 & .01 & .01 \\
\hline Feedstock Costs & & & 0.32 & 0.32 & 0.32 & 0.32 & 0.32 \\
\hline Plant Gate & & & 1.54 & 1.54 & 1.54 & 1.54 & 1.54 \\
\hline
\end{tabular}

\begin{tabular}{lllccccc}
\hline Remote Gas Reformer & & & & & & & \\
\hline Unit Costs & $\mathbf{2 0 2 0}$ & $\mathbf{2 0 2 5}$ & $\mathbf{2 0 3 0}$ & $\mathbf{2 0 3 5}$ & $\mathbf{2 0 4 0}$ & $\mathbf{2 0 4 5}$ & $\mathbf{2 0 5 0}$ \\
\hline Capital Costs & 0.6 & 0.6 & .6 & .6 & .6 & .6 & .6 \\
\hline O\&M & .64 & 0.64 & 0.64 & 0.64 & 0.64 & 0.64 & 0.64 \\
\hline Feedstock Costs & .76 & .76 & .76 & .76 & .76 & .76 & .76 \\
\hline Plant Gate & 2.00 & 2.00 & 2.00 & 2.00 & 2.00 & 2.00 & 2.00 \\
\hline
\end{tabular}

\begin{tabular}{lccccccc}
\hline Central Gas Reformer & & & & & & & \\
\hline Unit Costs & $\mathbf{2 0 2 0}$ & $\mathbf{2 0 2 5}$ & $\mathbf{2 0 3 0}$ & $\mathbf{2 0 3 5}$ & $\mathbf{2 0 4 0}$ & $\mathbf{2 0 4 5}$ & $\mathbf{2 0 5 0}$ \\
\hline Capital Costs & .26 & .26 & 0.26 & 0.26 & 0.26 & 0.26 & 0.26 \\
\hline O\&M & .22 & .22 & 0.23 & 0.23 & 0.23 & 0.23 & 0.23 \\
\hline Feedstock Costs & .9 & .9 & 1.03 & 1.03 & 1.03 & 1.03 & 1.03 \\
\hline Plant Gate & 1.38 & 1.38 & 1.52 & 1.52 & 1.52 & 1.52 & 1.52 \\
\hline
\end{tabular}




\begin{tabular}{llllllll}
\hline Central Biomass & & & & & & & \\
\hline Unit Costs & $\mathbf{2 0 2 0}$ & $\mathbf{2 0 2 5}$ & $\mathbf{2 0 3 0}$ & $\mathbf{2 0 3 5}$ & $\mathbf{2 0 4 0}$ & $\mathbf{2 0 4 5}$ & $\mathbf{2 0 5 0}$ \\
\hline Capital Costs & .45 & .45 & .45 & .45 & .45 & .45 & .45 \\
O\&M & .45 & .45 & .45 & .45 & .45 & .45 & .45 \\
Feedstock Costs & .51 & .51 & .51 & .51 & .51 & .51 & .51 \\
Plant Gate & 1.41 & 1.41 & 1.41 & 1.41 & 1.41 & 1.41 & 1.41
\end{tabular}

\begin{tabular}{lllllllc}
\hline Distributed Ethanol & & & & & & & \\
\hline Unit Costs & $\mathbf{2 0 2 0}$ & $\mathbf{2 0 2 5}$ & $\mathbf{2 0 3 0}$ & $\mathbf{2 0 3 5}$ & $\mathbf{2 0 4 0}$ & $\mathbf{2 0 4 5}$ & $\mathbf{2 0 5 0}$ \\
\hline Capital Costs & .44 & 0.44 & 0.44 & 0.44 & 0.44 & 0.44 & 0.44 \\
O\&M & .71 & .71 & .71 & .71 & .71 & .71 & .71 \\
Feedstock Costs & 1.35 & 1.35 & 1.35 & 1.35 & 1.35 & 1.35 & 1.35 \\
Plant Gate & 2.50 & 2.50 & 2.50 & 2.50 & 2.50 & 2.50 & 2.50
\end{tabular}

\begin{tabular}{lccccccc}
\hline $\begin{array}{l}\text { Central Electrolytic H2 } \\
\text { - Grid or Wind }\end{array}$ & & & & & & & \\
\hline Unit Costs & $\mathbf{2 0 2 0}$ & $\mathbf{2 0 2 5}$ & $\mathbf{2 0 3 0}$ & $\mathbf{2 0 3 5}$ & $\mathbf{2 0 4 0}$ & $\mathbf{2 0 4 5}$ & $\mathbf{2 0 5 0}$ \\
\hline Capital Costs & 0.24 & 0.24 & 0.24 & 0.24 & 0.24 & 0.24 & 0.24 \\
O\&M & 0.13 & 0.13 & 0.13 & 0.13 & 0.13 & 0.13 & 0.13 \\
Feedstock Costs & 1.34 & 1.34 & 1.34 & 1.34 & 1.34 & 1.34 & 1.34 \\
Plant Gate & 1.70 & 1.70 & 1.70 & 1.70 & 1.70 & 1.70 & 1.70
\end{tabular}

\begin{tabular}{|c|c|c|c|c|c|c|c|}
\hline $\begin{array}{l}\text { Distributed Wind } \\
\text { Electrolytic H2 }\end{array}$ & & & & & & & \\
\hline Unit Costs & 2020 & 2025 & 2030 & 2035 & 2040 & 2045 & 2050 \\
\hline Capital Costs & 0.68 & 0.68 & 0.68 & 0.68 & 0.68 & 0.68 & 0.68 \\
\hline O\&M & 0.51 & 0.51 & 0.51 & 0.51 & 0.51 & 0.51 & 0.51 \\
\hline Feedstock Costs & 1.65 & 1.65 & 1.65 & 1.65 & 1.65 & 1.65 & 1.65 \\
\hline Plant Gate & 2.84 & 2.84 & 2.84 & 2.84 & 2.84 & 2.84 & 2.84 \\
\hline
\end{tabular}

\section{(a) These production costs are achieved through program R\&D.}

Significant Changes in GPRA08-Modeled HFCIT Program Inputs from GPRA07 Analysis

The GPRA08 was modified to include several additional technologies and the component costs obtained from the H2A model. The production technologies for hydrogen, which were added from the GPRA07, include central coal gasification with and without co-product electricity, distributed ethanol, distributed electrolysis from wind-generated electricity, and central biomass gasification. The central coal gasification cases have carbon sequestration, which is a revision from GPRA07. 
The past GPRA analysis used the program goals to obtain the NEMS and MARKAL inputs. With the availability of the H2A Production model, the program goals and targets were used as inputs to the model to obtain the inputs for NEMS and MARKAL. The changes are reflected in the components costs for each technology listed in Table B-7.

\section{Hydrogen Availability at Stations}

An availability factor for hydrogen refueling stations is required by the NEMS-GPRA08 model. The assumptions used are as follows: 1) hydrogen will not be available at any stations until 2015, 2) $\mathrm{H} 2$ is projected to be available by regions in different years, 3) $\mathrm{H} 2$ is expected to begin penetration in the Pacific region followed by the other regions as outlined in Table B-8, and 4) the $\mathrm{H} 2$ stations in a particular region are projected to build up at the rate shown in Table B-9.

The first model developed to look at hydrogen use by Census region was the Regional H2 Model (Margaret Singh, Jim Moore, and William Shadis, "Hydrogen Demand, Production and Cost by Region to 2050," Argonne National Laboratory, June 23, 2005.). The model assumed a uniform FCV penetration rate across regions. However, during the development of that model, four analysts [(Singh, M. (ANL), J. Moore (TAE), S. Plotkin (ANL), and P. Patterson (DOE)], conducted their own mini-delphi study to determine the order in which $\mathrm{H} 2$ would be introduced into the regions used in the NEMS model. After some discussion, the order of the introduction was determined as shown in Table B-8. Subsequently, interactions with Sig Gronich of the Hydrogen Program led to the assigning of specific years at which the introduction of a hydrogen fueling infrastructure would begin. The logic was that the Pacific region would be first, because California will most likely lead in the introduction of hydrogen stations with its initiative to start in Los Angeles and eventually develop a "hydrogen highway"

(http://www.hydrogenhighway.ca.gov/). The second region selected was the Mid-Atlantic, which includes New York (but West South Central is second in Table B-8). This region is likely an early adopter of FCVs and hydrogen because of the need to meet strict environmental controls.

It was reasoned that the West South Central region (which includes Texas), the East North Central region, and the New England region would introduce hydrogen next. There is a capability to add hydrogen production capacity to the hydrogen currently being manufactured to serve refineries that are mostly in Texas (http://www.hgac.com/NR/rdonlyres/egkaxvc3i7pw7fgfhqx17dkdgd2sv7tbu3zdd3u71215ny2ihuhonxxhjow7cer eeq4xwbxvannlh3a6wsvwtrs5yhf/white+paper.pdf\#search $=\% 22$ hydrogen $\% 20$ highway $\% 2 \mathrm{C} \% 20 \mathrm{t}$ $\underline{\operatorname{exas} \% 22}$ )

The East North Central region includes Illinois, which has its own hydrogen highway plan (http://www.newtopiamagazine.net/archives/content/issue17/features/hydrogen.php). New England includes Boston, for which there is a plan to build a hydrogen highway to Washington, D.C. http://www.gatago.com/sci/energy/3644671.html.

The other regions were expected to lag behind, with the Mountain region being the last to introduce hydrogen because of the large percent of people living in rural areas that are hard to access and service with hydrogen. 


\section{Table B-8. Regional Hydrogen Vehicle Penetration}

1. Pacific (includes California and, specifically, Los Angeles where the first push will be made) -2015

2. West South Central (includes Texas where most of the $\mathrm{H} 2$ is now made) -2020

3. Mid-Atlantic (includes New York) - 2018

4. East North Central (includes Illinois, Ohio, and Michigan) -2020

5. South Atlantic (includes Virginia and Florida) - 2022

6. New England (includes Massachusetts) -2020

7. East South Central (Kentucky, Tennessee, Alabama, and Mississippi) -2027

8. West North Central (Dakotas to Missouri) -2028

9. Mountain (Montana to New Mexico) -2030

\section{Hydrogen Station Buildup for Region}

There are several FCV penetration scenarios that have been developed. David Greene has used the HyTrans model to show that in population-dense regions, the $\mathrm{H} 2$ share of fuel used in light vehicles could grow to about $30 \%$ in 15 years (with a FVC subsidy of $\$ 5,000$ ) [David Greene, "Modeling the Hydrogen Transition with HyTrans," presented at TRB Conference, January 10, 2005.] A study by Tellus showed that the percent of FCVs could be about $25 \%$ after 15 years if there is national interest in reducing carbon [Alison Bailie, et al, "Hydrogen Transitions in a Greenhouse Gas Constrained World," Tellus Institute, for DOE, August 2005.]

Also, penetration rates for other vehicle technologies can be used as a comparison for the potential penetration of hydrogen stations. The EPA report "Light-Duty Automotive Technology and Fuel Economy Trends: 1975 through 2006" (http://www.epa.gov/orcdizux/fetrends.htm) showed a penetration curve in Figure 63, Page 62 that is very similar to the curve that would be generated from the data in Table B-9.

\section{Table B-9. Hydrogen Station Buildup for Region}

$\begin{array}{cc}\text { Year } & \text { Percent of Stations } \\ 1 & 0.5 \\ 2 & 1 \\ 3 & 2 \\ 4 & 4 \\ 5 & 6 \\ 6 & 8 \\ 7 & 10 \\ 8 & 13 \\ 9 & 17 \\ 10 & 21 \\ 15 & 30 \\ 20 & 40 \\ 25 & 50 \\ 30 & 60 \\ 35 & 70 \\ 40 & 75 \\ 45 & 80\end{array}$


Significant Changes in GPRA08-Modeled HFCIT Program Inputs from GPRA07 Analysis

The GPRA07 modeled the hydrogen station build-out on an assumed national basis. For the GPRA08, the hydrogen station availability and build-out was developed for a regionalized buildout for the nation. The percent of stations available was based on input from industry in the Scenario Analysis Meeting (see Web site www.hydrogen.energy.gov for more information), which is provided in the above tables. This revised station build-out was used as input for the NEMS model for the GPRA08 analysis.

\section{FCV Market Penetration Methodology}

Brief descriptions of how the NEMS-GPRA08 and MARKAL-GPRA08 models estimate new vehicle technology penetration using the vehicle attributes can be found in other chapters and appendices of this report.

\section{Key Factors in Shaping the Market Adoption of Stationary Fuel Cells}

Key factors associated with the market penetration of stationary fuel cells include the energy efficiency (electrical and combined heat and power), installed cost, and maintenance cost of the fuel cells relative to other distributed and traditional electricity-generation technologies.

\section{Interim Outcomes of Stationary Fuel Cells}

The target market is the stationary power generation. Stationary power systems vary by application from industrial to individual consumer. In industrial applications, these systems are used to ensure reliability such as backup power supply and for emergency applications. The individual consumer would use the systems for similar applications but on a smaller scale.

The program outputs are fuel cell power systems with their associated efficiencies, reliability, and costs. These systems are produced by manufacturers once the program meets its goals and targets. How well these fuel cell applications sell in the marketplace is a function of incremental cost, reliability, and the overall efficiency.

\section{Methodology and Calculations for Stationary Fuel Cells}

Program Case Assumptions for Stationary Fuel Cells

Assumptions for distributed PEM fuel cells are based on the multiyear program plan (Ref.1). Capital costs and efficiencies were provided in the MYPP for 2005 and 2010. The costs are represented in 2003 dollars. No values were listed for maintenance costs, so the AEO2006 values are used. The costs and efficiencies assumed for NEMS-GPRA08 by 2025 were held constant through 2050 in MARKAL-GPRA08, which is a conservative assumption, because constant costs over a 25-year period is not likely.

The program goal capital costs were increased to account for the installation cost that is assumed in the Baseline fuel cells costs from the NREL report. ${ }^{30}$ In addition, the efficiencies in the 
multiyear plan are expressed in lower heating values and were converted to higher heating value efficiencies for use in NEMS-GPRA08.

\section{Residential 10kW PEMFC Program Case}

HFCIT Goals from Multiyear Plan

$\begin{array}{ccccc}\text { Year } & \begin{array}{c}\text { CHP System } \\ \text { Efficiency }^{28}\end{array} & \begin{array}{c}\text { Electrical } \\ \text { Efficiency }^{28}\end{array} & \begin{array}{c}\text { Equip. Cost } \\ (2003 \$ / \mathrm{kW})\end{array} & \begin{array}{c}\text { Maint. Cost } \\ (2003 \$ / \mathrm{kW}-\mathrm{yr})\end{array} \\ 2005 & 0.75 & 0.32 & 1500 & \mathrm{n} / \mathrm{a} \\ 2010 & 0.80 & 0.35 & 1000 & \mathrm{n} / \mathrm{a}\end{array}$

Model Inputs for HFCIT Goals

$\begin{array}{ccccc}\text { Year } & \begin{array}{c}\text { CHP System } \\ \text { Efficiency }^{28}\end{array} & \begin{array}{c}\text { Electrical } \\ \text { Efficiency }^{28}\end{array} & \begin{array}{c}\text { Installed Cost } \\ (2003 \$ / k W)\end{array} & \begin{array}{c}\text { Maint. Cost } \\ (2003 \$ / k W-y r)\end{array} \\ 2005 & 0.675 & 0.288 & 3300 & 264 \\ 2010 & 0.72 & 0.315 & 1800 & 184 \\ 2015 & 0.72 & 0.315 & 1800 & 168 \\ 2020 & 0.72 & 0.315 & 1800 & 168 \\ 2025 \text { to } 2050 & 0.72 & 0.315 & 1800 & 168\end{array}$

\section{Commercial 200kW Fuel Cell Program Case}

HFCIT Goals from Multiyear Plan

$\begin{array}{ccccc}\text { Year } & \begin{array}{c}\text { CHP System } \\ \text { Efficiency }^{28}\end{array} & \begin{array}{c}\text { Electrical } \\ \text { Efficiency }^{28}\end{array} & \begin{array}{c}\text { Equip. Cost } \\ (2003 \$ / k W)\end{array} & \begin{array}{c}\text { Maint. Cost } \\ (2003 \$ / k W-y r)\end{array} \\ 2005 & 0.75 & 0.32 & 1250 & \mathrm{n} / \mathrm{a} \\ 2010 & 0.80 & 0.40 & 750 & \mathrm{n} / \mathrm{a}\end{array}$

Model Inputs for HFCIT Goals

$\begin{array}{ccccc}\text { Year } & \begin{array}{c}\text { CHP System } \\ \text { Efficiency }^{28}\end{array} & \begin{array}{c}\text { Electrical } \\ \text { Efficiency }^{28}\end{array} & \begin{array}{c}\text { Installed Cost } \\ (2003 \$ / \mathrm{kW})\end{array} & \begin{array}{c}\text { Maint. Cost } \\ (2003 \$ / \mathrm{kW}-\mathrm{yr})\end{array} \\ 2005 & 0.675 & 0.288 & 3180 & 232 \\ 2010 & 0.72 & 0.36 & 1430 & 128 \\ 2015 & 0.72 & 0.36 & 1430 & 128 \\ 2020 & 0.72 & 0.36 & 1430 & 128 \\ 2025 \text { to } 2050 & 0.72 & 0.36 & 1430 & 128\end{array}$


Significant Changes in GPRA08 modeled HFCIT Program Inputs from Previous GPRA07Analysis

The inputs for the stationary fuel cell inputs to the GPRA08 analysis are the same as the GPRA07 analysis.

References

1. One gallon of gasoline is approximately equal to one kilogram of hydrogen on an energy basis.

2. This cost range results in equivalent fuel costs per mile for a hydrogen fuel cell vehicle compared to gasoline internal combustion engine and gasoline hybrid vehicles. The full explanation and basis for the hydrogen cost goal can be found in DOE Record 5013 (see www.hydrogen.energy.gov/program records.html)।

3. National Research Council and National Academy of Engineering, Committee on Alternatives and Strategies for Future Hydrogen Production and Use, The Hydrogen Economy: Opportunities, Costs, Barriers, and R\&D Needs (Washington, DC: National Academies Press, 2004) pg. 134, http://www.nap.edu/books/030909/632/html.

4. Oak Ridge National Laboratory, Transportation Energy Data Book: Edition 25, (December 2005)

5. U.S. Department of Energy, Solar and Wind Technologies for Hydrogen Production: Report to Congress, ESECS EE-3060, December 2005, retrieved February 3, 2006 from http://www.eere.energy.gov/hydrogenandfuelcells/pdfs/solar_wind for hydrogen dec 20 05.pdf.

6. The budget request combines Technology Validation and Infrastructure Validation into one key activity.

7. U.S. Department of Energy (Hydrogen Program), "Record 5027: Hydrogen Fuel Initiative (White House Press Release)," http://www.hydrogen.energy.gov/program_records.html.

8. National Research Council and National Academy of Engineering, Committee on Alternatives and Strategies for Future Hydrogen Production and Use, The Hydrogen Economy: Opportunities, Costs, Barriers, and R\&D Needs (Washington, DC: National Academies Press, 2004), http://www.nap.edu/books/030909/632/html.

9. U.S. Department of Energy, HFCIT Multi-Year Plan, 3-55.

10. Department of Energy Hydrogen Program, Record 5021: Fuel Cell System 2005 Cost vs. Goal, http://www.hydrogen.energy.gov/program_records.html.

11. U.S. Department of Energy, HFCIT Multi-Year Plan, 3-86.

12. U.S. Department of Energy, HFCIT Multi-Year Plan, 3-94.

13. U.S. Department of Energy, HFCIT Multi-Year Plan, 3-60. 
14. Eric Carlson, et al., "Cost Analysis of PEM Fuel Cell Systems for Transportation," National Renewable Energy Laboratory Subcontractor Report, NREL/SR-560-39104, (September 30, 2005), retrieved March 27, 2006, from http://www.nrel.gov/hydrogen/pdfs/39104.pdf.

15. U.S. Department of Energy, FY 2006 DOE Budget Request to Congress for Interior and Related Agencies: Energy Conservation, (February 2005), 316, retrieved January 20, 2006, from http://www.mbe.doe.gov/budget/06budget/Content/Volumes/Vol 7 INT.pdf.

16. U.S. Department of Energy, HFCIT Multi-Year Plan, 3-69.

17. U.S. Department of Energy, HFCIT Multi-Year Plan, 3-10.

18. U.S. Department of Energy (Hydrogen Program), "Record 5013: Hydrogen Cost Goal," http://www.hydrogen.energy.gov/program records.html.

19. "Hydrogen, Fuel Cells \& Infrastructure Technologies Program: Multi-Year Research, Development and Demonstration Plan" (Draft), U.S. Department of Energy, Energy Efficiency and Renewable Energy (June 3, 2003).

20. PSAT (POWERTRAIN SYSTEM ANALYSIS TOOLKIT): see http://www.transportation.anl.gov/software/PSAT/

21. Phillip Sharer and Aymeric Rousseau, "PSAT Results for GREET and GPRA - FE Adjusted 081705.xls," August 17, 2005.

22. Rousseau, Aymeric, "Number Associated with Presentation,” July 6, 2005.

23. Payback model developed by Jim Moore, TA Engineering (2003) and expanded by Margaret Singh, ANL (2005).

24. "Program Analysis Methodology: Office of Transportation Technologies, Quality Metrics 2003 Final Report," prepared by OTT Analytic Team, for Office of Transportation Technologies, U.S. Department of Energy (March 2002).

25. "Program Analysis Methodology: Office of Transportation Technologies, Quality Metrics 2003 Final Report," prepared by OTT Analytic Team, for Office of Transportation Technologies, U.S. Department of Energy (March 2002).

26. H2A production model information can be found on the following Web site: http://www.hydrogen.energy.gov/h2a analysis.html.

27. H2A delivery model information can be found on the following Web site: http://www.hydrogen.energy.gov/h2a analysis.html.

28. Efficiency is based on High Heating Value (HHV) of the input fuel.

29. Battelle, "Economic Analysis of PEM Fuel Cell Systems," October 16, 2006.

30. NREL, Gas-Fired Distributed Energy Resource Technology Characterizations, October 2003.

31 . The $6 \mathrm{wt} . \%$ means that $6 \%$ of the total weight (tank plus hydrogen) will be hydrogen. The storage energy density on a weight basis, as expressed by " $\mathrm{kWh} / \mathrm{kg}$ ", is the energy content of hydrogen that can be used to convert the weight percent value to an energy content for the hydrogen fuel tank. The storage energy density on a volume basis, as 
expressed by " $\mathrm{kWh} / \mathrm{Liter}$ ", is the amount of hydrogen energy contained in the tank divided by the volume of the tank. Information supplied by the Storage group of the DOE Hydrogen Program.

32. Program inputs for the NEMS and MARKAL models.

33. Some of the goals of the HFCIT program cannot be accomplished without the enabling technologies being developed by the FreedomCAR Vehicle Technologies (FCVT) program. Thus the HFCIT "baseline" case reflects an assumption of the success of the relevant portions of Electrochemical Energy Storage and Power Electronics of the FCVT program. 


\section{APPENDIX C - BIOMASS PROGRAM INPUTS FOR FY 2008 BENEFITS ESTIMATES}

Table of contents

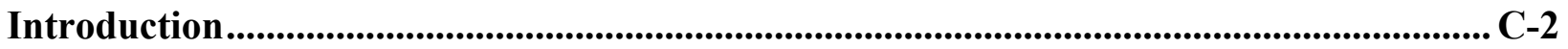

Significant Changes from Previous Analysis..................................................................................... C-3

The Baseline ("without DOE RD3" case) ……......................................................................... C-3

Target Market Description ............................................................................................ C-3

Baseline Adjustments to the AEO2006 Reference Case ..................................................... C-6

Representation of Program-Relevant Technologies in the AEO Reference Case .................. C-6

Removing Effects of Program Activities ....................................................................... C-7

Other Program-Relevant Adjustments to AEO Reference Case.............................................. C-7

Program Outputs ........................................................................................................................... C-7

Assumed Budget Projections …………………………........................................... C-7

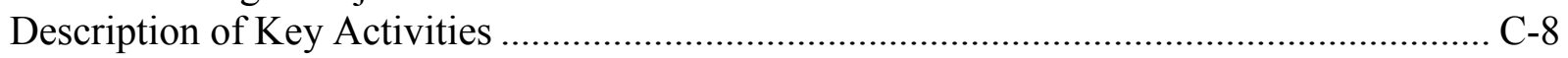

Program Outputs, Activities, and Milestones ………………....................................... C-10

Linkage of Outputs with Outcomes........................................................................................... C-11

Key Factors in Shaping Market Adoption of EERE Technologies ................................... C-12

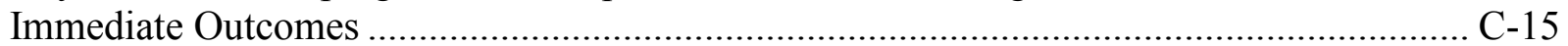

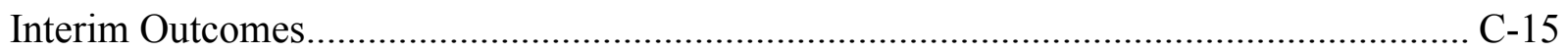

Summary of Inputs ............................................................................................................................... C-16

Bibliography ................................................................................................................................ C-19 


\section{Introduction}

\section{Program Summary}

On February 20, 2006, in his State of the Union Speech, President Bush announced the Advanced Energy Initiative. The Biofuels Initiative, a key component of the President's Initiative, is designed "to foster the breakthrough technologies needed to make cellulosic ethanol cost-competitive with corn-based ethanol by 2012, enabling greater use of this alternative fuel to help reduce future U.S. oil consumption" (White House 2006). The U.S. Department of Energy (DOE)'s Biomass Program is working to meet the ethanol-related goal of displacing up to 40 billion gallons of gasoline per year by 2030. Fuel ethanol is being targeted for the domestic gasoline market because gasoline vehicles are already using gasoline containing up to $10 \%$ ethanol. Furthermore, the automobile industry has produced and sold several million flexible fuel vehicles that can use either gasoline or any gasoline/ethanol mixture containing up to $85 \%$ ethanol by volume.

As an interim step leading to future biorefineries, the Office of the Biomas Program (OBP) is working with ethanol production plants (current biorefineries) on near-term technology aimed at increasing the ethanol production from corn kernels and enhancing the protein quality of the cattle feed co-product. The cattle feed is called distillers dried grain with solubles (DDGS). The current ethanol plants convert only the starch portion of the kernels to ethanol. The unconverted cellulosic fiber in the kernels and the small amount of "residual" starch (that is firmly bound to the fiber) show up in the DDGS, diluting its protein content and reducing its quality. Each ethanol biorefinery's output would increase if the program and its partners succeeded in converting the kernel fiber to ethanol. After the removal of the fiber and residual starch, the DDGS will be higher in protein content, making it more valuable as feed for poultry and swine. Success with the conversion of kernel fiber and residual starch will facilitate the industry's decision to partner with DOE and develop technology for other cellulosic feedstocks such as corn stover. The United States has considerable quantities of cellulosic biomass, including corn stover, wheat straw, rice straw, forest residues, the biomass component in urban wastes, etc. Future energy crops, e.g., fast-growing trees and grasses, would also be of increasing importance as cellulosic resources in the long term.

In summary, current dry mills use starch crops to produce ethanol and DDGS. By 2010, these corn biorefineries would convert some of the kernel fiber and residual starch to ethanol. By 2012, some of the dry mills would also produce chemicals or materials as co-products (Jechura 2005).

The existing corn ethanol biorefineries use natural gas and coal for process heat and power. In future biorefineries, the ethanol conversion process is expected to use waste biomass as a heat and power source such that natural gas requirements would be reduced. While the current analysis assumes that ethanol is the major output of biorefineries, future analyses could include additional fuels that OBP may identify later. In FY 2008 and future years, OBP plans to continue FY 2007 collaboration and enter into new partnerships with industry and others to advance the state of cellulosic ethanol production technology. 


\section{Significant Changes from Previous Analysis}

There are no significant changes from the prior-year analysis for corn ethanol. For cellulosic ethanol, the current analysis uses a slightly more conservative schedule for achieving plant cost targets. Updated cellulosic supply curves were used to estimate benefits in the post-2030 time frame. The additional feedstock availability offsets somewhat the effect of the more conservative schedule for achieving conversion cost targets.

\section{The Baseline ("without DOE RD3" case)}

Without OBP's resources, industry would rely on loan guarantees and other applicable policies in the Energy Policy Act when building up the biorefinery industry. These policies are aimed at demonstration and implementation, not research and development. Research and development activities are needed to continue to decrease the cost of converting cellulosic feedstocks to ethanol if the large volumes envisioned by 2030 are to be achieved. Although small volumes of cellulosic ethanol may be produced with niche, low-cost feedstocks, it would be difficult to foster a major bio-industry within two decades without the DOE support for RD3. The ethanol industry would continue RD3 on the production of ethanol from corn fiber/residual starch, but work on agricultural residues and forest residues would be greatly reduced. Some of the technologies could come from other countries' R\&D organizations. However, the deployment process for cellulosic ethanol requires the testing of new technology in costly pilot plants and demonstration plants. The investors would also want to see adequate progress made in feedstock production and collection before providing capital, because a pilot plant can cost up to $\$ 9$ million and a demonstration plant up to $\$ 30$ million. Farmers, i.e., feedstock producers, and farm equipment manufacturers must also actively participate before such projects can go forward. Therefore, it is anticipated that technological advances would be delayed by at least seven years for corn fiber/residual starch, 12 years for bio-based products technologies for dry mills, and 15 years for ethanol production technologies using cellulosic feedstock. The riskier cellulose conversion technologies would see a longer delay relative to the more near-term technology for corn fiber conversion.

\section{Target Market Description}

The dominant U.S. highway fuels are gasoline for light-duty vehicles (cars, minivans, vans, sports-utility vehicles, and certain light trucks), and diesel for buses and larger trucks. Gasoline accounts for approximately three-quarters of the oil used in this country's transportation sector. OBP focuses mostly on gasoline displacement at this time. Alcohol fuels are the most logical replacement fuels for light-duty vehicles because current gasoline engines could use various blends of alcohol fuel and gasoline with minimal modifications. Ethanol is the alcohol that has been approved by the U.S. Environmental Protection Agency (EPA) and car manufacturers for blending with gasoline up to $10 \%$ ethanol by volume. Ethanol is also the alcohol fuel approved for use in several other nations. Minor engine and vehicle modifications resulted in flexible fuel vehicles (FFVs) that can run on any blend of ethanol and gasoline, up to $85 \%$ ethanol. 
Corn ethanol biorefineries, both dry mills and wet mills, currently use solely the corn kernels (no cellulosic feedstock) to produce ethanol and some co-products such as animal feed additives (both dry and wet mills), or corn oil and high-fructose corn syrup (wet mills), and a number of fermentation products such as lactic acid and lysine.

According to the Renewable Fuels Association, as of August 2006, ethanol plants operating in the United States had a total production capacity of 4.5 billion gallons, with an additional capacity of 1.89 billion gallons under construction or in expansion (Renewable Fuels Association 2006). Ethanol competes in transportation fuel markets for light-duty vehicles. In 2005, the U.S. consumed approximately 140 billion gallons of motor gasoline (EIA 2006). Nearly 80 companies operate approximately 100 plants in the United States. A few are large agri-businesses such as ADM and Cargill, but many are smaller producers focusing on ethanol as their main product. Nearly half of the plants belong to farmers' cooperatives. The plants obtain corn feedstock from local growers, several of whom may also be part owners of the ethanol plants through the cooperative arrangement.

In 2004, the majority of the ethanol consumed was used as an oxygenate component for gasoline, and the remainder was used as a gasoline additive to improve octane. The primary market where ethanol is used as an oxygenate component consisted of approximately 36 billion gallons of reformulated gasoline (RFG) in 2003 (Reynolds 2004). Within this oxygenate market, in early 2004, methyl-tertiary-butyl-ether (MTBE) and ethanol each provided approximately $50 \%$ of the volume. MTBE in RFG is approximately $11 \%$ by volume, whereas ethanol is between $5.7 \%$ and $10 \%$ by volume. This cleaner-burning gasoline, called reformulated gasoline or RFG, is required by the Clean Air Act in metropolitan areas that the U.S. Environmental Protection Agency (EPA) identified as having the worst smog pollution. Other cities with lesser smog problems may choose to "opt in" and use RFG also. The Federal RFG Program was introduced in 1995. RFG is currently used in 17 states and the District of Columbia. About 30\% of gasoline sold in the United States is reformulated. Each oil company prepares its own formula that must meet federal emission reduction standards (Environmental Protection Agency 2006). To illustrate the size of this market, assuming an average ethanol concentration of $8.5 \%$ in the RFG market, 36 billion gallons of RFG would include 3 billion gallons of ethanol once ethanol completely replaces MTBE. By 2005, MTBE use declined to about 2 billion gallons, whereas ethanol demand increased to 4.0 billion gallons per year for both RFG and conventional gasoline (Schremp 2006). Ethanol has taken a larger share of the RFG market because MTBE has been or is being phased out in many states due to environmental concerns. Furthermore, EPACT 2005 did not contain language protecting MTBE sellers from liability. Some refiners have announced that they will cease using MTBE, and some pipeline operators have announced that they will not ship gasoline containing more than trace amounts of MTBE (Wheeler 2006).

Refinery operators do not blend ethanol with gasoline at the refinery. Instead, they produce a sub-grade, "base" gasoline, called reformulated blendstock for oxygenate blending (RBOB). The RBOB or base gasoline is not yet suitable for direct use in vehicles. Refinery operators ship this base gasoline, and ethanol plants ship ethanol to bulk terminals. The operators at bulk terminals blend the ethanol into the base gasoline to make RFG. Outside of California, RFG typically contains $10 \%$ ethanol by volume. California RFG is made with less ethanol, typically $5.7 \%$ by volume. Outside of the RFG market, ethanol is also blended with conventional regular 
gasoline, i.e., gasoline that is not RFG, to make "gasohol." Unlike RBOB, conventional regular gasoline is suitable for direct use in vehicles. The addition of ethanol results in gasohol with higher octane relative to conventional gasoline without ethanol. Gasohol consists of $90 \%$ gasoline and $10 \%$ ethanol by volume, with the ethanol serving as an octane enhancer and gasoline extender (i.e., ethanol increases the volume of fuel used in the light-duty vehicles segment). Gasohol is primarily marketed in the Midwest as mid-grade gasoline. Both gasohol and RFG (made by adding ethanol) contain ethanol. However, gasohol and RFG have somewhat different emissions characteristics. As discussed earlier, EPA or state environmental agencies require several metropolitan areas to use RFG because this cleaner-burning fuel helps reduce smog problems. A number of regions that do not face smog problems chose to use gasohol (not as clean burning as RFG) for supply and economic development reasons, not because of problems with smog.

When blended into gasoline, ethanol raises the vapor pressure of the mixture, while adding MTBE to gasoline has only a minor effect on vapor pressure. Because ethanol absorbs water, which is typically present in small quantities in the U.S. petroleum products pipeline system, ethanol and ethanol blends have not been routinely shipped via pipeline. Consequently, ethanol is shipped by rail, truck, and/or barge to bulk terminals, where it is blended into gasoline.

Vehicle fleets can be a source of additional demand for ethanol fuel. These include alternativefuel vehicles that have been either modified or manufactured to accommodate the use of E85, i.e., $85 \%$ ethanol and $15 \%$ gasoline by volume. The E85 vehicles are flexible-fuel vehicles that can use either gasoline or E85 or any gasoline blend containing up to $85 \%$ ethanol. As of late 2006, the National Ethanol Vehicle Coalition estimated that there are approximately 6 million FFVs on the road, both as fleet and non-fleet vehicles (National Ethanol Vehicle Coalition, 2006). However, only a small number of FFVs use E85, because E85 is not widely sold and it is usually not as cheap as gasoline for the same driving distance. The vehicle fleet market is dominated by government agencies, but also includes fleets owned by corporate entities and other organizations (taxi cabs, utilities, airport authorities, etc.). In 2004, the U.S. Department of Energy determined that a regulation requiring private and local government fleets to acquire alternative fuel vehicles (AFVs) is not necessary and, therefore, would not be promulgated. This ruling was pursuant to the investigation required by the Energy Policy Act of 1992, which revealed that an AFV requirement on private and local fleets would not appreciably increase the percentage of alternative fuel and replacement fuel used in motor vehicles (EERE 2004). The use of alternative fuels by government fleets would not displace a significant share of our gasoline consumption because the number of vehicles in government fleets is not significant. For example, the General Services Administration reported that the federal fleet included approximately 630,000 vehicles in 2005 (GSA 2006).

The market penetration of E85 has been much lower than for E10 because: (1) E85 has been frequently more expensive than gasoline on an energy-equivalent basis; (2) the availability of E85 refueling stations is limited; and, (3) an investment of approximately $\$ 50,000-60,000$ per gasoline station is required for installing a new 12,000 gallon underground storage tank for E85 (Morris 2003, Raabe 2006). This cost would be reduced with the EPAct tax credit of up to $\$ 30,000$ per gasoline station. Once sufficient ethanol is available at reasonable prices, the infrastructure barriers are not excessively difficult to overcome. For example, an automobile 
manufacturer can now produce a flexible-fuel version of any vehicle with only modest modifications to the engine. To minimize the cost of adding E85 storage capability, gasoline station owners could convert the existing mid-grade storage/dispensing system to E85 while retaining the capability to sell mid-grade gasoline. The owner may choose to upgrade the two dispensing systems for regular gasoline and premium gasoline such that he can still offer premium and regular, but has the option of mixing these two gasoline types to create mid-grade gasoline on demand. In this way, a gasoline station would be able to sell E85, and premium, midgrade, and regular gasoline.

\section{Baseline Adjustments to the AEO2006 Reference Case}

The Energy Information Administration (EIA) assumed that cellulosic ethanol will enter the market beginning in 2010, ramp up to 250 million gallons per year by 2012, and will grow no further (Radich 2006). This view of cellulosic ethanol growth appears to be too conservative. Technology can cross national boundaries through licensing and subsidiaries, and therefore one should not discount technological developments in other countries. Iogen, a Canadian enzymes manufacturer and biofuels technology developer, has built a small demonstration plant in Ottawa, Canada. At full capacity, Iogen's demonstration plant is designed to process about 30 metric tons per day of feedstock, and to produce approximately 2.5 million liters of ethanol per year. The plant uses wheat, oat, and barley straw as raw materials (Iogen 2004). Abengoa, a Spanish technology and engineering firm, plans to open a demonstration facility that makes ethanol out of wheat straw in Babilafuente (Salamanca), Spain. Commissioning is expected to start by the end of 2006. This plant will process 70 metric tons of agricultural residues, such as wheat straw, per day for producing more than 5 million liters of ethanol per year (Abengoa Bioenergy 2006). Japanese automaker Honda's research and development division and the Research Institute of Innovative Technology for the Earth (RITE) are developing technology to produce ethanol from soft biomass such as leaves and plant stalks (World Refining \& Fuels Today 2006). Within the United States, New York State is seeking proposals under a new \$20 million grant program to develop and construct a pilot cellulosic ethanol facility (NYSERDA 2006). There may be other organizations planning to commercialize cellulosic ethanol technology. To account for these developments, EERE modelers partially modified the constraints in the NEMS model to allow additional ethanol expansion through 2030 in the baseline but did not increase the number of FFV models (Wood 2006).

\section{Representation of Program-Relevant Technologies in the AEO Reference Case}

EIA's Annual Energy Outlook (AEO2006) includes corn ethanol technology and cellulosic ethanol technology but do not include the Biomass Program's effects. The Energy Policy Act of 2005 requires the use of 250 million gallons of cellulosic ethanol starting in 2012. In a personal communication, Tony Radich said that EIA does not believe that much capacity would be built at once, so they assumed that cellulosic ethanol will enter the market beginning in 2010 and ramp up to 250 million gallons per year by 2012 . EIA estimated a rather slow reduction in production costs, which limited the penetration of cellulosic ethanol to the required 250 million gallons in the AEO2006 Reference Case. In the High Oil Price Case, cellulosic ethanol would grow to 1.9 billion gallons per year by 2030 (Radich 2006). 
The AEO2006 Reference Case projects that corn ethanol will grow rapidly to 9.2 billion gallons per year by 2013, and grow very slowly thereafter to 11 billion gallons per year by 2030 . Furthermore, the AEO2006 Reference Case showed that no ethanol would be used in E85 through 2030. The reasons include the higher cost of ethanol relative to gasoline on an energy basis, and the cost of adding E85 refueling capabilities.

\section{Removing Effects of Program Activities}

In the non-program baseline, commercial cellulosic ethanol production was assumed to begin 15 years after the start of such production in the Program Case. EIA's 2012 start date for commercial production was removed.

\section{Other Program-Relevant Adjustments to AEO Reference Case}

The DOE Office of Energy Efficiency and Renewable Energy updated a number of cellulosic feedstock supply curves (agricultural residues, forest residues, and switchgrass) to reflect better analytic techniques used by the University of Tennessee in early 2006.

\section{Program Outputs}

This section shows the connection between the Biomass Program's budgets, activities, milestones, outputs, outcomes, and benefits.

\section{Assumed Budget Projections}

The FY 2008 budget request for the Biomass Program is confidential until after the budget submission to Congress. A summary of the recent and requested budgets, by major area, is shown in Table C-1. The House and Senate have not yet met in conference on the FY 2007 budget request as of late CY 2006.

The budget request for FY 2009 through 2011 is confidential until after the budget submission to Congress. We assumed also that annual budgets through FY 2019 would be at $80 \%$ of 2009-2011 funding level.

Table CError! No text of specified style in document.-1 Biomass Program Budget

\begin{tabular}{c|r|r|r|r|r|} 
& \multicolumn{6}{c|}{ (dollars in thousands) } \\
\cline { 2 - 6 } & $\begin{array}{r}\text { FY 2006 } \\
\text { Current } \\
\text { Appropriation }\end{array}$ & $\begin{array}{c}\text { FY 2007 } \\
\text { Request }\end{array}$ & $\begin{array}{c}\text { FY 2007 } \\
\text { House } \\
\text { Mark }\end{array}$ & $\begin{array}{c}\text { FY 2007 } \\
\text { Senate } \\
\text { Mark }\end{array}$ & $\begin{array}{c}\text { FY 2008 } \\
\text { Request }^{\mathrm{a}}\end{array}$ \\
\cline { 2 - 7 } Biomass and Biorefinery Systems R\&D & & & & & \\
Feedstock Infrastructure & 505 & 9,967 & 9,967 & 4,280 & 10,000 \\
Platforms Research and Development & 19,907 & 50,530 & 50,530 & 50,530 & 59,400 \\
Utilization of Platform Outputs R\&D & 23,479 & 89,190 & 89,190 & 139,190 & 109,163
\end{tabular}


Congressionally Directed Activities

Operating Total, Biomass and Biorefinery Systems R\&D

Capital Projects

Total, Biomass and Biorefinery Systems R\&D

\begin{tabular}{rrrrr}
46,827 & 0 & TBD & 19,000 & 0 \\
\hline 90,718 & 149,687 & 149,687 & 213,000 & 178,563 \\
0 & 0 & 0 & 0 & 15,700 \\
\hline 181,436 & 299,374 & 149,687 & 213,000 & 194,263
\end{tabular}

a. The amount of the request is confidential until after the budget submission to Congress.

\section{Description of Key Activities}

The Biomass Program focuses primarily on enabling integrated biorefineries that produce ethanol as the main output and, where possible, valuable co-products such as electricity and chemicals. Biorefineries use biochemical or thermochemical processes to convert feedstock into fuels and chemicals. A biochemical process involves the hydrolysis of biomass to sugars and subsequent fermentation of sugars to fuels or chemicals. The lignin residues that cannot be biochemically converted would be used as a fuel for the electricity and steam needed by the biorefinery. A thermochemical process involves the gasification of biomass to synthesis gases and subsequent conversion of the synthesis gases to fuels, chemicals, or heat and electricity. Additional information is in the Biomass Program's Multiyear Program Plan (Department of Energy 2005).

When processing lignocellulosic biomass, the biochemical biorefinery will convert the cellulosic portion of the biomass into ethanol and use, at least initially, the remaining lignin residues to generate process heat and electricity. Excess electricity will be sold to the grid, thereby reducing the net ethanol cost. The program assumed the co-production of a small quantity of non-fuel, bio-based chemicals or materials in corn ethanol biorefineries. For corn ethanol, these bio-based products were modeled as a "credit" that reduces the ethanol production cost.

\section{$\underline{\text { Feedstock Infrastructure }}$}

Feedstock Infrastructure activities support the targets shown in Table C-2. The activities consist of: (1) R\&D on future energy crops; (2) biomass collection and storage systems, including harvester development for the collection of agricultural residues and other cellulosic resources; and (3) development of supporting infrastructure and supply. DOE is establishing regional partnerships on feedstock development in collaboration with the United States Department of Agriculture (USDA), land grant universities, and private-sector consortia to ensure that the biorefineries will have access to plentiful feedstock supplies (including energy crops) at reasonable prices. The DOE Office of Science will also fund basic research to support this work, effectively increasing the probability of R\&D success.

\section{Platforms Research \& Development}

OBP is accelerating research on conversion technologies and process integration. OBP will expand partnerships to further improve the integration of pretreatment and enzyme operations that would lead to cheaper biomass-based sugars. This effort is required to support biorefinery validation projects with technology packages delivered to pilot plants and demonstration plants 
beginning in FY 2010 as shown in Table C-2. The Office of Science will also fund appropriate enabling research to increase the probability of achieving cost targets.

\section{$\underline{\text { Utilization of Platform Outputs }}$}

These activities consist of cost-shared projects to validate integrated biorefinery designs that will focus on pathways with feedstocks such as corn fiber, corn stover, and oilseeds for converting biomass to fuels, chemicals, and/or materials. OBP will accelerate the validation of industrialscale projects, an essential step in reducing technical risks associated with first-of-a-kind biorefineries. This acceleration will result in industrial-scale demonstrations whose dates are listed in Table C-2. Efforts will continue to integrate and test handling, pretreatment, hydrolysis, and fermentation operations to evaluate performance and costs of converting biomass to fuels and co-products.

Table C-2 shows the OBP outputs and associated activities and milestones. Table C-3 links the OBP outputs with eventual outcomes. 
Table C-2. Biomass Program: Outputs, Activities, and Milestones

\section{Outputs}

Enable first corn

biorefinery with corn

fiber and residual starch

Enable first pilot-scale

project with corn stover

Assist with legislation favorable to cellulosic ethanol, vehicles and fueling stations

Enable first demonstration-scale project with corn stover

Enable switchgrass commercialization

Enable first pilot-scale projects with switchgrass and forest residues

Enable first demonstration-scale project with switchgrass and/or forest residues

Enable next-generation cellulosic biorefineries for ethanol production
Associated Activities

RD\&D for corn fiber pathway at corn ethanol biorefineries

RD\&D with industry on pretreatment, hydrolysis and fermentation, and integrated validation at pilot scale

Provide White House with analyses and position papers as needed

Conduct RD\&D with industry for stover cost reduction

Scale up stover-based ethanol technology with industry partners

RD\&D with Office of Science, universities and USDA to improve switchgrass varieties in multiple regions

RD\&D with Office of Science and industry, leading to integrated validation at pilot scale

Scale up switchgrassbased ethanol technology with industry partners

RD\&D with Office of Science, USDA, and industry on production, collection, and storage of additional biomass resources. Partner with industry on demonstrations for longer- term feedstocks

\section{Associated Milestones}

Conclude commercial demonstration with industry partner to increase ethanol output by at least $4 \%$ for each biorefinery by 2009

Deliver technology package to pilot-scale project by 2010 . By 2012, evaluate process against target selling price of $\$ 1.07$ per gallon of ethanol with a $\$ 35 /$ ton feedstock cost or $\$ 1.22$ per gallon with a $\$ 45 /$ ton feedstock cost

Enactment in 2012 through re-authorized Farm Bill and Energy Policy Act

By 2013, deliver technology for stover collection and storage to demonstration-scale project at a cost of $\$ 35$ to $\$ 45$ per dry ton (depending on region and tillage)

By 2015 , evaluate demonstration-scale production against target yield of 90 gallons of ethanol per ton of feedstock

Increase switchgrass yield per acre by $10 \%$ at test sites by 2015 from current regional levels

Increase yield per acre by an additional $5 \%$ at test sites by 2019

Deliver technology packages to two pilot-scale projects by 2016 . By 2017 , evaluate production at pilot scale against target yield of 90 gallons per dry ton

By 2020, evaluate production at demonstration scale against target yield of 90 gallons per dry ton of feedstock

Deliver improved switchgrass and more competitive technologies for biomass production, collection, and storage to demonstration facilities. Industry partners construct, operate, and evaluate subsequent demonstration-scale projects. New biorefineries start up - 2023 through 2028

Currently, the ethanol conversion efficiency is approximately 70 gallons per dry ton of biomass. The maximum theoretical conversion efficiency is more than 110 gallons per dry ton for several cellulosic materials, as shown on the National Renewable Energy Laboratory (NREL)'s theoretical yield calculator Web site (http://www1.eere.energy.gov/biomass/ethanol_yield calculator.html). However, the targets in 
this analysis were kept below this limit. The current average switchgrass yield is nearly 5 dry tons per acre, per year; and expected improvements in yield are between $7 \%$ and $11 \%$ in 2015 relative to current varieties (Walsh 2006a). The cost range for cellulosic ethanol is reported by NREL at approximately $\$ 1.00$ to $\$ 1.40$ per gallon (Aden 2002) for a range of enzyme and fermentation performances and costs.

Table C-3. Biomass Program: Linkage of Outputs with Outcomes

\section{Outputs}

Enable first corn biorefinery with corn fiber and residual starch

Enable first pilotscale project with corn stover

\section{Associated Immediate Outcomes and dates}

Corn ethanol costs $2 \%$ less by 2010 thanks to DOE cofunding and collaboration

Pilot-scale validation in 2012 helps improve the design of demonstration plants, thereby reducing risks

Assist with legislation favorable to cellulosic ethanol, vehicles and fueling stations Enable first demonstration-scale project with corn stover
Enable switchgrass commercialization
Enable first pilotscale projects with switchgrass and forest residues

Enable first demonstration-scale projects with
Improved switchgrass varieties allow farmers and industry to collaborate on deployment beginning in 2019

Pilot-scale validation by 2017 helps improve the design of larger demonstration plants, thereby reducing risks for ethanol cost targets Successful demonstration leads to commercialization beginning in 2019

\section{Associated Interim Outcomes}

Ethanol industry deploys corn fiber and residual starch technology between 2010 and 2015

Facilitate industry's decision on demonstration projects after 2010. Farm equipment manufacturers accelerate $R \& D$ on residue harvesting and storage systems

Accelerate commercialization over the next 15 years

Industry deploys stover conversion beginning in 2015 , spurring deployment of wheat straw and similar residues. Farm equipment manufacturers begin production of efficient harvesting and storage systems. Spurred by success with residues, farmers and industry begin to cost-share switchgrass demonstrations

New biorefineries plan on using switchgrass in selected regions beginning in 2019. Farmers incorporate switchgrass in their decision process for future plantings

Farm equipment and logging equipment manufacturers accelerate R\&D on their respective harvesting and storage technologies

Industry deploys ethanol from switchgrass and/or forest residues beginning in 2019 .

\section{Associated Ultimate Outcomes}

Benefits, e.g. increased energy security, reduced emissions, etc.

Keep subsequent commercialization dates on target for benefits estimation

Benefits, e.g. increased energy security, reduced emissions, etc.

Keep commercialization date on target

Keep switchgrass commercialization date on target

Keep subsequent commercialization dates on target

Keep subsequent commercialization dates on target 
switchgrass and/or forest residues
Farmers make planting

decisions focusing on

switchgrass. Farm equipment

and logging equipment manufacturers begin production

of efficient harvesting and

storage equipment. Forest

industry and Forest Service

develop new forest

management approaches

Enable nextgeneration cellulosic biorefineries for ethanol production
Pilot and demonstrationscale projects enable additional biorefineries to use a wider variety of biomass resources
Biorefineries can keep production cost increases to a minimum even as higher demand pushes up biomass prices from 2020 on
Benefits, e.g. increased energy security, reduced emissions, etc.

\section{Key Factors in Shaping Market Adoption of EERE technologies}

Price - Ethanol subsidies are currently an important component of the market dynamics. Corn ethanol can compete in the high-value E10 market at current oil prices (\$61-\$64 as of late 2006). Refineries are willing to pay a higher price per gallon of ethanol for each 0.1 gallon of ethanol that will be blended with 0.9 gallon of base gasoline, because the ethanol fraction increases the octane of the gasoline/ethanol blend and helps reduce toxic emissions when E10 is used in vehicles. Beyond this first 10\% volume in gasoline, additional ethanol would not contribute any more to the octane increase or toxic emissions reduction. In other words, the refiners will not pay the same high price for the next increment of ethanol. The additional ethanol would have to compete with gasoline strictly on the ability to deliver energy to drive a number of miles. The paradox is that ethanol fetches higher prices when used in E10, but would have to be priced much lower for a larger volume of ethanol to be used in E85. If ethanol could be produced much more cheaplyand its supply became much greater-ethanol prices might come down sufficiently so that this paradox no longer exists.

Non-Price Factors - These include vehicle compatibility, infrastructure requirements, key consumer preferences/values, manufacturing factors, and policy factors.

\section{$\underline{\text { Vehicle compatibility }}$}

Essentially all gasoline vehicles in the United States can use the low-blend ethanol gasoline mixture (E10 or less). For high blends such as E85, automobile manufacturers have considerable experience in producing vehicles that meet the Environmental Protection Agency's requirements (Environmental Protection Agency 2000). Six million flex-fuel vehicles have been sold in the United States, including models of the Ford Taurus, Chevrolet S10 pickup truck, GMC Sonoma pickup truck, Isuzu Hombre pickup truck, Chrysler Voyager minivan, Dodge Caravan minivan, Chevrolet Silverado, and other models (General Motors Corp. 2006). U.S. car manufacturers have recently announced plans to increase E85 FFV production and to increase consumer awareness of these vehicles with beefed-up marketing campaigns (AFDC 2006, Detroit Free Press 2006). Manufacturers are making the FFV option standard on an increasing number of 
models. Therefore, there is no "non-FFV" option for those models. The issue of price differences between the FFV version and gasoline-only option does not arise.

\section{$\underline{\text { Infrastructure Requirements }}$}

A 2002 logistics study (Reynolds 2002) did not foresee any major infrastructure barriers to a substantial expansion of the ethanol industry in a set of scenarios that were analyzed. The scenarios included substantial movement of ethanol among and within different regions of the country by several different modes of transport. The study revealed that investments in transportation, storage, terminal upgrades, and retailing are possible without encountering significant "growing pains" for up to 10 billion gallons per year. The study looked primarily at the blend or E10 market. Existing pumps at retail stations could be converted from dispensing pure gasoline to E10 with only minor modifications and cost. However, new pumps would have to be installed to dispense E85, and the amortized costs to the retail station would depend on E85 throughput. The study assumed that E85 use is expected to be small compared to E10.

Although petroleum terminal improvements anticipated by the study represent significant capital investments for terminal operators, they amount to less than 1 cent per gallon of new ethanol volume, 0.1 cent per gallon of E10, on an amortized basis. With some assurance of increased throughput volumes at terminals (such as that provided by a federal renewable fuel standard), terminal operators could be expected to make the improvements.

The 2002 study found that the volume of product anticipated to be moved by railroad and river barge is a very small fraction of products moved by these industries. Furthermore, both the rail freight car building industry and the barge building industry have the capacity to build equipment that would keep pace with the increasing ethanol shipments from new plants.

There are also operational strategies the ethanol industry could employ that would mitigate the risk of supply disruptions caused by logistical glitches. Additional inventory levels at terminals and other storage locations could act as a cushion against delayed shipments and help ensure the smooth functioning of a growing market.

While the study did not find any serious logistical impediments to expansion of the ethanol industry, it did identify two areas of potential concern that merit further study. These are the availability of appropriate vessels and potential restrictions on barge movement in some areas of the U.S. inland waterway system as a result of vessel retirements.

Ships that are used to transport ethanol are subject to various regulations and requirements. The Merchant Marine Act of 1920, otherwise known as the Jones Act, requires that all ocean or waterway transportation from one U.S. port to another U.S. port be moved in a vessel built in the United States, owned by a U.S. person or corporate entity, manned by a certified U.S. crew and registered in the United States (U.S. flagged). Tankers meeting these specifications are known as Jones Act tonnage.

Vessels carrying petroleum products between U.S. ports are also subject to the Oil Pollution Act of 1990 (OPA90). This would include ethanol, because ethanol is normally transported after 
having been "denatured," with the addition of a small quantity of a petroleum product such as gasoline. OPA90 requires the use of double-hulled vessels and further requires the retirement of single-hulled vessels from petroleum product service by certain dates, based on their manufacture or rebuild date (Reynolds 2002).

When the ethanol market greatly exceeds 10 billion gallons per year, some of the aforementioned barriers could become constraining. The benefits analysis assumed that the United States, through the DOE Transportation Posture Plan and resulting roadmaps, would have implementation measures that would minimize the effects of these barriers. Initial coordination activities would be identified in a Posture Plan to be developed by the Biomass Program in FY 2007. Subsequently, EERE will develop a Transportation Posture Plan combining planning information from the Office of Science; the Vehicle Technologies, Biomass, and Hydrogen programs; and other federal agencies such as the departments of Transportation and Agriculture. It is reasonable to expect that the USDA will play a key role in R\&D on energy crops and overall sustainability analysis, OBP will continue to lead the RD\&D efforts with respect to biochemical and thermochemical conversion, the Vehicle Technologies Program will be the lead sponsor of automotive technology R\&D aimed at taking advantage of biofuels properties, and the Office of Science will sponsor basic R\&D that underpins the USDA and OBP research.

\section{$\underline{\text { Key Consumer Preferences or Values }}$}

E10 consumption has historically been concentrated in the Midwest. In recent years, ethanol use in coastal RFG increased dramatically as state bans on MTBE began taking effect. As a result, some coastal states are beginning to adopt policies to promote in-state ethanol production. E85 is likely to penetrate markets more easily in the Midwest where most of the ethanol is produced and consumers have a long history of using ethanol fuels. If the trend of increasing public awareness and environmental concern continues, this could become a significant positive factor in consumer choice in fuel markets in other regions outside of the Midwest. However, ethanol production costs must be lower than those of current corn ethanol and more competitive with gasoline in order for E85 infrastructure and acceptance to grow rapidly.

\section{$\underline{\text { Manufacturing Factors }}$}

While various biorefinery configurations are possible, the two fundamental platforms are fermentation (sugar-based) and gasification (syngas-based). EERE is working with private industry to further develop these platforms, from which a number of fuels (including ethanol) and chemicals may be derived. Pioneer plants will cost more because the technology would be new. With experience, the costs for each subsequent plant will decrease as a result of lessons learned and lower cost of capital associated with reduced risk. The Biomass Program has historically focused more on the fermentation platform for cellulosic ethanol, as this path was seen as a logical extension of the more mature starch-based ethanol process. This is also a result of the cost-reduction opportunities associated with the fast pace of biotechnology advances. Consequently, NREL and its subcontractors have extensively analyzed the process economics of the fermentation pathway. Because the focus on the syngas-based biorefinery is relatively new, our understanding of this pathway is not as developed as our understanding of the sugar-based pathway. For this reason, our analysis was limited to the sugar-based pathway. 


\section{$\underline{\text { Policy Factors }}$}

When NEMS and MARKAL analysts estimated the rate of market adoption, they assumed the continuation of existing laws, regulations, and policies (such as the ethanol tax incentive and the Renewable Fuels Standard) and continuing USDA and DOE investment in biomass technology RD\&D at current levels, consistent with current energy policy legislation. The incentives are expected to play a key role in reducing the costs and financial risks of pioneer cellulosic ethanol plants.

\section{Immediate Outcomes}

The immediate outcomes resulting from OBP activities include pilot-scale and demonstrationscale validation of new biorefinery technologies, industry's development of novel biomass harvesting and storage subsystems, and the availability of cost-competitive biomass resources when new biorefineries start up. Cost targets are in 2004 dollars. The cost data that OBP provided to EERE modelers are capital and operating costs (not prices) as required by NEMS and MARKAL. OBP assumed that three years are needed between the completion of a demonstration and the first year of commercialization.

\section{Interim Outcomes}

At this time, there are two fuel ethanol markets, the low-blend market (up to $10 \%$ ethanol in gasoline) and the high-blend market ( $85 \%$ ethanol in gasoline). The value of ethanol changes significantly from the first market to the second market because its valuation is based on two entirely different factors.

The low-blend market exists because reformulated gasoline is being produced by adding up to $10 \%$ ethanol to a base gasoline that is made of petroleum constituents. In the low-blend market, refineries are willing to pay a higher price per gallon of ethanol for each 0.1 gallon of ethanol that will be blended with 0.9 gallon of base gasoline because the ethanol fraction increases the octane of the gasoline/ethanol blend and helps reduce toxic emissions when E10 is used in vehicles. Blending ethanol with gasoline in higher concentrations (beyond the $10 \%$ needed for octane and environmental benefits) becomes less competitive because a gallon of ethanol has only two-thirds the energy of a gallon of gasoline. In 2006, however, the price of oil reached new highs, and the cost of producing corn ethanol compared favorably with the cost of producing gasoline on an energy-equivalent basis. Production capacity constrains the amount of ethanol that can enter the market, and the current production capacity for ethanol from corn is still significantly less than U.S. motor gasoline demand.

Ethanol is already widely used in gasoline and accepted as a component of transportation fuel in the target market. As the technology for producing cellulosic ethanol matures in the longer term, the retail value of cellulosic ethanol would become competitive with gasoline on an energy basis. At that point, fuel markets would likely accept nearly pure ethanol such as E85 because of its environmental characteristics and indigenous supply basis. In Brazil, for example, both E22 and E100 are readily available and most new car sales are flex-fueled vehicles that can use either fuel or any blend in between these limits. Increases in market penetration for ethanol will also be 
affected by competition from other alternative transportation fuels and success in building a nationwide E85 transportation and distribution infrastructure. Eventually, increases in market penetration may be constrained by the availability of feedstock, rather than market demand.

\section{Summary of Inputs}

The input that OBP provided to the EERE benefits models are discussed below.

\section{Biomass Supply}

The University of Tennessee (UT) and Oak Ridge National Laboratory (ORNL) developed cellulosic feedstock supply curves with the aid of POLYSYS (UT 2006) and other regionally detailed models (Walsh 2006). The supply curves represent quantities of different categories of feedstocks available at different prices and time periods. In NEMS and MARKAL, feedstock costs are adjusted to include $\$ 10.50$ per dry ton for transportation from the farm gate to the conversion facility, and feedstock supplies are allocated among different competing uses, e.g., biopower. In addition, the MARKAL analysis assumes that agricultural residues and bio-energy crops will increase at an annual rate of $1 \%$ and $1.4 \%$, respectively, during the analysis period, due to increasing agricultural productivity. NEMS has not yet incorporated the postulated productivity increases (Lavoie 2006).

While forest residues and urban wood wastes may not be optimal for sugar-based ethanol production, we recognize that future syngas-based fuels production may use forest residues and some urban wood wastes as feedstock. Therefore, these resources were assumed available to ethanol biorefineries along with the more appropriate resources (agricultural residues and switchgrass).

\section{Fossil Fuels and Carbon Calculations}

Energy and carbon benefits were calculated as the difference between the fossil energy use and carbon emissions in the Program and Baseline cases. Fossil energy use includes the fossil energy embedded in the final product, e.g., in gasoline, as well as the upstream fossil energy consumption, e.g., the fossil energy used to extract and transport oil, and refine the oil into gasoline. 


\section{Biorefinery Costs}

NEMS-GPRA08 analysis extends through 2030, while MARKAL-GPRA08 analysis extends through 2050. The Biomass Program analyst at NREL provided costs and other input through 2050. OBP based their cellulosic biorefinery concept on a plant whose main product is fuel ethanol, with electricity as a co-product. Excess electricity is sold to the grid and is modeled as a reduction in the cost of producing ethanol. The analysis is for a biorefinery with a total throughput of 2,000 dry metric tons of feedstock per day and with a conversion efficiency increasing from approximately 90 gallons of ethanol per dry ton of feedstock in 2015 to 94 gallons per dry ton in 2035, as a result of technological advances (Jechura 2005).

Table C-4. Cellulosic Ethanol Production Costs and Conversion Efficiency Targets

Costs in $2004 \$$ per Gallon (Without Feedstock Costs) (2012 costs: nominal \$1.07/gallon if added \$35/ton feedstock cost 2035 costs: nominal \$0.60/gallon if added \$35/ton feedstock cost)

$\begin{array}{cccccc}\text { Year } & \begin{array}{c}\text { Annualized } \\ \text { Operating }\end{array} & \begin{array}{l}\text { Ethanol } \\ \text { CatOH } \\ \$ / \text { gal EtOH }\end{array} & \begin{array}{l}\text { Yield } \\ \text { gal/ton }\end{array} & \begin{array}{l}\text { Electricity } \\ \text { Usage } \\ \text { kWh/gal }\end{array} & \begin{array}{c}\text { Nat Gas } \\ \text { Usage } \\ \text { MMBtu/gal }\end{array} \\ 2015 \$ 0.330 & \$ 0.430 & 90.1 & -2.06 & 0 \\ 2016 \$ 0.317 & \$ 0.419 & 90.3 & -2.06 & 0 \\ 2017 \$ 0.305 & \$ 0.407 & 90.5 & -2.06 & 0 \\ 2018 \$ 0.292 & \$ 0.396 & 90.8 & -2.06 & 0 \\ 2019 \$ 0.279 & \$ 0.384 & 91.0 & -2.05 & 0 \\ 2020 \$ 0.267 & \$ 0.373 & 91.2 & -2.05 & 0 \\ 2021 \$ 0.254 & \$ 0.362 & 91.4 & -2.05 & 0 \\ 2022 \$ 0.241 & \$ 0.350 & 91.6 & -2.05 & 0 \\ 2023 \$ 0.229 & \$ 0.339 & 91.8 & -2.05 & 0 \\ 2024 \$ 0.216 & \$ 0.328 & 92.1 & -2.05 & 0 \\ 2025 \$ 0.203 & \$ 0.316 & 92.3 & -2.04 & 0 \\ 2030 \$ 0.140 & \$ 0.259 & 93.4 & -2.04 & 0 \\ 2035 \$ 0.102 & \$ 0.225 & 94.0 & -2.03 & 0 \\ 2040 \$ 0.102 & \$ 0.225 & 94.0 & -2.03 & 0 \\ 2045 \$ 0.102 & \$ 0.225 & 94.0 & -2.03 & 0 \\ 2050 \$ 0.102 & \$ 0.225 & 94.0 & -2.03 & 0\end{array}$

Source: John Jechura , Adv Dry Mill Curve 8-25-2005 - DA changes.xls, National Renewable Energy Laboratory, after acceleration to be consistent with the Initiative's goal.

Consistent with current ethanol plants' financial practices, a real capital cost recovery factor of $15 \%$ is used in NEMS and MARKAL to calculate the per-gallon capital costs in each year. Cellulosic ethanol plants combust the lignin portion of the lignocellulosic feedstock to produce heat and electricity. The plants produce excess electricity that is sold into the grid. The negative numbers in the electricity use column represent the sale of the excess electricity. The electricity credit is computed by multiplying the price of electricity times the excess electricity production.

In addition to the benefits associated with cellulosic biorefineries, a smaller subset of benefits is associated with OBP's corn ethanol R\&D. Dry mills process corn into ethanol, distillers dried grain with solubles (DDGS), and carbon dioxide $\left(\mathrm{CO}_{2}\right)$. DDGS is sold into the animal feed 
market. Some dry mill operators sell their $\mathrm{CO}_{2}$ output, but the $\mathrm{CO}_{2}$ market is limited and therefore not considered in this analysis. As dry mills begin to deploy the technology to convert the fiber and residual starch in kernels to ethanol, there will be less fiber and starch in the DDGS co-product. The corn fiber and residual starch conversion process does not change the protein amount in the DDGS. This increases the value of the DDGS in the market place because pound for pound, its protein content is higher than before. Therefore the revenue to the ethanol producer from DDGS sales remains constant, while the plant makes more ethanol from the recovered fiber. The ethanol (denatured) yield per bushel will increase from 2.8 gallons in 2010 to more than 3.4 gallons in 2030 .

The degree to which ethanol technologies would progress in the absence of EERE's biomass RD3 has not been studied in detail. Instead, EERE adopted the methodology recommended by the National Research Council (NRC) to estimate how EERE RD3 funding would accelerate technology improvements. The NRC recommended using an N-year rule, in which technology deployment would be accelerated by $\mathrm{N}$ years with EERE or conversely delayed by $\mathrm{N}$ years in the absence of EERE. OBP assumed that without federal investment in RD\&D, technological advances would be delayed seven years for corn fiber/recalcitrant starch and 15 years for ethanol production technologies using cellulosic feedstock.

The reason for a moderate delay for the corn fiber/recalcitrant starch process is that industry has shown interest and willingness to cost-share R\&D in this area, and the estimated development time is short compared to that for cellulosic ethanol technology. OBP has already catalyzed work in this area, as indicated by several projects that are underway. It seems reasonable that, absent any further OBP involvement, industry would continue to build on work already accomplished, albeit at a slower rate.

The rationale for assuming a 15-year delay for standalone cellulosic ethanol biorefineries is industry's reticence to underwrite cellulosic ethanol research, because of its greater risk and cost. For example, for a decade, the enzyme industry failed to show interest in partnering with EERE to develop low-cost enzymes for cellulosic ethanol production. Only in 2000-2001 did they make the strategic decision to become key players in the development of the new ethanol industry. Feedstock collection infrastructure is another critical area in which industry has neglected to invest in the development of new technology. Sustained public/private collaboration is necessary before cellulosic ethanol can become competitive. 


\section{Bibliography}

Abengoa Bioenergy, 2006; http://www.abengoabioenergy.com/research/ index.cfm?page=11, 09-12-2006

Aden, A. et al., Lignocellulosic Biomass to Ethanol - Process Design and Economics, National Renewable Energy Laboratory report, May 2002

Alternative Fuels Data Center, GM Kicks Off National E85 Advertising Campaign, 01/05/2006, http://www.eere.energy.gov/afdc/progs/ddown.cgi?afdc/WHATS_NEW/528/1/0

Detroit Free Press, Miscellaneous Articles, April 25, 2006, http://www.idahoethanol.com/pages/news.html

Energy Information Administration, “Annual Energy Review 2005,” Table 5.11, page 147, for 2005 gasoline consumption.

Environmental Protection Agency, 2000. Federal and California Exhaust and Evaporative Emission Standards for Light-Duty Vehicles and Light-Duty Trucks, EPA420-B-00-001, February 2000. http://www.epa.gov/otaq/cert/veh-cert/b00001.pdf.

Environmental Protection Agency, 2000. Federal Certification Evaporative Emission Standards for Light-Duty Vehicles (Passenger Cars) and Light-Duty Trucks: Evaporative and Onboard Refueling (ORVR) Test Procedures (including NLEV and CVF programs), EPA420-B-00-001, February 2000, http://www.epa.gov/otaq/cert/veh-cert/b00001d.pdf.

Environmental Protection Agency, 2006. Reformulated Gasoline - Basic Information, 09-142006, http://www.epa.gov/otaq/rfg/information.htm

Department of Energy, 2005. Office of the Biomass Program, Multiyear Program Plan 20072012, 08-31-2005, http://www1.eere.energy.gov/biomass/pdfs/mypp.pdf

EERE 2004, Department of Energy, Energy Efficiency and Renewable Energy, http://www.eere.energy.gov/vehiclesandfuels/epact/pdfs/plf_final.pdf

General Motors Corp., 2006; http://www.gm.com/company/gmability/environment/ news issues/news/e85 041906.html, 09-12-2006.

GSA, 2006. http://72.14.205.104/search?q=cache:QS7dykyR1nMJ:www.gsa.gov/gsa/ cm_attachments/GSA_DOCUMENT/FFR2005_R2K-g6_0Z5RDZ-i34K-

pR.doc + Federal + fleet + size \&hl $=$ en\&gl $=$ us\&ct $=\bar{c} \operatorname{lnk} \& \mathrm{~cd}=5$

Ibsen, K., Wallace, R., Jones, S., and Werpy, T., 2005, Evaluating progressive technology scenarios in the development of the advanced dry mill biorefinery, NREL milestone completion report No. FY05-630, 03-04-2005, http://devafdc.nrel.gov/bcfcdoc/9071.pdf 
Iogen Corp, 2006; http://www.iogen.ca/company/faq/index.html, 09-12-2006

Jechura, J., 2005, Adv Dry Mill Curve 8-25-2005 - DA changes.xls, spreadsheet from NREL Biomass Program with adjustment in May 2006 to account for Biofuels Initiative funding expected for FY 2008.

Lavoie, B., 2006, GPRA08 Feedstock for NEMS 07-10-06; GPRA08 Feedstock for MARKAL 0710-06, Feedstock Extrapolations to MARKAL 07-10-06, Feedstock Extrapolations to NEMS 0711-06, documents by TMS for DOE-EERE.

McAloon, A., Taylor, F., Yee, W., Ibsen, K., and Wooley, R., Determining the Cost of Producing Ethanol from Corn Starch and Cellulosic Feedstocks, NREL/TP-580-28893, October 2000, http://www.ethanol-gec.org/information/briefing/16.pdf

Morris, D. A Commentary on the Hydrogen Economy and a Proposal for an Alternative Strategy, December 2003, http://www.newrules.org/electricity/betterway.pdf

National Ethanol Vehicle Coalition, 2006, http://www.e85fuel.com/e85101/faqs/ number_ffvs.php, 09-12-2006

NYSERDA, 2006. http://www.agmkt.state.ny.us/rfps/cellulosic ethanol/Cellulosic\%20 Ethanol\%20RFP\%203.pdf

Raabe, S. Corn o'plenty. Denver Post, 08-01-2006. http://www.denverpost.com/business/ci 4118797

Radich, T., 2006. EIA Biofuels Analyst's personal communication with Tien Nguyen, DOEEERE, 09-07-2006.

Renewable Fuels Association, 2006, http://www.ethanolrfa.org/industry/statistics/\#C, 09-122006 EERE AFDC 2006, http://www.eere.energy.gov/afdc/e85toolkit/success.html, 09-13-2006

Reynolds, R., 2002, Infrastructure Requirements for an Expanded Ethanol Industry, Jan. 15, 2002, http://www.devafdc.nrel.gov/pdfs/6235.pdf

Reynolds, R., 2004, Replacing the Volume and Octane Loss of Removing MTBE from Reformulated Gasoline, May 2004, http://www.ethanolrfa.org/objects/documents/116/mtbealternatives.pdf

Schremp, G., 2006, Phasing Out of MTBE, Impacts on Ethanol Supply; Presentation to National Association of State Energy Officials, August 2006, http://www.energy.ca.gov/2006publications/CEC-999-2006-003/CEC-999-2006-003.PDF 
Walsh, M., 2006b, U.S. Cellulosic Biomass Feedstock Supply and Distribution, 04-05-2006, paper prepared for Oak Ridge National Laboratory.

Wheeler, T., 2006, Refiners to Phase Out Use of MTBE, Baltimore Sun, Feb 17, 2006;

http://www.baltimoresun.com/news/local/harford/balmd.mtbe17feb17001554,0,5399305.story?coll=bal-local-harford

White House, 2006. President George W. Bush's State of the Union Address, www.whitehouse.gov/stateoftheunion/ 2006/energy/index.html

Wood, Frances, 2006. On-Location NEMS Team Leader's personal communication with Tien Nguyen of DOE-EERE in August 2006.

World Refining \& Fuels Today, 2006. Honda Plans Development of Cellulosic Ethanol, http://www.worldfuels.com/NEWSLET/WorldFuels_News/wf_Vol1_Issue149_20060915.html 


\section{APPENDIX D - SOLAR ENERGY TECHNOLOGIES PROGRAM INPUTS FOR FY 2008 BENEFITS ESTIMATES}

Table of contents

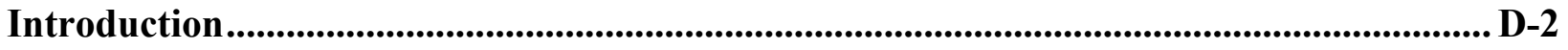

Significant Changes from Previous Analysis............................................................................. D-3

GPRA08 Solar Program Baseline Assumptions............................................................... D-4

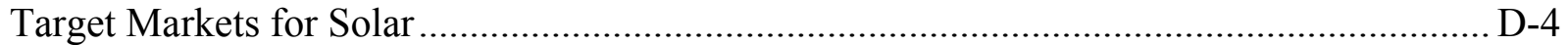

Baseline Adjustments to the AEO 2006 Reference Case ................................................ D-5

GPRA08 Solar Program Scenario Assumptions.............................................................. D-10

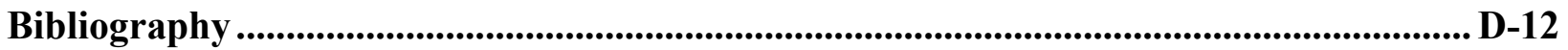




\section{Introduction}

The President's Solar America Initiative (SAI) was launched January 2006, as part of the Administration's Advanced Energy Initiative, and is being led by the U.S. Department of Energy's (DOE) Solar Energy Technologies Program (SETP). The primary mission of the SAI is to reduce the cost of photovoltaic (PV) technologies so that PV-generated electricity is costcompetitive with conventional electricity sources by 2015.

The SAI enhances DOE's business strategy of partnering with U.S. industry to accelerate commercialization of improved PV systems that can meet aggressive cost and installed capacity goals. Complementing the core R\&D and engineering activity of the SAI are technologyacceptance activities aimed at reducing market barriers and promoting market expansion of solar energy technologies through non-R\&D activities.

The SAI will drive toward accelerated commercialization of solar photovoltaic systems to a milestone in 2015, at which time they will be competitive with conventional sources of electricity in all domestic grid-tied market sectors: residential, commercial, and utility-scale markets. The main goals of this nine-year mission are:

- Substantively accelerate development of U.S.-produced PV systems so that PV-produced electricity reaches parity with the cost of electricity in select grid-tied target markets across the nation (identified in Table D-1).

- Expand the U.S.-installed domestic capacity of PV systems to 5-10 gigawatts (GW) by 2015.

Because the cost basis of electric energy in the target markets is cents per kilowatt-hour, SETP has established targets for PV systems based on the levelized cost of energy (LCOE) delivered by these systems. LCOE is a measure of total lifetime costs of a PV system divided by expected lifetime energy output, with appropriate adjustments for time value of money, etc. The overall cost goals for SAI are shown in Table D-1. These targets are based on Energy Information Administration (EIA) projections of relatively flat electricity prices (in real terms) over this time period, based on current conventional fuels. The 2005 Benchmark LCOEs of PV systems and target projections are based on SETP internal analyses and the U.S. PV Industry Roadmap (SEIA 2004). With the ultimate goal for SAI being cost parity with grid-generated electricity, SETP will revise these targets over time as new information warrants.

To implement the SAI, the SETP will pursue an R\&D strategy that is segmented into three manageable three-year phases. These phases will progressively reduce the cost of commercially available PV systems and components, and will ultimately yield commercial products and production processes that achieve the LCOE targets and support installed capacity targets by 2015. The first three-year phase is scheduled to run from early CY 2007 through early CY 2010; the second three-year phase is expected to run from early CY 2010 through early CY 2013; and the third three-year phase is expected to run from early CY 2013 through the end of CY 2015. 
Table D-1. Cost Targets for Grid-Connected PV Systems in Key Market Sectors

\begin{tabular}{|l|c|c|c|c|}
\hline Market & \multirow{2}{*}{$\begin{array}{c}\text { Current } \\
\text { Sector }\end{array}$} & \multicolumn{3}{|c|}{$\begin{array}{c}\text { Solar Electricity Cost }- \text { Current and Projected } \\
\text { (c/kWh) }\end{array}$} \\
& $\begin{array}{c}\text { Market } \\
\text { Range } \\
(\mathrm{c} / \mathrm{kWh})^{\mathrm{a}, \mathrm{b}}\end{array}$ & Benchmark & \multicolumn{2}{|c|}{ Target } \\
\cline { 3 - 6 } & & 2005 & 2010 & 2015 \\
\hline Residential $^{c}$ & $5.8-16.7$ & $23-32$ & $13-18$ & $8-10$ \\
\hline Commercial $^{c}$ & $5.4-15.0$ & $18-22$ & $9-12$ & $6-8$ \\
\hline Utility $^{d}$ & $4.0-7.6$ & $15-22$ & $10-15$ & $5-7$ \\
\hline
\end{tabular}

${ }^{\mathrm{a}}$ Costs are based on constant 2005 dollars.

${ }^{b}$ Current costs are based on electric-generation with conventional sources.

${ }_{d}^{c}$ Cost to customer (customer side of meter)

Cost of generation (utility side of meter)

Achieving the goals in Table D-1 will require reducing installed PV system costs by 50\%-60\% between 2005 and 2015 , from $\$ 5.50-\$ 8.50 / \mathrm{Wp}$ to $\$ 2.25-\$ 3.50 / \mathrm{Wp}$. ${ }^{1}$ These targets are reflected in the GPRA08 Solar Program Scenario presented below.

This appendix provides detailed information on the assumptions and methods employed to estimate the benefits of EERE's Solar Energy Technologies Program. The benefits analysis for the Solar Program utilized both NEMS and MARKAL as the analytical tools for estimating the program's benefits. As will be discussed below, a number of assumptions and structural modifications to the models were made in to represent the suite of solar technologies funded by the program as accurately as possible [ Photovoltaics and Concentrating Solar Power (CSP)].

\section{Significant Changes from Previous Analysis}

Most of the assumptions used in the FY08 analysis are the same as or very similar to those employed in the FY07 analysis. As in the FY07 analysis, the FY08 analysis reflects changes in the Solar Program's structure and funding implemented in FY07 as included in the President's Solar America Initiative.

\footnotetext{
${ }^{1}$ All monetary figures in this report are in 2005 U.S. dollars unless otherwise specified. Wp is the peak output of a PV module or system measured in wtts.
} 


\section{GPRA08 Solar Program Baseline Assumptions}

The primary driving factor in both NEMS and MARKAL for solar technology adoption is cost. For PV technology, the Solar Program Baseline (No DOE R\&D Case) cost projections are very similar to the projections in the AEO2006 reference case, which were based on the "Baseline" scenario in the U.S. PV industry roadmap (SEIA 2004). While the PV industry roadmap "Baseline" scenario included the PV program funded at the pre-SAI level, i.e., roughly one-half the SAI funding level, the U.S. and global PV industry has gained considerable momentum during the past couple of years. Thus, our GPRA08 Baseline cost projections take this momentum into account: Based on the program's benchmarked estimates, we assume that the cost of PV in 2005 is higher than in the AEO2006; however, by 2015, the projected GPRA08 baseline costs are roughly equivalent to the $A E O 2006$ projections. The overlap remains relatively close through 2030. Beyond 2030, the costs continue to decline, but at a relatively modest rate through 2050, ending slightly below the baseline PV industry roadmap projection. Thus, our baseline cost projection is consistent with the AEO2006 Reference Case and PV industry roadmap Baseline Scenario.

For CSP technology, the Solar Program Baseline simply used the AEO2006 Reference Case projection for CSP systems characteristics and costs.

To generate the Solar Program Baseline, a number of other changes were made to the AEO2006 Reference Case related to system size, incentives, etc. Before discussing these adjustments in detail, the target markets for solar technologies will be briefly described.

\section{Target Markets for Solar}

During the past decade, the global PV market has been experiencing explosive growth. For example, during the past decade (1996-2005), the average annual growth rate of the global PV industry was 35\% (Navigant 2006). The fastest-growing PV market segments during this period were the grid-connected residential and grid-connected commercial segments. Such rapid growth has created tremendous excitement about PV technology around the world within governments (EC 2004), industry (SEIA 2004, NEDO 2004, EPIA 2004) and the investment community (Rogol et al. 2006). During 2005, the global PV industry had $1.7 \mathrm{GW}$ of annual production and a revenue pool of $\$ 12$ billion (Rogol et al. 2006). At this point in time, the global PV industry is truly beginning to move into large-scale production and deployment.

The rapid growth in the global PV market during the past decade was driven largely by government subsidy programs - particularly in Japan, Germany, and a few states within the United States (California, New Jersey, Arizona, and New York). During the coming decades, as costs continue to decline and subsidies are phased out, industry analysts expect that the distributed grid-connected residential and grid-connected commercial markets will continue to expand rapidly and will become self-sustaining (Rogol 2006). Thus, the grid-connected residential and commercial markets have emerged as key markets for developing and expanding the use of PV technology. 
The SETP is focused on developing new solar solutions for the residential, commercial, and utility market sectors of grid-tied electric power. These are described as follows:

Residential Rooftop Market: Typically mounted on rooftops and ranging in size from less than $1 \mathrm{~kW}$ to $10 \mathrm{~kW}$, most commonly in the $3-4 \mathrm{~kW}$ range. These systems are connected to the grid on the retail (customer) side of the utility meter. These systems can be retrofitted onto existing homes or integrated into new construction through building-integrated PV (BIPV) designs.

Commercial Rooftop Market: Typically mounted on the large, flat roofs of commercial, institutional, and industrial buildings, ranging in size from less than $10 \mathrm{~kW}$ to more than $500 \mathrm{~kW}$. These systems are connected on the retail side of the utility meter. Retrofits and BIPV are possible applications in this market as well.

Utility Market: Large-scale (multi-megawatt) systems that displace conventional utilitygenerated intermediate load electricity (e.g., natural gas combined-cycle CCT plants) on a wholesale basis. Typically, utility PV systems are ground-mounted and range in size from 1MW to10MW, while much larger systems are currently under development. Designs include both fixed and tracking configurations. The utility market is also the target market for concentrating solar power (CSP) systems.

\section{Baseline Adjustments to the AEO2006 Reference Case}

Several changes from the AEO2006 Reference Case were incorporated into the GPRA08 Baseline. These changes include the following:

Revising projected PV cost. The residential and commercial PV system characteristics in the AEO2006 reference case were based on the "baseline" scenario provided in the U.S. PV Industry Roadmap (SEIA 2004). As shown in Figure D-1, the projected PV system costs in the GPRA08 Solar Program Baseline are very similar to the projection in the AEO2006 reference case. This Baseline was developed assuming that private industry would continue to improve firstgeneration PV (crystalline silicon) technology, that the entry into the marketplace of substantial quantities of second-generation PV (thin-films) technology would begin to occur around 2015, and that third-generation PV (organic, dye cells, etc.) technologies would continue to be locked out of the marketplace. This approach captures the notion of technological lock-in, i.e., when early use of a technology (i.e., crystalline silicon) creates a snowballing effect that enables it to become dominant in the marketplace for an extended period of time (Cowan and Kline 1996). In the GRPA08 Baseline, continuing incremental improvements in crystalline silicon technologywhich is currently the dominant PV technology in the marketplace-enable it to maintain an extended lock-in. Also, as shown in Figure D-1 and discussed below, changes in the program's structure and funding levels under the SAI are expected to result in accelerated cost reductions through 2015 under the GPRA08 Program case. 

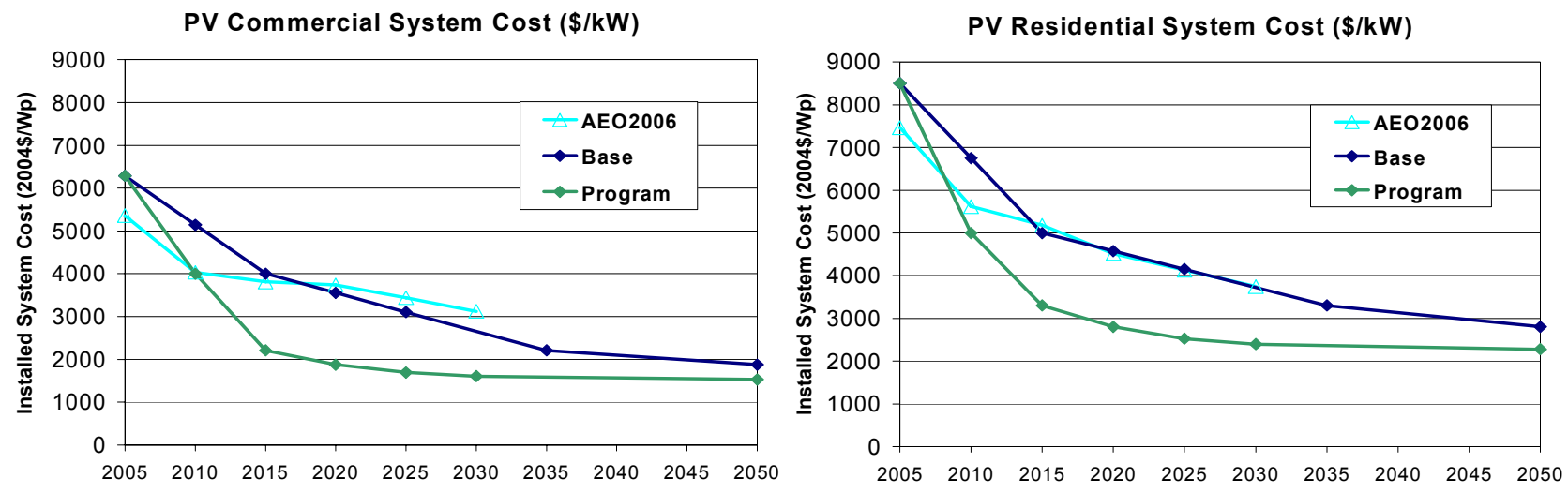

Figure D-1. Projected PV System Costs

Increasing the average commercial building system size. The $A E O 2006$ assumes that the size of commercial PV systems starts at $20 \mathrm{~kW}$ and increases to $45 \mathrm{~kW}$ over the projection period. This range of system sizes is much smaller than typical commercial systems being installed in the United States. Thus, in the GPRA08 cases, the average size of commercial PV systems is assumed to be $100 \mathrm{~kW}$ today, and to increase to $150 \mathrm{~kW}$ by 2015 and $200 \mathrm{~kW}$ by 2030 .

The $100 \mathrm{~kW}$ average starting size is in-line with what is happening in the marketplace today. For example, during 2005, under the California Public Utility Commission's Self-Generation Incentive Program, a total of 24.6 MW of PV were installed on 207 commercial buildings. This translates into an average system size of $119 \mathrm{~kW}$ per installation. The largest system integrator, PowerLight, installed 4.6 MW on 17 buildings, i.e., an average system size of $269 \mathrm{~kW}$ per installation (PV News October 2006). Clearly, the $100 \mathrm{~kW}$ per system starting size is reasonable for California. It is also reasonable for the rest of the United States, based on typical commercial roof sizes and PV packing density requirements, as described below.

To gain a better understanding of how much PV commercial buildings in the United States can accommodate, on average, a sample of data from 14 PV systems installed by PowerLight was examined. As shown in Table D-2, the average PV packing density for these systems was 10 $\mathrm{W} / \mathrm{sq}$. $\mathrm{ft}$. Given that commercially available PV modules are $13 \%-17 \%$ efficient, this is a reasonable packing density allowing for module spacing, stringing, etc.

Table D-2. Commercial System Size and Surface-Area Requirements

\begin{tabular}{lrrrr}
\hline PowerLight System Installation Location & $\begin{array}{r}\text { Date } \\
\text { Completed }\end{array}$ & $\begin{array}{r}\text { System Peak } \\
\text { Capacity (kW) }\end{array}$ & $\begin{array}{r}\text { PV Surface } \\
\text { Area (sq. ft.) }\end{array}$ & W/sq.ft. \\
\hline Santa Rita Jail - Alameda County, California & Apr-02 & 1,180 & 130,680 & 9.0 \\
Cypress Semiconductor - San Jose, California & Jul-02 & 335 & 26,100 & 12.8 \\
Fala Direct Marketing - Farmingdale, New York & Nov-02 & 1,010 & 102,700 & 9.8 \\
Fetzer Vineyards, Hopland, California & Jul-99 & 41 & 3,750 & 10.9 \\
Franchise Tax Board, Sacramento, California & Aug-02 & 470 & 50,000 & 9.4 \\
Greenpoint Manufacturing - Brooklyn, New York & Mar-03 & 115 & 11,500 & 10.0 \\
Mauna Lani Resort - Kohala Coast, Hawaii & Jan-02 & 528 & 43,330 & 12.2
\end{tabular}


Naval Base Coronado, California

Neutrogena Corporation - Los Angeles, California

Parker Ranch - Kameula, Hawaii

PSGA/Ortho-McNeil Facility - Pennsylvania

U.S. Coast Guard - Boston, Massachusetts

U.S. Postal Service - Marina del Rey, California

Yosemite National Park - Yosemite, California

\begin{tabular}{rrrr} 
Sep-02 & 924 & 81,470 & 11.3 \\
Aug-01 & 229 & 30,154 & 7.6 \\
Jan-01 & 209 & 20,000 & 10.5 \\
Apr-02 & 75 & 17,500 & 4.3 \\
Sep-99 & 37 & 3,800 & 9.7 \\
Nov-01 & 127 & 15,000 & 8.5 \\
Oct-01 & 47 & 4,500 & 10.4 \\
\hline & 5,327 & 540,484 & \\
\hline & 381 & 38,606 & 10 \\
\hline
\end{tabular}

Total

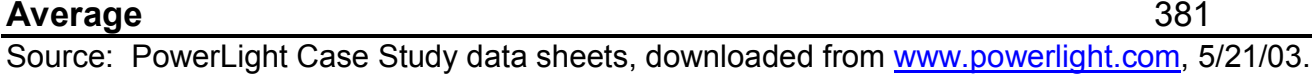

10

Note: Some of the locations shown in this table have multiple installations. In these cases, the total installed capacity is shown above and the most recent installation date is shown in the Date Completed column.

Using this packing density, the average commercial building size, and the average ratio of usable roof space to floor space, one can estimate the amount of PV that could be placed on average on commercial buildings. EIA estimates that the average U.S. commercial building size in 2000 was 14,700 square feet (EIA 2006b), and the International Energy Agency (IEA) estimates that a reasonable ratio of usable roof space to floor space is 0.7 (IEA 2001). Using these estimates, the average commercial building could easily accommodate a $100 \mathrm{~kW}$ PV system, i.e., with available roof space for PV at $0.7 * 14,700 \mathrm{sq} . \mathrm{ft} .=10,150 \mathrm{sq} . \mathrm{ft}$. Thus, setting the average system size at $100 \mathrm{~kW}$ is a conservative assumption based on industry trends, as well as the available roof space on a large share $(50+\%)$ of the commercial building stock.

The average commercial PV system size is likely to increase over time as cell efficiencies increase enabling larger systems to be installed on the same amount of square feet. In addition, as system costs decline, facades and other spaces (such as parking lots) could also be utilized for PV systems. Thus, a 200kW average system size on commercial buildings in 2030 is a reasonably conservative estimate.

Increasing the maximum share of commercial buildings with solar access. The AEO2006 assumes that up to $30 \%$ of commercial buildings have solar access (i.e., limited due to shading, roof type, etc.). In the GRPA08 cases, the maximum share of buildings with solar access was increased to $55 \%$. Similar to the assumptions described above regarding the ratio of usable roof space to floor space, the share of roof space suitable for PV installations was based on the published IEA report on integrated photovoltaics in buildings (IEA 2001). This report indicates that a reasonable estimate for the share of roofs suitable for PV installations is 55\%. This estimate includes shading and other factors that would limit the use of roofs for PV systems (IEA 2001).

Increasing the average residential building system size. The $A E O 2006$ assumes that the average size of a residential PV system is currently $2 \mathrm{~kW}$ and increases to $4 \mathrm{~kW}$ over the projection period. However, residential rooftop systems being installed in the United States during the past couple of years have been averaging $3.5-4.5 \mathrm{~kW} .{ }^{2}$ In fact, $4.4 \mathrm{~kW}$ is the average

\footnotetext{
${ }^{2}$ Based on data from the California Energy Commission's Emerging Renewables Program, downloaded on October 13, 2006, from www.energy.ca.gov/renewables/emerging renewables/index.html.
} 
size of residential PV systems installed under the California Energy Commission's Emerging Renewables Program during 2005. ${ }^{3}$

Thus, in the GPRA08 cases, the average residential PV system size is assumed to be 4kW. Note that the average home in the United States has 1,700 square feet of floor space, and this is expected to increase in the future (EIA 2006a, Table A4). Using data from EIA's residential energy-consumption survey (EIA 2001, Table HC1-2a) one can estimate a floor- to roof-space ratio of 0.7 (based on distribution of one-story, two-story, and three-story single-family homes). This is a conservative estimate-most homes have pitched roofs, which would increase the total available roof space (yet may make a significant portion of the roof oriented away from the sun). If a typical system can accommodate $10 \mathrm{~W} / \mathrm{sq}$. ft. (as above), then a $4 \mathrm{~kW}$ system would require roughly 400 square feet of roof space, which is well below the average available space allowing for multiple floors and pitched roofs. Thus, roof space is not a constraint for installing residential rooftop PV systems in the $4 \mathrm{~kW}$ range. Because the efficiency of PV cells is likely to improve, a trend toward larger systems on rooftops is likely to continue. Thus, based on available roof space and what is happening in the marketplace, setting the average system size at $4 \mathrm{~kW}$ is a conservative assumption.

Increasing the maximum share of residential buildings with solar access. The $A E O 2006$ assumes that up to $30 \%$ of residential buildings have solar access (i.e., limited due to shading, roof type, etc.). In the GRPA08 cases, the maximum share of residential buildings with solar access was increased to $60 \%$. This estimate accounts for the fact that some homes will not be suitable for PV systems due to shading, building orientation, roof construction, or other factors. This value was calculated from a combination of single-family homes (70\%) and multifamily homes (30\%), using a 75\%-25\% split between single-family and multifamily homes (EIA 2006a, Table A4). Thus, the average maximum share was set at $0.7 * 0.75+0.3 * 0.25=0.6$ - this is a national average. Clearly the maximum share of homes suitable for PV will vary considerably across the United States.

Including a declining PV buy-down program in California. This baseline is constructed under the assumption that the PV buy-down currently available in California will continue to decline over time as defined in the recently passed California Solar Initiative (CSI). As shown in Table D-3, under the CSI, one of two events can trigger an incentive reduction: when an incremental level of installed PV (in MW) is achieved under the CSI, or the end of the calendar year, whichever occurs first.

Table D-3: Triggers for Reductions in Rebate Levels

\begin{tabular}{|c|c|c|c|c|}
\hline & \multicolumn{2}{|c|}{ Rebates would change at the earliest of: } & \multicolumn{2}{|c|}{ Starting at \$2.80/watt equivalent in 2006 } \\
\hline "Bin" or Year & Date & Incremental MW & $\begin{array}{c}\text { Rebate Level } \\
\text { (\$/watt) }\end{array}$ & $\begin{array}{c}\text { Total \$ (million } \\
\$ \text { ) }\end{array}$ \\
\hline 0 & $\mathbf{1 / 1 / 0 6}$ & & $\mathbf{2 . 8}$ & \\
\hline 1 & $\mathbf{1 / 1 / 0 7}$ & 50 & $\mathbf{2 . 5}$ & 125 \\
\hline 2 & $\mathbf{1 / 1 / 0 8}$ & 70 & $\mathbf{2 . 2 5}$ & 157.5 \\
\hline 3 & $\mathbf{1 / 1 / 0 9}$ & 100 & $\mathbf{2 . 0}$ & 200 \\
\hline
\end{tabular}

${ }^{3}$ Also based on CEC data (source cited in note 2). For example, during 2005, a total of $17.2 \mathrm{MW}$ of PV was installed in 3,881 PV systems under the CEC program, with an average system size of $4.4 \mathrm{~kW}$. 


\begin{tabular}{|c|c|c|c|c|}
\hline 4 & $\mathbf{1 / 1 / 1 0}$ & 130 & $\mathbf{1 . 7 5}$ & 227.5 \\
\hline 5 & $\mathbf{1 / 1 / 1 1}$ & 170 & $\mathbf{1 . 5}$ & 255 \\
\hline 6 & $\mathbf{1 / 1 / 1 2}$ & 230 & $\mathbf{1 . 2 5}$ & 287.5 \\
\hline 7 & $\mathbf{1 / 1 / 1 3}$ & 300 & $\mathbf{1 . 0}$ & 300 \\
\hline 8 & $\mathbf{1 / 1 / 1 4}$ & 400 & $\mathbf{0 . 7 5}$ & 300 \\
\hline 9 & $\mathbf{1 / 1 / 1 5}$ & 500 & $\mathbf{0 . 5}$ & 250 \\
\hline 10 & $\mathbf{1 / 1 / 1 6}$ & 650 & $\mathbf{0 . 2 5}$ & 162.5 \\
\hline Totals: & & $\mathbf{2 6 4 0 M W}$ & & $\mathbf{\$ 2 . 3}$ billion \\
\hline
\end{tabular}

Source: http://www.cpuc.ca.gov/PUBLISHED/COMMENT_DECISION/51994.htm

As shown in Table D-3, the CSI incentives are automatically scheduled to be reduced each year by $10 \%$, and faster if program participation exceeds a predetermined capacity level. If costs decline and demand increases faster than expected, this structure lowers rebates earlier than on an annual basis. In the Baseline Scenario, the buy-down schedule was specified by date as shown in the table. This credit was included for the entire Pacific region. Given that a number of other state/local credits were not included in the GPRA Baseline (i.e., in Hawaii, Oregon, and Washington State), applying the California state-level credit to the whole Pacific region is likely to be a reasonable approximation.

Modifying the adoption rate of distributed generation technologies. The modification to the adoption rate was based on information provided by DOE's Distributed Energy Resources Program (Figure D-2). The adoption rate shown in the figure applies to PV as well as gas-fired CHP technologies. The AEO assumes that only relatively large buildings are suitable for distributed generation (DG) technologies, i.e., buildings that are at least four times the average size building. Because PV technology is more broadly applicable than CHP (PV system size can be easily scaled), the constraint on average building size for commercial installations was modified from being four times the average size, as in the AEO, to being only twice as large. This means that, in the model, only half of the commercial buildings are available for PV installations; and that, on average, these commercial buildings will have sufficient load to absorb the production from their PV system internally (even as the average PV system size increases to 200kW by 2030).

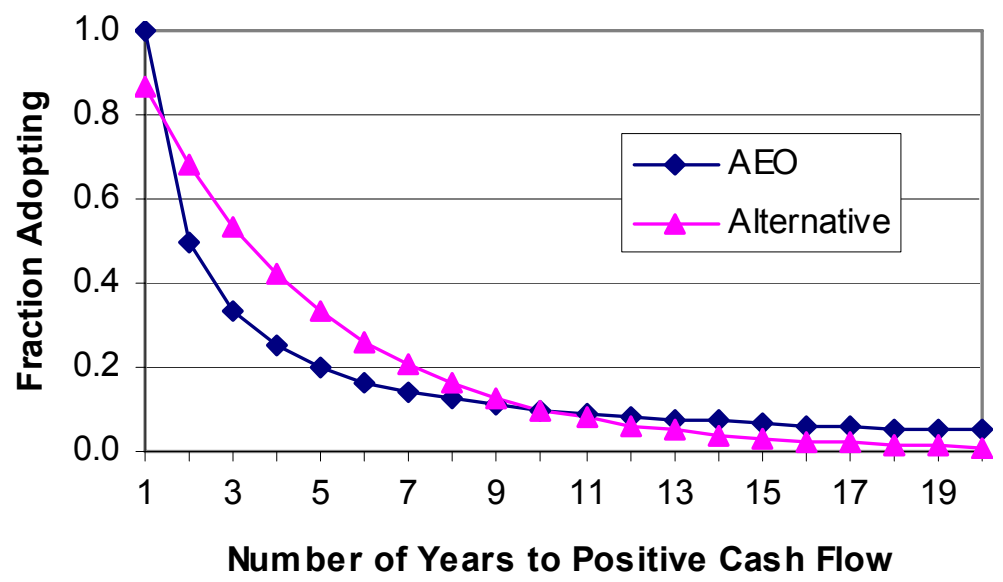

Figure D-2. Commercial-Sector DG Adoption Rates 
These changes lead to increased adoption of PV systems in the baseline. The AEO2006 assumptions about PV installations through the Million Solar Roofs or other programs were removed; however, as mentioned above, the subsidies available under the California Solar Initiative were included.

\section{GPRA08 Solar Program Scenario Assumptions}

Two key sets of assumptions related to technology characteristics were modified to generate the GPRA08 Solar Program Scenario. More aggressive technology targets were used for the range of solar technologies funded by the Solar Program: PV (distributed and central systems), and concentrating solar power (CSP). Both sets of technology characteristics were based on anticipated changes in the program's structure and funding to be implemented during FY07 under the SAI.

PV Technology Characteristics. To define a consistent set of long-term targets going out to 2050, a multilab, multitechnology team was assembled in 2003. This team produced a range of technology cost projections for use in NEMS under different funding and policy assumptions (for details, see Margolis and Wood 2004). In setting the targets used for PV technology in the GPRA08 analysis, we drew on the results from this team, as well as cost projections under various funding/policy assumptions in the U.S. PV Industry Roadmap (SEIA 2004). The targets shown in Table D-4 are consistent with expected funding for the program (Margolis and Wood 2004 and SEIA 2004). It is important to note that, beyond 2015, the targets are increasingly uncertain and are likely to be revised as the Solar Program continues to analyze the long-term prospects for technology cost reductions. Note that, on an annual basis, costs are assumed to decline linearly between the years shown in the tables below.

While the technology assumptions for commercial rooftop PV systems are shown above in Figure D-1, detailed data for PV systems in the three markets modeled are provided in Table D-4. Although the costs shown below are for specific years, the costs decline annually between the years shown. Note that in both the GPRA Baseline and Program scenarios, the AEO2006 Reference Case assumptions for solar insolation and capacity factors were used.

CSP Technology Characteristics. The data for CSP technology shown in Table D-5 are for California. The CSP costs are up to $13 \%$ higher in other regions that have less solar insolation to account for greater capacity and storage requirements. The annual capacity factors by 2020 range from $49 \%$ in the Upper Midwest to $74 \%$ in the Southwest. The capacity factors by time period were computed by Sandia analysts to optimize the timing of solar output for each region within the bounds of the storage potential. Note that the AEO2006 Reference Case assumptions include lower-cost CSP systems, but with significantly less storage and, therefore, lower electrical output.

The cost targets for CSP technology in the Solar Program scenario are based on a funding level consistent with the FY07 budget request and a funding level commensurate with those outlined in the Draft CSP Technology Transition Plan for years beyond FY07 (DOE 2005). 
Table D-4. PV Systems for Solar Program Case

\begin{tabular}{|c|c|c|c|c|c|c|}
\hline \multirow[b]{2}{*}{ Year } & \multicolumn{2}{|c|}{ Central Generation } & \multicolumn{2}{|c|}{ Residential Buildings } & \multicolumn{2}{|c|}{ Commercial Buildings } \\
\hline & $\begin{array}{l}\text { Installed } \\
\text { Price } \\
(2003 \$ / k W)\end{array}$ & $\begin{array}{c}\text { O\&M } \\
(2003 \$ / k W)\end{array}$ & $\begin{array}{c}\text { Installed } \\
\text { Price } \\
(2003 \$ / k W)\end{array}$ & $\begin{array}{c}\text { O\&M } \\
(2003 \$ / k W)\end{array}$ & $\begin{array}{c}\text { Installed } \\
\text { Price } \\
(2003 \$ / k W)\end{array}$ & $\begin{array}{c}\text { O\&M } \\
(2003 \$ / \mathrm{kW})\end{array}$ \\
\hline 2005 & 5,500 & 20 & 8,500 & 100 & 6,290 & 40 \\
\hline 2010 & 3,900 & 10 & 5,000 & 40 & 4,000 & 20 \\
\hline 2015 & 2,580 & 6 & 3,300 & 20 & 2,210 & 10 \\
\hline 2020 & 2,193 & 5 & 2,805 & 17 & 1,879 & 9 \\
\hline 2025 & 1,974 & 5 & 2,525 & 15 & 1,691 & 8 \\
\hline 2030 & 1,875 & 4 & 2,398 & 15 & 1,606 & 7 \\
\hline 2050 & 1,781 & 4 & 2,278 & 14 & 1,526 & 7 \\
\hline
\end{tabular}

Note: Installed costs do not include the impact of the existing investment tax credit. The O\&M costs shown in the table are annual O\&M costs.

Table D-5. Concentrating Solar Power for Solar Program Case

\begin{tabular}{|c|c|c|c|}
\hline Year & $\begin{array}{c}\text { Installed } \\
\text { Price } \\
\mathbf{( 2 0 0 3 \$ / k W )}\end{array}$ & $\begin{array}{c}\text { O\&M } \\
\text { (2003mills/kWh) }\end{array}$ & $\begin{array}{c}\text { Capacity } \\
\text { Factor }\end{array}$ \\
\hline 2010 & 3,510 & 7.8 & $65 \%$ \\
2020 & 2,462 & 4.0 & $72 \%$ \\
2025 & 2,199 & 3.6 & $72 \%$ \\
2030 & 1,993 & 3.2 & $72 \%$ \\
2035 & 1,879 & 3.1 & $72 \%$ \\
2040 & 1,826 & 3.0 & $72 \%$ \\
2050 & 1,797 & 2.9 & $72 \%$ \\
\hline
\end{tabular}




\section{Bibliography}

Cowan, Robin, and David Kline. 1996. The Implications of Potential "Lock-In" in Markets for Renewable Energy. National Renewable Energy Laboratory, Golden, Colorado. NREL/TP-46022112.

DOE (Department of Energy). 2006. Solar Energy Technologies Program - Multiyear Program Plan 2006-2011 (January). Office of Energy Efficiency and Renewable Energy, U.S. Department of Energy, Washington, D.C.

DOE. 2005. CSP Technology Transition Plan - Draft. Internal DOE draft document.

EIA (Energy Information Administration). 2006a. Annual Energy Outlook 2006. Energy Information Administration, U.S. Department of Energy, Washington, D.C.

EIA. 2006b. CBECS Detailed Tables 2003. Energy Information Administration, U.S. Department of Energy, Washington, D.C. As posted June 2006. Available at: http://www.eia.doe.gov/emeu/cbecs/cbecs2003/detailed tables_2003/detailed tables_2003.html.

EIA. 2001. Residential Energy Consumption Survey 2001. Energy Information Administration, U.S. Department of Energy, Washington, D.C. Available at: http://www.eia.doe.gov/emeu/recs/recs2001/detail tables.html.

EPIA (European Photovoltaic Industry Association). 2004. EPIA Roadmap. European Photovoltaic Industry Association, Brussels. www.epia.org.

IEA (International Energy Agency). 2001. Potential for Building Integrated Photovoltaics. St. Ursen, Switzerland. Report No: IEA - PVPS T7-4.

Margolis, Robert M. and Frances Wood. 2004. "The Role for Solar in the Long-Term Outlook of Electric Power Generation in the U.S." Paper presented at the IAEE North American Conference in Washington, DC, July 8-10.

Navigant Consulting. 2006. Photovoltaic Manufacturing Shipments 2005/2006. Navigant Consulting, Palo Alto, Calif. Report No. NPS-Supply1 (August).

NEDO (New Energy and Industrial Technology Development Organization). 2004. PV Roadmap Toward 2030 (Japanese PV Industry Roadmap). New Energy and Industrial Technology Development Organization, Japan. www.nedo.go.jp.

Rogol, Michael, Paul Choi, Joel Conkling, et al. 2006. Solar Annual 2006: The Gun Has Gone Off. Photon Consulting, Aachen, Germany.

SEIA (Solar Energy Industries Association). 2004. Our Solar Power Future: The U.S. Photovoltaic Industry Roadmap Through 2030 and Beyond. Solar Energy Industries Association, Washington, D.C. 


\section{APPENDIX E - WIND TECHNOLOGIES PROGRAM INPUTS FOR FY 2008 BENEFITS ESTIMATES}

Table of contents

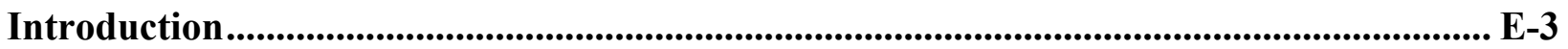

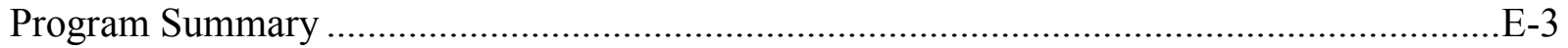

Significant Changes from Previous Analysis..................................................................................... E-4

The Baseline ("without DOE RD3" case) ............................................................................ E-5

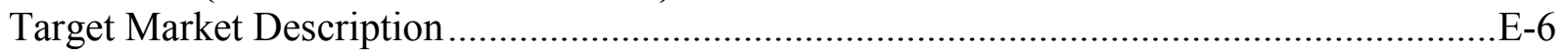

Baseline Market Acceptance............................................................................................

Representation of Program-Relevant Technologies in the AEO Reference Case ...................E-8

Baseline Adjustments to the AEO2006 Reference Case......................................................... E-8

Program Outputs .......................................................................................................................12

Assumed Budget Projections ……………………….......................................................

Description of Key Activities ..................................................................................

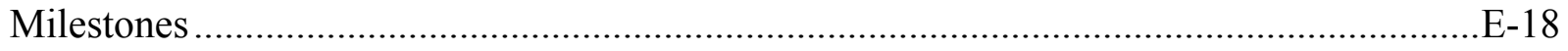

Program Outputs ………………………………………………………………….....

Translating Program Outputs to Market Outcomes................................................................. E-21

Key Factors in Shaping Market Adoption of EERE technologies........................................E-22

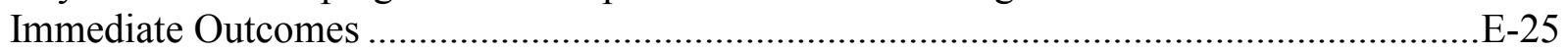

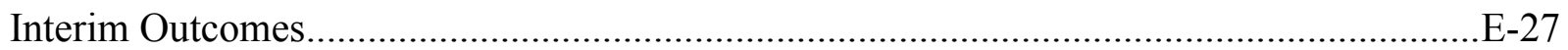

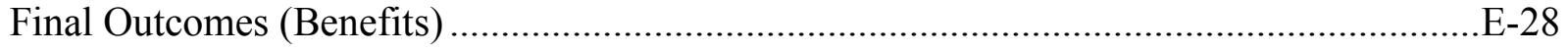

Summary of Inputs .................................................................................................................................... E-29

Bibliography ......................................................................................................................... E-30 


\section{List of tables}

Table E-1: U.S. Installed Wind Energy Capacity 2000-2006 ...................................................7

Table E-2: Wind Turbine Characteristics For GPRA Baseline Case (No Federal R\&D) ...........E-9

Table E-3: Baseline Case Model Inputs................................................................................... 10

Table E-4: FY 2008 Budget Request for Wind Energy Program ..........................................E-13

Table E-5: Estimated FY 2007 Budget By Performance Goal Category ...............................E-14

Table E-6: Planned Program Funding Through FY 2012 by Key Activity ............................E-14

Table E-7: Program Outputs, Activities, and Milestones ................................................... 21

Table E-8: Land-Based Turbine Characteristics for Calculating Capacity Factors..................E-25

Table E-9: Summary of Inputs to Models ("Immediate Outcomes" of Program R\&D) ...........E-29

\section{List of figures}

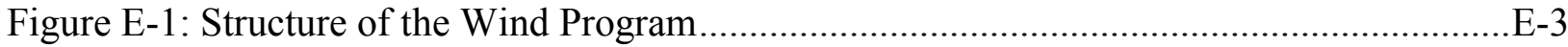

Figure E-2: Comparison of Base and Program Case COEs..................................................E-11

Figure E-3: Wind Program Strategic Planning Framework for Technical Needs ...................E-13

Figure E-4: Cost of Offshore Wind Plants Vs. Distance from Shore (ref UMASS) ................E-27 


\section{Introduction}

GPRA benefits for the Wind Technologies Program are estimated primarily from model projections of the market share for wind technologies, based on their economic characteristics. Two models are used for this purpose: MARKet ALlocation (MARKAL) and a modified version of the National Energy Modeling System (NEMS). This document describes the inputs and assumptions that are used by the models to calculate those benefits.

\section{Program Summary}

The Wind Program is one component of the Wind and Hydropower Technologies Program under the Office of Energy Efficiency and Renewable Energy (EERE) within the U.S. Department of Energy. The Wind Program focuses on two key areas for its mission-increasing the Technical Viability of wind systems through support of research and development and increasing wind energy deployment in the emerging marketplace through Technology Application activities.

Figure E-1 depicts the five projects within the two key areas that comprise the Wind Program.

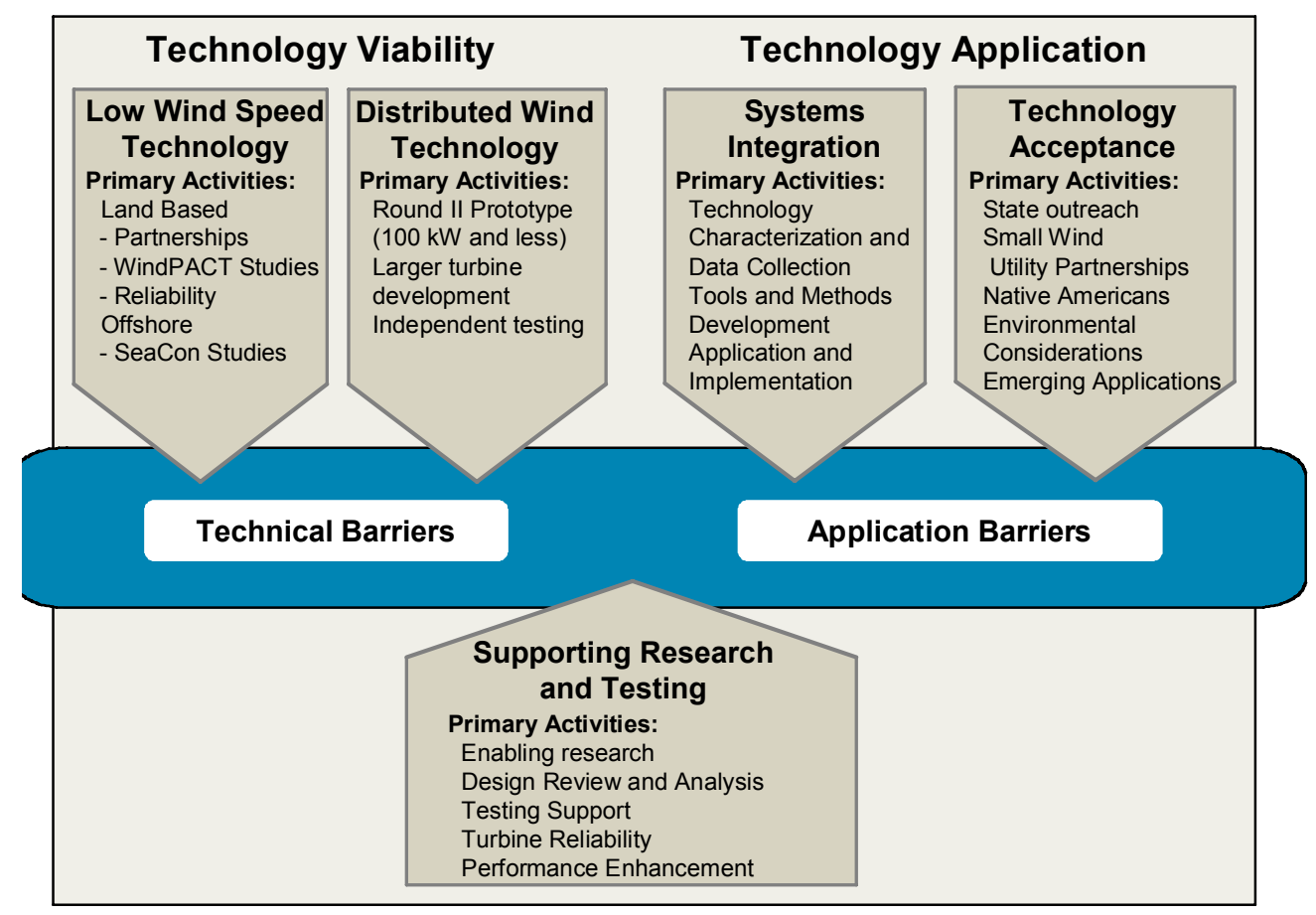

Figure E-1. Structure of the Wind Program

Under Technical Viability, the program sponsors R\&D projects in Low Wind Speed Technology (LWST), Offshore Wind Technology, and Distributed Wind Technology. All three projects are integrated with Supporting Research and Testing activities such as enabling technologies and testing support. The Wind Program's research portfolio includes both near-term and long-term focused research to provide a balance between the need to work with industry to solve pressing short-term technical issues and the need to maintain U.S. industry momentum as a technological 
innovator. Balancing this portfolio and ensuring a variety of approaches to achieve the goals are the challenges of the program-planning function.

To allow for increased use of wind systems, the Technology Application key activity sponsors research on Systems Integration and Technology Acceptance. These programs address many of the critical market challenges to the use of wind energy, including transmission constraints, interconnection, environmental impacts, and public acceptance. Figure E-1 also lists the key activities being undertaken by each of the program areas.

Within the context of this document, only areas addressed in Low Wind Speed Technology, both offshore and land-based, are covered within the context of the GPRA analysis. For this reason, the following text focuses primarily in these areas. More information on other program areas can be found in the Multiyear Program Plan (MYPP). (U.S. Department of Energy 2007)

\section{Significant Changes from Previous Analysis}

Offshore cost of energy (COE) goals have been revised, per below, from the FY 2007 analysis, and the program-case cost and performance tables have been revised to correspond to the new goals and funding assumptions.

- By 2014, reduce the COE from large wind systems in Class 6 winds to 7 cents/kWh (previously 5 cents/kWh) for shallow water (depths to 30 meters) offshore systems (from a baseline of 9.5 cents in FY 2005).

- By 2016, reduce the COE from large wind systems in Class 6 winds to 7 cents $/ \mathrm{kWh}$ (previously 5 cents/kWh) for transitional (depths to 60 meters) offshore systems (from a baseline of 12 cents in FY 2006).

The corresponding program and funding assumption is that more initial research must be undertaken to determine the government role in the future development of an offshore wind industry. This approach will expend limited effort until a programmatic go/no go decision is made in 2009. In addition, an evaluation of market risks for offshore technologies may also be a consideration. For this GPRA analysis, the program is assuming that, following a positive decision regarding the viability of this market area, a funding level per year will be split between the two technologies from 2011 onward with a shift from shallow to transitional technologies over time. (The amount of the request is confidential until after the budget submission to Congress.)

While MARKAL and NEMS currently do not have the capacity to model market penetration for distributed (small) wind turbines, that technology is nonetheless an important element of the DOE Wind Program. The current program goal for distributed wind is stated below.

- By 2007, reduce the COE from distributed wind systems in Class 3 winds to 10-15 cents/kWh in constant 2002 dollars. 


\section{The Baseline ("without DOE RD3" case)}

The GPRA FY 2008 baseline case cost and performance trajectory assumes that wind energy technology will continue to improve over time without EERE-sponsored R\&D. The wind energy industry comprises several major international manufacturers and many smaller manufacturers, consultants, and government and university researchers. Apart from the United States, the primary expertise currently lies in Europe. In addition, Japan, and, increasingly, India and China, will also provide expertise for future technology development. The baseline case projections for land-based technology include the assumption that somewhat more R\&D will be applied by nonEERE entities to continue to bring the cost of energy down. Europe has much less land available in all wind classes than the United States, but this is especially true in the higher classes. Therefore, European countries may be expected to focus some R\&D on lower wind speed technology, although a portion of that $R \& D$ will be transferable to turbines designed for higher wind speed regimes. In addition, because low wind speed technology increases the international market potential, manufacturers should be interested in continuing improvements. Finally, because past R\&D has focused on higher wind speed technology, there is more potential for technical improvements in low wind speed technology.

Despite the rationale for further development of low wind speed turbine technology, current trends among European turbine manufactures are toward improving shallow water offshore technologies that are suitable for higher wind resource areas, instead of further investments for R\&D in low wind speed, land-based technologies. In addition, the European renewable electricity sector has long held incentive programs for environmentally friendly energy technologies, which allow wind technologies to be cost competitive at a higher cost than would be acceptable in the U.S. market. Both of these factors indicate that, although technology improvement in Europe will impact the U.S. market, they are unlikely to address several issues specific to the U.S. market.

More than 700 megawatts of offshore wind energy capacity is operating in shallow waters off the shores of several European countries. Some of these countries are pursuing plans for major expansions of offshore wind power (U.S. Department of Energy 2007). Offshore turbines have been operating in Europe for more than 10 years, primarily using marinized versions of landbased wind turbines installed on monopile tube towers in shallow waters (under 20 meters). The primary drivers have been the limited availability of suitable land-based sites in Northern Europe and favorable wind energy pricing. The motivation to develop offshore wind energy technology was not considered relevant to the United States because of widely available U.S. land-based wind resources; however, the high cost of accessing these remote sites to provide power to coastal high-load centers has increased the desire to obtain a better understanding of the U.S. offshore potential. However, the lack of low-cost environmentally friendly energy supply options (especially in the Northeast); stable, positive market incentives; and the scarcity of excellent wind sites in proximity to load centers along the coasts have all increased the prospect of offshore wind technologies as an economically competitive electric power generation technology. 


\section{Target Market Description}

Large-scale wind energy is expected to penetrate in two market segments: the least-cost (competitive bulk power) power market, and the segment comprising a combination of voluntary (green power) and mandatory (green power or renewable portfolio standards) market programs or requirements. Because of the geographic diversity of the resource, wind energy is also available in any combination of grid-integration scenarios, including large or small plants at long or short distances from transmissions and distribution tie-in points. For instance, large amounts of offshore wind energy is available near load centers in the northeast region, whereas the wind resource in the southeast region is relatively far from the largest load centers in the western part of that region.

Currently, wind turbines in Class 6 wind sites $(6.4-7.0 \mathrm{~m} / \mathrm{s}$ at $10 \mathrm{~m}$ height) compete well against conventional power producers such as gas, oil, and hydropower; and the costs are becoming increasingly competitive with coal-fired power production. However, as the industry grows, the areas with Class 6 wind resources located close to load centers are dwindling, and wind growth is hampered as it expands to the more remote, windy regions of the country, such as the Great Plains. In many of these windier locations, grid connection is problematic because they are so far from load centers and because of capacity constraints on existing transmission lines. A 2005 study illustrates this for North Dakota and South Dakota (ABB 2005).

Class 4 wind sites $(5.6-6.0 \mathrm{~m} / \mathrm{s}$ at $10 \mathrm{~m}$ height) cover a much broader area of the nation, are on average five times closer to load centers, and represent 20 times more wind resource (Goldman 2002). However, the only way wind can currently take advantage of Class 4 sites economically is with the support of the Federal production tax credit (PTC), which has been available only intermittently. The PTC has been extended for no more than two years at a time, and there have been periods of uncertainty when the PTC has lapsed, which impedes the development of a solid manufacturing base in the United Stats. The Energy Policy Act of 2005 extended the PTC through calendar year 2007, but it is unclear whether it will be extended beyond that time. The uncertain availability of the tax credit forces the wind industry into a boom or bust cycle, reducing efficiency and increasing costs. Reducing wind energy cost to levels that are competitive without dependence on tax incentives is one of the drivers of the Wind Program.

Shallow-water sites between 5 and 50 nautical miles from shore, specifically in the constrained electricity markets along the East Coast, offer additional resources for wind power application. Estimates place these resources at approximately $900 \mathrm{GW}$ for regions that have been surveyed, assuming conservative restrictions, although only a fraction of that would likely be developed (U.S. Department of Energy 2007). A white paper including a detailed look at the state of the offshore industry, its development potential, and a further examination of the above estimates is due to be published by NREL in FY 2007 (Musial 2006). Gaining access to the shallow offshore market will allow wind technologies to supply competitive energy to the congested regions along the eastern seaboard.

In the mid- to longer term, offshore technology development will be focused on turbine support structures for installations at depths to approximately 60 meters; and technologies to offset inherent adversities such as increased distance from shore, decreased accessibility, and more 
severe environmental conditions. Pending a decision in 2009 by DOE to proceed, this technology development pathway would begin with a goal of 7 cents/kWh in Class 6 winds by 2016. If this technology is fully developed, then a total of $25 \%$ of surveyed resources between 5 and 50 nautical miles from shore would be available for wind deployment. Estimates of these resources add approximately $180 \mathrm{GW}$ to the available development potential in the surveyed regions (Musial 2004).

Distributed and small wind applications have also played a key, although smaller, role within the Wind Program, focusing primarily on wind turbines rated less than $100 \mathrm{~kW}$ in size. Continued downward trends in the COE of these turbines and expanded state-based subsidies are expected to greatly expand this market through 2011. Distributed Wind Technologies are currently not assessed as part of the GPRA benefits analysis.

\section{Baseline Market Acceptance}

In the United States, the large turbine wind energy market has boomed over the past few years, which is due, in large part, to the PTC and high conventional energy prices. Over a longer time frame, however, this market has been characterized by boom and bust cycles driven by the instability of the Federal PTC. Table E-1 shows the incremental installed wind capacity since 2000 and illustrates the sensitivity of annual installed capacity levels to the PTC, which was in place in 2001, 2003, and 2005. It also demonstrates the general mainstream acceptance of wind energy technology in the current market. When the technology is cost-effective, resulting from incentives such as the PTC, it is generally installed in relatively large and increasing numbers. With the extension in the PTC, the American Wind Energy Association (AWEA) is predicting several more years of installation rates greater than 2,000 MW/year. This, however, should not discredit the efforts that must continue to be applied to wind technology application as turbines are installed more broadly and closer to population load centers.

Recent increases in the cost of wind energy are not currently reflected in the cost figures used in either the baseline or program case analysis. Although cost increases are well documented, they are generally attributed to short-term market trends including the tightness of the turbine market due to the PTC, high foreign exchange rates between the United States and Europe, and currently high commodity process. All of these items are not expected to impact the cost of wind technology compared to other energy technologies over the long term.

Table E-1. U.S. Installed Wind Energy Capacity 2000-2006

\begin{tabular}{|c|c|c|}
\hline & $\begin{array}{l}\text { Annual Installed } \\
\text { Capacity (MW) }\end{array}$ & $\begin{array}{l}\text { Cumulative Installed } \\
\text { Capacity (MW) }\end{array}$ \\
\hline 2000 & 67 & 2,578 \\
\hline 2001 & 1,697 & 4,275 \\
\hline 2002 & 446 & 4,685 \\
\hline 2003 & 1,687 & 6,372 \\
\hline 2004 & 389 & 6,740 \\
\hline 2005 & 2,431 & 9,149 \\
\hline 2006 & 2,750 (est.) & 12,000 (est.) \\
\hline 2007 & $3,000-3,500$ (est.) & $15,000+$ (est.) \\
\hline
\end{tabular}

References: News Releases, American Wind Energy Association, May

12, 2005; January 24, 2006; October 24, 2006 


\section{Representation of Program-Relevant Technologies in the AEO Reference Case}

The Annual Energy Outlook (AEO), the Energy Information Administration's (EIA) 2006 Reference Case, assumes that any cost improvement over time results only from a learning (sometimes called "experience") effect that lowers cost proportional to the increase in cumulative installed volume, but not from R\&D advances. Because the AEO projects a small amount of penetration (and therefore little additional cumulative volume), the capital cost decrease in the AEO projections is negligible. The Reference Case also assumes no future improvements in energy production from $R \& D$ (input to NEMS in the form of a capacity factor).

The capacity factors for Wind Classes 4-6 in the AEO are determined using data provided to the Energy Information Administration (EIA) by wind plant operators. Although these reported values represent the electricity produced by that wind plant over the previous period, there are several reasons why the Wind Program thinks it's difficult, and potentially misleading, to match them with a specific wind resource level. First, these data represent a wide variety of wind resources geographically distributed over the country, which means characteristics of the wind, such as the shape of the wind speed distribution (the amount of time during the year that the wind is blowing at each discrete wind speed) and the level of wind shear (how wind speed changes with height), can vary widely. Second, wind resource data for a given wind plant is generally not publicly available because it is considered proprietary data. Therefore, correlation between the reported capacity factor data and wind power class associated with that turbine performance is quite difficult. Third, in many regions of the country, transmission systems are constrained such that, on occasion, wind plants might be required to curtail output at certain times. For plants that experience such a curtailment, this reduced power output affects the total production data reported to EIA, but is not identified separately. Although this might not affect many wind plants, it is unknown how many may be reporting less than their full potential output.

Finally, the wind characteristics of any given site vary naturally from year to year. Reported capacity factor data includes such variations. For example, climatic oscillations such as the Madden-Julian Oscillation or the El Nino Southern Oscillation cause interannual variability of wind resources. For any or all of these reasons, the reported data may not adequately capture the actual performance capability of the present wind turbine technology averaged over a longer time frame. Preliminary, ongoing measurements appear to be confirming that commercial energy production levels are indeed closer to the predicted value than characterized in AEO2006. However, this work is not yet publicly available (Hand 2006).

\section{Baseline Adjustments to the $A E O 2006$ Reference Case}

The GPRA 08 baseline case for land-based wind power technology is a modification of the AEO2006 Reference Case. That modification reflects that the Wind Program has a different view of the cost and performance characteristics of current technology, as well as the projected trajectory for future characteristics. While EIA indicates that the AEO projections reflect impacts of R\&D in line with historical levels, the projections show almost no improvement in cost or performance in future wind power technology from R\&D. The Wind Program's projections for future wind plant capacity factors and capital costs reflect larger improvements, compared to those in the AEO, i.e., capacity factors are higher and costs are lower. The Wind Program, 
therefore, believes that its trajectory would form a more appropriate Reference Case for the AEO, because historic rates of technology improvement have included impacts of DOE R\&D. Detailed rationale and analysis for the Program Case is presented in the "Immediate Outcomes" section later in this appendix.

To calculate the benefits from the DOE Wind Program, the GPRA 08 baseline case, unlike the AEO Reference Case, must reflect the absence of DOE-sponsored R\&D. For the GPRA 08 Baseline Case, the AEO2006 Reference Case capital cost is assumed for 2005 as the starting point. The 2005 capacity factor is the midpoint between the AEO value and the program value, as in past GPRA analyses. To remove the impacts of Wind Program activities from the Program Case, a cost/performance trajectory was created, whereby industry is assumed to achieve $60 \%$ of the COE reduction projected by the program at each five-year interval for all wind classes. This COE reduction level is supported by a preliminary analysis conducted by NREL staff that projected physical characteristics and performance levels of wind turbines likely to result if Federal research investment is discontinued. That analysis builds off of the extensive analysis underlying the Program Case. While the program focus is on low wind speed technology, much of the research is transferable to higher wind speed designs. Also, over the long term, industry is assumed to invest in higher wind speed R\&D, if needed. Therefore, as a first-order approximation, the $60 \%$ value is assumed for turbines designed for all wind power classes.

For both the Program and the Baseline Case, capacity factors are calculated for each five-year period using technical characteristics for a generic wind turbine comprising a composite of stateof-the-art designs operating in generic wind regimes. A spreadsheet-based model developed by NREL was used for these calculations (Laxson 2006). The model performs power and energy calculations for individual wind speed increments, or "bins" of $0.25 \mathrm{~m} / \mathrm{sec}$. Turbine parameters such as the rotor diameter, hub height, power rating, and maximum power coefficients are used by the model. The generic wind regimes are represented by Rayleigh probability distributions of wind speed with a mean value corresponding to each of the wind power Classes 4-6 (and 7, for transitional offshore resources in the program case). Vertical shear is assumed to follow the 1/7 power law. Losses associated with drivetrain efficiency are applied as a function of wind speed, and other losses associated with blade soiling, array effects, and availability are also applied. Availability is the percent of time the turbine is able to generate power when the wind is sufficient. The capacity factors represent the idealized performance of the generic wind turbines in each generic wind regime. Table E-2 shows the turbine characteristics used for the GPRA 08 baseline capacity factor calculations.

Table E-2. Wind Turbine Characteristics For GPRA Baseline Case (No Federal R\&D)

\begin{tabular}{|lrr|r|r|r|r|r|r|r|r|r|}
\hline & $\mathbf{2 0 0 5}$ & $\mathbf{2 0 1 0}$ & $\mathbf{2 0 1 5}$ & $\mathbf{2 0 2 0}$ & $\mathbf{2 0 2 5}$ & $\mathbf{2 0 3 0}$ & $\mathbf{2 0 3 5}$ & $\mathbf{2 0 4 0}$ & $\mathbf{2 0 4 5}$ & $\mathbf{2 0 5 0}$ \\
\hline \hline Turbine Rating (kW) & 1500 & 2500 & 3000 & 3000 & 3000 & 3000 & 3000 & 3000 & 3000 & 3000 \\
\hline Diameter (m) (Class 4) & 77 & 93 & 103 & 103 & 103 & 103 & 103 & 103 & 103 & 103 \\
\hline Diameter (m) (Classes 5-6) & 77 & 90 & 96 & 96 & 96 & 97 & 97 & 97 & 97 & 97 \\
\hline Hub Height (m) (Class 4) & 80 & 100 & 100 & 100 & 100 & 100 & 100 & 100 & 100 & 100 \\
\hline Hub Height (m) (Classes 5-6) & 80 & 90 & 100 & 100 & 100 & 100 & 100 & 100 & 100 & 100 \\
\hline Net Losses & 0.12 & 0.06 & 0.05 & 0.05 & 0.05 & 0.05 & 0.05 & 0.05 & 0.05 & 0.05 \\
\hline Availability & 0.98 & 0.98 & 0.98 & 0.98 & 0.98 & 0.98 & 0.98 & 0.98 & 0.98 & 0.98 \\
\hline
\end{tabular}


The Federal investment during the Low Wind Speed Turbine (LWST) program (2002 to present) is just beginning to be brought to commercial reality, so this investment will continue to reduce cost and improve performance in the next decade. Although it is assumed that the turbine size will continue to grow without Federal R\&D, the aggressive rotor growth achieved through advanced controls will be muted. Development of self-erecting towers without Federal support is unlikely to see strong commercialization in the near term, therefore restricting tower heights. Other technology development such as conversion to medium voltage, use of Silicon Carbide, inclusion of advanced gearing, and switching to super-conducting generators may occur; but there will probably be a delay in the adoption of these technologies. Improvements in drivetrain efficiency, while not as large as those from longer rotors and taller towers, are also assumed to be delayed or not implemented without federal R\&D support. Learning effects are assumed to reduce the installed capital cost by $0.5 \%$ to $1 \%$ over each interval with a cumulative reduction of about $6 \%$ by 2050 . Table E-3 shows the baseline case model inputs, including capital and operation and maintenance (O\&M) costs, and capacity factors. The table contains all baseline case inputs required for NEMS and MARKAL modeling.

Table E-3. Baseline Case Model Inputs

\begin{tabular}{|c|c|c|c|c|c|c|c|c|c|}
\hline $2004 \$ / k^{*}$ & & 2005 & 2010 & 2015 & 2020 & 2025 & 2030 & 2040 & 2050 \\
\hline \multicolumn{10}{|c|}{ Capital Costs } \\
\hline \multirow[t]{2}{*}{ Land-Based } & Classes $5 \& 6$ & 1167 & 1013 & 982 & 961 & 956 & 950 & 945 & 935 \\
\hline & Class 4 & 1167 & 1113 & 1061 & 1040 & 1024 & 1019 & 1008 & 998 \\
\hline \multirow[t]{2}{*}{ Offshore } & Shallow & 2118 & & & & & & & \\
\hline & Transitional & 2803 & & & & & & & \\
\hline \multicolumn{10}{|l|}{ O\&M Costs } \\
\hline Land-Based & All Classes & 27.6 & 25.2 & 24.2 & 24.2 & 23.1 & 22.1 & 22.1 & 22.1 \\
\hline \multirow[t]{2}{*}{ Offshore } & Shallow & 81 & & & & & & & \\
\hline & Transitional & 81 & & & & & & & \\
\hline \multicolumn{10}{|c|}{ Capacity Factors } \\
\hline \multirow[t]{3}{*}{ Land-Based } & Class 6 & 0.432 & 0.468 & 0.475 & 0.477 & 0.477 & 0.485 & 0.490 & 0.490 \\
\hline & Class 5 & 0.399 & 0.433 & 0.440 & 0.442 & 0.442 & 0.450 & 0.455 & 0.455 \\
\hline & Class 4 & 0.350 & 0.401 & 0.423 & 0.426 & 0.426 & 0.426 & 0.426 & 0.426 \\
\hline Offshore & Class 6 & 0.384 & & & & & & & \\
\hline \multirow[t]{2}{*}{ Shallow } & Class 5 & 0.337 & & & & & & & \\
\hline & Class 4 & 0.298 & & & & & & & \\
\hline Offshore & Class 7 & 0.423 & & & & & & & \\
\hline \multirow[t]{2}{*}{ Transitional } & Class 6 & 0.384 & & & & & & & \\
\hline & Class 5 & 0.337 & & & & & & & \\
\hline
\end{tabular}

Using these assumptions, the land-based COE in 2050 is approximately equal to the shallow offshore case with continued Federal funding, as shown in Figure E-2, using Class 6 wind resources to demonstrate (the same relationship holds for all wind classes). This also indicates that the industry (U.S. and/or international) will continue to lower the cost of land-based wind turbine systems in the absence of DOE assistance. 


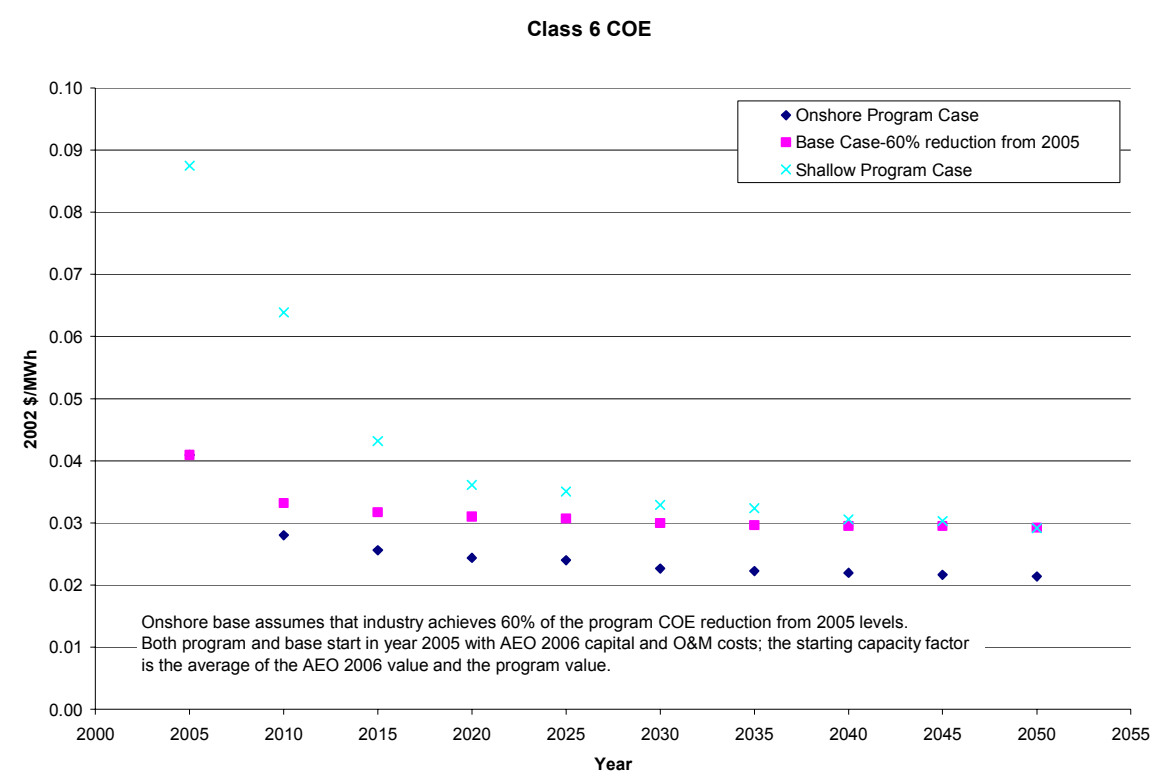

Figure E-2. Comparison of Base and Program Case COEs

Although the Baseline Case is tied to the current Program Case, the program does not expect to adjust these values if the program modifies the current goals based on funding changes. Such a scenario would, thus, create an indirect tie between the Baseline Case and the new Program Case. That is, the baseline inputs have been established so as to be realistic on their own, even though they were developed using the program case as a relative benchmark.

Offshore turbines were assumed to begin at a rating of $5 \mathrm{MW}$ in 2005, scaling to $10 \mathrm{MW}$ in future years. Availability of offshore turbines was assumed to begin at $85 \%$ in 2005 , increasing to $95 \%$ as the technology matures. The wind resource characteristics were also altered from a power law exponent of $1 / 7(0.14)$ to 0.12 , and a K factor of 2.0 (representing a Rayleigh Distribution) to 2.2 , based on preliminary resource data obtained by NREL.

Because the FY 2006 AEO does not model offshore wind technologies, and there are no domestic offshore installations, the program estimates for 2005 costs were based on installations in Europe. In GPRA 07, the offshore baseline simply assumed that the technology would follow the program cases, offset by 10 years. Tying the baseline case to the program case with an offset suggests that when the program case changes, the industry responds, which is not accurate. For GPRA 08, the direct connection between the program and baseline case has been removed, so that the program case can now be changed without affecting the baseline case.

The program uses the NEMS "revolutionary" technology learning rate to represent shallow offshore wind technology in the baseline case, starting at the 2005 program level. In this case, "Revolutionary" refers to technologies new to the market that are unlike existing or historical technologies, and therefore are subject to steeper rates of cost decline from learning by designers, manufacturers, installers, or operation and maintenance personnel, because there is more opportunity to find ways to reduce costs compared to better understood technologies. This reflects the program's belief that domestic shallow offshore installations are likely to occur very 
slowly, if at all, without investment from the Federal Government. In view of the significant European market for shallow offshore technologies, some of the related European R\&D activities could reduce the cost for the technology in the United States. However, the costs and difficulties associated with permitting and environmental assessment, and the differences between European and U.S. environmental conditions and policies, would likely slow the implementation of shallow-water offshore wind technologies dramatically in the absence of Federal R\&D support. European offshore installations are heavily subsidized, and it is highly unlikely that a U.S. offshore industry would develop without some sort of subsidy. The NEMS results show that the cost of shallow-water offshore wind technology never becomes generally competitive without Federal support.

Currently, three offshore projects are proposed in Massachusetts and New York that take advantage of prime locations and locally high base energy costs. Additional projects are proposed for the Gulf Coast, but wind resource assessment must be completed before NEMS can be used to model these facilities. The three proposed projects in the Northeast include Cape Wind at $468 \mathrm{MW}$, Hull Municipal Utility at $14.4 \mathrm{MW}$, and Long Island Offshore Wind Initiative at $140 \mathrm{MW}$. To spur some offshore wind development in NEMS, $250 \mathrm{MW}$ was specified to come online in 2009 in the Northeast region, and $75 \mathrm{MW}$ was specified to come online in the New York region. However, this did not stimulate significant cost reductions in offshore wind costs and so did not affect the simulation, which does not add any additional offshore wind energy generation beyond the $325 \mathrm{MW}$ by 2030 .

The shallow technology baseline case inputs were developed by assuming that capital costs and O\&M costs would decline according to the NEMS revolutionary technology learning rate, which results in a $20 \%$ cost reduction by 2025 . The capacity factors for the technology in 2025 were developed using a wind turbine performance model developed at NREL, assuming that the technology cost and performance are tied. Linear interpolation was then used to determine the capacity factors at intervals between 2005 and 2025. The values at 2030 were linearly extrapolated.

The program also uses the NEMS revolutionary technology learning rate to represent transitional offshore wind technology in the baseline case, starting at the program level of $12 \mathrm{cents} / \mathrm{kWh}$ in 2005. Although European governments and companies are actively pursuing shallow offshore technology, they are only timidly pursuing transitional depths on any scale that might transfer technology to the United States. Based on its different ocean seafloor topography, the United States has much more transitional water depth resource than is found in European coastal water. Considering the higher costs and risks, transitional offshore technology is very unlikely to occur without Federal investment in R\&D activities. The other baseline case inputs were developed similarly to those for the shallow offshore technology inputs.

\section{Program Outputs}

The program combines industry input, technical assessment, and peer review as central pillars of its efforts to ensure that resources are applied to important activities and industry-applicable results. The general approaches are used; and a strategic program review process combines with a detailed portfolio decision-making process. Figure E-3 provides an overview of the portfolio 
assessment process, while multiyear efforts are directed through coordinated strategic planning meetings with industry and departmental senior staff. As shown, the program uses an ongoing technical assessment process to monitor the status of wind technology and progress in achieving program cost goals, evaluate that status within the context of marketplace needs, and identify technological pathways that will lead to successful marketplace competition. The program also uses a formal peer review process to benefit from the guidance of industry and the research community and to provide an outside view of the program. As shown in Figure E-3, both the technical assessment and peer review processes provide inputs that the program management team considers in making decisions about strategic program directions and funding priorities.

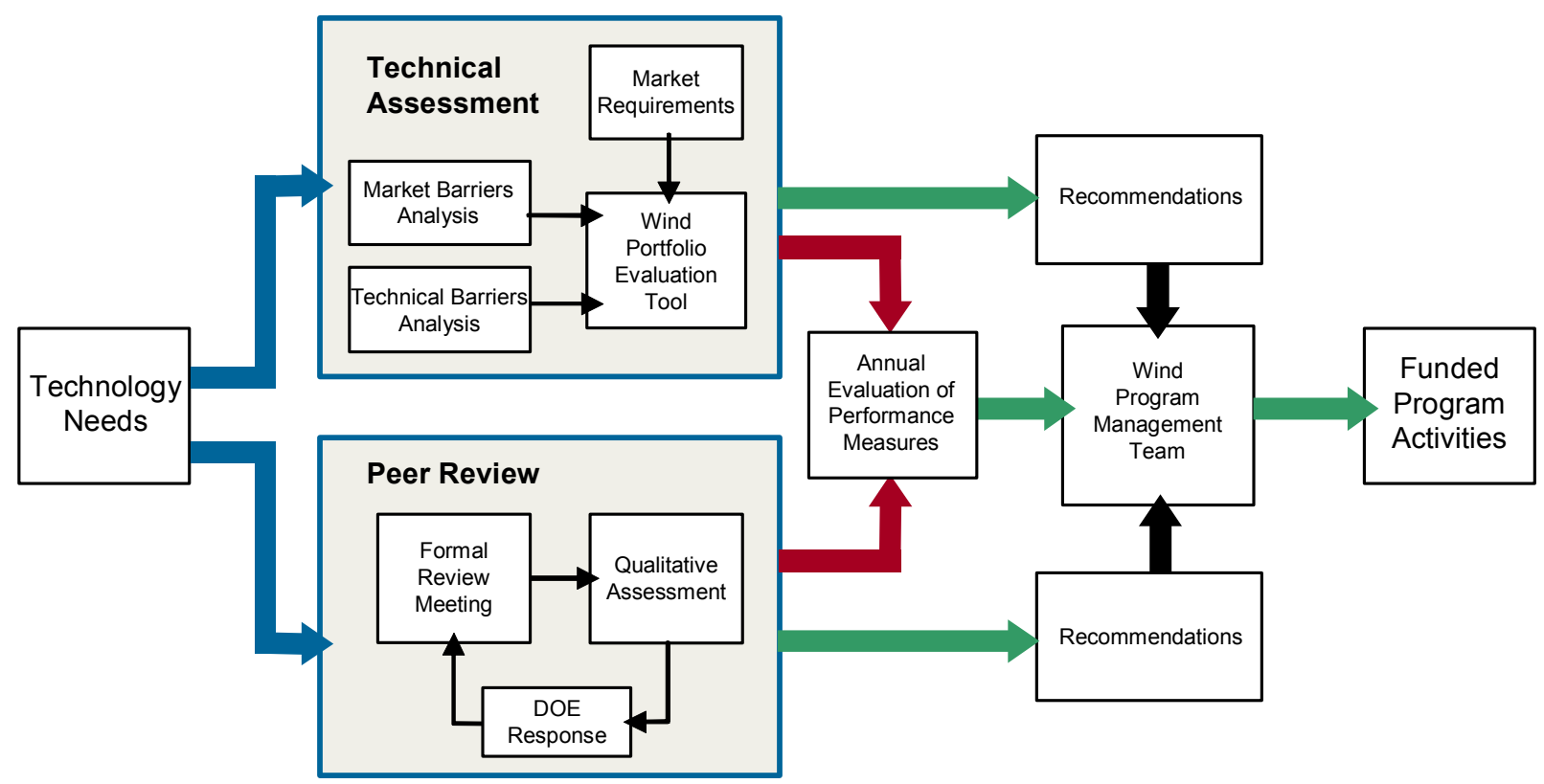

Figure E-3. Wind Program Strategic Planning Framework for Technical Needs

\section{Assumed Budget Projections}

The FY 2008 budget request is $\$ 40.069$ million, a \$3.75 million decrease from the FY 2007 request. A summary of the recent and requested budget by major activity area is shown in Table E-4. Funding for congressionally directed activities for FY 2007 and beyond is assumed to be zero.

Table E-4. FY 2008 Budget Request for Wind Energy Program

\begin{tabular}{|l|c|c|c|}
\hline \multicolumn{4}{|c|}{ Funding (\$ in thousands) } \\
\hline \multicolumn{1}{|c|}{ Activity } & $\begin{array}{c}\text { FY 2006 } \\
\text { Approp. }\end{array}$ & $\begin{array}{c}\text { FY 2007 } \\
\text { Request }\end{array}$ & $\begin{array}{c}\text { FY 2008 }^{\text {a }} \\
\text { Request }\end{array}$ \\
\hline Technology Viability & 18,353 & 35,905 & 27,200 \\
\hline Technology Application & 7,634 & 7,914 & 12,869 \\
\hline Congressionally Directed Activities & 12,870 & 0 & 0 \\
\hline TOTAL & $\mathbf{3 8 , 8 5 7}$ & $\mathbf{4 3 , 8 1 9}$ & $\mathbf{4 0 , 0 6 9}$ \\
\hline
\end{tabular}


An estimated breakout of the requested FY 2008 budget request by sub-key activity is shown in Table E-5. Figures are based on preliminary assessments.

Table E-5. Estimated FY 2008 Budget by Performance Goal Category

\begin{tabular}{|c|c|}
\hline Performance Goal Category & $\begin{array}{l}\text { Estimated } 2008 \\
\text { Budget }(\$ K)^{\mathrm{a}}\end{array}$ \\
\hline Low Wind Speed Technology & 5,843 \\
\hline Distributed Wind Technology & 3,850 \\
\hline Supporting Research and Testing & 16,850 \\
\hline Wind Grid Integration/Systems Integration & 5,950 \\
\hline Technology Application/Technology Acceptance and Coordination & 6,919 \\
\hline Small Business Innovative Research (not a specific category) & 657 \\
\hline
\end{tabular}

Assumed future funding for fiscal years 2008-2012 is provided in Table E-6; it is assumed to remain level through completion of offshore wind turbine goals in FY 2016. The program estimates the annual industry cost-sharing level to be approximately $50 \%$ of funds going to Low Wind Speed and Distributed Wind Technologies.

Table E-6. Planned Program Funding Through FY 2012 by Key Activity ${ }^{a}$

\begin{tabular}{|l|l|l|l|l|l|}
\hline & \multicolumn{5}{|c|}{ Fiscal Year Funding in \$K } \\
\hline & FY08 & FY09 & FY10 & FY11 & FY12 \\
\hline Technology Viability & 27,200 & 26,000 & 25,250 & 27,364 & 28,064 \\
\hline Technology Application & 12,869 & 14,069 & 14,819 & 12,705 & 12,005 \\
\hline
\end{tabular}

\section{Description of Key Activities}

The Wind Program seeks to improve the applicability of wind energy technologies through a coordinated program of applied research, cooperative technology development, strategic barrier removal, and dissemination of information and operating practices.

As discussed above, the program maintains two key focus activities, Technology Viability and Technology Application. The first activity consists of three sub-key activities, and the second activity consists of two sub-key activities. The development of strategic partnerships is a focus of both key activities. The program relies on cost-shared partnerships with industry for the development of new wind turbine designs, supported by applied research conducted through national laboratories and universities, and detailed testing of equipment in both controlled and field environments. Part of the role of R\&D is also to minimize various aspects of market risk.

In the application of wind energy technologies, the program works closely with industry and community groups to remove barriers facing wider acceptance. Through collaborations with organizations such as the Utility Wind Interest Group (UWIG) and the National Wind Coordinating Committee (NWCC), the program addresses specific areas of concern, such as systems integration, transmission limitations, and environmental impact, while working to educate the general public and state and local leaders on the opportunities and true impacts of wind energy technologies. 
Through continued coordination with the National Wind Technology Center (NWTC) at NREL, Sandia National Laboratories (SNL), and the DOE Project Management Center in Golden, Colorado, the program has developed the approach of coordinated partnerships as the most effective method through which it can achieve the desired program goals. From a technology perspective, as the wind turbines become larger and more complex, it has become impossible for the program to support the development of new technologies without heavy industry collaboration. For example, testing facilities for wind turbine blades and drivetrains were initially sponsored by DOE, but the facilities are now supported through partnerships with industry. In addition, working in close partnership with private entities allows the new technology and enabling research developed through the program to be quickly applied in the commercialization and deployment of new wind turbine designs. This approach bridges the gap between technology $R \& D$ and commercialization that has plagued many R\&D efforts.

Because of the cost focus of the GPRA modeling process, only key activities under the Low Wind Speed Technology, for both land-based and offshore technologies, and Supporting Research and Testing key sub-activities are incorporated. This subset of activities is discussed here. The complete set of program activities are described in detail in the Wind Program's Multiyear Program Plan (U.S. Department of Energy 2007).

The activity covering Low Wind Speed Technologies is subdivided into three specific project areas, land-based, offshore, and emerging applications, of which only the first two are addressed in GPRA. In these areas, the program primarily focuses on providing assistance to the wind turbine industry through cost-shared development partnerships and providing baseline research in support of program goals. DOE-EERE program management has directed the program to critically consider the need of the mainstream wind industry in determining the amount and relevance of DOE cost-shared technology development partnerships. As an alternative, DOE is considering other partnership approaches including collaborative research and development agreements (CRADAs) for the further development of innovative wind turbine technologies.

\section{Land-Based Wind Technologies}

This activity continues the existing development partnerships focused on advancing the development of large-scale wind power systems to primarily compete in Class 4 wind regimes. Current partnerships focus on component and full-scale turbine development projects. The program plans to reduce funding for all cost-shared collaborative partnerships following the completion of existing component and prototype development activities. A new series of Wind Partnerships for Advanced Component Technology (WindPACT) ${ }^{1}$ assessment efforts will be started in FY 2008 to help define program direction before the completion of the program goals in FY 2012.

\footnotetext{
${ }^{1}$ WindPACT assessment reports: http://www.nrel.gov/wind/windpact/. 


\section{Offshore Wind Technologies}

All current efforts will focus on the development of a basic understanding of the offshore market segment, including analysis of resources, resource impacts, technology, and markets. Most of these studies will be conducted through a series of Sea-based Concept Studies (SeaCon), which focus on offshore elements of wind technology. Through FY 2009, the program is planning on minimal expenditures for offshore wind technology partnerships and, accordingly, is showing limited technology improvements within the framework of the GPRA process.

In FY 2009, a programmatic decision will be made to determine whether there is a significant market and governmental role for offshore wind technologies. If a clear government role can be defined, a similar path of phased solicitations will be proposed to facilitate development of offshore technology. This activity requires a long-term, diverse technical focus that can only be achieved through multiyear phased solicitations to accommodate a range of concept design studies, component development and testing efforts, and full turbine prototype development activities. Based on the high-risk nature of development in offshore environments, the program expects to use cost-shared development partnerships as has been done successfully in the landbased applications.

\section{Supporting Research and Testing}

Through the Supporting Research and Testing (SR\&T) effort, research staff members at the NWTC and SNL perform wind technology research targeted to help industry improve the performance, operation, and cost of components and fully integrated turbine systems best suited for U.S. applications. To that end, program researchers work closely with industry to define and prioritize those research and testing activities that address long- and short-term requirements. Considering the complexity of the advancing technology and the size of new equipment that must be designed and tested, it appears unlikely that industry would make the advances similar in magnitude to past advances without Federal assistance.

Each of the general activities carried out under SR\&T focuses on advancing technologies that have the potential to reduce the COE of large utility-scale and smaller distributed wind systems. The main areas are discussed below.

\section{Turbine Reliability}

Modern wind technology deployments are relatively young, with a fleet average age of less than five years. Although wind turbines are designed with a 20 - to 30-year operational life, and some components have undergone equivalent life-cycle testing, many questions remain regarding the life of specific high-use components. To address the reliability of land-based, offshore, and distributed wind turbine technologies, this activity brings specialized technical expertise, comprehensive design and analysis tools, and unique testing facilities to bear on problems encountered in introducing new wind technology to the marketplace. It also includes the development of associated required testing capabilities and equipment needed to support turbine technologies as they grow in size. 
Technology Development and Validation

Technology Research and Development uses a technical pathway analysis to show impact of private/public partnerships and ensure that research activities can show direct applicability to specific Technical Improvement Opportunities (TIOs) that were identified through detailed market and technical assessments (Schreck and Laxson 2005). Research work covered by the area of Technology Development and Validation follow the same improvement opportunities and support the development of technology through the following laboratory-based research activities:

Advanced Rotor Development: The rotor of a wind turbine is a unique component. The rotor's blades control all the energy capture and almost all the loads, and are, therefore, a primary target of research to enable advanced rotor development. The challenge is to create the scientific knowledge base and engineering tools to enable blade designers to achieve optimum performance at the lowest possible cost, using new materials, advanced controls techniques, improved manufacturing processes, and enhanced design tools.

Site-Specific Design: Future wind energy installations will be in areas of significantly different wind resource potential and terrain roughness. Installations of land-based turbines will need to move into areas with lower wind speeds, using taller towers and longer blades to harvest more energy. Every structural strength requirement throughout the system is based on the expected maximum event and turbulence at the site. To continue to design for loads characteristic of more energetic sites would drive up the cost unnecessarily and limit wind's cost-effectiveness in other areas. Therefore, this subtask covers two areas. The first is the development of systematic methods for specifying site energy and load conditions. The other area is to conduct the field measurements that validate the methods, and to work in public-private partnerships to collect site-specific information in important regions of the country.

Generator, Drivetrain, and Power Electronics Efficiency Improvements: The generator, gearbox, and power converter represent roughly $25 \%$ of the installed capital cost of a modern wind turbine. Generators have historically been based on wound rotors or squirrel-cage induction designs, but such generator designs may not be ideal for wind turbines of the future. Because wind turbines operate for the largest percentage of their time at less than rated power, future designs of generators and power converters must be specialized and tailored to wind turbine operation. Of further importance is reliability of all components, because the generator and power converter are key points of failure in the total system. This task explores key enabling research areas that will contribute to improvements in converter and generator designs, focusing on generator and converter architecture, controls, and reliability.

Design Review and Analysis: As the Wind Program invests in the development of new technology through cost-shared contracts with industry, it will also be providing oversight and technical support to those activities. The Design Review and Analysis effort provides a means whereby the program can provide specialized expertise to industry-led activities. It also provides support to the necessary proposal evaluation process. The support and oversight not only assists industry, but also protects the Wind Program's investments in these partnerships by providing clear stage-gates in the development process and enhancing their chance of success. 
Testing Support: The Wind Program has unique facilities specifically developed to provide the testing capabilities needed to achieve LWST Project goals. Testing is conducted on full-scale LWST turbine systems installed in the field and on myriad turbine components and subsystems. Component testing includes utilizing the NWTC's specialized blade and dynamometer test facilities. Tests performed support research and development, certification, modeling and model validation, and technology characterization. Field-testing of turbine loads, power performance, power quality, and acoustic emissions are conducted in accordance with standards developed under the International Electrotechnical Commission (IEC).

Environmental Support: Wind energy is viewed by many segments of society as having a positive impact on the environment. It uses no fuel, produces electricity without producing greenhouse gases, and uses no fresh water for cooling or processing. However, as with any manmade technology, it does have an effect on the environment in which it operates. These effects are still under study and are being quantified to allow for intelligent mitigation. The program leads peer-reviewed research efforts to understand, avoid, and minimize these impacts, and will continue to do so as deemed appropriate.

\section{Performance Enhancement}

As the U.S. installed wind capacity increases over time, important lessons can be learned from long-term tracking and monitoring of turbine performance and reliability. This activity provides a means of linking with turbine manufacturers and wind plant operators to ensure that issues affecting performance and reliability of wind technology are addressed and incorporated into the Wind Program's R\&D portfolio.

\section{Milestones}

The program has defined goals for its Technology Viability and Technology Application activities that will position wind as an attractive advanced technology option for the 21 st century. These goals were:

- By 2012, reduce the COE from large wind systems in Class 4 winds to 3.6 cents/kWh in 2002 constant dollars, for land-based systems.

- By 2014, reduce the COE from large wind systems in Class 6 winds to 5 cents $/ \mathrm{kWh}$ in 2005 constant dollars for shallow water (depths to 30 meters) offshore systems (from a baseline of 9.5 cents/kWh in 2005 in 2005 constant dollars).

- By 2016, reduce the COE from large wind systems in Class 6 winds to 5 cents $/ \mathrm{kWh}$ in 2005 constant dollars for transitional (depths to 60 meters) offshore systems.

- By 2007, reduce the COE from distributed wind systems in Class 3 winds to 10-15 cents/kWh in constant 2002 dollars.

- By 2012, complete program activities addressing electric power market rules, interconnection impacts, operating strategies, and system planning needed for wind energy to compete without disadvantage to serve the Nation's energy needs.

- By 2010, facilitate the installation of at least $100 \mathrm{MW}$ of wind energy in 30 states. 
The program has also defined major and minor milestones, including annual targets that assist the program in measuring progress toward the overall program goals. The annual targets for 2006 are:

- Annual targets: COE of 4.2 cents/kWh (2002 constant dollars) for land-based Class 4 winds and 9.3 cents/kWh (2005 constant dollars) for offshore systems in Class 6 winds.

- Annual targets: Increase the number of states with more than $100 \mathrm{MW}$ in installed capacity to 19 .

In 2006, the program achieved the major milestones for low wind speed technologies, including the completion of concept studies and the fabrication and testing of turbine prototypes. Specifics include:

- Complete final report on Germanischer Lloyd AG certification for the FAST (Fatigue, Aerodynamics, structures, and Turbulence) design code and ADAMS ${ }^{\circledR}$ simulation prototyping.

- Complete Preliminary Design Review for second LWST Prototype.

- Complete fabrication of TPI Composites, Inc. subscale blade demonstrating structuralaerodynamic optimization.

For Technology Application, the expected outputs will be in the form of information and technical support needed to address integration barriers such as market rules, interconnection impacts, operating strategies, and system planning. Also needed is the reduction of legal, institutional, and zoning barriers to the use of wind, allowing more informed decision-making associated with land-based, offshore, and distributed wind applications. Technology Application milestones in 2006 included:

- Complete one Native American outreach and technical assistance activity.

- Complete one public power outreach and technical assistance activity.

- Complete one multistate outreach and technical assistance activity.

Because these tasks do not specifically support analysis conducted under GPRA, further details of these outputs are not provided in the text. However, it is important to note that they do significantly reduce market risk. More detail on these issues is available in the Program's Multiyear Plan (U.S. Department of Energy 2007) 


\section{Program Outputs}

The major outputs for the Wind Program are the development of new lower-cost technology and the ability to deploy this technology as barriers are addressed. Some of these outputs are reflected in the major milestones discussed above, whereas others represent major program successes such as the activities that contributed to the development of the General Electric's (GE's) highly successful 1.5-MW turbine that supplied more than half of the capacity added to the U.S. grid in 2003; led to the development of the 2.5-MW Liberty turbine by Clipper Windpower, which began manufacturing in 2006; led to the development of the SkyStream 1.8$\mathrm{kW}$ wind turbine by Southwest Wind Power; and facilitated the more than quadrupling of the number of states with more than $100 \mathrm{MW}$ of installed wind generation since 1999. Key program outputs are:

- U.S.-developed wind turbine technologies for low wind sites that compete in the full range of electricity markets.

- Offshore wind technologies that bring wind's benefits to coastal load centers, while limiting environmental and aesthetic impacts.

- Advanced, cost-effective small wind technologies for use in distributed markets.

- Techniques and knowledge to fully and equitably integrate wind systems into the national grid.

- Reduced institutional and informational barriers that would impede wind's use.

- In collaboration with other Federal organizations, develop transmission systems to bring wind energy from remote high resource areas to load centers.

Further details of the activities that impact the portions of the program that are covered under GPRA are provided in Table E-7. 
Table E-7. Program Outputs, Activities, and Milestones

\begin{tabular}{|c|c|c|}
\hline Output & Associated Activities & Associated Milestones \\
\hline $\begin{array}{l}\text { U.S.- } \\
\text { developed } \\
\text { wind turbine } \\
\text { technologies } \\
\text { for low wind } \\
\text { sites that } \\
\text { compete in the } \\
\text { full range of } \\
\text { electricity } \\
\text { markets }\end{array}$ & $\begin{array}{l}\text { Key activities } \\
\text { 1. IEC Accredited of Clipper } 2.5 \mathrm{MW} \\
\text { LWST turbine } \\
\text { 2. Certification of wind turbine design } \\
\text { codes } \\
\text { 3. Development of Northern Power } \\
\text { Systems Variable Speed Generator } \\
\text { 4. Development of new turbine blades } \\
\text { with structural-aerodynamic } \\
\text { optimization } \\
\text { 5. Aeroelastic and Coupled Dynamic } \\
\text { Response } \\
\text { 6. Design Code Development and } \\
\text { 7. Tupport } \\
\text { Turbulence Modeling and Array } \\
\text { 8. Intects } \\
\text { 9. Testing } \\
\text { 10. Environal Collaboration Support } \\
\text { Thental Support }\end{array}$ & $\begin{array}{l}\text { Complete final report on GL } \\
\text { certification for the FAST \& ADAMS } \\
\text { design codes (12/30/05) } \\
\text { Complete hub construction, power } \\
\text { electronics installation, and begin } \\
\text { commissioning process for CART III } \\
\text { turbine. (2/28/2006) } \\
\text { Complete Preliminary Design } \\
\text { Review for second LWST Prototype. } \\
\text { (3/31/06) } \\
\text { Begin laboratory testing of subscale } \\
\text { blades demonstrating structural- } \\
\text { aerodynamic optimization. (4/30/06) } \\
\text { Complete fabrication of TPI subscale } \\
\text { blade demonstrating structural-- } \\
\text { aerodynamic optimization. (6/30/06) } \\
\text { Conduct accredited field-testing of } \\
\text { Clipper } 2.5 \text { MW LWST turbine to IEC } \\
\text { standards. ( } 9 / 30 / 06)\end{array}$ \\
\hline $\begin{array}{l}\text { Offshore wind } \\
\text { technologies } \\
\text { that bring } \\
\text { wind's benefits } \\
\text { to coastal load } \\
\text { centers, while } \\
\text { limiting } \\
\text { environmental } \\
\text { and aesthetic } \\
\text { impacts }\end{array}$ & $\begin{array}{l}\text { Key activities } \\
\text { 1. Advancing the development of } \\
\text { technology that will allow offshore } \\
\text { wind to compete in bulk power } \\
\text { markets }\end{array}$ & $\begin{array}{l}\text { Publish and Present AIAA Paper on } \\
\text { Offshore Model Development and } \\
\text { Verification. (1/31/06) } \\
\text { Complete map validations for two } \\
\text { offshore areas. (8/31/06) } \\
\text { Complete LWST Offshore SR\&T } \\
\text { subcontract awards. (9/30/06) } \\
\text { Begin NEPA review process for 6- } \\
\text { MW Offshore Turbine. (9/30/06) } \\
\text { Draft "Large-Scale Development of } \\
\text { Offshore Wind Power in the United } \\
\text { States" white paper. (9/30/06) }\end{array}$ \\
\hline
\end{tabular}

\section{Translating Program Outputs to Market Outcomes}

By working directly with industry and other Federal, state, and local leaders, the program focuses on ensuring that program outputs lead directly to market outcomes. The specific nature of all program activities, from the coordinated public/private partnerships to targeted outreach, are focused on supporting wind technology integration into the energy sector. Through the strategic planning, peer review, and portfolio balancing processes, even research activities are 
closely aligned with industry and market development needs. The primary program outputs introduced above, reductions in cost of wind technologies for wind systems (both centrally stationed and distributed), and the increased deployment of wind technologies across the country by nature lead directly to market outcomes.

\section{Key Factors in Shaping Market Adoption of EERE Technologies}

\section{Price}

Through program-sponsored research, wind technology is projected to improve significantly during the next decade. This improvement is represented in the GPRA 08 modeling effort by a declining capital cost trajectory, lower O\&M costs, and increased performance. These projections match the program's performance goals, as described above. The Wind Program forms its goals using a probabilistic modeling technique. ${ }^{2}$ The projected COE numbers resulting from the cost and performance trajectories therefore represent figures that are close to the mean expected value, not the most optimistic or most conservative possible.

Although there is a standard mathematical formula for characterizing cost reductions in manufactured goods from "learning effects," there is no standard definition of the term, i.e., what effects it includes, nor is there an accepted single set of assumptions and overall methodological approach for calculating or predicting learning curve (sometimes referred to as "experience curve") impacts. Although some cost reductions may result from "learning" that is dependent on cumulative volume levels, other cost reductions may be obtained from economies of scale resulting from levels of annual volume of production. Therefore, the program's analysis reflects the potential, on a probabilistic basis, for corresponding cost reductions that would result from both learning curve effects and economies of scale, the latter including discounts for largervolume purchase of materials, parts, and components.

The Wind Program's "pathways analysis" assumes that there is at least a chance that the annual level of wind turbine manufacturing output will increase over time, along with cumulative volume. The program represents cost reductions from both annual and cumulative volume in a single number, for which an estimated range is discussed in the remainder of this section. The bottom end of that range is low enough $(2 \%)$ to represent reductions from any combination of annual or cumulative volume increases. A complete discussion of cost-reduction potential from learning effects and economies of scale can be found in Low Wind Speed Technology Pathways Analysis Methodology and Baseline Report to be published by NREL in FY 2007.

\footnotetext{
${ }^{2}$ The technique first requires a reference set of performance and capital and operating cost characteristics for wind plants, using a composite of leading-edge technology for the reference year. It next defines a set of Technology Improvement Opportunities (TIOs) that may lead to lower levelized cost of energy (COE). A set of quantitative estimates of improvements to COE equation inputs (e.g., turbine cost, net annual energy) is then made for each TIO. A wind plant COE spreadsheet model is then run using Monte Carlo simulation add-on software to obtain a probabilistic evaluation of COEs for possible turbine technology configurations, or "pathways," resulting from successful implementation of all possible combinations of those improvements. This approach captures the uncertainty of both R\&D outcomes (potential sizes of various improvements) and the probability of achieving any improvement (R\&D "success"), regardless of the improvement size.
} 
Among the parameters affecting the magnitude of the learning rate for a global technology are: exchange rates, choice of inflators to correct for inflation, use of production costs vs. market prices, choice of market boundaries and subsequent inclusion or exclusion of imports or exports from cumulative production levels, definition of production units (e.g., energy production, capacity or number of turbines) and cost or price (e.g., $\$ /$ turbine, $\$ / \mathrm{kW}$, $\$ /$ wind plant, $\$ / \mathrm{kWh}$ produced). In addition, off-the-shelf components of wind energy plants that are already mass produced will tend to show much less cost decrease over time than lower-volume, customdesigned, and custom-built components, because the former have already "come down" the learning curve (Brock 1995). The mix of these two different types of components will impact the learning rate. There is also uncertainty concerning whether learning rates remain constant over time or tend to decrease, causing cost reductions to diminish as market diffusion increases. There are arguments to support the possibility of either case occurring (Junginger 2005).

Although the application of learning curves to wind energy cost contains a large number of uncertainties, there have been many recent attempts to construct such curves from the growing set of empirical market data. Those data show that most reductions in cost for the various markets studied have been from $2 \%$ to $15 \%$ for every doubling of cumulative installed capacity. Despite the difficulties in applying learning curve theory to projection of future costs, the relatively narrow range of results across those many studies can be used to develop a reasonable range of estimates for potential cost reductions from learning. Accordingly, the Wind Program chose a range of $2 \%$ to $15 \%$ for overall capital cost reduction potential from learning by 2012 for land-based wind plants, with the expected value of 5\% chosen to skew the distribution of values toward the conservative side. In addition, lower rates of cost reduction were chosen for balanceof-station costs, O\&M costs, and replacement costs, because it was assumed that a larger percentage of learning from land-based experience transfers in these areas than in the specialized platforms that contribute heavily to the initial capital cost.

The program's projected cost reduction from learning and increased economies of scale can result from a wide range of assumptions for the combination of the learning and market diffusion rates (i.e., doublings of cumulative wind turbine production and increase in annual production levels). Even the maximum level of cost reduction estimated by $2012-15 \%$ - can be met by quite conservative combinations of those factors. In addition, the small, incremental cost reductions beyond 2012 for land-based wind plants, and in the later years for offshore plants (i.e., in years past, the point where they have met the program goals), can be easily justified by conservative assumptions regarding learning effects and economies of scale. However, one phenomenon that has recently surfaced that goes against the trend toward lower costs from increased production is that, in an expanding market, costs have been found to increase due to supply constraints. While reported by at least one manufacturer recently, this issue was not considered in the evaluation of impacts from learning.

Electricity produced from offshore locations is expected to be of higher value than many landbased locations in many cases, because proximity of several major load centers to the coasts could reduce transmission constraints and costs facing large-scale, land-based power generation. 


\section{Non-price Factors}

\section{Federal and State Policy}

Renewable energy credit (REC) markets, green power programs, California's mandatory carbon cap-and-trade system and other voluntary systems, and renewable portfolio standards (RPS) are all examples of ways such value is beginning to be recognized in the market. Currently, the major market driver for the development of wind technologies is the Federal production tax credit, which was extended through the end of 2007 by the Energy Policy Act of 2005. Additional installations of wind are being driven by state-based renewable portfolio standards, which are currently in effect in 20 states and the District of Columbia.

\section{Transmission/Integration}

The electric industry is in a challenging period characterized by changing, diverse, and nonuniform market rules and regulatory oversight, corporate restructuring, high competition, and technological change. The integration of renewable energy - including wind energy - into the supply mix is one of many issues the industry is grappling with before it can adopt this more competitive market structure. However, the utilities are concerned about possible impacts on system operations when a large amount of wind power is introduced into the electric power system, despite the fact that, by the end of 2005, approximately 58,000 MW of wind-generating capacity had been installed worldwide, and wind energy and cogeneration sometimes total as much as $100 \%$ of instantaneous generation in Denmark. Utility decision makers, state regulators, and investment bankers are unfamiliar with wind; and, therefore, they are overly cautious in their view of wind power as a generation asset. Principal among their concerns are potential system effects due to limitations in wind forecasting and the potential electrical system stability and dispatch implications. Their concerns, if not adequately addressed, could limit the development potential of wind power in this country. Recent developments, such as the release of the Utility Wind Integration State of the Art report by the Utility Wind Integration Group, cosigned by American Public Power Association (APPA), Edison Electric Institute (EEI), and National Rural Electric Cooperative Association (NRECA), however, demonstrate that wind power has entered the mainstream of national power generation, and multiple parties are working to address the key issues facing further wind integration.

The transmission of wind-based energy is also seen as a near-term challenge to the wider use of this technology. Key wind resource areas, such as the northern Great Plains and western Texas are separated from major load centers by limited transmission capacity. The development of new clean energy highways to move larger amounts of low-cost wind power to areas of high load concentration will be required to enable full uptake of these resources.

\section{Environmental / Acceptance}

Wind energy is viewed by many segments of society as having a positive impact on the environment. It uses no fuel, produces electricity without producing greenhouse gases, and uses no fresh water for cooling or processing. But, as with any manmade technology, it does have an effect on the environment in which it operates. Wind developments have the potential to reduce, fragment, or degrade habitat for wildlife, fish, and plants, as well as to directly and indirectly cause harm to biotic communities. 
Noise impacts resulting from construction, turbine operations, substation operations, and transmission lines in addition to visual impacts in less-developed areas are leading to increased acceptance pressures for wind technologies. Proper siting and equipment design and the use of setbacks from residential areas can help minimize these impacts. While the visual impact of wind turbines on the landscape is quite subjective, it poses a challenge to the continued growth of wind energy, particularly on ridgelines and mountaintops (this objection often being referred to as NIMBY - "not in my backyard"). As with noise and ecological impacts, visual aesthetics must be considered in the context of other types of development that affect the visual landscape.

\section{Immediate Outcomes}

Justification for Wind Program Case estimates of both current and future technology characteristics for land-based turbines are contained in a report to be published by NREL in FY 2007. This report, Low Wind Speed Technology Pathways Analysis Methodology and Baseline, will update earlier, preliminary documentation (Cohen 2004). The methodology described in that report was discussed earlier in this appendix on Page E-22. In addition, by using information obtained through R\&D conducted since the path analysis was completed, program researchers are currently updating the technical rationale, description, and potential for improvements in technology cost and performance that can reasonably contribute toward achieving the projected trajectory of those characteristics. The technology characteristics presented in this section reflect preliminary results from that update. The Wind Program plans to incorporate these new technical insights into an updated pathways analysis/risk analysis during FY 2007, which will be included in the FY 2009 GPRA report.

As a starting point for the Program Case cost and performance trajectory, the program splits the difference between the program capacity factor and the AEO capacity factor in 2005, as has been done in past years, and then adjusts to the program capacity factor for 2010 and beyond. The AEO capital cost for 2005 is used, but program costs decrease after that, aligning with the program's projections from 2010 onward. Table E-8 shows the turbine characteristics used for the capacity factor calculations in NREL's spreadsheet model.

Table E-8: Land-Based Turbine Characteristics for Calculating Capacity Factors

\begin{tabular}{|lrr|r|r|r|r|r|r|r|r|r|}
\hline & $\mathbf{2 0 0 5}$ & $\mathbf{2 0 1 0}$ & $\mathbf{2 0 1 5}$ & $\mathbf{2 0 2 0}$ & $\mathbf{2 0 2 5}$ & $\mathbf{2 0 3 0}$ & $\mathbf{2 0 3 5}$ & $\mathbf{2 0 4 0}$ & $\mathbf{2 0 4 5}$ & $\mathbf{2 0 5 0}$ \\
\hline \hline Turbine Rating (kW) & 1500 & 2500 & 3000 & 3000 & 3000 & 3000 & 3000 & 3000 & 3000 & 3000 \\
\hline Diameter (m) (Classes 3 \& 4) & 77 & 93 & 107 & 108 & 108 & 108 & 108 & 108 & 108 & 108 \\
\hline Diameter (m) (Classes 5-7) & 77 & 90 & 96 & 97 & 97 & 99 & 99 & 99 & 99 & 99 \\
\hline Hub Height (m) (Classes 3 \& 4) & 80 & 100 & 120 & 120 & 130 & 120 & 120 & 120 & 120 & 120 \\
\hline Hub Height (m) (Class 5-7) & 80 & 100 & 110 & 110 & 110 & 110 & 110 & 110 & 110 & 110 \\
\hline Peak Power Coefficient (Cp) & 0.47 & 0.50 & 0.51 & 0.51 & 0.51 & 0.52 & 0.52 & 0.52 & 0.52 & 0.52 \\
\hline Peak Conversion Efficiency & 0.95 & 0.96 & 0.97 & 0.97 & 0.98 & 0.98 & 0.98 & 0.98 & 0.98 & .098 \\
\hline Net Losses & 0.12 & 0.06 & 0.05 & 0.05 & 0.05 & 0.05 & 0.05 & 0.05 & 0.05 & 0.05 \\
\hline Availability & 0.98 & 0.98 & 0.98 & 0.98 & 0.98 & 0.98 & 0.98 & 0.98 & 0.98 & 0.98 \\
\hline
\end{tabular}

By averaging the program's estimated capacity factor and the AEO capacity factor for wind plant performance in 2005, the differences in methodology are mitigated. The transmission constraints that can cause curtailment in some cases are not related to the technology performance, nor are 
other interannual variations in wind resource levels that can cause energy production reported to EIA to be lower than calculated estimates would predict. It is assumed that these issues will be resolved or mitigated in the future. While still too early in the project, current analysis of wind plant performance and associated wind resource level for commercial several sites may help resolve some of these issues. Thus, the program's projected capacity factors based on technology improvement assumptions are used for future technology. One of the key barriers to the widespread implementation of wind technologies relates to the acceptance and integration of wind technologies into the national electric system. Increased funding in this area supports the President's Advanced Energy Initiative by opening up more of the Nation's vast wind resources to development and productive use. An expansion of these activities will include further collaboration between the Wind Program and the Office of Electricity Delivery Energy Reliability, who will work together to address the near-term to midterm risks of transmissionbased limitations being imposed on wind development. Increased funding will be directed to expanding the number of wind plant characterization, integration, and interconnection studies supported by the program, the addition of laboratory staff to provide analytical support, and establishment of regional wind integration teams to allow participation in regional forums as decisions about wind energy are made.

As discussed in the baseline case section, a spreadsheet model was used in conjunction with the turbine characteristics in Table E-8 to calculate capacity factors. In forming the values in Table E-8, assumptions were made regarding the physical dimensions of the technology, e.g., rotor diameter and hub height, with respect to progress toward the Technical Improvement Opportunities (TIOs) that were defined to achieve the cost of energy goals. The primary R\&D drivers of improved cost and performance are extended rotors and taller towers, which can be achieved through the use of sophisticated control designs, new materials, and innovative tower concepts. In addition, continued improvement of drivetrain technology and reliability also contribute to future improvements. There are a large number of potential combinations of components with such advancements that could result in turbine system designs with overall cost and performance improvements on the projected level.

Program analysis and documentation for offshore technology projections is an evolving process. The current and planned program-sponsored SeaCon studies will provide a much more detailed technical foundation for making such projections. To develop preliminary offshore cost and performance inputs, program analysts scaled capital costs over six periods from 2006 to 2025, using cost-reduction rates (i.e., capital cost reductions for each period corresponding to a doubling of installed capacity) typical of wind industry experience. The rates were assumed to include improvements in technology, increases in production volume, and "learning" improvements in manufacturing and wind plant installation. The doubling periods and costreduction rate used in the cost calculations were derived from IEA and European reports (Milborrow 2003). The rate was augmented by a one-time additional 10\% reduction in capital cost based on technology R\&D. The resulting levels of improvements to wind plant COE served as an upper boundary for program case estimates. That is, the program case projections in Table E-9 are all within the bounds established by the cost-scaling exercise. 


\section{Interim Outcomes}

Market penetration was estimated using NEMS (to 2030) and MARKAL (to 2050). The implementation of wind energy in NEMS and MARKAL is discussed in the appendices covering those models.

The program characterized the offshore resource potential by wind class, water depth, and region. For GPRA 07, costs were based on a wind plant distance of 20 miles from the substation, which is expected to be located at shoreline. This approach is not entirely accurate because it does not reflect the true costs based on distance from shore, and makes all of the shallow and transitional resources in each wind class available at the same price. Initial studies indicate that there is a moderate cost multiplier based on the costs of transmission (see Figure E-4) (University of Massachusetts 2006). Including these costs allows a more rational application of wind technology within the GPRA models. For this GPRA08 analysis, the program further split the resource data into two groups, the resource that is available at a distance of 5 to 20 miles and at 20 to 50 miles. Cost values were applied to these two groups as if all of the resources were located at 12.5 and 35 miles, respectively.

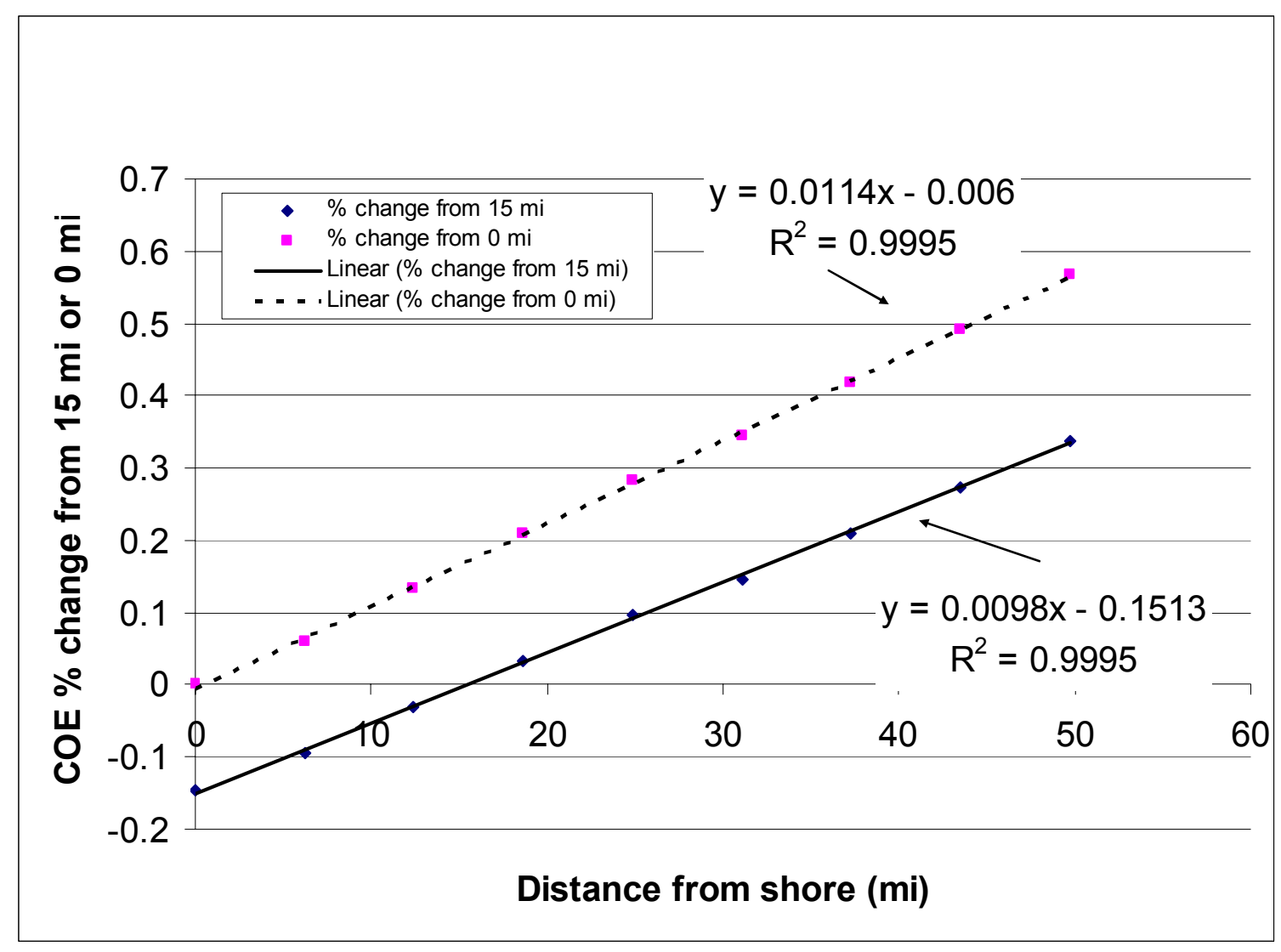

Figure E-4. Cost of Offshore Wind Plants Vs. Distance from Shore

It was necessary to make one other modification to the offshore wind resource inputs for the NEMS model. The current NEMS-GPRA 08 projections produce extremely high offshore wind penetration in the Southeastern Electric Reliability Council (SERC) region. To address this issue within the current GPRA cycle, a short-term solution was developed: the SERC offshore wind 
resource was reduced by the ratio of new electric generating capacity in Virginia, North Carolina, and South Carolina to the new capacity in the entire SERC region. The trend toward overestimation of the reduction factor, because not all new capacity will be met by wind generation, was assumed to cancel (on a first-order level) the trend toward underestimation, because there will be some wind generation that will be transmitted to other states in the SERC region. The original wind resource data set was scaled by maintaining the same proportion of resources for each wind power class, by distance from shore and depth of water. This, again, was estimated to result in an accurate estimate, to the first-order, and was assumed because more detailed analysis has not been performed.

\section{Final Outcomes (Benefits)}

The program does not calculate benefits outside of, or exogenous to, the integrated energy market models discussed in this report. The benefits reported in the primary part of this document represent the program's best estimate of the results of its technology development activities associated with large wind systems. The program does not currently assess the longterm benefits of its Technology Application or Distributed Wind Technology efforts, though may attempt to do this in the future. 


\section{Summary of Inputs}

Capital costs, capacity factors, and O\&M costs, which are used as inputs to the NEMS-GPRA 08 model for the Program Case, are provided in Table E-9. The projections match the program's performance goals, as described above. Projections for land-based wind plants are consistent with the analysis described in the MYPP (U.S. Department of Energy 2007). The capital costs do not include a contingency factor of 5\% for land-based wind and $7 \%$ for offshore wind, which is applied, as is done with other electric generating technology cost inputs, before being input to NEMS. Capital costs are overnight costs, i.e., they do not include financing during construction.

Table E-9: Summary of Inputs to Models ("Immediate Outcomes" of Program R\&D)

\begin{tabular}{|l|lrrrrrrrr|}
\hline 2004 Dollars & & $\mathbf{2 0 0 5}$ & $\mathbf{2 0 1 0}$ & $\mathbf{2 0 1 5}$ & $\mathbf{2 0 2 0}$ & $\mathbf{2 0 2 5}$ & $\mathbf{2 0 3 0}$ & $\mathbf{2 0 4 0}$ & $\mathbf{2 0 5 0}$ \\
\hline Capital Costs* & & & & & & & & & \\
Land Based & Classes 5\&6 & 1167 & 893 & 841 & 818 & 814 & 789 & 765 & 747 \\
& Class 4 & 1167 & 999 & 992 & 946 & 868 & 868 & 856 & 839 \\
\hline Offshore & Shallow & 2118 & 2037 & 1601 & 1125 & 941 & 922 & 873 & 844 \\
& Transitional & 2803 & 2765 & 2134 & 1251 & 1140 & 1004 & 951 & 892 \\
\hline O\&M Costs & & & & & & & & & \\
Land Based & All Classes & 27.6 & 24.4 & 22.6 & 20.9 & 19.3 & 18.0 & 15.4 & 13.2 \\
\hline Offshore & Shallow & 81 & 81 & 63 & 50 & 44 & 44 & 39 & 34 \\
& Transitional & 81 & 81 & 63 & 50 & 44 & 44 & 39 & 34 \\
\hline Capacity Factors & & & & & & & & \\
Land Based & Class 6 & 0.432 & 0.482 & 0.494 & 0.503 & 0.505 & 0.520 & 0.522 & 0.522 \\
& Class 5 & 0.399 & 0.446 & 0.459 & 0.468 & 0.470 & 0.484 & 0.487 & 0.487 \\
& Class 4 & 0.350 & 0.410 & 0.461 & 0.469 & 0.471 & 0.478 & 0.480 & 0.480 \\
\hline Offshore & Class 6 & 0.384 & 0.384 & 0.422 & 0.431 & 0.436 & 0.442 & 0.450 & 0.458 \\
Shallow & Class 5 & 0.337 & 0.337 & 0.375 & 0.385 & 0.389 & 0.395 & 0.403 & 0.410 \\
& Class 4 & 0.298 & 0.298 & 0.336 & 0.346 & 0.349 & 0.355 & 0.363 & 0.370 \\
\hline Offshore & Class 7 & 0.423 & 0.423 & 0.472 & 0.464 & 0.484 & 0.491 & 0.509 & 0.514 \\
Transitional & Class 6 & 0.384 & 0.384 & 0.433 & 0.422 & 0.442 & 0.449 & 0.466 & 0.471 \\
& Class 5 & 0.337 & 0.337 & 0.386 & 0.373 & 0.390 & 0.397 & 0.414 & 0.418 \\
*Does not include a 1.05 contingency factor applied to land-based systems and 1.07 to offshore systems (Cohen \\
2004, Musial 2004; U.S. Department of Energy 2007). Land-based costs were converted from 2002 dollars using a \\
CPI Inflator of 1.05. Offshore costs were converted from 2005 dollars using a GDP deflator of 0.97 \\
\hline
\end{tabular}




\section{Bibliography}

ABB Inc. Electric Systems Consulting, 2005. Dakotas Wind Transmission Study. Report No. 2005-10977-4 R1. Web site of Western Area Power Authority's Great Plains Regional Office http://www.wapa.gov/ugp/study/DakotasWind/FinalReports/, accessed November 8, 2006.

Brock, F., Koontz, R., and Cohen, J., 1995. The Effects of Increased Production on Wind Turbine Costs. Princeton Economic Research Inc. Unpublished report for the National Renewable Energy Laboratory.

Cohen, J. M., 2004. "Assessment of Potential Improvements in Large-Scale Low Wind Speed Technology." Global Windpower 2004 Conference Proceedings. American Wind Energy Association.

Energy Information Administration, 2005. Annual Energy Outlook 2005, Supplemental Tables (Tables 60-72).

Goldman, P., et al., 2002. "Advanced Low Wind Speed Technology Research and Development in the U.S. Department of Energy Wind Program." Proceedings of the 2002 Global Windpower Conference, Paris, France.

Hand, M., 2006. Personal communication. National Renewable Energy Laboratory. September 2006.

Junginger, M., 2005. Learning in Renewable Energy Technology Development. Ph.D. thesis. The Netherlands: Utrecht University. Web site of the University of Utrecht, Department of Science Technology and Society http://www.chem.uu.nl/nws, accessed November 8, 2006.

Laxson, A., Hand, M., Fingersh, L., 2006. Wind Turbine Design Cost and Scaling Model. NREL/TP-40566

Milborrow, D., 2003. "Offshore Wind Rises to the Challenge.” Windpower Monthly, Vol. 19 No. 4.

Musial, W., and Butterfield, S., 2004. Future for Offshore Wind Energy in the United States. National Renewable Energy Laboratory, Technical Report No.NREL/CP-500-36313. Web site of the National Renewable Energy Laboratory http://www.nrel.gov/docs/fy04osti/36313.pdf, accessed November 8, 2006.

Musial, W., Butterfield, C., Jonkman, J., Cohen, J., Ram, B., Schwartz, M. (In Press) Large Scale Offshore Wind Power in the United States: Technical Assessment of Opportunities and Barriers. National Renewable Energy Laboratory Technical Report No. TP-500-40745.

Parsons, B., Wan, Y, Elliot, D., 1995. "Estimates of Wind Resource Land Area and Power Potential in Close Proximity to Existing Transmission Lines." Proceedings of WindPower '95. American Wind Energy Association, p. 295. 
Schreck, S., and Laxson, A., 2005. Low Wind Speed Technologies Annual Turbine Technology Update (ATTU) Process for Land-Based, Utility-Class Technologies. NREL Report No. TP-50037505 .

University of Massachusetts, 2006. Chris Elkinton, personal communication, March 31, 2006.

U.S. Department of Energy, Wind and Hydropower Technologies Program, 2007. Wind Energy Multiyear Program Plan for 2008-2012, National Renewable Energy Laboratory, Technical Report No. NREL/TP-500-40593. 


\section{APPENDIX F - FREEDOMCAR AND VEHICLE TECHNOLOGIES PROGRAM INPUTS FOR FY 2008 BENEFITS ESTIMATES}

Table of contents

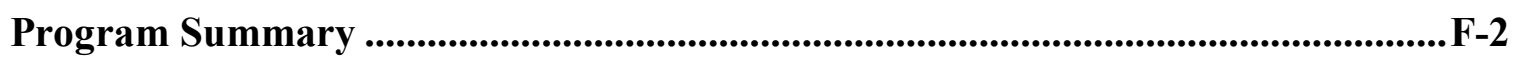

Light Vehicles ......................................................................................................................F-3

Significant Changes from Previous Analysis .............................................F-3

The Baseline ("without DOE RD3" case) ..................................................F-3

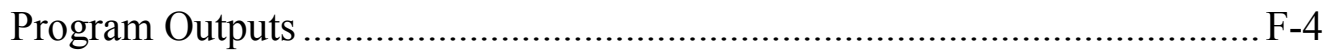

Translating Program Outputs to Market Outcomes ……………………......F-17

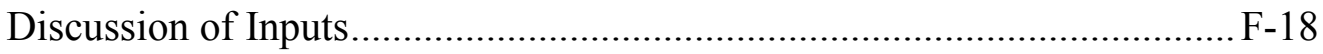

Heavy Vehicles ......................................................................................................

Significant Changes from Previous Analysis ..............................................F-33

The Baseline ("without DOE RD3" case) …………………………….....F-33

Program Outputs …………………………………............................F-33

Translating Program Outputs to Market Outcomes .....................................F-34

Target Market: Heavy Vehicle Target Market................................................F-35

Discussion of Inputs...............................................................................

Key Factors Shaping Market Adoption of Technology ……………….......F-40

Methodology and Calculations: Overview ……………………………....F-42

Heavy-Truck Energy Use Models: Workbooks, Inputs, and Outputs ..........F-49

Bibliography ...................................................................................................................F-53 


\section{Program Summary}

The FreedomCAR and Vehicle Technologies (FCVT) Program provides technology-focused research and development activities for: 1) improving the energy efficiency of current cars, light trucks, and heavy vehicles; and 2) developing technologies that will transition vehicle technology away from petroleum fuels. These activities could result in significant benefits over the next 30 years as more hybrid-electric vehicles, lightweight materials, low-temperature combustion regimes, and alternative fuels (including hydrogen) are used.

FCVT technology is aimed at light vehicles and heavy vehicles. Light vehicles include cars and light trucks (pickups, SUVs, minivans, and vans). Heavy vehicles include medium and heavy trucks and buses.

DOE works with its industry partners through two partnerships: the FreedomCAR and Fuel Partnership, and the $21^{\text {st }}$ Century Truck Partnership. These two partnerships are described at these Web sites: http://wwwl.eere.energy.gov/vehiclesandfuels/about/partnerships/freedomcar/index.html http://www1.eere.energy.gov/vehiclesandfuels/about/partnerships/21centurytruck/index.html

The FreedomCAR and Fuel Partnership (the Partnership) began in September 2003 as an expansion of the FreedomCAR Partnership, which was originally established in January 2002. The Partnership was established by Secretary of Energy Spencer Abraham and senior executives of DaimlerChrysler Corporation, Ford Motor Company, and General Motors Corporation. The CAR in FreedomCAR stands for Cooperative Automotive Research.

The Partnership is an effort to examine and advance the precompetitive, high-risk research needed to develop the component and infrastructure technologies necessary to enable a full range of affordable cars and light trucks, and the fueling infrastructure for them that will reduce the dependence of the Nation's personal transportation system on imported oil and minimize harmful vehicle emissions, without sacrificing freedom of mobility and freedom of vehicle choice.

The $21^{\text {st }}$ Century Truck Partnership is an industry-government collaboration among heavy-duty engine manufacturers, heavy-duty truck and bus manufacturers, heavy hybrid powertrain manufacturers, and four Federal Government agencies. The partners work cooperatively to develop a balanced portfolio of research aimed at achieving their research goals, coordinating their research activities as appropriate, and making effective use of the Nation's research universities and national laboratories. Proprietary research agreements between individual companies and Federal agencies, which cannot be shared with industrial competitors, will continue to be funded appropriately. By sharing information across four Federal agencies and 16 private companies, research can be focused on selected projects that show the greatest likelihood of near-term success and fleet-wide effectiveness.

This appendix is divided into a Light Vehicles section and a Heavy Vehicles section. 


\section{Light Vehicles}

\section{Significant Changes from Previous Analysis}

One of the new technologies specifically called out by the president in his 2006 State of the Union Address is the development of plug-in hybrid electric vehicles (PHEVs). PHEVs can draw some of their energy from the electric grid, thus further reducing oil use (as compared to the potential reduction from current HEVs) when electricity is produced from sources other than petroleum. Higher energy capacity batteries could provide an electric range for these vehicles of up to 40 miles daily (covering the commuting distance of many Americans). The battery energy could be restored by connecting to an electric outlet. Initiated in FY 2007, this promising research will be expanded in FY 2008 (under FCVT's Hybrid Electric Systems Subprogram) and in subsequent years. The FCVT Program expects to have the PHEV technology validated by 2014.

\section{The Baseline ("without DOE RD3" case)}

For light vehicles, it is assumed for the baseline that HEVs would continue to increase their market share over time, but that their fuel economy would not improve over what the Energy Information Administration's (EIA) Annual Energy Outlook (AEO) projects, because AEO assumptions were consistent with FCVT's technical judgment. It is assumed that PHEVs would not enter the market at all in the baseline, because the barriers (such as the performance and costs of batteries and fast chargers) are very high, and industry has shown no willingness to overcome them without Federal support.

\section{Target Market Description}

The light-vehicle market includes all cars and light trucks sold for both personal and business use. Today, the size of this market is approximately 17 million vehicle sales per year. The stock of cars and light trucks is about 230 million vehicles. EIA projects both sales and stock to grow to more than 21 million and 330 million respectively by 2030. Most vehicles are driven less than 250 miles per week. Most light vehicles use gasoline. The average light vehicle lasts about 16 years before being scrapped (Davis 2006, p. 3-13 and 3-15). Light-vehicle fuel economy has remained fairly flat during the past 15 years (Davis 2006, p. 4-7). The FCVT R\&D portfolio aims at achieving significant improvements in their energy efficiency. In addition, FCVT focuses on reducing the cost of, and overcoming technical barriers to, volume manufacturing of advanced technology vehicles.

\section{Baseline Adjustments to the AEO2006 Reference Case}

The HEV market penetration for 2030 was increased as explained below.

\section{Representation of Program-Relevant Technologies in the AEO Reference Case}

All the light-vehicle technologies are represented in the AEO, except for PHEVs. PHEVs were added to the EERE version of the National Energy Modeling System (NEMS). EIA (Maples, 
Transportation Working Group Meeting, September 29, 2006) indicated that future AEOs will include PHEVs. As assumed by EIA, the FCVT program expects that the performance of light vehicles, as represented by acceleration time to $60 \mathrm{mph}$, will continue to increase over time.

Removing Effects of Program Activities

There are none of these.

Other Program-Relevant Adjustments to AEO Reference Case

Based on an internal EERE analysis and the increasing sales of current HEVs, the AEO's HEV 2030 market penetration (9.5\% for cars and $8.6 \%$ for light trucks) was increased to $21 \%$ for cars and to $19 \%$ for light trucks in the EERE NEMS model. This is a $120 \%$ increase in the share for both cars and light trucks. The miles per gallon (mpg) values for HEVs assumed by EIA were used for these vehicles.

The Paumanok Estimates for worldwide HEV production has HEVs growing from 0.3 million in 2006 to 8 million in 2015 (http://www.ttiinc.com/object/me_zogbi_20060710.html). This indicates 2015 production of HEVs being 26 times the 2006 value. If translated to U.S. sales of HEVs, this would mean about 5.7 million HEVs sold in 2015. This is quite a bit higher than the 2006 AEO projection of about 1.2 million HEV sales in 2015. We estimated a much smaller increase in the EIA reference case - $120 \%$ more HEVs - for the GPRA reference case.

\section{Program Outputs}

The program outputs are shown in the logic diagram below as Exhibit F-1. This same logic chain applies to the Heavy Vehicle activity. The actual numerical benefits are shown in other parts of this documentation. 


\section{Exhibit F-1. Summary Program Logic Model for FCVT}

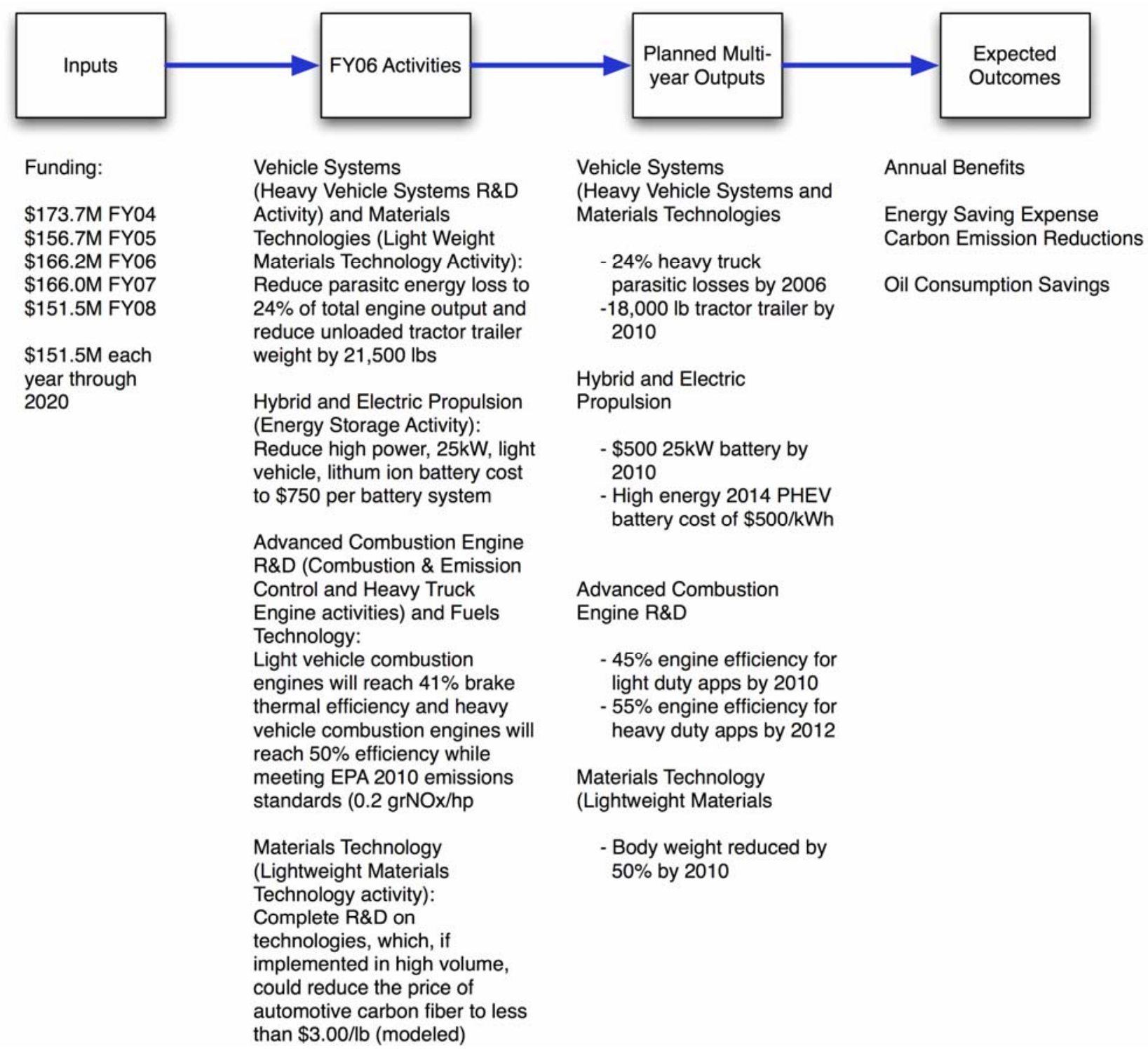

\section{Assumed Budget Projections}

The total FY 2008 budget request is shown in Table F-1. The budget for the Heavy Vehicle activity is included in that total. The over-target funding is necessary to meet the program targets. 
Table F-1. Funding by Strategic and Program Goal ${ }^{\mathrm{a}}$

\begin{tabular}{|c|c|c|c|c|c|c|}
\hline & \multicolumn{6}{|c|}{ (dollars in thousands) } \\
\hline & $\begin{array}{c}\text { FY } 2006 \\
\text { Current } \\
\text { Appropriation }\end{array}$ & $\begin{array}{l}\text { FY } 2007 \\
\text { Request }\end{array}$ & $\begin{array}{c}\text { FY } 2007 \\
\text { House } \\
\text { Mark }\end{array}$ & $\begin{array}{c}\text { FY } 2007 \\
\text { Senate } \\
\text { Mark }\end{array}$ & $\begin{array}{l}\text { FY } 2008 \\
\text { Request }\end{array}$ & $\begin{array}{c}\text { Over } \\
\text { Target } \\
\text { Increment }\end{array}$ \\
\hline \multicolumn{7}{|l|}{ Vehicle Technologies } \\
\hline Hybrid Electric Systems & 0 & 0 & 0 & 0 & 70,742 & $+9,922$ \\
\hline Vehicle Systems & 13,056 & 13,315 & 13,315 & 13,315 & 0 & 0 \\
\hline $\begin{array}{l}\text { Hybrid and Electric } \\
\text { Propulsion }\end{array}$ & 43,977 & 50,841 & 50,841 & 50,841 & 0 & 0 \\
\hline $\begin{array}{l}\text { Advanced Combustion } \\
\text { Engine R\&D }\end{array}$ & 41,628 & 46,706 & 52,613 & 46,706 & 32,000 & $+2,550$ \\
\hline Materials Technology & 35,269 & 29,786 & 29,786 & 29,786 & 22,881 & $+10,501$ \\
\hline Fuels Technology & 13,709 & 13,845 & 13,845 & 13,845 & 13,845 & 0 \\
\hline Technology Integration & 0 & 0 & 0 & 0 & 8,804 & $+4,893$ \\
\hline Innovative Concepts & 495 & 500 & 500 & 500 & 0 & 0 \\
\hline $\begin{array}{l}\text { Technology } \\
\text { Introduction }\end{array}$ & 6,250 & 11,031 & 16,638 & 15,031 & 0 & 0 \\
\hline Biennial Peer Reviews & 990 & 0 & 0 & 0 & 0 & 0 \\
\hline $\begin{array}{l}\text { Technical/Program } \\
\text { Management Support }\end{array}$ & 2,475 & 0 & 0 & 0 & 0 & 0 \\
\hline $\begin{array}{l}\text { Congressionally } \\
\text { Directed Activities }\end{array}$ & 24,255 & 0 & 0 & 10,000 & 0 & 0 \\
\hline $\begin{array}{l}\text { Total, Vehicle } \\
\text { Technologies }\end{array}$ & 182,104 & 166,024 & 177,538 & 180,024 & 148,272 & $+27,866$ \\
\hline
\end{tabular}

a. The amount of the request is confidential until after the budget submission to Congress. 
The out-year budgets through FY 2012 are shown in Table F-2. From FY 2013 through FY 2019, the annual budgets are assumed to be comparable to the FY 2012 budget.

\section{Table F-2. Out-Year Funding Profile by Subprogram ${ }^{a}$}

\begin{tabular}{|c|c|c|c|c|}
\hline & \multicolumn{4}{|c|}{ (dollars in thousands) } \\
\hline & FY 2009 & FY 2010 & FY 2011 & FY 2012 \\
\hline \multicolumn{5}{|l|}{ Vehicle Technologies } \\
\hline Hybrid Electric Systems & 70,637 & 70,585 & 70,546 & 70,487 \\
\hline $\begin{array}{l}\text { Advanced Combustion } \\
\text { Engine R\&D }\end{array}$ & 31,819 & 31,729 & 31,662 & 31,561 \\
\hline Materials Technology & 22,881 & 22,881 & 22,881 & 22,881 \\
\hline Fuels Technology & 13,845 & 13,845 & 13,845 & 13,845 \\
\hline Technology Integration & 8,804 & 8,804 & 8,804 & 8,804 \\
\hline $\begin{array}{l}\text { Congressionally Directed } \\
\text { Activities }\end{array}$ & 0 & 0 & 0 & 0 \\
\hline Total, Vehicle Technologies & 147,986 & 147,844 & 147,738 & 147,578 \\
\hline
\end{tabular}

\section{Description of Key Activities}

FCVT has worked with industry to identify the priority areas of research needed to develop advanced vehicle technologies to reduce and eventually eliminate petroleum use. These research areas and associated activities are Vehicle Systems; Hybrid and Electric Propulsion; Advanced Combustion Engines; and Fuels, Materials Technologies, and Technology Introduction.

Vehicle Systems integrates all other research activities and their performance targets to confirm the correct direction and ultimately the success of the FCVT Program. The Vehicle Systems Subprogram is comprised of three key activities: Simulation and Technology Validation, Heavy Vehicle Systems R\&D, and Light-Vehicle Systems R\&D.

Hybrid and Electric Propulsion focuses on the energy storage, power electronics, and electric machinery required for hybrid drive systems. The Energy Storage activity will reduce the cost of a $25 \mathrm{~kW}$ battery from $\$ 3,000$ (2004 baseline) to $\$ 500$ by 2010 . An integrated inverter/motor subsystem is not currently available on the market; but, if one were produced today, it is estimated that it would cost more than $\$ 40 / \mathrm{kW}$. By 2010, the Power Electronics and Electric Machinery Activity will reduce this cost to $\$ 12 / \mathrm{kW}$. This technology will support the 2014 PHEV target.

Advanced Combustion Engine R\&D and Fuels Technology aims to develop significantly more efficient engines and, eventually, a major reduction in petroleum consumption. Work in this area expands the fundamental knowledge of engine combustion and an understanding of the 
relationships between mobile emissions, quantifiable health hazards (to preclude introducing unintended human health impacts), and the advanced fuel requirements for these engines to realize their full potential. These subprograms will achieve a light-duty engine efficiency of $45 \%$ by 2010 (from 30\% in 2002), and a heavy-duty engine efficiency of $55 \%$ by 2013 (from $40 \%$ in 2002). The work will also identify fuel formulations by 2010 that will enable the replacement of at least $10 \%$ petroleum fuels (currently $3 \%$ ).

Materials Technologies includes the development of high-strength, lightweight materials for the frame, body, chassis, and powertrain systems for light- and heavy-duty vehicles. The targets are focused on affordability while meeting performance, safety, and reusability objectives. By 2012, material technologies will enable a 50\% weight reduction of automobiles (relative to the 1997 baseline) and $22 \%$ weight reduction of tractor-trailer combinations (relative to the 2003 baseline). The High Temperature Materials Laboratory at Oak Ridge National Laboratory (ORNL) provides state-of-the-art capabilities for fundamental and applied research to users.

Technology Introduction accelerates the adoption and use of alternative fuels and advanced technology vehicles to help meet national energy and environmental goals. It also contributes to the training of a specialized workforce suitable for the advanced vehicle technologies of the future. As identified in the National Energy Policy (National Energy Policy Development Group, 2001), consumer education and demonstration activities are critical in accelerating the use of advanced energy technologies.

Successful attainment of FCVT goals will provide the pathway for the United States to dramatically change its energy use and petroleum dependence. This will greatly reduce emissions and the transportation sector's contribution to greenhouse gases while sustaining mobility and the freedom of vehicle choice. This vision is necessary for future national energy security and will benefit all.

\section{Milestones and Outputs}

The milestones and outputs for the various FCVT light-vehicle activities are shown in Exhibits F-2 through F-7. 


\section{Exhibit F-2. Simulation and Technology Validation Network Chart}

\section{Simulation and Technology Validation Network Chart}

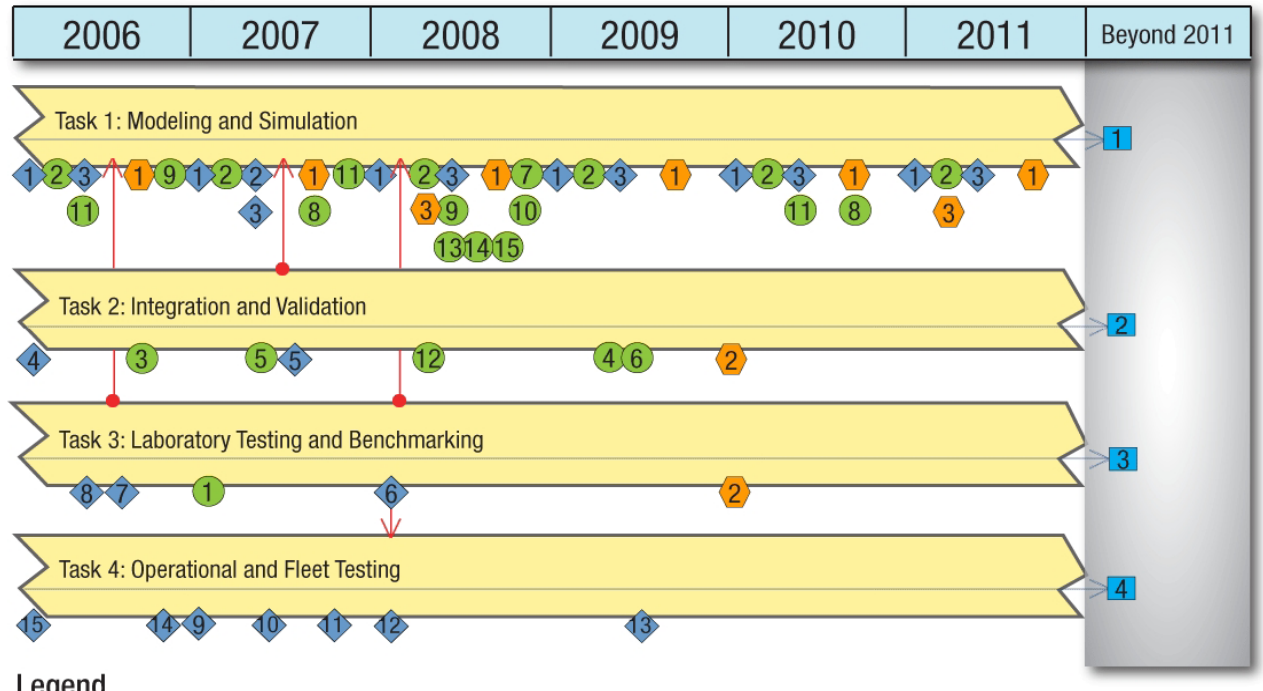

\begin{tabular}{|c|c|c|}
\hline$\bigcirc$ Milestone & Supporting Input & Technology Program Output \\
\hline $\begin{array}{l}\text { 1. Simulation software revision release } \\
\text { 2. Complete assessment of dual energy } \\
\text { storage technology } \\
\text { 3. Program technical targets evaluation and } \\
\text { review } \\
\text { 4. Completion of MATT system } \\
\text { 5. Fuel cell validation } \\
\text { 6. Hydrogen fuel cell benchmarking com- } \\
\text { plete } \\
\text { 7. Plug-in hybrid evaluation complete } \\
\text { 8. MY05 Accord hybrid benchmarking } \\
\text { complete } \\
\text { 9. Idle reduction demo \#1 final cooler } \\
\text { report } \\
\text { 10. Idle reduction demo \#2 final report on } \\
\text { road evaluations } \\
\text { 11. Idle reduction demo \#3 complete analy- } \\
\text { sis and final report } \\
\text { 12. Complete on-line installation of idle } \\
\text { reduction technologies } \\
\text { 13. Hydrogen fuel cell fleet testing complete } \\
\text { 14. 2nd Generation Orion hybrid bus testing } \\
\text { completed } \\
\text { 15. Technical and economic evaluation of } \\
\text { APS Hydrogen Fueling Pilot Plant }\end{array}$ & $\begin{array}{l}\text { 1. Hydrogen fuel cell vehicle for bench- } \\
\text { marking and fleet testing activities (from } \\
\text { industry) } \\
\text { 2. Revised program targets from each } \\
\text { technology area } \\
\text { 3. Fuel cell sub-system for integration and } \\
\text { validation (from industry) } \\
\text { 4. Integrated motor/inverter to meet } \\
\text { FreedomCAR goals from Advanced Power } \\
\text { Electronics and Electric Machines } \\
\text { 5. Prototype internal PM motor from } \\
\text { Advanced Power Electronics and Electric } \\
\text { Machines } \\
\text { 6. Thermal control system from Advanced } \\
\text { Power Electronics and Electric Machines } \\
\text { 7. Hybrid body-in-white weight and per- } \\
\text { formance data from Automotive Light- } \\
\text { weighting Materials } \\
\text { 8. Advanced Competition performance data } \\
\text { available for PSAT enhancement } \\
\text { 9. Technical data from Waste Heat Recovery } \\
\text { 10. Technical results from Combustion and } \\
\text { Emissions R\&D } \\
\text { 11. Technical data from Heavy Truck Engine } \\
\text { R\&D } \\
\text { 12. Validated power electronics cooling } \\
\text { technology available } \\
\text { 13. } 42 \mathrm{~V} \text { battery/ultracapacitor technical infor- } \\
\text { mation from Energy Storage R\&D } \\
\text { 14. Hybrid fuel cell battery prototypes and } \\
\text { technical results from Energy Storage } \\
\text { R\&D }\end{array}$ & $\begin{array}{ll}\text { 1. } & \text { Revised targets for advanced technology } \\
\text { components and subsystems } \\
\text { 2. } \\
\text { Validated technologies to industry } \\
\text { Simulation support to Advanced Competi- } \\
\text { tions } \\
\text { Recurring/On-going } \\
\text { 1. } \\
\text { 2. Model validation } \\
\text { Component validation, contingent on } \\
\text { technology availability }\end{array}$ \\
\hline
\end{tabular}


Exhibit F-3. Light-Vehicle Ancillary Systems R\&D Network Chart

Light Vehicle Ancillary Systems R\&D Network Chart

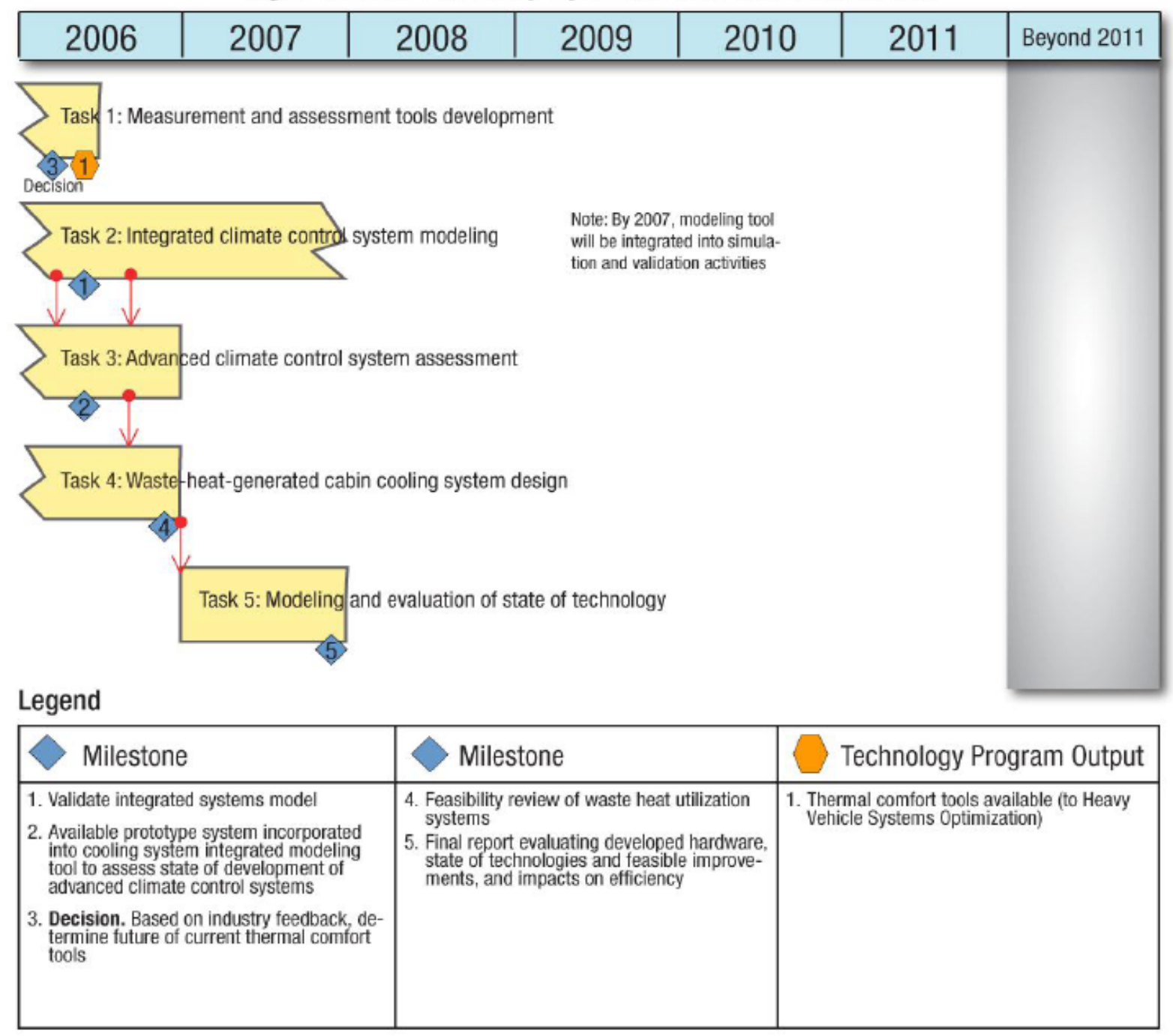




\section{Exhibit F-3 (continued). Light-Vehicle Ancillary Systems R\&D Network Chart}

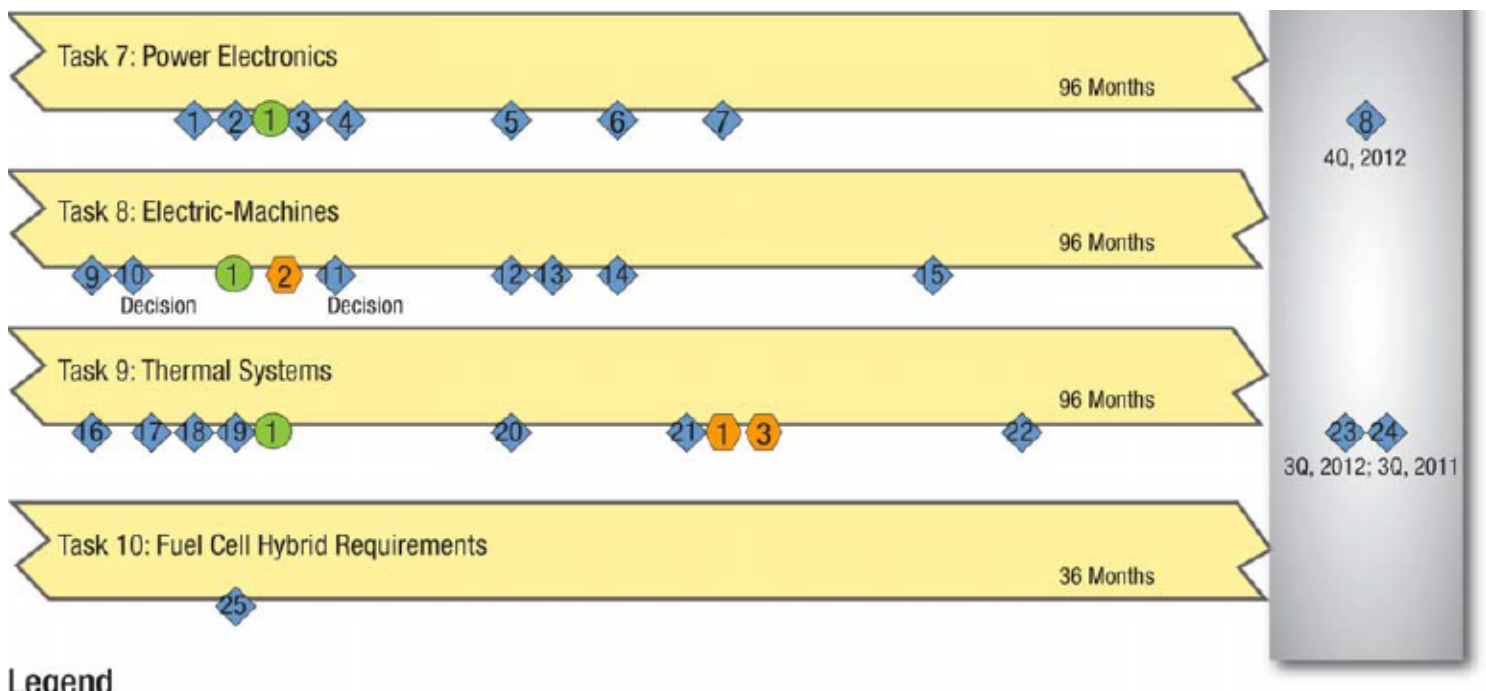

Legend

\begin{tabular}{|c|c|c|}
\hline Milestone & & Technology Program Output \\
\hline $\begin{array}{l}\text { 1. Receive Ballard DC/DC converter deliver- } \\
\text { ables for testing and evaluation } \\
\text { 2. Hardware delivery of high temperature } \\
\text { AlPM } \\
\text { 3. Completion of } 55 \mathrm{~kW} \mathrm{SiC} \mathrm{inverter} \mathrm{with} \mathrm{high} \\
\text { temp packaging } \\
\text { 4. Validate improvements in inverter pack- } \\
\text { aging methods with dual inverter } \\
\text { 5. Receive high temp, high capacitance } \\
\text { improved capacitors for testing and evalu- } \\
\text { ation } \\
\text { 6. Completion of cascade inverter build and } \\
\text { test, resulting in inverter size reduction to } \\
\text { 1/3 of Semikron } 2005 \text { inverter } \\
\text { 7. Complete build and evaluation of high } \\
\text { temperature multilevel converter system } \\
\text { with bidirectional DC/DC converter and } \\
50 \mathrm{~kW} \text { inverter } \\
\text { 8. Complete build of optimized DC/DC con- } \\
\text { verter for use in FC vehicles } \\
\text { 9. Completion of Phase } 1 \text { of industrial motor } \\
\text { project } \\
\text { 10. Decision. Verify that developments in } \\
\text { field-weakening techniques help attain } \\
\text { technical targets for PM motors } \\
\text { 11. Decision. Validate contribution of devel- } \\
\text { opments in magnet materials to technical } \\
\text { targets for motors }\end{array}$ & $\begin{array}{l}\text { 12. Receive Industrial RFP awardee motor for } \\
\text { testing and evaluation } \\
\text { 13. Complete build and evaluation of high } \\
\text { speed (1500rpm) reluctance IPM motor } \\
\text { with field enhancement/weakening } \\
\text { 14. Complete evaluation of optimized HSUPM } \\
\text { motor achieving } 1 / 2 \text { size reduction of THII } \\
\text { Prius } \\
\text { 15. Complete build and evaluation HSUPM } \\
\text { motor/generator with integrated inverters } \\
\text { and thermal cooling system } \\
\text { 16. Complete jet impingement modeling tool } \\
\text { for single and two phase cooling systems } \\
\text { 17. Complete validation testing of floating loop } \\
\text { 18. Complete prototype inverter with low } \\
\text { resistance IGBT } \\
\text { 19. Complete system analysis and specifica- } \\
\text { tions for air-cooled inverter/motor } \\
\text { 20. Produce first generation of carbon nano- } \\
\text { tube TIM } \\
\text { 21. Complete analysis and modeling of jet } \\
\text { impingement with nano-particle enriched } \\
\text { fluids } \\
\text { 22. Produce first generation of carbon nano- } \\
\text { tube to replace solder for die connection } \\
\text { 23. Complete prototype air cooled system } \\
\text { 24. Complete prototype inverter using carbon } \\
\text { nano-tube heat spreaders, nano-particle } \\
\text { working fluids and carbon nano-tube die } \\
\text { joint }\end{array}$ & $\begin{array}{l}\text { 1. Integrated inverter/motor to meet } \\
\text { Freedom CAR goals to Vehicle Systems } \\
\text { Analysis } \\
\text { 2. Prototype internal PM motor to Vehicle } \\
\text { Systems Analysis } \\
\text { 3. Thermal-management system to Vehicle } \\
\text { Systems Analysis } \\
\text { Supporting Input } \\
\text { Suling cell performance characteristics from } \\
\text { 1. Fuel ciT }\end{array}$ \\
\hline
\end{tabular}

Figure 3.2-4. Network Chart for Advanced Power Electronics and Electric Machines 


\section{Exhibit F-4. Energy Storage Group Network Chart}

\section{Energy Storage Group Network Chart}

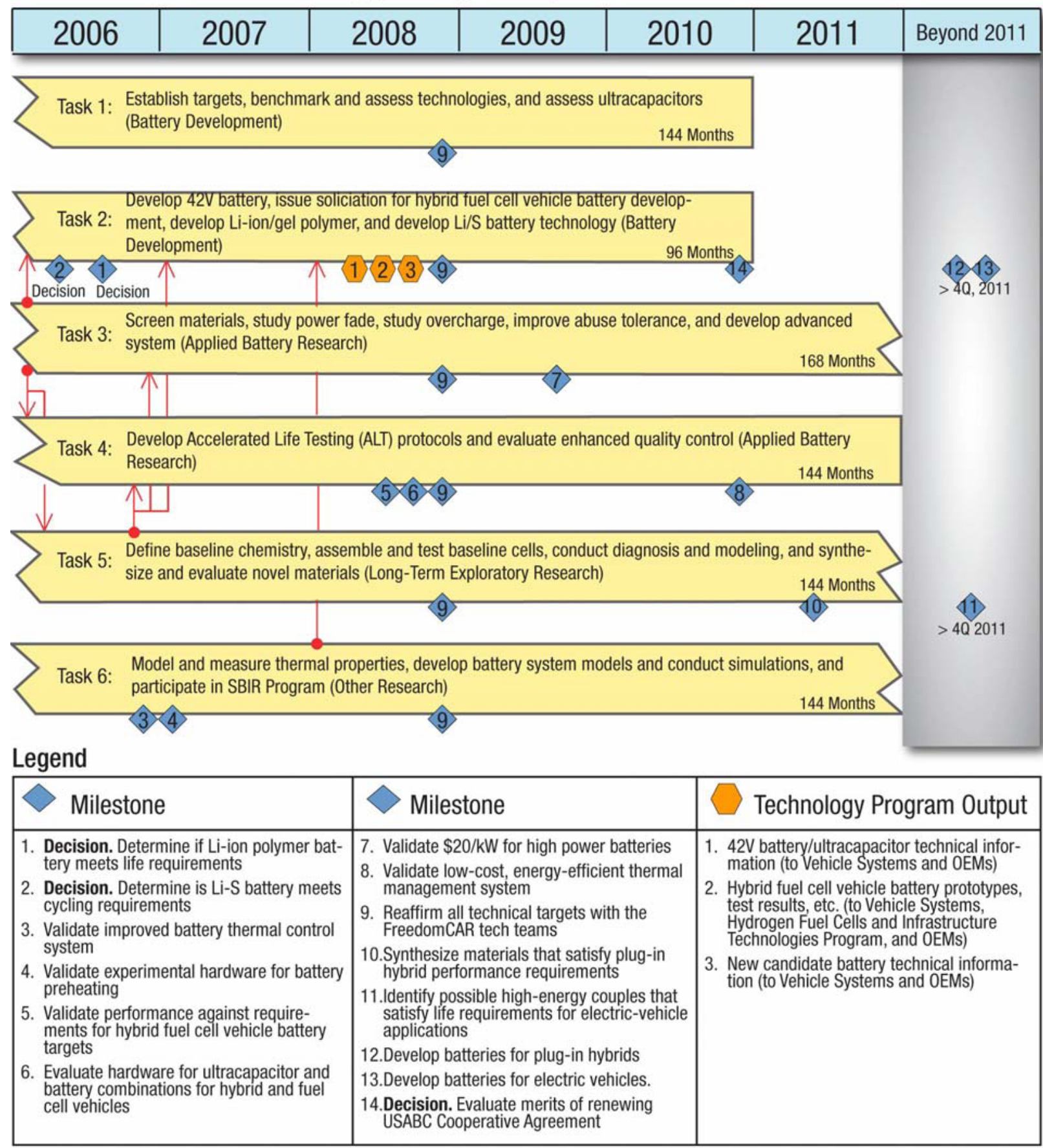




\section{Exhibit F-5. Advanced Power Electronics and Electric Machines Network Chart}

\section{Advanced Power Electronics and Electric Machines Network Chart}

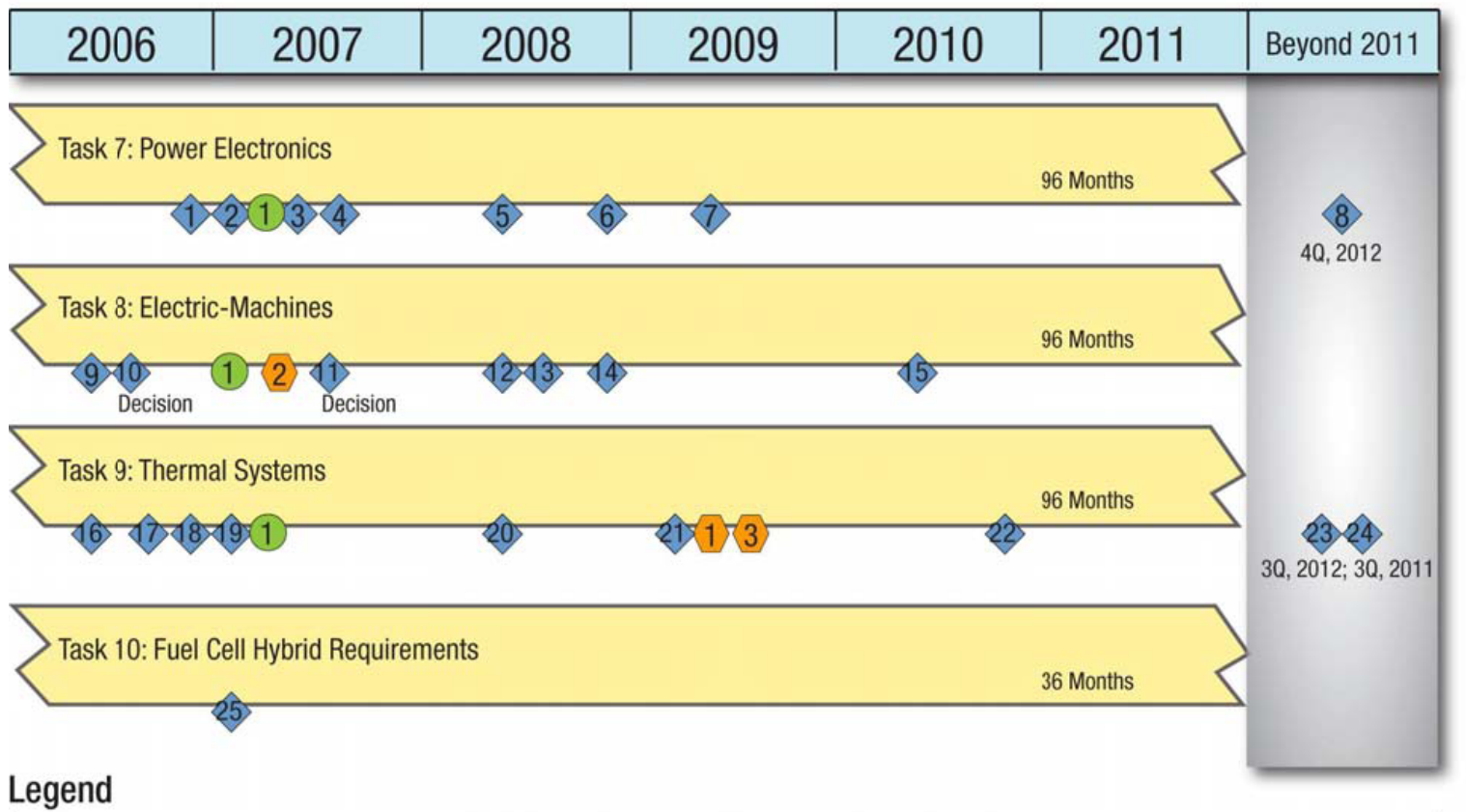

Legend

\begin{tabular}{|c|c|c|}
\hline$>$ Milestone & & Technology Program Output \\
\hline $\begin{array}{l}\text { 1. Receive Ballard DC/DC converter deliver- } \\
\text { ables for testing and evaluation } \\
\text { 2. Hardware delivery of high temperature } \\
\text { AlPM } \\
\text { 3. Completion of } 55 \mathrm{~kW} \mathrm{SiC} \text { inverter with high } \\
\text { temp packaging } \\
\text { 4. Validate improvements in inverter pack- } \\
\text { aging methods with dual inverter } \\
\text { 5. Receive high temp, high capacitance } \\
\text { improved capacitors for testing and evalu- } \\
\text { ation } \\
\text { 6. Completion of cascade inverter build and } \\
\text { test, resulting in inverter size reduction to } \\
\text { 1/3 of Semikron } 2005 \text { inverter } \\
\text { 7. Complete build and evaluation of high } \\
\text { temperature multilevel converter system } \\
\text { with bidirectional DC/DC converter and } \\
\text { 50kW inverter } \\
\text { 8. Complete build of optimized DC/DC con- } \\
\text { verter for use in FC vehicles } \\
\text { 9. Completion of Phase } 1 \text { of industrial motor } \\
\text { project } \\
\text { 10. Decision. Verify that developments in } \\
\text { field-weakening techniques help attain } \\
\text { technical targets for PM motors } \\
\text { 11. Decision. Validate contribution of devel- } \\
\text { opments in magnet materials to technical } \\
\text { targets for motors }\end{array}$ & $\begin{array}{l}\text { 12. Receive Industrial RFP awardee motor for } \\
\text { testing and evaluation } \\
\text { 13. Complete build and evaluation of high } \\
\text { speed (1500rpm) reluctance IPM motor } \\
\text { with field enhancement/weakening } \\
\text { 14. Complete evaluation of optimized HSUPM } \\
\text { motor achieving } 1 / 2 \text { size reduction of THII } \\
\text { Prius } \\
\text { 15. Complete build and evaluation HSUPM } \\
\text { motor/generator with integrated inverters } \\
\text { and thermal cooling system } \\
\text { 16. Complete jet impingement modeling tool } \\
\text { for single and two phase cooling systems } \\
\text { 17. Complete validation testing of floating loop } \\
\text { 18. Complete prototype inverter with low } \\
\text { resistance IGBT } \\
\text { 19. Complete system analysis and specifica- } \\
\text { tions for air-cooled inverter/motor } \\
\text { 20. Produce first generation of carbon nano- } \\
\text { tube TIM } \\
\text { 21. Complete analysis and modeling of jet } \\
\text { impingement with nano-particle enriched } \\
\text { fluids } \\
\text { 22. Produce first generation of carbon nano- } \\
\text { tube to replace solder for die connection } \\
\text { 23. Complete prototype air cooled system } \\
\text { 24. Complete prototype inverter using carbon } \\
\text { nano-tube heat spreaders, nano-particle } \\
\text { working fluids and carbon nano-tube die } \\
\text { joint }\end{array}$ & $\begin{array}{l}\text { 1. Integrated inverter/motor to meet } \\
\text { FreedomCAR goals to Vehicle Systems } \\
\text { Analysis } \\
\text { 2. Prototype internal PM motor to Vehicle } \\
\text { Systems Analysis } \\
\text { 3. Thermal-management system to Vehicle } \\
\text { Systems Analysis } \\
\text { Supporting Input } \\
\text { 1. Fuel cell performance characteristics from } \\
\text { HFCIT }\end{array}$ \\
\hline
\end{tabular}


Exhibit F-6. Automotive Lightweighting Materials Network Chart

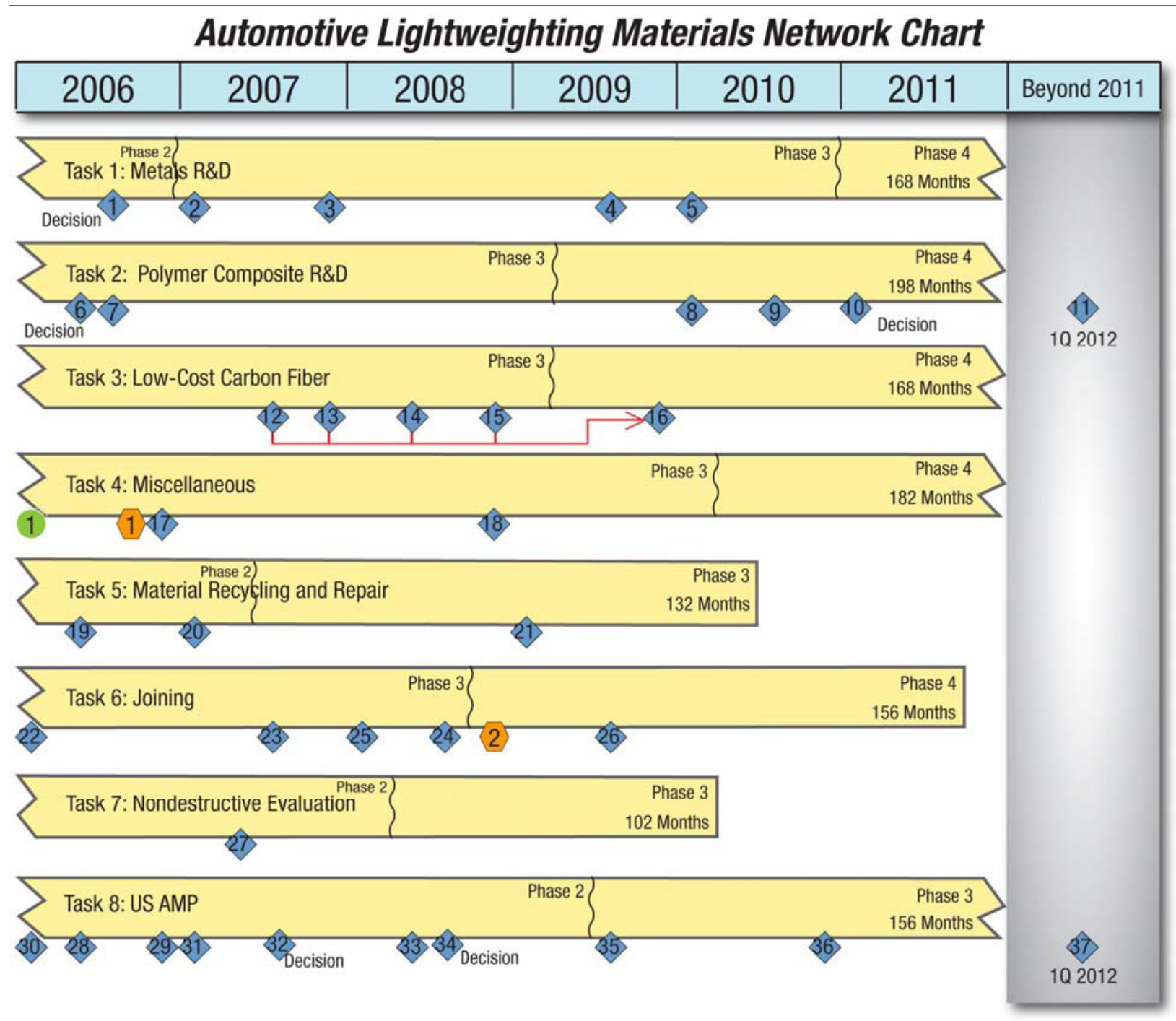




\section{Exhibit F-6 (continued). Automotive Lightweighting Materials Network Chart}

Legend

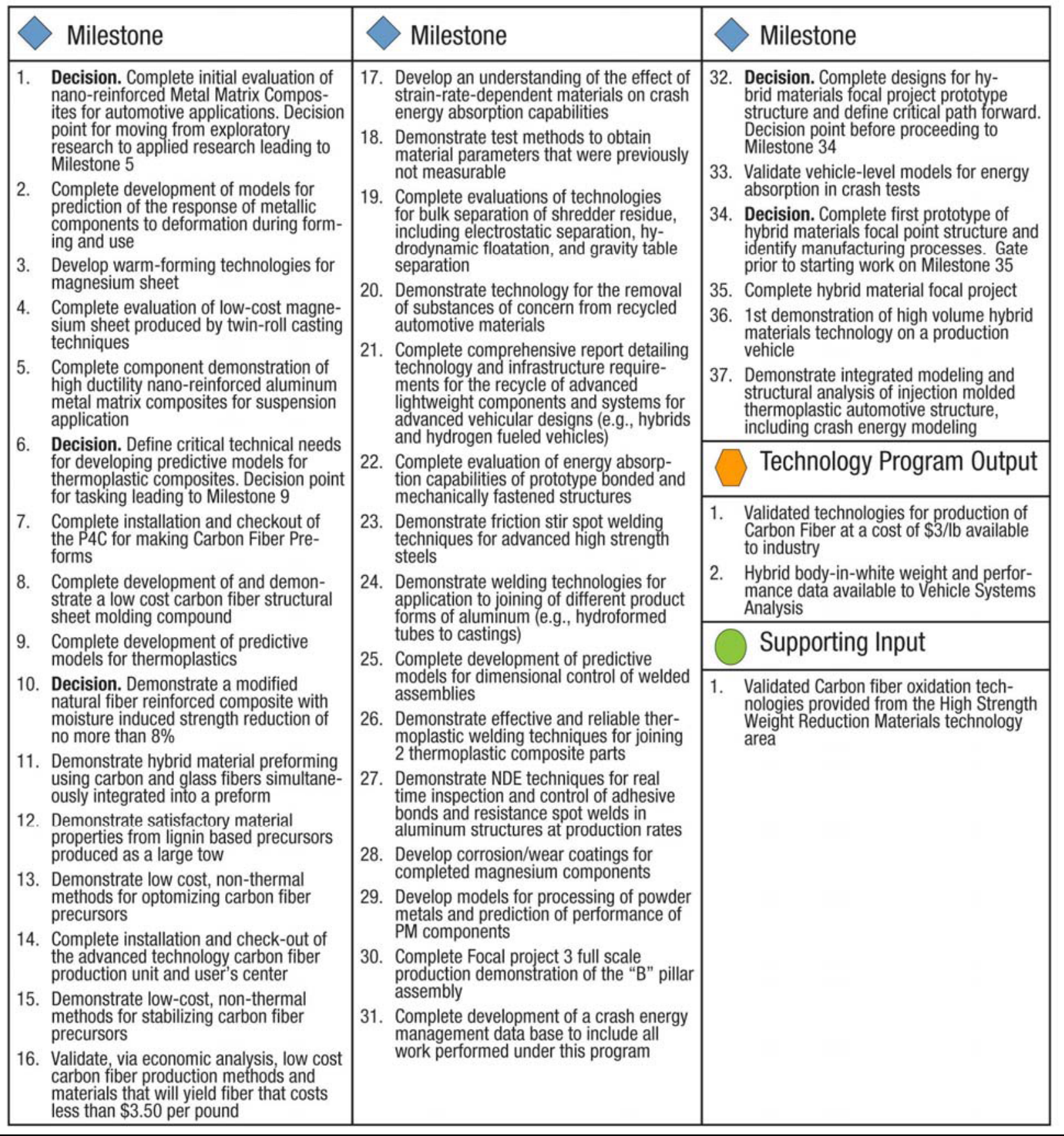

Projected Benefits of Federal Energy Efficiency and Renewable Energy Programs (FY 2006-FY 2050) Appendix F-FreedomCAR and Vehicle Technologies Program-Page F-15 
Exhibit F-7. High-Strength Weight Network Chart

\section{Hign Strength veignt Keauction Network Lnart}

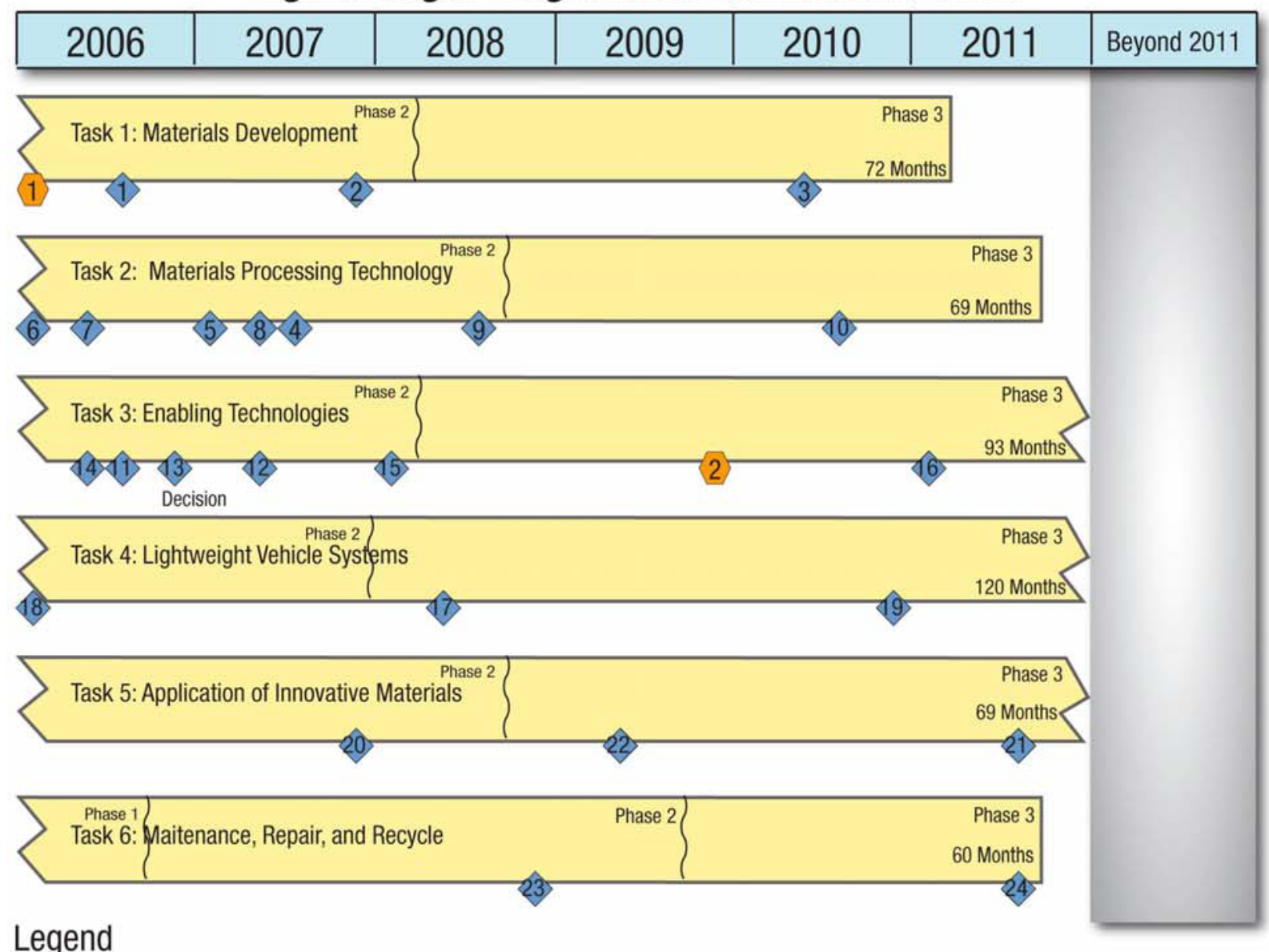

Legend

\section{Milestone}

1. Evaluate properties of magnesium metal matrix composites produced by various processing routes for application in heavy vehicle suspension components.

2. Evaluate performance of newly developed advanced braking materials in dynamometer tests

3. Evaluate the performance of polymer composite materials exposed to UV, weather extremes, and impact simulating long term road exposures

4. Complete fabrication of low-cost magnesium metal matrix composite component and initiate vehicle testing

5. Scale up processing technologies for production of formable $\mathrm{Mg}$ alloy sheet and validate performance on prototype components

6. Demonstrate continuous production of aluminum connecting rod with improved mechanical properties using advanced casting process

7. Evaluate durability of prototype superplastically formed aluminum components with road tests on full-size heavy vehicle

8. Manufacture full size leaf springs for heavy vehicle using low-cost titanium powders and advanced processing techniques

9. Demonstrate cost effective production of full-scale magnesium metal matrix composite components for heavy vehicle applications

\section{Milestone}

10. Evaluate performance of large, thin-wall drivetrain castings produced by advanced castings technologies

11.Validate friction stir processing process models using instrumented process samples and mechanical property test results

12.Demonstrate cost-effective rapid friction stir process foe joining lightweight, high strength materials in different product forms

13.Decision. Demonstrate ability of microstructural level simulation model to predict the response of a 1500 series steel during machining of heavy vehicle component

14.Demonstrate newly developed attachment techniques for carbon fiber composite heavy truck cross-members on full-size frame

15. Complete Friction Stir Welding trails on prototype assembly containing a combination of aluminum product forms (casting, extrusion, sheet)

16.Complete design guidelines for joints in hybrid materials structures

17. Complete design for hybrid materials focal project for Class 8 vehicles

18. Complete construction of prototype tanker trailer demonstrating $20 \%$ weight reduction

19. Demonstrate acceptable performance of prototype hybrid materials focal project structure with vehicle tests

\section{Milestone}

20. Complete validation tests on polymer composite lateral cross members on full size Class 8 vehicle

21. Complete validation testing of full scale prototype aluminum foam cab component for Class 8 vehicles

22.Evaluate properties of high strength, light weight materials strengthened by nanosize structures

23.Complete lab-scale demonstration of recycling process for metal matrix composites.

24. Complete development of field deployable system for early detection of component degradation to allow for preventive maintenance and begin vehicle testing.

\section{Technology Program Output}

1. Validated carbon fiber oxidation technologies provided to the Automotive Lightweighting materials technology areas

2. Composite of dissimiliar joining technologies available to industry 


\section{Translating Program Outputs to Market Outcomes}

The target market is light vehicles (cars and light trucks). Light vehicles are purchased by buyers who vary from one another with respect to driving patterns, number of miles driven each year, and the need for vehicle attributes such as towing, number of seats, and interior volume. Buyers also differ with respect to their desire for acceleration, safety, range, and fuel economy. Thus, there are many vehicle attributes that compete with fuel economy when buyers choose their new vehicles.

The program outputs are vehicle components with their associated efficiencies and costs. These technology components are then placed into new vehicles produced by the manufacturers. How well these advanced vehicles sell in the marketplace is a function of many variables such as: incremental cost when first introduced (which can be affected by company pricing decisions and government incentives and regulations), which model they're introduced in first, the overall fuel efficiency of the advanced vehicle (taking into account any performance changes in the vehicle), and fuel prices.

\section{Key Factors in Shaping Market Adoption of EERE technologies}

As noted above, key factors associated with the adoption of new vehicle technologies include how the new vehicle technologies compare with the baseline vehicle technologies in terms of the following vehicle attributes:

- Vehicle Price

- Fuel Economy

- Range

- Maintenance Cost

- Acceleration

- Top Speed

- Luggage Space.

Of these, vehicle price and fuel economy are the most important. The average buyer is likely to want a three-year payback: i.e., the incremental vehicle cost of the new vehicle technology should be no higher than the fuel savings achieved in three years of vehicle use. The three-year payback assumption was taken from the 2002 CAFE study by the National Academy of Sciences (Ref 4 ). In addition, the consumer's actions can be significantly affected by the following nonvehicle attributes:

- Fuel Price

- Fuel Availability.

Also important are manufacturing and policy factors. For example, manufacturers have not shown much interest in producing PHEVs, which is obviously a barrier to market adoption that needs to be overcome. Alternatively, the Department of Transportation increased light-truck CAFE standards slightly for Model Year 2008-2011. This means that technologies that improve 
the fuel economies of light trucks will be adopted in the baseline case.

(http://www.nhtsa.dot.gov/portal/site/nhtsa/menuitem.43ac99aefa80569eea57529cdba046a0/).

\section{Discussion of Inputs}

\section{Alternate Technology Light Vehicle (ATV) Market}

The alternate technology light vehicles (ATVs) included in the FCVT Program are: gasoline hybrid vehicles, diesel hybrid vehicles, plug-in hybrid vehicles (PHEVs), advanced diesel, and advanced gasoline vehicles. The market for these technologies includes all cars and light trucks sold for both personal and business use. In the current market, annual new vehicle sales are approximately 17 million. The stock of cars and light trucks is about 230 million vehicles. EIA projects both sales and stock to grow to more than 21 million and 330 million respectively by 2030 (EIA-AEO2006). Additional growth is expected post-2030, as explained in Chapter 2 of EERE GPRA Benefits documentation for the FY 2008 budget request and in the appendix describing the long-term modeling.

\section{Methodology and Calculations}

The factors listed above are used in the modeling of new vehicle technology penetration by the NEMS and MARKet ALlocation (MARKAL) models. ATV attributes and other factors are discussed below.

\section{ATV Attributes: General}

ATV attributes were developed based on the FCVT program goals, discussions with FCVT program managers, Powertrain Systems Analysis Toolkit (PSAT) modeling, payback analysis, and review of past GPRA characterizations (Argonne National Laboratory PSAT; Sharer 2005; Rousseau 2005; Moore 2003; Office of Transportation Technologies 2002). The simulation model PSAT was used to evaluate the fuel economy and performance of light vehicles using various technologies. Payback analysis was used to estimate what the incremental price of ATVs would be (given the fuel economies from the PSAT model) when they become cost-competitive with conventional vehicles. It is assumed that the incremental price for new light-vehicle technologies will equal that value at which a three-year payback would be achieved. The price estimates are described in further detail below. Other attributes were based on a review of past GPRA characterizations and discussions with FCVT program managers.

Because the NEMS and MARKAL models require different levels of detail, FCVT provided two separate vehicle characterizations. In both cases, most of the ATV attributes were characterized as ratios to the attributes of conventional vehicles. For NEMS, the dollar value of the price increments were provided. The attributes are for new vehicles in the year listed. In Table F-3, attributes are provided for all six car classes and six light-truck classes that NEMS uses.

In Table F-4, MARKAL input consists of vehicle prices and fuel economy attributes for two aggregate categories, cars and light trucks. Unlike NEMS, MARKAL does not disaggregate these categories into various classes. 
Table F-3. ATV Attributes Input to NEMS

(All units are ratios to the conventional gasoline vehicles of the specific year, except for the incremental prices.) (Shown in 2004 dollars.)

\begin{tabular}{|c|c|c|c|c|c|c|c|c|c|c|c|c|c|c|c|}
\hline & \multicolumn{5}{|c|}{ 2-SEATER } & \multicolumn{5}{|c|}{ MINI-COMPACT } & \multicolumn{5}{|c|}{ SUB-COMPACT } \\
\hline & Market & $\begin{array}{c}\text { Price } \\
\text { Puccess }\end{array}$ & Price & & & Market & Price & $\begin{array}{l}\text { Price } \\
\text { Mature }\end{array}$ & & & Market & Price & Price & & \\
\hline & $\begin{array}{l}\text { Intro. } \\
2014\end{array}$ & $\begin{array}{c}\text { Success } \\
\mathbf{2 0 1 9}\end{array}$ & $\begin{array}{c}\text { Mature } \\
\mathbf{2 0 2 4}\end{array}$ & $\begin{array}{l}2025 \\
\mathbf{2 0 2 5}\end{array}$ & $\begin{array}{l}2030 \\
\mathbf{2 0 3 0}\end{array}$ & $\begin{array}{l}\text { Intro. } \\
2018\end{array}$ & $\begin{array}{c}\text { Success } \\
\mathbf{2 0 2 3}\end{array}$ & $\begin{array}{c}\text { Mature } \\
\mathbf{2 0 2 8}\end{array}$ & $\begin{array}{l}2025 \\
\mathbf{2 0 2 5}\end{array}$ & $\begin{array}{l}2030 \\
\mathbf{2 0 3 0}\end{array}$ & $\begin{array}{l}\text { Intro. } \\
2012\end{array}$ & $\begin{array}{c}\text { Success } \\
2017\end{array}$ & $\begin{array}{c}\text { Mature } \\
\mathbf{2 0 2 2}\end{array}$ & $\begin{array}{l}2025 \\
\mathbf{2 0 2 5}\end{array}$ & $\begin{array}{l}2030 \\
\mathbf{2 0 3 0}\end{array}$ \\
\hline Incremental Vehicle Price (\$) & 1577 & 1249 & 1124 & 1120 & 1164 & 1554 & 1152 & 1068 & 1104 & 1086 & 1290 & 1028 & 956 & 945 & 981 \\
\hline Range & 1.20 & 1.20 & 1.20 & 1.20 & 1.20 & 1.20 & 1.20 & 1.20 & 1.20 & 1.20 & 1.20 & 1.20 & 1.20 & 1.20 & 1.20 \\
\hline Maintenance Cost & 1.00 & 0.90 & 0.90 & 0.90 & 0.90 & 0.90 & 0.90 & 0.90 & 0.90 & 0.90 & 0.90 & 0.90 & 0.90 & 0.90 & 0.90 \\
\hline Acceleration & 1.00 & 1.00 & 1.00 & 1.00 & 1.00 & 1.00 & 1.00 & 1.00 & 1.00 & 1.00 & 1.00 & 1.00 & 1.00 & 1.00 & 1.00 \\
\hline Top Speed & 1.00 & 1.00 & 1.00 & 1.00 & 1.00 & 1.00 & 1.00 & 1.00 & 1.00 & 1.00 & 1.00 & 1.00 & 1.00 & 1.00 & 1.00 \\
\hline Luggage Space & 1.00 & 1.00 & 1.00 & 1.00 & 1.00 & 1.00 & 1.00 & 1.00 & 1.00 & 1.00 & 1.00 & 1.00 & 1.00 & 1.00 & 1.00 \\
\hline Fuel Economy & 1.33 & 1.39 & 1.40 & 1.40 & 1.43 & 1.38 & 1.40 & 1.42 & 1.40 & 1.43 & 1.31 & 1.36 & 1.40 & 1.40 & 1.43 \\
\hline Diesel Hybrid & 2016 & 2021 & 2026 & 2025 & 2030 & 2020 & 2025 & 2030 & 2025 & 2030 & 2016 & 2021 & 2026 & 2025 & 2030 \\
\hline Incremental Vehicle Price (\$) & 2396 & 1844 & 1648 & 1677 & 1673 & 2350 & 1682 & 1562 & 1682 & 1562 & 2031 & 1559 & 1392 & 1415 & 1410 \\
\hline Range & 1.25 & 1.25 & 1.25 & 1.25 & 1.25 & 1.25 & 1.25 & 1.25 & 1.25 & 1.25 & 1.25 & 1.25 & 1.25 & 1.25 & 1.25 \\
\hline Maintenance Cost & 1.05 & 1.05 & 1.05 & 1.05 & 1.05 & 1.05 & 1.05 & 1.05 & 1.05 & 1.05 & 1.05 & 1.05 & 1.05 & 1.05 & 1.05 \\
\hline Acceleration & 1.00 & 1.00 & 1.00 & 1.00 & 1.00 & 0.90 & 0.90 & 0.90 & 0.90 & 0.90 & 0.90 & 0.90 & 0.90 & 0.90 & 0.90 \\
\hline Top Speed & 1.00 & 1.00 & 1.00 & 1.00 & 1.00 & 0.90 & 0.90 & 0.90 & 0.90 & 0.90 & 0.90 & 0.90 & 0.90 & 0.90 & 0.90 \\
\hline Luggage Space & 0.95 & 0.95 & 0.95 & 0.95 & 0.95 & 0.95 & 0.95 & 0.95 & 0.95 & 0.95 & 0.95 & 0.95 & 0.95 & 0.95 & 0.95 \\
\hline Fuel Economy & 1.66 & 1.76 & 1.77 & 1.76 & 1.80 & 1.76 & 1.76 & 1.80 & 1.76 & 1.80 & 1.66 & 1.76 & 1.77 & 1.76 & 1.80 \\
\hline Gasoline Hybrid & 2013 & 2018 & 2023 & 2025 & 2030 & 2011 & 2016 & 2021 & 2025 & 2030 & 2010 & 2014 & 2019 & 2025 & 2030 \\
\hline Incremental Vehicle Price (\$) & 1613 & 1361 & 1266 & 1257 & 1297 & 1378 & 1196 & 1188 & 1169 & 1211 & 1222 & 1036 & 1070 & 1061 & 1093 \\
\hline Range & 1.25 & 1.25 & 1.25 & 1.25 & 1.25 & 1.25 & 1.25 & 1.25 & 1.25 & 1.25 & 1.25 & 1.25 & 1.25 & 1.25 & 1.25 \\
\hline Maintenance Cost & 1.05 & 1.05 & 1.05 & 1.05 & 1.05 & 1.05 & 1.05 & 1.05 & 1.05 & 1.05 & 1.05 & 1.05 & 1.05 & 1.05 & 1.05 \\
\hline Acceleration & 1.00 & 1.00 & 1.00 & 1.00 & 1.00 & 1.00 & 1.00 & 1.00 & 1.00 & 1.00 & 1.00 & 1.00 & 1.00 & 1.00 & 1.00 \\
\hline Top Speed & 1.00 & 1.00 & 1.00 & 1.00 & 1.00 & 0.90 & 0.90 & 0.90 & 0.90 & 0.90 & 0.90 & 0.90 & 0.90 & 0.90 & 0.90 \\
\hline Luggage Space & 0.95 & 0.95 & 0.95 & 0.95 & 0.95 & 0.95 & 0.95 & 0.95 & 0.95 & 0.95 & 0.95 & 0.95 & 0.95 & 0.95 & 0.95 \\
\hline Fuel Economy & 1.37 & 1.47 & 1.52 & 1.52 & 1.55 & 1.33 & 1.43 & 1.52 & 1.52 & 1.55 & 1.31 & 1.39 & 1.50 & 1.52 & 1.55 \\
\hline
\end{tabular}


Table F-3 (continued)

\begin{tabular}{|c|c|c|c|c|c|c|c|c|c|c|c|c|c|c|c|}
\hline & \multicolumn{5}{|c|}{ 2-SEATER } & \multicolumn{5}{|c|}{ MINI-COMPACT } & \multicolumn{5}{|c|}{ SUB-COMPACT } \\
\hline & $\begin{array}{l}\text { Market } \\
\text { Intro. }\end{array}$ & $\begin{array}{c}\text { Price } \\
\text { Success }\end{array}$ & $\begin{array}{l}\text { Price } \\
\text { Mature }\end{array}$ & 2025 & 2030 & $\begin{array}{c}\text { Market } \\
\text { Intro. }\end{array}$ & $\begin{array}{c}\text { Price } \\
\text { Success }\end{array}$ & $\begin{array}{l}\text { Price } \\
\text { Mature }\end{array}$ & 2025 & 2030 & $\begin{array}{l}\text { Market } \\
\text { Intro. }\end{array}$ & $\begin{array}{c}\text { Price } \\
\text { Success }\end{array}$ & $\begin{array}{l}\text { Price } \\
\text { Mature }\end{array}$ & 2025 & 2030 \\
\hline Plug-in HEV 40 & 2024 & 2029 & 2034 & 2025 & 2030 & 2024 & 2029 & 2034 & 2025 & 2030 & 2024 & 2029 & 2034 & 2025 & 2030 \\
\hline Incremental Vehicle Price (\$) & 2900 & 2128 & 1938 & 2733 & 1938 & 2667 & 1966 & 1791 & 2515 & 1791 & 2384 & 1747 & 1591 & 2246 & 1591 \\
\hline Range & 1.10 & 1.10 & & 1.10 & 1.10 & 1.10 & 1.10 & & 1.10 & 1.10 & 1.10 & 1.10 & & 1.10 & 1.10 \\
\hline Maintenance Cost & 1.05 & 1.04 & & 1.05 & 1.03 & 1.05 & 1.04 & & 1.05 & 1.04 & 1.05 & 1.04 & & 1.05 & 1.04 \\
\hline Acceleration & 1.00 & 1.00 & & 1.00 & 1.00 & 1.00 & 1.00 & & 1.00 & 1.00 & 1.00 & 1.00 & & 1.00 & 1.00 \\
\hline Top Speed & 1.00 & 1.00 & & 1.00 & 1.00 & 1.00 & 1.00 & & 1.00 & 1.00 & 1.00 & 1.00 & & 1.00 & 1.00 \\
\hline Luggage Space & 1.00 & 1.00 & & 1.00 & 1.00 & 1.00 & 1.00 & & 1.00 & 1.00 & 1.00 & 1.00 & & 1.00 & 1.00 \\
\hline Fuel Economy & 1.49 & 1.51 & 1.52 & 1.49 & 1.52 & 1.49 & 1.51 & 1.52 & 1.49 & 1.52 & 1.49 & 1.51 & 1.52 & 1.49 & 1.52 \\
\hline
\end{tabular}




\section{Table F-3 (continued)}

\section{COMPACT}

Market Price Price

Intro. Success Mature

$20112016 \quad 2021$

Advanced Diesel

Incremental Vehicle Price

(\$)

Range

Maintenance Cost

Acceleration

Top Speed

Luggage Space

Fuel Economy

Diesel Hybrid

Incremental Vehicle Price

(\$)

Range

Maintenance Cost

Acceleration

Top Speed

Luggage Space

Fuel Economy

Gasoline Hybrid

Incremental Vehicle Price

(\$)

Range

Maintenance Cost

Acceleration

Top Speed

Luggage Space

Fuel Economy

$1151 \quad 933$

$1.20 \quad 1.20$

$\begin{array}{lll}0.90 & 0.90 & 0.90\end{array}$

$\begin{array}{lll}1.00 & 1.00 \quad 1.00\end{array}$

$\begin{array}{lll}1.00 & 1.00 \quad 1.00\end{array}$

$1.00 \quad 1.00 \quad 1.00$

$\begin{array}{lll}1.30 & 1.35 & 1.40\end{array}$

2014

1801

1.25

1.05

0.90

0.90

0.95

$1.60 \quad 1.73$

1.73

20

1183

1.25

1.05

1.00

0.90

$\begin{array}{ll}0.95 & 0.95\end{array}$

$1.31 \quad 1.35$

\section{MEDIUM CAR}

Market Price Price

Intro. Success Mature

20252030

885

1.20

0.90

1.00

$1.00 \quad 1.00$

1.40

1.43

2025

2030

2014

2089

1.25

1.05

0.90

0.90

0.95

1.61

0.95
1.76

1.76

1410

1.25

1.05

1.00

0.90

0.85

1.32

0.95

1.45
$1.00 \quad 1.00$

$1.05 \quad 1.05$

$0.90 \quad 0.90$

$0.90 \quad 0.90$

$0.95 \quad 0.95$

$1003 \quad 1061$

$1.25 \quad 1.25$

$1.05 \quad 1.05$

$0.90 \quad 0.90$

$\begin{array}{ll}0.90 & 0.90 \\ 0.95 & 0.95\end{array}$

\section{LARGE CAR}

Market Price Price

Intro. Success Mature 20252030

$\begin{array}{lllll}2009 & 2014 & 2019 & 2025 & 2030\end{array}$

$\begin{array}{lllll}1477 & 1129 & 1092 & 1072 & 1108\end{array}$

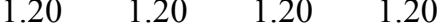

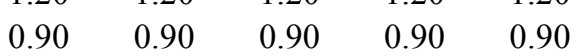

$\begin{array}{lllll}1.00 & 1.00 & 1.00 & 1.00 & 1.00\end{array}$

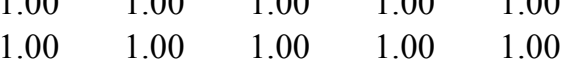

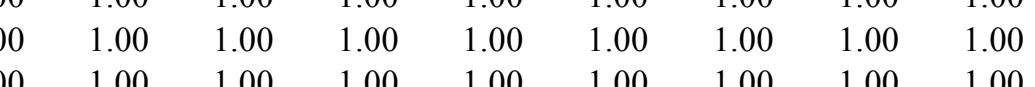

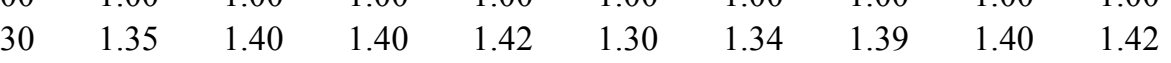

$2019 \quad 2024 \quad 2025$

$\begin{array}{llll}1648 & 1482 & 1478 & 1504\end{array}$

201

$2025 \quad 2030$

$\begin{array}{llll}1.25 & 1.25 & 1.25 & 1.25\end{array}$

1.05

0.90

1.05

2247

1769

1583

1.25

1.05

$1.05 \quad 1.05$

$0.90 \quad 0.90$

0.90

0.90

0.95

1.76

$\begin{array}{llll}1.73 & 1.76 & 1.76 & 1.79\end{array}$

2019

20252030

1128

1453

1190

1217

1205

$1.25 \quad 1.25$

$1.05 \quad 1.05$

1.25

1.05

$\begin{array}{lllll}0.90 & 0.90 & 0.90 & 0.90 & 0.90\end{array}$

$0.90 \quad 0.90$

0.90
1.00

1.00
0.85

0.90

0.95

1.25

1.05

0.90

0.90

0.95

1.49

0.90

$\begin{array}{ll}1.51 & 1.54\end{array}$ 


\section{Table F-3 (continued)}

\section{COMPACT}

Market Price Price

Intro. Success Mature

2020

Plug-in HEV 40

Incremental Vehicle Price

(\$)

Range

Maintenance Cost

Acceleration

Top Speed

Luggage Space

Fuel Economy

$2256 \quad 1611 \quad 1480$

$\begin{array}{lll}1.10 & 1.10 & 1.10\end{array}$

$\begin{array}{lll}1.10 & 1.05 & 1.03\end{array}$

$\begin{array}{lll}1.00 & 1.00 \quad 1.00\end{array}$

$\begin{array}{lll}0.95 & 1.00 \quad 1.00\end{array}$

$\begin{array}{lll}0.90 & 1.00 \quad 1.00\end{array}$

$\begin{array}{lll}1.49 & 1.49 \quad 1.52\end{array}$

\section{MEDIUM CAR}

Market Price Price

Intro. Success Mature 2025

$2021 \quad 2026 \quad 2031$

2025

$1848 \quad 2174$

$\begin{array}{lllllll}1611 & 1480 & 2628 & 1883 & 1717 & 1844 & 1720 \\ 1.10 & 1.10 & 1.10 & 1.10 & 1.10 & 1.10 & 1.10\end{array}$

$2830 \quad 2026$

$1.10 \quad 1.10$

$\begin{array}{llll}1.05 & 1.03 & 1.10 & 1.05 \\ 1.00 & 1.00 & 1.00 & 1.00\end{array}$

$\begin{array}{lllllll}1.05 & 1.03 & 1.10 & 1.06 & 1.04 & 1.05 & 1.03\end{array}$

$1.00 \quad 1.00$

$1.00 \quad 1.00$

$1.00 \quad 1.00$

$1.00 \quad 1.00$

$0.95 \quad 1.00$

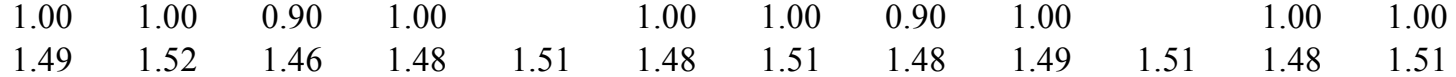

$1.10-1.10$

$1.00 \quad 1.00$ 


\section{Table F-3 (continued)}

SMALL SUV

Intro. Success Mature 2025

$\begin{array}{llll}2008 & 2013 & 2018 & 2025\end{array}$

Advanced Diesel

Incremental Vehicle Price

(\$)

Range

Maintenance Cost

Acceleration

Top Speed

Luggage Space

Fuel Economy

\section{Diesel Hybrid}

ncremental Vehicle Price

Range

Maintenance Cost

Acceleration

Top Speed

Luggage Space

Fuel Economy

Gasoline Hybrid

Incremental Vehicle Price

(\$)

Range

Maintenance Cost

Acceleration

Top Speed

Luggage Space

Fuel Economy

$\begin{array}{llll}2912 & 2027 & 1788 & 1754\end{array}$

$\begin{array}{lll}1.20 & 1.20 & 1.20\end{array}$

$\begin{array}{lll}0.90 & 0.90 & 0.90\end{array}$

$\begin{array}{lll}1.00 & 1.00 \quad 1.00\end{array}$

$\begin{array}{lll}1.00 & 1.00 \quad 1.00\end{array}$

$\begin{array}{lll}1.00 & 1.00 \quad 1.00\end{array}$

$\begin{array}{lll}1.78 & 1.77 \quad 1.76\end{array}$

$20112016 \quad 2021$

$3181 \quad 2330 \quad 2101$

$\begin{array}{lll}1.20 & 1.20 & 1.20\end{array}$

$\begin{array}{lll}1.05 & 1.05 & 1.05\end{array}$

$\begin{array}{lll}1.00 & 1.00 \quad 1.00\end{array}$

$\begin{array}{lll}1.00 & 1.00 & 1.00 \\ 2.02 & 2.05 & 2.08\end{array}$

$2007 \quad 2012 \quad 2017$

$2817 \quad 1994 \quad 1840$

$\begin{array}{lll}1.25 & 1.25 & 1.25\end{array}$

$\begin{array}{lll}1.05 & 1.05 & 1.05\end{array}$

$\begin{array}{lll}0.90 & 0.90 & 0.90\end{array}$

$\begin{array}{lll}1.00 & 1.00 \quad 1.00\end{array}$

$\begin{array}{lll}1.00 & 1.00 & 1.00 \\ 1.77 & 1.79 & 1.84\end{array}$
LARGE SUV

Market Price Price

Intro. Success Mature 2025

$2017 \quad 2025$

$\begin{array}{lll}0.90 & 0.90 \quad 0.90\end{array}$

$0.90 \quad 0.90$

$1.00 \quad 1.00 \quad 1.00$

$0.90 \quad 0.90$

$1.00 \quad 1.00$

$1.00 \quad 1.00$

$\begin{array}{lllllll}1.00 & 1.00 & 1.00 & 1.00 & 1.00 & 1.00 & 1.00\end{array}$

$1.79 \quad 1.85$

$1.78 \quad 1.78$

1.76

\section{0}

2025

$2077 \quad 2110$

$1.20 \quad 1.20$

$1.05 \quad 1.05$

$0.90 \quad 0.90$

38992835

$\begin{array}{ll}1.20 & 1.20 \\ 1.05 & 1.05\end{array}$

$1.05 \quad 1.05$

$0.90 \quad 0.90$

$\begin{array}{lllllll}1.00 & 1.00 & 1.00 & 1.00 & 1.00 & 1.00 & 1.00\end{array}$

$1.00 \quad 1.00$

$1.00 \quad 1.00$

$\begin{array}{ll}1.00 & 1.00 \\ 1.00 & 1.00\end{array}$

$2.12 \quad 2.19 \quad 2.04$

2.12

\section{$2008-2013$}

$1834 \quad 1878$

$3414 \quad 2453$

$1.25 \quad 1.25$

$1.05 \quad 1.05$

$1.25 \quad 1.25$

$2260 \quad 2252$

$\begin{array}{lllllll}1.25 & 1.25 & 1.25 & 1.25 & 1.25 & 1.25 & 1.25 \\ 1.05 & 1.05 & 1.05 & 1.05 & 1.05 & 1.05 & 1.05\end{array}$

$\begin{array}{llll}0.90 & 0.90 & 0.90 & 0.90\end{array}$

$\begin{array}{lllllll}1.00 & 1.00 & 1.00 & 1.00 & 1.00 & 1.00 & 1.00 \\ 1.00 & 1.00 & 1.00 & 1.00 & 1.00 & 1.00 & 1.00\end{array}$

$1.00 \quad 1.00$

$\begin{array}{lll}1.77 & 1.80 \quad 1.85\end{array}$

$1.79 \quad 1.85$

$2025 \quad 2030$

$\begin{array}{lll}1.20 & 1.20 & 1.20\end{array}$

$\begin{array}{lll}1.05 & 1.05 \quad 1.05\end{array}$

$\begin{array}{lll}1.05 & 1.05 & 1.05 \\ 0.90 & 0.90 & 0.90\end{array}$

$2.12 \quad 2.19$

\section{$2018 \quad 2025 \quad 203$}

$1.25-1.25 \quad 2300$

$\begin{array}{lll}0.90 & 0.90 \quad 0.90\end{array}$

$\begin{array}{lll}1.00 & 1.00 \quad 1.00\end{array}$

$1.91 \quad 1.97$

\begin{tabular}{ccccc}
\multicolumn{5}{c}{ SMALL TRUCK } \\
Market & Price & Price & & \\
Intro. & Success & Mature & 2025 & 2030 \\
$\mathbf{2 0 0 8}$ & $\mathbf{2 0 1 3}$ & $\mathbf{2 0 1 8}$ & $\mathbf{2 0 2 5}$ & $\mathbf{2 0 3 0}$ \\
& & & & \\
1918 & 1452 & 1427 & 1476 & 1537 \\
1.20 & 1.20 & 1.20 & 1.20 & 1.20 \\
0.90 & 0.90 & 0.90 & 0.90 & 0.90 \\
1.00 & 1.00 & 1.00 & 1.00 & 1.00 \\
1.00 & 1.00 & 1.00 & 1.00 & 1.00 \\
1.00 & 1.00 & 1.00 & 1.00 & 1.00 \\
1.43 & 1.48 & 1.57 & 1.63 & 1.69 \\
& & & & \\
$\mathbf{2 0 1 2}$ & $\mathbf{2 0 1 7}$ & $\mathbf{2 0 2 2}$ & $\mathbf{2 0 2 5}$ & $\mathbf{2 0 3 0}$ \\
& & & & \\
2723 & 2044 & 1878 & 1871 & 1913 \\
0.90 & 0.90 & 0.90 & 0.90 & 0.90 \\
1.05 & 1.05 & 1.05 & 1.05 & 1.05 \\
0.90 & 0.90 & 0.90 & 0.90 & 0.90 \\
0.90 & 0.90 & 0.90 & 0.90 & 0.90 \\
0.80 & 0.90 & 0.90 & 0.90 & 0.90 \\
1.84 & 1.91 & 1.97 & 1.99 & 2.06 \\
& & & & \\
$\mathbf{2 0 1 0}$ & $\mathbf{2 0 1 5}$ & $\mathbf{2 0 2 0}$ & $\mathbf{2 0 2 5}$ & $\mathbf{2 0 3 0}$ \\
& & & & \\
2060 & 1631 & 1574 & 1580 & 1636 \\
1.25 & 1.25 & 1.25 & 1.25 & 1.25 \\
1.05 & 1.05 & 1.05 & 1.05 & 1.05 \\
0.90 & 0.90 & 0.90 & 0.90 & 0.90 \\
0.90 & 0.90 & 0.90 & 0.90 & 0.90 \\
0.80 & 0.95 & 1.00 & 1.00 & 1.00 \\
1.55 & 1.63 & 1.72 & 1.76 & 1.82
\end{tabular}




\section{Table F-3 (continued)}

SMALL SUV

Market Price Price

Intro. Success Mature 2025

Plug-in HEV 40

Incremental Vehicle Price

(\$)

Range

Maintenance Cost

Acceleration

Top Speed

Luggage Space

Fuel Economy
201

$\begin{array}{lllll}3493 & 2507 & 2264 & 2396 & 2269\end{array}$

$\begin{array}{lllll}1.10 & 1.10 & 1.10 & 1.10 & 1.10\end{array}$

$\begin{array}{lllll}1.10 & 1.05 & 1.04 & 1.05 & 1.03\end{array}$

$\begin{array}{lllll}1.00 & 1.00 & 1.00 & 1.00 & 1.00\end{array}$

$0.95 \quad 1.00$

$0.90 \quad 1.0$

$\begin{array}{llll}1.81 & 1.85 & 1.91 & 1.87\end{array}$

1.00
LARGE SUV

Market Price Price

Intro. Success Mature 2025 2030

$\begin{array}{lllll}2020 & 2025 & 2030 & 2025 & 2030\end{array}$

2858

$\begin{array}{lllll}4376 & 3142 & 2858 & 3142 & 2858\end{array}$

$\begin{array}{lll}1.10 & 1.10 & 1.10\end{array}$

$\begin{array}{lll}1.10 & 1.05 & 1.03\end{array}$

1.10

1.05

$1.00 \quad 1.00$

$1.00 \quad 1.00$

$1.00 \quad 1.00$

$\begin{array}{lllll}1.83 & 1.87 & 1.94 & 1.87 & 1.94\end{array}$

1.10

1.10
1.03

1.00

1.00

0.95
0.90

\section{SMALL TRUCK}

Market Price Price

Intro. Success Mature 20252030

$\begin{array}{lllll}2022 & 2027 & 2032 & 2025 & 2030\end{array}$

$\begin{array}{lllll}3083 & 2240 & 2052 & 2562 & 2052\end{array}$

$\begin{array}{llll}1.10 & 1.10 & 1.10 & 1.10\end{array}$

$\begin{array}{llll}1.10 & 1.04 & 1.05 & 1.03\end{array}$

$\begin{array}{llll}1.00 & 1.00 & 1.00 & 1.00\end{array}$

$\begin{array}{llll}0.95 & 1.00 & 1.00 & 1.00\end{array}$

$\begin{array}{llll}0.90 & 1.00 & 1.00 & 1.00\end{array}$

$\begin{array}{lllll}1.70 & 1.75 & 1.78 & 1.72 & 1.78\end{array}$ 


\section{Table F-3 (continued)}

CARGO (Incl. 2b) TRUCK

Market Price Price

Intro. Success Mature 2025

$200620112016 \quad 2025$

Advanced Diesel

Incremental Vehicle Price

(\$)

Range

Maintenance Cost

Acceleration

Top Speed

Luggage Space

Fuel Economy

\section{Diesel Hybrid}

Incremental Vehicle Price

Range

Maintenance Cost

Acceleration

Top Speed

Luggage Space

Fuel Economy

Gasoline Hybrid

ncremental Vehicle Price

(\$)

Range

Maintenance Cost

Acceleration

Top Speed

Luggage Space

Fuel Economy

2505

$\begin{array}{lll}1.20 & 1.20 & 1.20\end{array}$

$\begin{array}{lll}0.90 & 0.90 & 0.90\end{array}$

$1.00 \quad 1.00 \quad 1.00$

$\begin{array}{lll}1.00 & 1.00 \quad 1.00\end{array}$

$\begin{array}{lll}1.00 & 1.00 \quad 1.00\end{array}$

$1.43 \quad 1.45 \quad 1.53$

20

$3649-2705 \quad 2450$

$\begin{array}{lll}0.90 & 0.90 & 0.90\end{array}$

$\begin{array}{lll}1.05 & 1.05 \quad 1.05\end{array}$

$\begin{array}{lll}0.90 & 0.90 & 0.90\end{array}$

$\begin{array}{lll}0.90 & 0.90 \quad 0.90\end{array}$

$\begin{array}{lll}0.80 & 0.90 \quad 0.90\end{array}$

$\begin{array}{lll}1.90 & 1.96 \quad 2.00\end{array}$

\section{0}

27112145

$\begin{array}{lll}1.25 & 1.25 & 1.25 \\ 1.05 & 1.05 & 1.05\end{array}$

$\begin{array}{lll}1.05 & 1.05 & 1.05 \\ 0.90 & 0.90 & 0.90\end{array}$

$\begin{array}{lll}0.90 & 0.90 \quad 0.90\end{array}$
MINIVAN

Market Price Price

Intro. Success Mature 2025

20182025

$\begin{array}{llllll}0.80 & 0.95 & 1.00 & 1.00 & 1.00 & 0.90\end{array}$

$\begin{array}{llllll}1.55 & 1.63 & 1.72 & 1.76 & 1.82 & 1.77\end{array}$

2013

2018

$\begin{array}{lll}1.00 & 1.00 & 1.00 \\ 1.00 & 1.00 & 1.00\end{array}$

$0.90 \quad 0.90$

$1.00 \quad 1.00 \quad 1.00$

$1.00 \quad 1.00 \quad 1.00$

$1.63 \quad 1.69$

$1.00 \quad 1.00$

\section{3}

$\begin{array}{lll}1.05 & 1.05 & 1.09\end{array}$

$0.90 \quad 0.90$

0.90

$1.05 \quad 1.05$

$1.99 \quad 2.06 \quad 2.03$

$2.06 \quad 2.10$

$2025 \quad 2030$

20192025

025

2030

LARGE VAN

Intro Price

Success Mature 2025

$\begin{array}{lllll}2030 & 2006 & 2011 & 2016 & 2025\end{array}$

$\begin{array}{llllllllllll}1930 & 2004 & 2759 & 1958 & 1740 & 1719 & 1765 & 2627 & 1884 & 1692 & 1654 & 1695\end{array}$

$\begin{array}{lllllll}1.20 & 1.20 & 1.20 & 1.20 & 1.20 & 1.20 & 1.20\end{array}$

0.90

$\begin{array}{lll}1.20 & 1.20 & 1.20\end{array}$

0.90

1.00

1.00

$\begin{array}{llll}0.90 & 0.90 & 0.90 & 0.90\end{array}$

$1.00 \quad 1.00$

1.00

$1.00 \quad 1.00$

$\begin{array}{lll}1.00-1.00 & 1.00-1.00\end{array}$

$\begin{array}{llll}1.78 & 1.78 & 1.79 & 1.85\end{array}$

2012

(1.77

20252030

$\begin{array}{llllllllllll}2495 & 2495 & 3082 & 2262 & 2042 & 2036 & 2067 & 2947 & 2179 & 1973 & 1959 & 1986\end{array}$

$\begin{array}{lll}1.05 & 1.05 & 1.05\end{array}$

$\begin{array}{llll}0.90 & 0.90 & 0.90 & 0.90\end{array}$

$\begin{array}{lllll}1.09 & 1.05 & 1.05 & 1.05 & 1.05 \\ 0.90 & 0.90 & 0.90 & 0.90 & 0.90\end{array}$

$\begin{array}{llllllllllll}90 & 0.90 & 0.90 & 0.90 & 0.90 & 0.90 & 0.90 & 0.90 & 0.90 & 0.90 & 0.90 & 0.90\end{array}$

$\begin{array}{llllllllllll}0.90 & 0.90 & 0.90 & 0.90 & 0.90 & 0.90 & 0.90 & 0.90 & 0.90 & 0.90 & 0.90 & 0.90\end{array}$

$2.12 \quad 2.19$

$2.02 \quad 2.05 \quad 2.09$

$2.12 \quad 2.19$

2030

$\begin{array}{lllll}2010 & 2015 & 2020 & 2025 & 2030\end{array}$

$\begin{array}{llllllllllll}2066 & 2133 & 2628 & 1949 & 1801 & 1798 & 1840 & 2495 & 1881 & 1738 & 1730 & 1768\end{array}$

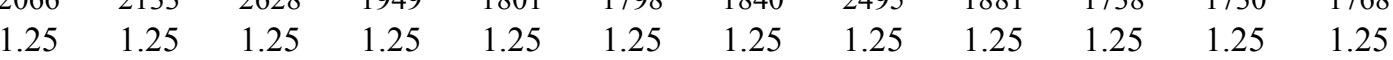

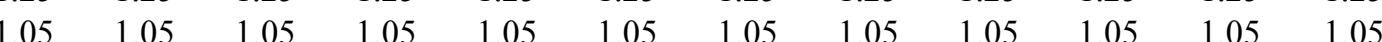

$\begin{array}{llllllllllll}1.05 & 1.05 & 1.05 & 1.05 & 1.05 & 1.05 & 1.05 & 1.05 & 1.05 & 1.05 & 1.05 & 1.05 \\ 0.90 & 0.90 & 0.90 & 0.90 & 0.90 & 0.90 & 0.90 & 0.90 & 0.90 & 0.90 & 0.90 & 0.90\end{array}$

$\begin{array}{lllllllll}0.90 & 0.90 & 0.90 & 0.90 & 0.90 & 0.90 & 0.90 & 0.90 & 0.90 \\ 0.90 & 0.90 & 0.90 & 0.90 & 0.90 & 0.90 & 0.90 & 0.90 & 0.90\end{array}$

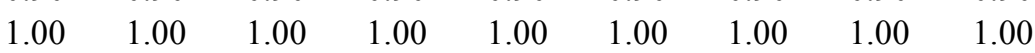

$\begin{array}{llll}1.81 & 1.86 \quad 1.91 \quad 1.97\end{array}$

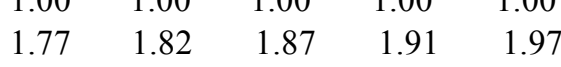




\section{Table F-3 (continued)}

CARGO (Incl. 2b) TRUCK

Market Price Price

Intro Success Mature 2025

2020

Plug-in HEV 40

Incremental Vehicle Price

(\$)

Range

Maintenance Cost

Acceleration

Top Speed

Luggage Space

Fuel Economy

2025

$4230 \quad 3045 \quad 2785$

$1.10 \quad 1.10 \quad 1.10$

$1.10 \quad 1.05 \quad 1.03$

$1.00 \quad 1.00 \quad 1.00$

$\begin{array}{lll}0.95 & 1.00 \quad 1.00\end{array}$

$\begin{array}{lll}0.90 & 1.00 \quad 1.00\end{array}$

$\begin{array}{lll}1.68 & 1.72 \quad 1.78\end{array}$

\section{MINIVAN}

Market Price Price

Intro. Success Mature 2025

2030

2025

2030

3384
$3045 \quad 2785$

1.10

$1.10 \quad 1.10 \quad 1.10$

$\begin{array}{lll}1.05 & 1.03 & 1.05\end{array}$

$1.00 \quad 1.00 \quad 1.00$

$\begin{array}{lll}1.00 & 1.00 & 1.00\end{array}$

$\begin{array}{lll}1.87 & 1.94 & 1.87\end{array}$
$1.00 \quad 1.00 \quad 1.00$

\begin{tabular}{cccccc}
\multicolumn{7}{c}{ LARGE VAN } \\
2030 & Market & Price & Price \\
$\mathbf{2 0 3 0}$ & $\mathbf{2 0 2 1}$ & $\mathbf{2 0 2 6}$ & $\mathbf{2 0 3 1}$ & $\mathbf{2 0 2 5}$ & $\mathbf{2 0 3 0}$ \\
& & & & & \\
2216 & 3223 & 2318 & 2114 & 2492 & 2114 \\
1.10 & 1.10 & 1.10 & & 1.10 & 1.10 \\
1.03 & 1.10 & 1.05 & & 1.05 & 1.03 \\
1.00 & 1.00 & 1.00 & & 1.00 & 1.00 \\
1.00 & 0.95 & 1.00 & & 1.00 & 1.00 \\
1.00 & 0.90 & 1.00 & & 1.00 & 1.00 \\
1.94 & 1.84 & 1.88 & 1.94 & 1.87 & 1.94
\end{tabular}




\section{Table F-3 (continued)}

Advanced Gasoline Incremental Vehicle Price (\$)

Range

Maintenance Cost

Acceleration

Top Speed

Luggage Space

Fuel Economy

\section{2-SEATER}

MINI-COMPACT

$2015 \quad 2020$
SUB-COMPACT

$2015 \quad 2020 \quad 2025$

333

666

Advanced Gasolin
Incremental Vehicle Price
Range
Maintenance Cost
Acceleration
Top Speed
Luggage Space
Fuel Economy

$\begin{array}{cc}2010 & \mathbf{2 0 1 5} \\ 76 & 363 \\ & \\ & \end{array}$

\section{MEDIUM CAR}

$2020 \quad 2025$

2025
539

2030

553

589

2010

82

2015

LARGE CAR

$2015 \quad 2020$

2025

2030

1.10

1.19

1.19

1.22

1.01

1.10

1.19

1.19

1.22 


\section{Table F-3 (continued)}

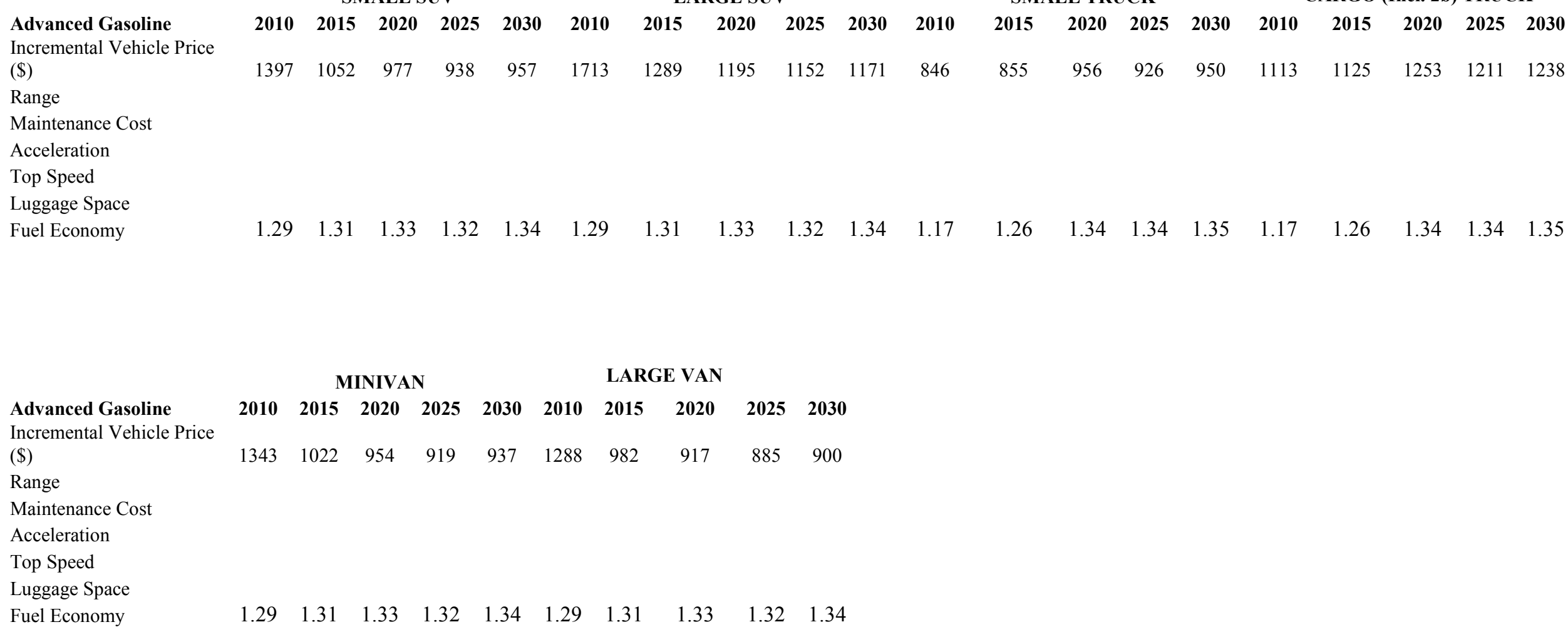


Table F-4. ATV Attributes for Input to MARKAL

(Units are ratios to the conventional gasoline vehicles of the specific year. Prices are in 2004 dollars.)

\section{Ratios to Conventional Vehicles}

\begin{tabular}{|c|c|c|c|c|c|c|c|}
\hline \multicolumn{8}{|c|}{ 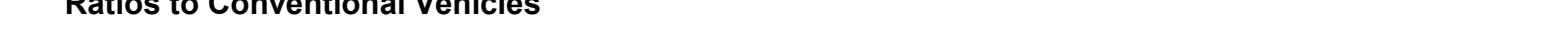 } \\
\hline CARS & \multicolumn{6}{|c|}{ CARS } & 2050 \\
\hline Advanced Gasoline & MPG & 1.01 & 1.19 & 1.20 & 1.22 & 1.25 & 1.26 \\
\hline & Incremental Price & & & & & & 1.020 \\
\hline Diesel & $\begin{array}{c}\text { MPG } \\
\text { Incremental Price }\end{array}$ & 1.29 & 1.40 & $\begin{array}{l}1.40 \\
1.022\end{array}$ & 1.43 & 1.46 & $\begin{array}{l}1.58 \\
1.025\end{array}$ \\
\hline Gasoline HEV & $\begin{array}{c}\text { MPG } \\
\text { Incremental Price }\end{array}$ & 1.32 & 1.51 & $\begin{array}{l}1.52 \\
1.039\end{array}$ & 1.55 & 1.58 & $\begin{array}{c}1.72 \\
1.030\end{array}$ \\
\hline Diesel HEV & $\begin{array}{c}\text { MPG } \\
\text { Incremental Price }\end{array}$ & 1.51 & 1.76 & $\begin{array}{l}1.76 \\
1.043\end{array}$ & 1.79 & 1.83 & $\begin{array}{c}1.99 \\
1.040\end{array}$ \\
\hline PHEV40 & $\begin{array}{l}\text { MPG on gasoline } \\
\text { kWh/mil } \\
\text { Incremental Price }\end{array}$ & $\begin{array}{l}1.29 \\
0.20\end{array}$ & $\begin{array}{l}1.48 \\
0.20\end{array}$ & $\begin{array}{l}1.49 \\
0.20056\end{array}$ & $\begin{array}{l}1.52 \\
0.20\end{array}$ & $\begin{array}{l}1.55 \\
0.20\end{array}$ & $\begin{array}{l}1.68 \\
0.20 \\
1.045\end{array}$ \\
\hline \multicolumn{8}{|l|}{ LIGHT TRUCKS } \\
\hline Advanced Gasoline & $\begin{array}{c}\text { MPG } \\
\text { Incremental Price }\end{array}$ & 1.25 & 1.33 & 1.33063 & 1.34 & 1.36 & $\begin{array}{l}1.33 \\
1.030\end{array}$ \\
\hline Diesel & $\begin{array}{c}\text { MPG } \\
\text { Incremental Price }\end{array}$ & 1.67 & 1.70 & $\begin{array}{l}1.74 \\
1.034\end{array}$ & 1.80 & 1.86 & $\begin{array}{l}1.93 \\
1.035\end{array}$ \\
\hline Gasoline HEV & $\begin{array}{c}\text { MPG } \\
\text { Incremental Price }\end{array}$ & 1.70 & 1.82 & $\begin{array}{l}1.86 \\
1.061\end{array}$ & 1.92 & 1.99 & $\begin{array}{l}2.07 \\
1.040\end{array}$ \\
\hline Diesel HEV & $\begin{array}{c}\text { MPG } \\
\text { Incremental Price }\end{array}$ & 1.95 & 2.03 & $\begin{array}{l}2.07 \\
1.064\end{array}$ & 2.15 & 2.22 & $\begin{array}{l}2.31 \\
1.050\end{array}$ \\
\hline PHEV40 & $\begin{array}{l}\text { MPG on gasoline } \\
\text { kWh/mil } \\
\text { Incremental Price }\end{array}$ & $\begin{array}{l}1.67 \\
0.26\end{array}$ & $\begin{array}{l}1.78 \\
0.26\end{array}$ & $\begin{array}{l}1.82 \\
0.26073\end{array}$ & $\begin{array}{l}1.89 \\
0.26\end{array}$ & $\begin{array}{l}1.95 \\
0.26\end{array}$ & $\begin{array}{c}2.02 \\
0.26 \\
1.055\end{array}$ \\
\hline
\end{tabular}




\section{Estimation of ATV MPG Estimates}

This section explains how PSAT results have been used to develop the fuel economy inputs to the GPRA models. The same methodology was applied to estimate fuel cell vehicles' (FCVs) fuel economy. The section mentions FCVs, but we do not present the FCV MPG estimates in this appendix.

1. There are two GPRA models: NEMS and MARKAL. The NEMS model requires characterization of six cars and six light trucks (LTs) for each technology to 2030. The MARKAL model requires characterization of an average car and an average LT for each technology to 2050. Table F-5 summarizes the vehicle classes used in both models.

Table F-5. Vehicle Classes Used in Various Models

\begin{tabular}{|c|c|c|c|c|c|c|}
\hline & \multicolumn{6}{|c|}{ Car Classes } \\
\hline MARKAL & \multicolumn{5}{|c|}{ Cars } \\
\hline NEMS & $\begin{array}{c}\text { Two- } \\
\text { seater }\end{array}$ & $\begin{array}{c}\text { Mini- } \\
\text { compact }\end{array}$ & $\begin{array}{c}\text { Sub- } \\
\text { compact }\end{array}$ & Compact & Medium & Large \\
\hline PSAT & & & \multicolumn{5}{|c|}{ Light Truck Classes } & Midsize & \\
\hline & \multicolumn{7}{|c|}{ Light Trucks } \\
\hline MARKAL & Small & $\begin{array}{c}\text { Large } \\
\text { SUV }\end{array}$ & $\begin{array}{c}\text { Small } \\
\text { Truck }\end{array}$ & $\begin{array}{c}\text { Cargo } \\
\text { Truck }\end{array}$ & Minivan & $\begin{array}{c}\text { Large } \\
\text { Van }\end{array}$ \\
\hline NEMS & SUV & SUV & & Pick-up & & \\
\hline PSAT & & SUV &
\end{tabular}

2. The PSAT model itself only provides fuel economy estimates for four of the 12 vehicle classes required by NEMS. The four classes in PSAT are also presented in Table F-5: They include compact and midsize cars, a SUV, and a pickup. PSAT results for those four classes, thus, must be adjusted to develop the fuel economy estimates required by the GPRA models. This adjustment is made as discussed below using a simple spreadsheet model.

3. Two sets of PSAT results were used in this analysis. One set of PSAT results (new vehicle fuel economies) were provided for five vehicle technologies (advanced gasoline, gasoline HEV, advanced diesel, diesel HEV, and FCV) in three vehicle classes types (midsize car, SUV, and pickup) in two years (2010 and 2020) (Ref. 3). "Low," "high," and "average" results were provided. The "high" results are the only one of the three sets of results that represents achievement of the goals of the FCVT (and HFCIT) program to 2020 for these three vehicle types; therefore, we used the "high" results in our analysis. Because PSAT results were not available for the compact car, we assumed that the "high" results of the midsize cars also apply to the compact cars. (We do not use the same fuel economies, but instead use the same ratio or "X" factor of ATV fuel economy relative to the baseline gasoline vehicle fuel economy.)

4. For GPRA, estimates for the period to 2050 are developed. The PSAT results discussed above only extend to 2020. Another set of PSAT results were provided for two vehicle technologies (gasoline HEV and FCV) in three vehicle types (compact car, midsize car, and SUV) in four years (2010, 2020, 2035, and 2050) (Ref. 4). Again, "low" and "high" results were provided. Using the "high" results, we estimated the improvement rate in fuel economy from 2020 to 2035 and 2035 to 2050 for the midsize car and SUV for these two technologies. We then applied the 
improvement rates for the gasoline HEV to the 2020 estimates developed in No. 3 (midsize car to midsize and compact car, and SUV to SUV and pickup) to generate new vehicle fuel economy estimates to 2050 for all the technologies (except the FCV).

5. Given the new vehicle fuel economies developed for advanced technologies in No. 3 and for comparable conventional vehicles in No. 4, the final fuel economy ratios or X factors for those five technologies (advanced gasoline, gasoline HEV, advanced diesel, diesel HEV, and FCV) in four vehicle types (compact car, midsize car, SUV, and pickup) in several years $(2010,2020$, 2025, 2030, 2035, and 2050) are estimated.

6. For NEMS, the fuel economy $\mathrm{X}$ factor of the compact cars is assumed to apply also to the minicompact, subcompact, and two-seater vehicles because these vehicle classes have a lot in common with respect to vehicle attributes, such as performance. The $\mathrm{X}$ factor of the midsize cars is assumed to apply to medium and large cars because they are similar. The X factor of the SUV (which is a large SUV according to the NEMS classification) is assumed to apply to large and small SUVs and all vans because vans are closer to SUVs than to pickups. The X factor of the pickup (which is a large pickup, according to the NEMS classification) is assumed to apply to both small and large pickups.

7. The fuel economy estimates finalized in No. 5 and No. 6 are for 2010, 2020, 2025, and 2030. For NEMS, we also need to provide estimates for intervening years. For those intervening years, we used linear interpolation to estimate the $\mathrm{X}$ factors.

8. As stated above, MARKAL uses only one aggregate car class and one aggregate light-truck class. We examined current sales volumes of the six different car classes and six different lighttruck classes. Based on that examination, we weighted the compact and midsize cars 50-50 to estimate the X factor of an average car; and we weighted the SUV and pickup 67-33 to estimate the $\mathrm{X}$ factor of an average light truck. EIA projects very little change in class shares over the 2006 to 2030 period; therefore, we do not project any change in this analysis.

9. The two sets of PSAT results used to estimate ATV MPG estimates did not include results for plug-in hybrids (PHEVs). Instead, we assumed that PHEV40s, when operating on the engine, average $98 \%$ of the fuel economy achieved by HEVs. We assumed that PHEV40s, when operating on the battery, average $0.2 \mathrm{kWh} /$ mile (cars) and $0.26 \mathrm{kWh} / \mathrm{mile}$ (light trucks). Travel on battery is assumed to be $40 \%$ of total travel.

\section{Incremental Vehicle Price Estimates}

As indicated above, payback analysis was used to estimate what the incremental price of ATVs would be when they become cost-competitive with conventional vehicles, which is a goal of the program. The incremental price equals the present value of the energy cost reduction achieved by ATVs over three years, assuming a $7.5 \%$ discount rate (This IRS discount rate was selected in 2000 when this payback model was built. If we were to use the 2006 IRS discount rate, it would be 5.8\%.), and the following fuel prices (which are from the AEO2006 projections) per gasoline gallon equivalent: $\$ 2.08$ for gasoline, $\$ 2.03$ for diesel, $\$ 2.82$ for $\mathrm{H} 2$, and $\$ 3.11$ for electricity. Incremental prices are higher in the early years of market introduction. In fact, we developed three sets of prices for each class of vehicle for input to NEMS. Prices were developed for a 
"market introduction" date, a "price success" date, and a "price maturity" date. The price at "price maturity" is the "final" incremental price, the price at "market introduction" is 50\% higher than it would be if the technology was "mature," and the price at "price success" is $10 \%$ higher than it would be if the technology were "mature." These dates vary for the different technologies.

For MARKAL, we weighted the incremental prices estimated for each technology in 2030 in the same manner that we weighted the fuel economy estimates as described in No.10 of Section 1.3.1. We then assumed a gradually declining incremental price to 2050 for each technology.

ATV Market-Penetration Methodology

Brief descriptions of how NEMS and MARKAL projected new vehicle technology penetration using these vehicle attributes can be found in the main body of the FY 2008 budget request's benefits documentation. 


\section{Heavy Vehicles}

\section{Significant Changes from Previous Analysis}

Two significant changes have been made in this year's benefit estimates. One involves removing two technology activities from the analysis. The other involves modifying the model that determines market penetration.

The FCVT program had a reduction in their budget for FY08, so two Heavy Truck (HT) technologies were removed from their portfolio: 1) hybrid heavy trucks and 2) weight reduction. The dropping of these two activities (rather than others) was due, in part, to the fact that these activities had relatively small benefits in the GPRA07 benefits estimates provided to the FCVT program last year.

The TRUCK model was also changed so that there are now two types of Class 7 and 8 trucks: 1) Combinations and 2) Single Unit. This replaces the three types used previously. This was done so that the HT classes would be the same as those for which data are available from DOT and that were used in the HT VISION model.

\section{The Baseline ("without DOE RD3" case)}

The projection that is in $A E O 2006$ is accepted as the appropriate baseline. It has heavy-truck onroad mpg growing slightly from 6.0 in 2004 to 6.8 in 2030 . This is an increase of $15 \%$ without the EERE program.

\section{Program Outputs}

The technologies for which benefits are estimated for heavy trucks are the three shown in Tables F-6 and F-7 for 2010 and for 2020-2050.

Table F-6. Efficiency Improvement Contributions - 2010

\begin{tabular}{|c|l|r|r|r|r|}
\hline \multirow{2}{*}{ Number } & \multicolumn{1}{|c|}{ Item } & \multicolumn{2}{|c|}{ Type 1 } & \multicolumn{2}{c|}{ Type 2 } \\
\cline { 2 - 7 } & & $\begin{array}{c}\text { Fuel } \\
\text { Economy, } \\
\mathbf{m p g}\end{array}$ & $\begin{array}{c}\text { Single } \\
\text { Technol. } \\
\text { Benefit, } \\
\%\end{array}$ & $\begin{array}{c}\text { Fuel } \\
\text { Economy, } \\
\mathbf{m p g}\end{array}$ & $\begin{array}{c}\text { Single } \\
\text { Technol. } \\
\text { Benefit, } \\
\%\end{array}$ \\
\cline { 2 - 7 } & & $\mathrm{A}$ & $\mathrm{B}$ & $\mathrm{A}$ & $\mathrm{B}$ \\
\hline \hline 1 & Baseline & 6.1 & $0.0 \%$ & 6.7 & $0.0 \%$ \\
\hline 2 & Auxiliary Loads Electrification & 6.1 & $0.5 \%$ & 6.8 & $2.5 \%$ \\
\hline 4 & Engine Efficiency, WHR & 7.6 & $24.6 \%$ & 8.2 & $22.9 \%$ \\
\hline \hline 5 & Aerodynamic Load Reduction & 6.3 & $3.0 \%$ & 6.8 & $1.9 \%$ \\
\hline $\mathbf{6}$ & Sum of Individual Benefits & -- & $28.1 \%$ & & $27.4 \%$ \\
\hline
\end{tabular}


Table F-7: Efficiency Improvement Contributions - 2020-2050

\begin{tabular}{|c|c|c|c|c|c|}
\hline \multirow[t]{3}{*}{ Number } & & \multicolumn{2}{|c|}{ Type 1} & \multicolumn{2}{|c|}{ Type 2} \\
\hline & Item & $\begin{array}{c}\text { Fuel } \\
\text { Economy, } \\
\text { mpg }\end{array}$ & $\begin{array}{c}\text { Single } \\
\text { Technol. } \\
\text { Benefit, } \\
\%\end{array}$ & $\begin{array}{c}\text { Fuel } \\
\text { Economy, } \\
\text { mpg }\end{array}$ & $\begin{array}{c}\text { Single } \\
\text { Technol. } \\
\text { Benefit, } \\
\%\end{array}$ \\
\hline & & A & B & A & B \\
\hline 1 & Baseline & 6.1 & $0.0 \%$ & 6.7 & $0.0 \%$ \\
\hline 2 & $\begin{array}{l}\text { Auxiliary Loads } \\
\text { Electrification }\end{array}$ & 6.2 & $0.9 \%$ & 7.0 & $4.3 \%$ \\
\hline 3 & Engine Efficiency, WHR & 8.8 & $44.3 \%$ & 9.4 & $40.9 \%$ \\
\hline 4 & $\begin{array}{l}\text { Aerodynamic Load } \\
\text { Reduction }\end{array}$ & 6.5 & $6.1 \%$ & 6.8 & $1.9 \%$ \\
\hline 5 & $\begin{array}{l}\text { Sum of Individual } \\
\text { Benefits }\end{array}$ & -- & $51.4 \%$ & & $47.1 \%$ \\
\hline 6 & Combined Effects & 9.4 & $154.6 \%$ & 10.0 & $149.8 \%$ \\
\hline
\end{tabular}

The sources and basis for these assumptions are as described below:

Auxiliary Loads Reduction is the improvement in vehicle fuel economy by changing some of the vehicle functions from mechanical to electrical. For example, the brake air compressor, oil pump, and water pump can be energized electrically, instead of mechanically, and be made more efficient.

(See http://www1.eere.energy.gov/vehiclesandfuels/pdfs/success/more electric truck 04.pdf)

Engine Efficiency is the improvement in vehicle fuel economy by making the diesel engine more efficient. This is done by optimizing the engine design, improving the waste heat recovery (WHR), using advanced fuel injection and engine control strategies, reducing friction losses, and using robust sensors for control systems.

(See http://www1.eere.energy.gov/vehiclesandfuels/technologies/engines/printable_versions/ heavy truck_engine.html )

Aerodynamic Load Reduction is the improvement in vehicle fuel economy through the alteration of the shape of heavy trucks to decrease the aerodynamic resistance (drag) on them as they travel at highway speeds. (See http://eed.llnl.gov/aerodrag/pdf/aerodrag2.pdf)

\section{Translating Program Outputs to Market Outcomes}

This section describes the assumptions and market characterization used for estimating benefits for the Heavy Vehicle Technologies activities. The scope of the effort includes: 
- Characterizing baseline and advanced technology vehicles for Class 3-6 and Class 7 and 8 trucks. Gross Vehicle Weights for these vehicle classes are as follows (Davis 2006):
○ Class 3: $10,001-14,000$
○ Class 4: 14,001-16,000
○ Class 5: $16,001-19,500$
○ Class 6: 19, $501-26,000$
○ Class $7: 26,001-33,000$
○ Class 8: 33,001 lbs and up,

- Identifying technology goals associated with the FCVT Program,

- Estimating the market potential of technologies that improve fuel efficiency and/or use alternative fuels.

This determines the petroleum savings associated with the advanced heavy vehicle technologies. These estimates are developed at the program-element level to assist project prioritization.

In the recent past, the Heavy Vehicles activity expanded its technical involvement to more broadly address various sources of energy loss as compared to focusing more narrowly on engine efficiency and alternative fuels. This broadening of focus has continued in the activities planned for FY08. These changes are the result of a planning effort that occurred during FY05 and FY06.

The Heavy Vehicle Activities supported by FCVT are not represented in the NEMS model. The details on mileage distribution and varying payback years are also not included in the NEMS model. These are the reasons why the EERE TRUCK and associated models are used to estimate the market penetration of advanced heavy vehicle technologies. NEMS and MARKAL used the results to estimate the benefits reported in the FY 2008 budget request. The FCVT approach and outputs for the Heavy Vehicles Optimization activity is illustrated in Exhibit F-8.

\section{Target Market: Heavy Vehicle Target Market}

"Heavy Vehicles" are defined in this analysis as including Classes 3 through 6 (Medium Trucks) and Classes 7 and 8 (Heavy Trucks). The Heavy Truck classes are further subdivided by end-use types, i.e., Long-Haul, Intermediate, and Local Use. Vehicle Inventory and Use Survey (VIUS) data from the Department of Transportation (http://www.census.gov/svsd/www/vius/products.html) were examined for all vehicles in use and vehicles 2 years old or less (Argonne National Laboratory, PSAT). Subsequently, the Heavy Truck vehicle market was disaggregated into these three end-use types. The specific vehicle configurations grouped in each of the three types have similar patterns of travel and annual vehicle mile use patterns (as compared to vehicle use). The vehicle type segments comprise the vehicle configurations listed below:

- Type 1, Class 7 and 8 - Single unit, Conventional Powerplant (Diesel and Gasoline);

- Type 2, Class 7 and 8 - Combination units (e.g., tractor trailers), Conventional Powerplant (Diesel only) 


\section{Exhibit F-8. Heavy Vehicles Optimization Network Chart}

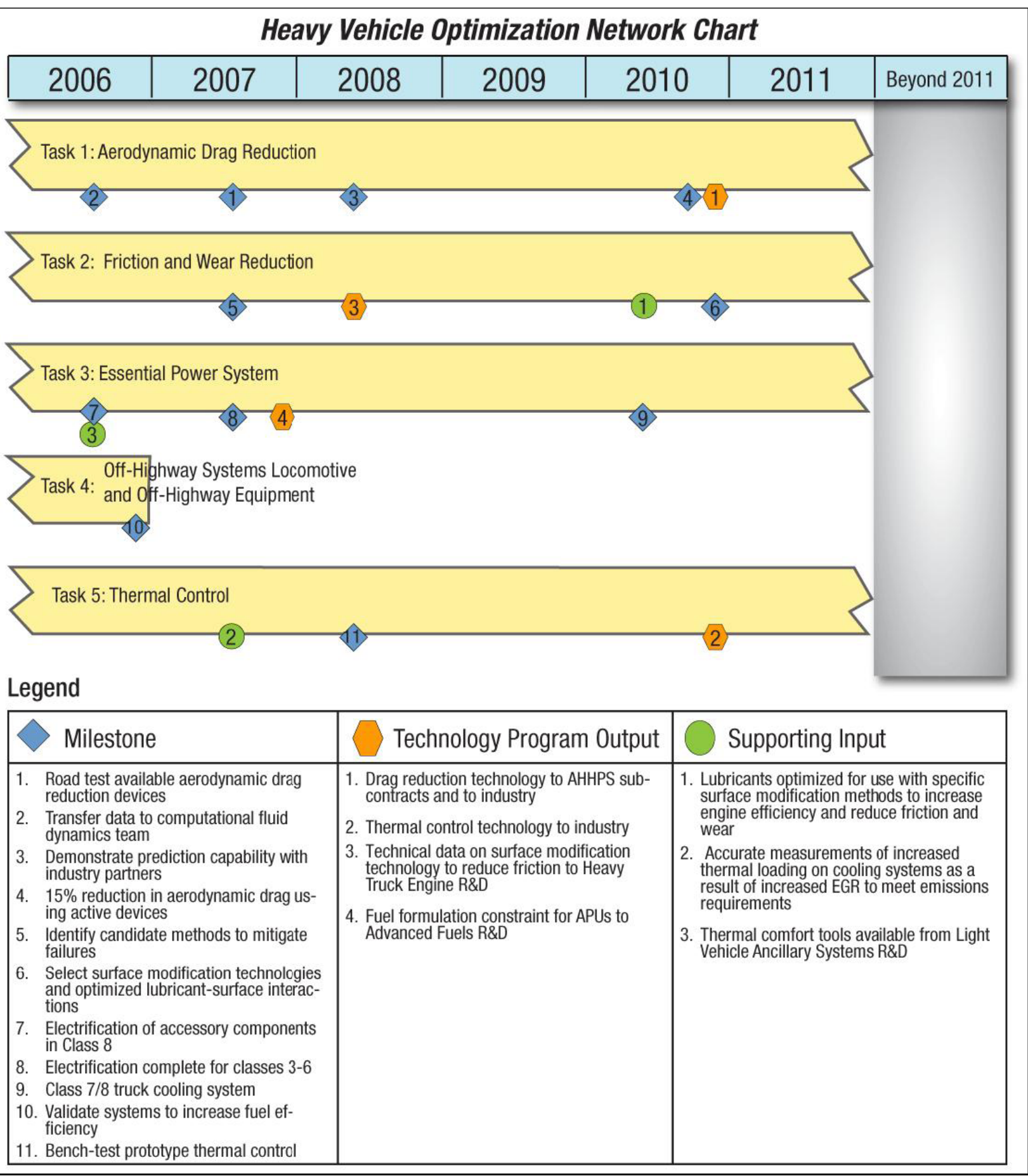


The lower-speed characteristics of Type 1 trucks greatly reduce the potential efficiency benefits in that sector compared to Type 2. For similar reasons, fuel economy improvements due to other speed-dependent measures such as improved tires will have lower benefit here than in the other two types. However, electrification of accessories may have a greater effect in the Type 1 sector.

Distances traveled by Type 2 vehicles are typically greater than Type 1, which implies that the typical speeds are higher. These characteristics make them a somewhat better market sector for speed-dependent measures such as advanced tires. In general, Type 2 vehicles are the best candidates for technologies that reduce drivetrain losses or vehicle losses.

Refueling characteristics, i.e., central-source or noncentral-source, also are considered in the market characteristics, as it is easier to deploy an alternative fuel for centrally refueled vehicles.

Forty travel-distance categories for medium trucks and heavy trucks are represented in the model. These categories were determined using travel distributions developed with the VIUS data by Oak Ridge National Laboratory (Davis, S. 2001; Davis, S. 2005; Bureau of Census, 1999).

Exhibit F-9 shows the distribution of annual travel for the two types of Class 7 and 8 vehicles. Type 2 vehicles display the greatest amount of annual travel of all heavy vehicle classes as is evidenced in part by the curve's peaking in the 120,000- to 130,000-mile segment.

Exhibit F-10 shows the vehicle use pattern for Local or Type 1 Heavy Trucks. The distributions based both on vehicles and vehicle-miles traveled are indicated. Exhibit F-11 shows the same information as Exhibit F-2, but for Type 2 trucks. For Type 1, the distribution peaks in the 20,000 - to 39,000-mile segment. Similar information for gasoline and diesel medium trucks is shown in Exhibit F-12.

An analysis of vehicle use patterns showed that centrally refueled vehicles travel less than noncentrally refueled vehicles. For the latter, the majority of travel occurs from 100,000 to 140,000 miles per year. In the central refueling segment, the majority of travel occurs in a more even distribution between 20,000 and 140,000 miles per year. 


\section{Exhibit F-9. Class 7 and 8 Trucks - Single and Combination Units: Distribution of Trucks and}

Trucks Vehicle Miles

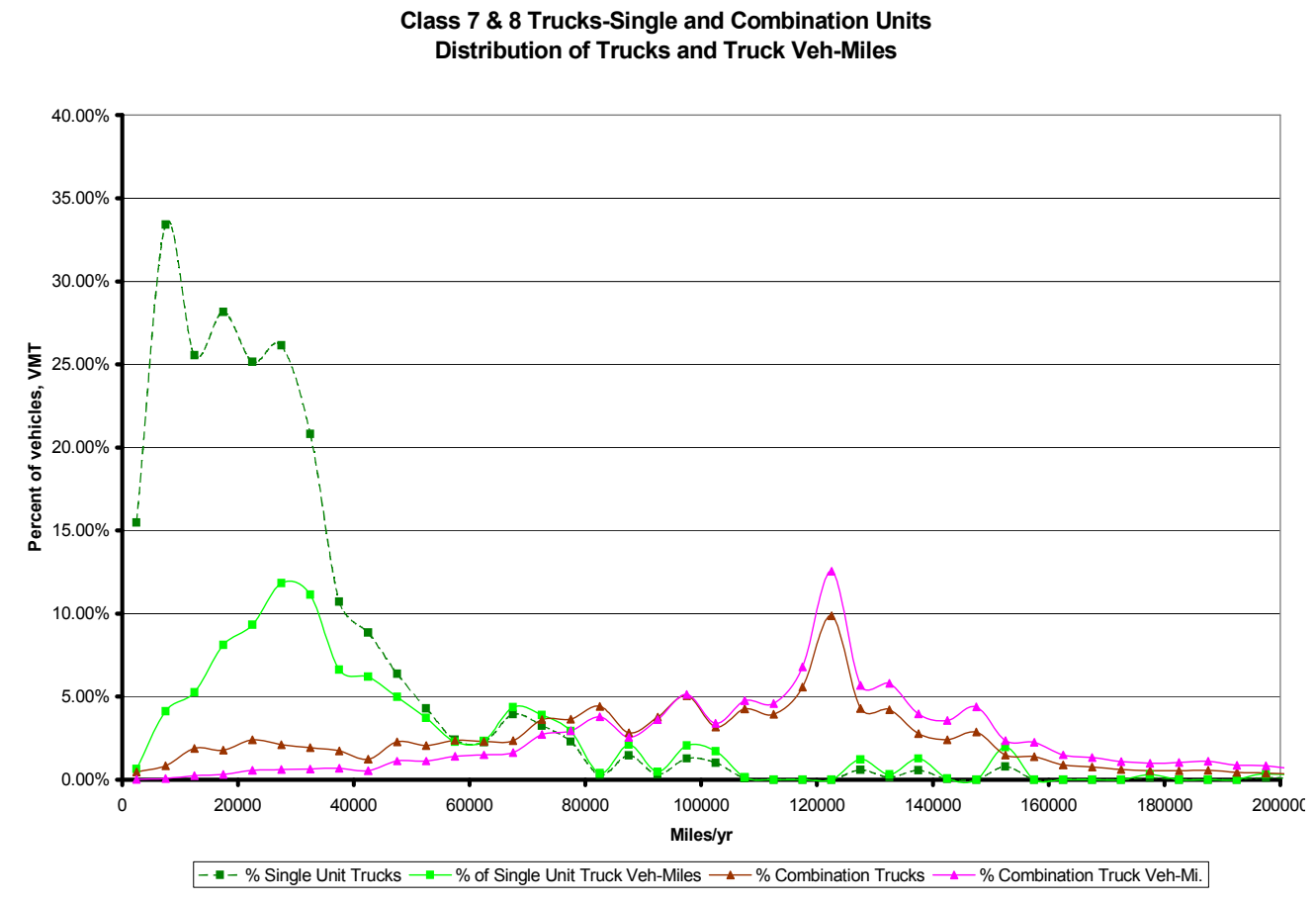

Exhibit F-10. Class 7 and 8 Trucks - Combination Units: Distribution of Trucks and Truck Vehicle Miles

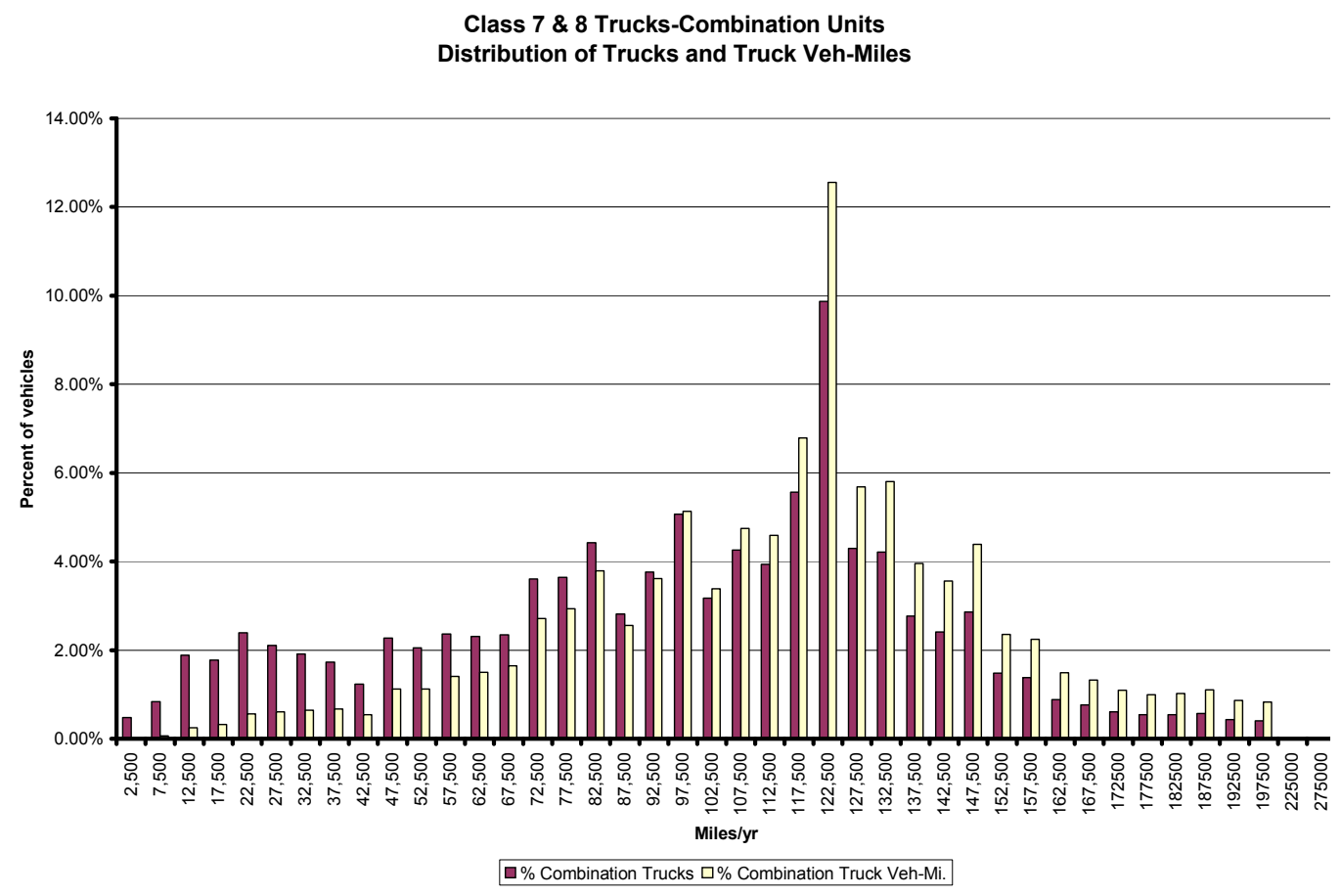

Projected Benefits of Federal Energy Efficiency and Renewable Energy Programs (FY 2008-FY 2050) Appendix F - Freedcom CAR and Vehicle Technologies Program - Page F-38 


\section{Exhibit F-11. Distribution of Class 7 and 8 Single-Unit Trucks}

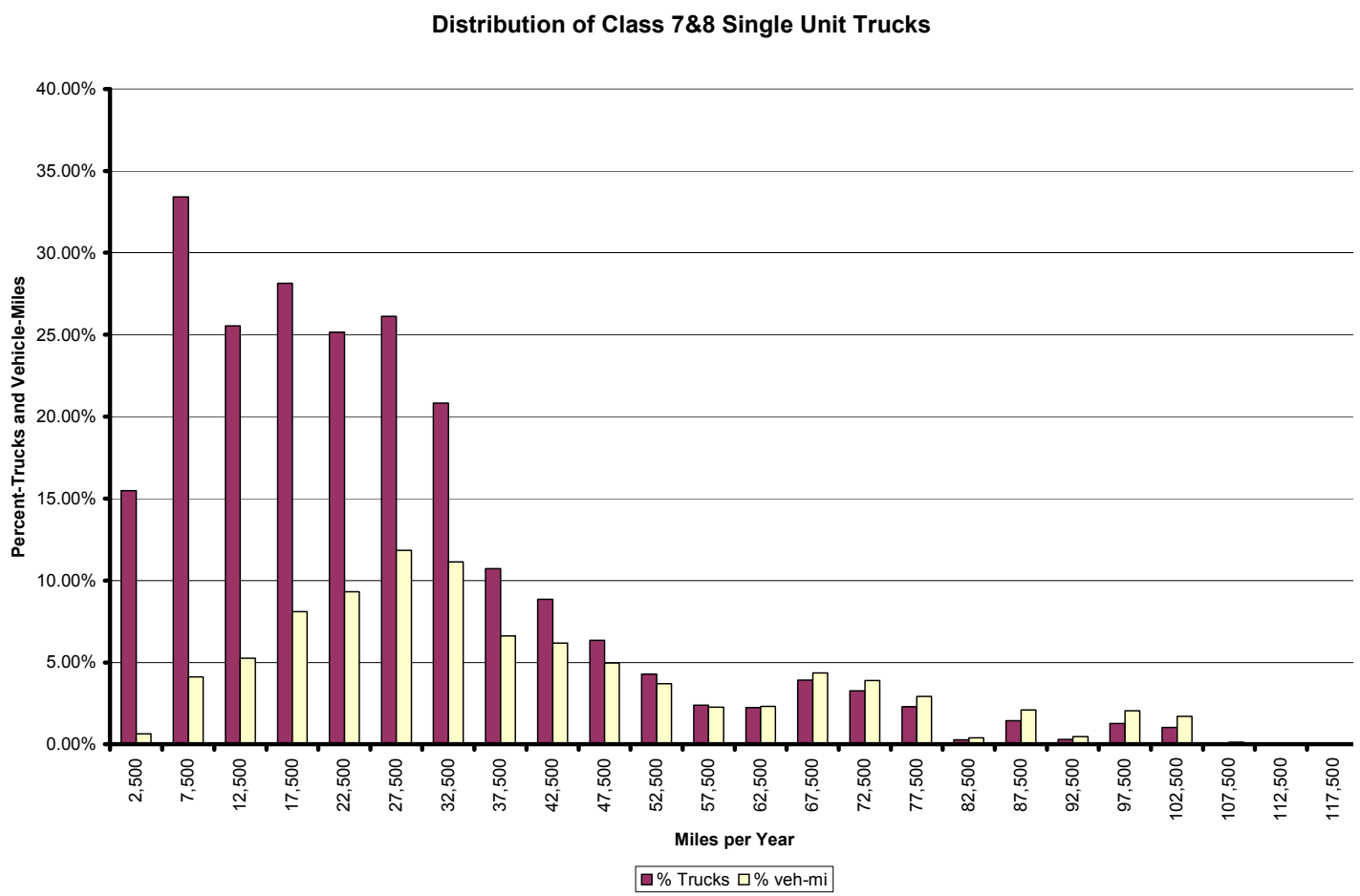

Exhibit F-12. Travel Distributions for Classes 3-6 Trucks

Class 3-6 Trucks-Gasoline \& Diesel Units Distribution of Trucks and Truck Veh-Miles

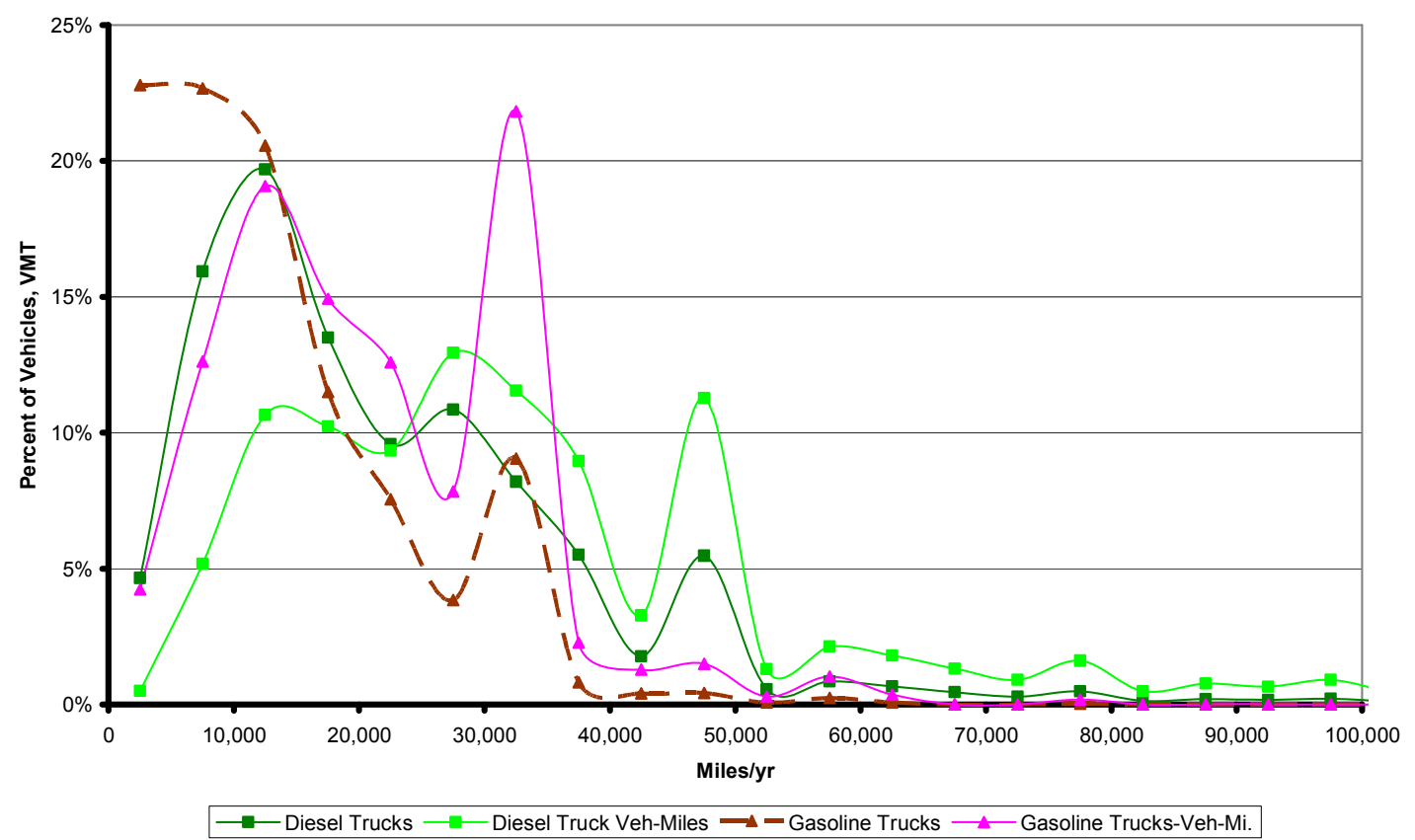




\section{Discussion of Inputs}

Heavy vehicle market characteristics that are pertinent to the analysis are summarized in Table F-8. In the medium-truck market segment (Classes 3 through 6), all vehicle types, with the exception of automobiles transport, travel about 20,000 miles per year on average. Heavy trucks, depending on type, travel an average of 40,000 miles to 92,000 miles per year. The base fuel economy for all three truck types was updated using VIUS 2002 data (Bureau of the Census 1999).

Table F-8: Heavy-Vehicle Characteristics (2002)

\begin{tabular}{|c|c|c|c|c|c|}
\hline Vehicle Type & $\begin{array}{c}\text { Class } 7 \& 8 \\
\text { Type } 1\end{array}$ & $\mid \begin{array}{c}\text { Class } 7 \& 8 \\
\text { Type } 2\end{array}$ & $\begin{array}{c}\text { Class } 3 \\
\text { through } 6 \\
\text { Diesel } \\
\end{array}$ & $\begin{array}{c}\text { Class } 3 \\
\text { through } 6 \\
\text { Gasoline } \\
\end{array}$ & Comments \\
\hline Body Types & $\begin{array}{c}\text { Combination } \\
\text { Units }\end{array}$ & $\begin{array}{l}\text { Single } \\
\text { Units }\end{array}$ & - & -- & \\
\hline $\begin{array}{l}\text { Fuel Economy } \\
\text { (Baseline) }\end{array}$ & 6.10 & 6.70 & 8.90 & 9.40 & \\
\hline $\begin{array}{l}\text { Fuel Economy } \\
\text { Improvement, \% }\end{array}$ & $155 \%$ & $150 \%$ & $145 \%$ & $144 \%$ & $\begin{array}{l}\text { Combined effect of FCVT } \\
\text { Technologies, } 2020-2050\end{array}$ \\
\hline $\begin{array}{l}\text { Average Miles } \\
\text { Traveled, miles }\end{array}$ & 96,300 & 13,000 & 23,100 & 11,800 & \\
\hline $\begin{array}{l}\text { Portion of Heavy } \\
\text { Truck Fuel Use, \% }\end{array}$ & $72 \%$ & $13 \%$ & $11 \%$ & $4 \%$ & Estimated--Year 2005 \\
\hline $\begin{array}{l}\text { Portion of Vehicle } \\
\text { Travel < } 50 \text { k Miles, }\end{array}$ & $5 \%$ & $68 \%$ & $84 \%$ & $98 \%$ & \\
\hline $\begin{array}{l}\text { Portion of Vehicle } \\
\text { Travel } 50 \mathrm{k} \text { to } 100 \mathrm{k}\end{array}$ & $26 \%$ & $25 \%$ & $12 \%$ & $2 \%$ & \\
\hline $\begin{array}{l}\text { Portion of Vehicle } \\
\text { Travel }>100 \mathrm{k}\end{array}$ & $69 \%$ & $7 \%$ & $4 \%$ & $0 \%$ & \\
\hline
\end{tabular}

\section{Key Factors Shaping Market Adoption of Technology}

Table F-9 shows the payback distribution assumed in the TRUCK model. This payback distribution was generated from an American Trucking Association's survey conducted in 1997 to determine the payback investment criteria for an investment in energy conservation. The survey of 224 motor carriers revealed that paybacks of one to four years were acceptable for energy-conserving technologies. The survey found that, for example, $16.4 \%$ of the truck operators responding require a payback of one year on an investment.

Based on those findings, we modeled the market acceptance of the various technologies based on payback performance. The average heavy truck is in use for 28 years (Davis 2006, p. 3-27). Average fuel economy increased from $5.6 \mathrm{mpg}$ in 1992 to $5.8 \mathrm{mpg}$ in 2002 (Davis 2006, p. 5-6). 
Table F-9. ATA Survey Payback Preference Distribution

\begin{tabular}{|c|c|}
\hline $\begin{array}{c}\text { Number of } \\
\text { Years }\end{array}$ & $\begin{array}{c}\text { Percent of } \\
\text { Motor Carriers }\end{array}$ \\
\hline 1 & $16.4 \%$ \\
\hline 2 & $61.7 \%$ \\
\hline 3 & $15.5 \%$ \\
\hline 4 & $6.4 \%$ \\
\hline
\end{tabular}

\section{Effects of Lower Emissions on Heavy Vehicle Fuel Economy}

The Environmental Protection Agency (EPA) has initiated regulation of emissions from Heavy Trucks. Industry is responding by modifying engine technology and diesel fuel=refining processes. Some reduction in fuel economy with the new engines is also expected as the combustion process optimization is addressing reduction of emissions. These changes will impose both operating and capital costs on truck operators, because meeting the emissions requirements typically penalizes fuel economy.

One such EPA rule addressed Ultra-low-Sulfur Diesel (ULSD). The ULSD rule is designed to lower the sulfur content of transportation diesel fuel produced by refineries by 2007 . The content of other pollutants, including nitrogen oxides $\left(\mathrm{NO}_{\mathrm{X}}\right)$, particulate matter $(\mathrm{PM})$, and hydrocarbons (HC) are being reduced as well.

These new standards have started to go into effect with 2004 engines and will continue on for model years 2007 and 2010 for highway vehicles, and later for other applications. Major elements of these rules include the following:

- Reduce nitrogen oxides and fine particulate matter $\left(\mathrm{PM}_{2.5}\right)$ from new heavy-duty highway diesels (e.g., trucks and buses) by about 90\%, effective in 2007 for PM, and 2007-2010 for NOx.

- Reduce the sulfur content in highway diesel fuel to 15 ppm ("ultra-low sulfur diesel" fuel, or "ULSD" fuel) beginning in late 2006.

- Reduce NOx and $\mathrm{PM}_{2.5}$ from new heavy-duty nonroad diesels (e.g., construction, farming, and logging equipment) by about 90\%, effective in the 2011-2014 time frame, depending on the pollutant and the size of engine.

- Reduce the sulfur content in diesel fuel used in stationary engines in two steps, to 500 ppm in 2007 and 15 ppm beginning in 2010. 
- Reduce the sulfur content in diesel fuel used in new locomotive and many marine engines in two steps, to $500 \mathrm{ppm}$ in 2007 and $15 \mathrm{ppm}$ beginning in 2012.

In addition, in December 2000, EPA published new emission standards for on-road, heavy-duty diesel engines that would take effect beginning in 2007. The standards will have emission levels of PM at $0.01 \mathrm{~g} / \mathrm{bhp}-\mathrm{hr}, \mathrm{NO}_{\mathrm{x}}$ at $0.20 \mathrm{~g} / \mathrm{bhp}-\mathrm{hr}$, and $\mathrm{HC}$ at $0.14 \mathrm{~g} / \mathrm{bhp}-\mathrm{hr}$. The new standards apply to diesel-powered vehicles with gross vehicle weight (GVW) of 14,000 pounds or more. The PM standard applies to all on-road heavy and medium-duty diesel engines. Starting in 2007 and running through 2009, the EPA is giving the manufacturers some flexibility in meeting the new standards. They have the option of meeting the average of the 2004 and $2007 \mathrm{NO}_{\mathrm{x}}$ and $\mathrm{HC}$ emissions levels $(1.1 \mathrm{~g} / \mathrm{bhp}-\mathrm{hr})$. In addition, if manufacturers produced low-emission engines in 2006, then that amount can be deducted from their 2007 requirements.

The EPA rule-making process requires a cost analysis for the technologies required to meet the new standards. The costs for the new emission control technologies for the 2004 models assumed that fuel injection and turbocharger improvements would be adopted, regardless of the new standards. So, in estimating increases in engine costs, the EPA excluded $50 \%$ of the technology cost from the total estimated cost. The incremental costs for heavy-duty engines were estimated at $\$ 803$ in 2004 , decreasing to $\$ 368$ in 2009 . The EPA also estimated the increase in annual nonfuel operating cost for heavy-duty engines to be $\$ 104$ for the maintenance of the exhaust gas recirculation (EGR).

The effect of additional equipment that is used for treating emissions was also considered. The added weight of the equipment requires additional horsepower output from the engine, which results in a reduction in fuel efficiency. The EPA expects NOx adsorbers to be the most likely emission-control technology applied by the industry. NOx adsorber regeneration will require small injections of diesel fuel for "light off" and desorption of stored $\mathrm{NO}_{\mathrm{x}}$ for downstream catalysis under rich-burn conditions. This could result in additional fuel use beyond combustion for propulsion of $2 \%-4 \%$, depending on system maturity. The majority of the reduction in efficiency is associated with the control of sulfur-containing emissions (Clean Air Task Force 2006, EIA 2001, Vyas 2002).

\section{Methodology and Calculations: Overview}

The analysis of the benefits expected from achieving the goals of the Heavy Vehicle Technologies Subprogram was based on four primary reference sources:

- Technology energy efficiency and fuel-use characteristics — as provided by the managers of the technology programs;

- Vehicle characteristics and use information - as obtained from the 1997 VIUS. This provides information on both vehicle performance characteristics, such as fuel economy, and vehicle-use patterns such as miles traveled per year (Argonne National Laboratory, PSAT);

- Truck operator investment requirements - as provided by a survey of owner-operators performed by the American Trucking Association in 1997 (American Trucking Association 1997); 
- Important "background" information, such as energy prices and baseline technology fuel economies - as provided in the Annual Energy Outlook (Reference Case) prepared by the Energy Information Administration (EIA 2006). This information is used in the market penetration methodology of the TRUCK model, which is needed to estimate future fuel economies. Fuel prices beyond 2030 are based on extrapolating the prices in AEO in the 2030 to 2050 period using that average annual change from 2020 to 2030 .

The methodology involves the definition of the energy conservation or displacement and cost attributes of the advanced technologies being fostered by FCVT, the characterization of the markets affected, and the estimation of the benefits. Several models are used. Specifically, initial benefits estimates are generated through the linkage of four spreadsheet models (Singh 2003, Moore 2005):

- HTEB - Heavy-Truck Energy Balance Model (Version 2.0)

- TRUCK 3.0 - Heavy-Vehicle Market Penetration Model

- VISION 2006

- Heavy Truck Summary (HVS) report generator.

The relationship of these four models is indicated in Exhibit F-13. ${ }^{1}$ Cost estimates are developed separately.

The Heavy Truck Energy Balance Model (HTEBM) was developed to assess the overall fuel economy effect of several changes to the vehicle involving both the engine and other elements of the vehicle. This steady-state model accounts for energy losses based on user-selected inputs of vehicle use. The fuel economies of new advanced heavy-vehicle technologies estimated with the HTEB model are presented in Table F-10.

\footnotetext{
1 The HTEB was developed by William Shadis and James Moore of TA Engineering Inc.The TRUCK (2.0) Model was developed as a collaborative effort, initially by John Maples of Oak Ridge National Laboratory (ORNL), with assistance from James Moore, of TA Engineering Inc. Subsequent enhancements have been performed by Shadis and Moore (TA Engineering). The Vision model was developed by John Maples, Anant Vyas, and Margaret Singh of ANL. The Heavy Truck Summary Model is a report-generating spreadsheet. It was initially developed by Maples, and has subsequently been modified by TA Engineering.
} 
Table F-10. Advanced Heavy-Vehicle Characterization (New Vehicles)

\begin{tabular}{|c|c|c|c|c|c|c|c|c|c|c|c|}
\hline & Characteristic & \multicolumn{2}{|c|}{2010} & \multicolumn{2}{|c|}{2020} & \multicolumn{2}{|c|}{2030} & \multicolumn{2}{|c|}{2040} & \multicolumn{2}{|c|}{2050} \\
\hline 1 & $\begin{array}{l}\text { Fuel Economy Class 7-8, } \\
\text { Combination (Type 1) } \\
\text { mpg Multiplier }\end{array}$ & & 1.29 & & 1.55 & & 1.55 & & 1.55 & & 1.55 \\
\hline 2 & $\begin{array}{l}\text { Fuel Economy Class 7-8, } \\
\text { Single Unit (Type 2) } \\
\text { mpg Multiplier }\end{array}$ & & 1.28 & & 1.50 & & 1.50 & & 1.50 & & 1.50 \\
\hline 3 & $\begin{array}{l}\text { Fuel Economy Class 3-6 } \\
\text { Gasoline, mpg Multiplier }\end{array}$ & & 1.24 & & 1.45 & & 1.45 & & 1.45 & & 1.45 \\
\hline 4 & $\begin{array}{l}\text { Fuel Economy Class 3-6- } \\
\text { Diesel, mpg Multiplier }\end{array}$ & & 1.24 & & 1.44 & & 1.44 & & 1.44 & & 1.44 \\
\hline 5 & $\begin{array}{l}\text { Class 7-8, lincremental } \\
\text { Cost, \$ }\end{array}$ & $\$$ & 30,000 & $\$$ & 15,000 & $\$$ & 10,000 & & 10,000 & & 10,000 \\
\hline 6 & $\begin{array}{l}\text { Class 3-6 Gasoline, } \\
\text { Incremental Cost, \$ }\end{array}$ & $\$$ & 5,000 & $\$$ & 2,000 & $\$$ & 1,500 & $\$$ & 1,500 & $\$$ & 1,500 \\
\hline 7 & $\begin{array}{l}\text { Class 3-6 Diesel, } \\
\text { Incremental Cost, \$ }\end{array}$ & $\$$ & 7,500 & $\$$ & 2,500 & $\$$ & 2,000 & $\$$ & 2,000 & $\$$ & 2,000 \\
\hline
\end{tabular}


Exhibit F-13. Heavy-Truck Benefits Analysis Models

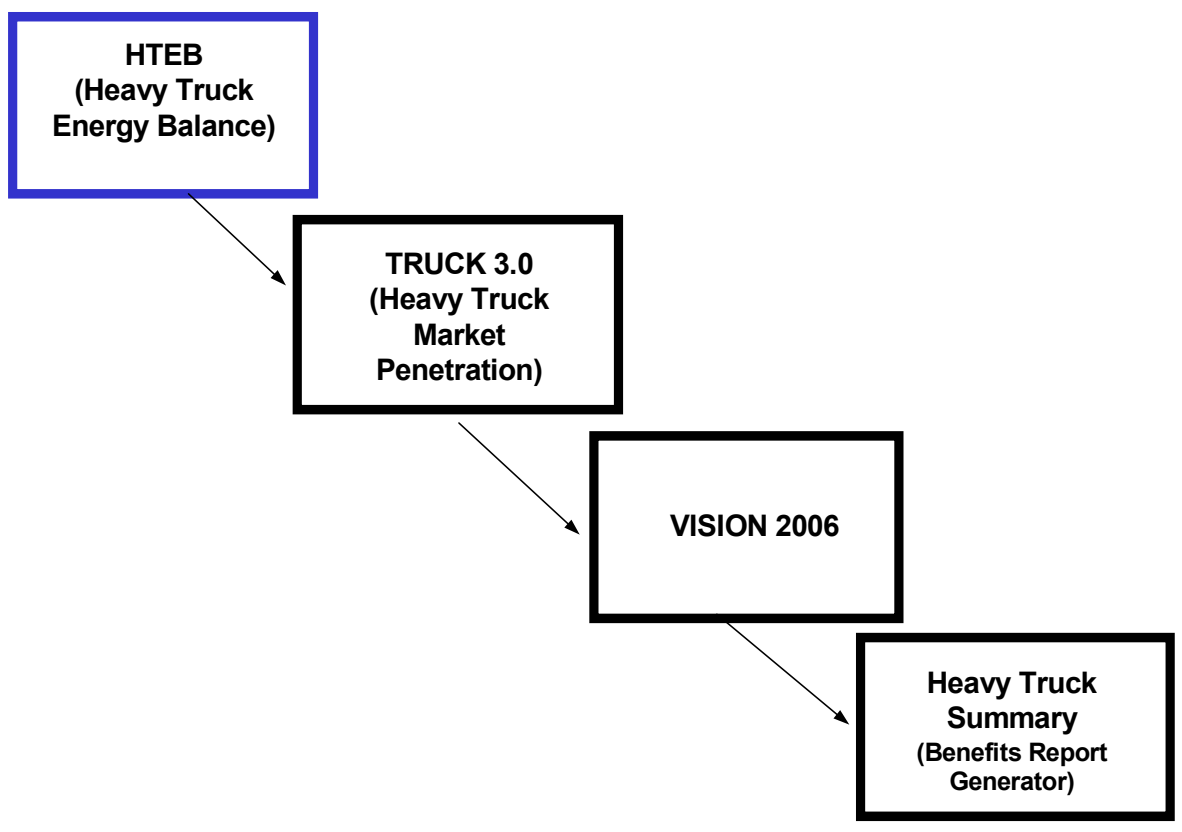

Table F-11. Example Price and Efficiency Schedule for Advanced Technologies

\begin{tabular}{|c|c|c|c|c|}
\hline \multirow[b]{3}{*}{ Year } & \multicolumn{4}{|c|}{ Class $7 \& 8$ Vehicle Assumptions } \\
\hline & \multicolumn{2}{|c|}{$\begin{array}{c}\text { Type } 1 \\
\text { Non-Hybrid Trucks }\end{array}$} & \multicolumn{2}{|c|}{$\begin{array}{c}\text { Type } 2 \\
\text { Non-Hybrid Trucks }\end{array}$} \\
\hline & $\begin{array}{c}\text { Non-Hybrid } \\
\text { Measures Cost } \\
(2003 \$)\end{array}$ & $\begin{array}{c}\text { Efficiency } \\
\text { Ratio }\end{array}$ & $\begin{array}{c}\text { Non-Hybrid } \\
\text { Measures Cost } \\
(2003 \$)\end{array}$ & $\begin{array}{l}\text { Efficiency } \\
\text { Ratio }\end{array}$ \\
\hline 2006 & 42,000 & 1.138 & 42,000 & 1.137 \\
\hline 2010 & 30,000 & 1.289 & 30,000 & 1.285 \\
\hline 2015 & 20,000 & 1.289 & 20,000 & 1.285 \\
\hline 2020 & 15,000 & 1.546 & 15,000 & 1.498 \\
\hline 2025 & 10,000 & 1.546 & 10,000 & 1.498 \\
\hline 2030 & 10,000 & 1.546 & 10,000 & 1.498 \\
\hline 2035 & 10,000 & 1.546 & 10,000 & 1.498 \\
\hline 2040 & 10,000 & 1.546 & 10,000 & 1.498 \\
\hline 2045 & 10,000 & 1.546 & 10,000 & 1.498 \\
\hline 2050 & 10,000 & 1.546 & 10,000 & 1.498 \\
\hline
\end{tabular}

The price estimates for these vehicles are also presented in Table F-10. All prices are in 2004 dollars. Technology cost is not really estimated; any assumed added cost is selected to have a two-year payback. As an example, the price schedule for the Table F-10 technologies in the Long Haul vehicle application is indicated in Table F-11. This process was replicated for Medium Trucks to develop similar cost estimates. 
The values for fuel economy improvement from HTEBM and cost are then input to TRUCK 3.0. This model was developed to estimate the potential market impacts of new technologies on the medium and heavy truck market. The results generated by this model are:

- Market penetrations, in units of percent of new vehicles sold for each type and class of vehicle, and

- Composite fuel economy rating (new mpg) of the vehicles sold for each truck type.

The TRUCK 3.0 model estimates market penetration based on the cost-effectiveness of the new technology. Cost-effectiveness is measured as the incremental cost of the new technology less the expected energy savings of that technology over a specified time period in relation to specified payback periods. The TRUCK model market penetration calculation method for Class 7 and 8, Type 1 vehicles is described in Exhibit F-14.

The market penetration results are supplied through a link to the VISION model (Singh 2003). The VISION model is used to estimate preliminary or first-order oil/energy use and $\mathrm{CO}_{2}$ emissions from highway vehicles through 2050 by program element. It contains a baseline estimate of heavy vehicle energy use to 2050. Through 2030 that baseline is the same as that of the AEO.

For the period from 2030 to 2050 the baseline energy use is very similar to that of MARKAL. By inputting the market penetration and fuel economy of the advanced heavy vehicle technologies into the model, an alternative estimate of future heavy vehicle energy use is generated and benefits relative to the baseline can be estimated.

Since VISION does not disaggregate Types 1 and 2 Heavy Trucks or Medium Trucks, the fuel economy multipliers generated by Truck 3.0 are aggregated on both a sales and VMT-weighted basis for input to VISION. These aggregated fuel economy multipliers are provided in Exhibit 15. Specifically, the factors in cells that are highlighted in yellow are provided for input to the NEMS and MARKAL models.

The baseline fuel economies for each market sector are determined based on the AEO fuel economy projection (extrapolated to 2050) using a calculation methodology to determine what the fuel economy of each market sector needs to be consistent with AEO. The market penetration estimates presented in Exhibit 16 are the factors ultimately used in the EERE-wide integrated analysis.

Finally, the Heavy Truck Summary report generator summarizes the first order benefits for the period covering 2000 through 2050. Benefits include the following:

- Heavy Truck Petroleum Use and Savings, by Class 3-6 and Class 7-8, Million BPD

- Heavy Truck Petroleum Savings - \%

- Class 7\&8 Truck Savings by Program Element (Technology), Million BPD

- Local Use Truck Savings by Program Element (Technology), Million BPD

- Intermediate Truck Savings by Program Element (Technology), Million BPD

- Long-Haul Truck Savings by Program Element (Technology), Million BPD.

These first order benefits have been generated and will be reported in a forthcoming report. The FCVT benefits cannot be generated by the NEMS and MARKAL models. 


\section{Exhibit 14: Truck Payback Algorithm-Type 1 Trucks (Combinations)}

\begin{tabular}{|c|c|c|}
\hline Spreadsheet Location & Description & Comments \\
\hline Column A & Year & Identifies year for which values, calcuations and results are representative. \\
\hline Columns B - F & Fuel Economy by Technology & $\begin{array}{l}\text { Values are developed based on baseline technology mpg assumptions and } \\
\text { efficiency ratios for advanced technologies. }\end{array}$ \\
\hline Column G & Cost of Alternative Fuel in \$/GGE & Links to Fuel Prices Page \\
\hline Columns H - I & $\begin{array}{l}\text { Calculates annual savings for } 2 \text { alternative } \\
\text { technologies }\end{array}$ & $\begin{array}{l}\text { For Advanced Diesel: } \\
\text { (VMT(C10)×\$/GGE/Baseline MPG - VMT x \$/GGE/Adv. Diesel MPG) }\end{array}$ \\
\hline Columns J - M & $\begin{array}{l}\text { Calculates Net Present Value of Savings for } \\
\text { 'Advanced Diesel' }\end{array}$ & Column J: 1 Year, K: 2 years, L: 3 years; M: 4 years \\
\hline Columns N - Q & $\begin{array}{l}\text { Calculates Net Present Value of Savings for } \\
\text { 'Alternative Fuel Technology' }\end{array}$ & Column N: 1 Year, O: 2 years, P: 3 years; Q: 4 years \\
\hline Columns R - U & $\begin{array}{l}\text { If-then Statement to determine 'Cost Effectiveness } \\
\text { Factor' (CEF) }\end{array}$ & $\begin{array}{l}\text { If NPV of savings is > Cost of Technology, cell value is (cost - } \\
\text { NPVSavings)/Cost; Otherwise cell value is } 0 . \text { Columns are for paybacks of } 1,2 \text {, } \\
3 \text {, and } 4 \text { years. }\end{array}$ \\
\hline Column V & $\begin{array}{l}\text { Technology purchase cost 'Alternative Fuel } \\
\text { Technology' }\end{array}$ & Values are linked to Cost values on 'Inputs' page. \\
\hline Column W - Z & $\begin{array}{l}\text { Repeats calcuations in Columns R through U for } \\
\text { 'Alternative Fuel Technology' }\end{array}$ & \\
\hline Column AA & $\begin{array}{l}\text { If-then Statement to determine 'Technology } \\
\text { Adoption Factor' (TAF) for 'Advanced Diesel' }\end{array}$ & $\begin{array}{l}\text { If 'Cost Effectiveness Factor' for Year } 1 \text { PB is 0, cell value }=100 \text {; Otherwise }(100 \\
((\exp (1995 \text { CE Factor-Current Yr. Factor) }-1) / 10 \times 100)\end{array}$ \\
\hline Column AB & $\begin{array}{l}\begin{array}{l}\text { Continuation of TAF Calculation for Year } 1 \text { Payback } \\
\text { market }\end{array} \\
\end{array}$ & If $\mathrm{AA}<0$, cell value is 1 ; Otherwise the Value is the same as $\mathrm{AA}$. \\
\hline Columns AC + AD & Repeat $A A$ and $A B$ for 2 year payback market & \\
\hline Columns AE + AF & Repeat $\mathrm{AA}$ and $\mathrm{AB}$ for 3 year payback market & \\
\hline Columns AG + AH & Repeat $\mathrm{AA}$ and $\mathrm{AB}$ for 4 year payback market & \\
\hline Columns Al - AP & $\begin{array}{l}\text { Repeat Columns AA through AH methodology for } \\
\text { 'Alt. Fuel Technology' }\end{array}$ & \\
\hline Column AQ & $\begin{array}{l}\text { If-then statement. Start of Market Penetration for } \\
\text { 'Advanced Diesel' }\end{array}$ & $\begin{array}{l}\text { If } \mathrm{AB}=100, \text { then cell value is } 0 \text {; Otherwise cell value is } \\
(1 /(1+\text { Abvalue/exp }(-2 \times \text { Col. } R \text { CEF for } 1 \text { Year PB }))\end{array}$ \\
\hline Column AR & Same as $\mathrm{AQ}$, but for 2 year PB market. & \\
\hline Column AS & Same as $A Q$, but for 3 year PB market. & \\
\hline Column AT & Same as $A Q$, but for 4 year PB market. & \\
\hline Column AU & $\begin{array}{l}\text { Final, Step 1; Weighted average market penetration } \\
\text { for year } 1 \text { through year } 4 \text { markets weighting factors }\end{array}$ & $\begin{array}{l}\text { Weighting factors are based on ATA survey results and are listed at the top of } \\
\text { Columns AQ-AT. }\end{array}$ \\
\hline Column AV & $\begin{array}{l}\text { Final, Step 2: Reduces Market Penetration to } \\
\text { account for market penetration of 'Atl. Fuel } \\
\text { Technology' and stay below } 100 \% \text { share. }\end{array}$ & $=+\left(\mathrm{AU}+(1-\mathrm{BA})^{*} \mathrm{AU}\right) / 2$ \\
\hline Columns AW - AZ & $\begin{array}{l}\text { Same as columns AQ - AT for 'Alterntive fuel } \\
\text { technology'. }\end{array}$ & \\
\hline Column BA & $\begin{array}{l}\text { Final, Step 1; For 'Alt. Fuel Tech.', weighted average } \\
\text { market penetration for year } 1 \text { through year } 4 \\
\text { markets weighting factors }\end{array}$ & \\
\hline Column BB & $\begin{array}{l}\text { Final, Step 2: Reduces Market Penetration to } \\
\text { account for market penetration of 'Atl. Fuel } \\
\text { Technology' and stay below } 100 \% \text { share. }\end{array}$ & \\
\hline Columns BD - BN & $\begin{array}{l}\text { Macro Results Array-Centrally Refueled Advanced } \\
\text { Diesels }\end{array}$ & $\begin{array}{l}\text { Results from running the calculation for centrally refueled Type } 1 \text { trucks are } \\
\text { printed in this part of spreadsheet }\end{array}$ \\
\hline BO & $\begin{array}{l}\text { Final Step 3: 'Advanced Diesel' (Centrally Refueled) } \\
\text { Summation of \%VMT that is centrally refueled for } \\
\text { the VMT range (e.g. } 0-19.9 k)^{*} \% \text { Market penetration } \\
\text { for BD - BN array. }\end{array}$ & Results are linked to Market Penetration Page \\
\hline Columns BQ - CA & $\begin{array}{l}\text { Macro Results Array-Centrally Refueled Alternative } \\
\text { Fuels }\end{array}$ & $\begin{array}{l}\text { Macro results are printed in this part of spreadsheet. Alt Fuel technology only } \\
\text { competes in Centrally Refueled Segment }\end{array}$ \\
\hline $\mathrm{CB}$ & $\begin{array}{l}\text { Final Step 3: 'Alt. Fuel' Summation of } \% \text { VMT that is } \\
\text { centrally refueled for the VMT range (e.g. } 0-19.9 k)^{\star} \% \\
\text { Market penetration for BD - BN array. }\end{array}$ & Results are linked to Market Penetration Page \\
\hline Columns CD - CN & $\begin{array}{l}\text { Macro Results Array-Non Centrally Refueled } \\
\text { Advanced Diesels }\end{array}$ & Macro results are printed in this part of spreadsheet \\
\hline CO & $\begin{array}{l}\text { Final Step 3: 'Advanced Diesel' (Non-centrally } \\
\text { refueled) Summation of \%VMT that is centrally } \\
\text { refueled for the VMT range (e.g. } 0-19.9 k)^{*} \% \text { Market } \\
\text { penetration for BD - BN array. }\end{array}$ & Results are linked to Market Penetration Page \\
\hline
\end{tabular}

Projected Benefits of Federal Energy Efficiency and Renewable Energy Programs (FY 2008-FY 2050) Appendix F-FreedomCAR and Vehicle Technologies Program - Page F-47 


\section{Exhibit 15: Advanced Heavy Vehicle Market Penetration and Fuel Economy Results for NEMS}

\section{GPRA 08 Heavy Vehicle Benefits Results for NEMS Modeling}

\begin{tabular}{|c|c|c|c|c|c|c|c|c|c|c|c|c|}
\hline \multirow[b]{2}{*}{ Year } & \multicolumn{6}{|l|}{ Class $7 \& 8$} & \multicolumn{6}{|l|}{ Class 3 - 6} \\
\hline & $\begin{array}{c}\text { Combined } \\
\text { Market } \\
\text { Penetration, } \\
\% \text { VMT }\end{array}$ & $\begin{array}{l}\text { Base MPG } \\
\text { (VISION- } \\
\text { Adusted) in } \\
\text { gasoline } \\
\text { equivalent } \\
\text { gallons }\end{array}$ & \begin{tabular}{|c|} 
Fuel \\
Economy \\
Multiplier only \\
for trucks \\
with new \\
techology \\
which \\
achieve the \\
market \\
penetration \\
shown in \\
Column 2 and \\
Relative to \\
2005Truck \\
\end{tabular} & \begin{tabular}{|c|} 
\\
Fuel Economy \\
for All New \\
Technology \\
Sales, \\
mpg \\
\\
\end{tabular} & $\begin{array}{l}\text { Estimate of } \\
\text { fuel economy } \\
\text { for all new 7-8 } \\
\text { trucks }\end{array}$ & \begin{tabular}{|c||} 
Estimate of $X$ \\
factor to input \\
to VISION \\
(only those \\
for 2010, \\
2020,2030, \\
$2040+2050$ \\
are input)
\end{tabular} & $\begin{array}{c}\text { Combined } \\
\text { Market } \\
\text { Penetration, } \% \\
\text { VMT }\end{array}$ & $\begin{array}{l}\text { Base MPG } \\
\text { (VISION } \\
\text { Adjusted) in } \\
\text { gasoline } \\
\text { equivalent } \\
\text { gallons }\end{array}$ & $\begin{array}{c}\text { Fuel Economy } \\
\text { Multiplier only } \\
\text { for trucks with } \\
\text { new techology } \\
\text { which achieve } \\
\text { the market } \\
\text { penetration } \\
\text { shown in } \\
\text { Column 10 } \\
\text { Relative to 2005 } \\
\text { Truck }\end{array}$ & $\begin{array}{c}\text { Fuel Economy } \\
\text { for All New } \\
\text { Technology } \\
\text { Sales, } \\
\text { mpg }\end{array}$ & $\begin{array}{c}\begin{array}{c}\text { Estimate of } \\
\text { fuel }\end{array} \\
\text { economy for } \\
\text { all new 3-6 } \\
\text { trucks }\end{array}$ & \begin{tabular}{|c} 
Estimate of $X$ \\
factor to input \\
to VISION (only \\
those for 2010, \\
2020,2030, \\
$2040+2050$ are \\
input)
\end{tabular} \\
\hline 1 & 2 & 3 & \begin{tabular}{|c|}
4 \\
\end{tabular} & 5 & 6 & 7 & 8 & 9 & 10 & 11 & 12 & 13 \\
\hline 2000 & $0 \%$ & 6.15 & 1.00 & 6.15 & 6.15 & 1.00 & $0 \%$ & 8.83 & 1.00 & 8.59 & 8.83 & 1.00 \\
\hline 2001 & $0 \%$ & 6.15 & 1.00 & 6.15 & 6.15 & 1.00 & $0 \%$ & 8.80 & 1.00 & 8.59 & 8.80 & 1.00 \\
\hline 2002 & $0 \%$ & 6.15 & 1.00 & 6.15 & 6.15 & 1.00 & $0 \%$ & 8.77 & 1.00 & 8.59 & 8.77 & 1.00 \\
\hline 2003 & $0 \%$ & 6.15 & 1.00 & 6.15 & 6.15 & 1.00 & $0 \%$ & 8.73 & 1.00 & 8.59 & 8.73 & 1.00 \\
\hline 2004 & $0 \%$ & 6.15 & 1.00 & 6.15 & 6.15 & 1.00 & $0 \%$ & 8.70 & 1.00 & 8.59 & 8.70 & 1.00 \\
\hline 2005 & $0 \%$ & 6.15 & 1.00 & 6.15 & 6.15 & 1.00 & $0 \%$ & 8.59 & 1.00 & 8.59 & 8.59 & 1.00 \\
\hline 2006 & $0 \%$ & 6.15 & 1.01 & 6.22 & 6.15 & 1.00 & $0 \%$ & 8.57 & 1.01 & 8.69 & 8.57 & 1.00 \\
\hline 2007 & $0 \%$ & 6.15 & 1.02 & 6.29 & 6.15 & 1.00 & $0 \%$ & 8.56 & 1.02 & 8.79 & 8.56 & 1.00 \\
\hline 2008 & $0 \%$ & 6.15 & 1.03 & 6.36 & 6.15 & 1.00 & $0 \%$ & 8.56 & 1.03 & 8.88 & 8.56 & 1.00 \\
\hline 2009 & $0 \%$ & 6.15 & 1.05 & 6.43 & 6.15 & 1.00 & $0 \%$ & 8.55 & 1.05 & 8.98 & 8.55 & 1.00 \\
\hline 2010 & $0 \%$ & 6.15 & 1.06 & 6.50 & 6.15 & 1.00 & $0 \%$ & 8.55 & 1.06 & 9.08 & 8.56 & 1.00 \\
\hline 2011 & $0 \%$ & 6.15 & 1.11 & 6.80 & 6.15 & 1.00 & $1 \%$ & 8.55 & 1.10 & 9.41 & 8.56 & 1.00 \\
\hline 2012 & $0 \%$ & 6.15 & 1.15 & 7.10 & 6.15 & 1.00 & $1 \%$ & 8.55 & 1.13 & 9.74 & 8.57 & 1.00 \\
\hline 2013 & $0 \%$ & 6.15 & 1.20 & 7.39 & 6.15 & 1.00 & $1 \%$ & 8.56 & 1.17 & 10.07 & 8.57 & 1.00 \\
\hline 2014 & $1 \%$ & 6.16 & 1.25 & 7.69 & 6.16 & 1.00 & $2 \%$ & 8.56 & 1.21 & 10.40 & 8.59 & 1.00 \\
\hline 2015 & $2 \%$ & 6.17 & 1.42 & 8.73 & 6.20 & 1.00 & $3 \%$ & 8.56 & 1.34 & 11.49 & 8.62 & 1.01 \\
\hline 2016 & $4 \%$ & 5.96 & 1.47 & 9.02 & 6.04 & 1.01 & $6 \%$ & 8.57 & 1.36 & $\begin{array}{l}11.66 \\
\end{array}$ & 8.71 & 1.02 \\
\hline 2017 & $9 \%$ & 6.00 & 1.52 & 9.32 & 6.19 & 1.03 & $10 \%$ & 8.57 & 1.38 & 11.84 & 8.82 & 1.03 \\
\hline 2018 & $14 \%$ & 6.03 & 1.56 & 9.62 & 6.35 & 1.05 & $17 \%$ & 8.57 & 1.40 & 12.01 & 9.01 & 1.05 \\
\hline 2019 & $24 \%$ & 6.03 & 1.61 & 9.91 & 6.66 & 1.10 & $32 \%$ & 8.57 & 1.42 & 12.19 & 9.46 & 1.10 \\
\hline 2020 & $43 \%$ & 6.04 & 1.54 & 9.47 & 7.14 & 1.18 & $41 \%$ & 8.57 & 1.44 & 12.36 & 9.82 & 1.15 \\
\hline 2021 & $43 \%$ & 6.04 & 1.54 & $\begin{array}{l}9.47 \\
\end{array}$ & 7.17 & 1.19 & $44 \%$ & 8.62 & 1.44 & 12.36 & 9.95 & 1.15 \\
\hline 2022 & $51 \%$ & 6.08 & 1.54 & 9.47 & 7.45 & 1.22 & $45 \%$ & 8.62 & 1.44 & 12.36 & 9.96 & 1.16 \\
\hline 2023 & $55 \%$ & 6.09 & 1.54 & 9.47 & 7.56 & 1.24 & $45 \%$ & 8.62 & 1.44 & 12.36 & 9.99 & 1.16 \\
\hline 2024 & $57 \%$ & 6.10 & 1.54 & 9.47 & 7.65 & 1.26 & $47 \%$ & 8.62 & 1.44 & 12.36 & 10.06 & 1.17 \\
\hline 2025 & $63 \%$ & 6.16 & 1.54 & 9.47 & 7.91 & 1.28 & $54 \%$ & 8.82 & 1.44 & 12.36 & 10.45 & 1.18 \\
\hline 2026 & $63 \%$ & 6.16 & 1.54 & 9.47 & 7.91 & 1.28 & $56 \%$ & 8.82 & 1.44 & 12.36 & 10.49 & 1.19 \\
\hline 2027 & $64 \%$ & 6.16 & 1.54 & 9.47 & 7.92 & 1.29 & $56 \%$ & 8.82 & 1.44 & 12.36 & 10.49 & 1.19 \\
\hline 2028 & $63 \%$ & 6.16 & 1.54 & 9.47 & 7.91 & 1.28 & $56 \%$ & 8.82 & 1.44 & 12.36 & 10.49 & 1.19 \\
\hline 2029 & $64 \%$ & 6.16 & 1.54 & 9.47 & 7.92 & 1.29 & $57 \%$ & 8.82 & 1.44 & 12.36 & 10.55 & 1.20 \\
\hline 2030 & $64 \%$ & 6.17 & 1.54 & 9.47 & 7.93 & 1.28 & $59 \%$ & 8.82 & 1.44 & 12.36 & 10.61 & 1.20 \\
\hline 2031 & $64 \%$ & 6.18 & 1.54 & 9.47 & 7.94 & 1.28 & $61 \%$ & 8.85 & 1.44 & 12.36 & 10.72 & 1.21 \\
\hline 2032 & $64 \%$ & 6.20 & 1.54 & 9.47 & 7.95 & 1.28 & $66 \%$ & 8.87 & 1.44 & 12.36 & 10.89 & 1.23 \\
\hline 2033 & $64 \%$ & 6.21 & 1.54 & 9.47 & 7.96 & 1.28 & $66 \%$ & 8.90 & 1.44 & 12.36 & 10.91 & 1.23 \\
\hline 2034 & $64 \%$ & 6.22 & 1.54 & 9.47 & 7.97 & 1.28 & $66 \%$ & 8.93 & 1.44 & 12.36 & 10.92 & 1.22 \\
\hline 2035 & $64 \%$ & 6.24 & 1.54 & 9.47 & 7.99 & 1.28 & $66 \%$ & 8.95 & 1.44 & 12.36 & 10.94 & 1.22 \\
\hline 2036 & $64 \%$ & 6.25 & 1.54 & 9.47 & 8.00 & 1.28 & $66 \%$ & 8.98 & 1.44 & 12.36 & 10.95 & 1.22 \\
\hline 2037 & $65 \%$ & 6.27 & 1.54 & 9.47 & 8.03 & 1.28 & $66 \%$ & 9.01 & 1.44 & 12.36 & 10.97 & 1.22 \\
\hline 2038 & $65 \%$ & 6.28 & 1.54 & 9.47 & 8.04 & 1.28 & $66 \%$ & 9.03 & 1.44 & 12.36 & 10.98 & 1.22 \\
\hline 2039 & $65 \%$ & 6.29 & 1.54 & 9.47 & 8.06 & 1.28 & $66 \%$ & 9.06 & 1.44 & 12.36 & 11.00 & 1.21 \\
\hline 2040 & $65 \%$ & 6.31 & 1.54 & 9.47 & 8.07 & 1.28 & $66 \%$ & 9.09 & 1.44 & 12.36 & 11.01 & 1.21 \\
\hline 2041 & $65 \%$ & 6.32 & 1.54 & 9.47 & 8.08 & 1.28 & $66 \%$ & 9.12 & 1.44 & 12.36 & 11.03 & 1.21 \\
\hline 2042 & $65 \%$ & 6.34 & 1.54 & 9.47 & 8.09 & 1.28 & $66 \%$ & 9.14 & 1.44 & 12.36 & 11.04 & 1.21 \\
\hline 2043 & $65 \%$ & 6.35 & 1.54 & 9.47 & 8.10 & 1.27 & $66 \%$ & 9.17 & 1.44 & 12.36 & 11.06 & 1.21 \\
\hline 2044 & $66 \%$ & 6.37 & 1.54 & 9.47 & 8.11 & 1.27 & $66 \%$ & 9.20 & 1.44 & 12.36 & 11.07 & 1.20 \\
\hline 2045 & $66 \%$ & 6.38 & 1.54 & 9.47 & 8.12 & 1.27 & $66 \%$ & 9.23 & 1.44 & 12.36 & 11.09 & 1.20 \\
\hline 2046 & $66 \%$ & 6.40 & 1.54 & 9.47 & 8.13 & 1.27 & $66 \%$ & 9.26 & 1.44 & 12.36 & 11.11 & 1.20 \\
\hline 2047 & $66 \%$ & 6.41 & 1.54 & 9.47 & 8.14 & 1.27 & $66 \%$ & 9.28 & 1.44 & 12.36 & 11.13 & 1.20 \\
\hline 2048 & $66 \%$ & 6.43 & 1.54 & 9.47 & 8.15 & 1.27 & $67 \%$ & 9.31 & 1.44 & 12.36 & 11.14 & 1.20 \\
\hline 2049 & $66 \%$ & 6.44 & 1.54 & 9.47 & 8.16 & 1.27 & $67 \%$ & 9.34 & 1.44 & 12.36 & 11.16 & 1.20 \\
\hline 2050 & $66 \%$ & 6.45 & 1.54 & 9.47 & 8.18 & 1.27 & $67 \%$ & 9.37 & 1.44 & 12.36 & 11.19 & 1.19 \\
\hline
\end{tabular}




\section{Heavy-Truck Energy Use Models: Workbooks, Inputs, and Outputs}

Specific workbooks used in the modeling system are listed below. Exhibit 16 provides a detailed view of the relationships among the four principal models. In practice, calendar dates indicating times of use are added to the file names for specific energy benefits analysis exercises, but these are omitted in this discussion.

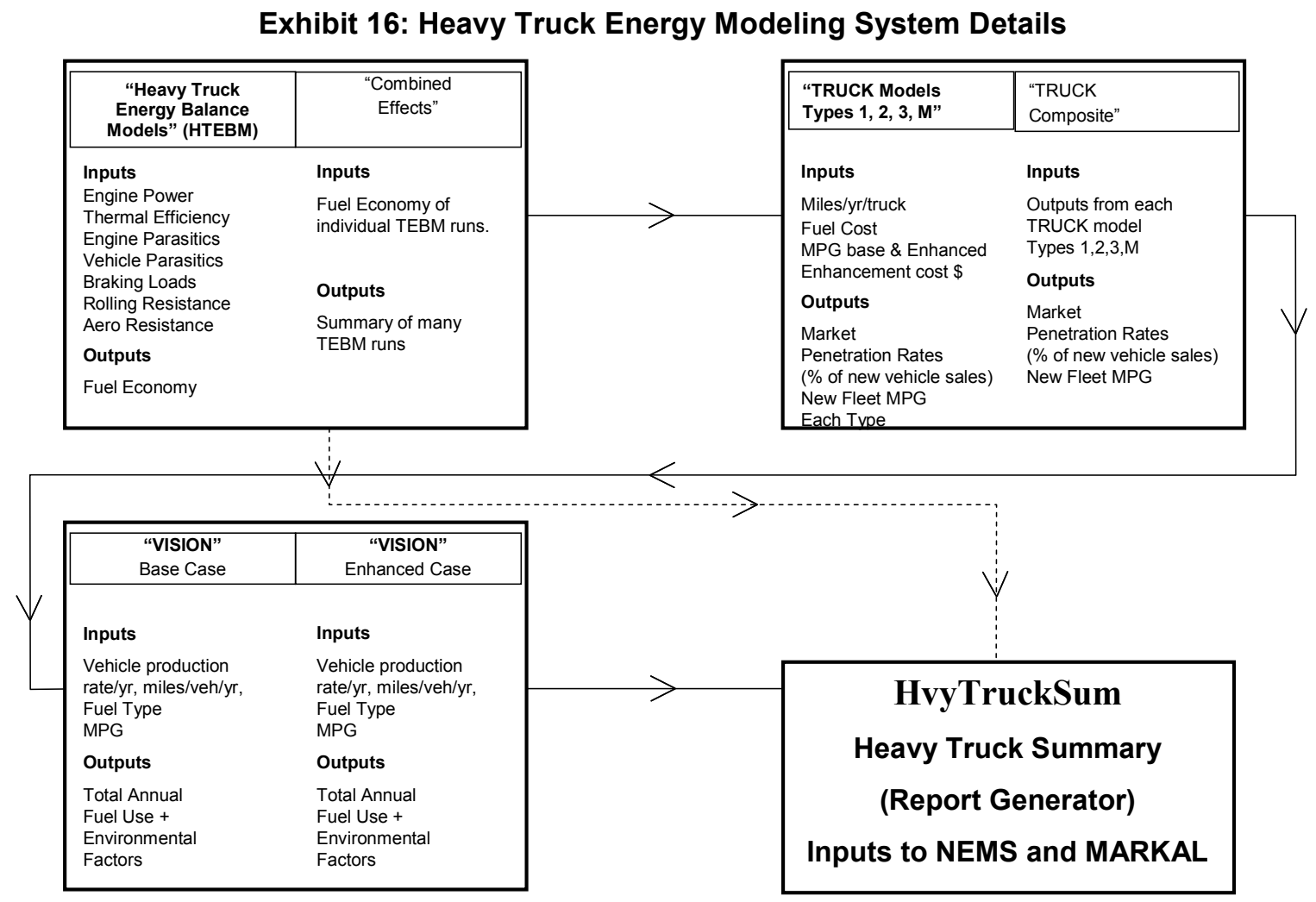

1. Heavy Truck Energy Balance Model (HTEBM)-Version 3.0 (Ref. 18).

- Energy Balance Workbook-Baseline Model

- Energy Balance Workbook-Technology Model(s) (copied from the Baseline Model)

- Combined Effects (used to allocate fuel savings among several technologies).

2. TRUCK (Market Penetration) Models

- $\quad$ TRUCK-2 Type 1 (projects market penetration of Class 7 and 8, Type 1 heavy trucks to 2050).

- $\quad$ TRUCK-2 Type 2 (projects market penetration of Class 7 and 8, Type 2 heavy trucks to 2050$)$. 
- TRUCK-2 Type M (projects market penetration of Classes 3-6 Type heavy trucks to 2050).

- TRUCK-2 Composite (combines all Type 1,2, and M results to obtain summary market penetrations and fleet average fuel economies).

\section{VISION MODELS}

- VISION 2006 AEO ICE MPG Base Case (projects energy use of baseline truck fleet to 2050).

- VISION GPRA0 8Veh.Mi-1 (projects energy use of improved truck fleet to 2050).

4. Inputs to NENS and MARKAL for official EERE GRPA benefits estimates. Also, inputs to HvyTrkSum-GPRA-V1 which calculates energy and carbon savings by HT type (which NEMS and MARKAL cannot do) for use by FCVT for their own internal analysis.

\section{HTEBM (Heavy Truck Energy Balance Model) Version 2.0}

The Heavy Truck Energy Balance Model is based on a simplified calculation of average road loads experienced by typical heavy trucks. It calculates an average fuel economy that balances the truck engine output with the needs to meet engine friction, accessory loads, auxiliary loads and road loads (rolling resistance, aerodynamic resistance, and vehicle braking loads). The model is a method to match baseline vehicles with actual road-load fuel economy results and then to estimate the variations in fuel economy that will occur when various engine and vehicle operational characteristics are changed. Therefore, it is important that actual, simulation-based, or program goals for road-load vehicle fuel economy values be available.

Fuel savings result from a combination of technologies-load reducing technologies and engine efficiency-increasing technologies. Each technology under consideration and each analysis year requires a separate run of HTEBM. Because each run includes both input assumptions and results, they need to be maintained for adequate support and documentation.

Engine/Vehicle improvements that lead to reduced fuel use can be categorized under the following headings.

- Increased engine cycle efficiency

- Increase compression ratio

- Reduced engine thermal losses

- Reduced engine internal friction loads

- Air-Breathing Losses

- Pistons \& Piston Rings

- Rod and crankshaft bearings

- Valve train/camshaft

- Reduced engine accessory loads

- Fuel Injector

- Power Steering

- Oil Pump 
- Coolant Pump

- Engine fan

- Reduced drive-train parasitic loads

- Transmission

- Driveshaft

- Axle/Transaxle

- Differential

- Axle \& Wheel bearings

- Brake Drag

- Reduced vehicle auxiliary system loads

- Alternator

- Air Conditioner

- Air Brake Compressor

- Reduced road-loads

- Aerodynamic loads

- Rolling resistance loads

- Braking loads.

For this benefits analysis, analysts developed vehicle characteristics to support fuel economy goals in 2010, 2020, 2030, 2040, and 2050.

"Combined Effects" Workbook" - The results of the multiple runs of HTEBM are collected in this summary workbook. Whereas HTEBM permits only one set of conditions per run, "Combined Effects" can store any number of HTEBM results.

The Combined Effects Submodel is used to allocate the fuel savings among the several technologies included in the Truck Technology option. This is done by assuming that the percentage of fuel savings attributable to each separate technology will be proportional to the relative fuel economy improvement of each separate technology, taken separately.

Currently, "Combined Effects" includes three individual heavy vehicle technologies (accessory loads reduction, engine efficiency increase, and aerodynamic drag reduction). These can be varied to other technologies or Technology Program definitions by the user, if desired.

\section{TRUCK 3.0 Market Penetration Models}

The fuel-saving technologies under analysis are characterized in the TRUCK 3.0 models in terms of the projected fuel economy improvement ratio (new fuel economy divided by the baseline fuel economy), the installed cost of the improvement (\$ per vehicle), and the cost of the fuel type being used. Market penetration occurs for technologies that meet payback values of four years or less. If technology cost information is not available, cost equivalent to a two-year payback is assumed. TRUCK 3.0 can be set to assume the following heavy truck fuels: diesel fuel, gasoline, liquefied propane gas (LPG), ethanol, compressed natural gas (CNG), or electricity (battery storage). 
The output for each truck type is a projection of market penetration rates (percent of new vehicle sales) by class and type through 2050. The absolute number of trucks projected to be equipped with the new technology is calculated in the VISION model (see below).

\section{“TRUCK Composite” Submodel}

This model collects the market penetration data from the four TRUCK models. It was created as a separate workbook because the TRUCK models are all driven by macros and with distinct inputs. The market penetration and fuel economy results for each of the truck types are linked to this workbook.

\section{VISION Models}

VISION Base Case Model - The VISION models accept average new fleet MPG values for Class 3-6 and Class 7 and 8 vehicles and calculate the amount of fuel used each year as these vehicles mature, age, and eventually wear out within the operating fleet. Calculations are made for 2000 to 2050 .

VISION Enhanced Case Model - This version of VISION calculates the fleet energy use assuming that the proposed technologies (fuel savings technologies) are introduced into the new vehicle fleet as calculated by the TRUCK models. Fuel economy and market penetration results from the TRUCK models are consolidated into a single value (for each year to 2050) for Class 7 and 8, and a single value for Classes 3 through 6, using VMT data to weight the fuel economies of each truck type.

\section{Heavy Truck Summary Model (HvyTrkSum)}

Key inputs and results of the Truck Model analysis are summarized in the HvyTrkSum workbook. The format used here is intended to meet the needs and requirements of DOE EERE. HvyTrkSum results form the basis of the benefits of the Heavy Truck program elements. 


\section{Bibliography}

American Trucking Association, 1997 Return on Investment Survey, Arlington Va., 1997.

Argonne National Laboratory, PSAT (POWERTRAIN SYSTEM ANALYSIS TOOLKIT): see http://www.transportation.anl.gov/software/PSAT/

Clean Air Task Force, Diesel Federal Rulemaking, http://www.catf.us/projects/diesel/rulemaking.php, accessed on 10/04/2006

Davis, S., et al, Transportation Energy Data Book, Edition 25, ORNL-6974, 2006.

Davis, S., Personal Communication, ORNL, June 2005

Davis, S., Personal Communication, ORNL, November 2001

DOE Program on Parasitic Energy Loss Reduction for Class $7 \& 8$ Trucks (Heavy Vehicle Systems Optimization), DOE, April 18, 2006.

Efficiency Improvement through Reduction of Friction and Wear in Powertrain Systems, Bohdan Lisowsky, Eaton, April 19, 2006.

EIA, Annual Energy Outlook 2006 With Projections to 2030, Department of Energy, Washington, D. C., (http://www.eia.doe.gov/bookshelf.html Library/Archives-Forecasting).

EIA, The Transition to Ultra-Low-Sulfur Diesel Fuel: Effects on Prices and Supply 2. Efficiency and Cost Impacts of Emission Control Technologies: http://www.eia.doe.gov/oiaf/servicerpt/ulsd/chapter2.html, last updated on 06/12/2001

Maples, J., Transportation Working Group Meeting, EIA, September 29, 2006

Moore, J, Payback model from TA Engineering (2003) and expanded by Margaret Singh, ANL (2005).

Moore, J. Heavy Truck Energy Balance Model User Comments Guide, Revised-Draft; TA Engineering, Inc.; July 20, 2005

National Energy Policy Development Group, Report of the National Energy Policy Development Group, May 2001.

National Research Council, "Effectiveness and Impact of Corporate Average Fuel Economy (CAFÉ) Standards", NAS, 2002.

Office of Efficiency and Renewable Energy, Strategic Plan U.S. Department of Energy, DOE/GO-102002-1649 (October 2002).

Office of FreedomCAR and Vehicle Technologies, FreedomCAR and Vehicle Technologies R \& D Plan (Draft), August 22, 2003, U.S. Department of Energy. 
Office of Transportation Technologies, Program Analysis Methodology: Office of Transportation Technologies, Quality Metrics 2003 Final Report, U.S. Department of Energy (March 2002).

Parasitic Energy Loss Mechanism Impact on Vehicle System Efficiency, George Fenske, Robert Erck, Layo Ajayi, Ali Erdemir, and Osman Eryilmaz, ANL, April 18, 2006.

Rousseau, A, Number Associated with Presentation, Argonne National Laboratory, July 6, 2005.

Sharer, P. and Rousseau, A. PSAT Results for GREET and GPRA - FE Adjusted 081705.xls, Argonne National Laboratory, August 17, 2005.

Singh, M., Vyas, A., Steiner, E. VISION Model: Description of Model Used to Estimate the Impact of Highway Vehicle Technologies and Fuels on Energy Use and Carbon Emissions to 2050, ANL/ESD/04-1 (Dec. 2003).

U.S. Bureau of the Census, 2002 Vehicle Inventory and Use Survey, EC97TV-US, Washington, D. C., 1999.

Vyas, A., Saricks, C., Stodolsky, F., The Potential Effect of Future Energy-Efficiency and Emissions-Improving Technologies on Fuel Consumption of Heavy Trucks. Argonne National Laboratory. August 2002. 


\section{APPENDIX G - BUILDING TECHNOLOGIES PROGRAM INPUTS FOR FY 2008 BENEFITS ESTIMATES}

Table of contents

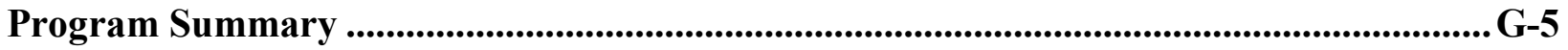

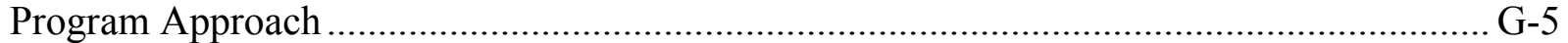

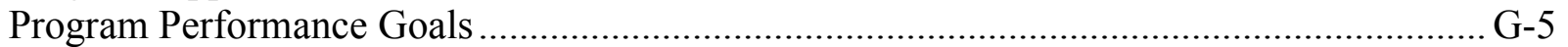

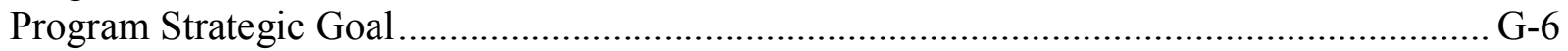

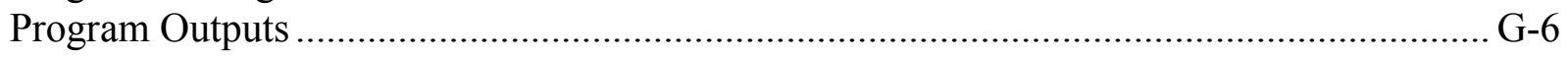

Significant Changes from Previous Analysis................................................................................ G-7

The Baseline ("without DOE RD3" case) ...................................................................................6-8

Baseline Adjustments to the AEO2006 Reference Case ....................................................... G-9

Representation of Program-Relevant Technologies in the AEO Reference Case .................. G-9

Removing Effects of Program Activities .......................................................................... G-9

Other Program-Relevant Adjustments to AEO Reference Case.............................................. G-9

Residential Buildings Integration - Research and Development: Building America ........ G-9

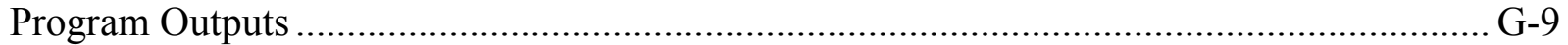

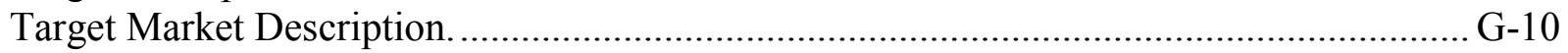

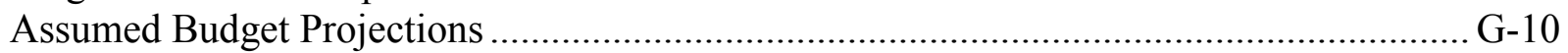

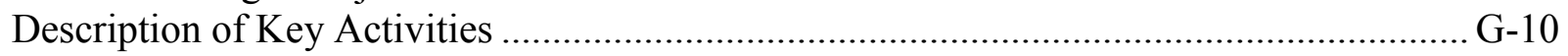

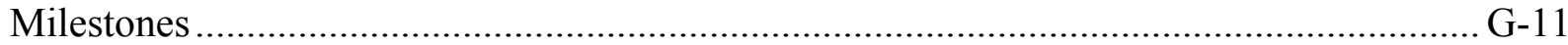

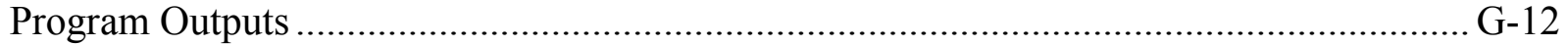

Translating Program Outputs to Market Outcomes .............................................................. G-14

Key Factors in Shaping Market Adoption of EERE technologies....................................... G-14

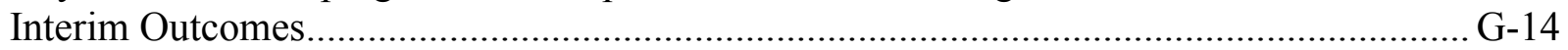

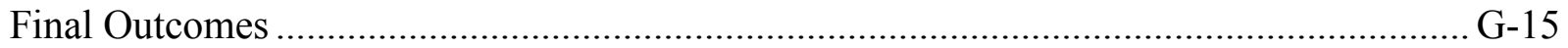

Commercial Buildings Integration - Research and Development .......................................G-16

Program Outputs ................................................................................................... G-16

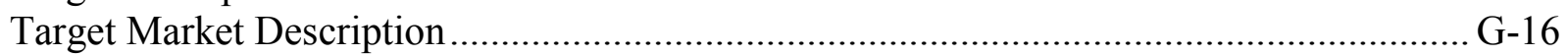

Assumed Budget Projections ……………………………............................................

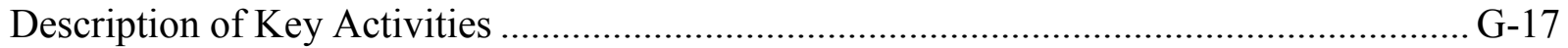

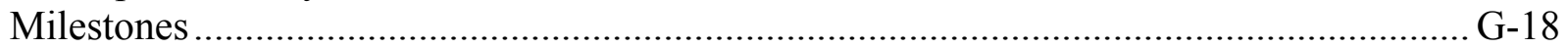

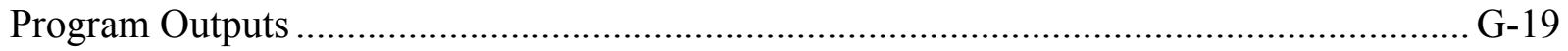

Translating Program Outputs to Market Outcomes .......................................................... G-20

Key Factors in Shaping Market Adoption of EERE technologies........................................ G-21

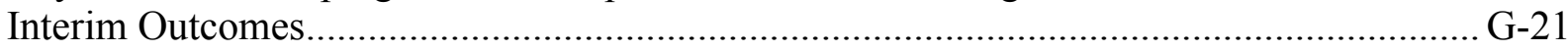


Emerging Technologies - Lighting Research and Development ..................................... G-22

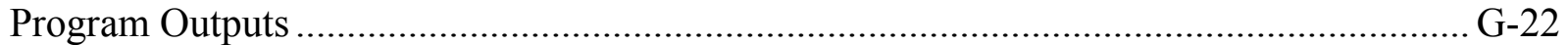

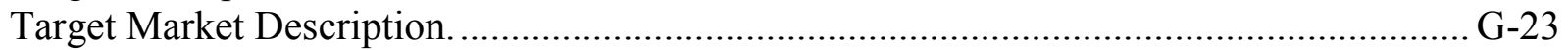

Assumed Budget Projections ............................................................................... G-24

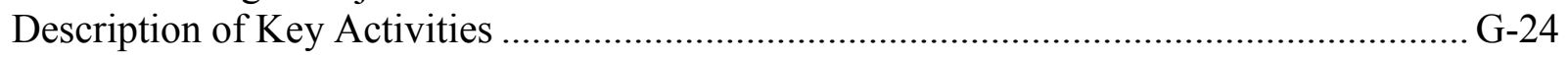

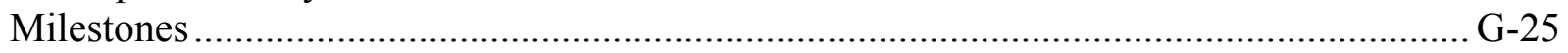

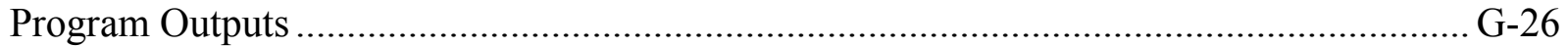

Translating Program Outputs to Market Outcomes ............................................................ G-27

Key Factors in Shaping Market Adoption of EERE technologies..................................... G-28

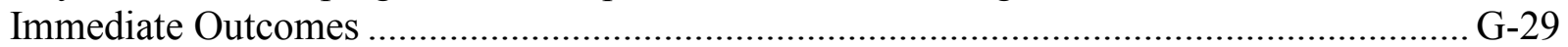

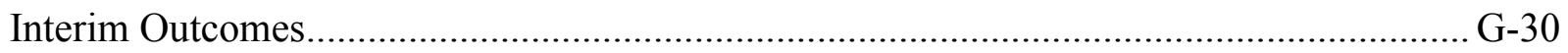

Emerging Technologies - Space Conditioning and Refrigeration R\&D ......................... G-31

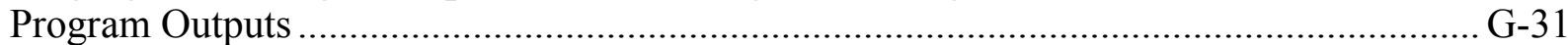

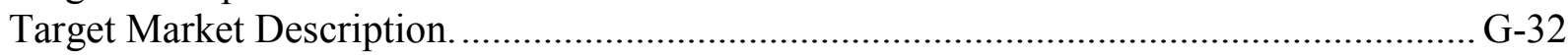

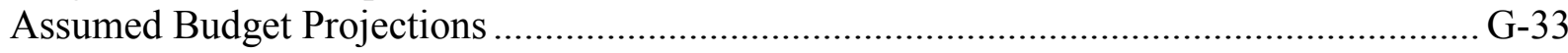

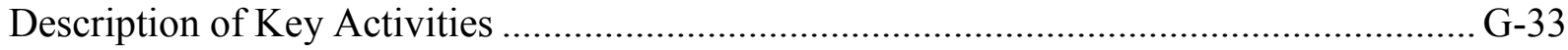

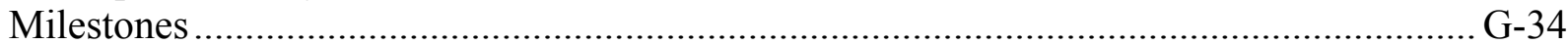

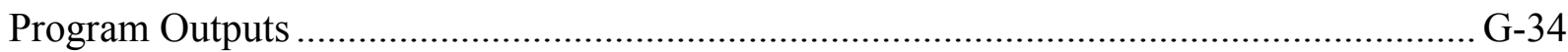

Translating Program Outputs to Market Outcomes ......................................................... G-36

Key Factors in Shaping Market Adoption of EERE technologies.................................... G-36

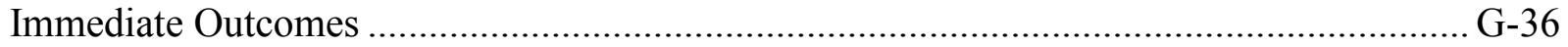

\section{Emerging Technologies - Building Envelope R\&D: Thermal Insulation and Building} Materials ...................................................................................................................................6-37

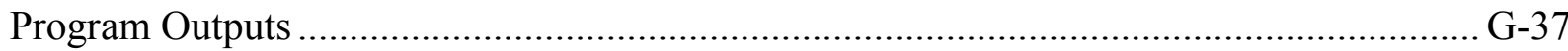

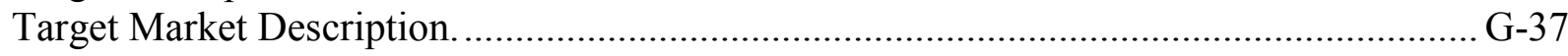

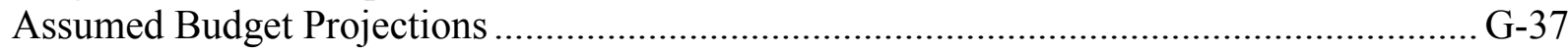

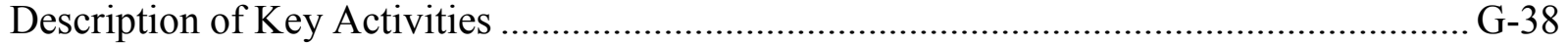

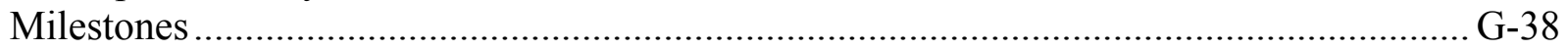

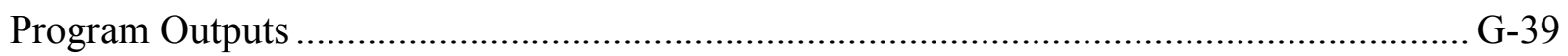

Translating Program Outputs to Market Outcomes ................................................... G-41

Key Factors in Shaping Market Adoption of EERE technologies.................................... G-41

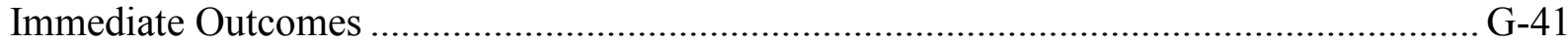

Emerging Technologies - Building Envelope R\&D: Windows Technologies ..................... G-46

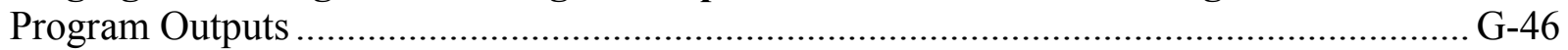

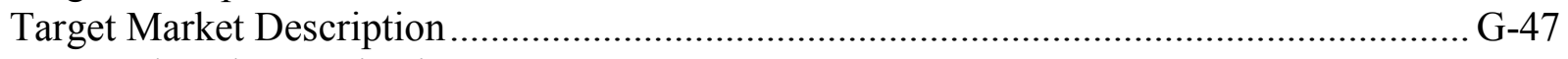

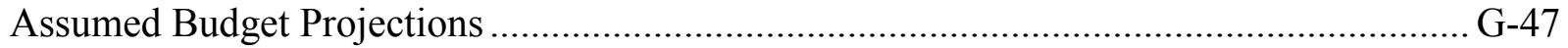

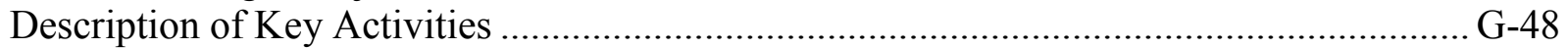

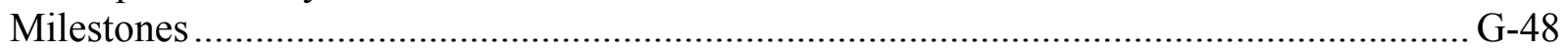

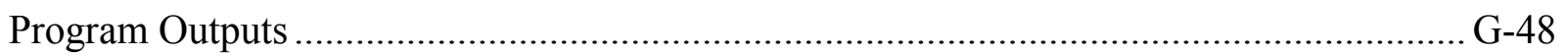

Translating Program Outputs to Market Outcomes ....................................................... G-50

Key Factors in Shaping Market Adoption of EERE technologies................................... G-51

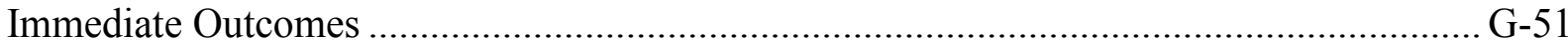

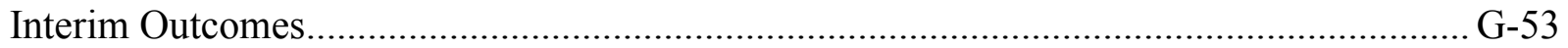


Emerging Technologies - Analysis Tools and Design Strategies.................................... G-55

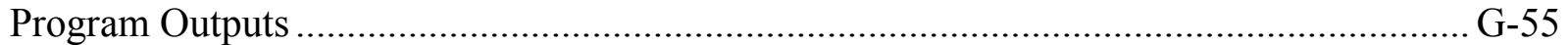

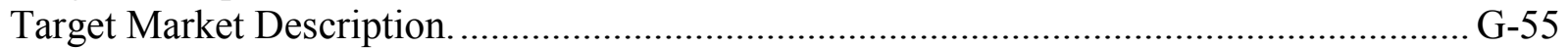

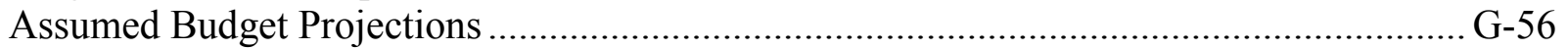

Description of Key Activities ................................................................................... G-56

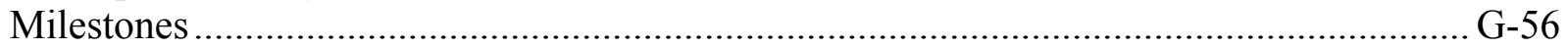

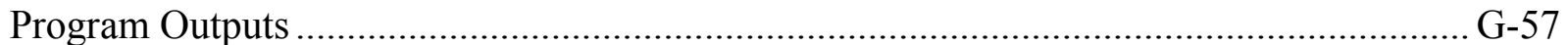

Translating Program Outputs to Market Outcomes ....................................................... G-60

Equipment Standards and Analysis ............................................................................60

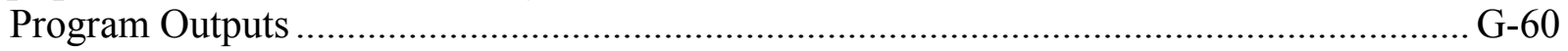

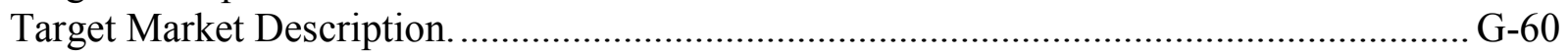

Assumed Budget Projections ........................................................................................... G-61

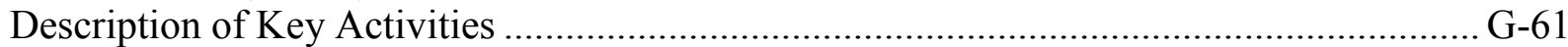

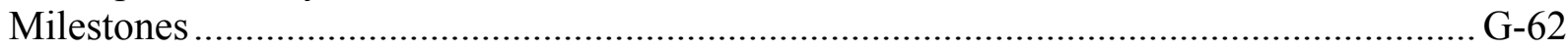

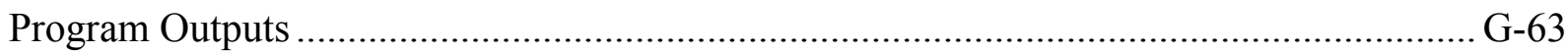

Translating Program Outputs to Market Outcomes ...................................................... G-64

Key Factors in Shaping Market Adoption of EERE technologies......................................6-64

Final Outcomes (Benefits) ............................................................................................65

Technology Validation and Market Introduction - Building Energy Codes ...................... G-68

Program Outputs ....................................................................................................... G-68

Target Market Description ............................................................................................ G-69

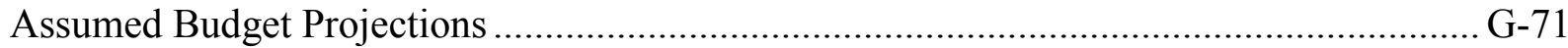

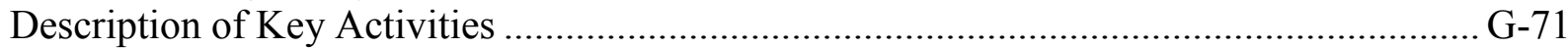

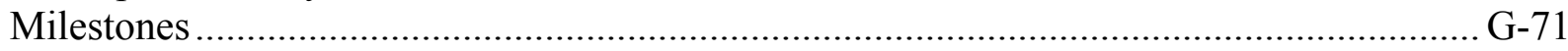

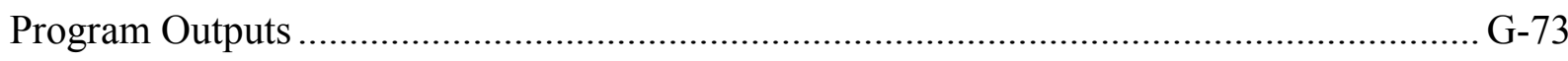

Translating Program Outputs to Market Outcomes ......................................................... G-76

Key Factors in Shaping Market Adoption of EERE technologies....................................... G-77

Final Outcomes (Benefits) ................................................................................... G-77

Technology Validation and Market Introduction - Rebuild America ...................................8-80

Target Market Description..........................................................................................

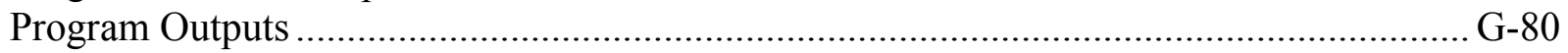

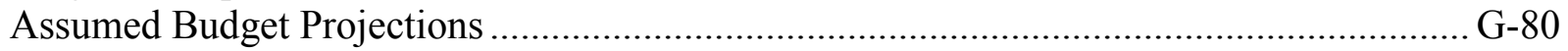

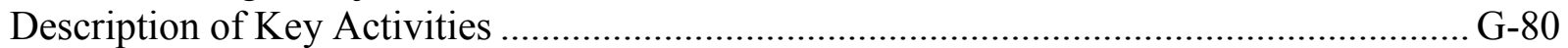

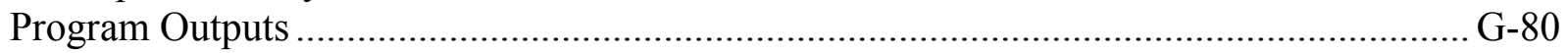

Translating Program Outputs to Market Outcomes ……………………………………...... G-81

Key Factors in Shaping Market Adoption of EERE technologies......................................... G-81

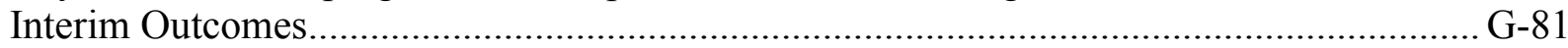

Technology Validation and Market Introduction - Energy Star.......................................... G-82

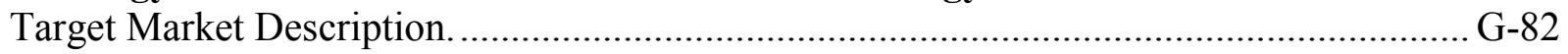

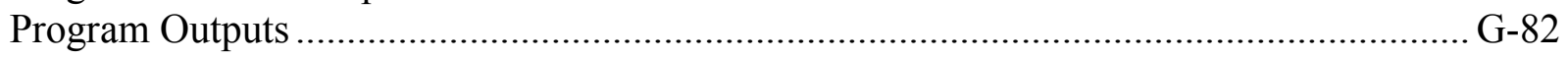

Assumed Budget Projections …………………………………………………...... G-82

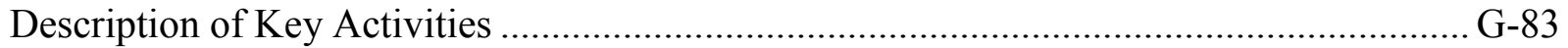

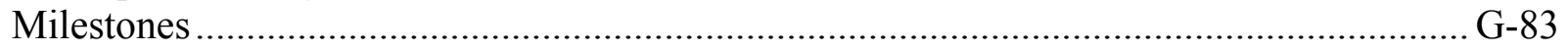


Program Outputs

Translating Program Outputs to Market Outcomes ............................................................. G-84

Interim Outcomes. 


\section{Program Summary}

The mission of the Building Technologies (BT) Program is to develop technologies, techniques, and tools for making residential and commercial buildings more energy efficient, productive, and affordable. This involves research, development, demonstration, and technology transfer activities in partnership with industry, government agencies, universities, and national laboratories (BTP 2005).

\section{Program Approach (BTP 2005)}

BT has identified a three-strategy approach to overcome barriers and achieve the goal of Zero Energy Buildings (ZEB) by 2025. The three strategies: 1) Research and Development, 2) Regulatory Activities, and 3) Technology Validation and Market Introduction, have evolved from careful consideration of the goal and a thorough situation analysis. BT subprograms are designed to capitalize on the interactive, synergistic benefits of the three implementation strategies.

The three strategies build on each other, and their crosscutting nature should make the program stronger than if the strategies were pursued in isolation. A prioritized and integrated portfolio of research and development establishes the technology base for future energy savings.

In addition to the Research and Development of efficient technologies, the Regulatory Activities will eliminate the most inefficient existing technologies in the market. Technology Validation and Market Introduction will speed the introduction of new technologies and the widespread use of highly efficient technologies already on the market and provide valuable feedback for future R\&D.

The three strategies, in combination, form the complete approach to reducing energy consumption in buildings. BT's challenge is to bring the appropriate strategies to bear in order to exploit the opportunities, while designing programs that give appropriate consideration to the marketplace and barriers to energy efficiency.

\section{Program Performance Goals (BTP 2005)}

Each of the three BT strategies has a performance goal that contributes to achievement of the BT strategic goal including:

- Research and Development: Accelerate the introduction of highly efficient technologies and practices through R\&D to achieve net-zero energy homes by 2020 and net-zero energy buildings by 2025 .

- Regulatory Activities: By 2010, issue 13 formal proposals, consistent with enacted law, for enhanced product standards and test procedures to increase the minimum efficiency levels of buildings.

- Technology Validation and Market Introduction: Remove technical, financial, and availability hurdles to new, emerging energy-efficient technologies to achieve net-zero energy homes by 2020 and net-zero energy buildings by 2025 . 


\section{Program Strategic Goal (BTP 2005)}

The Department's Strategic Plan identifies four strategic goals (one each for defense, energy, science, and environmental aspects of the mission) plus seven general goals that tie to the strategic goals. The Building Technologies Program supports the following DOE strategic and program goals, shown in Figure G-1.

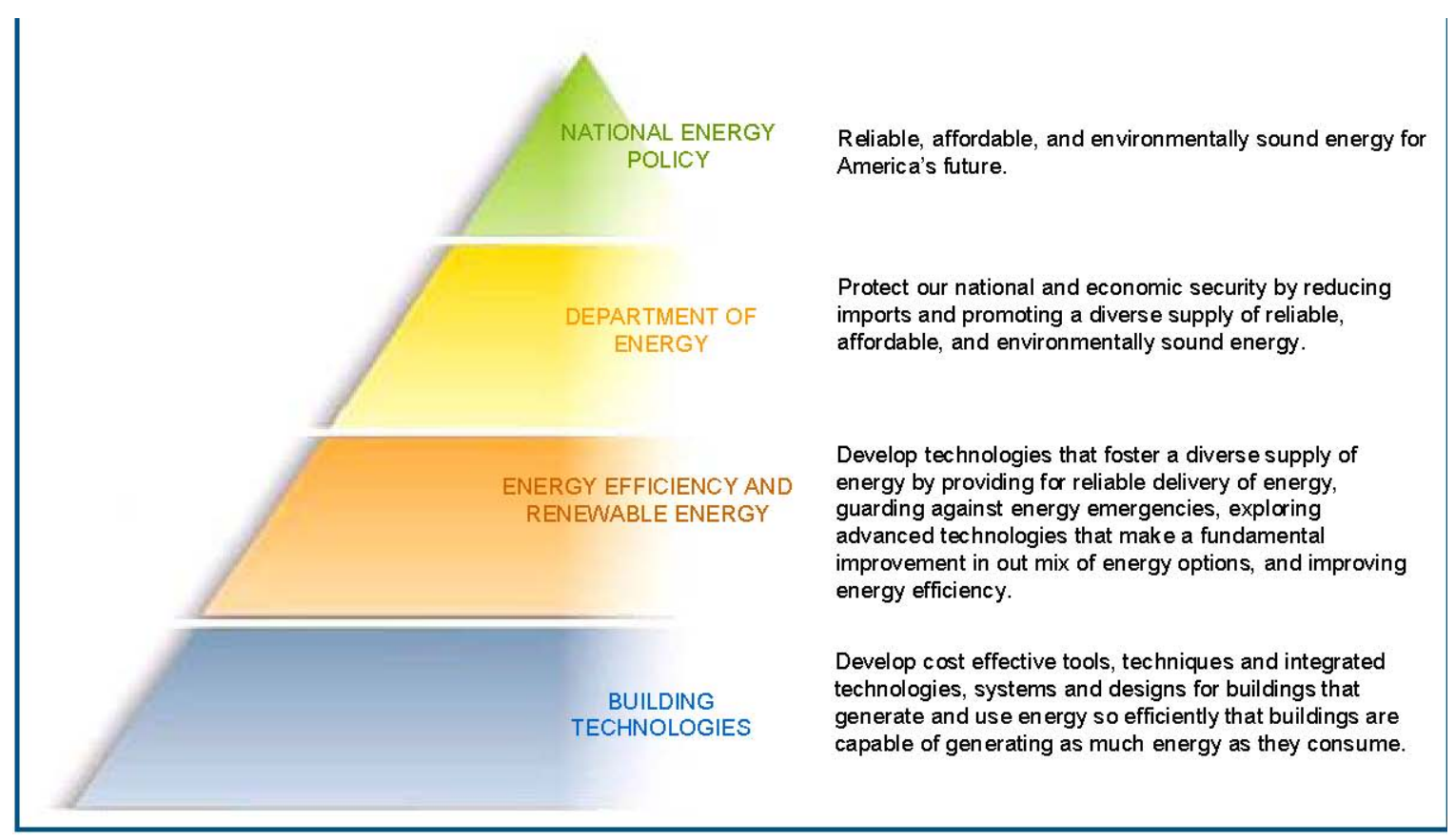

Figure G-1: Building Technologies Program Goal Cascade (BTP 2005)

In support of the president's policies and initiatives, BT has embraced the strategic goal of developing Net-Zero Energy Buildings (ZEB) to reduce national energy demand. The program has defined its strategic goal more specifically as:

To create technologies and design approaches that enable net-zero energy buildings at low incremental cost by 2025. A net-zero energy building is a residential or commercial building with greatly reduced needs for energy through efficiency gains $(60 \%$ to $70 \%$ less than conventional practice), with the balance of energy needs supplied by renewable technologies. These efficiency gains will have application to buildings constructed before 2025 resulting in a substantial reduction in energy use throughout the sector.

\section{Program Outputs (BTP 2005)}

The key outputs from the Building Technologies Program are the technologies and systems that allow the building community, contractors, and building owners to reduce their energy consumption and costs. Below are some key outputs for the next five years:

Research and Development:

- For residential buildings, five technology packages that can reduce energy consumption in new buildings by at least $40 \%$. 
- In commercial buildings, key technology pathways to achieve $30 \%$ to $50 \%$ reduction in purchased energy in new, small commercial buildings relative to ASHRAE 90.1-2004 as the baseline.

- Continued development of white-light solid-state lighting, reaching a commercial efficacy of 100 lumens per watt by 2011.

- An improved EnergyPlus, which can evaluate $90 \%$ of the state-of-the art technologies under development by BT R\&D

Regulatory Activities:

- Test procedures for torchieres, ceiling fans, commercial reach-in refrigerators, vending machines and beverage merchandisers, and incandescent reflector lamps

- Final rules for performance standards for distribution transformers, commercial unitary $\mathrm{AC} / \mathrm{HP}$, furnaces and boilers, and ASHRAE products

- Upgraded 2009 International Energy Conservation Code to include improved lighting, envelope, and mechanical requirements

Technology Validation and Market Introduction:

- New criteria for clothes washers and dishwashers, and the expansion of the program to include water heaters, solid-state lighting, and other emerging products.

\section{Significant Changes from Previous Analysis}

Table G-1 outlines the activities characterized for the GPRA08 Building Technologies Program and identifies any changes from the FY07 GPRA effort. Characterizations and inputs for these activities were provided to the Department of Energy's (DOE's) Office of Energy Efficiency and Renewable Energy (EERE) as inputs to EERE's integrated modeling effort.

Table G-1: Building Technologies Activities

\begin{tabular}{|c|c|c|c|c|}
\hline $\begin{array}{c}\text { BT } \\
\text { Subprogram }\end{array}$ & BT Activity & $\begin{array}{c}\text { Inputs } \\
\text { Changed } \\
\text { from } \\
\text { FY07? }\end{array}$ & $\begin{array}{l}\text { Reason for } \\
\text { Change }\end{array}$ & $\begin{array}{l}\text { FY08 Budget } \\
\text { (in millions \$) }\end{array}$ \\
\hline $\begin{array}{l}\text { Residential } \\
\text { Buildings } \\
\text { Integration }\end{array}$ & $\begin{array}{l}\text { Research \& Development: Building } \\
\text { America }\end{array}$ & Yes & Change in funding & 19.75 \\
\hline $\begin{array}{l}\text { Commercial } \\
\text { Buildings } \\
\text { Integration }\end{array}$ & Commercial Research \& Development & Yes & $\begin{array}{l}\text { Change in } \\
\text { direction }\end{array}$ & 7.00 \\
\hline \multirow{5}{*}{$\begin{array}{l}\text { Emerging } \\
\text { Technologies }\end{array}$} & Lighting R\&D: Controls & Dropped & Change in funding & \\
\hline & Lighting R\&D: Solid State Lighting & Yes & $\begin{array}{l}\text { More recent } \\
\text { research }\end{array}$ & \multirow[t]{2}{*}{19.28} \\
\hline & Lighting R\&D: SSL Market Acceptance & Yes & $\begin{array}{l}\text { Change in } \\
\text { modeled activity }\end{array}$ & \\
\hline & $\begin{array}{l}\text { Space Conditioning \& Refrigeration } \\
\text { R\&D: Thermotunneling Based Cooling }\end{array}$ & No & No Change & \multirow[b]{2}{*}{2.85} \\
\hline & $\begin{array}{l}\text { Space Conditioning \& Refrigeration: } \\
\text { Integrated Heat Pump }\end{array}$ & Yes & $\begin{array}{l}\text { More recent } \\
\text { research }\end{array}$ & \\
\hline
\end{tabular}




\begin{tabular}{|c|c|c|c|c|}
\hline & $\begin{array}{l}\text { Space Conditioning \& Refrigeration: } \\
\text { Condensing Gas Water Heater }\end{array}$ & New & $\begin{array}{l}\text { Change in } \\
\text { modeled activities }\end{array}$ & \\
\hline & $\begin{array}{l}\text { Building Envelope R\&D: Electrochromic } \\
\text { Windows }\end{array}$ & Yes & $\begin{array}{l}\text { More recent } \\
\text { research }\end{array}$ & \multirow{3}{*}{4.71} \\
\hline & Building Envelope R\&D: Superwindows & Yes & $\begin{array}{l}\text { More recent } \\
\text { research }\end{array}$ & \\
\hline & $\begin{array}{l}\text { Building Envelope R\&D: Low-E Market } \\
\text { Acceptance }\end{array}$ & Yes & $\begin{array}{l}\text { More recent } \\
\text { research }\end{array}$ & \\
\hline & $\begin{array}{l}\text { Building Envelope R\&D: Next } \\
\text { Generation Attic }\end{array}$ & Yes & $\begin{array}{l}\text { More recent } \\
\text { research }\end{array}$ & \multirow{3}{*}{2.41} \\
\hline & $\begin{array}{l}\text { Building Envelope R\&D: Advanced Wall } \\
\text { Systems }\end{array}$ & Yes & $\begin{array}{l}\text { More recent } \\
\text { research }\end{array}$ & \\
\hline & $\begin{array}{l}\text { Building Envelope R\&D: Next } \\
\text { Generation Envelope Materials }\end{array}$ & No & No Change & \\
\hline & Analysis Tools and Design & Yes & $\begin{array}{l}\text { Change in } \\
\text { direction }\end{array}$ & 2.65 \\
\hline \multirow{4}{*}{$\begin{array}{l}\text { Equipment } \\
\text { Standards and } \\
\text { Analysis }\end{array}$} & Standards: Distribution Transformers & Dropped & Completed & \multirow{4}{*}{15.64} \\
\hline & Standards: Electric Motors, 1-200 HP & Yes & $\begin{array}{l}\text { Change in } \\
\text { activities }\end{array}$ & \\
\hline & Standards: HID Lamps & Dropped & $\begin{array}{l}\text { Change in } \\
\text { activities }\end{array}$ & \\
\hline & $\begin{array}{l}\text { Standards: Equipment Efficiency } \\
\text { Standards }\end{array}$ & Yes & $\begin{array}{l}\text { Change in } \\
\text { activities }\end{array}$ & \\
\hline \multirow{11}{*}{$\begin{array}{l}\text { Technology } \\
\text { Validation } \\
\text { and Market } \\
\text { Introduction }\end{array}$} & Residential Building Energy Codes & Yes & $\begin{array}{l}\text { Change in } \\
\text { direction }\end{array}$ & 0.50 \\
\hline & Commercial Building Energy Codes & Yes & $\begin{array}{l}\text { Change in } \\
\text { direction }\end{array}$ & 0.50 \\
\hline & Rebuild America & Yes & $\begin{array}{l}\text { Change in } \\
\text { direction }\end{array}$ & 2.83 \\
\hline & Energy Star: CFLs & Yes & $\begin{array}{l}\text { Change in market } \\
\text { assumption }\end{array}$ & \multirow{8}{*}{6.78} \\
\hline & Energy Star: Windows & Yes & $\begin{array}{l}\text { More recent } \\
\text { research }\end{array}$ & \\
\hline & Energy Star: Refrigerators & Yes & $\begin{array}{l}\text { Change in market } \\
\text { assumption }\end{array}$ & \\
\hline & Energy Star: Room AC & Yes & $\begin{array}{l}\text { Change in market } \\
\text { assumption }\end{array}$ & \\
\hline & Energy Star: Home Performance & Yes & $\begin{array}{l}\text { Change in market } \\
\text { assumption }\end{array}$ & \\
\hline & Energy Star: Dishwashers & No & No Change & \\
\hline & Energy Star: Clothes Washers & Yes & $\begin{array}{l}\text { Change in market } \\
\text { assumption }\end{array}$ & \\
\hline & Energy Star: Solid State Lighting & New & New activity & \\
\hline
\end{tabular}

a. Budget request numbers are confidential until after the Department submits its budget to Congress via OMB.

\section{The Baseline ("without DOE RD3” case)}

In most cases, the following baseline information applies to all BT activities. Exceptions are noted in the individual project's documentation. Because it is specific to each project, the Target Market Description is included in the individual projects' documentation. 


\section{Baseline Adjustments to the $A E O 2006$ Reference Case}

BT assumed that the $A E O 2006$ Reference Case adequately captured the technological improvements that would occur in the absence of the program. In the AEO2006 Commercial Reference Case, shell improvements for new buildings can be up to $22 \%$ more efficient than the 1999 building stock; and, through 2030, new building shells are assumed to improve by $8 \%$, while existing building stock efficiency is assumed to improve 6\% over the 1999 stock efficiency (EIA 2006c).

Within the AEO2006 Residential Reference Case, one of the implicit assumptions is that there will be no radical changes in technology or consumer behavior through 2030. Additional assumptions for the residential reference case include: 1) no new efficiency regulations, beyond what is already in law, nor new government efficiency programs; 2) technologies that have not achieved widespread acceptance already will not achieve significant penetration by 2030;3) currently available technologies will evolve in both cost and efficiency; and 4) consumers in the future will behave similarly to current consumer behavior (EIA 2006c).

\section{Representation of Program-Relevant Technologies in the AEO Reference Case}

The BT portfolio impacts buildings in the residential and commercial sectors. The equipment and building envelope assumptions are contained in the NEMS model documentation for those modules (EIA 2006a, EIA 2006b).

\section{Removing Effects of Program Activities}

As discussed in the previous paragraphs, BT assumed that no program-related impacts are included in the $A E O 2006$ Reference Case; therefore, nothing was removed from the Reference Case to establish the "non-program" baseline.

\section{Other Program-Relevant Adjustments to AEO Reference Case}

No other corrections were made to the AEO2006 Reference Case.

The remainder of this appendix contains the project-specific documentation for the BT inputs.

\section{Residential Buildings Integration - Research and Development: Building America}

\section{Program Outputs (BTP 2005)}

The Residential Integration subprogram, Building America, focuses on improving the efficiency of the approximately 1.6 million new homes built each year (NAHB 2004). These improvements are accomplished through research, development, demonstrations, and technology transfer of system-based strategies. The system-based strategies improve the energy efficiency through integrating residential energy uses, such as space heating and cooling, ventilation, water heating, lighting, and home appliances. These activities support efforts to develop strategies to integrate solar energy applications and other renewable technologies into net-zero energy homes. Outputs from the subprogram include technology package research reports, which represent research results achieving a targeted level of performance. Derived from these results are Best Practices manuals tailored for specific climate regions. 


\section{Target Market Description (BTP 2005).}

The residential market is the largest user of energy for buildings. It represents $52.5 \%$ of the total energy used by buildings, accounting for 21.7 quadrillion Btus (quads) in 2005 (Building Energy Data Book 2005, hereafter BEDB). New homes offer larger energy savings potential for less money than existing homes. The Residential Integration Subprogram, or Building America, is targeting single-family homes because they are the single most important home sector from the perspective of energy use and growth in energy use. Single-family homes currently consume $80.1 \%$ of the energy used for residential buildings, while multifamily and mobile homes use 19.9\% (BEDB 2005). Single-family homes account for four-fifths of the residential energy use, and during the next decade, the single-family sector is projected to grow and account for more than $70 \%$ of new housing units. Multifamily and manufactured homes will account for only about $30 \%$ of new housing units (Berson et al. 2004).

\section{Assumed Budget Projections}

BT assumed level funding of $\$ 19,570,000$ throughout the analysis period (2008-2025).

\section{Description of Key Activities (US DOE 2006a)}

The residential systems research, driven by the performance targets by climate zone and the financial constraint of zero or less net cash flow expenditures, is applied in three phases for each climate zone. During the three phases, Building America acts as a national residential energy systems test bed where homes with different system options are designed, built, and tested at three levels of system integration, including research houses, production prototype houses, and community-scale housing. A summary of the three phases is shown in Figure G-2. 


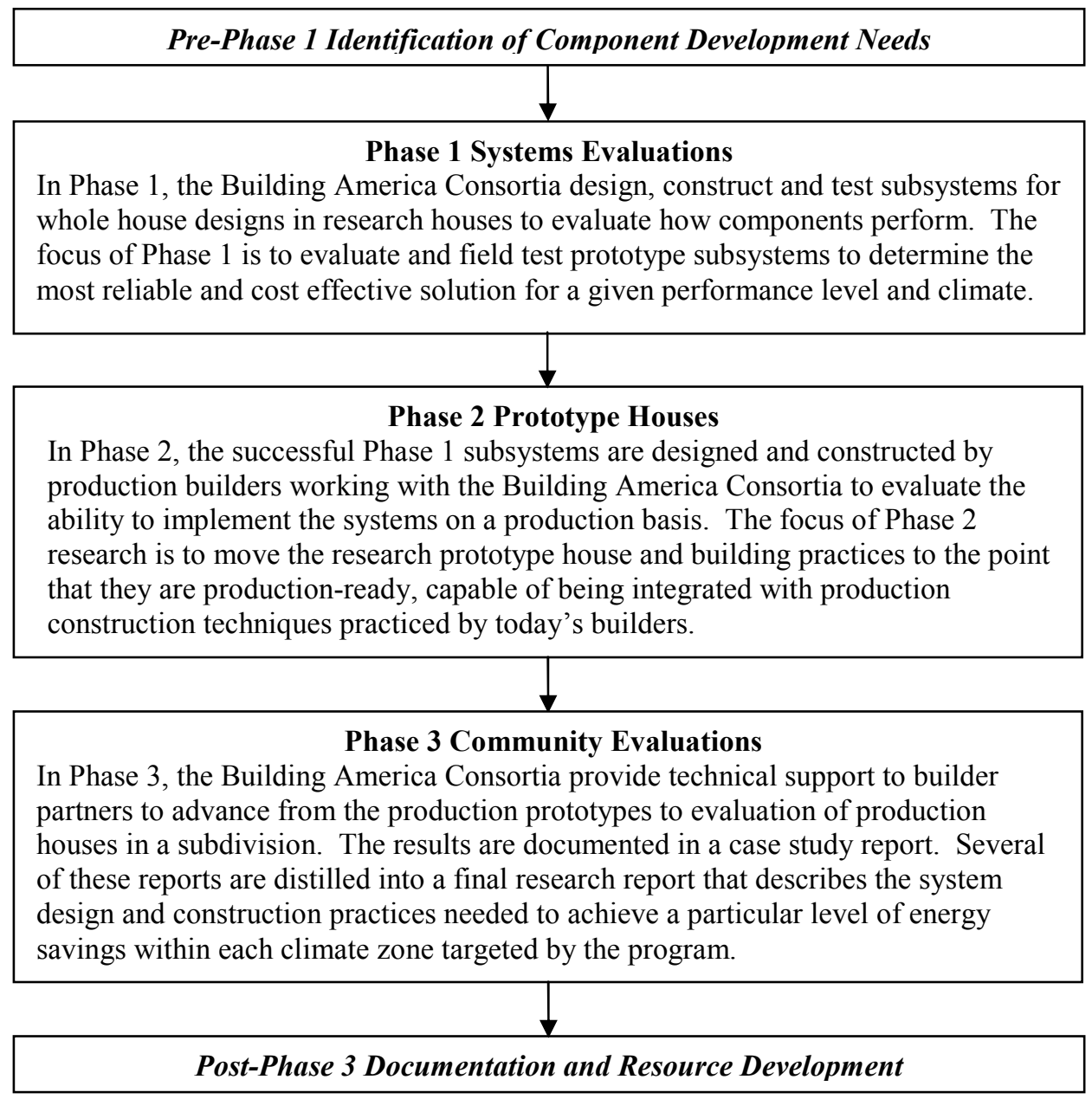

Figure G-2: Residential Integration Systems Approach (BTP 2005)

From the technology package research reports developed from Phase 3, "Best Practices" manuals are designed for builders, manufacturers, homeowners, Realtors, educators, insurance companies, and mortgage providers. The Best Practices manuals present the research results in illustrated text that is targeted to a specific audience to make it easy to assimilate, and synthesizes research findings into energy-efficient processes for the building industry.

Each research stage currently takes approximately three years to complete. For more advanced energy efficiency levels at and above $50 \%$ whole-house savings, the system research process is expected to take additional iterations of whole-house testing before implementation in production-ready homes.

More detail can be found in BT's Multiyear Program Plan (BTP 2005).

\section{Milestones}

The Residential Integration performance targets can be translated into a schedule for the threephase systems engineering approach. The figures below show the schedule for whole-house and 
component tasks. The end of each task is the milestone and marks where the go/no go decision occurs for the next phase.

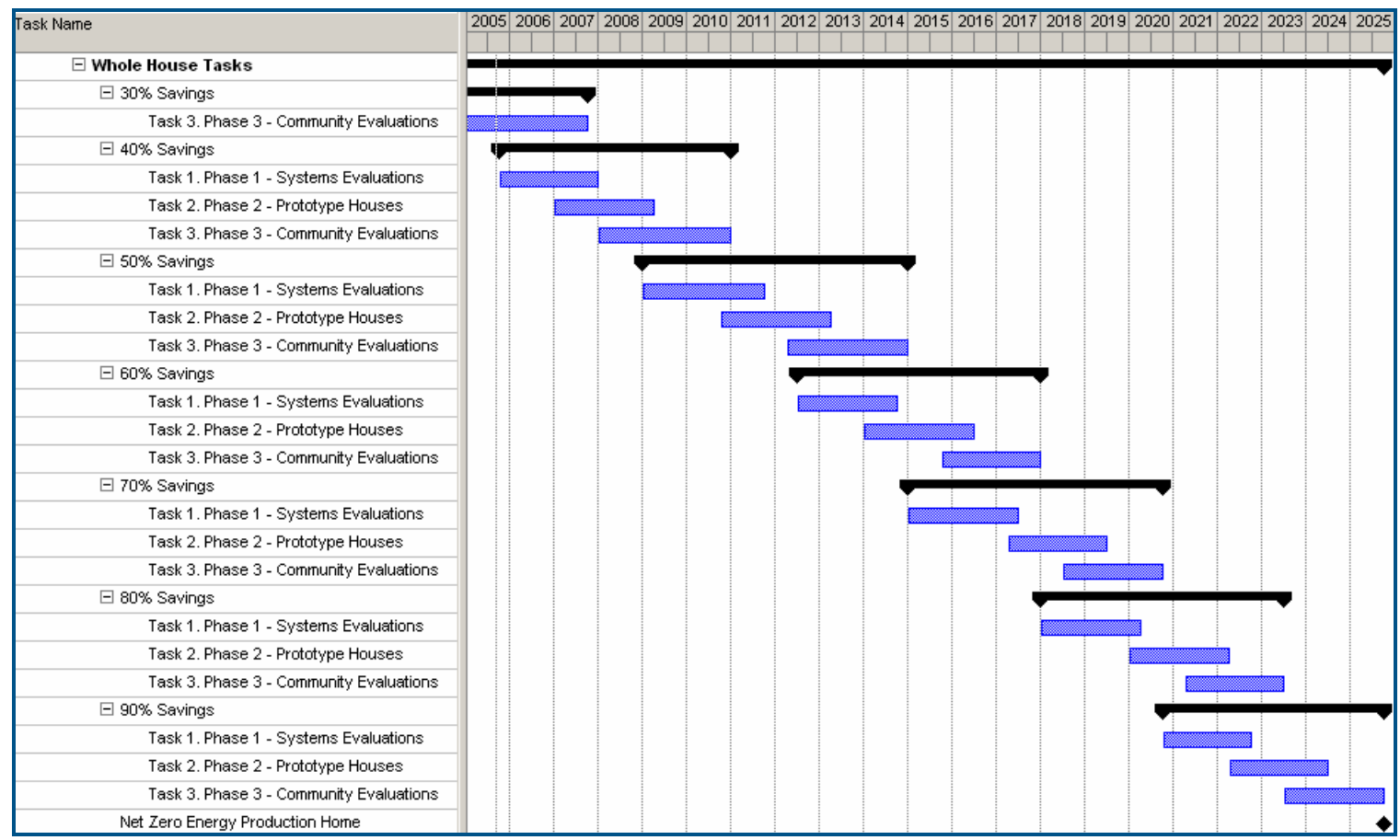

Figure G-3: Building America System Research Gantt Chart (BTP 2005)

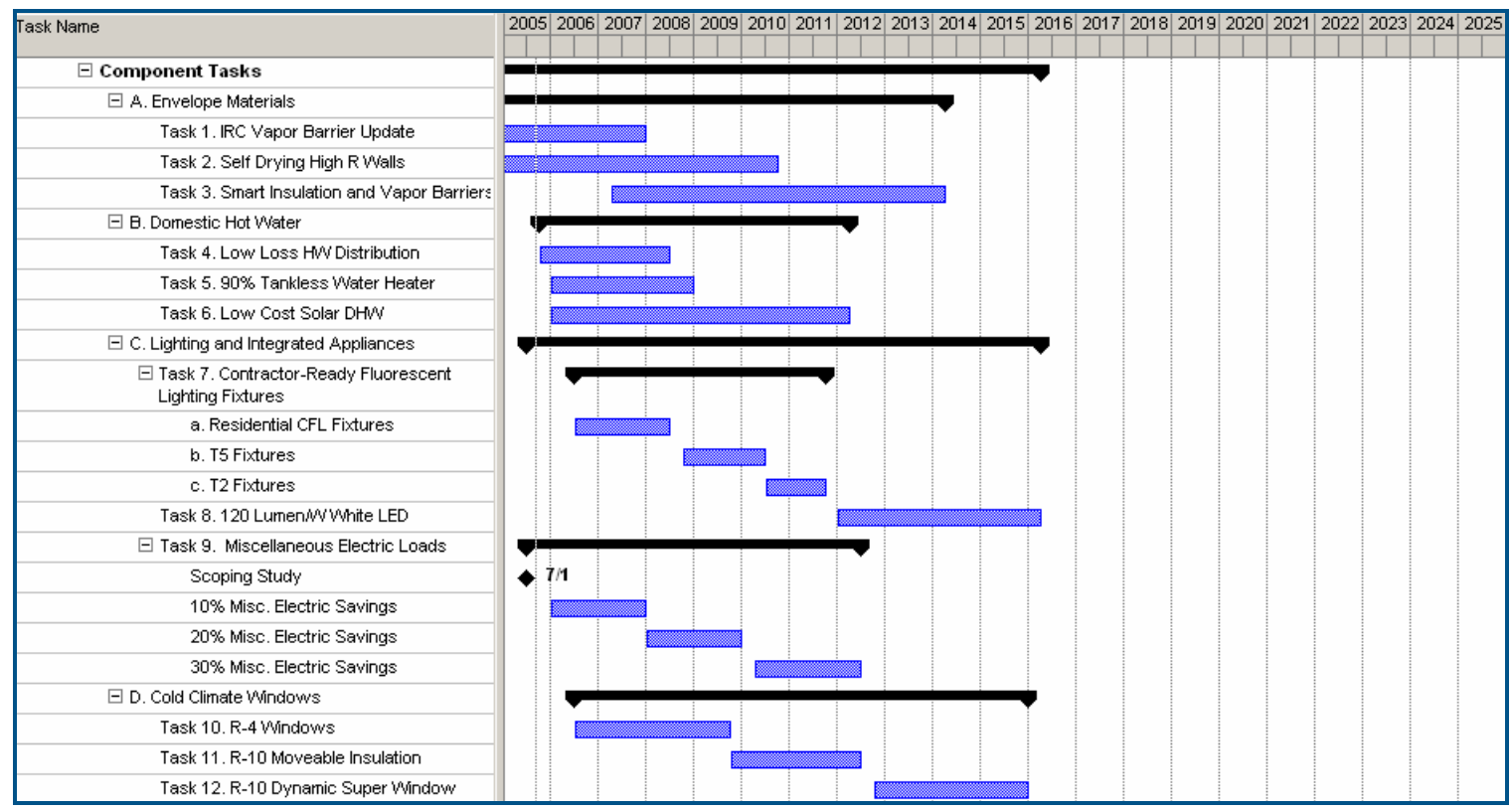

Figure G-4: Residential System Component Needs Gantt Chart (BTP 2005)

Program Outputs (BTP 2005)

The Residential Integration Subprogram will develop integrated energy efficiency and onsite/renewable power solutions that will be evaluated on a production basis in subdivisions to 
reduce whole-house energy use in new homes by an average ${ }^{1}$ of $50 \%$ by 2015 and $90 \%$ by 2020 compared to the Building America Benchmark ${ }^{2}$ (NREL 2004) at zero or less net cash flow. ${ }^{3}$

Building America developed the following performance goals for each phase of the systems approach. The performance targets show the energy savings that will be reached on the path to net-zero energy homes (ZEH).

Table G-2: Residential Integration Performance Goals (BTP 2005) ${ }^{4}$

\begin{tabular}{lcccccc}
\hline \multirow{2}{*}{ Characteristics } & Units & \multicolumn{5}{c}{ Year } \\
\cline { 3 - 7 } & & $\mathbf{2 0 0 7}$ & $\mathbf{2 0 1 0}$ & $\mathbf{2 0 1 5}$ & $\mathbf{2 0 1 9}$ & $\mathbf{2 0 2 0}$ \\
\hline Average Source Energy Savings & $\%$ & 30 & 40 & 50 & 60 & 90 \\
\hline Cost & $\$$ & & \multicolumn{3}{c}{ Zero or Less Net Cash Flow } \\
\hline
\end{tabular}

To ensure meeting the interim targets along the path to ZEH, Building America has also specified the following interim performance targets for each climate region below. These performance targets also serve as the annual Joule milestones for the program.

Table G-3: Phase 3 Residential Integration Performance Targets by Climate Region (BTP 2005)

\begin{tabular}{cccccc}
\hline $\begin{array}{c}\text { Target } \\
\text { (Energy Savings) }\end{array}$ & Marine & Hot Humid & $\begin{array}{c}\text { Hot/Mixed } \\
\text { Dry }\end{array}$ & Mixed Humid & Cold \\
\hline $30 \%$ & 2006 & 2007 & 2005 & 2006 & 2005 \\
\hline $40 \%$ & 2008 & 2010 & 2007 & 2008 & 2009 \\
\hline $50 \%$ & 2011 & 2015 & 2012 & 2013 & 2014 \\
\hline
\end{tabular}

The performance goals are aimed at achieving the strategic goal of ZEH by 2025. The performance targets are incremental, 30\%-40\%-50\%, to manage research risks, closely track progress, and allow early identification and targeting of barriers to achieving the strategic goal of $\mathrm{ZEH}$ at zero or less net cash flow. Hence, the Building America system research strategy increases the performance targets leading toward long-term strategic goals based on the successful development of system solutions at the previous performance level.

Each of the performance goals is measured by comparing energy savings against the Building America Research Benchmark. This benchmark is based on the International Energy Conservation Code of 2000 (IECC 2000) and also includes lighting energy, appliance energy,

\footnotetext{
${ }^{1}$ The distinction between the average savings and the range of savings is important because it is not cost-effective (or even possible without wasteful engineering) to design a net-zero energy home for every possible potential occupant. Because the range of possible occupant behavior is large, the average savings target in 2025 is $90 \%$. This average will include a significant number of homes that achieve $100 \%$ savings, ensuring that the goal of net zero energy homes is met.

${ }^{2}$ The Building America Research Benchmark Definition consists of the 2000 IECC envelope requirements plus lighting, appliances, and plug-load energy levels derived from best available research studies and energy use data for 1990s housing stock.

${ }^{3}$ Net cash flow is the monthly mortgage payment for energy options minus the monthly utility bill cost savings. "Zero or less net cash flow" means that monthly utility bill cost savings are greater than the monthly mortgage payment for energy options. In other words, the increase in a 30-year mortgage payment is offset by the energy savings.

${ }^{4}$ Year of completion of annual JOULE targets in six climate regions. Energy savings are measured relative to BA Research Benchmark. This schedule assumes that funding for Phase 1-3 system research activities will remain at FY 2005 levels.
} 
and plug-in device loads (i.e., plug loads). Progress can also be measured by the number of design packages developed, researched, and evaluated.

\section{Translating Program Outputs to Market Outcomes (BTP 2005)}

Construction of new homes requires the combined efforts of a large number of suppliers and contractors whose efforts are coordinated by a large number of builders. Because of the high costs of failure, the residential construction industry is highly risk-intolerant and first-cost sensitive. Energy efficiency designs are further complicated by the development of new systems and the relatively low level of R\&D investment. The key market barriers to development of advanced residential energy systems are the large number of market players, the relatively low level of investment in R\&D relative to other sectors of the economy, and strict requirements for market acceptance based on achievement of low incremental costs and high reliability.

\section{Key Factors in Shaping Market Adoption of EERE technologies}

- $\quad$ Price (ZEH 2003, LBNL spreadsheet using cost and performance data from NREL's BEopt software): ${ }^{5}$

○ $40 \%$ whole-house savings increases the price by $\$ 3,300 /$ household $(\mathrm{HH})$

○ $60 \%$ whole-house savings increases the price by $\$ 10,000 / \mathrm{HH}$

○ $70 \%$ whole-house savings increases the price by $\$ 18,500 / \mathrm{HH}$

○ By 2020, incremental prices are assumed to fall by $50 \%$.

- One hundred percent savings (including renewable resources) increases the price by $\$ 31,000 / \mathrm{HH}$, over the Benchmark case declining to $\$ 9,100$ by 2020 .

- In developing the cost of solar technologies as part of the $70 \%$ incremental cost, BT assumed that the Solar Program meets it stated goal.

- Incremental prices to achieve energy savings in existing homes have not yet been determined; thus, energy savings for existing homes was not modeled based on cost and performance.

\section{Interim Outcomes}

The performance goal for existing residential is to reduce whole-house energy use by $20 \%$ over the Benchmark case by 2010. The expected market uptake is based on U.S. Census renovated space estimates and project management input (U.S. Census Bureau 2000).

\footnotetext{
$\mathbf{5}$ The spreadsheet model is unreleased Beta version of a tool developed by K. Caughlin at LBNL that uses the output generated by NREL's BEOpt (a building optimization and cost model) to predict the optimal cost-effective energy performance for new homes. BEOpt simulates energy performance for various combinations of new energy-saving building technologies and estimates their associated construction costs. The LBNL spreadsheet model estimates a smooth cost function based upon output from BEOpt. From this cost function, the model estimates the economically optimal performance level of whole-house energy use using the mortgage interest rate (including tax savings) as a discount rate. Increases in performance over time are based on an assumed annual average reduction in technology costs, based on economies of scale and learning by builders.
} 
Table G-4: Estimated Market Penetration for Existing Residential Housing Stock

\begin{tabular}{ll}
\hline Year & $\begin{array}{l}\text { Percent of } \\
\text { Existing Stock }\end{array}$ \\
\hline 2008 & 0.0000 \\
\hline 2009 & 0.0000 \\
\hline 2010 & 0.0092 \\
\hline 2011 & 0.0203 \\
\hline 2012 & 0.0336 \\
\hline 2013 & 0.0487 \\
\hline 2014 & 0.0653 \\
\hline 2015 & 0.0829 \\
\hline 2016 & 0.1006 \\
\hline 2017 & 0.1178 \\
\hline 2019 & 0.1337 \\
\hline 2020 & 0.1479 \\
\hline
\end{tabular}

\section{Final Outcomes}

The savings for this project were estimated in a new spreadsheet tool developed by LBNL to analyze the benefits of the Building America project. This tool relies on performance and cost information generated by NREL's BEopt software. The actual percentage savings for a home built in a future year will depend on balancing the increase in mortgage cost with the reduction in energy cost. Total national energy savings depend as well on the application of the marketpenetration curves. Initial penetration of zero-net energy designs began in the southwest in 2003. In that analysis, the number of homes impacted by the Building America program was assumed to exceed 400,000 by 2020 . The market penetration curves were developed based on market diffusion curves developed by PNNL (Elliott et al. 2004).

Table G-5: Building America Savings Estimates for New Buildings

\begin{tabular}{ll}
\hline Year & TBTU Primary \\
& Energy Savings
\end{tabular}

\begin{tabular}{lr}
\hline 2008 & 27.07 \\
\hline 2009 & 39.64 \\
\hline 2010 & 56.21 \\
\hline 2011 & 75.85 \\
\hline 2012 & 98.99 \\
\hline 2013 & 120.31 \\
\hline 2014 & 142.38 \\
\hline 2015 & 164.10 \\
\hline 2016 & 184.54 \\
\hline 2017 & 213.15 \\
\hline 2018 & 242.38 \\
\hline 2019 & 272.26 \\
\hline 2020 & 302.65 \\
\hline
\end{tabular}




\begin{tabular}{ll}
\hline 2021 & 333.97 \\
\hline 2022 & 366.71 \\
\hline 2023 & 400.42 \\
\hline 2024 & 434.28 \\
\hline 2025 & 467.75 \\
\hline 2026 & 501.73 \\
\hline 2027 & 536.16 \\
\hline 2028 & 570.84 \\
\hline 2029 & 605.66 \\
\hline 2030 & 640.63 \\
\hline
\end{tabular}

\section{Commercial Buildings Integration - Research and Development}

\section{Program Outputs (BTP 2005)}

The Commercial Integration Subprogram addresses energy-savings opportunities in new and existing commercial buildings ( $\$ 254$ billion spent annually for new capital construction and $\$ 113$ billion for renovation). This subprogram focuses on research, development, and demonstration of whole building technologies, design methods, and operational practices. Technologydevelopment efforts focus on crosscutting, whole-building technologies, such as sensors and controls, and more energy-efficient ventilation systems. These efforts support the ZEB goal not only by reducing building energy needs, but also by developing design methods and operating strategies, which incorporate solar and other renewable technologies into commercial buildings.

\section{Target Market Description (BTP 2005).}

Commercial buildings currently consume $47.5 \%$ of the total energy used by buildings, accounting for 19.7 quads in 2005. The commercial market is the second largest user of energy for buildings, but its energy use is increasing more rapidly than residential buildings (BEDB 2005). By 2025, the commercial market will use as much energy as the residential market.

The EIA provides 20 different classifications of commercial building types. These buildings are as diverse as large, core-dominated office buildings to hospitals, operated 24/7 to small retail stores operated for 10 hours, and include scientific laboratories with intensive ventilation and power requirements, as well as houses of worship with relatively light and occasional energy requirements. Using the approach employed by EIA, the commercial sector is characterized by 10 primary building types as shown in Table G-6.

Table G-6: Commercial Buildings Types (BEDB 2005)

\begin{tabular}{lccc}
\hline Building Type & $\begin{array}{c}\text { Percent Total } \\
\text { Energy Use }\end{array}$ & $\begin{array}{c}\text { Primary Energy Intensity } \\
\text { (kBtu/ft'/yr) }\end{array}$ & $\begin{array}{c}\text { Average Building } \\
\text { Size } \mathbf{( 1 , 0 0 0 \mathbf { f t } ^ { 2 } )}\end{array}$ \\
\hline Warehouse & $8 \%$ & 86 & 17.4 \\
\hline Education & $10 \%$ & 135 & 26.5 \\
\hline Public Order & $1 \%$ & 139 & 16.2 \\
\hline Public Assembly & $6 \%$ & 167 & 14.4 \\
\hline $\begin{array}{l}\text { Mercantile \& } \\
\text { Service }\end{array}$ & $21 \%$ & 180 & 25.0 \\
\hline
\end{tabular}




\begin{tabular}{lccc}
\hline Lodging & $7 \%$ & 196 & 29.5 \\
\hline Office & $22 \%$ & 218 & 16.3 \\
\hline Health care & $8 \%$ & 337 & 23.0 \\
\hline Food Service & $7 \%$ & 470 & 5.3 \\
\hline Food Sales & $4 \%$ & 532 & 5.7 \\
\hline
\end{tabular}

Table G-6 provides estimates from EIA's Commercial Building Energy Consumption Survey (CBECS) survey for both primary energy use intensity and the share of the total energy use. The data in the table are sorted from least to most energy intensive; grocery stores (food sales) are three times more energy intensive than retail stores, as a gross average for the respective sectors. Although this table offers some initial insight as to where BT might target its scarce R\&D resources, the building-type approach has some limitations. Principally, it compels a discussion of building type, across 20 types of buildings; ${ }^{6}$ when, in fact, the diversity of energy use within building types shows that buildings are more similar in many end uses than the table reveals.

One approach to saving energy in the commercial sector has been to improve the technology of energy-using components used in buildings; however, this approach does not account for interactions among components, such as lighting and air conditioning. A more robust energy savings approach is to consider the interactions among components by using computersimulation programs like EnergyPlus. ${ }^{7}$

\section{Assumed Budget Projections}

BT assumed level funding throughout the analysis period (2008-2025). The amount of the request is confidential until after the budget submission to Congress.

\section{Description of Key Activities (BTP 2005)}

In 2005, BT completed an optimization analysis to define a hierarchy of building performance levels that might be achievable in the marketplace over the next 20 years (see Table G-7). This hierarchy recognizes that realizing "net-zero" energy performance in actual buildings, from small offices to large hospitals, is a challenging, longer-term goal, and that a pathway of performance outcomes is appropriate, as demonstrated in the table below. This analysis will identify research gaps and help prioritize future research.

Table G-7: Hierarchy of Building Performance Levels (BTP 2005)

\begin{tabular}{lcc}
\hline \multicolumn{1}{c}{ Performance Level } & $\begin{array}{c}\text { Savings } \\
\text { Goal }\end{array}$ & Target Year \\
\hline High Performance Buildings (HPB): & & \\
\hline Net Zero Energy Buildings (ZEB) & $100 \%$ & $2020-2025$ \\
\hline Ultra-Low Energy Buildings (ULEB) & $75 \%$ & $2015-2020$ \\
\hline Low Energy Buildings (LEB) & $50 \%$ & $2010-2015$ \\
\hline Better Practice & $20-30 \%$ & $\begin{array}{c}\text { Available } \\
\text { now }\end{array}$ \\
\hline Conventional Good Practice (Code Compliant) & Baseline & \\
\hline
\end{tabular}

\footnotetext{
${ }^{6}$ Not all types are shown in Table G-6.

${ }^{7}$ EnergyPlus is a building energy simulation program for modeling building heating, cooling, lighting, ventilating, and other energy flows, developed by the Commercial R\&D Subprogram: http://www.eere.energy.gov/buildings/energyplus/ .
} 
To realize 50-100\% savings over the next 20-25 years, BT's technical approach will involve two distinct paths, as follows:

- High Performance Buildings (HPB) using systems integration approaches, embedded in design strategies, and;

- Integrated Systems Research (ISR) that is critical to the efficient functioning of the building and equipment, such as controls, indoor environmental quality, and information technology applied to buildings.

More detail on these paths is contained in BT's Multiyear Program Plan (BTP 2005).

Milestones (BTP 2005)

The Gantt chart shown in Figure G-5 identifies Commercial Integration key activities in high performance buildings and integrated systems research. In the area of HPB, BT will conduct three assessments to help guide the program design of this activity through 2010 . They include:

1. Participation in the development of the American Society of Heating, Refrigerating, and Air-Conditioning Engineers (ASHRAE) 30\% Design Guides for small commercial buildings;

2. Analysis to determine the HPB construction and design products actually desired by the market;

3. Determination of the level of DOE involvement in developing the energy efficiency criteria of the Green Building Council's next version of the Leadership in Energy and Environmental Design (LEED) rating (Version 3);

4. Evaluation of technology pathways resulting from the BEopt commercial building optimization studies; and

5. Participation in an ASHRAE sponsored building ventilation workshop.

For the Integrated Systems Research portfolio, much activity here is focused on conducting technical and market opportunity assessments (Step 2) and ranking the opportunities relative to each other (Step 3). All of this is necessary to determine a robust systems research portfolio, one derived from the results of analysis. For these reasons, there are a number of workshops and studies in the near term in the Gantt chart, which also explains a number of "go/no-go" decision points featured for controls, O\&M, and daylighting. For each "go/no-go," DOE shall determine the level of potential savings, the need for technological breakthrough, and whether or not the $\mathrm{R} \& \mathrm{D}$ role is inherently a Federal responsibility. 


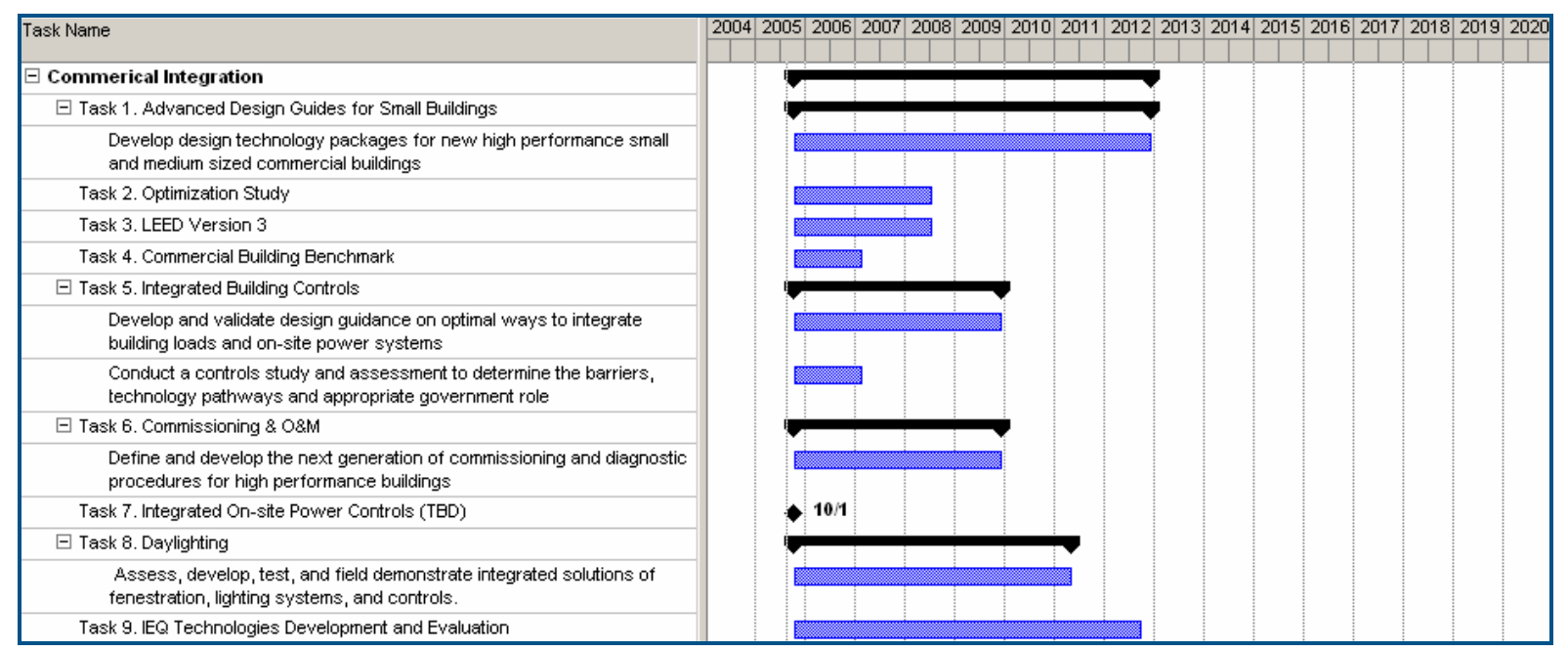

Figure G-5: Commercial Integration Gantt Chart (BTP 2005)

\section{Program Outputs (BTP 2005)}

In order to reach net-zero energy buildings by 2025, DOE will develop integrated whole-building strategies to enable commercial buildings to be designed, constructed, and operated to use $70 \%$ less energy relative to ASHRAE Standard 90.1-2004. The balance of the buildings' energy requirements $(30 \%)$ will be met by renewable energy sources.

Going forward, the Commercial Integration team will collaborate with ASHRAE, AIA, IESNA, USGBC, ${ }^{8}$ and other appropriate partners to develop advanced design guides for small- and medium-sized commercial buildings. By 2009, the BT goal is to develop the initial series of five advanced design guides at 30\% above ASHRAE Standard 90.1-2004. The effort will set out a prioritized schedule that allows for adaptation of information generated in initial guides in the series and focuses effort on specific needs of each new guide. Further, the effort will lead (with positive peer review and market impact assessment of initial efforts) to collaborative work on a second series of guides at 50\% above 90.1-2004 Standard (or an adjusted baseline, if appropriate).

\footnotetext{
${ }^{8}$ American Society of Heating, Refrigerating and Air-Conditioning Engineers (ASHRAE), American Institute of Architects (AIA), Illuminating Engineering Society of North America (IESNA), U.S. Green Building Council (USGBC).
} 
Table G-8: High Performance Commercial Buildings Performance Targets (BTP 2005)

\begin{tabular}{lcccc}
\hline \multicolumn{1}{c}{ Characteristics } & Units & \multicolumn{3}{c}{ Calendar Year } \\
\cline { 3 - 5 } & & $\mathbf{2 0 0 6}$ & $\mathbf{2 0 0 9}$ & $\mathbf{2 0 1 1}$ \\
\hline Whole-Building Energy Use & $\begin{array}{c}\text { \% Energy } \\
\text { Savings }\end{array}$ & 30 & 30 & 50 \\
Target Reductions & Number & 1 & 5 (draft) & 5(draft) \\
\hline $\begin{array}{l}\text { Advanced Design Guides for } \\
\text { Small- and Medium-Sized } \\
\text { Buildings }\end{array}$ & & & & \\
\hline
\end{tabular}

As shown in Table G-9, BT has begun a series of studies and assessments in Integrated Systems Research to identify the technical pathways and appropriate government role in Commercial Building Integration. Most of these assessments were completed in FY 2006 and will be used to determine appropriate efficiency and performance metric targets. Studies already completed have shown that we can reduce energy use by $15 \%$ by implementing system commissioning procedures at least once during a building's life cycle.

Table G-9: Integrated Systems Research Targets (BTP 2005)

\begin{tabular}{lcccc}
\hline \multicolumn{1}{c}{ Characteristics } & Units & \multicolumn{3}{c}{ Calendar Year } \\
\cline { 2 - 5 } & & $\mathbf{2 0 0 6}$ & $\mathbf{2 0 0 9}$ & $\mathbf{2 0 1 1}$ \\
\hline Commissioning and O\&M & $\begin{array}{c}\text { Reports and } \\
\text { Assessments }\end{array}$ & 0 & 1 & TBD \\
\hline Integrated Building Controls & $\begin{array}{c}\text { Reports and } \\
\text { Assessments }\end{array}$ & 1 & 1 & TBD \\
\hline $\begin{array}{l}\text { Integrated On-Site Power } \\
\text { Controls }\end{array}$ & $\begin{array}{c}\text { Reports and } \\
\text { Assessments }\end{array}$ & 0 & 1 & TBD \\
\hline Daylighting & $\begin{array}{c}\text { Reports and } \\
\text { Assessments }\end{array}$ & 1 & 1 & TBD \\
\hline IAQ & $\begin{array}{c}\text { Reports and } \\
\text { Assessments }\end{array}$ & 3 & 2 & TBD \\
\hline
\end{tabular}

Translating Program Outputs to Market Outcomes (BTP 2005)

The challenges inherent in designing and operating high performance and net-zero energy buildings demand a number of breakthroughs, in technology_-including software and information technology — and in the fundamental knowledge of how to integrate and operate technology so as to optimize whole-building performance. Systems integration and improved component technology (HVAC, lighting, windows, etc.) is required to achieve progressively higher levels of energy performance. ${ }^{9}$ Also required is a much richer understanding of the market itself, given the heterogeneity of the commercial buildings Subsector, which varies widely across the dimensions of size, surface-to-volume ratio, vintage of construction,

\footnotetext{
${ }^{9}$ By buildings "systems integration," we mean the design, construction, and operation of the commercial building as an integrated system so as to maximize energy performance and occupant satisfaction. Careful daylighting design - for example involves care in the specification of building orientation, window area, the performance of windows, interior design, and the control of electric lighting systems so as to maximize the use of natural light. A systems approach, as embedded in a "design package," will carefully integrate all of these factors to optimize building energy performance, including electric lighting and space heating and cooling.
} 
complexity of function, ownership, occupancy, and energy use. This understanding is necessary to target the R\&D to realize the largest opportunities to save energy in real buildings.

\section{Key Factors in Shaping Market Adoption of EERE technologies}

- Price:

○ Total Building Price of Conventional Technology (RS Means 2002): Average of $\$ 101 / \mathrm{ft}^{2}$ for the targeted new commercial and multifamily; $\$ 0$ for existing buildings.

- Total Building Price of BT Technology (Kats 2003): $\$ 103 / \mathrm{ft}^{2}$ for new commercial and multifamily, increasing to $\$ 107 / \mathrm{ft}^{2}$ in $2020^{10} ; \$ 4 / \mathrm{ft}^{2}$ for existing buildings.

○ Incremental Price (Kats 2003): 2\% above base for new buildings, increasing to 6\% above base in $2020 ; \$ 4 / \mathrm{ft}^{2}$ for existing buildings.

\section{Interim Outcomes}

BT projects that Commercial R\&D in combination with Analysis Tools and Design Strategies reduces purchased energy use by $30 \%$ to $50 \%$ by 2010 in new small- to medium-sized commercial construction as compared with ASHRAE 90.1-2004, increasing to 70\% savings by 2020 (BTP 2005). These programs also plan to save 30\% in targeted existing buildings. Although this project does not explicitly exclude any particular building type, the types of commercial buildings that will most likely be impacted by the technologies developed by this project primarily include small commercial buildings with relatively higher energy use intensities such as assembly, education, food service, food sales, lodging, mercantile and service, and office buildings.

Penetration curves were developed based on market diffusion curves developed by PNNL (Elliott et al. 2004), which is based on a Bass diffusion model for various DOE-2 building shell (e.g., windows, insulation) technologies. BT assumed that this project accelerates the adoption of relevant energy-savings products, technologies, and designs by five years, based on guidance provided by NRC 2001.

\footnotetext{
${ }^{10}$ Cost estimates corresponding with $70 \%$ energy savings are based on escalation estimates associated with similar energy savings in residential sector. Cost escalation estimates are based on Navigant Consulting's Residential Optimization Model (Version 5.7).
} 
Table G-10: Commercial R\&D/Analysis Tools Penetration and Performance Characteristics

\begin{tabular}{|c|c|c|c|c|}
\hline \multirow[t]{3}{*}{ Year } & \multicolumn{2}{|c|}{ Market Penetration } & \multicolumn{2}{|l|}{ Performance } \\
\hline & $\begin{array}{l}\text { New } \\
\text { Commercial } \\
\text { SF }\end{array}$ & $\begin{array}{l}\text { Existing } \\
\text { Commercial } \\
\text { SF }\end{array}$ & New & Existing \\
\hline & $\%$ & $\%$ & $\begin{array}{l}\text { \% energy } \\
\text { savings }\end{array}$ & $\begin{array}{l}\text { \% energy } \\
\text { savings }\end{array}$ \\
\hline 2008 & 0.0 & 0.0 & 30.00 & 15.00 \\
\hline 2009 & 0.0 & 0.0 & 31.82 & 25.00 \\
\hline 2010 & 5.5 & 0.0 & 33.64 & 30.00 \\
\hline 2011 & 9.1 & 0.0 & 35.45 & 30.00 \\
\hline 2012 & 13.2 & 0.9 & 37.27 & 30.00 \\
\hline 2013 & 17.7 & 2.0 & 39.09 & 30.00 \\
\hline 2014 & 22.4 & 3.4 & 40.91 & 30.00 \\
\hline 2015 & 21.7 & 4.9 & 42.73 & 30.00 \\
\hline 2016 & 22.8 & 6.5 & 44.55 & 30.00 \\
\hline 2017 & 23.0 & 7.4 & 46.36 & 30.00 \\
\hline 2018 & 22.3 & 8.0 & 48.18 & 30.00 \\
\hline 2019 & 20.9 & 8.4 & 50.00 & 30.00 \\
\hline 2020 & 18.8 & 8.5 & 51.82 & 30.00 \\
\hline 2021 & 16.4 & 8.3 & 53.64 & 30.00 \\
\hline 2022 & 13.8 & 7.7 & 55.45 & 30.00 \\
\hline 2023 & 11.4 & 6.9 & 57.27 & 30.00 \\
\hline 2024 & 9.2 & 6.1 & 59.09 & 30.00 \\
\hline 2025 & 7.2 & 5.1 & 60.91 & 30.00 \\
\hline 2026 & 5.6 & 4.2 & 62.73 & 30.00 \\
\hline 2027 & 4.3 & 3.4 & 64.55 & 30.00 \\
\hline 2028 & 3.3 & 2.7 & 66.36 & 30.00 \\
\hline 2029 & 2.5 & 2.1 & 68.18 & 30.00 \\
\hline 2030 & 1.9 & 1.6 & 70.00 & 30.00 \\
\hline
\end{tabular}

\section{Emerging Technologies - Lighting Research and Development}

\section{Program Outputs (BTP 2005)}

Lighting research and development (R\&D) is a critical element of the Building Technologies Program. The BT goal is to achieve lighting technologies with double the efficacy of today's most efficient lighting sources, linear and compact fluorescents. ${ }^{11}$ Our primary targets are solid-

\footnotetext{
${ }^{11}$ Linear fluorescent lamps offer efficacies as high as 80 lumens per watt. Compact fluorescent lamps, a derivative of this technology, are less efficient (approximately 60 lumens per watt); however, they still offer a four-fold improvement over traditional incandescent bulbs.
} 
state lighting devices and technologies that will produce white light with efficacies ${ }^{12}$ in reaching nearly160 lumens per watt in commercial products by 2025, with an interim target of 95 lumens per watt projected by $2012 .{ }^{13}$ In assessing program impacts, it is recognized that solid-state lighting is capturing increasing attention by private firms and will lead to improved products in the long term even without the DOE effort. ${ }^{14}$ After 2012, market forces are assumed to be able to produce products with efficacies of more than 100 lumens per watt by 2020 . However, the ontinuing DOE R\&D activities are assumed to drive up efficacies significantly higher than what may be viewed as a profit-maximizing level by the industry.

\section{Target Market Description (BTP 2005).}

Energy consumption for all lighting in the United States is estimated to be 8.2 quads, or about $22 \%$ of the total electricity generated (LMC I 2003). On a national basis, Figure G-6 provides a breakdown by end-use sector of the energy consumption for lighting our homes, offices, and other applications throughout the country. The figure shows that more than half of these 8.2 quads were consumed in the commercial sector, the largest energy user for lighting. This is one of the principal markets the DOE has targeted to develop more efficient technologies, as lighting contributes to a building's internal heat generation and subsequent air-conditioning loads at peak electric demand times.

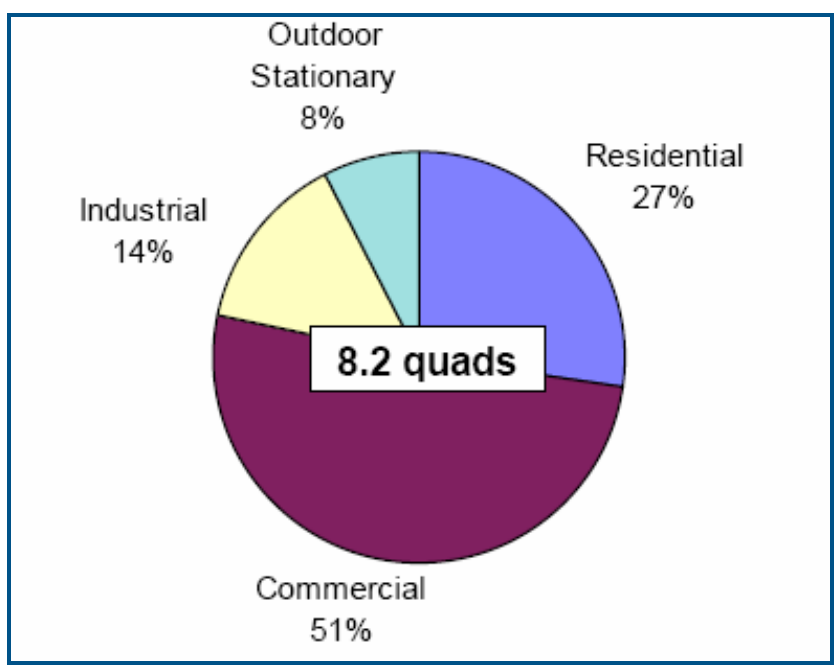

Figure G-6: National Primary Energy Consumption for Electricity for Lighting, 2001 (LMC I 2003)

\footnotetext{
${ }^{12}$ For solid-state lighting technologies, the performance target is focused on the energy efficiency rating of the device. The unit of performance commonly used when discussing light sources and systems is lumens of light produced per watt of energy consumed. The technical term for this metric is "efficacy" measured in lumens per watt. Several lighting products, including fluorescent lamps and incandescent reflector lamps, are regulated using an efficacy target. The efficacy projections for solid-state lighting are generated for laboratory devices because the Lighting R\&D portfolio does not have direct influence over commercially offered products.

${ }^{13}$ These efficacies pertain to devices that are assumed will compete with four-foot fluorescent lamps. Efficiencies for products that will compete directly with incandescent lamps, with somewhat better lighting quality characteristics than fluorescent products, are assumed to have lower efficacies.

${ }^{14}$ Assumed increases for SSL devices in all segments of the lighting market are explicitly included in the GPRA baseline. This baseline shows significantly higher penetration of SSL devices than what was contained in the EIA reference case for the 2007 AEO.
} 
Looking only at the commercial and residential sectors, the total energy use for lighting was approximately 6.4 quads (LMC I 2003). Nationally, total energy use in commercial and residential buildings in 2001 was approximately 38.0 quads, of which electricity use was approximately 26.6 quads (BEDB 2005). Thus, in these two building sectors, lighting constituted approximately $17 \%$ of total building energy consumption, or approximately $24 \%$ of total building electricity use.

Figure G-7 illustrates the breakdown by sector of national energy consumption for lighting in units of site (end use) electricity consumption (terawatt-hours/year), disaggregated by source type. These units represent the electrical energy consumed on-site for lighting throughout the United States.

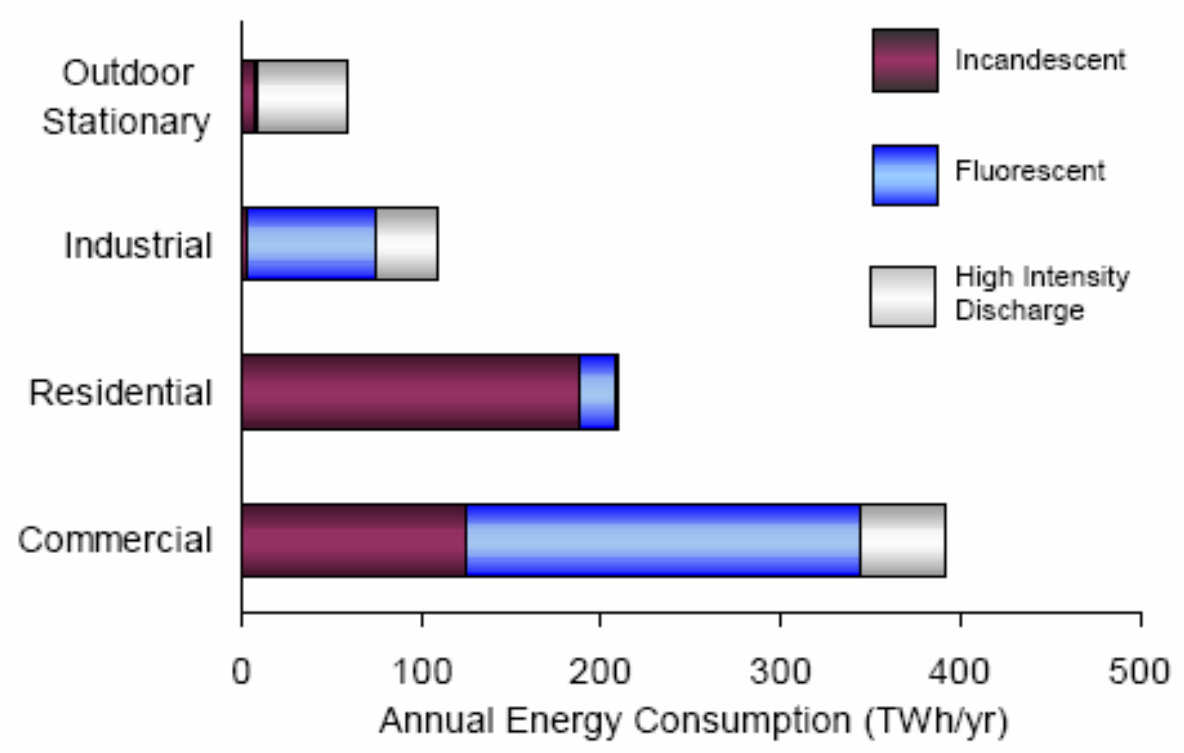

Figure G-7: National Lighting Energy Consumption by Sector and Source (LMC I 2003)

The figure shows that fluorescent sources in the commercial sector are the single largest lighting energy-consuming segment in the United States, slightly greater than incandescent lamps in the residential sector. However, across all sectors, incandescent is the leading electricity consumer in the United States consuming 321 terawatt-hours per year (TWh/yr). Fluorescent lighting is a close second with approximately $313 \mathrm{TWh} / \mathrm{yr}$ and High Intensity Discharge (HID) is third with approximately $130 \mathrm{TWh} / \mathrm{yr}$ (LMC I 2003).

\section{Assumed Budget Projections}

BT assumed level funding throughout the analysis period (2008-2025). The amount of the request is confidential until after the budget submission to Congress.

\section{Description of Key Activities (BTP 2005)}

The R\&D agenda of the Solid-State Lighting (SSL) activities are established through an annual consultative process with the general lighting industry, compound semiconductor industry, universities, research institutions, national laboratories, trade organizations, other industry consortia, and the Next Generation Lighting Industry Alliance (DOE's competitively selected 
Solid-State Lighting Partnership). The high-priority tasks are competitively bid and awarded to entities whose proposals meet these priorities and the SSL portfolio's stated objectives. The Solid-State Lighting activity classifies its projects into four R\&D classes: LED Core Technology, LED Product Development, OLED Core Technology, and OLED Product Development. Tasks in Core Technology are truly innovative and groundbreaking, fill technology gaps, provide enabling knowledge or data, and represent a significant advancement in the SSL knowledge base. These Core Technology tasks are focused on gaining precompetitive knowledge for future application to products, for use by other organizations. Product Development tasks are the systematic use of knowledge gained from basic and applied research to develop or improve commercially viable materials, devices, or systems. Technical activities are focused on a targeted market application with fully defined price, efficacy, and other performance parameters necessary for success of the proposed product. Product development encompasses the technical activities of product concept modeling through to the development of test models and field ready prototypes. Within each R\&D class, there are active, detailed R\&D agendas that contribute to the larger programmatic objective.

The SSL portfolio presently funds 11 core priority R\&D topics and seven product development priority R\&D topics (based on FY 2005 Solid-State Lighting Workshop prioritized R\&D topics). Each year, the R\&D topics are reviewed for progress on currently funded projects, completion of topical areas, new topics to start, and advice from the Alliance and the research community. The agenda is reprioritized for upcoming solicitations.

\section{Milestones (BTP 2005)}

For each project/task activity identified, BTP prepared a Gantt chart to show the critical milestones, off-ramps, and transfer points for the Lighting subprogram. Each of the nine bars appearing in the Gantt chart is discussed in detail in BT's Multiyear Program Plan (BTP 2005).

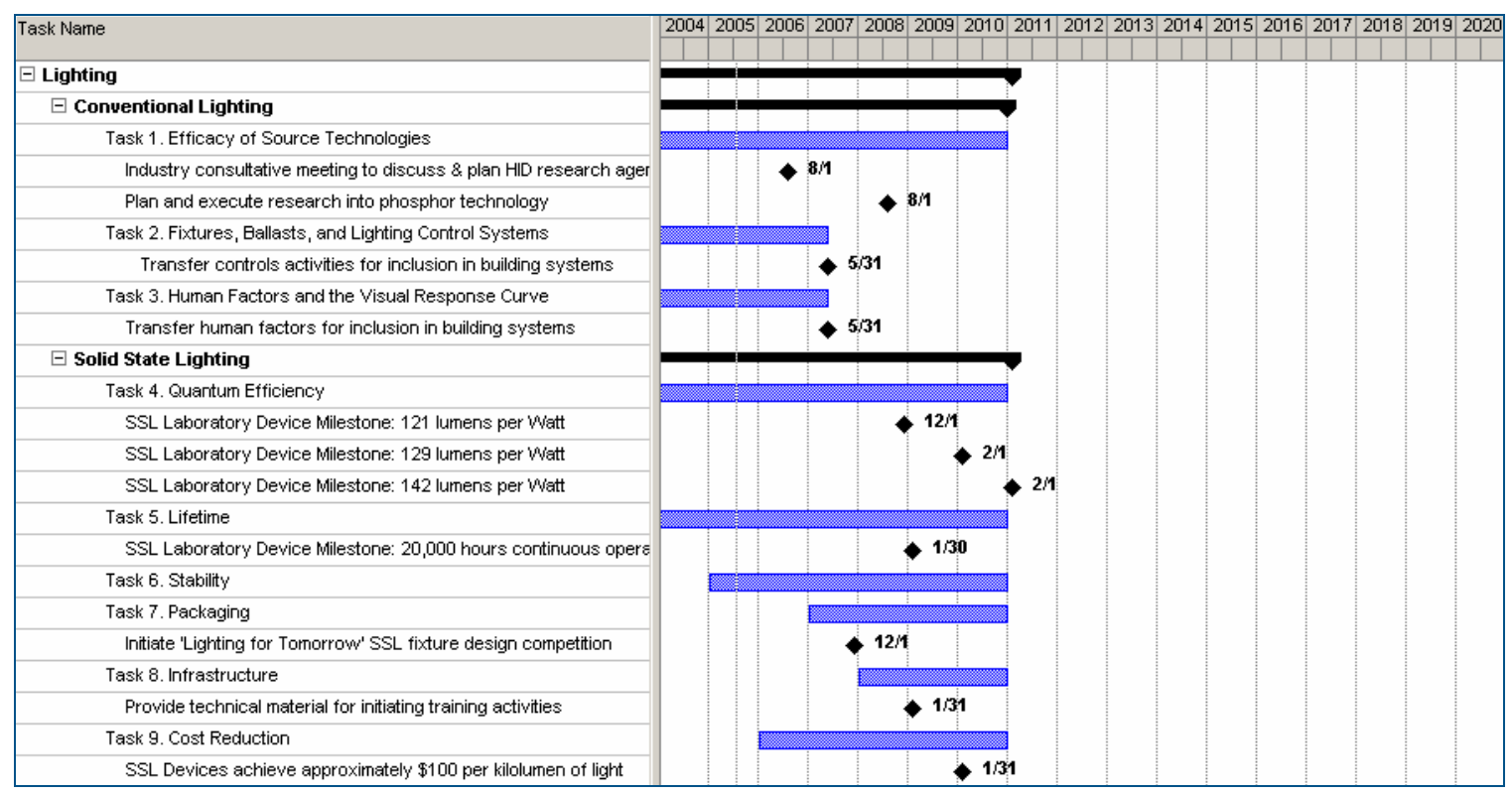

Figure G-8: Lighting Gantt Chart (BTP 2005) 
Program Outputs (BTP 2005)

The Lighting portfolio is a critical subprogram of the larger Building Technologies Program. Its strategic goal clearly states where the program is headed in terms of energy savings. The objective is not tied to any one technology or approach, but rather encompasses a portfolio of activities. The anticipated outcome is stated below:

The Lighting strategic goal reads as follows:

By 2025, develop and demonstrate energy-efficient, high-quality, cost-effective, long-lasting lighting technologies that have the technical capability of illuminating our buildings using 50\% less electricity compared to technologies in 2005.

The objective incorporates two critical components - an energy savings target and a device performance target. The following text discusses these two pillars of the technical objective.

The energy-savings goal ties back to the BT Program mission of increasing the energy efficiency of buildings and the concomitant benefits associated with those savings. The objective is looking at more than the replacement of incandescent technologies (and these are in use in 2005), but the more efficient fluorescent sources, as well, which were identified as the largest single user of electricity for lighting in commercial buildings. In this technical objective, Building Technologies is targeting the development of solid-state lighting devices and technologies that will have the capability of producing light at more than double those of fluorescent technologies. Efficacies in excess of 160 lumens per watt for market products are projected, with 200 lumens per watt targeted for the laboratory.

The performance targets for conventional technology and solid-state lighting are shown below. Separate targets were developed for each, to accommodate different metrics of performance used by experts in each field, and to account for differences in the applications where these technologies will be installed.

The efficacy projections for solid-state lighting are generated for laboratory devices because the Lighting portfolio does not have direct influence over commercially offered products. The anticipated rate of performance improvement is shown in Figure G-9, with an industry-guided estimate of the commercial device expected. 


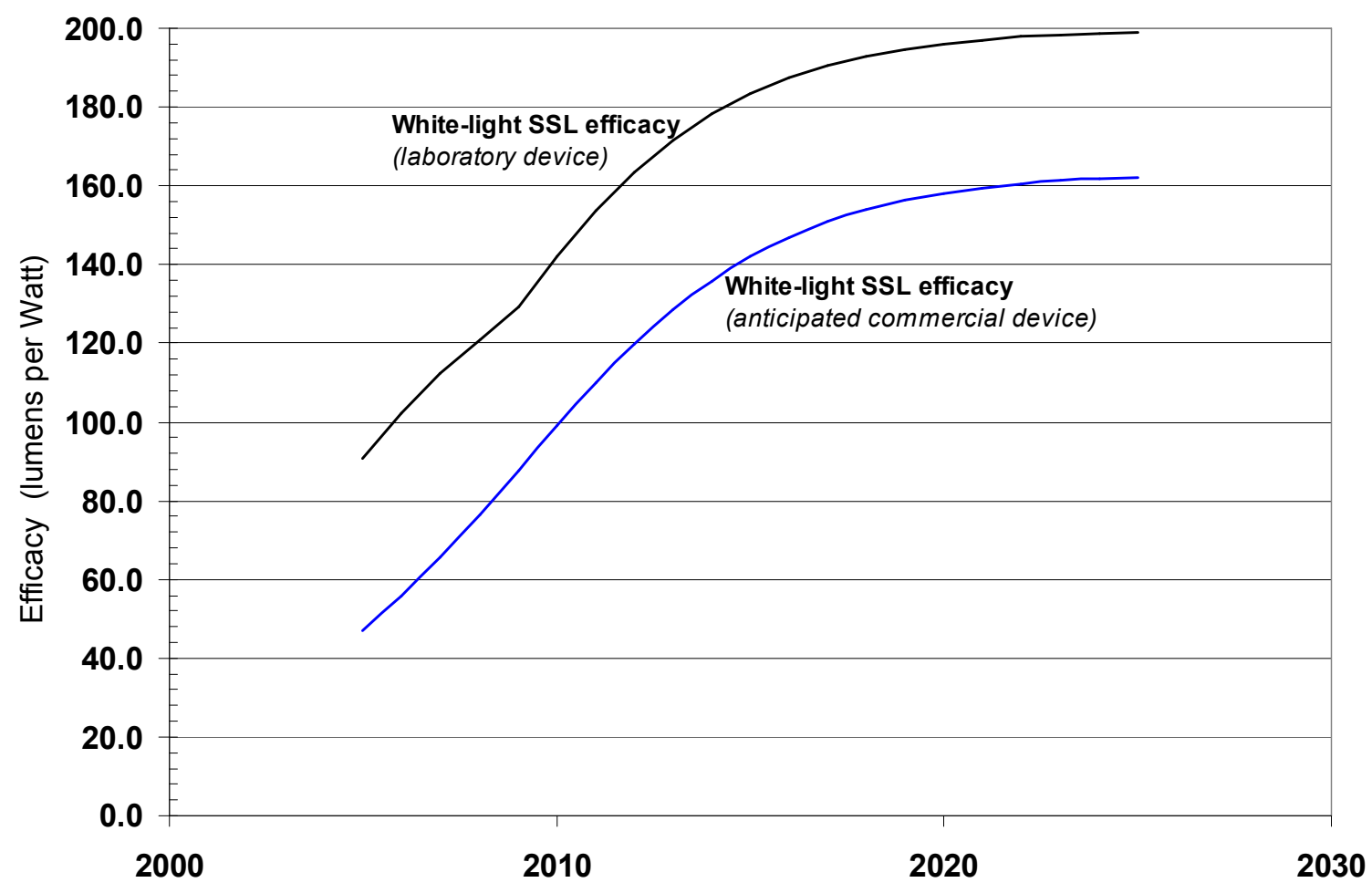

Figure G-9: Plot of Efficacy Projection for White-Light SSL Laboratory Devices (BTP 2005)

This projection is translated into point values in Table G-11, with the five-year target milestones.

Table G-11: Point Values of Efficacy Projections for White-Light SSL Laboratory Devices (BTP 2005)

\begin{tabular}{lcccccc}
\hline \multirow{1}{*}{ Characteristics } & Units & \multicolumn{5}{c}{ Calendar Year } \\
\cline { 3 - 6 } & & $\mathbf{2 0 0 5}$ & $\mathbf{2 0 1 0}$ & $\mathbf{2 0 1 5}$ & $\mathbf{2 0 2 0}$ & $\mathbf{2 0 2 5}$ \\
\hline $\begin{array}{l}\text { Solid-State Lighting } \\
\text { Performance }\end{array}$ & Lumens/watt & 71 & 142 & 183 & 196 & 199 \\
\hline
\end{tabular}

\section{Translating Program Outputs to Market Outcomes (BTP 2005)}

Lighting activities in conventional lighting technology will decrease the lighting power density per unit area. In 2001, the national average lighting power density was approximately 1.8 watts per square foot for the commercial sector (LMC I 2003). The installed base is estimated to be approximately 1.5 watts per square foot in 2005 due to efficiency improvements. During the next two decades, the installed base of lighting in commercial buildings, with new technologies and capabilities provided by the Lighting activities, is projected to decrease from 1.5 in 2005 to 0.9 watts per square foot in 2025. This reduction is attributable to market-driven efficiency improvements as well as new construction codes (e.g., ASHRAE 90.1 and California's Title 24) and ongoing industry and government research activities in conventional lighting technologies. This reduction represents a $45 \%$ savings over the 2001 level of 1.8 watts per square foot. 
Considering the anticipated growth in demand for lighting over the next two decades, this reduction in lighting power density translates into about 20\% lighting energy savings by 2025 (or approximately 2.0 quads of primary energy consumption savings). However, not all of these savings will be directly attributable to the Lighting subprogram - those savings driven by codes and standards such as ASHRAE 90.1 and California Title 24 do not qualify as benefits derived from the Lighting subprogram. Lighting experts estimate that approximately one-quarter of the savings in a commercial building will be voluntary, leveraged by Lighting subprogram activities.

To aid in the deployment efforts of solid-state lighting technologies, BTP also sponsors two activities, Solid-State Lighting Acceptance and Energy Star: Solid-State Lighting.

Key Factors in Shaping Market Adoption of EERE technologies

- Price: Table G-12 contains the prices used in the analysis. The prices for each year and category are the same as the baseline price; the corresponding lamp efficacy is different.

Table G-12: Solid-State Lighting System Lamp and Ballast Cost [2006 \$/thousand lumens (kIm)]

\begin{tabular}{|c|c|c|c|c|}
\hline Year & $\begin{array}{r}\text { Low Color } \\
\text { Rendering } \\
\text { Index } \\
(\mathrm{CRI})\end{array}$ & $\begin{array}{r}\text { Medium } \\
\text { Color } \\
\text { Rendering } \\
\text { Index } \\
(\mathrm{CRI}) \\
\end{array}$ & $\begin{array}{r}\text { High } \\
\text { Color } \\
\text { Rendering } \\
\text { Index } \\
\text { (CRI) }\end{array}$ & $\begin{array}{r}\text { Very High } \\
\text { Color } \\
\text { Rendering } \\
\text { Index } \\
\text { (CRI) }\end{array}$ \\
\hline 2005 & $\$ 40.63$ & $\$ 68.83$ & $\$ 133.82$ & $\$ 199.69$ \\
\hline 2006 & $\$ 28.14$ & $\$ 50.86$ & $\$ 112.92$ & $\$ 175.40$ \\
\hline 2007 & $\$ 19.08$ & $\$ 37.64$ & $\$ 92.34$ & $\$ 147.31$ \\
\hline 2008 & $\$ 12.91$ & $\$ 27.91$ & $\$ 72.51$ & $\$ 117.31$ \\
\hline 2009 & $\$ 8.88$ & $\$ 20.75$ & $\$ 54.60$ & $\$ 88.61$ \\
\hline 2010 & $\$ 6.31$ & $\$ 15.49$ & $\$ 39.71$ & $\$ 64.08$ \\
\hline 2011 & $\$ 4.70$ & $\$ 11.61$ & $\$ 28.29$ & $\$ 45.09$ \\
\hline 2012 & $\$ 3.69$ & $\$ 8.75$ & $\$ 20.06$ & $\$ 31.48$ \\
\hline 2013 & $\$ 3.06$ & $\$ 6.65$ & $\$ 14.41$ & $\$ 22.26$ \\
\hline 2014 & $\$ 2.66$ & $\$ 5.10$ & $\$ 10.62$ & $\$ 16.22$ \\
\hline 2015 & $\$ 2.41$ & $\$ 3.95$ & $\$ 8.13$ & $\$ 12.37$ \\
\hline 2016 & $\$ 2.25$ & $\$ 3.27$ & $\$ 6.58$ & $\$ 9.94$ \\
\hline 2017 & $\$ 2.14$ & $\$ 2.83$ & $\$ 5.60$ & $\$ 8.42$ \\
\hline 2018 & $\$ 2.07$ & $\$ 2.58$ & $\$ 5.01$ & $\$ 7.48$ \\
\hline 2019 & $\$ 2.01$ & $\$ 2.43$ & $\$ 4.65$ & $\$ 6.90$ \\
\hline 2020 & $\$ 1.97$ & $\$ 2.34$ & $\$ 4.42$ & $\$ 6.54$ \\
\hline 2021 & $\$ 1.94$ & $\$ 2.29$ & $\$ 4.28$ & $\$ 6.31$ \\
\hline 2022 & $\$ 1.92$ & $\$ 2.25$ & $\$ 4.19$ & $\$ 6.16$ \\
\hline 2023 & $\$ 1.89$ & $\$ 2.22$ & $\$ 4.12$ & $\$ 6.07$ \\
\hline 2024 & $\$ 1.87$ & $\$ 2.19$ & $\$ 4.08$ & $\$ 6.00$ \\
\hline 2025 & $\$ 1.86$ & $\$ 2.17$ & $\$ 4.04$ & $\$ 5.95$ \\
\hline 2026 & $\$ 1.84$ & $\$ 2.15$ & $\$ 4.01$ & $\$ 5.91$ \\
\hline 2027 & $\$ 1.82$ & $\$ 2.13$ & $\$ 3.99$ & $\$ 5.88$ \\
\hline 2028 & $\$ 1.81$ & $\$ 2.11$ & $\$ 3.96$ & $\$ 5.85$ \\
\hline 2029 & $\$ 1.79$ & $\$ 2.10$ & $\$ 3.94$ & $\$ 5.82$ \\
\hline 2030 & $\$ 1.78$ & $\$ 2.08$ & $\$ 3.92$ & $\$ 5.80$ \\
\hline
\end{tabular}


Immediate Outcomes

The Solid-State Lighting (SSL) activity develops and accelerates the introduction of solid-state lighting and seeks to achieve the following for lighting:

- Significantly greater efficacy than conventional sources, such as T8 fluorescents (160 lumens per watt for commercial SSL lamps by 2025, compared to approximately 100 lumens per watt for linear T8 fluorescent).

- Easy integration into building systems of the future

- Ability to provide the appropriate color and intensity for any application

- Ability to last 20,000 to 100,000 hours

- Ability to readily supplement natural sunlight.

Key assumptions concerning the likely dates of introduction and the expected efficacies were influenced by two sources: 1) "Solid-State Lighting Research and Development Portfolio," a multiyear program plan prepared for the DOE in consultation with an industry forum (Navigant Consulting 2006); and 2) a more extended study conducted by Navigant Consulting for BT in late 2003 (Navigant Consulting 2003); the study presented price and performance improvement curves for solid-state lighting that were developed in close consultation with industry experts.

Table G-13: Solid-State Lighting System Efficacies (Lumens per Watt)

\begin{tabular}{rrrrr}
\hline Year & Low CRI & $\begin{array}{r}\text { Medium } \\
\text { CRI }\end{array}$ & High CRI & $\begin{array}{r}\text { Very High } \\
\text { CRI }\end{array}$ \\
\hline 2005 & 63.6 & 35.3 & 27.9 & 20.5 \\
\hline 2006 & 74.7 & 43.6 & 36.0 & 28.4 \\
\hline 2007 & 86.6 & 53.1 & 44.7 & 36.3 \\
\hline 2008 & 98.8 & 63.7 & 54.0 & 44.3 \\
\hline 2009 & 111.0 & 75.2 & 63.8 & 52.4 \\
\hline 2010 & 122.7 & 87.2 & 73.8 & 60.4 \\
\hline 2011 & 133.8 & 99.2 & 83.9 & 68.6 \\
\hline 2012 & 144.0 & 111.0 & 93.9 & 76.8 \\
\hline 2013 & 153.2 & 122.0 & 103.5 & 85.1 \\
\hline 2014 & 161.2 & 132.0 & 112.7 & 93.4 \\
\hline 2015 & 168.1 & 141.0 & 121.4 & 101.8 \\
\hline 2016 & 174.1 & 148.7 & 129.4 & 110.0 \\
\hline 2017 & 179.1 & 155.3 & 136.3 & 117.2 \\
\hline 2018 & 183.3 & 160.8 & 141.5 & 122.2 \\
\hline 2019 & 186.9 & 165.4 & 145.5 & 125.6 \\
\hline 2020 & 189.9 & 169.3 & 148.6 & 127.9 \\
\hline 2021 & 192.5 & 172.4 & 151.0 & 129.6 \\
\hline 2022 & 194.6 & 175.0 & 152.9 & 130.7 \\
\hline 2023 & 196.5 & 177.2 & 154.4 & 131.6 \\
\hline 2024 & 198.1 & 179.0 & 155.7 & 132.3 \\
\hline 2025 & 199.5 & 180.6 & 156.8 & 133.0 \\
\hline 2026 & 200.7 & 182.0 & 157.7 & 133.5 \\
\hline 2027 & 201.9 & 183.1 & 158.6 & 134.0 \\
\hline 2028 & 202.9 & 184.2 & 159.4 & 134.5 \\
\hline 2029 & 203.9 & 185.2 & 160.1 & 135.0 \\
\hline 2030 & 204.8 & 186.0 & 160.7 & 135.5 \\
\hline & & & &
\end{tabular}




\section{Interim Outcomes}

\section{Lighting R\&D: SSL Market Acceptance}

The program goal is to achieve a high penetration of high-efficacy SSL products without allowing low-efficacy SSL products to get entrenched. The Energy Star activity sets the requirements for labeling and promotes the use of Energy Star-rated products. The Market Acceptance activity will attempt to educate the market and encourage buyers not to purchase low-efficacy products. The combined result will be that the programs will actually diminish nearterm sales and increase sales further out. This would happen because Energy Star labeling and market education will change the mix of technologies being purchased from what it would have been without Energy Star labeling and education programs:

- low-efficacy SSL will not gain the imprimatur of Energy Star and, thus, we assume, will not gain market acceptance, which will limit sales

- those products that can meet the Energy Star labeling requirements will be relatively costly, which will also limit sales.

Conversely, in the future, we anticipate that Energy Star will continuously require greater and greater efficacy (as the baseline technologies improve), which will result in SSL being costeffective in more applications.

Figure G-10 illustrates the "New Sales Market Penetration." This will result in penetration curves like the following with 2030 values of 50\% without SSL Market Acceptance/Energy Star SSL and 70\% with SSL Market Acceptance/Energy Star SSL. The penetration curves were developed based on historical diffusion rates. The dominant type of diffusion model is most likely the mixed-influence model introduced by Frank Bass (1969). The Bass model incorporates parameters that reflect both external (e.g., mass media communication) and internal influences (e.g., word of mouth). In 1998, PNNL conducted a study for DOE/BT to estimate the Bass specification for 10 selected energy-efficient building products available in the marketplace today (Elliott et al. 2004). The PNNL study examined the historical market penetration for 10 energy-efficient products related to the buildings sector. Diffusion models were estimated for each product, based on the specification proposed by Bass (1969). The technologies were placed into four separate categories: 1) lighting, 2) HVAC and refrigeration (HVAC/R), 3) envelope, and 4) other. Generic curves for these categories were developed based on the 10 technologies. More detail about the parameters developed for each curve can be found in Elliott et al. 2004. 


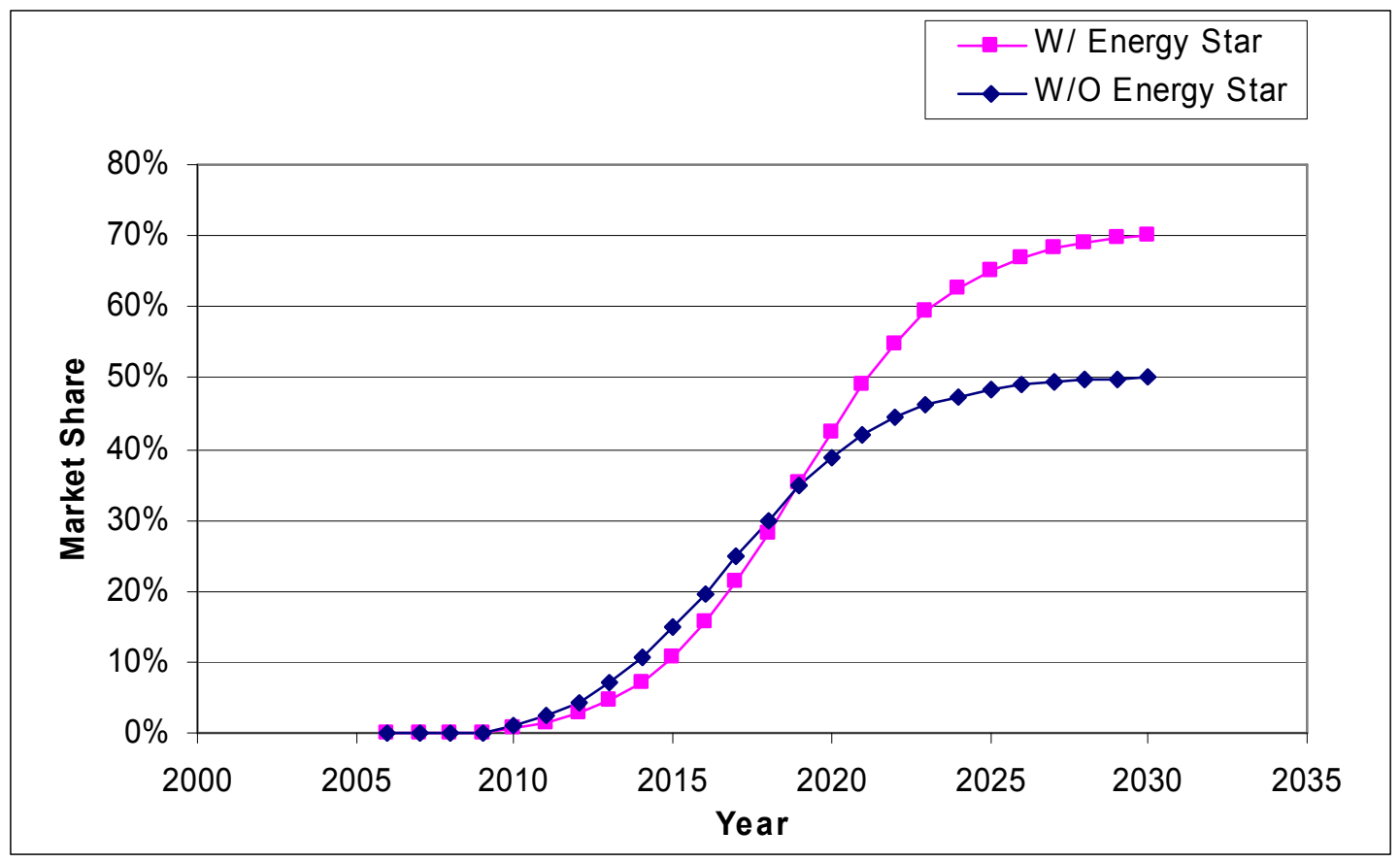

Figure G-10: New Sales of Solid-State Lighting Market Penetration

These inputs were incorporated into the NEMS-GPRA08 and MARKAL-GPRA08 models as described in the corresponding chapters of this document.

\section{Emerging Technologies - Space Conditioning and Refrigeration R\&D}

\section{Program Outputs (US DOE 2006a)}

In the past, R\&D and efficiency standards have focused on increasing the efficiency of the various individual units. Raising the minimum efficiency standard for residential unitary equipment from 10 to 13 Seasonal Energy Efficiency Ratio (SEER) ${ }^{15}$ is one key example. New approaches are now needed to further advance heating, ventilation, and air conditioning (HVAC) system efficiency.

Although the energy efficiency of HVAC equipment has increased substantially in recent years, new approaches, including radically new ideas, are needed to continue this trend. The dramatic reductions in HVAC energy consumption necessary to support the ZEB goals require a systemsoriented approach that characterizes each element of energy consumption, identifies alternatives, and determines the most cost-effective combination of options. Therefore, the first task in this effort will involve system characterizations, identification of necessary upgrades to analysis tools, and an assessment of cost and performance of alternative solutions.

\footnotetext{
${ }^{15}$ SEER measures how efficiently a cooling system will operate over an entire cooling season, as opposed to a single outdoor temperature. Higher SEERs indicate higher efficiencies.
} 


\section{Target Market Description (BTP 2005)}

Space conditioning equipment for residential and commercial buildings consumes approximately $38 \%$ of the total energy used in buildings, and electric cooling is an important contributor to summer peak electricity demand (BEDB 2005).

In residential buildings, space heating is the dominant component of energy consumption, accounting for $32.3 \%$ (vs. $11.3 \%$ for space cooling). Natural gas-fired furnaces and boilers are by far the most common heating systems; fuel-oil based systems and hydronic systems each account for less than $15 \%$ of heating energy consumption.

Water heating constitutes the next largest element of residential energy consumption after space conditioning, accounting for $12.6 \%$ of primary energy consumption. In commercial buildings, HVAC is the single largest component of primary energy consumption, accounting for $30.7 \%$ ( $14.0 \%$ for heating, $10.9 \%$ for cooling, and $5.8 \%$ for ventilation), while water heating is substantially smaller, at 6.3\% (BEDB 2005), although it is a significant end-use in some building types, such as hotels, hospitals, and restaurant.

The majority of space-conditioning equipment sold in the United States (approximately 70-80\% in most years) meets the minimum efficiency standard level mandated by DOE regulations (BTP 2005), with the remainder exceeding the standard level. In recent years, the HVAC industry has seen only modest improvements in equipment efficiency, largely driven by the efficiency standards. The 13 SEER minimum standard scheduled to take effect in 2006 will cause another large step increase in equipment efficiency. However, it is likely, at least in the next few years, that shipments of units with SEER greater than 13 will amount to less than $10 \%$ of the market, and most of these will probably be at 14 SEER. Premium HVAC systems sold in the United States will typically incorporate features that are valued by the customer, such as reduced noise and better fit and finish, but have little or no impact on efficiency.

The challenges to selling high efficiency water heating are even greater than for HVAC. Unlike appliances or even HVAC, there are few if any premium features of a water heater (e.g., comfort, aesthetics, image, enhanced functionality) that can be combined with efficiency to increase the sales of high efficiency products. Furthermore, most replacements are emergency replacement sales where immediate availability is essential and upgrading to more energy efficient units is not feasible or even considered. Finally, the relatively small energy costs of water heating to individual consumers can make it difficult to justify a higher first-cost product. Electric heat pump water heaters (HPWH) and condensing gas-fired water heaters offer significant energy savings over conventional products, but, until recently, have very high price premiums and have therefore achieved a very limited market share. For example, of the 4 to 5 million residential electric water heaters sold annually in the United States, only a few thousand are heat pump water heaters, whose efficiency can be more than double that of conventional units. A new condensing gas has recently been introduced to the market at only a modest cost premium

The basic design concept for both vapor-compression HVAC systems and water heaters has changed very little in decades. These products look much the same today as they did 20 years ago. Because incremental improvements and minimum efficiency standards (e.g., NAECA, 
EPACT, ASHRAE 90.1) have captured much of the "low-hanging fruit" available for further efficiency gains, new design approaches are necessary.

\section{Assumed Budget Projections}

BT assumed level funding throughout the analysis period (2008-2025). The amount of the request is confidential until after the budget submission to Congress.

\section{Description of Key Activities (BTP 2005)}

The HVAC efforts can be broadly divided into two distinct elements for the Zero Energy Home $(\mathrm{ZEH})$ :

- Development of HVAC Equipment and Design Options

- Integrated Water Heating Systems

\section{HVAC Equipment and Design Options for the ZEH}

The focus of HVAC R\&D efforts will be on system energy consumption, rather than simply the energy efficiency ratio (EER) ${ }^{16}$ or SEER, which do not capture the impacts of the entire HVAC system. The baseline for comparison is the International Energy Conservation Code 2003 benchmark. HVAC equipment will also need to be designed specifically to meet ZEH building loads, which will be quite different in magnitude and relative proportions (e.g., cooling/heating/dehumidification and domestic hot water) than those of current buildings.

This effort is specifically targeted to achieving demonstration of two to three design concepts that have the long-term potential to reduce annual HVAC energy consumption by $50 \%$ in new residential buildings (without taking into account building load reductions from other factors), relative to Building America Benchmarks, with an estimated simple payback period of three years or less. The design concepts must also address other critical Building America needs such as humidity control, uniform comfort, and indoor air quality. For design concepts that combine space conditioning and water heating, energy consumption payback period targets will be calculated relative to Building America Benchmark totals for both functions.

\section{Integrated Water Heating Systems for the ZEH}

Integrated systems that perform other functions in addition to water heating will become increasingly valuable in ZEH design. Beyond water heating energy savings, such products would provide other benefits or reduce energy costs in other ways (e.g., by providing dehumidification, or by combining functions or using waste heat from other appliances). Systems that combine water heating with other functions (e.g. space conditioning) and/or recover waste heat from other appliances or combined heat and power (CHP) systems will also be evaluated and possibly developed under this plan.

More detail on each of these elements can be found in BT's Multiyear Program Plan (BTP 2005).

\footnotetext{
${ }^{16}$ EER is a measure of how efficiently a cooling system will operate when the outdoor temperature is at a specific level (usually $\left.95^{\circ} \mathrm{F}\right)$. Higher EERs indicate higher efficiencies.
} 
Milestones (BTP 2005)

The Gantt chart in Figure G-11 shows tasks within the two primary activities planned for the HVAC and Water Heating R\&D program. An additional subactivity, addressing needs for lowloss hot water distribution systems, may be added in subsequent years, if appropriate R\&D needs are identified as a result of ongoing field studies.

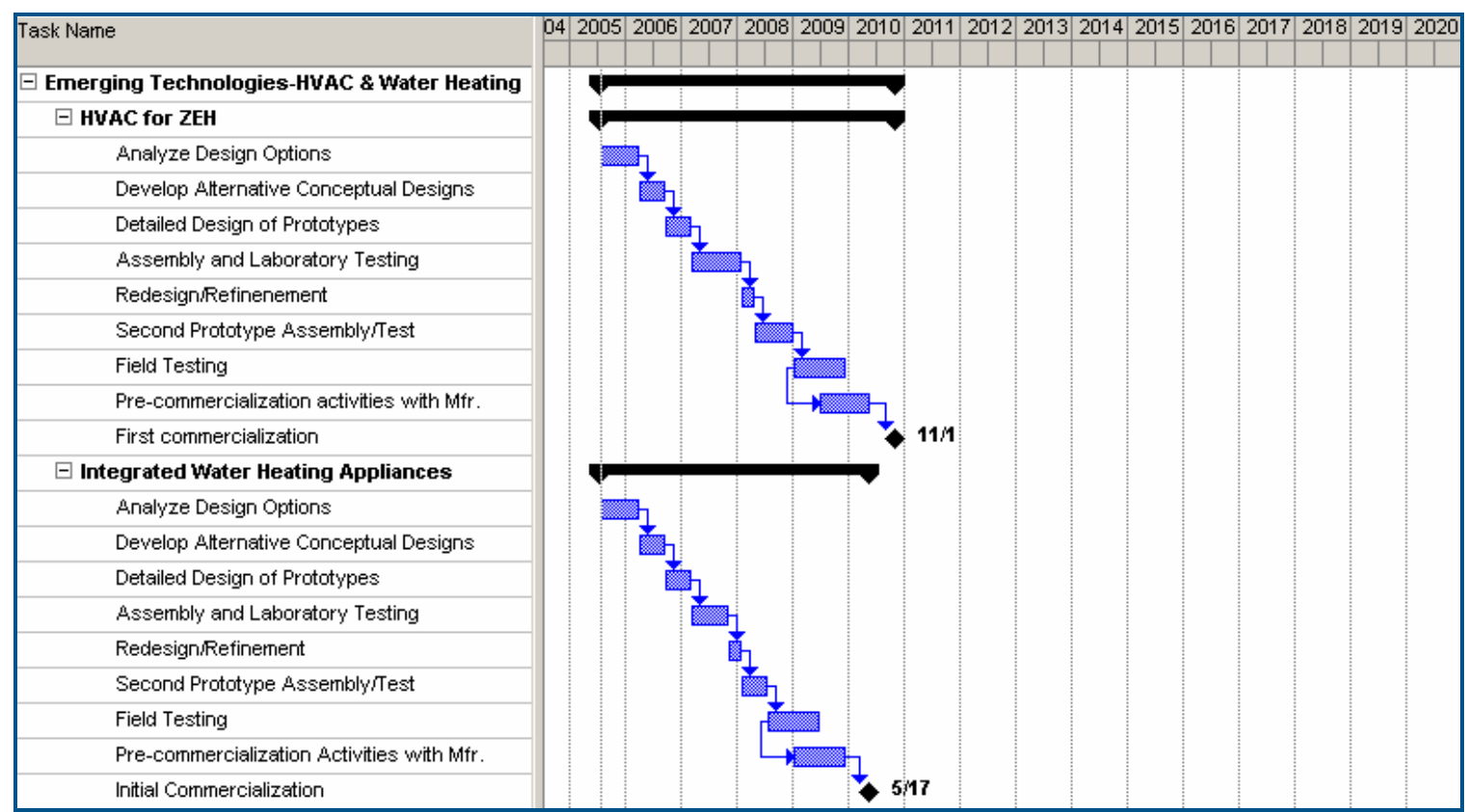

Figure G-11: HVAC \& Water Heating Gantt Chart (BTP 2005)

\section{Program Outputs (BTP 2005)}

Achieving the residential ZEB goals will require the development of space cooling and heating equipment that reduces energy consumption by $50 \%$ relative to the International Energy Conservation Code 2003 benchmark (ZEH 2003). BT's goal is to develop technologies with the long-term potential to meet this goal with an estimated simple payback period no greater than three years. For water heating, BT's target payback period is five years. 
Table G-14: HVAC and Water Heating Performance Goals (BTP 2005)

\begin{tabular}{|c|c|c|c|c|}
\hline \multirow[t]{2}{*}{ Characteristics } & \multirow[t]{2}{*}{ Units } & \multicolumn{3}{|c|}{ Year } \\
\hline & & 2005 & 2010 & 2015 \\
\hline $\begin{array}{l}\text { Residential Annual HVAC Energy Consumption } \\
\text { Reduction vs. } 2003 \text { Baseline (with simple } \\
\text { payback } \leq 3 \text { years) }\end{array}$ & $\%$ & Baseline & 50 & - \\
\hline $\begin{array}{l}\text { Commercial Annual HVAC Energy Consumption } \\
\text { Reduction vs. } 2003 \text { Baseline }\end{array}$ & $\%$ & Baseline & - & 80 \\
\hline $\begin{array}{l}\text { Residential Annual Water Heating Energy } \\
\text { Consumption Reduction vs. } 2003 \text { Baseline (with } \\
\text { simple payback } \leq 5 \text { years) }\end{array}$ & $\%$ & Baseline & 50 & 80 \\
\hline
\end{tabular}

The HVAC and Water Heating R\&D activity is fully aligned with the strategic goals of the BT program, specifically by developing technologies, products, and solutions that support the ZEB effort, initially focusing on residential buildings, but with the expectation of addressing commercial ZEB needs in the long term. To ensure that our R\&D activities remain aligned with these strategic goals as they evolve, we will work closely with the residential and commercial integration subprograms, through periodic meetings, research collaboration, and by participating in their program review meetings.

The long-term measure for the HVAC and Water Heating subprogram is the number of HVAC technology packages designed for new residential buildings. These technology packages must demonstrate through field or laboratory testing the potential to reduce annual HVAC energy consumption by $50 \%$ in new residential buildings (without taking into account building load reductions from other factors), relative to Building America benchmarks with an estimated simple payback period of three years or less (five years for water heating). The performance metric targets for the next five years are in Table G-15.

Table G-15: HVAC and Water Heating Performance Metrics (BTP 2005)

\begin{tabular}{lcccc}
\hline \multicolumn{1}{c}{ Characteristics } & Units & \multicolumn{3}{c}{ Year } \\
\cline { 3 - 5 } & Number & $\mathbf{2 0 0 6}$ & 2008 & 2010 \\
\hline $\begin{array}{l}\text { HVAC Technology Packages for } \\
\text { New Residential Buildings }\end{array}$ & Number & $\begin{array}{c}1 \\
\text { (conceptual } \\
\text { design) }\end{array}$ & 2 (field testing) & 2 (commercialized) \\
\hline $\begin{array}{l}\text { Integrated Water Heating } \\
\text { Appliances }\end{array}$ & $\begin{array}{c}1 \\
\text { (conceptual } \\
\text { design) }\end{array}$ & 2 (field testing) & 1 (commercialized) \\
\hline
\end{tabular}

The design concepts must also address other critical Building America needs such as humidity control, uniform comfort, and indoor environmental quality (IEQ). Several different design approaches will be necessary for optimal performance in different climate zones and building types. 


\section{Translating Program Outputs to Market Outcomes}

\section{Key Factors in Shaping Market Adoption of EERE technologies}

- Price:

○ Centrally Ducted Air-Source Integrated Heat Pump: Cost at market introduction is expected to be 2.5 times the cost of a conventional heat pump without water heating capability ( $\$ 2,700$ vs. $\$ 1,100$ for a 1.5 ton unit). The cost in five years is expected to be 1.7 times cost of conventional heat pump without water heating capability $(\$ 1,900$ vs. $\$ 1,100$ for a 1.5 ton unit).

- Thermotunneling Based Cooling: Cost at market introduction is expected to be $75 \%$ of the cost of conventional technology; cost at maturity (10 years) is expected to be $25 \%$ of the cost of conventional technology.

- Condensing Gas Water Heater: Baseline cost is \$200 for a conventional gas water heater; BT technology cost is $\$ 440$ for a condensing gas water heater (both have the same installation costs).

\section{Immediate Outcomes}

\section{Space Conditioning R\&D: Centrally Ducted Air-Source Integrated Heat Pump}

The program objective is to develop an air-to-air integrated heat pump (IHP) system that can meet the air heating, cooling, dehumidifying, ventilating, and water heating (WH) requirements of a tight-envelope, mechanically ventilated, near-zero-energy house (ZEH). Target energy savings is $50 \%$ relative to $\mathrm{ZEH}$ with an appropriate suite of benchmark equipment meeting the same needs. The targeted baseline is assumed to be represented by a SEER 13 and heating seasonal performance factor (HSPF) ${ }^{17} 7.7$ heat pump and EF 0.9 water heater.

This integrated heat pump concept uses a variable-speed modulating compressor, two variable speed fans, one variable speed pump, and a total of four heat exchangers (two air to refrigerant, one water to refrigerant, and one air to water) to meet all the HVAC and water heating loads.

\section{Space Conditioning R\&D: HVAC Competitive R\&D}

The program develops innovative HVAC and water heating equipment that offers the potential for significant energy savings. Projects are proposed and selected as part of a competitive solicitation process. Individual projects are funded for a maximum of three years. At the end of the project, DOE's goal is for the technology to be made available commercially.

In as much as the technologies under development are in flux, we determined that the best way to capture the potential of the competitive portfolio would be via evaluation of two representative technologies: thermotunneling cooling and condensing gas water heaters.

- For gas water heaters there are three energy factor $(\mathrm{EF})^{18}$ options within the NEMSGPRA methodology: $0.59 \mathrm{EF}, 0.61 \mathrm{EF}$, and a very expensive $0.86 \mathrm{EF}$ unit. The BT condensing gas water heater is modestly priced ${ }^{19}$ and has an energy factor of 0.79 . While

\footnotetext{
${ }^{17} \mathrm{HSPF}$ is the measurement of how efficiently all residential and some commercial heat pumps will operate in their heating mode over an entire normal heating season. The higher the HSPF, the more efficient the system.

${ }^{18} \mathrm{EF}$ indicates a water heater's overall energy efficiency based on the amount of hot water produced per unit of fuel consumed over a typical day. Higher EFs indicate higher efficiencies.

${ }^{19}$ Baseline cost is $\$ 200$ for a conventional gas water heater; BT technology cost is $\$ 440$ for a condensing gas water heater (both have the same installation costs).
} 
the technology was introduced in 2006, this is only an example of the types of technologies that are being developed. On average, in any given year, technologies being funded under this program are in their second year of funding. Hence, one additional year of development should be assumed (following the funding FY) with market introduction the following year. Therefore, for FY08 funding, BT assumed market introduction of 2010.

- Research indicates that the thermotunneling cooling technology should perform at about $65 \%$ of Carnot efficiency while the conventional counterparts have coefficients of performance $(\mathrm{COPs})^{20}$ that are about $40-50 \%$ of Carnot efficiency. Within NEMS-GPRA, the technology will compete against residential split system air-conditioning technologies with SEERs of 13,15, and 19.5; on the commercial side, it will compete against numerous chillers with COPs of 5.2 to 7.3 and rooftop units with energy efficiency ratios (EERs) of 8.9 to 13.5 . At $65 \%$ of Carnot, the equivalent performance of thermotunneling cooling is about a SEER of 21.0 for residential technologies, a COP of 7.5 for chillers, and an EER of 14.5 for rooftop units.

These inputs were incorporated into the NEMS-GPRA08 and MARKAL-GPRA08 models as described in the corresponding chapters of this document.

Emerging Technologies - Building Envelope R\&D: Thermal Insulation and Building Materials

\section{Program Outputs (US DOE 2006a)}

The Building Envelope program element will contribute to Zero Energy Buildings by advancing a portfolio of new insulation and membrane materials, including improved exterior insulation finishes, with both residential and commercial wall application. The next generation of attic/roof systems integrating thermal mass, ventilation and advanced insulated roof structures will be applied to the residential new construction market.

\section{Target Market Description (BTP 2005)}

The BT Program's long-range goal of developing ZEB by 2025 will require more cost-effective, durable, and efficient building envelopes. To make ZEB affordable, efforts to reduce the energy required for the building are a necessary complement to efforts to reduce the cost of renewable, on-site power. Forty percent of the primary energy used in a residence is spent on space heating and cooling (BEDB 2005). Reducing heat loss and heat gain through the envelope will significantly facilitate attainment of a practical ZEB because a significant amount of space heating and cooling energy is lost through inefficient envelopes. The importance of the Building Envelope Subprogram has been recognized by the Building Integration Subprogram, as exemplified by the ambitious envelope targets in the Building America list of optimizationcritical component needs (ZEH 2003).

\section{Assumed Budget Projections}

BT assumed level funding throughout the analysis period. The amount of the request is confidential until after the budget submission to Congress.

\footnotetext{
${ }^{20} \mathrm{COP}$ is the measurement of how efficiently a heating or cooling system (particularly a heat pump in its heating mode and a chiller for cooling) will operate at a single outdoor temperature condition. When applied to the heating modes of heat pumps, that temperature condition is usually $47^{\circ} \mathrm{F}$. Higher COPs indicate higher efficiencies.
} 


\section{Description of Key Activities}

The Building Envelope Subprogram is focused on meeting the Building Envelope objectives outlined by conducting collaborative R\&D with national laboratories, industry partners, standards and professional societies, and universities, including international participation as appropriate.

\section{Develop the Next Generation of Envelope Materials}

The program strategy is to create the opportunity for envelopes to contribute to ZEB by advancing a portfolio of new insulation and membrane materials, including the exterior finishes, having residential and commercial application. The needs for new envelope materials have been expressed in a number of roadmaps (US DOE 2001; US HUD 2004a; US HUD 2004b).

\section{Develop the Next Generation of Attic Systems}

The goal for the advanced attic systems project is to make attics constructed by 2010 twice as efficient as Building America's regional benchmarks. Attics were selected because practical solutions for constructing an energy-efficient attic do not exist and that attic and roofing systems represent a significant percentage of the aggregate residential building component loads (BEDB 2005; Anderson 2004). Achieving this ambitious goal will require a well-coordinated collection of technical advances, using an effective collaboration of engineering and scientific resources (US DOE 2001; US HUD 2004b).

\section{Develop the Advanced Wall Systems}

The goal for the advanced wall systems project is to make these systems constructed by 2010 twice as efficient as Building America's regional benchmarks. A market resistance to increased wall thickness has jeopardized opportunities to improve the energy efficiency of this envelope component in many regions. Therefore, advanced materials and systems that deliver significant improvements in energy performance without increasing wall thickness are needed.

More detail on each of these strategies can be found in BT's Multiyear Program Plan (BTP 2005).

\section{Milestones}

For each project/task activity identified, a Gantt chart has been prepared to show the critical milestones, off-ramps, and transfer points. 

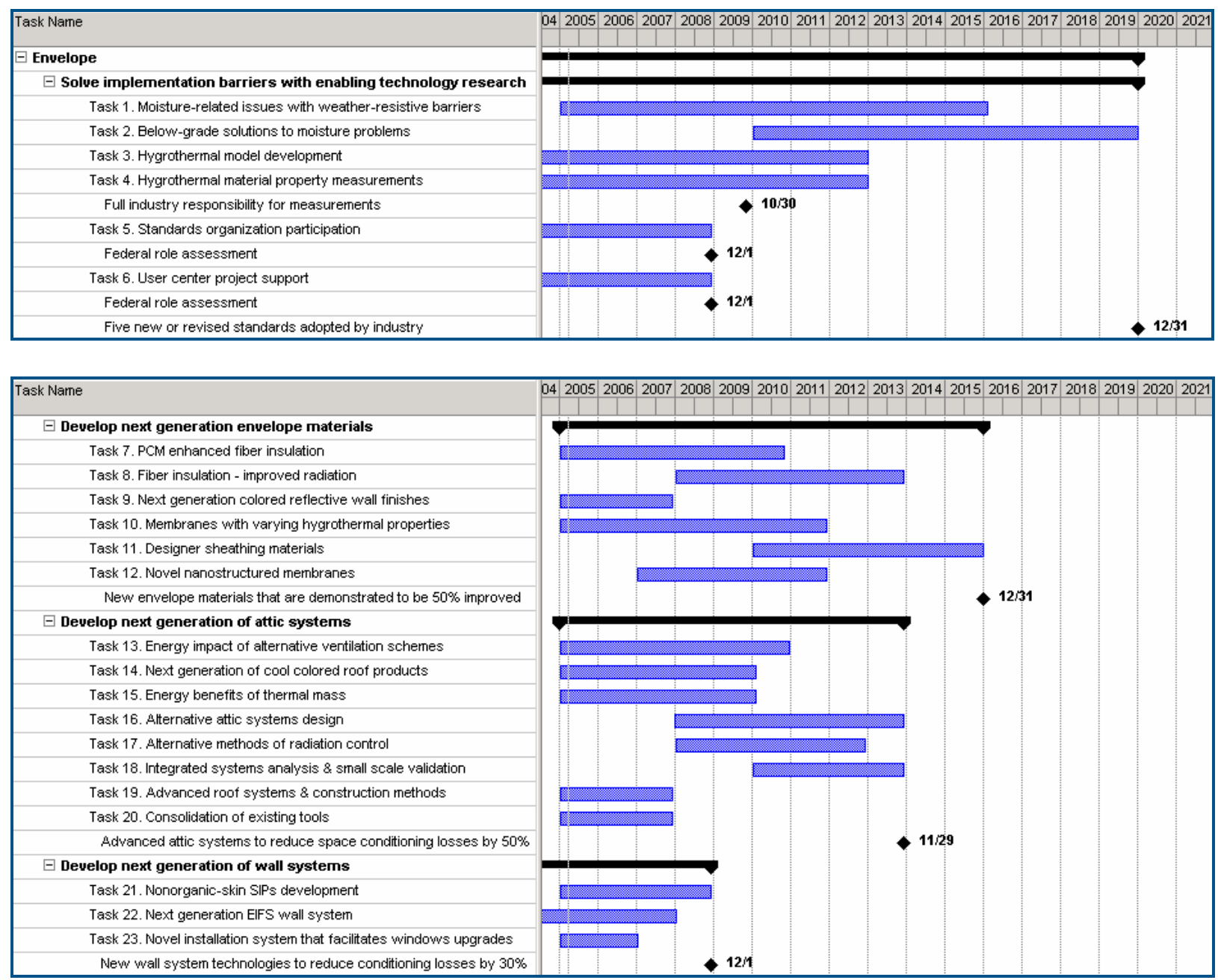

Figure G-12: Envelope Gantt Chart (BTP 2005)

\section{Program Outputs (BTP 2005)}

The strategic goals have been defined with consideration of their energy-saving potential toward the ZEB goal and the research gaps noted in a recent Building America/Emerging Technologies planning meeting (US DOE 2004a). These objectives have been organized to address major building envelope systems, promising new material developments and enabling technologies.

- Develop the Next Generation of Envelope Materials: By 2015, develop and demonstrate innovative materials that either: (1) will have effective thermal performance improved by $50 \%$ relative to functionally comparable components of the Building America regional baseline new construction; or (2) resolve durability-related problems (moisture, termite, structural, etc.) that may increase envelope failure risk.

- Develop the Next Generation of Attic Systems: By 2013, develop advanced attic technologies for single-family residences that reduce the space-conditioning requirements attributable to attics by 50\% compared to Building America regional baseline new construction at no additional operating cost and no additional envelope failure risk. 
- Develop the Advanced Wall Systems: By 2009, develop advanced wall technologies for single-family residences that reduce the space-conditioning requirements attributable to walls by $30 \%$ compared to Building America regional baseline new construction at no additional operating cost and no additional envelope failure risk.

Table G-16 lists the performance goals for the Building Envelope subprogram. All performance measurements are relative to historical baselines that have been set as the Building America regional baseline new construction. One important constraint included for many components of strategies is that of "no additional operating cost," which is defined here as the sum of the mortgage-amortized installed cost and the annual energy costs savings. Ensuring the durability of the envelope is also an integral aspect of these targets.

Table G-16: Envelope Performance Goals (BTP 2005)

\begin{tabular}{|c|c|c|c|c|}
\hline \multirow[t]{2}{*}{ Characteristics } & \multirow[t]{2}{*}{ Units } & \multicolumn{3}{|c|}{ Calendar Year } \\
\hline & & $\begin{array}{l}2004 \\
\text { Status }\end{array}$ & 2007 Target & 2010 Target \\
\hline $\begin{array}{l}\text { Advanced attic/roof } \\
\text { system }\end{array}$ & R-Value ${ }^{21}$ & 30 & 35 & $\begin{array}{l}\text { Dynamic annual } \\
\text { performance equal to } \\
\text { conventional R-45 }\end{array}$ \\
\hline $\begin{array}{l}\text { Color reflectivity } \\
\text { (applicable to both walls } \\
\text { and roofs) }\end{array}$ & $\begin{array}{l}\text { Solar } \\
\text { reflectivity }\end{array}$ & $10 \%$ & $40 \%^{22}$ & $40 \%^{23}$ \\
\hline $\begin{array}{l}\text { Moisture property } \\
\text { measurements }\end{array}$ & $\begin{array}{c}\text { Test } \\
\text { methods }\end{array}$ & $\begin{array}{l}\text { Nonun- } \\
\text { iform }\end{array}$ & $\begin{array}{l}\text { Uniform set of } \\
\text { definitions, } \\
\text { interlaboratory } \\
\text { comparisons } \\
\text { underway for } 2 \\
\text { methods }\end{array}$ & $\begin{array}{c}\text { Interlaboratory } \\
\text { comparisons } \\
\text { underway for } 3 \\
\text { additional methods. }{ }^{24}\end{array}$ \\
\hline $\begin{array}{l}\text { Accelerated roof surface } \\
\text { durability tests }\end{array}$ & Time & $\begin{array}{c}3 \\
\text { years }\end{array}$ & & 6 months \\
\hline Wall insulation & R-Value & 10 & $\begin{array}{l}\text { Dynamic annual } \\
\text { performance equal to } \\
\text { conventional } \mathrm{R}-20^{25}\end{array}$ & $\begin{array}{l}\text { Dynamic annual } \\
\text { performance equal to } \\
\text { conventional } \mathrm{R}-20^{26}\end{array}$ \\
\hline $\begin{array}{l}\text { Panelized wall with non- } \\
\text { organic faces, suitable for } \\
\text { termite-prone regions }\end{array}$ & R-value & 7 & $\begin{array}{l}\text { Dynamic annual } \\
\text { performance equal to } \\
\text { conventional } \mathrm{R}-20^{27}\end{array}$ & $\begin{array}{l}\text { Dynamic annual } \\
\text { performance equal to } \\
\text { conventional } \mathrm{R}-20^{28}\end{array}$ \\
\hline
\end{tabular}

\footnotetext{
${ }^{21} \mathrm{R}$-value is the measurement of how effectively a material resists the transfer of heat via conduction. The higher the R-value, the less heat transfer can take place.

${ }^{22}$ Durability not yet assured at interim target.

${ }^{23}$ With attractive dark appearance, and with long-term durability of both reflective properties and appearance.

${ }^{24}$ Interlaboratory tests are a critical testing ground used during the development of new standard test methods. Standards are

seldom accepted by consensus organizations until the proposed method has been subjected to this form of peer review.

${ }^{25}$ Interim target NOT subject to cost constraints and may not be in commercial production.

${ }^{26}$ No additional operating cost, traditional 3.5-in. wall dimension, with acceptable durability characteristics.

${ }^{27}$ Interim target NOT subject to cost constraints.

${ }^{28}$ No additional operating cost, traditional 3.5-in. wall dimension, with acceptable durability characteristics.
} 


\section{Translating Program Outputs to Market Outcomes (BTP 2005)}

Building envelope designs and material selections are typically constrained by cost. This is particularly true during new construction when many homes are built on speculation. Even for retrofit applications, improvements that add cost are very difficult to market unless those costs can be recovered through reduced energy bills. Also, the building envelope industry is highly fragmented. It is unlikely that an envelope is constructed with products from a single manufacturer. Often, a building envelope constructed in the field joins elements that have never been combined exactly the same way before. The number of potential combinations of components is astronomical. Issues associated with how products perform together are seldom addressed.

\section{Key Factors in Shaping Market Adoption of EERE technologies}

- Price:

○ Next-Generation Attic: At market introduction: 30\% above conventional insulation material costs or about $\$ 165 /$ single family house. At maturity (10 years): equal to conventional.

- Advanced Wall Systems: At market introduction: 30\% above conventional insulation and window material costs or about $\$ 1,980 /$ single-family house. At maturity (10 years): equal to conventional.

○ Next-Generation Envelope Materials: At market introduction: 30\% above conventional insulation material costs or about \$535/single family house. At maturity (10 years): equal to conventional.

\section{Immediate Outcomes}

The general approach for GPRA envelope calculations was to simulate the effect of an envelope technology using the Facility Energy Decision System (FEDS) model ${ }^{29}$ for many different building types, sizes, vintages, and locations (PNNL 2002). For each technology, the impact was simulated in more than 10,000 buildings:

- 7,200 commercial buildings are run to cover 15 climate zones (BT developed climate zones for IECC 2004 supplement), 10 building types, 6 sizes, and 8 vintages ( 7 existing and 1 new).

- 2,835 residential buildings are run to cover 15 climate zones (BT developed climate zones for IECC 2004 supplement), 3 building types, 9 sizes, and 7 vintages ( 6 existing and 1 new).

Because NEMS-GPRA08 only models one of each building type in each of the nine census regions, the FEDS results needed to be aggregated for input into NEMS-GPRA08. This aggregation is performed by applying city and floor area weighted averages to the FEDS results to represent the loads within a census region. More detail about this process is contained in Elliott et al. 2004.

The heating and cooling loads were calculated for each building with and without the envelope technology being evaluated. The changes in the heating and cooling loads are used to modify the heating and cooling envelope factors in NEMS-GPRA08 and MARKAL-GPRA08; more detail

\footnotetext{
${ }^{29}$ The Facility Energy Decision System (FEDS) is a building energy simulation tool developed for building energy analysis. 
on the incorporation of these inputs is in the corresponding NEMS and MARKAL chapters of this report.

\section{Building Envelope R\&D: Thermal Insulation and Building Materials - Next-Generation} Attic

The Next-Generation Attic simulation runs were conducted in FEDS using the following baseline and BT technology assumptions:

- $\quad$ Baseline Roof U-value ${ }^{30}=0.0333 \mathrm{Btu} / \mathrm{hr} \cdot \mathrm{ft}^{2} \cdot \mathrm{F}^{\circ}(\mathrm{BTP} 2005)$

○ Shingle or shake roof with attic

$\circ$ Unconditioned

- $\quad$ Next Generation Roof U-value $=0.027059 \mathrm{Btu} / \mathrm{hr} \cdot \mathrm{ft}^{2} \cdot \mathrm{F}^{\circ}$

- Shingle or shake roof with attic

- Conditioned (overall heating load was reduced $4.5 \%$ and cooling load was reduced $2.25 \%$ due to ducts being located the conditioned space)

\footnotetext{
${ }^{30} \mathrm{U}$-value is the measurement of how much heat can be conducted through a building component (such as a wall or window). As such, it is the opposite of R-value, which measures the ability of material to resist heat conduction. The higher the U-value, the more heat the material(s) will allow to be transferred through it.
} 
Table G-17 contains the resulting energy savings and load reductions based on these simulations.

Table G-17: Next-Generation Attic Performance Inputs

\begin{tabular}{ll}
\hline Amount of Heating Savings (Load & Amount of Cooling Savings (Load \\
Reduction) New Buildings: & Reduction) New Buildings: \\
\hline New England: & New England: \\
Load Reduction 5.0 MMBtu/household & Load Reduction 0.5 MMBtu/household \\
Percentage Reduction 11.6\% & Percentage Reduction 4.6 \\
Middle Atlantic & Middle Atlantic \\
Load Reduction 5.0 MMBtu/household & Load Reduction 0.5 MMBtu/household \\
Percentage Reduction 11.6\% & Percentage Reduction 4.6 \\
East North Central: & East North Central: \\
Load Reduction 5.9 MMBtu/household & Load Reduction 0.4 MMBtu/household \\
Percentage Reduction 11.2\% & Percentage Reduction 3.9 \\
West North Central: & West North Central: \\
Load Reduction 6.3 MMBtu/household & Load Reduction 0.5 MMBtu/household \\
Percentage Reduction 11.0\% & Percentage Reduction 4.6 \\
South Atlantic: & South Atlantic: \\
Load Reduction 1.9 MMBtu/household & Load Reduction 1.5 MMBtu/household \\
Percentage Reduction 12.5\% & Percentage Reduction 4.7 \\
East South Central: & East South Central: \\
Load Reduction 2.5 MMBtu/household & Load Reduction 1.4 MMBtu/household \\
Percentage Reduction 12.1\% & Percentage Reduction 4.9 \\
West South Central: & West South Central: \\
Load Reduction 1.5 MMBtu/household & Load Reduction 1.9 MMBtu/household \\
Percentage Reduction 12.7\% & Percentage Reduction 5.2 \\
Mountain: & Mountain: \\
Load Reduction 3.4 MMBtu/household & Load Reduction 1.9 MMBtu/household \\
Percentage Reduction 12.1\% & Percentage Reduction 6.4 \\
Pacific: & Pacific: \\
Load Reduction 1.7 MMBtu/household & Load Reduction 0.9 MMBtu/household \\
Percentage Reduction 14.5\% & Percentage Reduction 5.9 \\
National: & National: \\
Load Reduction 3.3 MMBtu/household & Load Reduction 1.3 MMBtu/household \\
Percentage Reduction 11.9\% & Percentage Reduction 5.1 \\
\hline & \\
\hline &
\end{tabular}

Building Envelope R\&D: Thermal Insulation and Building Materials - Advanced Wall Systems

The Advanced Wall Systems simulation runs were conducted in FEDS using the following baseline and BT technology assumptions:

- $\quad$ Baseline Opaque Wall U-value $=0.054118 \mathrm{Btu} / \mathrm{hr} \cdot \mathrm{ft}^{2} \cdot \mathrm{F}^{\circ}$

- $\quad$ Advanced Opaque Wall U-value $=0.027059 \mathrm{Btu} / \mathrm{hr} \cdot \mathrm{ft}^{2} \cdot \mathrm{F}^{\circ}$ 
Table G-18 contains the resulting energy savings and load reductions based on these simulations.

Table G-18: Advanced Wall Systems Performance Inputs

\begin{tabular}{|c|c|}
\hline $\begin{array}{l}\text { Amount of Heating Savings (Load } \\
\text { Reduction) New Buildings: }\end{array}$ & $\begin{array}{l}\text { Amount of Cooling Savings (Load } \\
\text { Reduction) New Buildings: }\end{array}$ \\
\hline New England: & New England: \\
\hline Load Reduction 5.7 MMBtu/household & Load Reduction 0.0 MMBtu/household \\
\hline Percentage Reduction $13.3 \%$ & Percentage Reduction $-0.2 \%$ \\
\hline Middle Atlantic & Middle Atlantic \\
\hline Load Reduction 5.7 MMBtu/household & Load Reduction 0.0 MMBtu/household \\
\hline Percentage Reduction $13.3 \%$ & Percentage Reduction $-0.2 \%$ \\
\hline East North Central: & East North Central: \\
\hline Load Reduction 6.7 MMBtu/household & Load Reduction -0.1 MMBtu/household \\
\hline Percentage Reduction $12.6 \%$ & Percentage Reduction $-1.1 \%$ \\
\hline West North Central: & West North Central: \\
\hline Load Reduction 7.0 MMBtu/household & Load Reduction 0.0 MMBtu/household \\
\hline Percentage Reduction $12.3 \%$ & Percentage Reduction $-0.1 \%$ \\
\hline South Atlantic: & South Atlantic: \\
\hline Load Reduction 2.5 MMBtu/household & Load Reduction 0.4 MMBtu/household \\
\hline Percentage Reduction $16.8 \%$ & Percentage Reduction $1.2 \%$ \\
\hline East South Central: & East South Central: \\
\hline Load Reduction 3.3 MMBtu/household & Load Reduction 0.4 MMBtu/household \\
\hline Percentage Reduction $16.1 \%$ & Percentage Reduction $1.6 \%$ \\
\hline West South Central: & West South Central: \\
\hline Load Reduction 2.3 MMBtu/household & Load Reduction 0.8 MMBtu/household \\
\hline Percentage Reduction $18.9 \%$ & Percentage Reduction $2.1 \%$ \\
\hline Mountain: & Mountain: \\
\hline Load Reduction 4.1 MMBtu/household & Load Reduction 1.3 MMBtu/household \\
\hline Percentage Reduction $14.6 \%$ & Percentage Reduction $4.5 \%$ \\
\hline Pacific: & Pacific: \\
\hline Load Reduction 2.4 MMBtu/household & Load Reduction 0.0 MMBtu/household \\
\hline Percentage Reduction $21.1 \%$ & Percentage Reduction $-0.1 \%$ \\
\hline National: & National: \\
\hline Load Reduction 4.0 MMBtu/household & Load Reduction 0.5 MMBtu/household \\
\hline Percentage Reduction $14.2 \%$ & Percentage Reduction $1.8 \%$ \\
\hline
\end{tabular}

\section{Building Envelope R\&D: Thermal Insulation and Building Materials - Next-Generation Envelope Materials}

The Next-Generation Envelope Materials simulation runs were conducted in FEDS using the following baseline and BT technology assumptions: 
Baseline:

Wall has R-value of $10 \mathrm{hr} \cdot \mathrm{ft}^{2} \cdot \mathrm{F}^{\circ} / \mathrm{Btu}\left(\mathrm{U}\right.$-value $\left.=0.1 \mathrm{Btu} / \mathrm{hr} \cdot \mathrm{ft}^{2} \cdot \mathrm{F}^{\circ}\right)$ and includes fenestration.

Roof has R-value of $30 \mathrm{hr} \cdot \mathrm{ft}^{2} \cdot \mathrm{F}^{\circ} / \mathrm{Btu}\left(\mathrm{U}-\mathrm{value}=0.0333 \mathrm{Btu} / \mathrm{hr}^{\circ} \cdot \mathrm{ft}^{2} \cdot \mathrm{F}^{\circ}\right)$.

- Windows

○ $15 \%$ of wall area

- Double pane wood or vinyl

$\circ \quad \mathrm{U}$-value $=0.36 \mathrm{Btu} / \mathrm{hr} \cdot \mathrm{ft}^{2} \cdot \mathrm{F}^{\circ}$

$\circ \quad$ Shading coefficient $=0.48$

- Opaque Wall

○ $85 \%$ of wall area

○ Wood siding on wood frame

○ U-value $=0.055118 \mathrm{Btu} / \mathrm{hr} \cdot \mathrm{ft}^{2} \cdot \mathrm{F}^{\circ}$

- Roof

- Shingle or shake roof with attic

- Unconditioned

- Insulation R-value is 29.2

Next Generation:

Wall has R-value of $11.1 \mathrm{hr} \cdot \mathrm{ft}^{2} \cdot \mathrm{F}^{\circ} / \mathrm{Btu}\left(\mathrm{U}-\mathrm{value}=0.090031 \mathrm{Btu} / \mathrm{hr} \cdot \mathrm{ft}^{2} \cdot \mathrm{F}^{\circ}\right)$ and includes fenestration.

Roof has R-value of $43.8 \mathrm{hr} \cdot \mathrm{ft}^{2} \cdot \mathrm{F}^{\circ} / \mathrm{Btu}\left(\mathrm{U}-\right.$ value $\left.=0.022834 \mathrm{Btu} / \mathrm{hr} \cdot \mathrm{ft}^{2} \cdot \mathrm{F}^{\circ}\right)$.

- Windows (unchanged)

○ $15 \%$ of wall area

- Double pane wood or vinyl

○ U-value $=0.36 \mathrm{Btu} / \mathrm{hr}^{\prime} \mathrm{ft}^{2} \cdot \mathrm{F}^{\circ}$

$\circ \quad$ Shading coefficient $=0.48$

- Opaque Wall

○ $85 \%$ of wall area

○ Wood siding on wood frame

○ U-value $=0.042389 \mathrm{Btu} / \mathrm{hr} \cdot \mathrm{ft}^{2} \cdot \mathrm{F}^{\circ}$

- Roof

- Shingle or shake roof with attic

○ Unconditioned 
Table G-19 contains the resulting energy savings and load reductions based on these simulations.

Table G-19: Next-Generation Envelope Materials Performance Inputs

\begin{tabular}{ll}
\hline Amount of Heating Savings (Load & Amount of Cooling Savings (Load \\
Reduction) New Buildings: & Reduction) New Buildings: \\
\hline New England: & New England: \\
Load Reduction 5.5 MMBtu/household & Load Reduction 0.2 MMBtu/household \\
Percentage Reduction 12.7\% & Percentage Reduction 2.1\% \\
Middle Atlantic & Middle Atlantic \\
Load Reduction 5.5 MMBtu/household & Load Reduction 0.2 MMBtu/household \\
Percentage Reduction 12.7\% & Percentage Reduction 2.1\% \\
East North Central: & East North Central: \\
Load Reduction 6.4 MMBtu/household & Load Reduction 0.1 MMBtu/household \\
Percentage Reduction 12.0\% & Percentage Reduction 1.0\% \\
West North Central: & West North Central: \\
Load Reduction 6.7 MMBtu/household & Load Reduction 0.2 MMBtu/household \\
Percentage Reduction 11.7\% & Percentage Reduction 2.1\% \\
South Atlantic: & South Atlantic: \\
Load Reduction 2.3 MMBtu/household & Load Reduction 0.9 MMBtu/household \\
Percentage Reduction 15.2\% & Percentage Reduction 2.9\% \\
East South Central: & East South Central: \\
Load Reduction 2.9 MMBtu/household & Load Reduction 0.9 MMBtu/household \\
Percentage Reduction 14.5\% & Percentage Reduction 3.2\% \\
West South Central: & West South Central: \\
Load Reduction 1.9 MMBtu/household & Load Reduction 1.4 MMBtu/household \\
Percentage Reduction 16.3\% & Percentage Reduction 3.7\% \\
Mountain: & Mountain: \\
Load Reduction 3.9 MMBtu/household & Load Reduction 1.8 MMBtu/household \\
Percentage Reduction 13.8\% & Percentage Reduction 5.9\% \\
Pacific: & Pacific: \\
Load Reduction 2.2 MMBtu/household & Load Reduction 0.5 MMBtu/household \\
Percentage Reduction 19.0\% & Percentage Reduction 3.4\% \\
National: & National: \\
Load Reduction 3.8 MMBtu/household & Load Reduction 0.9 MMBtu/household \\
Percentage Reduction 13.3\% & Percentage Reduction 3.5\% \\
\hline & \\
\hline & \\
&
\end{tabular}

Emerging Technologies - Building Envelope R\&D: Windows Technologies

Program Outputs (U.S. DOE 2006a)

Window performance will also be vital to reaching the residential and commercial buildings goals. Development of cost-effective, highly efficient glazing and fenestration systems for all building types and all parts of the country will require a portfolio of technologies matched to those types and climatic conditions. Figure G-13 lists the performance measurement targets for the Windows element. All performance measurements are relative to historical baselines that 
have been set as the baseline new construction in 2003. The next generation of highly insulated and dynamic windows can provide net energy gains in climates with heating loads and can dramatically reduce cooling loads and peak electricity demand to achieve ZEB.

\section{Target Market Description (BTP 2005)}

Windows typically contribute about $30 \%$ of overall building heating and cooling loads (BEDB 2005) with an annual impact of about 4.7 quadrillion Btu, with an additional potential savings of 1 quadrillion Btu from daylight use.

The role of windows as a "net energy gainer" is a unique role for windows relative to most other building systems. Furthermore, building owners do not need to be convinced to "add windows" to their buildings to save energy - they will always choose windows for view, aesthetics, etc. But they do need to have the right high-performance window technologies available to specify from the marketplace, and they need to know which window technologies, sizes, and applications are best for which building type, orientation, and climate. Windows are intrinsically multifunctional - the same product that must minimize solar gain in the summer should maximize it in the winter; the same product that provides useful daylight must minimize glare. This represents a significant challenge to manufacturers, specifiers, and owners, because these dynamic functions are not well-served by current technology.

The term "Windows" is used generically here for a wide range of "fenestration systems," combinations of glazing, sash, frames, shading elements, and other energy-control features. These can be inserted into vertical walls, or become the entire façade, they can be used in sloped glazing applications, and they are used as skylights and other forms of roof glazings. Custom units are applied to light wells, light pipes, and other daylighting redirection technologies. Windows are applicable to all building types in all parts of the country. About $60 \%$ of window sales are to the residential sector and $40 \%$ to commercial, so that this program targets both types of buildings. Approximately half of all windows sold are in new construction, and half are installed in existing buildings so that both new construction and renovation are included in the R\&D program (LBNL 2002).

The energy and demand impacts of windows are complex in that they do not intrinsically consume energy resources. A window can add to a heating or cooling load, thus requiring energy to maintain comfort. But a window can provide heat to a home in winter without being hooked to a gas line or electric line as a furnace must be. A window can also comfortably light a room throughout most of the day without requiring a hookup to the electric grid. Because windows are not directly connected to metered and purchased energy flows, their impacts on building energy use are via other building systems, such as space conditioning and lighting. These linkages are sometimes complex, and the net energy impacts of these systems in buildings must typically be calculated rather than metered.

\section{Assumed Budget Projections}

BT assumed level funding throughout the analysis period. The amount of the request is confidential until after the budget submission to Congress. 
Description of Key Activities (BTP 2005)

Development of cost-effective, highly efficient glazing and fenestration systems for all building types and all parts of the country will require a portfolio of projects that address the key objectives outlined above. The general approach for the subprogram is, therefore, to conduct a tiered research and development program with several key elements:

1) R\&D on smart glazings, insulating window systems, and daylighting technologies;

2) Lab and field testing to quantify and demonstrate the benefits of new technologies for industry; and

3) Development of improved analytical tools and software to enhance the ability of industry to assess, adopt, and commercialize new technologies, thereby reducing industry risk.

More detail on these elements is contained in BT's Multiyear Program Plan (BTP 2005).

\section{Milestones (BTP 2005)}

For each project/task activity identified, a Gantt chart has been prepared to show the critical milestones, off-ramps, and transfer points.

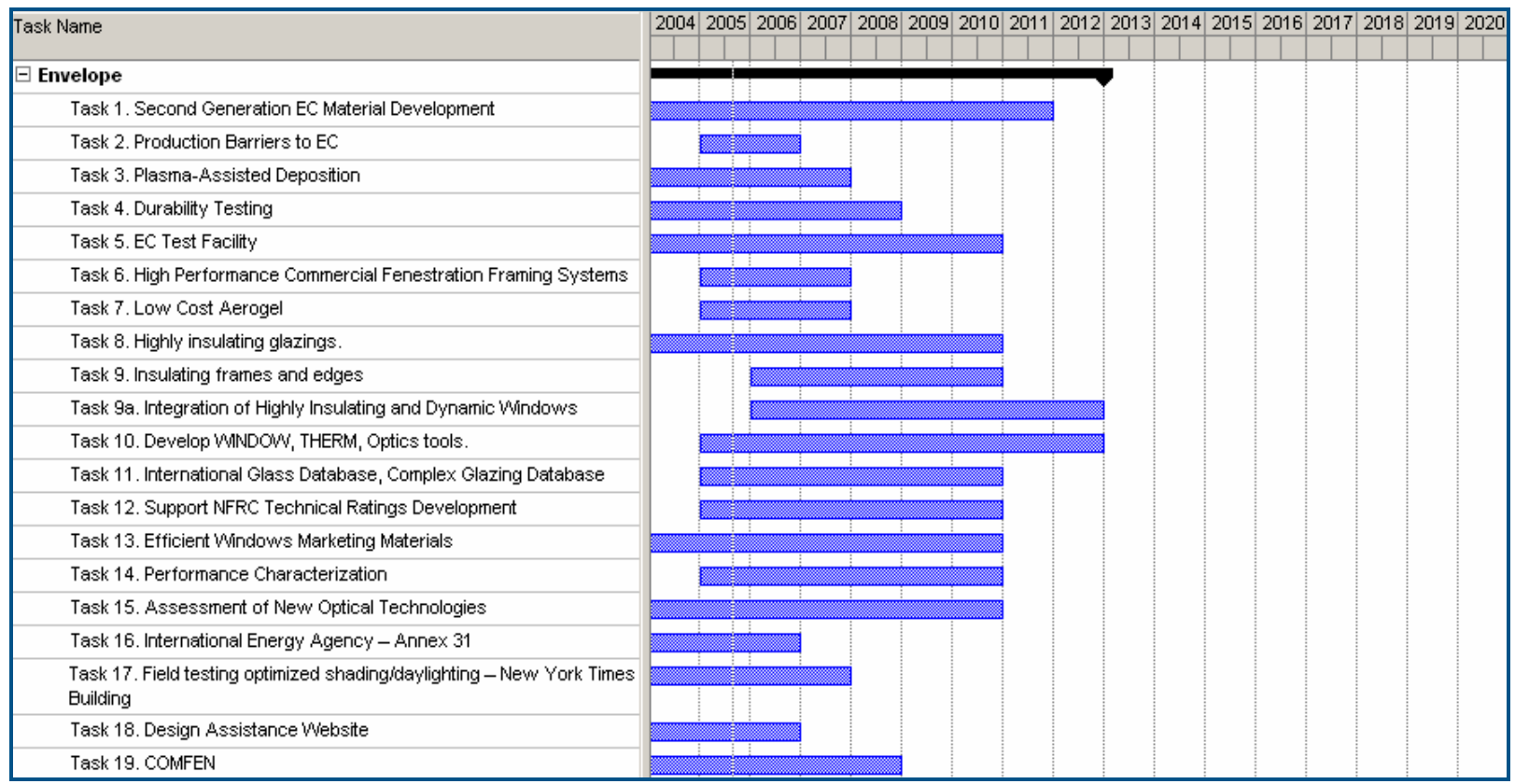

Figure G-13: Windows Gantt Chart (BTP 2005)

Program Outputs (BTP 2005)

Given the conceptual performance evaluation of windows in the Nation's building stock, the Windows R\&D element has four objectives. They are listed below with a rationale for how the generic performance requirements above are translated into these objectives.

Objective 1: Dynamic Windows. Develop optical switching coatings that provide dynamic control of sunlight over a wide range (center glass: Visible Transmittance VT: 0.65 - 0.02;

SHGC: 0.5 - 0.08) while meeting market requirements for cost, size, durability, appearance; and 
which can be integrated into building control systems to provide energy, demand, and comfort improvements in all buildings in all climates. ${ }^{31}$

Objective 2: Highly Insulating Windows. Reduce heat loss rates of windows and skylights from current market values (Energy Star) of 0.35 to $0.1 \mathrm{Btu} /{ }^{\circ} \mathrm{F}-\mathrm{hr}-\mathrm{ft}^{2}$ using technology solutions that meet market needs for cost, optical clarity, weight, durability, manufacturability, etc. Provide solutions with high solar heat gain for use in northern climates. The overall objective includes not only improvements in center of glass but with edge and frame conditions also. ${ }^{32}$

Objective 3: Enabling Technology Research for Efficient Products. Develop the tools and resources needed to accurately predict component, product, and systems thermal, optical, and energy performance under a full range of operating conditions. Objectives need to be quantitative. $^{33}$

Objective 4: Daylighting and Advanced Façade Systems. Develop daylighting technologies that displace $50-90 \%$ of annual electric lighting needs in perimeter zones, and extend perimeter zones to increase building-wide savings. Develop integrated façade solutions that achieve net 60 $80 \%$ energy and demand savings compared to facades that meet ASHRAE requirements for typical climates. $^{34}$

Table G-20 lists the performance measurement targets for the Windows and Daylighting element. All performance measurements are relative to historical baselines that have been set as the baseline new construction in 2003.

\footnotetext{
${ }^{31}$ The range of control is needed to provide the equivalent of a clear window in the clear state and a highly reflective window that can modulate bright sun to comfortable levels. The range of control can be provided in two ways: intrinsically in the glass system, or as an "add-on" shade, blind or similar element that modifies the window properties. These "mechanical" devices inevitably have operating mechanisms that require periodic replacement. Thus, the ultimate objective for the industry is to provide the control function within the glass system.

32 An end-use breakdown of window energy impacts shows that heating energy is currently the largest end use. The most direct way to reduce heating energy is to reduce thermal losses as addressed in this objective. The reduction in $U$ value must be balanced by providing a suitably high solar heat gain coefficient in winter to capture sunlight.

${ }^{33}$ Windows are unlike almost any other building system in that a single set of windows will never provide optimal performance in all building types and climates. State-of-the-art measurement and simulation tools are essential to guide public- and privatesector R\&D investments in new technology, to guide architects and engineers in their integrated design of complete building systems, and provide feedback on how actual field performance compares to predictions. These tools and resources provide enormous leverage since they are made available to the entire industry, and have been shown to be accurate and unbiased.

${ }^{34}$ The single largest energy use in most commercial buildings is lighting and the use of daylighting technologies in smart facades to capture daylighting benefits addresses this need. To offset electric lighting energy, three requirements must be met: daylight must be admitted and distributed as needed; overall intensity must be controlled to provide glare control and prevent overheating or adverse cooling impacts; and electric lighting must be controlled, e.g. dimmed, to save energy and reduce demand. Success requires a degree of integration that is not currently available in U.S. markets.
} 
Table G-20: Windows Performance Goals (BTP 2005)

\begin{tabular}{|c|c|c|c|c|c|c|}
\hline \multirow[t]{2}{*}{ Characteristic } & \multirow[t]{2}{*}{ Units } & \multicolumn{5}{|c|}{ Calendar Year } \\
\hline & & $\begin{array}{l}2003 \\
\text { Status }\end{array}$ & $\begin{array}{l}2007 \\
\text { Target }\end{array}$ & $\begin{array}{l}2010 \\
\text { Target }\end{array}$ & 2015 Target & $\begin{array}{l}2020 \\
\text { Target }\end{array}$ \\
\hline \multirow{5}{*}{$\begin{array}{l}\text { Dynamic } \\
\text { Solar } \\
\text { Control }\end{array}$} & Price/Sq Ft. & $\$ 85-100$ & $\$ 50$ & $\$ 20$ & $\$ 8$ & $\$ 5$ \\
\hline & Size (Sq. Ft.) & 8 & 16 & $20-25$ & $25+$ & $25+$ \\
\hline & $\begin{array}{l}\text { Visual } \\
\text { Transmittance }\end{array}$ & 60 to $4 \%$ & 60 to $4 \%$ & 65 to $3 \%$ & 65 to $2 \%$ & 65 to $2 \%$ \\
\hline & $\begin{array}{l}\text { Solar Heat Gain } \\
\text { Coefficient }\end{array}$ & $\begin{array}{l}0.50 \text { to } \\
0.10\end{array}$ & $\begin{array}{l}0.50 \text { to } \\
0.10\end{array}$ & $\begin{array}{l}0.53 \text { to } \\
0.09\end{array}$ & 0.53 to 0.09 & $\begin{array}{l}0.53 \text { to } \\
0.09\end{array}$ \\
\hline & $\begin{array}{l}\text { Durability* } \\
\text { (ASTM Tests) }\end{array}$ & Med & High & High & High & High \\
\hline $\begin{array}{l}\text { Enabling } \\
\text { Technology } \\
\text { Research } \\
\text { for Efficient } \\
\text { Products }\end{array}$ & $\begin{array}{l}\text { Tool Capability for } \\
\text { Residential (R), } \\
\text { Commercial (C) } \\
\text { and New Tech. } \\
(\mathrm{N})\end{array}$ & $\begin{array}{l}\text { R- Yes } \\
\text { C-No } \\
\text { N- No }\end{array}$ & $\begin{array}{c}\text { R- Fully } \\
\text { C - Partial } \\
\text { N-No }\end{array}$ & $\begin{array}{l}\text { R- Fully } \\
\text { C - Fully } \\
\text { N - Partial }\end{array}$ & $\begin{array}{l}\text { Assess need } \\
\text { for industry } \\
\text { support }\end{array}$ & $\begin{array}{l}\text { Assess } \\
\text { need for } \\
\text { industry } \\
\text { support }\end{array}$ \\
\hline \multirow{2}{*}{$\begin{array}{l}\text { Highly } \\
\text { Insulated } \\
\text { Windows }\end{array}$} & U-Value & $0.33-0.50$ & $0.20-0.25$ & 0.17 & 0.10 & 0.10 \\
\hline & $\begin{array}{l}\text { Incremental Cost } \\
\$ / \mathrm{ft}^{2}\end{array}$ & $\begin{array}{l}\text { IG Base } \\
\text { cost: } \$ 3\end{array}$ & 5 & 5 & 4 & 3 \\
\hline \multirow[t]{3}{*}{$\begin{array}{l}\text { Daylight } \\
\text { Redirecting }\end{array}$} & $\begin{array}{l}\text { Percent Lighting } \\
\text { Energy Savings }\end{array}$ & 40 & 50 & 50 & 60 & 60 \\
\hline & $\begin{array}{l}\text { Perimeter Zone } \\
\text { depth, Feet }\end{array}$ & 12 & 15 & 20 & 20 & 30 \\
\hline & $\begin{array}{l}\text { Incremental Cost } \\
\$ / \mathrm{ft}^{2}\end{array}$ & 3 & 8 & 8 & 6 & 6 \\
\hline
\end{tabular}

${ }^{*}$ Represents component durability, system reliability will be address in future years < 20K cycles - Low; $20 \mathrm{~K}-50 \mathrm{~K}$

Cycles - Medium; > 50K Cycles - High

Translating Program Outputs to Market Outcomes (BTP 2005)

Traditionally, the building industry has been slow to innovate; and, once proven, innovation changes the marketplace slowly. The commercialization of low-E and other innovations has been studied to better understand the drivers that support successful innovation. Based on this work, the program leverages several market realities to overcome obstacles in the marketplace:

1) The fenestration marketplace serves a variety of distribution pathways, price points, and architectural styles. Early adopters (and therefore potential partners) may be large existing manufacturers (e.g., Andersen windows led the market with Low-E products) or a smaller niche player catering to a specialty market (Southwall offered highly insulating glazings in the 1990s).

2) The "ideal" window that works everywhere is a myth. The variation in building type, climate, orientation, human factors, etc. means that multiple solutions must be developed to meet national needs.

3) Windows serve numerous non-energy needs, e.g., view, acoustics, appearance, and are highly desired by most building owners. Coupling energy functions with other desired occupant benefits is a strategy for maximizing market impacts of efficient products. 
Low-E market penetration was accelerated by the marketing arguments for improved comfort and UV-fading resistance.

4) Windows will increasingly become dynamic and "smart" with sensors and active control elements. These units must be integrated with other smart building elements, e.g., dimmable lighting, and integrated into the overall building control system.

Window designs and material selections are typically constrained by cost, performance, and nonenergy performance, including appearance. These parameters take on different weights in new vs. retrofit decision making and between residential and nonresidential, and between owneroccupied vs. leased space. Windows are a very "visible" element in most homes, unlike insulation, which is hidden from view. But window performance is complex to understand and because windows do not directly consume energy, their impacts on home or business energy bills are often misunderstood.

\section{Key Factors in Shaping Market Adoption of EERE technologies}

- Price:

- Dynamic Windows: Current cost is $\$ 75$ to $\$ 100$ per square foot and expected to fall to an incremental cost of $\$ 3 / \mathrm{ft}^{2}$ above low-e by 2030 .

- Highly Insulating Windows: The incremental cost over Low-E is expected to be $\$ 5.00 / \mathrm{ft}^{2}$ in $2010, \$ 4.00 / \mathrm{ft}^{2}$ in 2015 , and $\$ 3.00 / \mathrm{ft}^{2}$ in 2020 (BTP 2005).

\section{Immediate Outcomes}

The general approach for GPRA window calculations was to simulate the effect of a window technology using the FEDS model for many different building types, sizes, vintages, and locations. For each technology, the impact was simulated in more than 10,000 buildings:

- 7,200 commercial buildings are run to cover 15 climate zones (BT developed climate zones for IECC 2004 supplement), 10 building types, 6 sizes, and 8 vintages (7 existing and 1 new).

- 2,835 residential buildings are run to cover 15 climate zones (BT developed climate zones for IECC 2004 supplement), 3 building types, 9 sizes, and 7 vintages (6 existing and 1 new).

Because NEMS-GPRA08 only models one of each building type in each of the nine census regions, the FEDS results needed to be aggregated for input into NEMS-GPRA08. This aggregation is performed by applying city and floor area weighted averages to the FEDS results to represent the loads within a census region. More detail about this process is contained in Elliott et al. 2004.

The heating and cooling loads were calculated for each building with and without the window technology being evaluated. The changes in the heating and cooling loads are used to modify the heating and cooling envelope factors in NEMS-GPRA08; more detail on the incorporation of these inputs is in the corresponding NEMS and MARKAL chapters of this report.

\section{Building Envelope R\&D: Windows - Dynamic Windows}

The purpose of this activity is to develop optical switching coatings that provide dynamic control of sunlight over a wide range (center glass: Visible Transmittance (VT): 0.65 - 0.02; Solar Heat Gain Coefficient (SHGC): 0.5 - 0.08) while meeting market requirements for cost, size, 
durability, and appearance. Dynamic windows will also need the ability to be integrated into building control systems to provide energy, demand, and comfort improvements in all buildings in all climates. Multiple paths with multiple technologies are being investigated. FY08 efforts will focus on the development of a second-generation product that is fully sputter-coated.

The Dynamic Windows (Electrochromic windows) simulation runs were conducted using the following technology assumptions:

Heating: U-Factor $=0.25 \mathrm{Btu} / \mathrm{hr}^{\prime} \cdot \mathrm{ft}^{2} \cdot{ }^{\circ} \mathrm{F} ; \mathrm{SHGC}=0.6$

Cooling: U-Factor $=0.25 \mathrm{Btu} / \mathrm{hr} \cdot \mathrm{ft}^{2} \cdot{ }^{\circ} \mathrm{F} ; \mathrm{SHGC}=0.1$

Table G-21 contains the resulting energy savings and load reductions based on these simulations.

Table G-21: Dynamic Windows Performance Inputs

\begin{tabular}{ll}
\hline Amount of Savings (Load Reduction) Existing & $\begin{array}{c}\text { Amount of Savings (Load Reduction) New } \\
\text { Buildings: }\end{array}$ \\
Buildings: & Northern New: \\
\hline Northern Existing: & Commercial Heating: $1.83 \mathrm{MMBtu} / \mathrm{ksf}$ \\
Commercial Heating: $1.61 \mathrm{MMBtu} / \mathrm{ksf}$ & Commercial Cooling: $4.62 \mathrm{MMBtu} / \mathrm{ksf}$ \\
Commercial Cooling: $4.58 \mathrm{MMBtu} / \mathrm{ksf}$ & North Central New: \\
North Central Existing: & Commercial Heating: $1.88 \mathrm{MMBtu} / \mathrm{ksf}$ \\
Commercial Heating: $1.66 \mathrm{MMBtu} / \mathrm{ksf}$ & Commercial Cooling: $5.80 \mathrm{MMBtu} / \mathrm{ksf}$ \\
Commercial Cooling: $5.52 \mathrm{MMBtu} / \mathrm{ksf}$ & South Central New: \\
South Central Existing: & Residential Heating: $3.91 \mathrm{MMBtu} / \mathrm{household}$ \\
Residential Heating: $4.38 \mathrm{MMBtu} / \mathrm{household}$ & Residential Cooling: $11.16 \mathrm{MMBtu} / \mathrm{household}$ \\
Residential Cooling: $11.30 \mathrm{MMBtu} / \mathrm{household}$ & Commercial Heating: $0.94 \mathrm{MMBtu} / \mathrm{ksf}$ \\
Commercial Heating: $0.88 \mathrm{MMBtu} / \mathrm{ksf}$ & Commercial Cooling: $5.75 \mathrm{MMBtu} / \mathrm{ksf}$ \\
Commercial Cooling: $5.51 \mathrm{MMBtu} / \mathrm{ksf}$ & Southern New: \\
Southern Existing: & Residential Heating: $3.00 \mathrm{MMBtu} / \mathrm{household}$ \\
Residential Heating: $3.61 \mathrm{MMBtu} / \mathrm{household}$ & Residential Cooling: $7.51 \mathrm{MMBtu} / \mathrm{household}$ \\
Residential Cooling: $7.76 \mathrm{MMBtu} / \mathrm{household}$ & Commercial Heating: $0.56 \mathrm{MMBtu} / \mathrm{ksf}$ \\
Commercial Heating: $0.53 \mathrm{MMBtu} / \mathrm{ksf}$ & Commercial Cooling: $3.05 \mathrm{MMBtu} / \mathrm{ksf}$ \\
Commercial Cooling: $2.92 \mathrm{MMBtu} / \mathrm{ksf}$ & Weighted South Central and Southern Average \\
Weighted South Central and Southern Existing: & New: \\
Residential Heating: $4.16 \mathrm{MMBtu} / \mathrm{household}$ & Residential Heating: $3.65 \mathrm{MMBtu} / \mathrm{household}$ \\
Residential Cooling: $10.28 \mathrm{MMBtu} / \mathrm{household}$ & Residential Cooling: $10.13 \mathrm{MMBtu} / \mathrm{household}$ \\
Weighted National Average Existing: & Weighted National Average New: \\
Commercial Heating: $1.28 \mathrm{MMBtu} / \mathrm{ksf}$ & Commercial Heating: $1.43 \mathrm{MMBtu} / \mathrm{ksf}$ \\
Commercial Cooling: $4.81 \mathrm{MMBtu} / \mathrm{ksf}$ & Commercial Cooling: $4.96 \mathrm{MMBtu} / \mathrm{ksf}$ \\
Commercial Lighting Savings: $5 \%$ in all regions & Commercial Lighting Savings: $5 \%$ in all regions \\
\hline
\end{tabular}

\section{Building Envelope R\&D: Windows - Highly Insulating Windows}

The purpose of this activity is to reduce heat-loss rates of windows and skylights from current market values of 0.35 (Energy Star) to $0.1 \mathrm{Btu} / \mathrm{hr}^{\bullet} \mathrm{ft}^{2}{ }^{\circ} \mathrm{F}$ using technology solutions that meet market needs for cost, optical clarity, weight, durability, manufacturability, etc. R\&D will provide solutions with high solar heat gain for use in northern climates. The overall objective includes not only improvements in center of glass, but with edge and frame conditions also. 
Multiple paths with multiple technologies are being investigated. FY08 efforts will focus on the development of a near-term product with moderate risk - krypton-filled triple pane windows with the center being very lightweight $\left(\mathrm{U}\right.$-value $\left.=0.2 \mathrm{Btu} / \mathrm{hr}^{\bullet} \mathrm{ft}^{2} \bullet{ }^{\circ} \mathrm{F}\right)$; and, longer-term, a higherrisk vacuum glazing that will meet the performance goal. In 2010, the nearer-term product (UFactor $0.20 \mathrm{Btu} / \mathrm{hr}^{\bullet} \mathrm{ft}^{2}{ }^{\circ} \mathrm{F}$ ) is expected to be available; and, by 2016 , the longer-term product (UFactor $0.10 \mathrm{Btu} / \mathrm{hr}^{\circ} \mathrm{ft}^{2}{ }^{\circ} \mathrm{F}$ ) is anticipated. The goal is $65 \%$ of window sales in new residential buildings and $33 \%$ in existing buildings by 2020 .

The Highly Insulating Windows (Superwindows) simulation runs were conducted using the following technology assumptions:

Northern Heating: U-Factor $=0.10 \mathrm{Btu} / \mathrm{hr} \cdot \mathrm{ft}^{2} \cdot{ }^{\circ} \mathrm{F} ; \mathrm{SHGC}=0.6087$

Northern Cooling: U-Factor $=0.10 \mathrm{Btu} / \mathrm{hr} \cdot \mathrm{ft}^{2} \cdot{ }^{\circ} \mathrm{F} ; \mathrm{SHGC}=0.2609$

Northern Central Heating: U-Factor $=0.10 \mathrm{Btu} / \mathrm{hr}^{\circ} \cdot \mathrm{ft}^{2} \cdot{ }^{\circ} \mathrm{F} ; \mathrm{SHGC}=0.6087$

Northern Central Cooling: U-Factor $=0.10 \mathrm{Btu} / \mathrm{hr} \cdot \mathrm{ft}^{2} \cdot{ }^{\circ} \mathrm{F} ; \mathrm{SHGC}=0.2609$

South Central Heat and Cool: U-Factor $=0.20 \mathrm{Btu} / \mathrm{hr}^{\circ} \mathrm{ft}^{2} \cdot{ }^{\circ} \mathrm{F} ; \mathrm{SHGC}=0.1304$

Southern Heat and Cool: U-Factor $=0.20 \mathrm{Btu} / \mathrm{hr}^{\circ} \cdot \mathrm{ft}^{2} \cdot{ }^{\circ} \mathrm{F} ; \mathrm{SHGC}=0.1304$

Table G-22 contains the resulting energy savings and load reductions based on these simulations.

Table G-22: Highly Insulating Windows Performance Inputs

\begin{tabular}{|c|c|}
\hline $\begin{array}{l}\text { Amount of Savings (Load Reduction) Existing } \\
\text { Buildings: }\end{array}$ & $\begin{array}{l}\text { Amount of Savings (Load Reduction) New } \\
\text { Buildings: }\end{array}$ \\
\hline $\begin{array}{l}\text { Northern Existing: } \\
\text { Residential Heating: } 11.15 \mathrm{MMBtu} / \text { household } \\
\text { Residential Cooling: } 4.31 \mathrm{MMBtu} \text { /household } \\
\text { North Central Existing: } \\
\text { Residential Heating: } 9.18 \mathrm{MMBtu} / \text { household } \\
\text { Residential Cooling: } 5.15 \mathrm{MMBtu} \text { /household } \\
\text { South Central Existing: } \\
\text { Residential Heating: } 0.02 \mathrm{MMBtu} / \text { household } \\
\text { Residential Cooling: } 10.32 \mathrm{MMBtu} / \text { household } \\
\text { Southern Existing: } \\
\text { Residential Heating: } 1.90 \mathrm{MMBtu} / \text { household } \\
\text { Residential Cooling: } 6.66 \mathrm{MMBtu} \text { /household } \\
\text { Weighted National Average Existing: } \\
\text { Residential Heating: } 6.51 \mathrm{MMBtu} / \text { household } \\
\text { Residential Cooling: } 6.44 \mathrm{MMBtu} / \text { household }\end{array}$ & 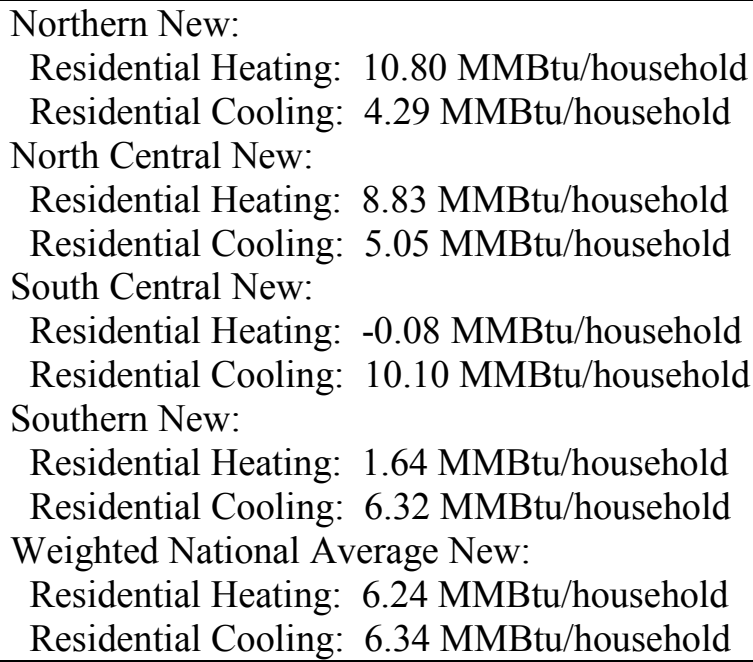 \\
\hline
\end{tabular}

Interim Outcomes

Building Envelope R\&D: Windows - Low-E Market Acceptance/Energy Star Windows The purpose of this activity is increase the market penetration of Low-E windows. Several subactivities are in place to help accomplish the goal.

- Developing the tools [WINDOW6, THERM, COMFEN and other software to serve industry needs (BTP 2005)] and resources needed to accurately predict component, product, and systems thermal, optical, and energy performance under a full range of operating conditions. 
- Training and education for utilities, manufacturers, and Building America.

- Establishing requirements for Energy Star labeling

The current program focus has been on residential and will be shifting to commercial as the residential market becomes dominated by Low-E windows. Efforts in FY08 will focus on tools and technical assistance programs that are applicable to both residential and commercial fenestration. Energy Star performance goals are expected to be established for dynamic windows by 2010 .

The Low-E Market Acceptance simulation runs were conducted using the following technology assumptions:

Northern: U-Factor $=0.35 \mathrm{Btu} / \mathrm{hr} \cdot \mathrm{ft}^{2} \cdot{ }^{\circ} \mathrm{F} ; \mathrm{SHGC}=0.6$

North Central: U-Factor $=0.40 \mathrm{Btu} / \mathrm{hr} \cdot \mathrm{ft}^{2} \cdot{ }^{\circ} \mathrm{F} ; \mathrm{SHGC}=0.55$

South Central: U-Factor $=0.40 \mathrm{Btu} / \mathrm{hr}^{\circ} \cdot \mathrm{ft}^{2} \cdot{ }^{\circ} \mathrm{F} ; \mathrm{SHGC}=0.40$

Southern: U-Factor $=0.65 \mathrm{Btu} / \mathrm{hr} \cdot \mathrm{ft}^{2} \cdot{ }^{\circ} \mathrm{F} ; \mathrm{SHGC}=0.40$

Table G-23 contains the resulting energy savings and load reductions based on these simulations. These savings are evenly split with the Energy Star Windows Program.

Table G-23: Low-E Market Acceptance Performance Inputs

\begin{tabular}{|c|c|}
\hline $\begin{array}{l}\text { Amount of Savings (Load Reduction) Existing } \\
\text { Buildings: }\end{array}$ & $\begin{array}{l}\text { Amount of Savings (Load Reduction) New } \\
\text { Buildings: }\end{array}$ \\
\hline Northern Existing: & Northern New: \\
\hline Residential Heating: $8.30 \mathrm{MMBtu} /$ household & Residential Heating: $8.17 \mathrm{MMBtu} /$ household \\
\hline Residential Cooling: $0.19 \mathrm{MMBtu} /$ household & Residential Cooling: $0.06 \mathrm{MMBtu} /$ household \\
\hline Commercial Heating: $5.73 \mathrm{MMBtu} / \mathrm{ksf}$ & Commercial Heating: $6.24 \mathrm{MMBtu} / \mathrm{ksf}$ \\
\hline Commercial Cooling: $-0.58 \mathrm{MMBtu} / \mathrm{ksf}$ & Commercial Cooling: $-0.45 \mathrm{MMBtu} / \mathrm{ksf}$ \\
\hline North Central Existing: & North Central New: \\
\hline Residential Heating: 2.94 MMBtu/household & Residential Heating: 2.88 MMBtu/household \\
\hline Residential Cooling: $1.79 \mathrm{MMBtu} /$ household & Residential Cooling: $1.72 \mathrm{MMBtu} /$ household \\
\hline Commercial Heating: $2.77 \mathrm{MMBtu} / \mathrm{ksf}$ & Commercial Heating: $2.98 \mathrm{MMBtu} / \mathrm{ksf}$ \\
\hline Commercial Cooling: $0.68 \mathrm{MMBtu} / \mathrm{ksf}$ & Commercial Cooling: $0.74 \mathrm{MMBtu} / \mathrm{ksf}$ \\
\hline South Central Existing: & South Central New: \\
\hline Residential Heating: 0.00 MMBtu/household & Residential Heating: 0.09 MMBtu/household \\
\hline Residential Cooling: 10.39 MMBtu/household & Residential Cooling: $10.50 \mathrm{MMBtu} /$ household \\
\hline Commercial Heating: 0.66 MMBtu/ksf & Commercial Heating: 0.75 MMBtu/ksf \\
\hline Commercial Cooling: $5.62 \mathrm{MMBtu} / \mathrm{ksf}$ & Commercial Cooling: $5.91 \mathrm{MMBtu} / \mathrm{ksf}$ \\
\hline Southern Existing: & Southern New: \\
\hline Residential Heating: -1.77 MMBtu/household & Residential Heating: -1.48 MMBtu/household \\
\hline Residential Cooling: $8.77 \mathrm{MMBtu} /$ household & Residential Cooling: $9.18 \mathrm{MMBtu} / \mathrm{household}$ \\
\hline Commercial Heating: -0.14 MMBtu/ksf & Commercial Heating: $-0.14 \mathrm{MMBtu} / \mathrm{ksf}$ \\
\hline Commercial Cooling: $4.98 \mathrm{MMBtu} / \mathrm{ksf}$ & Commercial Cooling: $5.21 \mathrm{MMBtu} / \mathrm{ksf}$ \\
\hline Weighted National Average Existing: & Weighted National Average New: \\
\hline Residential Heating: $3.82 \mathrm{MMBtu} /$ household & Residential Heating: 3.82 MMBtu/household \\
\hline Residential Cooling: $4.42 \mathrm{MMBtu} /$ household & Residential Cooling: 4.43 MMBtu/household \\
\hline Commercial Heating: $3.08 \mathrm{MMBtu} / \mathrm{ksf}$ & Commercial Heating: $3.36 \mathrm{MMBtu} / \mathrm{ksf}$ \\
\hline Commercial Cooling: $2.07 \mathrm{MMBtu} / \mathrm{ksf}$ & Commercial Cooling: $2.25 \mathrm{MMBtu} / \mathrm{ksf}$ \\
\hline
\end{tabular}




\section{Emerging Technologies - Analysis Tools and Design Strategies}

\section{Program Outputs (U.S. DOE 2006a)}

BT has established aggressive goals to create a new generation of residential and commercial building technologies by 2025 that will enable zero-energy buildings. Similar technologies and design approaches will also be applied to improve the performance of existing buildings. These ZEB goals cannot be met only through research to significantly improve the performance of components (e.g., windows, appliances, heating and cooling equipment, lighting). To achieve $70 \%-80 \%$ reductions in load, a revolutionary approach to building design and operation is required that is coupled with careful integration with onsite renewable energy supplies as well as thermal and electrical storage. ${ }^{35}$ This, in turn, requires new design strategies and powerful simulation tools that support evaluation of new ZEB demand-reduction and energy-supply technologies.

\section{Target Market Description (BTP 2005).}

Architects, engineers, and other building designers have always "envisioned" buildings before construction begins. In the $20^{\text {th }}$ century, this process began with pencil sketches and inked drawings. These 2-D representations were sometimes supplemented with 3-D scale models to better understand spatial relationships and appearance. The engineering side of construction was supported by an elaborate infrastructure of tables and manuals that documented workable solutions derived from analytical calculations, cumulative empirical data, and the rules of thumb widely used in the construction industry. With built-in safety factors and incremental advances based on new findings, these approaches were adequate to support the slowly evolving buildings sector through most of the past century.

With the price shocks of the 1970s, interest in building energy efficiency changed the information-management needs of designers. The subsequent availability of cheap desktop computing and its software infrastructure continue to revolutionize virtually all aspects of design and construction. However, in most cases, computers are relegated to doing conventional tasks, albeit more quickly and accurately. But there are also emerging opportunities where computers and simulation tools can provide novel analysis of complex interactions between systems and new performance insights that are revolutionizing building design and operation. Computers are certainly useful tools to sum up the overall heat loss of a building more accurately and quickly than by hand. But powerful new simulation tools - which in a few minutes can calculate the behavior of building control systems and the resultant impact on energy use, peak demand, equipment sizing, and occupant comfort-provide performance insights that have been previously unattainable. It is precisely these insights that are needed if the building community is to break away from a "business as usual" approach to energy use in buildings.

\footnotetext{
${ }^{35}$ Building energy performance, particularly in ZEB, is the result of interactions among many elements including climate (outdoor temperature, humidity, solar radiation, and illumination), envelope heat and moisture transfer, internal heat gains, lighting power, HVAC equipment, controls, thermal and visual comfort, and energy cost - and these complex interactions cannot be understood and quantified without simulation tools. For example, the effect of daylighting dimming controls on the electric lights with daylighting has several effects: lighting electricity use goes down as does the heat gain from lights. Lower heat from lights reduces cooling use (amount depends on cooling equipment efficiency); but in the winter, it can significantly increase the heating energy. Thus, the annual impact of daylighting on energy use requires detailed calculations that consider these interactions. In a series of field evaluation case study reports, NREL found that simulation tools were one of the essential elements for tuning the building design as well as the operating building performance [Torcellini, Judkoff and Crawley (2004)].
} 
With software tool development dating back to the 1970s, BT software tools are the benchmark against which other tools are tested. The predecessor program to EnergyPlus, DOE-2.1E, currently is the underlying calculation engine ${ }^{36}$ for more than 20 tools and the basis for building energy standards development and research throughout the world.

\section{Assumed Budget Projections}

BT assumed level funding throughout the analysis period. The amount of the request is confidential until after the budget submission to Congress.

\section{Description of Key Activities (BTP 2005)}

By 2015, BT research will develop, test, and release analysis tools that robustly support BT whole-building, component, and systems R\&D; and support evaluation and decision-making of ZEB energy-efficiency and supply technologies and systems during new building design and existing building retrofit. A staged approach will be taken so that earlier product releases will address a subset of the BT subprograms. In this staged approach, control and optimization will be addressed first (2007), followed by predictive controls (2008), and, finally, extension to emerging technologies (2009).

The plan relies on three strategies to maximize the future potential energy savings:

- Extend the capabilities of energy analysis tools: Develop increasingly more robust versions of EnergyPlus that can be used to design net-zero energy and high-performance buildings including advanced and near-market technologies and systems, building integrated PV, on-site CHP, controls optimization, and multizone airflow and pollution transport.

- Validate Energy Analysis Tools: Validate and test EnergyPlus calculations and performance. Extend IEA and ANSI/ASHRAE Standard 140-2004 to cover full matrix of validation methods for building simulation tools.

- Deploy Analysis Tools: Work with leading-edge A\&E firms and key HVAC manufacturers to encourage their use of EnergyPlus software. The larger buildings tend to have some of the larger and more innovative designers. BT's Analysis Tools activities will focus on these high-value building projects that between them influence almost half of building energy use. Work with the International Alliance for Interoperability to ensure that building energy is integral to the interoperability standards. Work with firms providing user interfaces by providing technical assistance with operational issues of EnergyPlus.

More detail on these strategies can be found in BT's Multiyear Program Plan (BTP 2005).

Milestones (BTP 2005)

The following Gantt chart displays the tools activities, milestones, and decision points for the key tasks that BT will focus on in the Analysis Tools activity.

\footnotetext{
${ }^{36}$ DOE BT develops an unbiased, reliably tested "engine" for calculating building energy flows. This engine is then used by the private and public sectors in the underlying calculation engine for a wide variety of tools and user interfaces.
} 


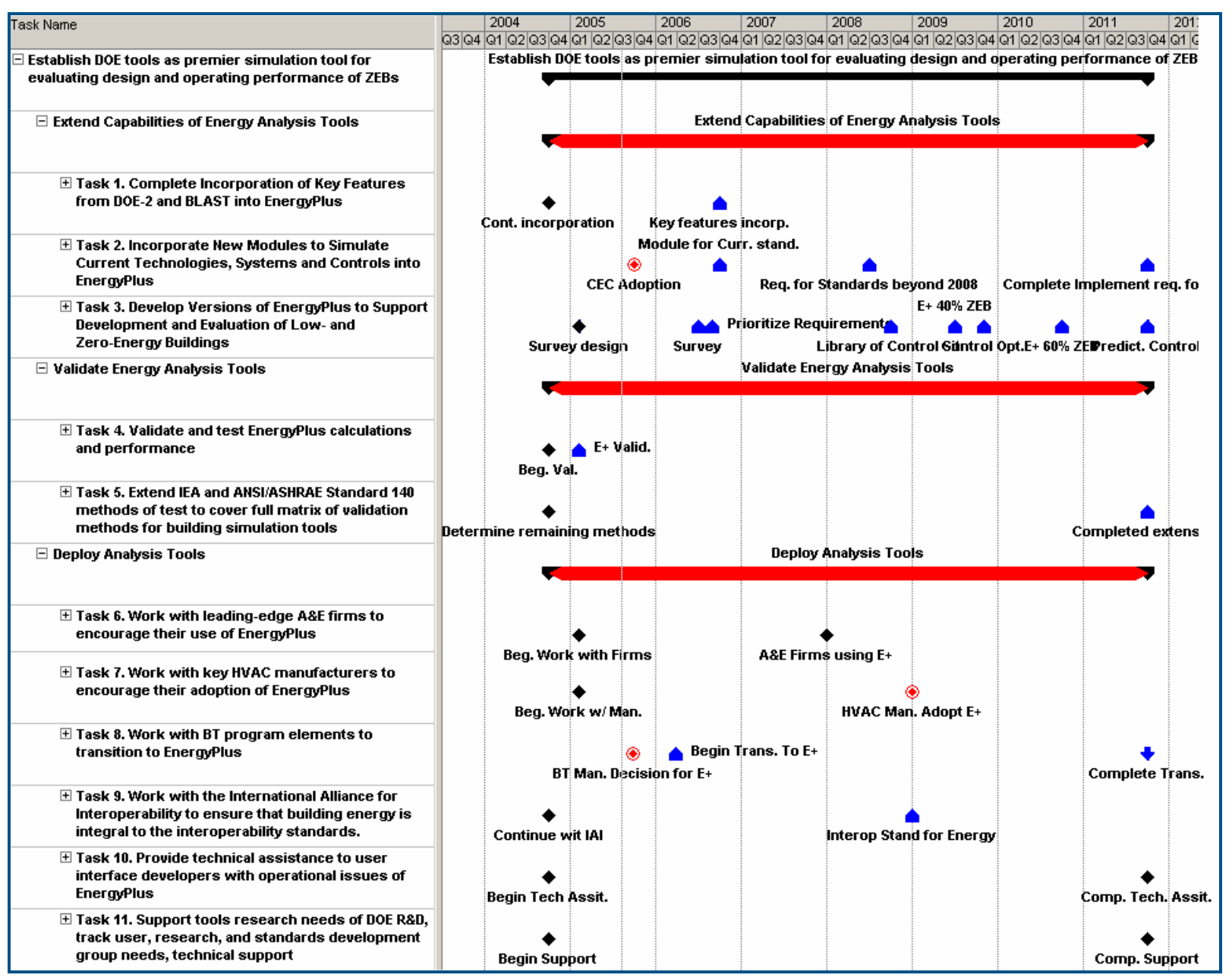

Figure G-14: Analysis Tools Gantt Chart (BTP 2005)

Program Outputs (BTP 2005)

The primary technical goal of this program is to establish BT software tools as the primary calculation engine for evaluating the design and operating energy performance of integrated lowand net-zero energy buildings including control sensors, strategies, and systems; building performance in operation; and integrated airflow analysis.

The performance goals for this subprogram are shown in Table G-24 - key goals include:

- Coverage of state-of-the-art building energy efficiency and renewable energy and other ZEB technologies that analysis tools can evaluate

- Methods of Test Coverage of Whole-Building Analysis Tools

- BT subprograms that currently employ building simulation tools that use EnergyPlus for program research and analysis 
Table G-24: Analysis Tools Performance Goals (BTP 2005)

\begin{tabular}{|c|c|c|c|c|c|}
\hline \multirow{2}{*}{\multicolumn{2}{|c|}{ Characteristics }} & \multirow[t]{2}{*}{ Units } & \multicolumn{3}{|c|}{ Calendar Year } \\
\hline & & & 2004 Status & 2008 Target & 2010 Target \\
\hline \multicolumn{6}{|c|}{ Extend the Capabilities: } \\
\hline 1. & $\begin{array}{l}\text { Coverage of state-of-the- } \\
\text { art building energy- } \\
\text { efficiency and renewable } \\
\text { energy and other ZEB } \\
\text { technologies that } \\
\text { analysis tools can } \\
\text { evaluate }^{37}\end{array}$ & Percent & 30 & 75 & 90 \\
\hline \multicolumn{6}{|c|}{ Validate Energy Analysis Tools: } \\
\hline 2 & $\begin{array}{l}\text { Methods of Test } \\
\text { Coverage of Whole- } \\
\text { Building Analysis Tools }\end{array}$ & $\begin{array}{l}\text { Methods } \\
\text { Covered }\end{array}$ & 2 & 4 & 6 \\
\hline \multicolumn{6}{|c|}{ Deploy Analysis Tools: } \\
\hline & $\begin{array}{l}\text { BT subprograms that } \\
\text { currently employ building } \\
\text { simulation tools that use } \\
\text { EnergyPlus for program } \\
\text { research and analysis }\end{array}$ & $\begin{array}{l}\text { Number of } \\
\text { subprogram } \\
\text { s }\end{array}$ & 2 & 6 & 11 \\
\hline & $\begin{array}{l}\text { Interoperability with } \\
\text { other building design } \\
\text { tools }^{38}\end{array}$ & Percent & 25 & 35 & 50 \\
\hline & $\begin{array}{l}\text { Design firms trained and } \\
\text { provided continuing } \\
\text { assistance on the use of } \\
\text { EnergyPlus }\end{array}$ & Number & 3 & 9 & 9 \\
\hline & $\begin{array}{l}\text { Extend EnergyPlus to } \\
\text { other broader based } \\
\text { engineering design tools } \\
\text { (TRACE and HAP) }\end{array}$ & Number & 0 & 2 & 2 \\
\hline
\end{tabular}

\footnotetext{
${ }^{37}$ Including advanced and near-market technologies and systems, building integrated PV, on-site CHP/DER, controls strategies, predictive/optimization control systems, and multizone airflow and pollution transport.

${ }^{38}$ Includes CAD geometry, CAD HVAC, CAD lighting and electrical, HVAC design, cost estimating, and project management. Current status is full interoperability with CAD geometry (the most difficult issue for interoperability) and the capability for interoperability with CAD HVAC but there is no other tool yet able to share data.
} 
Table G-25: Status of Validation Method of Test Coverage: Analysis Tools (BTP 2005)

\begin{tabular}{llll}
\hline \multicolumn{1}{c}{ Method of Test Type } & \multicolumn{1}{c}{ Building Envelope } & \multicolumn{1}{c}{ HVAC System and Plant } \\
\hline Analytical & Whole- & - Working Document of IEA & - ANSI/ASHRAE Standard 140- \\
& Building & Task 22 (Finland) & 2004 [based on IEA HVAC \\
& Simulation & - ASHRAE 1052-RP (OSU) & BESTEST Vol. 1 (NREL)] \\
& & - ASHRAE RP 865 (PSU/TAMU) \\
\cline { 2 - 4 } & Simplified & & - HVAC BESTEST Fuel-Fired \\
& Programs & & Furnace (NRCan) \\
\hline Empirical & Whole- & - ETNA/GENEC Tests (EDF) & -lowa ERS tests for VAV, \\
& Building & - BRE/DMU Tests (BRE) & Daylighting-HVAC, and Economizer \\
& Simulation & & Control (lowa ERS) \\
\cline { 2 - 4 } & Simplified & & \\
& Programs & & - ANSI/ASHRAE Standard 140- \\
& Whole- & - ANSI/ASHRAE Standard & 2004 [based on HVAC BESTEST \\
& Building & 140-2001 [based on IEA & Vol. 2 (NREL)] \\
& Simulation & Envelope BESTEST (NREL) & - RADTEST Radiant Heating \\
& & & (Switzerland) \\
\hline & & & \\
\cline { 2 - 4 } & Simplified & - HERS BESTEST (NREL) & \\
\cline { 2 - 4 } & Programs & - Florida BESTEST (NREL) & \\
\cline { 2 - 3 } & &
\end{tabular}

The strategic goal for Analysis Tools is to establish our software tools as the primary calculation engine of choice for evaluating the design and operating energy performance of integrated lowand net-zero energy buildings. This objective will be measured by the percent coverage of stateof-the-art building energy efficiency, renewable energy, and energy supply technologies that EnergyPlus can evaluate as compared to other similar software including DOE-2 and BLAST. In this case, the objective is considered met when EnergyPlus can evaluate $90 \%$ (by 2010) of the state-of-the-art technologies under development (by 2010) or planned (by 2015) by BT R\&D.

The second part of this first goal is to establish EnergyPlus as the primary software tool for BT program research, planning and analysis. This objective is measured first by the ability of EnergyPlus to address technical aspects of the BT subprogram, for instance, integrated building controls. Second, this objective is measured by the number of subprograms that rely on building simulation tools that, in turn, actually use EnergyPlus. In both cases, the objective is considered met when $90 \%$ of the subprograms use EnergyPlus by 2010. By using a common tool and set of analysis benchmarks, BT research and standards development will be more effective.

The second objective is to work with designers of high-volume, high-visibility, large buildings to demonstrate the value of building simulation. First, this effort will focus on the leading firms which now use DOE-2 for building energy simulation to move them toward EnergyPlus through training workshops (three each year for three years with continued support). This objective will be measured by how many of these firms successfully transition to EnergyPlus. In this case, the objective is considered met if two-thirds of these firms use EnergyPlus regularly by 2008. Secondly, continuous testing and validation (using industry standards) as new capabilities are added will demonstrate that EnergyPlus can accurately simulate actual building performance and energy savings. 
Each of the performance goals has a measurable path forward including how well EnergyPlus can deal with state-of-the-art technologies for net-zero and low-energy buildings, and how many other BT subprograms have transitioned from other tools to EnergyPlus.

\section{Translating Program Outputs to Market Outcomes (BTP 2005)}

The Analysis Tools and Design Strategies project researches the interrelationship of energy systems and building energy performance, develops various building analysis tools to more accurately model energy use in new and existing buildings, and provides recommendations and strategies to cost-effectively lower energy use and improve building performance. Zero-energy building goals will require a revolutionary approach to building design and operation coupled with careful integration with onsite renewable energy supplies as well as thermal and electric storage. Analysis Tools and Design Strategies support this goal by developing powerful simulation tools that support evaluation of new ZEB demand-reduction and energy supply technologies, and by supporting the various decision points throughout the life cycle of building design and operation. The project also focuses on non-software solutions such as improved standards, guidelines, and performance measurements, all of which bring about excellence in designing new buildings.

The Analysis Tools and Design Strategies project supports both Commercial Buildings Integration and Residential Buildings Integration $R \& D$ and is modeled in combination with these programs, as a key component to achieving the energy saving goals. The sections on Residential and Commercial Buildings Integration contain the modeling inputs used for Analysis Tools and Design Strategies.

\section{Equipment Standards and Analysis}

\section{Program Outputs (US DOE 2006a)}

The goal of the Equipment Standards and Analysis Subprogram is to develop minimum energy efficiency standards that are technologically feasible and economically justified. During FY 2005 and FY 2006, DOE has identified and implemented significant enhancements to rulemaking activities. DOE has made a commitment to clear the backlog of delayed actions that accumulated during prior years, while simultaneously implementing all new requirements of the Energy Policy Act of 2005.

\section{Target Market Description (U.S. DOE 2006b).}

The movement for Federal appliance efficiency standards started in the 1970s. At that time, several states, including California, were adopting state appliance efficiency standards. The Energy Policy and Conservation Act of 1975 (EPCA) established a Federal energy conservation program for major household appliances by calling for appliance efficiency targets. However, little progress was made to establish standards until the 1980s.

By 1986, appliance manufacturers realized that uniform Federal standards were preferable to a variety of state standards. The National Appliance Energy Conservation Act of 1987 established minimum efficiency standards for many household appliances: refrigerators, refrigeratorfreezers, freezers, room air conditioners, fluorescent lamp ballasts, incandescent reflector lamps, 
clothes dryers, clothes washers, dishwashers, kitchen ranges and ovens, pool heaters, television sets (withdrawn in 1995), and water heaters. Congress set initial Federal energy efficiency standards and established schedules for DOE to review these standards.

Standards for some fluorescent and incandescent reflector lamps, plumbing products, electric motors, and commercial water heaters, and HVAC systems were added in the Energy Policy Act of 1992 (EPAct). EPAct allowed for the future development of standards for many other products. EPAct also provided for voluntary testing and consumer information programs for office equipment, luminaries, and windows. The existence of a Federal standard for energy or water conservation products preempts state standards, unless the state standard is identical to the Federal standard. States may petition DOE for an exemption from Federal standards, under certain circumstances.

Assumed Budget Projections

BT assumed level funding throughout the analysis period (2008-2025). The amount of the request is confidential until after the budget submission to Congress.

Description of Key Activities (BTP 2005)

This subprogram carries out activities in three areas: labeling, test procedures, and mandatory energy conservation standards.

- Labeling: The Federal Trade Commission (FTC) is required to prescribe labeling rules for residential appliances. DOE and FTC share responsibility for labeling commercial equipment.

- Test Procedures: DOE outlines the test procedures that manufacturers must use to certify that their appliances meet the standards. The test procedures measure the energy efficiency and energy use, and provide an estimate of the annual operating cost of each appliance. Test procedures are typically maintained by industry associations and incorporated by reference into the rules set by DOE.

- Mandatory Energy Conservation Standards: DOE establishes Federal standards to keep consistent, national energy efficiency requirements for selected appliances and equipment. By law, DOE must upgrade standards to the maximum level of energy efficiency that is technically feasible and economically justified. DOE strives to establish standards that maximize consumer benefits and minimize negative impacts on manufacturers and others. 
Milestones

Table G-26: Multiyear Schedule to Issue One Standard for Each Product in Backlog, and to Develop One Standard for Each Product per EPAct 2005 (U.S. DOE 2006b)

\begin{tabular}{|c|c|c|c|c|c|}
\hline $\begin{array}{l}\text { Rulemaking } \\
\text { Team }\end{array}$ & Rule Type & Product(s) & $\begin{array}{l}\text { EPACT } \\
2005, \\
\text { Backlog, } \\
\text { Other } \\
\end{array}$ & $\begin{array}{l}\text { Approx. } \\
\text { Rule } \\
\text { Initiation } \\
\text { Date } \\
\end{array}$ & $\begin{array}{l}\text { Final } \\
\text { Action } \\
\text { Date }\end{array}$ \\
\hline \multirow[t]{2}{*}{ Heating Team } & \multirow[t]{2}{*}{ Standards } & $\begin{array}{l}\text { - Furnaces and Boilers } \\
\text { (Residential) [Backlog Cycle } 1 \\
\text { including Mobile Home } \\
\text { Furnaces, Backlog Cycle } 2 \text { for } \\
\text { Small Furnaces] }\end{array}$ & Backlog & $\mathrm{NA}$ & $\begin{array}{l}\text { Sept } \\
2007\end{array}$ \\
\hline & & $\begin{array}{l}\text { - Water Heaters (Residential) } \\
\text { [Backlog Cycle 2] } \\
\text { - Direct Heating Equipment } \\
\text { [Backlog Cycle 1] } \\
\text { - Pool Heaters [Backlog Cycle } \\
\text { 1] }\end{array}$ & $\begin{array}{l}\text { Backlog } \\
\text { Backlog } \\
\text { Backlog }\end{array}$ & $\begin{array}{l}\text { FY2006, } \\
\text { Q4 }\end{array}$ & $\begin{array}{l}\text { March } \\
2010\end{array}$ \\
\hline \multirow{4}{*}{$\begin{array}{l}\text { Transformers } \\
\text { and Motors } \\
\text { Team }\end{array}$} & $\begin{array}{l}\text { Determination } \\
\text { Analysis }\end{array}$ & - Small Electric Motors & Backlog & NA & $\begin{array}{l}\text { June } \\
2006\end{array}$ \\
\hline & \multirow[t]{2}{*}{ Standards } & $\begin{array}{l}\text { - Distribution Transformers, MV } \\
\text { Dry-Type and Liquid- } \\
\text { Immersed }\end{array}$ & Backlog & NA & $\begin{array}{l}\text { Sept } \\
2007\end{array}$ \\
\hline & & $\begin{array}{l}\text { Electric Motors, 1-200 HP } \\
\text { [Backlog Cycle 1] }\end{array}$ & Backlog & $\begin{array}{l}\text { FY2008, } \\
\text { Q1 }\end{array}$ & $\begin{array}{l}\text { June } \\
2011\end{array}$ \\
\hline & $\begin{array}{l}\text { Test } \\
\text { Procedure }\end{array}$ & - Distribution Transformers & Backlog & NA & $\begin{array}{l}\text { April } \\
2006\end{array}$ \\
\hline \multirow[t]{4}{*}{ Lighting Team } & $\begin{array}{l}\text { Determination } \\
\text { Analysis }\end{array}$ & $\begin{array}{l}\text { - High-Intensity Discharge } \\
\text { Lamps }\end{array}$ & Backlog & NA & $\begin{array}{l}\text { June } \\
2010\end{array}$ \\
\hline & \multirow[t]{3}{*}{ Standards } & $\begin{array}{l}\text { Ceiling Fan Light Kits (other } \\
\text { than those with prescribed } \\
\text { standards) }\end{array}$ & $\begin{array}{l}\text { EPACT } \\
2005\end{array}$ & NA & $\begin{array}{l}\text { Jan } \\
2007\end{array}$ \\
\hline & & $\begin{array}{l}\text { - Incandescent Reflector } \\
\text { Lamps [Backlog Cycle 1] } \\
\text { - Fluorescent Lamps [Backlog } \\
\text { Cycle 1] } \\
\text { - Incandescent General Service } \\
\text { Lamps [Backlog Cycle 1] }\end{array}$ & $\begin{array}{l}\text { Backlog } \\
\text { Backlog } \\
\text { Backlog }\end{array}$ & $\begin{array}{l}\text { FY2006, } \\
\text { Q3 }\end{array}$ & $\begin{array}{l}\text { June } \\
2009\end{array}$ \\
\hline & & $\begin{array}{l}\text { - Fluorescent Lamp Ballasts } \\
\text { [Backlog Cycle 2] }\end{array}$ & Backlog & $\begin{array}{l}\text { FY2008, } \\
\text { Q1 }\end{array}$ & $\begin{array}{l}\text { June } \\
2011\end{array}$ \\
\hline \multirow{3}{*}{$\begin{array}{l}\text { Home } \\
\text { Appliance } \\
\text { Team }\end{array}$} & \multirow[t]{3}{*}{ Standards } & $\begin{array}{l}\text { - Dishwashers (Residential) } \\
\text { [Backlog Cycle 2] }\end{array}$ & Backlog & $\begin{array}{l}\text { FY2006, } \\
\text { Q2 }\end{array}$ & $\begin{array}{l}\text { March } \\
2009\end{array}$ \\
\hline & & $\begin{array}{l}\text { - Ranges and Ovens (Electric } \\
\text { and Gas) and Microwave } \\
\text { Ovens [Backlog Cycle } 1 \text { for } \\
\text { Gas, Backlog Cycle } 2 \text { for } \\
\text { Electric] } \\
\text { - Dehumidifiers (Residential } \\
\text { [Revision] } \\
\text { - Clothes Washers } \\
\text { (Commercial) [Revision 1] }\end{array}$ & $\begin{array}{l}\text { EPACT } \\
2005 \\
\text { EPACT } \\
2005 \\
\end{array}$ & & \\
\hline & & $\begin{array}{l}\text { - Clothes Dryers (Residential) } \\
\text { [Backlog Cycle 2] }\end{array}$ & Backlog & $\begin{array}{l}\text { FY2008, } \\
\text { Q1 }\end{array}$ & $\begin{array}{l}\text { June } \\
2011 \\
\end{array}$ \\
\hline
\end{tabular}




\begin{tabular}{|c|c|c|c|c|c|}
\hline $\begin{array}{l}\text { Rulemaking } \\
\text { Team }\end{array}$ & Rule Type & Product(s) & $\begin{array}{l}\text { EPACT } \\
2005, \\
\text { Backlog, } \\
\text { Other }\end{array}$ & $\begin{array}{l}\text { Approx. } \\
\text { Rule } \\
\text { Initiation } \\
\text { Date }\end{array}$ & $\begin{array}{l}\text { Final } \\
\text { Action } \\
\text { Date }\end{array}$ \\
\hline & & $\begin{array}{l}\text { - Room Air Conditioners } \\
\text { [Backlog Cycle 2] }\end{array}$ & Backlog & & \\
\hline \multirow[t]{3}{*}{$\begin{array}{l}\text { Space Cooling } \\
\text { Team }\end{array}$} & \multirow[t]{2}{*}{ Standards } & $\begin{array}{l}\text { - Packaged Terminal Air } \\
\text { Conditioners and Heat Pumps }\end{array}$ & Backlog & $\begin{array}{l}\text { FY2006, } \\
\text { Q4 }\end{array}$ & $\begin{array}{l}\text { Sept } \\
2008\end{array}$ \\
\hline & & $\begin{array}{l}\text { - Central Air Conditioners and } \\
\text { Heat Pumps (Residential) } \\
\text { [Backlog Cycle 2] }\end{array}$ & Backlog & $\begin{array}{l}\text { FY2008, } \\
\text { Q2 }\end{array}$ & $\begin{array}{l}\text { June } \\
2011\end{array}$ \\
\hline & $\begin{array}{l}\text { Test } \\
\text { Procedure }\end{array}$ & $\begin{array}{l}\text { - Central Air Conditioners and } \\
\text { Heat Pumps (Residential }\end{array}$ & Other & NA & $\begin{array}{l}\text { Sept } \\
2007\end{array}$ \\
\hline \multirow{4}{*}{$\begin{array}{l}\text { Commercial } \\
\text { Refrigeration } \\
\text { Team }\end{array}$} & \multirow[t]{3}{*}{ Standards } & $\begin{array}{l}\text { - Refrigerated Bottle or Canned } \\
\text { Beverage Vending Machines }\end{array}$ & $\begin{array}{l}\text { EPACT } \\
2005 \\
\end{array}$ & $\begin{array}{l}\text { FY2006, } \\
\text { Q3 }\end{array}$ & Aug 2009 \\
\hline & & $\begin{array}{l}\text { - Ice-Cream Freezers, Self- } \\
\text { Contained Commercial } \\
\text { Refrigerators, Freezers, and } \\
\text { Refrigerator-Freezers without } \\
\text { Doors, and Remote- } \\
\text { Condensing Commercial } \\
\text { Refrigerators, Freezers and } \\
\text { Refrigerator-Freezers (initial) }\end{array}$ & $\begin{array}{l}\text { EPACT } \\
2005\end{array}$ & $\begin{array}{l}\text { FY2006, } \\
\text { Q2 }\end{array}$ & Jan 2009 \\
\hline & & $\begin{array}{l}\text { - Automatic Ice Makers } \\
\text { (Commercial) [Revision 1] }\end{array}$ & $\begin{array}{l}\text { EPACT } \\
2005 \\
\end{array}$ & $\begin{array}{l}\text { FY2011, } \\
\text { Q3 }\end{array}$ & Jan 2015 \\
\hline & $\begin{array}{l}\text { Test } \\
\text { Procedure }\end{array}$ & $\begin{array}{l}\text { - Ice-Cream Freezers, Self- } \\
\text { Contained Commercial } \\
\text { Refrigerators, Freezers, and } \\
\text { Refrigerator-Freezers without } \\
\text { Doors, and Remote- } \\
\text { Condensing Commercial } \\
\text { Refrigerators, Freezers and } \\
\text { Refrigerator-Freezers }\end{array}$ & $\begin{array}{l}\text { EPACT } \\
2005\end{array}$ & NA & Jan 2008 \\
\hline \multirow{3}{*}{$\begin{array}{l}\text { Battery } \\
\text { Chargers and } \\
\text { External Power } \\
\text { Supplies Team }\end{array}$} & $\begin{array}{l}\text { Determination } \\
\text { Analysis }\end{array}$ & $\begin{array}{l}\text { - Battery Chargers and } \\
\text { External Power Supplies }\end{array}$ & $\begin{array}{l}\text { EPACT } \\
2005\end{array}$ & NA & Aug 2008 \\
\hline & Standards & $\begin{array}{l}\text { - Battery Chargers and } \\
\text { External Power Supplies } \\
\text { (Contingent on Determination) }\end{array}$ & $\begin{array}{l}\text { EPACT } \\
2005\end{array}$ & $\begin{array}{l}\text { FY2008, } \\
\text { Q4 }\end{array}$ & Aug 2011 \\
\hline & $\begin{array}{l}\text { Test } \\
\text { Procedure }\end{array}$ & $\begin{array}{l}\text { - Battery Chargers and } \\
\text { External Power Supplies }\end{array}$ & $\begin{array}{l}\text { EPACT } \\
2005 \\
\end{array}$ & NA & Feb 2007 \\
\hline $\begin{array}{l}\text { Other EPACT } \\
2005\end{array}$ & $\begin{array}{l}\text { Test } \\
\text { Procedure }\end{array}$ & $\begin{array}{l}\text { - } 11 \text { Test Procedures } \\
\text { Prescribed by EPACT } 2005\end{array}$ & $\begin{array}{l}\text { EPACT } \\
2005\end{array}$ & NA & Nov 2006 \\
\hline
\end{tabular}

Program Outputs (U.S. DOE 2006a)

The Equipment Standards and Analysis Subprogram will continue ongoing rule-making activities and add new ones for the following product categories that will continue in FY 2008:

- Residential Water Heaters

- Direct Heating Equipment

- Pool Heaters

- Ceiling Fan Light Kits [EPAct 2005]

- Battery Chargers and External Power Supplies [EPAct 2005] 
- Incandescent Reflector Lamps

- Fluorescent Lamps

- Incandescent General Service Lamps

- Residential Dishwashers

- Ranges and Ovens and Microwave Ovens (Electric and Gas)

- Dehumidifiers (Residential) [EPAct 2005]

- Commercial Clothes Washers [EPAct 2005]

- Refrigerated Bottle or Canned Beverage Vending Machines [EPAct 2005]

- Packaged Terminal Air Conditioners

- Ice Cream Freezers, Self-Contained Commercial Refrigerators, Freezers, and Refrigerator-Freezers without doors, and remote-condensing commercial refrigerators, freezers and refrigerator-freezers [EPAct 2005]

The specific standards and test-procedure activities listed above have been identified considering existing obligations, new legislative directives, and input from a broad range of external stakeholders. In FY 2008, final rules will be issued for two to five products, including battery chargers and external power supplies and packaged terminal air conditioners.

\section{Translating Program Outputs to Market Outcomes}

Congress passed laws setting initial Federal energy efficiency standards and establishing schedules for DOE to review and revise these standards. Standards benefit consumers by requiring that appliance manufacturers reduce the energy and water use of their products - and, thus, the costs to operate them.

\section{Key Factors in Shaping Market Adoption of EERE technologies}

- Price: By law, DOE must upgrade standards to the maximum level of energy efficiency that is technically feasible and economically justified. DOE strives to establish standards that maximize consumer benefits and minimize negative impacts on manufacturers and others.

- Non-price factors

- Policy factors: The Appliance Standards activity is conducted pursuant to Title III, Part B, of the Energy Policy and Conservation Act (EPCA). EPCA established test procedures, conservation targets (followed by standards if targets are not set), and labeling requirements for certain major household appliances. EPCA also provided for DOE to establish test procedures for evaluating compliance by manufacturers with applicable efficiency standards. In 1978, DOE was authorized to set mandatory energy efficiency standards for 13 household appliances and products under the National Energy Conservation and Policy Act (NECPA). In 1987, EPCA was amended and updated by the National Appliance Energy Conservation Act (NAECA), which superseded existing state requirements. NAECA also contains requirements and deadlines for updating the initial standards through rulemakings conducted by DOE using criteria included in the law. The Energy Policy Act of 1992 (EPAct 1992) further amended EPCA to expand the coverage of the standards program, established a labeling program for commercial products, and also allowed for the future development of standards for many other products. The Energy Policy Act of 2005 (EPAct 2005) 
significantly expands and changes the DOE's regulatory requirements in appliance standards. EPAct 2005 establishes numerous prescriptive standards for many types of products and expands the DOE's authority to regulate other product areas.

\section{Final Outcomes (Benefits)}

DOE undertakes the setting of equipment standards authorized via three major legislative acts: the 1987 NAECA, EPAct 1992, and EPAct 2005. The objective of these standards is to set minimum levels of energy efficiency for equipment that will save both energy and overall cost from a consumer perspective.

In early 2006, DOE laid out a five-year plan to set efficiency standards on new products and to update the standards for other products set in prior rulemakings. For the FY 2008 GPRA process, an estimate of the total savings from all of these products is reported, rather than estimated savings from each product. Prior to the actual detailed analysis of a specific product, there is no definitive method to select the most appropriate level of the standard from which to estimate energy savings. Furthermore, publishing initial assumptions for specific products in this analysis may inappropriately suggest final rulemakings that appear to be endorsed by DOE. It is important to avoid such an outcome. Thus, a reasonable method of generating and presenting the estimates energy savings from this project shall involve the use of preliminary analysis done for the 2005 Priority Setting process (U.S. DOE 2004c) and subsequently aggregating the savings across all products.

The products considered in the FY08 GPRA analysis include those for which rulemaking activities are expected over the period 2008 through 2011. These products are listed in the document "five-year schedule.pdf" found on the BT Web site: http://www.eere.energy.gov/buildings/appliance standards/2006 schedule setting.html. For these products, preliminary estimates of energy savings from alternative potential efficiency levels were developed as part of the FY 2005 priority setting process conducted by BT. These spreadsheets are available from:

http://www.eere.energy.gov/buildings/appliance standards/priority setting.html (a zip file of size $855 \mathrm{~KB})$. The products considered in the analysis are:

1) Incandescent lighting

2) Ranges and ovens

3) Dishwashers

4) Room air conditioners

5) Pool heaters

6) Commercial refrigeration equipment

As part of the development of the spreadsheets used in the FY 2005 priority setting process, the energy savings spreadsheets often contain several potential efficiency levels that may be considered for a standard. For the GPRA process, the standard level chosen generally tends to be in the mid- to lower range of these potential levels (i.e., to generate a conservative level of savings). When the product is covered by the Energy Star program, the Energy Star efficiency level is typically selected. 
Table G-27: Total Savings for Electricity and Gas from Various Products Scheduled for Rulemakings Between 2008 and 2011

\begin{tabular}{lrrrrrr}
\hline Year & \multicolumn{2}{c}{ Total } & \multicolumn{2}{c}{ Residential } & \multicolumn{2}{c}{ Commercial } \\
\cline { 2 - 7 } & $\begin{array}{r}\text { Electricity } \\
\text { (TBtu, site) }\end{array}$ & $\begin{array}{r}\text { Natural Gas } \\
\text { (TBtu) }\end{array}$ & $\begin{array}{r}\text { Electricity } \\
(\text { TBtu, site) }\end{array}$ & $\begin{array}{r}\text { Natural Gas } \\
\text { (TBtu) }\end{array}$ & $\begin{array}{r}\text { Electricity } \\
\text { (TBtu, site) }\end{array}$ & $\begin{array}{r}\text { Natural Gas } \\
(\text { TBtu })\end{array}$ \\
\hline 2010 & 21.7 & 1.6 & 12.3 & 1.4 & 9.4 & 0.1 \\
\hline 2011 & 43.3 & 4.1 & 24.5 & 3.8 & 18.8 & 0.4 \\
\hline 2012 & 48.4 & 6.7 & 27.1 & 6.1 & 21.3 & 0.6 \\
\hline 2013 & 53.4 & 9.3 & 29.7 & 8.4 & 23.7 & 0.8 \\
\hline 2014 & 58.4 & 11.8 & 32.2 & 10.7 & 26.2 & 1.1 \\
\hline 2015 & 63.4 & 14.4 & 34.8 & 13.1 & 28.6 & 1.3 \\
\hline 2016 & 68.4 & 17.0 & 37.4 & 15.4 & 31.0 & 1.6 \\
\hline 2017 & 73.5 & 19.5 & 40.0 & 17.7 & 33.5 & 1.8 \\
\hline 2018 & 78.5 & 22.1 & 42.5 & 20.1 & 35.9 & 2.0 \\
\hline 2019 & 81.3 & 24.7 & 45.1 & 22.4 & 36.2 & 2.3 \\
\hline 2020 & 83.6 & 27.2 & 47.3 & 24.7 & 36.3 & 2.5 \\
\hline 2021 & 85.9 & 29.8 & 49.4 & 27.0 & 36.5 & 2.7 \\
\hline 2022 & 88.2 & 32.4 & 51.5 & 29.4 & 36.7 & 3.0 \\
\hline 2023 & 90.1 & 34.7 & 53.2 & 31.5 & 36.9 & 3.2 \\
\hline 2024 & 91.9 & 37.1 & 54.9 & 33.6 & 37.1 & 3.4 \\
\hline 2025 & 92.8 & 39.4 & 55.6 & 35.8 & 37.2 & 3.7 \\
\hline 2026 & 93.6 & 40.8 & 56.3 & 37.0 & 37.2 & 3.8 \\
\hline 2027 & 94.4 & 42.2 & 57.1 & 38.2 & 37.3 & 4.0 \\
\hline 2028 & 95.2 & 43.5 & 57.8 & 39.4 & 37.4 & 4.1 \\
\hline 2029 & 95.2 & 43.5 & 57.8 & 39.4 & 37.4 & 4.1 \\
\hline 2030 & 95.2 & 43.5 & 57.8 & 39.4 & 37.4 & 4.1 \\
\hline
\end{tabular}

As separate savings estimates for standards related to small motors were published as part of the FY 2007 GPRA, separate estimates for this product category are published for the FY 2008 GPRA.

\section{Electric Motors, 1-200 HP}

BT assumed that the entire stock of existing motors is replaced with motors meeting the standard by 2027 (the standard goes into effect in 2012, so within 15 years, the estimated lifetime, all motors have been replaced). Subsequent increases in savings are only from increases in new sales (as opposed to replacement sales).

Energy performance assumptions are based on U.S. DOE 2004c, and include the following:

- Base Case: Average electric motor energy consumption: 25.61 thousand $\mathrm{kWh} / \mathrm{yr}$ (industrial) and 12.80 thousand $\mathrm{kWh} / \mathrm{yr}$ (commercial)

- Performance: Standard results in 1.7\% average reduction in energy for industrial; $2 \%$ average reduction in energy for commercial.

- Start Date: Effective date of standard is 2012. 
Expected Market Uptake: BT assumed that the entire stock of existing motors is replaced with motors meeting the standard by 2025 (the standard goes into effect in 2010, so within 15 years, the estimated lifetime, all motors have been replaced). Subsequent increases in savings are only from increases in new sales (as opposed to replacement sales).

Based on forecasted shipment data (U.S. DOE 2004c), Table G-28 and Table G-29 contain the energy savings calculations.

Table G-28: Annual Industrial Energy Savings

\begin{tabular}{|c|c|c|c|c|c|c|}
\hline Year & $\begin{array}{l}\text { Shipment } \\
\text { forecast }\end{array}$ & $\begin{array}{l}\text { Baseline } \\
\text { Consumption } \\
\text { for units sold } \\
\text { in year } \\
\text { (million kWh) }\end{array}$ & $\begin{array}{l}\% \text { covered } \\
\text { by } \\
\text { standards }\end{array}$ & $\begin{array}{l}\text { Savings } \\
\text { for } \\
\text { current } \\
\text { vintage } \\
\text { (million } \\
\text { kWh) }\end{array}$ & $\begin{array}{l}\text { Saving } \\
\text { for } \\
\text { Installed } \\
\text { Base } \\
\text { (million } \\
\text { kWh) }\end{array}$ & $\begin{array}{l}\text { Total } \\
\text { Delivered } \\
\text { Savings } \\
\text { (TBtu/yr) }\end{array}$ \\
\hline 2008 & $1,224,000$ & $31,346.3$ & $100 \%$ & 0.0 & - & - \\
\hline 2009 & $1,248,480$ & $31,973.3$ & $100 \%$ & 0.0 & - & - \\
\hline 2010 & $1,273,450$ & $32,612.7$ & $100 \%$ & 0.0 & - & - \\
\hline 2011 & $1,298,919$ & $33,265.0$ & $100 \%$ & 0.0 & - & - \\
\hline 2012 & $1,324,897$ & $33,930.3$ & $100 \%$ & 576.8 & 576.8 & 2.0 \\
\hline 2013 & $1,351,395$ & $34,608.9$ & $100 \%$ & 588.4 & $1,165.2$ & 4.0 \\
\hline 2014 & $1,378,423$ & $35,301.1$ & $100 \%$ & 600.1 & $1,765.3$ & 6.0 \\
\hline 2015 & $1,405,991$ & $36,007.1$ & $100 \%$ & 612.1 & $2,377.4$ & 8.1 \\
\hline 2016 & $1,434,111$ & $36,727.2$ & $100 \%$ & 624.4 & $3,001.8$ & 10.2 \\
\hline 2017 & $1,462,793$ & $37,461.8$ & $100 \%$ & 636.9 & $3,638.6$ & 12.4 \\
\hline 2018 & $1,492,049$ & $38,211.0$ & $100 \%$ & 649.6 & $4,288.2$ & 14.6 \\
\hline 2019 & $1,521,890$ & $38,975.2$ & $100 \%$ & 662.6 & $4,950.8$ & 16.9 \\
\hline 2020 & $1,552,328$ & $39,754.7$ & $100 \%$ & 675.8 & $5,626.6$ & 19.2 \\
\hline 2021 & $1,583,375$ & $40,549.8$ & $100 \%$ & 689.3 & $6,316.0$ & 21.6 \\
\hline 2022 & $1,615,042$ & $41,360.8$ & $100 \%$ & 703.1 & $7,019.1$ & 23.9 \\
\hline 2023 & $1,647,343$ & $42,188.0$ & $100 \%$ & 717.2 & $7,736.3$ & 26.4 \\
\hline 2024 & $1,680,290$ & $43,031.8$ & $100 \%$ & 731.5 & $8,467.8$ & 28.9 \\
\hline 2025 & $1,713,895$ & $43,892.4$ & $100 \%$ & 746.2 & $9,214.0$ & 31.4 \\
\hline 2026 & $1,748,173$ & $44,770.3$ & $100 \%$ & 761.1 & $9,975.1$ & 34.0 \\
\hline 2027 & $1,783,137$ & $45,665.7$ & $100 \%$ & 199.5 & $10,174.6$ & 34.7 \\
\hline 2028 & $1,818,800$ & $46,579.0$ & $100 \%$ & 203.5 & $10,378.1$ & 35.4 \\
\hline 2029 & $1,855,176$ & $47,510.6$ & $100 \%$ & 207.6 & $10,585.7$ & 36.1 \\
\hline 2030 & $1,892,279$ & $48,460.8$ & $100 \%$ & 211.7 & $10,797.4$ & 36.8 \\
\hline
\end{tabular}


Table G-29: Annual Commercial Energy Savings

\begin{tabular}{|c|c|c|c|c|c|c|}
\hline Year & $\begin{array}{l}\text { Shipment } \\
\text { forecast }\end{array}$ & $\begin{array}{l}\text { Baseline } \\
\text { Consumption } \\
\text { for units sold } \\
\text { in year } \\
\text { (million kWh) }\end{array}$ & $\begin{array}{l}\% \text { covered } \\
\text { by } \\
\text { standards }\end{array}$ & $\begin{array}{l}\text { Savings } \\
\text { for } \\
\text { current } \\
\text { vintage } \\
\text { (million } \\
\text { kWh) }\end{array}$ & $\begin{array}{l}\text { Savings } \\
\text { for } \\
\text { Installed } \\
\text { Base } \\
\text { (million } \\
\text { kWh) }\end{array}$ & $\begin{array}{l}\text { Total } \\
\text { Delivered } \\
\text { Savings } \\
\text { (TBtu/yr) }\end{array}$ \\
\hline 2008 & 663,000 & $8,489.6$ & $100 \%$ & 0.0 & - & - \\
\hline 2009 & 676,260 & $8,659.4$ & $100 \%$ & 0.0 & - & - \\
\hline 2010 & 689,785 & $8,832.6$ & $100 \%$ & 0.0 & - & - \\
\hline 2011 & 703,581 & $9,009.3$ & $100 \%$ & 0.0 & - & - \\
\hline 2012 & 717,653 & $9,189.5$ & $100 \%$ & 183.8 & 183.8 & 0.6 \\
\hline 2013 & 732,006 & $9,373.2$ & $100 \%$ & 187.5 & 371.3 & 1.3 \\
\hline 2014 & 746,646 & $9,560.7$ & $100 \%$ & 191.2 & 562.5 & 1.9 \\
\hline 2015 & 761,579 & $9,751.9$ & $100 \%$ & 195.0 & 757.5 & 2.6 \\
\hline 2016 & 776,810 & $9,947.0$ & $100 \%$ & 198.9 & 956.4 & 3.3 \\
\hline 2017 & 792,346 & $10,145.9$ & $100 \%$ & 202.9 & $1,159.4$ & 4.0 \\
\hline 2018 & 808,193 & $10,348.8$ & $100 \%$ & 207.0 & $1,366.3$ & 4.7 \\
\hline 2019 & 824,357 & $10,555.8$ & $100 \%$ & 211.1 & $1,577.5$ & 5.4 \\
\hline 2020 & 840,844 & $10,766.9$ & $100 \%$ & 215.3 & $1,792.8$ & 6.1 \\
\hline 2021 & 857,661 & $10,982.2$ & $100 \%$ & 219.6 & $2,012.4$ & 6.9 \\
\hline 2022 & 874,814 & $11,201.9$ & $100 \%$ & 224.0 & $2,236.5$ & 7.6 \\
\hline 2023 & 892,311 & $11,425.9$ & $100 \%$ & 228.5 & $2,465.0$ & 8.4 \\
\hline 2024 & 910,157 & $11,654.4$ & $100 \%$ & 233.1 & $2,698.1$ & 9.2 \\
\hline 2025 & 928,360 & $11,887.5$ & $100 \%$ & 237.8 & $2,935.8$ & 10.0 \\
\hline 2026 & 946,927 & $12,125.3$ & $100 \%$ & 242.5 & $3,178.3$ & 10.8 \\
\hline 2027 & 965,866 & $12,367.8$ & $100 \%$ & 63.6 & $3,241.9$ & 11.1 \\
\hline 2028 & 985,183 & $12,615.1$ & $100 \%$ & 64.8 & $3,306.7$ & 11.3 \\
\hline 2029 & $1,004,887$ & $12,867.5$ & $100 \%$ & 66.1 & $3,372.9$ & 11.5 \\
\hline 2030 & $1,024,985$ & $13,124.8$ & $100 \%$ & 67.5 & $3,440.3$ & 11.7 \\
\hline
\end{tabular}

These inputs were incorporated into the NEMS-GPRA08 and MARKAL-GPRA08 models as described in their corresponding chapters of this document.

\section{Technology Validation and Market Introduction - Building Energy Codes}

\section{Program Outputs}

Building energy codes define the minimum requirements for new construction, including additions and alterations to existing buildings. Building energy codes set minimum requirements for building thermal envelope performance, building mechanical system performance, ${ }^{39}$ and building lighting and power system performance (commercial buildings only). Commercial

\footnotetext{
${ }^{39}$ The efficiency of many classes of HVAC equipment, especially equipment generally used in residences, is preemptively regulated by manufacturing standards resulting from the National Appliance Energy Conservation Act of 1987 (NAECA) and is therefore outside the scope of building energy codes.
} 
building energy codes also set building mechanical equipment requirements that are the starting point for DOE's equipment standards rulemakings.

Target Market Description (BTP 2005).

Building energy codes do not address all of the energy use in residential or commercial buildings. Table G-30 shows residential and commercial energy use subject to building energy codes requirements. Note that building end uses are the sum of energy used by appliances, equipment, and systems used to serve a particular building load. While building energy codes do not typically cover appliances or equipment, building energy codes do cover systems and the building thermal envelope, which are significant drivers in both space heating and space cooling.

\section{Table G-30: Residential and Commercial Energy Use Subject to Building Energy Codes} (BTP 2005)

\begin{tabular}{ccc}
\hline \multicolumn{1}{c}{ Sector } & Residential $^{1}$ & Commercial $^{2}$ \\
\hline End Use & & \\
\hline Space Heating & Covered & Covered \\
\hline Water Heating & Covered & Covered \\
\hline Space Cooling & Covered & Covered \\
\hline Lighting & Not Covered & Covered \\
\hline Ventilation & Not Considered & Covered \\
\hline Refrigeration & Not Covered & Not covered \\
\hline Wet Clean & Not Covered & Not Considered \\
\hline Electronics & Not Covered & Not covered \\
\hline Cooking & Not Covered & Not covered \\
\hline Computers & Not Covered & Not covered \\
\hline Other & Partially Covered ${ }^{6}$ & Not covered \\
\hline${ }^{1}$ Residential end-use taken from 2004 BEDB Table 1.2.3 & \\
${ }^{2}$ Commercial end-uses taken from 2004 BEDB Table 1.3.3 & \\
${ }^{3}$ End-use not broken out in residential table & \\
${ }^{4}$ Clothes washing/drying and dishwashing & \\
${ }^{5}$ End-use not listed in commercial table. This would be considered industrial use. \\
${ }^{6}$ Pool and hot tub heaters and motors are covered in some building energy codes
\end{tabular}

Note that the above table does not imply that end uses that are not covered by building energy codes are not regulated by any standards. The residential refrigeration and wet clean (laundry and dishwashing) end uses are addressed by DOE's appliance standards project. Nor does the fact that an end use is covered by building energy codes indicate that the Building Energy Codes Subprogram is solely responsible for that end use. For example, space heating, water heating, and space cooling responsibility are shared between building energy codes (which address the building envelope and mechanical systems) and appliance standards (which address the mechanical equipment).

Table G-31 is derived from the same tables in the 2004 BEDB to show what portion of building energy use is impacted by building energy codes. For each end use that is listed as covered in Table G-30, the estimated site and primary energy impacts are listed. 
Table G-31: Residential and Commercial Energy Use Subject to Building Energy Codes (BTP 2005)

\begin{tabular}{|c|c|c|c|c|}
\hline \multirow{2}{*}{$\begin{array}{c}\text { Sector } \\
\text { End Use }\end{array}$} & \multicolumn{2}{|c|}{ Residential Quads $^{1}$} & \multicolumn{2}{|c|}{ Commercial Quads $^{2}$} \\
\hline & Site & Primary & Site & Primary \\
\hline Space Heating & 5.56 & 6.62 & 1.99 & 2.46 \\
\hline Water Heating & 1.75 & 2.66 & 0.82 & 1.13 \\
\hline Space Cooling & 0.80 & 2.59 & 0.64 & 2.04 \\
\hline Lighting & Not covered & Not covered & 1.36 & 4.37 \\
\hline Ventilation & Not split out & Not split out & 0.31 & 1.01 \\
\hline Refrigeration & Not covered & Not covered & Not covered & Not covered \\
\hline Wet Clean & Not covered & Not covered & Not covered & Not covered \\
\hline Electronics & Not covered & Not covered & Not covered & Not covered \\
\hline Cooking & Not covered & Not covered & Not covered & Not covered \\
\hline Computers & Not covered & Not covered & Not covered & Not covered \\
\hline Other & Assumed zero & Assumed zero & Not covered & Not covered \\
\hline $\begin{array}{l}\text { Adjustment to } \\
\text { SEDS }\end{array}$ & Not covered & Not covered & Not covered & Not covered \\
\hline Total Covered & 8.11 & 11.87 & 5.12 & 11.01 \\
\hline Total Sector & 11.30 & 20.91 & 8.28 & 17.43 \\
\hline Percent Covered & $72 \%$ & $57 \%$ & $62 \%$ & $64 \%$ \\
\hline
\end{tabular}

While the table above indicates that a considerable fraction of both residential and commercial sector energy use is subject to building energy codes, it bears repeating that this coverage is shared with appliance standards, and also that this coverage is for new construction in new and existing buildings. A strict separation of the impact of building energy codes from appliance standards is not easy, and no attempt to do so is made here. In general, the conventional approach for heating and cooling end use is that building energy codes primarily affect the performance of envelope characteristics such as the level of insulation and efficiency of windows. ${ }^{40}$ For commercial lighting, the approach is to assume that building codes affect the required illumination levels without directly mandating specific technologies.

Estimating the impact of the new construction-only aspect of building energy codes is somewhat easier. New construction represents a fraction of the total buildings sector, as shown in Table G-32.

\footnotetext{
${ }^{40}$ For the purposes of the energy savings for the GPRA process, the interaction between equipment and envelope, with respect to codes and standards, is deemed not to be very important in the near term. For example, according to Table G-26, a revision to the standard for residential central air conditioners and heat pumps is not expected before 2011 . The most recent change in the standard - to an efficiency level of SEER 13 - just became effective at the beginning of 2006. Unless there are significant increases in electricity prices or dramatic improvements in technology, the standard is unlikely to increase significantly in the near term. (Note that, also in this case, more than a decade elapsed before the last major change in the efficiency standard for central air conditioners and heat pumps.)
} 
Table G-32: Annual New Construction as a Fraction of Total Building Sector (BTP 2005)

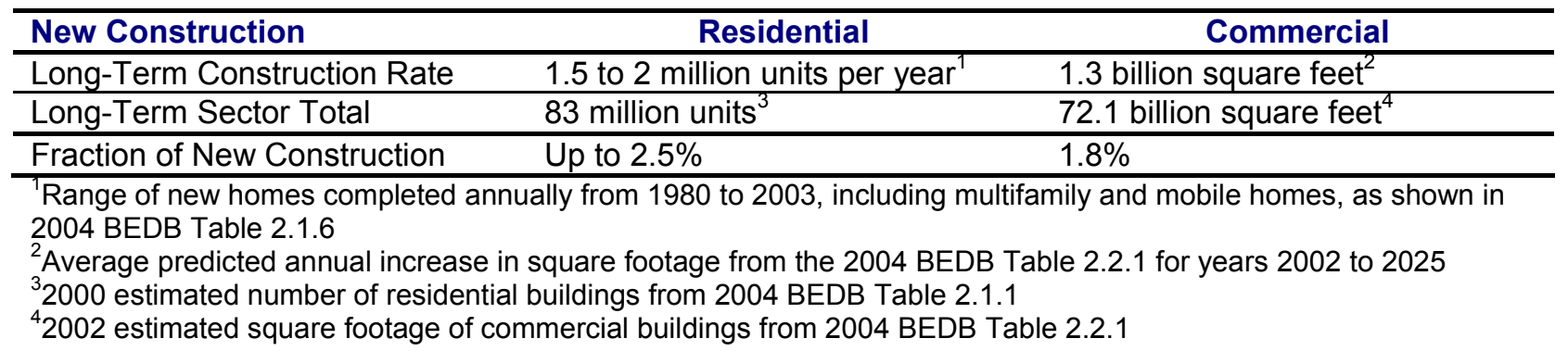

While Table G-32 indicates that the turnover rate for both the residential and commercial sectors is approximately equal (at about $2 \%$ per year), it should be noted that the commercial sector statistics are based on net increases in floor space, rather than actual new construction, and are therefore probably low because of commercial demolition. According to Tables 2.1.1 and 2.2.1 of the 2004 BEDB, $3 \%$ of the residential housing stock (units) and $9 \%$ of commercial building stock by floor space was "post-2000" in 2002. This statistic indicates that the turnover of commercial building stock is considerably faster than in the residential sector; which, in turn, indicates that building energy codes (and appliance standards) may be more significant agents of change in the commercial sector than in the residential sector.

\section{Assumed Budget Projections}

BT assumed level funding throughout the analysis period. The amount of the request is confidential until after the budget submission to Congress.

\section{Description of Key Activities (BTP 2005)}

There are a large number of tasks associated with the voluntary-commercial, voluntaryresidential, Federal-commercial, Federal-residential, and manufactured housing aspects of BT's Building Energy Codes subprogram.

More detail on these strategies can be found in BT's Multiyear Program Plan (BTP 2005).

Milestones (BTP 2005)

Milestones and schedules for BT's building energy codes efforts are driven largely by the schedules of the voluntary sector code processes in which BT participates. Both ASHRAE and the International Code Council (ICC) are now on three-year cycles, with ASHRAE scheduled to deliver new versions of Standard 90.1 at the end of 2004, 2007, and so on. ICC's current cycle is scheduled to deliver new versions in 2006, 2009, and so on, essentially two years off of the ASHRAE cycle. ICC also issues a mid-cycle supplementary version of their code for those states interested in somewhat more current requirements. While ASHRAE accepts change proposals at any time under their continuous maintenance policy, the majority of activity with regard to ASHRAE Standards is focused on their semiannual meetings. ICC code change proposals are only accepted at certain times. For the 2006 IECC, proposed changes were due at the end of August 2004, approximately 16-18 months before the code itself is actually published.

These voluntary sector code efforts also drive BT's determination of energy savings activities (due one year after release of a new version of the baseline code or standard) and Federal standards activities (typically revised after major enhancements in the corresponding voluntary 
sector standard). Looking out over the next six years, the significant dates in Figure G-15 can be noted. Significant milestones for Federal standards are not shown because of BT's lack of control over the actual release dates of these rulemakings.

The ASHRAE Standard 90.1 and ICC IECC Determination Milestones are the appropriate times for BT to determine whether the building energy codes program is meeting its joule metrics because these will be the times that actual savings on Standard 90.1 (commercial) and the IECC (residential) are prepared. In a sense, these are go/no go points in that BT can determine to abandon or redouble efforts in building energy codes at these points based on the determinations.

The overall outcome for both residential and commercial codes is essentially a $6 \%$ to $11 \%$ increase in stringency in codes by the year 2010, continuing on to a $19 \%$ to $35 \%$ increase in stringency in codes by the year 2025. As noted previously, increasing the stringency of the minimum mandatory requirements in building energy codes can only help make it easier for DOE to meet its ZEB goals.

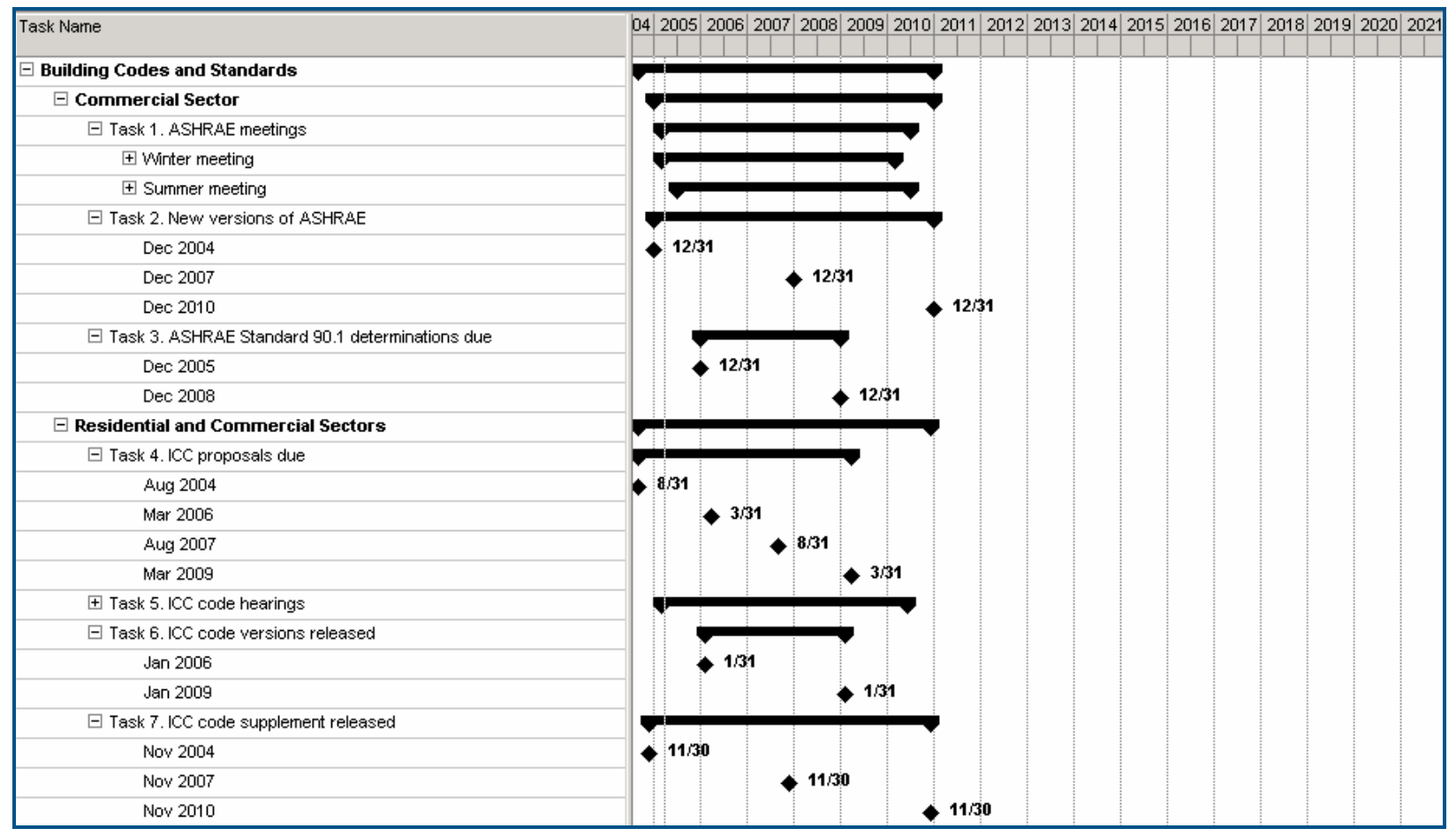

\begin{tabular}{|c|c|c|c|c|c|c|c|c|c|c|c|c|c|c|c|c|c|}
\hline Task Name & 042005 & 2006 & 2007 & 2008 & 2009 & 2010 & 2011 & 2012 & 2013 & 32014 & 42015 & 2016 & 2017 & 2018 & 2019 & 2020 & 2021 \\
\hline$\square$ Residential Sector & & & & & & & & & & & & & & & & & \\
\hline$\square$ Task 8. ICC IECC determinations due & & & & & & & & & & & & & & & & & \\
\hline $\operatorname{Jan} 2007$ & & & $1 / 3$ & & & & & & & & & & & & & & \\
\hline Jan 2010 & & & & & & $-1 / 31$ & & & & & & & & & & & \\
\hline$\square$ Federal Sector & $\nabla$ & & & & & & & & & & & & & & & & \\
\hline Task 9. FEDRES (TBD) & 1 & & & & & & & & & & & & & & & & \\
\hline Task 10. FEDCOM (TBD) & 1 & & & & & & & & & & & & & & & & \\
\hline$\square$ Above Code Milestones & & & & & & & & & & & & & & & & & \\
\hline Task 11. ASHRAE SP 102 publication & $1 / 31$ & & & & & & & & & & & & & & & & \\
\hline
\end{tabular}

Figure G-15: Building Energy Codes Gantt Chart (BTP 2005) 
Program Outputs (BTP 2005)

The strategic goals of the Building Energy Codes Subprogram are to:

(1) Drive the development of voluntary-sector building energy codes to achieve energy savings in new residential and commercial construction of approximately $3 \%$ to $6 \%$ every three years during the 2005 to 2025 period.

(2) Continually update the Federal-sector building energy codes to achieve energy savings in new Federal construction of approximately $30 \%$ beyond corresponding voluntary-sector building energy codes during the 2005 to 2025 period.

The milestones of the Building Energy Codes Subprogram are listed below for the residential, commercial, and Federal sectors. The use of milestones instead of targets is indicative of the fact that the Building Energy Codes subprogram participates in code and standard development processes that are owned and controlled by other organizations. The building energy codes listed here will be published on the dates mentioned with or without DOE participation. DOE's role is to support the development of these building energy codes and achieve the desired energy savings outcomes described below. The only targets associated with building energy codes are the Joule metrics associated with the subprogram. These are discussed following the list of milestones.

Residential Sector

- By 2008, have published in the Federal Register a determination that the 2006 International Energy Conservation Code will increase the energy efficiency of residential buildings, initiating a requirement that the states and territories certify by 2009 to the DOE that they have determined whether they should update their residential codes to meet or exceed the 2006 edition of the IECC.

- By 2008, have upgraded the technical assistance core tools and materials to assist states to upgrade their codes to the 2006 IECC.

- By 2010, have supported the upgrade of the 2009 International Energy Conservation Code to include improved envelope and mechanical requirements for residential buildings.

Commercial Sector

- By 2008, have supported the upgrading of Standard 90.1-2007, Energy Efficient Design of Buildings Except Low Rise Residential Buildings, to include:

- Additional lighting control requirements, including occupancy sensors;

- Improved building envelope requirements because of integrated design considerations;

- Cool roof requirements; and

- Improved mechanical system requirements related to demand control ventilation, energy recovery, and variable-speed drive pumps.

- By 2008, have upgraded the technical assistance core tools and materials to assist states to upgrade their codes to Standard 90.1-2006.

- By 2010, have supported the upgrading of the 2009 International Energy Conservation Code to include improved lighting, envelope, and mechanical requirements for commercial buildings.

- By 2011, have supported the upgrading of Standard 90.1-2010, Energy Efficient Design of Buildings Except Low Rise Residential Buildings, to include: 
- Continuous air barrier and other envelope infiltration requirement

- Advanced lighting controls (including daylighting)

- Improved mechanical system control and selection.

\section{Federal Sector}

- By 2008, issue an upgraded Federal commercial building energy code that will use at least $12 \%$ less energy than buildings built to 10 CFR 434 (1989).

- By 2010, propose an upgraded Federal commercial building energy code to meet or exceed Standard 90.1-2008.

BT's targets in building energy codes are to improve the stringency of various sector codes by specified amounts per year. For both the residential and commercial sectors, the BT Joule metric is "analyze and develop code change proposals that are expected to result in a cost-effective improvement in energy efficiency in residential/commercial buildings of approximately $1 \%$ to $2 \%$ per year." Because both the ICC and ASHRAE building energy codes are on three-year development cycles, the concept of an annual improvement in the codes is not really applicable. However, multiplying the annual goal by a factor of 3 to get a code development cycle goal is appropriate. Targets for various sectors are shown in Table G-33.

Table G-33: BT Improvement Goals for Building Energy Codes ${ }^{41}$ (BTP 2005)

\begin{tabular}{ll}
\hline \multicolumn{1}{c}{ Sector } & \multicolumn{1}{c}{ Goal } \\
\hline Voluntary Residential & $\begin{array}{l}3 \% \text { to } 6 \% \text { per code change cycle relative to } \\
\text { previous code }\end{array}$ \\
\hline Federal Residential & Equivalent to Energy Star \\
\hline Voluntary Commercial & $\begin{array}{l}3 \% \text { to } 6 \% \text { per code change cycle relative to } \\
\text { previous code }\end{array}$ \\
\hline Federal Commercial & $\begin{array}{l}\text { Voluntary sector code plus all cost-effective } \\
\text { measures (based on federal sector economics) } \\
\text { (targeted at } 30 \% \text { above voluntary sector) }\end{array}$ \\
\hline
\end{tabular}

BT's building energy codes efforts are not focused on high-performance buildings (as many other BT activities are) but rather on a slow, but inevitable improvement in the baseline practice of new construction by establishing ever-increasing minimum performance standards. A rate of $1 \%$ to $2 \%$ per year, compounded over time, can provide significant energy savings in new construction and can significantly transform marketplace dynamics to lower resistance of new and innovative products and construction practices. Table G-34 shows the resulting levels of efficiency that will be achieved in codes if the building energy codes goals are achieved.

${ }^{41}$ Expressed in code-change cycles rather than annual metrics. 
Table G-34: Potential Increase in Code Stringency as a result of BT at $1 \%$ to $2 \%$ Improvement per Year $^{42}$ (BTP 2005)

\begin{tabular}{ccc}
\hline Year & 1\% Per Year Improvement & 2\% Per Year Improvement \\
\hline 2004 (Baseline) & 1.00 & 1.00 \\
\hline 2005 & 0.99 & 0.98 \\
\hline 2006 & 0.98 & 0.96 \\
\hline 2007 & 0.97 & 0.94 \\
\hline 2008 & 0.96 & 0.92 \\
\hline 2009 & 0.95 & 0.90 \\
\hline 2010 & 0.94 & 0.89 \\
\hline$\ldots$ & $\ldots$ & $\ldots$ \\
\hline 2025 & 0.81 & 0.65 \\
\hline
\end{tabular}

Table G-34 indicates the power of codes to influence building energy use over a long period of time. BT's building energy codes efforts should result in stringency increases of $6 \%$ to $11 \%$ in new construction by the year 2010, with the potential to achieve $19 \%$ to $35 \%$ savings if these efforts are carried out until 2025. An increasing majority of the 2 million new homes and millions of new commercial square footage per year eventually falls under new more stringent energy codes and the savings add up.

However, the ability of codes to influence building energy use depends on the ability of codes to continuously improve. In the codes world, code improvement is typically tied to costeffectiveness. Improvement in codes tends to occur in one of three ways:

1. The costs of new technologies are reduced sufficiently that they can be considered for inclusion as mandates in codes;

2. Code developers become more clever in how they determine cost-effectiveness; or

3. Economic parameters change enough to make existing technologies appear more attractive.

The Building Energy Codes Subprogram seeks to identify new cost-effective technologies or new ways to determine cost-effectiveness in their efforts to improve codes. For example, work is going on now to determine if a cost credit for downsizing HVAC equipment as a result of improved building envelopes could be used to help cost-justify those improved envelopes. This is a simple application of integrated design principles commonly used in individual building designs, but applying that same principle to the generic building designs considered in building energy codes is challenging.

Historical evaluations of commercial building energy codes improvement indicate that this goal of $1 \%-2 \%$ per year is achievable, although the improvements do tend to come in larger chunks. For example, energy savings in ASHRAE Standard 90.1 from 1989 to 1999 were estimated at about 4\% site and 6\% source (U.S. DOE 2004b). ${ }^{43}$ Savings in Standard 90.1 from 1999 to 2001

\footnotetext{
${ }^{42}$ Expressed as energy consumption relative to a 2004 baseline.

${ }^{43}$ Site energy includes only the energy delivered to the building site. Source energy includes generation and transmission losses for electricity.
} 
were negligible, but savings from 2001 to 2004 are estimated to be at least $4 \%$ site and $6 \%$ source.

Because BT's building energy codes targets are expressed as annual (or code cycle) increases in code stringency, these are targets that can be measured and tracked by simply evaluating the applicable code or standard using the same energy saving analysis used in the preparation of DOE's formal determinations of energy savings. This will require perhaps more frequent analysis of the energy savings of building energy codes than has occurred previously, and it will certainly require that analysis efforts in the voluntary commercial sector expand to include both ASHRAE Standard 90.1 and the ICC IECC, but the process of comparing old and new versions of a code or standard is usually straightforward. ${ }^{44}$

\section{Translating Program Outputs to Market Outcomes (BTP 2005)}

The primary risks and barriers in both DOE's larger codes efforts and in BT's specific building energy codes efforts tend to be more political or economic than technical. The basic premise in the development of all building energy codes is that whatever is required by the code or standard should be so obviously beneficial to the building or building owner or building occupants that there is little opposition to the requirement (except, possibly, for entrenched special interests). This is the basis for the consensus processes that various code-writing organizations tend to follow. Thus, the Building Energy Codes Subprogram faces none of the technical risk associated with the development of new building technologies or new construction techniques. If those new technologies or techniques are developed and shown to be cost-effective, then they may eventually be incorporated into building energy codes. But, as a general rule, building energy codes are developed to be technology neutral by the code development organizations such as ASHRAE and ICC. Neither of these organizations is interested in "pushing" specific technologies for fear of stifling innovation and to avoid being accused of favoritism or market manipulation by competitors in the marketplace. Because BT is only one of many players in the processes controlled by ASHRAE and ICC, BT is essentially constrained to remain technologyneutral as well.

The single largest barrier faced by the Building Energy Codes Subprogram is opposition to regulation and especially opposition to increased stringency of regulation on a particular component, system, or building.

This opposition is commonly expressed in terms of economics, but opposition also takes the form of detailed questioning of assumptions, baseline conditions, methodologies, etc. The bottom line is that it makes sense to many participants in the buildings community to oppose at least some aspects of building energy codes and so opposition is spirited. The role of the subprogram in all this is to provide thorough, balanced, and well-documented analysis that will lead to the incorporation of cost-effective improvements to building energy codes. This is where the bulk of the effort in this subprogram takes place.

\footnotetext{
${ }^{44}$ The exceptions are new codes that have significant changes in format and/or scope or that contain a mixture of efficiency improvements and degradations. 
Key Factors in Shaping Market Adoption of EERE technologies

- Price: BT assumed a five-year payback period on investment to develop incremental investment costs, based on previous benefit-cost studies of energy codes ${ }^{45}$ (i.e., an annual energy cost savings of \$1 implies an initial investment of \$5).

- Non-price factors

o Policy factors: The Building Energy Codes SubProgram is an information resource on national model energy codes. The subprogram works with other government agencies, state and local jurisdictions, national code organizations, and industry to promote stronger building energy codes and help states adopt, implement, and enforce those codes.

Final Outcomes (Benefits)

Residential Building Energy Codes.

The Residential Building Energy Codes project improves the minimum or baseline energy efficiency of new Federal and model residential building codes. The project promulgates upgraded standards for Federal residential buildings. The project works with ICC to upgrade the energy-efficiency requirements of its model energy codes. State, and local jurisdictions then adopt and implement these upgraded model energy codes. The long-term goal is to improve the minimum energy efficiency by $1 \%$ to $2 \%$ per year for new low-rise residential building construction over the period of 2005 through 2025 (BTP 2005).

The IECC's ongoing activities are expected to lead to more stringent residential standards in the future. The Department of Energy is assumed to play a major role in developing the analytical and economic basis for such standards. For the GPRA process, these activities are subsumed into a single upgrade of the IECC standard projected to become available in the latter part of the current decade (2009). Based on the BT goals for building codes shown in Table G-33, a 10\% improvement in stringency is taken to approximate the improvement that could be achieved over next several three-year code cycles. As discussed in the text, for example, the overall percentage reduction in the past two major changes in the commercial energy code (ASHRAE Standard 90.1-1989 to ASHRAE Standard 90.-2004) was about 8\% in site energy terms and $12 \%$ in source energy terms. Improvements beyond this level were not considered, as they may depend on major changes in construction practice, material costs, or energy prices to show economic justification. The spreadsheet model used to develop national energy savings from improved codes does not consider the building-specific economics of proposed new codes, but rather tries to reflect the accelerated adoption and increased compliance that can be attributed to the DOE building codes activities. As such, the $10 \%$ improvement can be viewed as a near-term programmatic goal, rather than an output from a building economic optimization model. Without these DOE-funded activities, an equivalent national (IECC) standard would not be developed within the time frame of the analysis.

The codes training and assistance activities funded by the BT impact both adoption and compliance with national model codes (e.g., IECC 2006 Standard 90.1). The availability of compliance software and other training assistance is assumed to accelerate the adoption of standards by states and local jurisdictions. Based on the historical experience of the 1990s, states

\footnotetext{
${ }^{45}$ See case studies presented on Building Energy Codes Web site for more information: http://www.energycodes.gov/implement/tech_assist_reports.stm.

Projected Benefits of Federal Energy Efficiency and Renewable Energy Programs (FY 2008-FY 2050) Appendix G-Building Technologies Program - Page G-77
} 
are assumed to adopt standards from three to 10 years earlier than they would without the existence of the DOE training and assistance activities. These activities are also assumed to have a large impact on the compliance with changes in the code, measured by the percentage of potential savings obtainable from one edition of the code to the next.

Table G-35 contains the energy savings estimates for the residential codes activities.

Table G-35: Energy Savings Estimates for Residential Codes

\begin{tabular}{lrrrrrr}
\hline Year & \multicolumn{3}{c}{ New Code } & \multicolumn{4}{c}{ Technical Assistance } \\
\cline { 2 - 9 } & $\begin{array}{l}\text { Electricity } \\
\text { (TBtu) }\end{array}$ & $\begin{array}{c}\text { Gas } \\
\text { (TBtu) }\end{array}$ & $\begin{array}{c}\text { Oil } \\
\text { (TBtu) }\end{array}$ & $\begin{array}{l}\text { Electricity } \\
\text { (TBtu) }\end{array}$ & $\begin{array}{c}\text { Gas } \\
\text { (TBtu) }\end{array}$ & $\begin{array}{l}\text { Oil } \\
\text { (TBtu) }\end{array}$ \\
\hline 2008 & 0.2 & 0.2 & 0.0 & 0.9 & 1.3 & 0.2 \\
\hline 2009 & 0.3 & 0.6 & 0.1 & 2.7 & 3.9 & 0.7 \\
\hline 2010 & 0.6 & 1.1 & 0.2 & 4.2 & 6.0 & 1.1 \\
\hline 2011 & 1.1 & 1.9 & 0.3 & 6.1 & 9.0 & 1.7 \\
\hline 2012 & 1.6 & 3.0 & 0.5 & 8.2 & 12.3 & 2.3 \\
\hline 2013 & 2.3 & 4.4 & 0.8 & 10.2 & 16.2 & 3.0 \\
\hline 2014 & 3.0 & 6.1 & 1.2 & 12.2 & 20.1 & 3.6 \\
\hline 2015 & 3.9 & 8.0 & 1.6 & 14.2 & 24.0 & 4.3 \\
\hline 2016 & 4.9 & 10.3 & 2.0 & 16.0 & 27.7 & 4.8 \\
\hline 2017 & 6.0 & 12.8 & 2.6 & 17.9 & 31.2 & 5.4 \\
\hline 2018 & 7.2 & 15.4 & 3.1 & 19.6 & 34.7 & 5.9 \\
\hline 2019 & 8.5 & 18.1 & 3.6 & 21.2 & 38.0 & 6.5 \\
\hline 2020 & 9.8 & 21.0 & 4.1 & 22.8 & 41.2 & 7.0 \\
\hline 2021 & 11.2 & 23.8 & 4.7 & 24.4 & 44.4 & 7.5 \\
\hline 2022 & 12.6 & 26.7 & 5.2 & 26.0 & 47.6 & 8.0 \\
\hline 2023 & 14.0 & 29.7 & 5.8 & 27.6 & 50.7 & 8.5 \\
\hline 2024 & 15.4 & 32.7 & 6.3 & 29.2 & 53.9 & 9.0 \\
\hline 2025 & 16.8 & 35.7 & 6.9 & 30.8 & 57.1 & 9.5 \\
\hline 2026 & 18.3 & 38.7 & 7.4 & 32.3 & 60.2 & 10.0 \\
\hline 2027 & 19.7 & 41.7 & 7.9 & 33.9 & 63.4 & 10.4 \\
\hline 2028 & 21.2 & 44.7 & 8.5 & 35.5 & 66.6 & 10.9 \\
\hline 2029 & 22.7 & 47.8 & 9.0 & 37.1 & 69.7 & 11.4 \\
\hline 2030 & 24.2 & 50.8 & 9.5 & 38.6 & 72.9 & 11.9 \\
\hline & & & & & &
\end{tabular}

These inputs were incorporated into the NEMS-GPRA08 and MARKAL-GPRA08 models as described in their corresponding chapters of this document.

\section{Commercial Building Energy Codes.}

The Commercial Building Energy Codes project improves the minimum energy efficiency of new commercial and multifamily high-rise buildings and additions and alterations to existing buildings requiring code permits. The project promulgates upgraded energy-efficiency requirements for Federal commercial and high-rise residential building types. Similarly, the project works with model energy code groups to upgrade the energy-efficiency requirements of their codes. These upgraded national energy standards are then adopted by Federal, state, and local jurisdictions as part of their building codes. The project's long-term goal is to improve 
minimum energy efficiency in new commercial building construction by $1 \%$ to $2 \%$ per year over the period 2005 through 2025. Energy use will be reduced by states and local jurisdictions widely adopting the national standards as building energy codes.

BT fundamentally assumes that the ongoing activities of the ASHRAE 90.1 committee will lead, if past is any guide to prologue, to more stringent commercial-building standards in the future. DOE is assumed to play a major role in developing the analytical and economic basis for such standards. For the GPRA process, these activities are subsumed in a single upgrade of the ASHRAE standard (currently, ASHRAE Standard 90.1-2004), estimated to become available in the latter part of the current decade. The GPRA analysis assumes that the overall result of these upgrades is to reduce electricity consumption by $10 \%$ and natural gas consumption by $10 \%$ in covered end uses (heating, cooling, and lighting) in new commercial buildings. For the scenario involving a new commercial code (circa 2009), we assume that states will adopt that code over a period extending from 2011 to 2022, with a mean adoption year of 2015. This assumption presumes no separate training and assistance activities funded by DOE.

The codes training and assistance activities impact both adoption and compliance with national model codes (e.g., ASHRAE Standard 90.1). The availability of compliance software and other training assistance is assumed to accelerate the adoption of standards by states and local jurisdictions. Based on the historical experience of the 1990s, states are assumed to adopt standards from three to 10 years earlier than they would without the existence of the DOE training and assistance activities. These activities are also assumed to have a large impact on the compliance with changes in the code, measured by the percentage of potential savings obtainable from one edition of the code to the next. Table G-36 contains the energy savings estimates for the commercial codes activities.

Table G-36: Energy Savings Estimates for Commercial Codes

\begin{tabular}{lrrrrrr}
\hline Year & \multicolumn{3}{c}{ New Code } & \multicolumn{3}{c}{ Technical Assistance } \\
\cline { 2 - 8 } & $\begin{array}{l}\text { Electricity } \\
\text { (TBtu) }\end{array}$ & $\begin{array}{l}\text { Gas } \\
\text { (TBtu) }\end{array}$ & $\begin{array}{c}\text { Oil } \\
\text { (TBtu) }\end{array}$ & $\begin{array}{l}\text { Electricity } \\
\text { (TBtu) }\end{array}$ & $\begin{array}{c}\text { Gas } \\
\text { (TBtu) }\end{array}$ & $\begin{array}{l}\text { Oil } \\
\text { (TBtu) }\end{array}$ \\
\hline 2008 & 0.0 & 0.0 & 0.0 & 1.1 & -0.5 & 0.0 \\
\hline 2009 & 0.0 & 0.0 & 0.0 & 3.6 & -1.6 & 0.0 \\
\hline 2010 & 0.2 & 0.0 & 0.0 & 7.8 & -3.3 & 0.0 \\
\hline 2011 & 0.4 & 0.1 & 0.0 & 12.8 & -5.1 & 0.0 \\
\hline 2012 & 0.8 & 0.2 & 0.0 & 18.4 & -7.1 & 0.0 \\
\hline 2013 & 1.5 & 0.4 & 0.0 & 25.0 & -9.1 & 0.0 \\
\hline 2014 & 2.1 & 0.6 & 0.0 & 31.7 & -11.2 & 0.0 \\
\hline 2015 & 3.0 & 0.9 & 0.0 & 38.8 & -13.4 & 0.0 \\
\hline 2016 & 3.9 & 1.3 & 0.0 & 46.2 & -15.6 & 0.0 \\
\hline 2017 & 4.8 & 1.7 & 0.0 & 53.8 & -17.8 & 0.0 \\
\hline 2018 & 5.8 & 2.2 & 0.0 & 61.4 & -20.0 & 0.0 \\
\hline 2019 & 6.9 & 2.7 & 0.0 & 68.9 & -22.1 & 0.0 \\
\hline 2020 & 8.1 & 3.2 & 0.0 & 76.2 & -24.1 & 0.0 \\
\hline 2021 & 9.3 & 3.8 & 0.0 & 83.1 & -26.1 & 0.0 \\
\hline
\end{tabular}

\footnotetext{
${ }^{46}$ Gas savings will often be negative to reflect the additional heating needed when converting buildings over to more efficient lighting systems.
} 


\begin{tabular}{lrrrrrr}
\hline Year & \multicolumn{3}{c}{ New Code } & \multicolumn{3}{c}{ Technical Assistance } \\
\cline { 2 - 8 } & $\begin{array}{l}\text { Electricity } \\
\text { (TBtu) }\end{array}$ & $\begin{array}{l}\text { Gas } \\
\text { (TBtu) }\end{array}$ & $\begin{array}{c}\text { Oil } \\
\text { (TBtu) }\end{array}$ & $\begin{array}{l}\text { Electricity } \\
\text { (TBtu) }\end{array}$ & $\begin{array}{l}\text { Gas } \\
\text { (TBtu) })^{46}\end{array}$ & $\begin{array}{l}\text { Oil } \\
\text { (TBtu) }\end{array}$ \\
\hline 2022 & 10.7 & 4.4 & 0.0 & 89.9 & -27.9 & 0.0 \\
\hline 2023 & 12.2 & 5.1 & 0.0 & 96.6 & -29.7 & 0.0 \\
\hline 2024 & 13.8 & 5.8 & 0.0 & 103.2 & -31.5 & 0.0 \\
\hline 2025 & 15.3 & 6.5 & 0.0 & 109.7 & -33.2 & 0.0 \\
\hline 2026 & 17.0 & 7.3 & 0.0 & 116.1 & -34.9 & 0.0 \\
\hline 2027 & 18.6 & 8.1 & 0.0 & 122.4 & -36.6 & 0.0 \\
\hline 2028 & 20.2 & 8.9 & 0.0 & 128.6 & -38.3 & 0.0 \\
\hline 2029 & 21.8 & 9.8 & 0.0 & 134.8 & -39.9 & 0.0 \\
\hline 2030 & 23.4 & 10.7 & 0.0 & 140.9 & -41.5 & 0.0 \\
\hline
\end{tabular}

These inputs were incorporated into the NEMS-GPRA08 and MARKAL-GPRA08 models as described in their corresponding chapters of this document.

\section{Technology Validation and Market Introduction - Rebuild America}

\section{Target Market Description.}

Commercial buildings currently consume $47.5 \%$ of the total energy used by buildings, accounting for 19.7 quads in 2005. The commercial market is the second largest user of energy for buildings, but its energy use is increasing more rapidly than residential buildings (BEDB 2005). By 2025, the commercial market will use as much as energy as the residential market.

\section{Program Outputs}

Rebuild America aids in the deployment of commercial R\&D.

\section{Assumed Budget Projections}

BT assumed level funding throughout the analysis period. The amount of the request is confidential until after the budget submission to Congress.

\section{Description of Key Activities (U.S. DOE 2006a)}

The Rebuild America program element is aligned with the BT's research and development activities to accelerate the adoption of advances in building integrated design, software tools, practices and advanced controls, equipment and lighting. The program element will continually expand and update its technical assistance and delivery mechanisms and partners to effectively transfer the technological advances in R\&D

\section{Program Outputs}

Today's public and commercial buildings can use substantially less energy, while providing more comfortable and productive environments. The idea behind Rebuild America's technical assistance services is to provide effective tools and information to decision makers that are vital to stimulating action. In partnership with State Energy Offices, Rebuild America provides targeted tools and analysis that can facilitate major energy efficiency or renewable energy improvements in public and multifamily housing, K-12 schools, colleges and universities, local and state governments, and commercial buildings. 


\section{Translating Program Outputs to Market Outcomes}

Rebuild America is working with states and communities to connect people, resources, ideas, and practices for energy solutions to community needs. Using an integrated systems approach to schools, housing, public and commercial buildings, factories, and electricity transmission systems, Rebuild America helps to:

- Increase the number of high-performance buildings

- Implement energy efficiency and renewable energy improvements

- Provide technical assistance tools, resources, and services

\section{Key Factors in Shaping Market Adoption of EERE technologies}

- Price: On average, the incremental cost to achieve specified energy savings is $2 \%$ above base for new buildings, increasing to $6 \%$ above base in $2020 ; \$ 4 /$ s.f. for existing commercial buildings.

Interim Outcomes

Rebuild America is currently in transition from being an independent deployment subprogram under the Weatherization and Intergovernmental Program to supporting Commercial R\&D in the Building Technology program. This deployment program is most appropriately modeled as an acceleration of market adoption of components, tools, and design strategies developed as part of Commercial R\&D and Analysis Tools and Design Strategies. To model Rebuild America, BT projects that the additional deployment provided by Rebuild America efforts will accelerate the adoption of highly efficient tools and design strategies by an additional two years. Penetration curves were developed based on market diffusion curves developed by PNNL (Elliott et al. 2004). Table G-37 contains the estimates of acceleration effect, in terms of market penetration percentages of this deployment subprogram.

Table G-37: Market Penetration for Rebuild America

\begin{tabular}{lrr}
\hline Year & \multicolumn{2}{c}{ Net Penetration (Two-year acceleration) } \\
\cline { 2 - 3 } & New Buildings (\%) & Existing Buildings (\%) \\
\hline 2008 & 5.5 & 0.0 \\
\hline 2009 & 9.1 & 0.0 \\
\hline 2010 & 7.7 & 0.9 \\
\hline 2011 & 8.6 & 2.0 \\
\hline 2012 & 9.3 & 2.4 \\
\hline 2013 & 9.6 & 2.8 \\
\hline 2014 & 9.4 & 3.2 \\
\hline 2015 & 8.9 & 3.4 \\
\hline 2016 & 8.1 & 3.5 \\
\hline 2017 & 7.1 & 3.5 \\
\hline 2018 & 6.0 & 3.3 \\
\hline 2019 & 5.0 & 3.0 \\
\hline 2020 & 4.0 & 2.6 \\
\hline 2021 & 3.1 & 2.2 \\
\hline
\end{tabular}




\begin{tabular}{lll}
\hline 2022 & 2.4 & 1.8 \\
\hline 2023 & 1.9 & 1.5 \\
\hline 2024 & 1.4 & 1.2 \\
\hline 2025 & 1.1 & 0.9 \\
\hline 2026 & 0.8 & 0.7 \\
\hline 2027 & 0.6 & 0.5 \\
\hline 2028 & 0.5 & 0.4 \\
\hline 2029 & 0.3 & 0.3 \\
\hline 2030 & 0.3 & 0.2 \\
\hline
\end{tabular}

\section{Technology Validation and Market Introduction - Energy Star}

\section{Target Market Description (BTP 2005)}

DOE's Energy Star activities include developing technical requirements and qualifications by

- defining Energy Star criteria for its designated products;

- monitoring standards for future Energy Star product categories;

- raising the bar on Energy Star labels when market penetration goals are reached and technology advances allow, especially following the establishment of higher minimum standards;

- promoting the manufacturing and purchasing of Energy Star products; and

- cosponsoring appropriate awards.

Table G-38 shows the market share of Energy Star-labeled products between 1999 and 2003, demonstrating the increase in the efficiency of purchased appliances during the history of the subprogram.

Table G-38: Market Penetration of Energy Star-Qualified Products (BTP 2005)

\begin{tabular}{lccccc}
\hline Product & $\mathbf{1 9 9 9}$ & $\mathbf{2 0 0 0}$ & $\mathbf{2 0 0 1}$ & $\mathbf{2 0 0 2}$ & $\mathbf{2 0 0 3}$ \\
\hline $\begin{array}{l}\text { Energy Star Qualified Clothes } \\
\text { Washers }\end{array}$ & $9 \%$ & $9 \%$ & $10 \%$ & $16 \%$ & $23 \%$ \\
\hline Energy Star Qualified Dishwashers & $12 \%$ & $11 \%$ & $20 \%$ & $36 \%$ & $57 \%$ \\
\hline Energy Star Qualified Refrigerators & $24 \%$ & $27 \%$ & $17 \%$ & $20 \%$ & $26 \%$ \\
\hline Energy Star Qualified Room AC & $13 \%$ & $18 \%$ & $12 \%$ & $36 \%$ & $29 \%$ \\
\hline
\end{tabular}

\section{Program Outputs}

Energy Star uses government/industry partnerships to promote adoption of energy efficient building products and appliances through voluntary labeling. By improving energy efficiency in buildings, Energy Star serves several important policy objectives, including two main objectives: saving energy and saving money.

\section{Assumed Budget Projections}

BT assumed level funding throughout the analysis period. The amount of the request is confidential until after the budget submission to Congress. 
Description of Key Activities (BTP 2005)

A key part of the Energy Star process is revising the product criteria levels as the market share of qualified products increase, or as Federal standards establish a new baseline by which products are measured. The frequency of the criteria revisions are a function of the product in question, how quickly manufacturers can change their production processes, the incremental savings and costs for each product, and the level of support for the products in the efficiency program sponsor community. This process of criteria setting, distribution network building, and consumer education will continue to constitute the bulk of DOE's effort on the Energy Star program between now and 2010. However, the increases in Federal efficiency standards and the fact that some technologies are beginning to reach the limits of their technical potential poses several programmatic challenges for Energy Star over the next five years:

- The energy and financial savings from some compliant products are becoming increasingly irrelevant to consumers. For example, Energy Star-qualified refrigerators save the average consumer less than $\$ 10$ per year.

- Retailers' and other distributors' profit margins from product sales are decreasing, and many are emphasizing service delivery as a focus over the next several years.

- National and state energy policymakers and electric and gas utilities are increasingly focused on growth in peak demand. Many of the current Energy Star-qualified products provide minimal peak savings.

- There also exists an energy savings potential in existing homes, coming from system, rather than product, optimization. For example, most of the efficiency gains from central air-conditioning products come from proper installation and improvement of air handling systems, not from increasing equipment efficiency levels.

DOE will address these challenges adopting the following four strategies:

- Increasing the stringency of the criteria for compliance with Energy Star levels for existing products, where remaining cost-effective potential exists.

- Increasing the market share of Energy Star-labeled products through increased collaboration with new partners, such as state energy offices.

- Accelerating the introduction of the next generation of efficient products developed through other BT and EERE programs.

- Partner with other Federal agencies in developing an Energy Star-based, whole-house approach to efficiency, providing consumers a "pathway" to achieving a more affordable and comfortable home through proper equipment selection and systems improvements.

More detail on each of these strategies can be found in BT's Multiyear Program Plan (BTP 2005).

Milestones (BTP 2005)

For each project/task activity identified, a Gantt chart has been prepared to show the critical milestones, off-ramps, and transfer points. 


\begin{tabular}{|c|c|c|c|c|c|c|c|c|c|c|c|c|c|c|c|c|c|c|}
\hline Task Name & 2004 & 2005 & 2006 & 2007 & 2008 & 2009 & 2010 & 2011 & 2012 & 2013 & 2014 & 2015 & 2016 & 2017 & 2018 & 2019 & 2020 & 2021 \\
\hline \multicolumn{19}{|l|}{$\square$ Energy Star } \\
\hline \multicolumn{19}{|l|}{$\square$ Enhancing Existing Product } \\
\hline \multicolumn{19}{|l|}{ † Task 1. Criteria Changes/Technical lssues } \\
\hline \multicolumn{19}{|l|}{$\square$ Task 2. Consumer Education } \\
\hline \multicolumn{19}{|l|}{ Implement display unit labeling guidelines (labeling) } \\
\hline \multicolumn{19}{|l|}{ Task 3. Expanding Product Distribution Channels } \\
\hline \multicolumn{19}{|l|}{$\square$ Task 4. Data Gathering/Tracking } \\
\hline \multicolumn{19}{|l|}{ Refine CFL shipment data and provide detailed trend reports to [} \\
\hline \multicolumn{19}{|l|}{$\square$ Increasing the Impact of Energy Star } \\
\hline \multicolumn{19}{|l|}{ Task 5 . Improve marketing/outreach } \\
\hline \multicolumn{19}{|l|}{ Task 6 . Build stronger network via the state and regional offices } \\
\hline \multicolumn{19}{|l|}{ Task 7. Improve communication and program integration within EERE } \\
\hline \multicolumn{19}{|l|}{ Task 8 . Strengthen partnerships among DOE, EPA, and HUD } \\
\hline \multicolumn{19}{|l|}{$\square$ Accelerating the Introduction of Advanced Products } \\
\hline \multicolumn{19}{|l|}{$\boxplus$ Task 9. Stakeholder meetings } \\
\hline \multicolumn{19}{|l|}{ Task 10. Coordinated Pilots } \\
\hline \multicolumn{19}{|l|}{ † Task 11. Policy Institutionalization } \\
\hline \multicolumn{19}{|l|}{$\square$ Whole Home Improvement } \\
\hline \multicolumn{19}{|l|}{ Task 12. Technical } \\
\hline \multicolumn{19}{|l|}{$\square$ Task 13. Consumer Outreach } \\
\hline \multicolumn{19}{|l|}{ Finalize Energy Star messaging for HVAC systems } \\
\hline \multicolumn{19}{|l|}{ 曰 Task 14. Market Infrastructure } \\
\hline Post whole-house integration materialsicontentfools on the wek & & \& $2 / 2$ & & & & & & & & & & & & & & & & \\
\hline
\end{tabular}

Figure G-16: Energy Star Gantt Chart (BTP 2005)

Program Outputs (BTP 2005)

The overall objective of the Energy Star Subprogram is to accelerate the commercialization and increase the market share of energy-efficient products and services in residential and commercial marketplaces to help American consumers realize more than 1.2 quads and $\$ 23$ billion in energy savings by 2010 (D\&R International 2005). Full commercialization of these technologies will be essential to helping BT realize its goal of achieving cost-effective, net-zero energy buildings by 2025.

The key specific performance goals are included in Table G-39.

Table G-39: Energy Star Performance Goals (BTP 2005)

\begin{tabular}{|c|c|c|c|}
\hline \multirow[t]{2}{*}{ Strategy } & \multicolumn{3}{|c|}{ Targets } \\
\hline & 2007 & 2009 & 2010 \\
\hline $\begin{array}{l}\text { Enhancing Existing } \\
\text { Product }\end{array}$ & $\begin{array}{l}\text { - New Criteria: } \\
\text { Clothes Washer } \\
\text { and Dishwasher }\end{array}$ & & $\begin{array}{l}\text { - New Criteria: Room Air } \\
\text { Conditioner and } \\
\text { Refrigerators }\end{array}$ \\
\hline $\begin{array}{l}\text { Accelerating the } \\
\text { Introduction of } \\
\text { Advanced Products }\end{array}$ & & $\begin{array}{l}\text { - Introduction of SSL } \\
\text { into Energy Star }\end{array}$ & $\begin{array}{l}\text { - Introduction of advanced } \\
\text { products (Heat Pump } \\
\text { Water Heaters, PV } \\
\text { Dynamic Window } \\
\text { systems) into Energy Star }\end{array}$ \\
\hline
\end{tabular}

Translating Program Outputs to Market Outcomes (BTP 2005)

The biggest risk to the realization of Energy Star's goals is losing the ability to leverage the energies and resources of the network. As the past decade has demonstrated, huge market shifts have occurred when this network has coordinated their efforts on promoting specific technologies. However, as the needs of each of the partners change, so will the Energy Star 
approach and types of technologies promoted. For example, many utilities and local energy planners are concentrating on controlling the growth of peak electric and gas demand, which most of the existing Energy Star-labeled technologies do not address in any significant fashion. In addition, the retailers are increasingly focused on using services, not products, as their main profit drivers for the next few years. To ensure Energy Star continues to occupy its place in the market, the subprogram will have to evolve and ensure it addresses these critical market needs.

Interim Outcomes

\section{Energy Star: CFLs}

The program goal is to increase sales of CFLs over what would have occurred without Energy Star. (Note this is different from any other Energy Star technology where the goal is to improve efficacy/efficiency of the products in the market and where the focus is, thus, on the top $20 \%$ to $30 \%$ of the market. For CFLs, more than $90 \%$ are Energy Star rated.) The program sets the requirements for labeling and promotes the use of Energy Star-rated products. Through these actions, the market penetration of high-efficacy CFLs is increased.

Table G-40: Energy Star: CFL Market Penetration for all CFLs (80\%-90\% of CFLs are Energy Star)

\begin{tabular}{lc}
\hline Year & Market Penetration \\
\hline 1999 & $0.5 \%$ \\
\hline 2000 & $0.5 \%$ \\
\hline 2001 & $1.7 \%$ \\
\hline 2002 & $1.9 \%$ \\
\hline 2003 & $2.0 \%$ \\
\hline 2004 & $2.0 \%$ \\
\hline 2005 & $2.3 \%$ \\
\hline 2006 & $5.0 \%$ \\
\hline 2007 & $5.5 \%$ \\
\hline 2008 & $6.0 \%$ \\
\hline 2009 & $6.5 \%$ \\
\hline 2010 & $7.0 \%$ \\
\hline 2011 & $7.5 \%$ \\
\hline 2012 & $8.0 \%$ \\
\hline
\end{tabular}

Energy Star Windows/Building Envelope R\&D: Windows - Low-E Market Acceptance The purpose of this activity is to increase the market penetration of Low-E windows. Several sub-activities are in place to help accomplish the goal.

- Developing the tools [WINDOW6, THERM, COMFEN and other software to serve industry needs (BTP 2005)] and resources needed to accurately predict component, product, and systems thermal, optical, and energy performance under a full range of operating conditions.

- Training and education for utilities, manufacturers, and Building America.

- Establishing requirements for Energy Star labeling

The current focus has been on residential and will being shifting to commercial as the residential market becomes dominated by Low-E windows. Efforts in FY08 will focus on tools and 
technical assistance programs that are applicable to both residential and commercial fenestration. Energy Star performance goals are expected to be established for dynamic windows by 2010 .

The Energy Star: Windows simulation runs were conducted in FEDS using the following technology assumptions:

Northern: U-Factor $=0.35 \mathrm{Btu} / \mathrm{hr} \cdot \mathrm{ft}^{2} \cdot{ }^{\circ} \mathrm{F} ; \mathrm{SHGC}=0.6$

North Central: U-Factor $=0.40 \mathrm{Btu} / \mathrm{hr} \cdot \mathrm{ft}^{2} \cdot{ }^{\circ} \mathrm{F} ; \mathrm{SHGC}=0.55$

South Central: U-Factor $=0.40 \mathrm{Btu} / \mathrm{hr}^{\circ} \cdot \mathrm{ft}^{2} \cdot{ }^{\circ} \mathrm{F} ; \mathrm{SHGC}=0.40$

Southern: U-Factor $=0.65 \mathrm{Btu} / \mathrm{hr} \cdot \mathrm{ft}^{2} \cdot{ }^{\circ} \mathrm{F} ; \mathrm{SHGC}=0.40$

Table G-41 contains the resulting energy savings and load reductions based on these simulations. These savings are evenly split with the Low-E Market Acceptance Program.

Table G-41: Energy Star Windows Performance Inputs

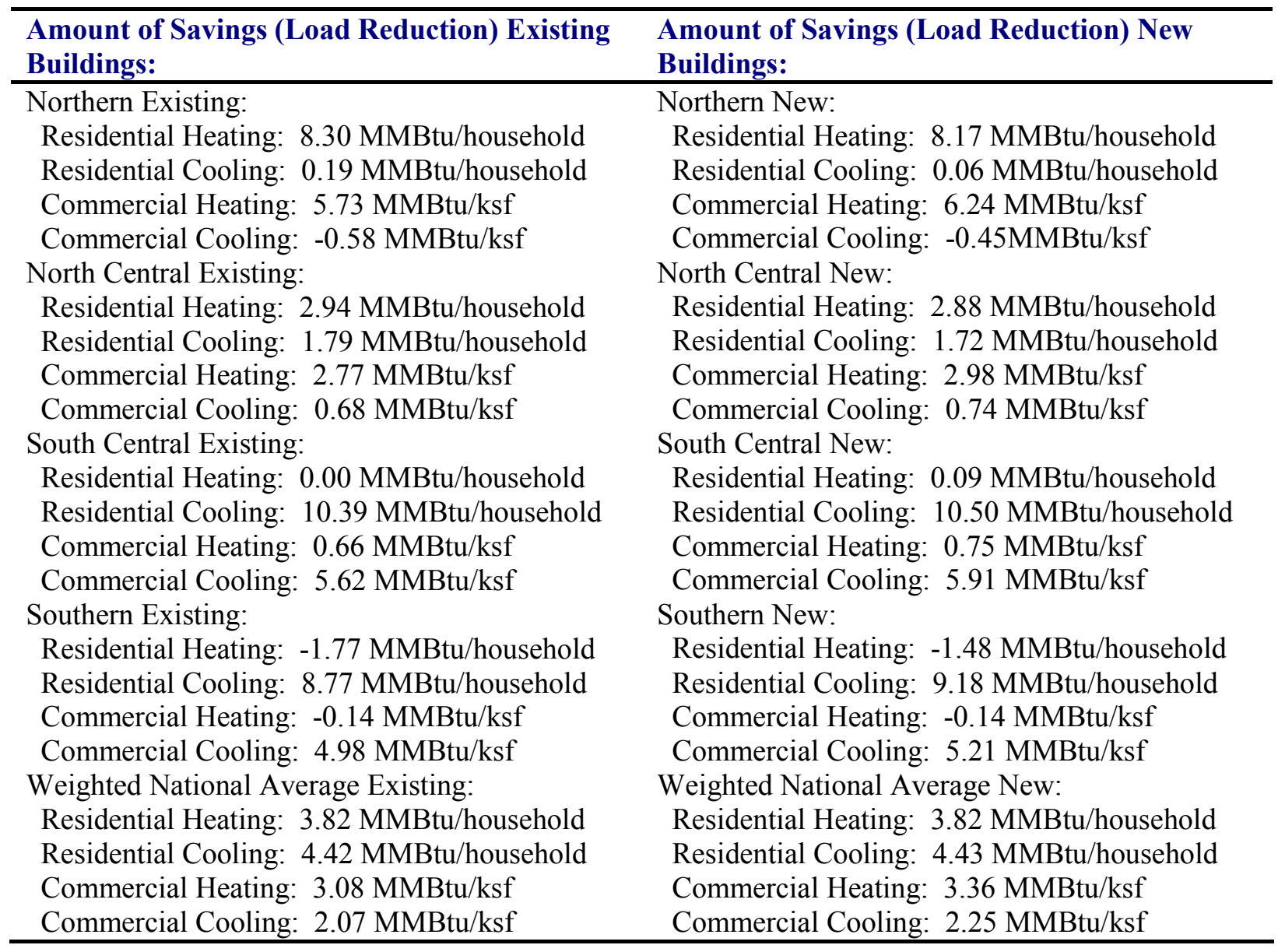

\section{Energy Star: Appliances - Refrigerators}

According to the most recent information from the EPA Energy Star Web site, ${ }^{47}$ about 33\% of refrigerator sales in 2004 met Energy Star criteria (energy consumption 15\% below the NAECA

\footnotetext{
${ }^{47} \mathrm{http}: / /$ www.energystar.gov/index.cfm?c=manuf_res.pt_appliances 
standard last updated in 2002.) No change in the NAECA standard is envisioned in the foreseeable future, as refrigerators are not included in DOE's five-year schedule for appliance rulemakings (i.e., through 2011).

Currently, the Energy Star activity is modeled in the residential module of the NEMS energy model. Several models of refrigerators are included in the technology database of the model, one of which represents the class of refrigerators meeting the Energy Star criteria. With the current set of parameters representing the discount rate consumers (implicitly) employ in their choice of refrigerators, together with the current equipment and electricity prices, the NEMS model projects an approximately 20\% share for Energy Star refrigerators. The discount rate serves as the mechanism in the model by which the Energy Star promotional activities influence consumers to purchase more efficient appliances.

For the GPRA analysis, BT does not intend to try to "calibrate" NEMS to yield the current Energy Star sales. Rather, a key parameter affecting the average consumer discount rate was adjusted to yield a roughly 10 percentage point increase in the share of Energy Star refrigerators (thus, raising the share from $20 \%$ to $30 \%$ ). As in prior GPRA analyses, the betal parameter is adjusted to reflect a change in the discount rate. The parameter value in the NEMS AEO2006 baseline model is $0 .-0229$. That value is adjusted to -0.0055 to reflect the impact of Energy Starrelated activities, and implicitly lowers the average discount rate.

\section{Energy Star: Appliances - Room Air Conditioners}

According to the most recent information from the EPA Energy Star Web site (see footnote above for refrigerators), about 35\% of room air-conditioner sales in 2004 met Energy Star criteria (energy consumption roughly 10\% below the NAECA standard last updated in 2001.) No change in the NAECA standard is envisioned in the foreseeable future, as room air conditioners are classified as "backlog" in DOE's five-year schedule for appliance rulemakings, with action expected before 2011.

Currently, the Energy Star activity is modeled in the residential module of the NEMS energy model. Three models of room air conditioners are included in the technology database of the model, only one of which clearly meets the Energy Star efficiency criterion. As described in a short memo to EIA in 2005, the cost and performance of various room air conditioners in the NEMS database appears to be flawed. Based on an examination of available information (including visits to both Home Depot and Lowe's), the incremental cost of an Energy Star unit appears to only be about $\$ 40$. If adjustments are made to the middle-efficiency unit in the NEMS database along with a revision of the consumer discount rate (from $150 \%$ to $400 \%$ ), the model generates a market share of about $14 \%$ for this high efficiency air conditioner. ${ }^{48}$ A subsequent adjustment in the discount rate to $140 \%$, to reflect greater consumer awareness of efficient air conditioners due to Energy Star, yields a market share of roughly $35 \%$. We assume that this

\footnotetext{
${ }^{48}$ In the standard input for the 2007 AEO version of NEMS, the parameters that implicitly represent the average consumer discount rate were -0.017 (beta1) and -0.012 (beta2). The discount rate is roughly the fraction (beta1/beta2), or in this case, $142 \%$. However, the Energy Star model in this version of the model had a cost premium of more than $\$ 200$. With the adjustment of the cost data that lowers this premium, the discount is presumed to be higher to yield the same Energy Star penetration. Whether the parameters in the NEMS residential model should be taken as valid measure of the discount rate is still an open question. For the GPRA modeling, the input and parameter adjustments were made in order to achieve the roughly 20 percentage point increase in market share that corresponds to the Energy Star target impact.
} 
incremental change in the market share $(\sim 20 \%)$ represents the impact of the Energy Star program.

As in the prior GPRA analyses, the betal parameter in the residential rtekty.txt file is adjusted to reflect a change in the discount rate. For room air conditioners, the baseline input data for room air conditioners should be changed. These changes apply to both the performance (energy efficiency rating - EER) and cost of the mid-efficiency model in the NEMS rtekty.txt file. To reflect the impact of Energy Star activities, the efficiency is adjusted to be $10 \%$ greater than the baseline unit, and the cost differential should be set to $\$ 40$. The beta1 parameter should also be changed to -0.048 . For the Energy Star case, the betal parameter should be changed to -0.018 . Preferably, this parameter should be adjusted over a three-year period beginning in 2008.

\section{Energy Star: Appliances - Clothes Washers}

Typically, the Energy Star activity seeks to penetrate a minimum of $20 \%$ of the total market with qualified products. According to the most recent information, about $27 \%$ of clothes washers in 2004 met Energy Star criteria (energy consumption roughly $25 \%$ below the NAECA standard last updated in 2004.) The stringency of the NAECA standard will increase in January 2007 along with the criteria for Energy Star designation.

Currently, the Energy Star activity is modeled in the residential module of the NEMS energy model. Three efficiency levels of room air conditioners are included in the technology database of the model, only one of which clearly meets the 2007 Energy Star criteria. With the current parameter set in NEMS, fewer than 10,000 units of this model are expected to be sold in 2010, out of a total market of more than 7 million. According to the model's current choice behavior parameters, consumers are assumed to place a very high value on the first cost of clothes washers, with a discount rate in the range of $400 \%$. A reduction of roughly $70 \%$ in the discount rate yields a market share of the (2007) Energy Star unit of about 10\%. Given the high cost of this very efficient unit (\$950) compared to models just meeting the NAECA standard, a 10\% share influenced by Energy Star is deemed to be a reasonable intermediate goal of the program.

As in the prior GPRA analyses, the beta1 parameter in the residential rtekty.txt file is adjusted to reflect a change in the discount rate. For the Energy Star case, the betal parameter should be changed to from -0.03811 to -0.01211 . Preferably this parameter should be adjusted over a threeyear period beginning in 2008 .

\section{Energy Star: Home Performance}

Home Performance with Energy Star is a joint effort with the Environmental Protection Agency to develop and support pilot projects that promote whole-house retrofits for existing homes in order to save energy, and reduce heating, cooling, and lighting loads by roughly $25 \%$, on average. Home Performance's three main components include whole-house inspections, marketing efforts, and quality assurance.

The Building Technology Program is considering the possibility of moving some of the Home Performance program administration to national retailers and contractors, and regional home improvement centers such as Lowe's or Home Depot. The near-term goal is to develop partnerships with these retailers, where the retailers would train their own employees to become 
energy inspectors and raters, where their incentive would be to promote the sale of certain energy-efficient components at their stores. These partners would do the testing, train inspectors and raters, prioritize the work, and eventually make the "sale."

BT assumed that the cost of Home Performance pilot projects (the average price per household) would be $\$ 9,000$. Currently, Pilot Project homeowners are spending between $\$ 8,000$ and $\$ 10,000$ in retrofits through the Pilot Project activity (Energy Star 2003).

The penetration rates for Home Performance with Energy Star were developed using a diffusion model based on Fisher and Pry (1971). The equation for determining market diffusion over time is:

$$
N(t)=\frac{\kappa}{1+\exp \left(-\frac{\ln (81)}{\Delta t}\left(t-t_{m}\right)\right)}
$$

Where $\mathrm{K}=$ Maximum market share potential

$\mathrm{tm}=$ year in which $50 \%$ of potential is reached

$\Delta \mathrm{t}=$ time to grow from $10 \%$ to $90 \%$ of potential (years)

For Home Performance with Energy Star, $\mathrm{k}=0.0002 \%, \mathrm{tm}=17$, and $\Delta \mathrm{t}=20$. These values were developed through trial and error to achieve the expected annual household impact in 2008 and in "out" years (Andrews 2004).

Table G-42 displays the resulting estimated number of homes impacted based on the penetration curve developed.

Table G-42: Energy Star: Home Performance Estimated Market Penetration

\begin{tabular}{lc}
\hline Year & $\begin{array}{c}\text { Annual Number of } \\
\text { Homes }\end{array}$ \\
\hline 2008 & 859 \\
\hline 2009 & 1,052 \\
\hline 2010 & 1,284 \\
\hline 2011 & 1,562 \\
\hline 2012 & 1,891 \\
\hline 2013 & 2,279 \\
\hline 2014 & 2,729 \\
\hline 2015 & 3,245 \\
\hline 2016 & 3,828 \\
\hline 2017 & 4,474 \\
\hline 2018 & 5,177 \\
\hline 2019 & 5,927 \\
\hline
\end{tabular}




\begin{tabular}{ll}
\hline 2020 & 6,709 \\
\hline 2021 & 7,503 \\
\hline 2022 & 8,291 \\
\hline 2023 & 9,053 \\
\hline 2024 & 9,771 \\
\hline 2025 & 10,434 \\
\hline 2026 & 11,031 \\
\hline 2027 & 11,557 \\
\hline 2028 & 12,010 \\
\hline 2029 & 12,395 \\
\hline 2030 & 12,714 \\
\hline
\end{tabular}




\section{Bibliography}

2005 Buildings Energy Data Book. 2005. (BEDB 2005). U.S. Department of Energy, Office of Planning, Budget Formulation, and Analysis, Energy Efficiency and Renewable Energy. Prepared by D\&R International, Ltd.

Anderson, R., et al. November 2004. (Anderson 2004) Analysis of System Strategies Targeting Near-Term Building America Energy-Performance Goals for New Single-Family Homes.

National Renewable Energy Laboratory. Report No. TP-550-36920.

Andrews, K. 2004 (Andrews 2004). Personal Communication. DOE Program Manager.

Annual Energy Outlook 2006. (AEO2006). Energy Information Administration.

Appendix A: FY2005 Technical Support Document. 2004. (US DOE 2004c). U.S. Department of Energy. Accessed online at

http://www.eere.energy.gov/buildings/appliance standards/pdfs/fy05 priority_setting_app_a.pdf

Berson, D., et al. 2004. America's Home Forecast: The Next Decade for Housing and Mortgage Finance. Homeownership Alliance. (Berson 2004)

Building America Meetings Series: Quarterly All-Teams Planning Meeting Notes, November 16-18, 2004. (US DOE 2004a). U.S. Department of Energy, Building America Program. Washington, DC.

Building Technologies Program. August 2005. (BTP 2005) Research, Development and Demonstration Plan: Planned program activities for 2006-2011. Available online at http://www.eere.energy.gov/buildings/about/mypp.html

Building Envelope Technology Roadmap. May 2001. (U.S. DOE 2001). U.S. Department of Energy, Office of Energy Efficiency and Renewable Energy, May 2001.

Characterization of the Non-Residential Fenestration Market. November 2002. (LBNL 2002). Lawrence Berkeley National Laboratories and Northwest Energy Efficiency Alliance. Prepared by Eley Associates. Report No. 02-106.

Commercial Buildings Determinations: Explanation of the Analysis and Spreadsheet, Last revised April 1, 2004. (U.S. DOE 2004b) U.S. Department of Energy, Office of Energy Efficiency and Renewable Energy.

Elliott, D.B., D.M. Anderson, D.B. Belzer, K.A. Cort, J.A. Dirks, D.J. Hostick. 2004. (Elliott et al., 2004). Methodological Framework for Analysis of Buildings-Related Programs: The GPRA Metrics Effort. PNNL-14697. Pacific Northwest National Laboratory, Richland, Washington. 
Energy Information Administration, March 2006 (EIA 2006a). Model Documentation Report: Commercial Sector Demand Module of the National Energy Modeling System. DOE/EIA-M066 (2006). Accessible at http://tonto.eia.doe.gov/FTPROOT/modeldoc/m066(2006).pdf

Energy Information Administration, March 2006 (EIA 2006b). Model Documentation Report: Residential Sector Demand Module of the National Energy Modeling System. DOE/EIA-M067 (2006). Accessible at http://tonto.eia.doe.gov/FTPROOT/modeldoc/m067(2006).pdf

Energy Information Administration, March 2006 (EIA 2006c). Assumptions to the Annual Energy Outlook 2006. DOE/EIA-0554(2006).

Energy Savings Potential of Solid-State Lighting in General Illumination Applications. 2003. (Navigant Consulting 2003). Prepared for DOE's Office of Building Technologies by Navigant Consulting, Washington D.C.

Energy Star Program Analysis. January 2005. (D\&R International 2005). D\&R International.

"Energy Star Tackles Existing Homes." August 2003. (Energy Star 2003). Energy Design Update, Volume 23, No. 8.

Fisher, J.C., and R.H. Pry. 1971. (Fisher and Pry 1971). "A Simple Substitution Model of Technological Change.” Technological Forecasting and Social Change, 3, 75-88.

Kats, Greg (Capital E), et al. October 2003. (Kats 2003). "The Costs and Financial Benefits of Green Buildings," A Report to California's Sustainable Building Task Force.

National Association of Home Builders. 2004.(NAHB 2004). Annual Housing Starts (19782004)

National Renewable Energy Laboratory. December 29, 2004. (NREL 2004) Building America Research Benchmark Definition. Available online at http://www.eere.energy.gov/buildings/building_america/pdfs/37529.pdf

National Research Council. 2001 (NRC 2001). Energy Research at DOE: Was It Worth It? Washington, D.C.

Pacific Northwest National Laboratory. 2002. (PNNL 2002) Facility Energy Decision System User's Guide, Release 5.0. PNNL-10542, Rev. 3, Richland, Washington

RS Means Company, Inc. 2002. (RS Means 2002). "RS MEANS Square Foot Costs.” 23rd Edition, Kingston, MA.

Solid-State Lighting Research and Development Portfolio: Multiyear Program Plan FY07-FY12. March 2006. (Navigant Consulting 2006). Prepared for DOE's Building Technologies Program by Navigant Consulting, Washington D.C. 
Technology Roadmap: Advanced Panelized Construction, 2003 Progress Report. May 2004. (U.S. HUD, 2004a). U.S. Department of Housing and Urban Development, Office of Policy Development and Research. Prepared by Newport Partners, LLC.

Technology Roadmap: Energy Efficiency in Existing Homes, Volume Three: Prioritized Action Plan. May 2004 (US HUD 2004b). U.S. Department of Housing and Urban Development, Office of Policy Development and Research. Prepared by Newport Partners, LLC.

Torcellini, P.A., Judkoff, R., and Crawley, D.B. September 2004. (Torcellini et al. 2004). "Lessons Learned: High-Performance Buildings," ASHRAE Journal, September. 2004, pp. S411 .

U.S. Census Bureau. March 2000. (U.S. Census Bureau 2000). 1997 Economic Census Construction Geographic Area Series.” U.S. Department of Commerce. Washington D.C.

U.S. Department of Energy FY 2008 Draft Budget Request. July 2006. (U.S. DOE 2006a)

U.S. Department of Energy. Energy Conservation Standards Activities. January 2006 (U.S. DOE 2006b). U.S. Department of Energy. Washington, D.C.

U.S. Lighting Market Characterization, Volume 1: National Lighting Inventory and Energy Consumption Estimate. November 2003. (LMC I 2003) U.S. Department of Energy, Office of Energy Efficiency and Renewable Energy, Building Technologies Program. Prepared by Navigant Consulting Inc.

Zero Energy Homes' Opportunities for Energy Savings: Defining the Technology Pathways through Optimization Analysis. October 2003. (ZEH 2003). U.S. Department of Energy, Building Technologies Program. Prepared by Navigant Consulting Inc. 


\section{APPENDIX H - INDUSTRIAL TECHNOLOGIES PROGRAM INPUTS FOR FY 2008 BENEFITS ESTIMATES}

\section{Table of contents}

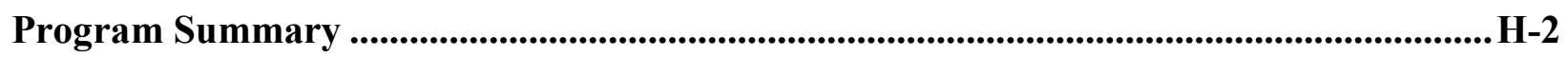

Significant Changes from Previous Analysis..................................................................................H-3

The Baseline ("without DOE RD3") Case …………........................................................

Target Market Description.................................................................................................. H-4

Baseline Adjustments to the AEO2006 Reference Case........................................................ H-6

Representation of Program-Relevant Technologies in the AEO Reference Case ................... H-6

Removing Effects of Program Activities.......................................................................... H-6

Other Program-Relevant Adjustments to AEO Reference Case ………….............................. H-6

Program Outputs ...................................................................................................................................

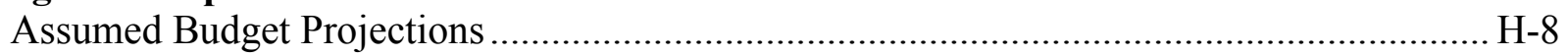

Description of Key Activities .....................................................................................

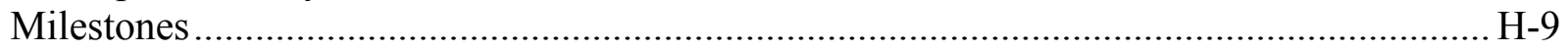

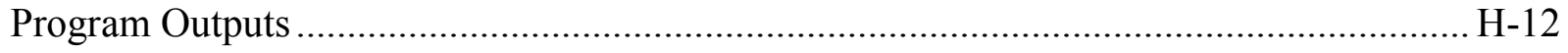

Translating Program Outputs to Market Outcomes.....................................................................H-12

Key Factors in Shaping Market Adoption of EERE technologies........................................ H-16

Immediate Outputs..................................................................................................

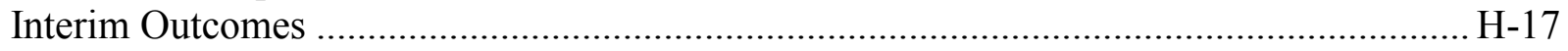

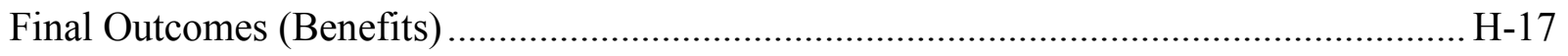

Summary of Inputs ................................................................................................................. H-20

Bibliography ..............................................................................................................................................26 


\section{Program Summary}

The Industrial Technologies Program (ITP) will continue its mission of supporting the development of energy-efficient, clean manufacturing technologies by partnering with the industrial sector. ITP has embraced leaner and more agile operating practices to lower industrial energy intensity with reduced resources. By analyzing opportunities, coordinating with other EERE programs, and dynamically refocusing activities, ITP will leverage the current FY 2008 budget request of approximately $\$ 45.998$ million to boost energy efficiency in a sector whose current energy use is approximately 33 quadrillion Btu, one-third of the U.S. total. The annual cost of U.S. industrial energy consumption is about $\$ 300$ billion (at 2005 prices); and, therefore, each $1 \%$ reduction in this energy demand achieved through efficiency improvements will save the Nation about $\$ 3$ billion annually.

Evolving energy, environmental, and economic challenges facing U.S. industry present ITP with abundant opportunities and options for R\&D focus. At the same time, resource constraints and fiscal prudence call for more sharply focused strategies that will achieve maximum measurable results for the Nation. In defining our R\&D investment strategies, a broad range of relevant information and trends are taken into account. These include:

- Analyses of technology impacts on energy use during basic materials manufacturing, downstream fabrication, forming and assembly, product end use, and recycling and recovery of energy and materials

- Evolving business patterns and structural shifts in U.S. manufacturing

- Volatility in supply and price of fuels and feedstocks, especially petroleum and natural gas

- Maintaining technological leadership in global markets

- Growing worldwide concern about climate change impacts

- Significance of profits, jobs, and competitiveness to U.S. economic security

- Movement overseas of manufacturing and critical capital equipment suppliers

To achieve national goals and benefit industries and communities across the Nation, ITP plays a key role in guiding research by developing more energy-efficient technologies. Technologies that improve energy efficiency typically deliver associated benefits in reduced emissions, decreased waste by-products, improved competitiveness, and (potentially) enhanced product quality. ITP seeks to strategically maximize and develop better metrics for capturing the aggregate benefit of increased industrial energy efficiency to American society.

In view of the existing challenges, trends, opportunities, and resources, ITP plans to re-examine some aspects of its technology R\&D portfolio such as:

- Research alternatives for natural gas to reduce vulnerability to critical supply and price volatilities, with a focus on energy-intensive industries such as chemicals and steel.

- Identification of crosscutting research opportunities for melting, high-temperature processing, fabrication, and forming of ferrous and nonferrous metals and glass.

- Expansion of current research to address technical challenges in energy conversion systems (e.g., Super Boiler, waste heat recovery), separations (e.g., advanced drying), and alternative chemical reactions. 
- Exploring next-generation manufacturing concepts to respond to strategic needs and to produce transformational outcomes that enhance U.S. technological leadership.

\section{Significant Changes from Previous Analysis}

The budget request calls for a transition in ITP's program planning unit structure beginning in FY 2008 from one focused on R\&D addressed to (1) specific vision industries of the future, (2) crosscutting R\&D, and (3) technical assistance [including Industrial Assessment Centers (IAC) and Best Practices] to a more explicitly crosscutting structure with three new R\&D program components:

- Energy-Intensive Process R\&D,

- Fuel and Feedstock Flexibility

- Interagency Manufacturing R\&D

And inclusion of two new technical assistance program components:

- Voluntary Industrial Partnerships

- State Collaboratives.

ITP will allocate new FY 2008 projects among these program components, and will phase out funding for the industry-specific planning unit projects as each project is completed. It is expected that transition to the new crosscutting planning structure will be completed within two to three years. However, GPRA08 benefits are necessarily based on analysis of the FY 2007 program portfolio, because the specific content of the FY 2008 portfolio is as yet unknown.

\section{The Baseline ("without DOE RD3") Case}

AEO2006 projects industrial energy consumption to grow by nearly $23 \%$ between 2006 and 2030, despite continuation of the historical trends toward lower industrial energy intensity. Between 1980 and 2004, aggregate industrial energy intensity, measured as industrial delivered energy per dollar of GDP, declined by 3\% per year, and industrial delivered energy per dollar of industrial value of shipments declined by $1.6 \%$ per year. These trends were caused by a greater focus on energy efficiency after the energy price shocks of the 1970s and 1980s and a reduction in the share of manufacturing activity accounted for by the most energy-intensive industries. In the AEO2006 reference case, these trends continue at a slower pace through 2030. Industrial energy use per dollar of GDP declines by $2.1 \%$ per year on average from 2004 through 2030, and energy use per dollar of industrial value of shipments declines by $1.2 \%$ per year. The expected rates of decline in industrial energy intensity are less rapid than those from 1980 to 2004, in part because the nonmanufacturing portion of industrial value of shipments (agriculture, mining, and construction) grows more slowly than the manufacturing portion, which includes the more energy-intensive industrial sectors.

Continued baseline improvement in energy productivity was accounted for in the ITP methodology. ITP's methodology essentially subtracts a fixed "next-best" baseline technology from a fixed advanced technology to obtain unit technology savings. The conventional technology with which each new technology was compared was generally the best currently available technology — not a projected technology that might or might not exist at the time of market introduction or the average technology in current use. The energy savings of a new 
technology due to government R\&D were determined by the number of years the technology's market introduction is accelerated as a result of ITP funding. Only the difference relative to the baseline case, i.e., the slice of net energy savings attributable to the program's effort, was counted as benefits. In this way, the methodology incorporated an assumption (consistent with NEMS-GPRA 08) that the energy intensity of industrial production will steadily improve, and that Federal cofunding only temporarily accelerates the rate of improvement in the targeted production activities. Acceleration periods ranged from 3 to 38 years, with an average of approximately 8 years.

While the historic industry-level rate of improvement in production energy intensity tends to follow fairly smooth curves of monotonic improvement, it is very difficult to predict the future energy performance of as-yet unidentified new technologies to perform specific functions. In addition, the best currently available technology is often not yet widely adopted in the market, so that when the ITP technology enters the market, the current best-available technology may still represent the next-best decision alternative for many cases. As a result, the use of current best available technology as a comparison point for new technology investment may have the tendency to understate rather than overstate the impact of a new technology savings. Of still greater significance, taking credit for only that slice of savings due to the presumed acceleration of the new technology's market introduction date was intended to eliminate any overestimation of savings due to the underlying rate of capital turnover-driven technology improvement.

Due to differences in the analytical approach of the NEMS-GPRA08 model and MARKAL GPRA08 model, and ITP's bottom-up energy-savings projection methodology, it was not possible to definitively match the base-case assumptions of NEMS with the implicit base case in the GPRA study. NEMS-GPRA08 addresses the entire industry group in a top-down manner, assigning energy intensities to a comprehensive set of activities to project total industry energy use under alternative assumptions. In contrast, the bottom-up ITP GPRA study specified the unit energy savings of a particular set of advanced technologies, each in comparison to a bestavailable commercial technology alternative. ITP GPRA benefits consist of savings resulting from the acceleration of market entry for each technology. The two approaches are not inconsistent. The NEMS-GPRA08 model and the MARKAL-GPRA08 model provide the context for benefit measurement in the overall economic framework.

\section{Target Market Description}

As stated earlier, the industrial sector currently uses one-third of all U.S. energy supplies. This energy is consumed in processes and activities operating at substantially less than theoretical maximum efficiencies, leading to many significant technological and market transformational opportunities to reduce the energy intensity of industrial production. Many technological opportunities are intrinsically related to non-energy productivity improvements such as reduced capital and operating costs, increased plant production, reduced in-plant scrap rates, and reduced pollution control costs. Another feature of the markets for energy-efficient industrial production technology is that intense global competition is the norm, and U.S. technological leadership in these major production equipment supply chains is vital to our international competitiveness and economic success. 
Advanced industrial energy efficiency technologies under development with program support will enter a variety of specialized markets, including those for production equipment, plant energy conversion and distribution, heat recovery, process control, and waste-reduction equipment. These markets vary in many ways, including their size and growth rate, degree of specialization, the scale and lifetime of unit capital investments, U.S. technological competitiveness, and the degree to which non-energy considerations such as productivity are important in investment decisions.

The production of industrial commodity products such as paper, steel, aluminum, chemicals, and glass is very capital intensive, and involves a large number of specialized production methods that have evolved over many decades. This diversity leads to complex technology and market characterizations, and has led to a relatively large number of technology R\&D initiatives being required to address the principal targets of opportunity. In FY 2008, ITP will begin to refocus its R\&D support toward crosscutting, multiple-application, enabling technologies such as advanced materials and combustion science, and on crosscutting technology platforms such as advanced distillation and Super Boiler technologies. The pace of improvements in energy intensity in these important production applications is limited by the R\&D resources addressing technical challenges, the economic performance of the industries involved, and the rate of turnover of capital-intensive plant and equipment.

Underlying fuel prices, the electricity generation and distribution fuel mix and heat rates, and sector economic growth rates - used in the NEMS-GPRA08 runs that produced the ultimate results from ITP's energy-savings inputs-were chosen to be consistent with the reference case in the Department of Energy's (DOE/EIA) Annual Energy Outlook 2006. ITP's off-line calculation of fuel and electricity savings for individual projects and program-element activities did not refer explicitly to macro-baseline projection of energy consumption quantities; rather, a unique market growth rate was specified in each of the Technology Impact Projections Model ${ }^{1}$ runs performed for GPRA08. This permitted the analysts to differentiate among highly varied market outlooks for specific energy-using activities within various industry groups. Except for several chemicals-industry market targets with short-term growth rates of more than $5 \%$, the range of these annual market growth rates was from $-1 \%$ to $5 \%$, with an average close to 2.4 percent. By comparison, short-term AEO 2006 annual growth rates for highly aggregated energy intensive industries ranged from $0.7 \%$ to $2.9 \%$ and averaged $1.6 \%$. The wider range of shortterm growth rates specified for the less-aggregated and selectively growing energy-use activities targeted by the model runs seems logically consistent.

The target market for each of the R\&D technologies included in the ITP study was described qualitatively and quantitatively in a spreadsheet-based Technology Impact Projections Model run (summarized in Table H-6). The technologies were grouped based on common production

\footnotetext{
${ }^{1}$ Fifty-five Technology Impact Projections Model runs performed in the GPRA08 off-line benefits study are documented in “GPRA08 Quality Metrics - Methodology and Results," draft, June 2006, by Energetics Incorporated. The Technology Impacts Model is described in the same document. In summary, this model is a system of spreadsheets designed to calculate (1) the unit differences between the new and existing technology in fuels and electricity use during one unit's operating year, (2) the size and projected growth of the new technology market, (3) the schedule of development milestones leading to commercial introduction of the new technology assuming a successful DOE R\&D program, (4) the "acceleration period," or number of years by which the commercial introduction is advanced by the DOE R\&D program, (5) the market-penetration curve characterizing the technology's likely path toward market saturation assuming commercial success, and (6) projected national energy savings impacts due to the acceleration of the new technology by the DOE program.
} 
activity Impact Targets. This specification of target markets was done to facilitate the identification of potentially overlapping markets. Where potentially overlapping markets were found, either the market was split between the two competing technologies or only one spreadsheet model run was used to represent both technologies.

Markets were initially defined in terms of the total number of technology units potentially in use at the year of introduction. Next, this number was reduced to the fraction of those units considered technically and economically accessible. The number of technology units was further reduced to the likely achievable technology market share accessible to the technology as compared to other advanced technologies. Finally, the target market was reduced to the savings potential attributable to the program. The market size was adjusted annually by the spreadsheet logic, based on the specified annual percentage market growth rate.

\section{Baseline Adjustments to the AEO2006 Reference Case}

ITP did not make any baseline adjustments to the $A E O 2006$ reference case because no redundancies between the program energy savings and the assumptions of $A E O 2006$ were identified.

\section{Representation of Program-Relevant Technologies in the AEO Reference Case}

The AEO Reference Case describes broad structural and technological baseline trends underway in many of the energy-intensive industries that could affect the likely impact of the advanced technologies analyzed for GPRA08. However, the off-line ITP GPRA08 analysis took into account these trends, such as the trend toward electric arc furnaces in the steel industry and the trend toward secondary smelting of aluminum, as well as other market-related developments in the characterization of both the new technology and the next-best conventional technologies, and also in the sizes and growth rates assigned to future markets for each ITP technology.

Reference Case baseline technology improvements can be seen principally as the effect of continual replacement of retired capital equipment with newer, more efficient production equipment. The program accelerates the availability of the most advanced energy-using equipment, temporarily enlarging and improving the mix of technology options available to industrial decision-makers when certain energy-intensive equipment is purchased. Thus, the AEO Reference Case can be assumed to include best-available current technology, absent the acceleration of this technology's availability due to the Federal program.

\section{Removing Effects of Program Activities}

The AEO Reference Case does not explicitly exclude the effects of historically funded programs such as ITP. Nevertheless, ITP's off-line benefits assessment methodology did not require the construction of a "non-program" baseline, because the methodology counted only the slice of net energy savings for each industry associated with the acceleration of certain advanced technologies' availability.

\section{Other Program-Relevant Adjustments to AEO Reference Case}

ITP did not make any adjustments to the AEO Reference Case. 


\section{Program Outputs}

The logic model is presented in Figure H-1. For this purpose, program activities can be divided into two main areas: R\&D and Technical Assistance. R\&D milestones are project-specific and range from basic research advances to in-plant demonstrations. Technical Assistance milestones include information dissemination and the formation of new partnerships. R\&D outputs are focused on energy efficiency and performance improvements. Technical assistance outputs can be quantified in terms of audits completed and plants impacted. External factors such as fuel commodity prices and government regulations impact interim outcomes, such as commercialization and market penetration.

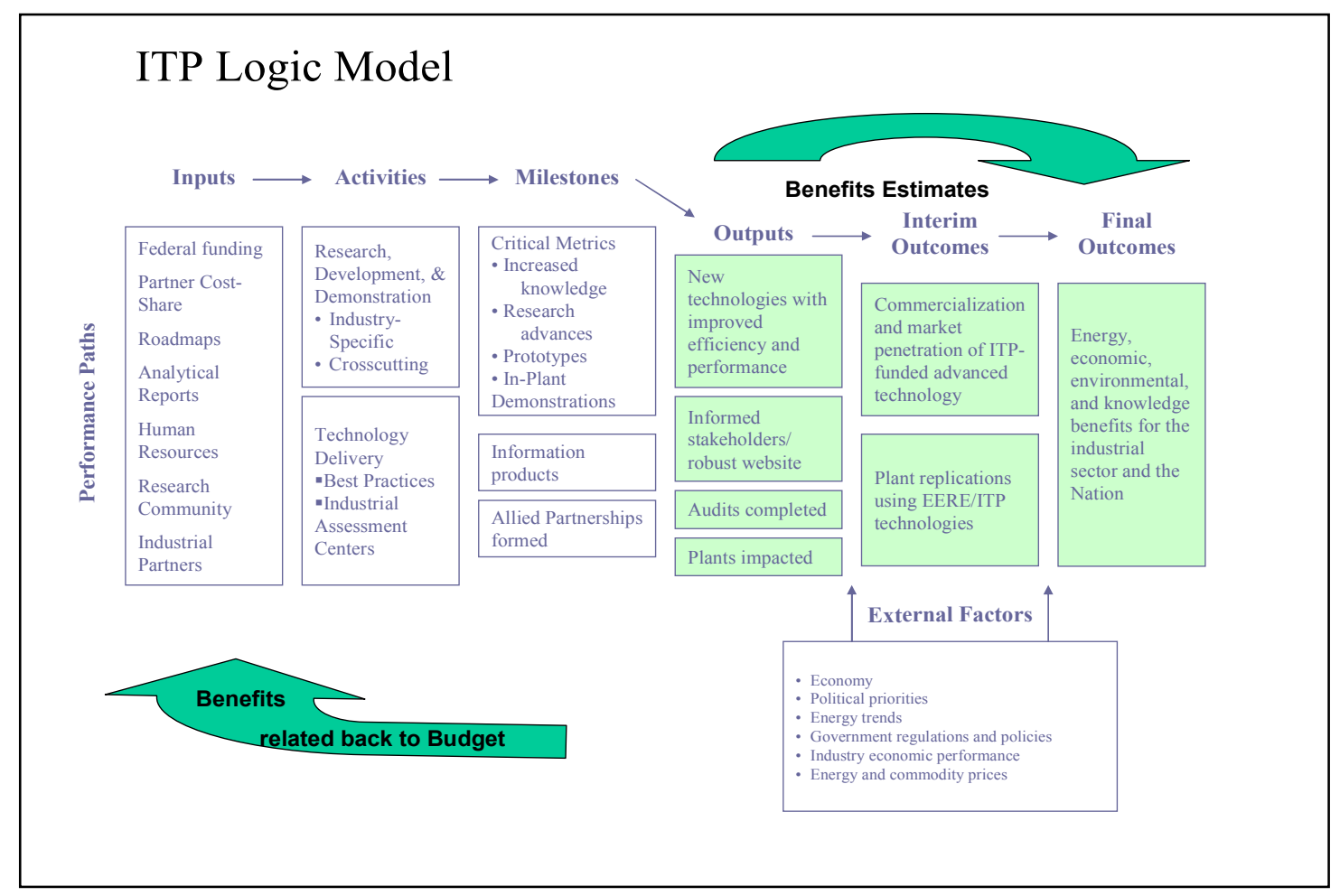

Figure H-1: ITP Logic Model 


\section{Assumed Budget Projections}

Table H-1 shows the funding scenario that is currently anticipated for the Industrial Technologies Program over the next five years. The program will use the convening power of government to form working groups for future industrial cooperation in new R\&D program components: (i) Energy-Intensive Process R\&D, (ii) Interagency Manufacturing R\&D, and (iii) Industrial Fuels and Feedstock Flexibility. Work in these areas will begin in FY 2008. Additionally, two new Technical Assistance program components, (i) Voluntary Partnerships and (ii) State Collaboratives, will begin in FY 2008.

\section{Priorities:}

- The program is shifting its focus from more industry-specific R\&D to broader crosscutting and transformational initiatives with higher potential impacts.

\section{Reallocations to Support EERE Priorities:}

- The program shift will provide the foundation for the next generation of manufacturing processes to dramatically improve the energy efficiency and environmental performance of the energy intensive and waste-intensive industries.

- The Technical Assistance portion of the program will explore better technology validation and delivery strategies to increase the adoption of energy efficiency technologies and operating practices. The Best Practices activity will continue to conduct energy savings assessments to reduce manufacturing plant natural gas consumption in support of the Secretary of Energy's "Easy Ways to Save Energy" campaign.

Table H-1: ITP Funding Scenario (\$ thousands)

\begin{tabular}{|c|c|c|c|c|c|}
\hline FY2006 & FY & FY & FY & FY & FY \\
Appropriation & $\mathbf{2 0 0 7}$ & $\mathbf{2 0 0 8}$ & $\mathbf{2 0 0 9}$ & $\mathbf{2 0 1 0}$ & $\mathbf{2 0 1 1}$ \\
\hline 56,855 & 45,563 & 45,998 & 45,998 & 45,998 & 45,998 \\
\hline
\end{tabular}

\section{Description of Key Activities}

In addition to the three new R\&D program components (Energy-Intensive Process R\&D, Interagency Manufacturing R\&D, and Industrial Fuels and Feedstock Flexibility) and two new non-R\&D components (Voluntary Industrial Partnerships and State Collaborative Assistance), ITP will begin to bring to completion its activities begun under the previous program structure. The specific content of these new program components in FY 2008 is not known at this time. For the purposes of the FY 2008 GPRA study, (a) Energy-Intensive Process R\&D, (b) Interagency Manufacturing R\&D, and (c) Fuel and Feedstock Flexibility planning units were assumed to be similar in their results to the previous Industries of the Future (IOF) Specific and Crosscutting R\&D program components, and (a) Voluntary Industrial Partnerships and (b) State Collaborative planning units were assumed to be similar in results to the previous Technical Assistance program component. 


\section{R\&D Activities}

ITP's FY 2008 off-line GPRA study used the FY 2007 portfolio as a surrogate for the as-yet unknown FY 2008 projects, assuming that the results will not vary too greatly when adjusted for the differences in funding magnitude. In FY 2007, ITP was oriented around R\&D in the following industries:

- Aluminum

- Chemicals

- Forest Products

- Metal Casting

- Steel

ITP also supported R\&D in several Crosscutting Technologies that are used extensively throughout industry, including:

- Combustion

- Materials

- Sensors and Automation

Projects underway in these planning units will be continued toward completion in FY 2008, and new R\&D projects, as-yet unknown but focused on the new EERE priorities, will be initiated in the following subprogram areas:

- Energy-Intensive Process R\&D

- Interagency Manufacturing R\&D

- Fuel and Feedstock Flexibility

\section{Non-R\&D Activities}

In FY 2007, ITP conducted non-R\&D activities under the Technical Assistance subprogram:

- Industrial Assessment Centers

- Best Practices

Ongoing work in these planning units will be continued, and two new subprogram areas will be added, which will also undertake additional, as-yet unknown projects focused on EERE priorities:

- Voluntary Industrial Partnerships

- State Collaborative Assistance

\section{Milestones}

The program milestones for the Industrial Technologies Program are presented in Table H-2. These milestones extend the FY 2007 program structure with significant milestones from FY 2008 through FY 2011. No milestones are yet known for the new program components. 
Table H-2: Program Milestones 2008-2011

\begin{tabular}{|c|c|c|}
\hline Year & $\begin{array}{l}\text { FY } 2007 \\
\text { Planning Unit }\end{array}$ & Description \\
\hline FY 2008 & Aluminum & $\begin{array}{l}\text { Complete the final design of a } 7,000 \mathrm{lb} / \mathrm{hr} \text { production ITM, with } 50 \% \text { energy savings } \\
\text { potential. }\end{array}$ \\
\hline FY 2008 & Chemicals & $\begin{array}{l}\text { Install a pilot unit and conduct field test for a natural gas removal technology that will } \\
\text { replace existing cryogenic process and recover } 70 \% \text { of } C 2 \text {. }\end{array}$ \\
\hline FY 2008 & Forest Products & $\begin{array}{l}\text { Commercial availability of underwater sparker that improves the efficiency of } \\
\text { contaminant removal in the paper recycling process by } 10-15 \% \text {. }\end{array}$ \\
\hline FY 2008 & Metal Casting & $\begin{array}{l}\text { Establish new melting practices with } 10 \% \text { energy savings in producing steel } \\
\text { castings. }\end{array}$ \\
\hline FY 2008 & Steel & $\begin{array}{l}\text { Complete laboratory scale development of scale free reheat furnace. Confirm reheat } \\
\text { furnace environment can be tailored to eliminate formation of difficult to remove iron } \\
\text { oxide scale (current processes } 1 \% \text { to } 2.5 \% \text { of product weight) to a negligible surface } \\
\text { amount. }\end{array}$ \\
\hline FY 2008 & Combustion & $\begin{array}{l}\text { Complete development of liquid fuel capability for }>94 \% \text { efficiency } 300 \mathrm{hp} \text { firetube } \\
\text { boiler. }\end{array}$ \\
\hline FY 2008 & Materials & $\begin{array}{l}\text { Demonstrate new refractory materials production and applications techniques for } \\
\text { refractory systems with } 20 \% \text { better thermal efficiencies and } 100 \% \text { better life spans } \\
\text { than conventional refractories for industrial processes. }\end{array}$ \\
\hline FY 2008 & Sensors/ Automation & Demonstrate $80 \%$ steel bar surface defect reduction. \\
\hline FY 2008 & Best Practices & $\begin{array}{l}\text { Initiate EPACT section } 106 \text { voluntary industry commitments supporting corporate } \\
\text { energy management. }\end{array}$ \\
\hline FY 2008 & IACs & 2.7 TBtu/yr total new Assessment Savings. \\
\hline FY 2009 & Aluminum & Install a production ITM at an Aleris facility, with $50 \%$ energy savings. \\
\hline FY 2009 & Chemicals & $\begin{array}{l}\text { Demonstrate a micro channel reaction oxy-deyhdrogenation technology that will } \\
\text { achieve } 82 \% \text { selectivity for production of olefins. }\end{array}$ \\
\hline FY 2009 & Forest Products & $\begin{array}{l}\text { Successful demonstration at mill scale of a pulping technology that can reduce the } \\
\text { natural gas demand for lime kiln firing by } 10 \% \text {. }\end{array}$ \\
\hline FY 2009 & Metal Casting & Complete the development of smart coatings to extend die life by over $10 \%$. \\
\hline FY 2009 & Steel & $\begin{array}{l}\text { (1) Make quality iron nodules at least } 100 \text { degrees } C \text { below the current process } \\
\text { temperature of } 1500 \text { degrees C . (2) control furnace atmosphere and use Western } \\
\text { coals as the reductant; resulting also in reduced use of natural gas. }\end{array}$ \\
\hline FY 2009 & Combustion & $\begin{array}{l}\text { Conclude first phase of development of }>94 \% \text { efficiency watertube boilers capable of } \\
1500 \text { deg and } 1500 \text { psi steam and select one project to carry forward to field trials. }\end{array}$ \\
\hline FY 2009 & Materials & $\begin{array}{l}\text { Validate performance of a sensing element in a simulated service environment for } \\
\text { application in closed-loop, feedback control of industrial combustion with fuel } \\
\text { savings of up to } 24 \text { trillion Btu/yr. }\end{array}$ \\
\hline FY 2009 & Sensors/Automation & $\begin{array}{l}\text { Demonstrate that inferential wireless motor monitoring is equivalent to direct } \\
\text { measurement. }\end{array}$ \\
\hline FY 2009 & Best Practices & Save Energy Now Round 4 energy savings assessment application process opens. \\
\hline FY 2009 & IACs & 2.7 TBtu/yr total new Assessment Savings. \\
\hline
\end{tabular}

Projected Benefits of Federal Energy Efficiency and Renewable Energy Programs (FY 2008-FY 2050) Appendix H - Industrial Technologies Program - Page H-10 


\begin{tabular}{|c|c|c|}
\hline Year & $\begin{array}{c}\text { FY } 2007 \\
\text { Planning Unit }\end{array}$ & Description \\
\hline FY 2010 & Aluminum & $\begin{array}{l}\text { Begin the operation of a production ITM at an Aleris facility, with } 50 \% \text { energy } \\
\text { savings. }\end{array}$ \\
\hline FY 2010 & Chemicals & $\begin{array}{l}\text { Complete the development of a microchannel distillation technology that will } \\
\text { revolutionize distillation technology in general and improve the overall distillation } \\
\text { column efficiency by over } 40 \% \text {. }\end{array}$ \\
\hline FY 2010 & Forest Products & $\begin{array}{l}\text { Demonstrate a non-evaporative paper dewatering technology that can reduce drying } \\
\text { steam demand by } 40 \% \text {. }\end{array}$ \\
\hline FY 2010 & Metal Casting & $\begin{array}{l}\text { Complete the development of design tools for producing die castings with } 10 \% \\
\text { higher strength. }\end{array}$ \\
\hline FY 2010 & Steel & $\begin{array}{l}\text { Complete development of new iron-making process with Western coals, but without } \\
\text { the need of using either coke or natural gas as a feedstock. Reducing coke usage } \\
\text { from } 0.340 \text { metric ton per ton (current usage) iron to zero. Reducing natural gas } \\
\text { usage from } 4 \text { billion joules per metric ton to zero. }\end{array}$ \\
\hline FY 2010 & Combustion & $\begin{array}{l}\text { Conclude first field trial of }>94 \% \text { efficiency watertube boilers capable of } 1500 \text { deg } \\
\text { and } 1500 \text { psi steam. }\end{array}$ \\
\hline FY 2010 & Materials & $\begin{array}{l}\text { Demonstrate } 50 \% \text { improvement in friction, wear and component life for hydraulic } \\
\text { components and cutting tools coated with ultra-hard coatings for reduction of friction } \\
\text { losses and catastrophic shutdowns during industrial operations. }\end{array}$ \\
\hline FY 2010 & Sensors/ Automation & $\begin{array}{l}\text { Verify ability of inferential data management system to collect and integrate different } \\
\text { data types. }\end{array}$ \\
\hline FY 2010 & Best Practices & Save Energy Now Round 5 energy savings assessment application process opens. \\
\hline FY 2010 & IACs & 2.7 TBtu/yr total new Assessment Savings. \\
\hline FY 2011 & Aluminum & $\begin{array}{l}\text { Begin the efforts in scaling up the ITM capacity to } 150,000 \mathrm{lb} / \mathrm{hr} \text {, with } 50 \% \text { energy } \\
\text { savings potential. }\end{array}$ \\
\hline FY 2011 & Chemicals & $\begin{array}{l}\text { Complete development of a hybrid distillation technology that will improve the overall } \\
\text { distillation column separation efficiency by } 40 \% \text {. }\end{array}$ \\
\hline FY 2011 & Forest Products & $\begin{array}{l}\text { Develop a non-evaporative weak black liquor concentration method that can } \\
\text { concentrate black liquor to } 35 \% \text { solids. }\end{array}$ \\
\hline FY 2011 & Metal Casting & $\begin{array}{l}\text { Develop an innovative casting process with } 20 \% \text { improvement in productivity and } \\
\text { energy efficiency. }\end{array}$ \\
\hline FY 2011 & Steel & $\begin{array}{l}\text { Complete research on a steel-making process based on the concept of continuously } \\
\text { melting, refining, alloying, and casting quality steel from scrap. Reducing energy use } \\
\text { to } 6.6 \text { billion joules per metric ton from nearly } 7.4 \text { billion joules (good practice) from } \\
\text { steel scrap. }\end{array}$ \\
\hline FY 2011 & Combustion & $\begin{array}{l}\text { Conclude second field trial of }>94 \% \text { efficiency watertube boilers capable of } 1500 \mathrm{deg} \\
\text { and } 1500 \mathrm{psi} \text { steam. }\end{array}$ \\
\hline FY 2011 & Materials & $\begin{array}{l}\text { Demonstrate }>15 \% \text { energy savings and costs for aerogel -insulation of large } \\
\text { diameter pipes for energy efficient complex steam systems }\end{array}$ \\
\hline FY 2011 & Sensors/ Automation & $\begin{array}{l}\text { Complete creation of first inferential process control system to reduce product } \\
\text { rejection rate by } 80 \%\end{array}$ \\
\hline FY 2011 & Best Practices & Save Energy Now Round 6 energy savings assessment application process opens \\
\hline FY 2011 & IACs & 2.7 TBtu/yr total new Assessment Savings \\
\hline
\end{tabular}

Projected Benefits of Federal Energy Efficiency and Renewable Energy Programs (FY 2008-FY 2050) Appendix H-Industrial Technologies Program - Page H-11 


\section{Program Outputs}

ITP program outputs are completed new energy-efficient technologies, informed markets, completed plant assessments, and new partnerships. The GPRA08 study anticipates the completion of 55 advanced technologies, most of these ready for commercialization by FY 2011 (see Table H-7), IAC energy assessments at approximately 600 small- and medium-size plants per year, and Energy Saving Assessments at approximately 200 large plants per year.

\section{Translating Program Outputs to Market Outcomes}

Interim outcomes for ITP are the commercialization of advanced technologies in the marketplace. Final outcomes include the energy savings and other benefits resulting from operation of the new technologies in their intended markets. To understand how rapidly the potential impact of the technology may be felt, the market penetration of the technology must be projected. This is based on two estimates: the technology development and commercialization timeline, and the market penetration curve.

\section{Technology Development \& Commercialization Timeline}

The commercial introduction of a technology normally occurs after a significant demonstration is completed or an operating prototype is developed, and after an adequate test and evaluation period. Other prerequisites include the readiness of the production facilities, dissemination of information, initial marketing and sales, or other "start-up" factors. To capture this lengthy process, ITP analysts indicate the timeline for developing and introducing the technology into the market. This includes the years for when an initial prototype, refined prototype, and commercial prototype of the technology has or will be completed; and the year when the technology will be commercially introduced. An initial prototype is the first prototype of the technology. A refined prototype represents changes to the initial prototype but not a commercially scaled-up version. A commercial prototype is the first commercial-scale version of the technology. Commercial introduction is achieved when the first unit beyond the commercial prototype is operating. Prototype and commercial introduction years should be consistent with technology development program plans. Two values for a commercial introduction year are used. One reflects when the technology is projected to be introduced if the program proceeds as expected (With-ITP case). The other reflects when the technology would have entered the market if the program had not been involved (Without-ITP case). If the technology has no chance of being commercially introduced without the program, then Year 2050 is entered for the Without-ITP case. The difference in commercial introduction years for the With-ITP and Without-ITP cases is referred to as the acceleration period. As mentioned earlier, acceleration periods vary by industry and by technology.

\section{Market Penetration Curve (Technology Class)}

New technologies normally penetrate a market following a familiar "s" curve, the lower end representing the above uncertainties overcome by "early adopters." The curve tails off at the far future where some may never adopt the new technology. Of importance is the major portion of the "s" curve where the new technology is penetrating the market 
and benefits are being reaped. The rate at which technologies penetrate their markets varies significantly: penetrations of heavy industrial technologies - with long asset lives and requiring large capital investments - generally take place over decades, while simple (and often cheaper) process or control changes can penetrate much more rapidly. The actual penetration rate varies as a function of economic, environmental, competitive, productivity, regulatory, and other factors.

As an integral component of the ITP benefits assessment and analysis process, a large volume of actual penetration rates of past and present technologies were analyzed, normalized, and grouped into five classes based on a number of characteristics and criteria. ITP analysts completed Table H-3 for each R\&D project by adding the project title in the top row and either a, b, c, d, or e in the right-hand column for those characteristics for which a judgment was possible. The overall technology market penetration curve selection was entered in the second row at the right under "Score." Note that the characteristics (rows) are relatively independent, and a given technology will likely fit best in different classes for different characteristics. By examining the pattern, however, one can, based on best judgment and experience, select the most likely class (rate) at which the new technology may penetrate the market. For example, ITP analysts may deem that a few characteristics could dominate future adoption decisions to such a great extent that a particular class of penetration rate is justified. There also may be "windows of opportunity" where significant replacements of existing equipment may be expected to occur at some point in the future for other reasons. ITP analysts inserted into the spreadsheet the class of penetration rate believed most likely, all things considered, and provide a narrative of the rationale for selection, if not obvious, from Table H-3.

For additional assistance, Table $\mathbf{H}-\mathbf{4}$ shows actual technologies and the class of their historical penetration rates. Comparison of the new technology, by analogy or similarity, with these examples provides additional insight into selecting the appropriate penetration rate that might be expected for the new technology. Figure H-2 graphs the historical market penetrations of industrial production technology innovations used in developing the market penetration classes.

The Technology Impact Projections Model translates the number of new technology units operating in each projection year into final energy savings outcomes by multiplying by the difference in the unit annual energy use of the new the conventional technology. As described above, each new technology is assumed to enter the market without the ITP support after the "acceleration period," so that only the net energy savings are credited to the program. 
Table H-3. Selecting the Market-Penetration Rate Class

\begin{tabular}{|c|c|c|c|c|c|c|}
\hline \multirow{2}{*}{$\begin{array}{l}\text { Technology/project } \\
\text { Characteristic }\end{array}$} & & \multirow[b]{2}{*}{ b } & \multirow[b]{2}{*}{ c } & \multirow[b]{2}{*}{ d } & \multirow[b]{2}{*}{ e } & \multirow[t]{2}{*}{$\begin{array}{l}\text { Score } \\
(a, b, c, d, e)\end{array}$} \\
\hline & $\mathbf{a}$ & & & & & \\
\hline Time to saturation & $5 \mathrm{yrs}$ & $10 \mathrm{yrs}$ & 20 yrs & $40 \mathrm{yrs}$ & $>40 \mathrm{yrs}$ & na \\
\hline \multicolumn{7}{|l|}{ Technology factors } \\
\hline $\begin{array}{l}\text { Payback } \\
\text { discretionary }\end{array}$ & $<<1 \mathrm{yr}$ & $<1 \mathrm{yr}$ & $1-3$ yrs & $3-5 \mathrm{yrs}$ & $>5 \mathrm{yrs}$ & \\
\hline $\begin{array}{l}\text { Payback } \\
\text { nondiscretionary* }\end{array}$ & $<<1 \mathrm{yr}$ & $<1 \mathrm{yr}$ & $1-2 \mathrm{yrs}$ & $2-3 \mathrm{yrs}$ & $>3$ yrs & \\
\hline Equipment life & $<5 \mathrm{yrs}$ & $5-15$ yrs & $15-25 \mathrm{yrs}$ & $25-40$ yrs & $>40 \mathrm{yrs}$ & \\
\hline $\begin{array}{l}\text { Equipment } \\
\text { replacement }\end{array}$ & None & Minor & $\begin{array}{l}\text { Unit } \\
\text { operation }\end{array}$ & Plant section & $\begin{array}{l}\text { Entire } \\
\text { plant }\end{array}$ & \\
\hline $\begin{array}{l}\text { Impact on product } \\
\text { quality }\end{array}$ & $\$ \$$ & $\$ \$$ & $\$ \$$ & $\$$ & $0 /-$ & \\
\hline $\begin{array}{l}\text { Impact on plant } \\
\text { productivity }\end{array}$ & $\$ \$$ & $\$ \$$ & $\$ \$$ & $\$$ & $0 /-$ & \\
\hline $\begin{array}{l}\text { Technology } \\
\text { experience }\end{array}$ & $\begin{array}{l}\text { New to } \\
\text { U.S. only }\end{array}$ & $\begin{array}{l}\text { New to } \\
\text { U.S. only }\end{array}$ & $\begin{array}{l}\text { New to } \\
\text { Industry }\end{array}$ & New & New & \\
\hline \multicolumn{7}{|l|}{ Industry factors } \\
\hline $\begin{array}{l}\text { Growth (\%per } \\
\text { annum) }\end{array}$ & $>5 \%$ & $>5 \%$ & $2-5 \%$ & $1-2 \%$ & $<1 \%$ & \\
\hline Attitude to risk & Open & Open & Cautious & Conservative & Averse & \\
\hline External factors & Forcing & Forcing & Driving & None & None & na \\
\hline \multicolumn{7}{|l|}{ Gov't regulation } \\
\hline Other & & & & & & \\
\hline
\end{tabular}

${ }^{*}$ Payback is defined as capital outlay for new technology divided by savings before taxes and depreciation. In the case of discretionary investments (i.e., replacement of existing equipment before the end of its economic life), capital outlay is total cost of new technology. In the case of nondiscretionary investments (i.e., replacement of existing equipment at the end of its economic life and new installations), capital is the capital cost of the new technology capital cost of the current technology. 
Table H-4: Examples of Industrial Innovations

\begin{tabular}{|c|c|c|c|c|c|}
\hline Class & A & B & C & D & $E$ \\
\hline Aluminum & & $\begin{array}{l}\text { Treatment of } \\
\text { used cathode } \\
\text { liners }\end{array}$ & $\begin{array}{l}\text { Strip casting, } \\
\text { VOC } \\
\text { incinerators }\end{array}$ & & \\
\hline Chemicals & $\begin{array}{l}\text { New series of } \\
\text { dehydrogenation } \\
\text { catalyst } \\
\text { (incremental } \\
\text { change) }\end{array}$ & $\begin{array}{l}\text { CFCs -> } \\
\text { HCFCs, } \\
\text { incrementally } \\
\text { improved } \\
\text { catalysts, } \\
\text { membrane- } \\
\text { based chlor- } \\
\text { alkali }\end{array}$ & $\begin{array}{l}\text { Polypropylene } \\
\text { catalysts, } \\
\text { solvent to } \\
\text { water-based } \\
\text { paints, PPE- } \\
\text { based AN }\end{array}$ & $\begin{array}{l}\text { Synthetic } \\
\text { rubber \& fibers }\end{array}$ & \\
\hline Forest Products & & & $\begin{array}{l}\text { Impulse drying, } \\
\text { de-inking of } \\
\text { waste } \\
\text { newspaper }\end{array}$ & $\begin{array}{l}\text { Kraft pulping, } \\
\text { continuous } \\
\text { paper machines }\end{array}$ & \\
\hline Glass & & $\begin{array}{l}\text { Lubbers glass } \\
\text { blowing, } \\
\text { Pilkington float } \\
\text { glass }\end{array}$ & $\begin{array}{l}\text { Particulate } \\
\text { control, } \\
\text { regenerative } \\
\text { melters, } \\
\text { oxygenase in } \\
\text { glass furnaces }\end{array}$ & & \\
\hline Metals Casting & $\begin{array}{l}\text { New shop floor } \\
\text { practice }\end{array}$ & & & & \\
\hline Petroleum & $\begin{array}{l}\text { New series HDS } \\
\text { catalysts }\end{array}$ & $\begin{array}{l}\text { Alkylation } \\
\text { gasoline }\end{array}$ & $\begin{array}{l}\text { Thermal } \\
\text { cracking, } \\
\text { catalytic } \\
\text { cracking }\end{array}$ & $\begin{array}{l}\text { Residue } \\
\text { gasification, } \\
\text { flexicoking }\end{array}$ & \\
\hline Steel & $\begin{array}{l}\text { Improved EAF } \\
\text { operating } \\
\text { practice (e.g. } \\
\text { modify electric/ } \\
\text { burner heating } \\
\text { cycle to } \\
\text { minimize dust } \\
\text { generation) }\end{array}$ & $\begin{array}{l}\text { BOF steel } \\
\text { making }\end{array}$ & $\begin{array}{l}\text { Oxyfuel burners } \\
\text { for steel, Level } \\
\text { II reheat } \\
\text { furnace } \\
\text { controls, } \\
\text { Continuous } \\
\text { casting, } \\
\text { particulate } \\
\text { control on EAF, } \\
\text { Hightop } \\
\text { pressure blast } \\
\text { furnace }\end{array}$ & $\begin{array}{l}\text { Open hearth } \\
\text { technology, } \\
\text { EAF technology }\end{array}$ & \\
\hline Other & & $\begin{array}{l}\text { Advanced } \\
\text { refrigerator } \\
\text { compressors, } \\
\text { oxygen flash } \\
\text { copper } \\
\text { smelting, } \\
\text { solvent } \\
\text { extraction with } \\
\text { liquid ion } \\
\text { exchange }\end{array}$ & $\begin{array}{l}\text { Fluegas } \\
\text { desulfurization } \\
\text { (coal-fired } \\
\text { utilities), low } \\
\mathrm{NO}_{\mathrm{x}} \text { industrial } \\
\text { burners, } \\
\text { industrial gas } \\
\text { turbines, ore } \\
\text { beneficiation }\end{array}$ & & $\begin{array}{l}\text { Dry-kiln cement, } \\
\text { industrial } \\
\text { ceramic } \\
\text { recuperators } \\
\text { Industrial heat } \\
\text { pumps }\end{array}$ \\
\hline
\end{tabular}




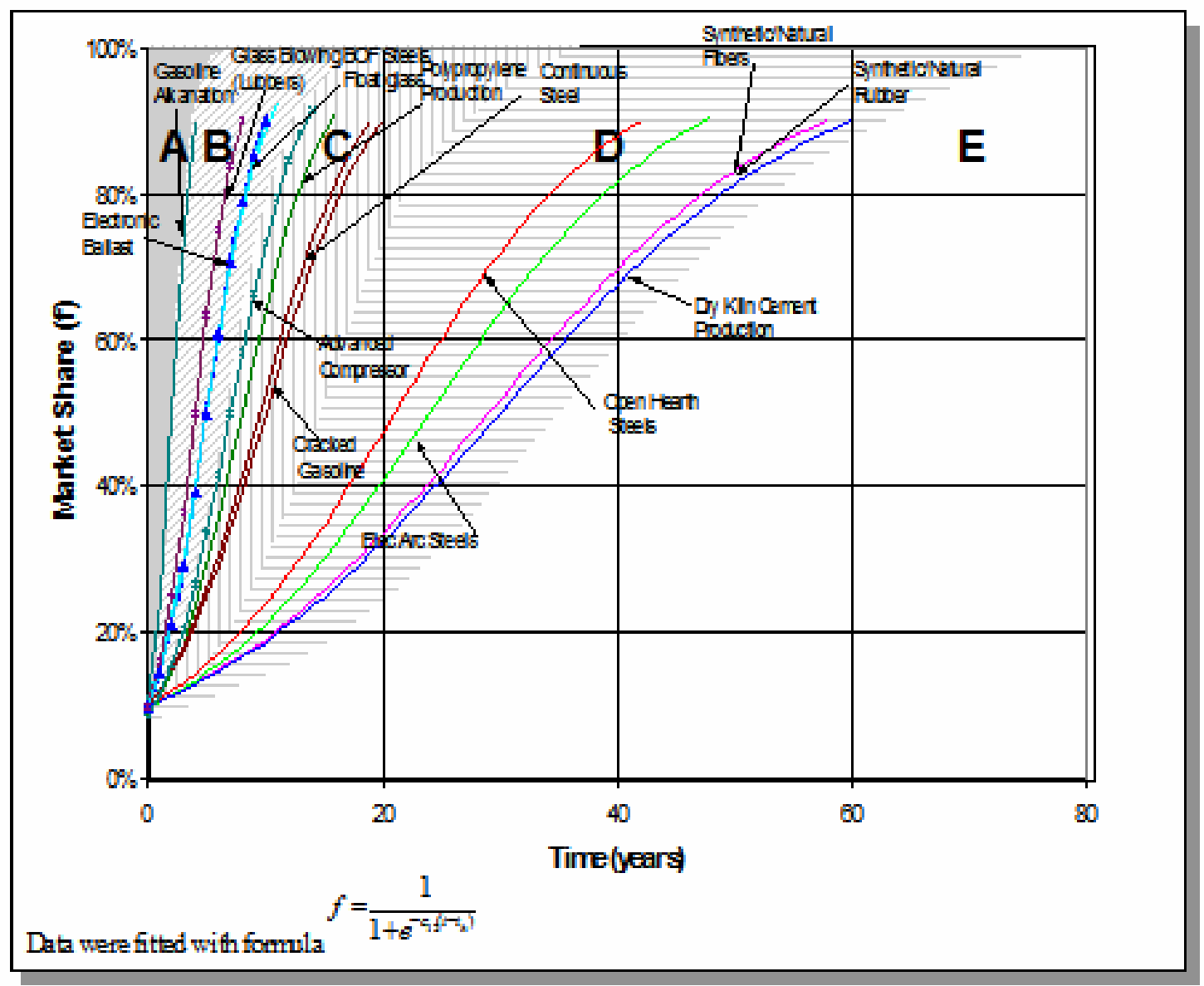

Figure H-2: Market-Penetration Rate Classes

\section{Key Factors in Shaping Market Adoption of EERE technologies}

\section{Price}

ITP methodology places little emphasis on cost-based estimation of market penetration, because useful cost information on industrial technologies in the R\&D stage of development is, in nearly all cases, not available. Instead, relative costs in the form of the expected payback period, were one of numerous market-driving factors in matching the market-penetration schedule with each innovative technology (see previous section). These market-penetration schedules are typical of historical industrial-sector technology innovations, whose characteristic payback period, scale, equipment lifetime, impact on product quality, relevant experience level, market growth rate, attitude to risk, and other factors were matched to each innovative technology to select the best market-penetration schedule. 


\section{Non-price Factors}

- Key Consumer Preferences/Values.

Several consumer preference/value issues were incorporated in the ITP market-penetration curve selection technique. These include factors such as technology scale, equipment lifetime, impact on product quality, etc., listed above.

\section{- Manufacturing Factors.}

The benefits-estimation approach requested the analyst to estimate the year in which the technology is expected to be successfully developed at the successive stages of (1) completion of initial R\&D, (2) initial system prototype, (3) refined prototype, (4) commercial prototype, and finally (5) commercial introduction, given the push provided by the ITP program support. These estimates were documented as part of each spreadsheet model run.

\section{- Policy Factors.}

In the great majority of cases, no policy factors were considered significant to the market introduction and acceptance of ITP technologies. However, for cases where a regulation or other policy will drive the market to accept a new technology solution, the market-penetration curve selection procedure was set up to accept this information and allow it to play a role in the analysis. Any such influence was discussed in documentation provided in the spreadsheet model run. No new policies were assumed for the GPRA08 runs.

\section{Immediate Outputs}

ITP outputs, as shown in Figure H-2, include completed new technologies with improved efficiency and performance, informed stakeholders, and energy assessments and audits completed. No immediate outcomes are included in the logic chain.

\section{Interim Outcomes}

Interim outcomes include the commercialization and market penetration of ITP-funded advanced technologies and plant replications using EERE/ITP technologies.

\section{Final Outcomes (Benefits)}

Final outcomes are the energy savings and other benefits for the industrial sector and the Nation associated with the support provided by the Program. ITP's off-line study reported here computed only energy savings, which were subsequently used by NEMS and MARKAL analysts to produce the full complement of integrated energy-related environmental and economic benefits required for GPRA.

As discussed above, energy savings for R\&D projects were calculated in GPRA08 using the Technology Impact Projections Model, a spreadsheet system with which each of 55 advanced technologies included in the FY 2007 portfolio was analyzed (see Table H-6). The analysis used the methodology described here and summed it to produce results that were extended to represent the R\&D component of the ITP Program. The results for Industries of the Future (IOF) planning units were extended to the new FY 2008 R\&D program components using the same average energy savings per dollar of budget request. 
The Industrial Assessment Centers and BestPractices non-R\&D activities were assessed based on retrospective analysis of performance data accumulated over a period of years. Quality Metrics for these planning units assume that continuation of these activities will result in benefits that are proportional to documented experience at historical budget levels. These analyses assume no continuing contributions from prior program expenditures, but only assume that future expenditures will produce results proportionate to those reported for past expenditures. The results for IAC and Best Practices planning units were extended to the new non-R\&D program components using the same average energy savings per dollar of budget request.

The Industrial Assessment Center (IAC) activity within the Industrial Technologies Program (ITP) has been successfully generating energy savings for more than 25 years. Twenty-six Industrial Assessment Centers located within engineering departments at top universities across the United States conduct comprehensive energy assessments for small- and medium-sized manufacturers and train the future workforce of energy engineers. The IAC generates savings through three main delivery channels: 1) IAC energy assessments, 2) assessments conducted by members of the IAC alumni and 3) the popular IAC database Web site, which includes data from more than 13,000 assessments as well as self-assessment manuals and similar resources.

Projected output and outcome performance estimates rely on information from the IAC assessment database, the IAC student registry, and evaluation work conducted by Oak Ridge National Laboratory (ORNL). The projections assume a flat budget based on the budget request for FY 2007. The IAC database documents savings recommendations and implementation history for plant assessments conducted over a 25 -year period, covering more than 13,000 assessments and nearly 100,000 savings recommendations. ${ }^{2}$

The IAC student registry, established more recently in FY 2001, tracks the progress of students from their starting date through their departure. Finally, ORNL evaluations have studied the longer-term effects of plant assessments, career paths of IAC alumni and the savings potential of Web-based materials offered by the IAC. The calculation of energy savings for the IAC activity is summarized in Table H-7.

The Industrial Technologies Program's (ITP) BestPractices activity is designed to provide industrial plant managers with information to evaluate and implement opportunities for improving the efficiency of energy-intensive systems within their production facilities. These energy-intensive systems include those with motors and drives, pumps, air compressors, steam, fans, and process heat. Estimates of energy savings outcome were developed by ORNL and are based on preliminary results from FY2005 activities and early results from FY2006 Energy Saving Assessments (ESAs). ${ }^{3}$ These estimates reflect a focus on key participants and four main delivery channels of BestPractices.

BestPractices relies on four main delivery channels to disseminate technical information to a target audience of manufacturing establishments with high annual energy consumption (greater

\footnotetext{
${ }^{2}$ The IAC assessment database is at www.iac.rutgers.edu.

${ }^{3}$ Data used in the GPRA analysis reflect the most recent data available at the time of the GPRA analysis and do not reflect finalized FY 2005 participant levels from the BestPractice Tracking Sytem (BPTS), nor does it reflect all programmatic changes implemented in response to the Save Energy Now Secretarial Initiative. Therefore, outcomes for FY 2005 activities documented in reports published after this GPRA08 analysis will include a more accurate representation of FY 2005 performance.
} 
than $\$ 3$ million per year). Considerable numbers of medium-sized manufacturers (with energy costs under $\$ 3$ million per year) also participate in the program. The main delivery channels include: 1) Energy Saving Assessments (ESAs), 2) End-User training, 3) software, and 4) specialists qualified by BestPractices to address industrial applications of energy-intensive steam, fan, pumping, compressed air, and process heating systems.

BestPractices output performance in the four main delivery channels is measured in terms of the number of unique domestic plants represented within the initial reach and the number of unique plants that are believed to take action to implement energy projects. The initial reach represents the total number of participating plants identified in each of the BestPractices delivery channels. The BP Tracking System ${ }^{4}$ provides data on initial reach and participant affiliation, including identification of unique plants. The number of unique plants is then scaled back using data from the literature or participant feedback to estimate the number of unique, U.S. plants taking action due to this information dissemination.

The basic methodology for estimating the energy outcome of BestPractices is a combination of averaged energy savings reported by ESAs and calculated savings for training, software use, and Qualified Specialists. Energy benefits generated by ESAs are based on engineering estimates of savings identified in assessment reports and plant-consumption levels. Savings associated with unique U.S-based plants that implement projects following interaction with Qualified Specialists, or by participation in training or use of software, are estimated using historical assessment data from BestPractices and the Industrial Assessment Centers (IAC). The calculation of energy savings for BestPractices is summarized in Table H-8.

The methodology used to calculate the benefits of the IAC and Best Practices programs is described in detail in Energetics Incorporated, "GPRA08 Quality Metrics - Methodology and Results," draft, June 2006.

\footnotetext{
${ }^{4}$ The BP Tracking System contains general participant information for all annual BestPractices activities. Data from FY 2005 activities recorded in the BP Tracking System was used for the preparation of the GPRA 2008 report. This information is used to categorize participants as unique plants and to eliminate overcounting for those that participate in multiple activities.

Additionally, only participants representing domestically located, unique plants are used in the projected savings estimates.
} 


\section{Summary of Inputs}

Final results of the ITP off-line benefits assessment are presented in Table $\mathbf{H - 5}$. These results were normalized to the FY 2008 budget request: (a) for all R\&D programs, based on 55

Technology Impact Projections Model runs for technologies in the FY 2007 portfolio, and (b) for all Technical Assistance programs, based on the historical performance-based analyses of the FY 2007 IAC and Best Practices planning units. Table H-6 summarizes the Technology Impact Projections Model runs, and Tables H-7 and H-8 summarize the calculation of IAC and Best Practices energy savings, respectively.

Table H-5: GPRA08 ITP Total Energy Savings

\begin{tabular}{|c|c|c|c|c|c|c|c|c|c|}
\hline Impact By Year & 2008 & 2009 & 2010 & 2015 & 2020 & 2025 & 2030 & 2040 & 2050 \\
\hline \multicolumn{10}{|l|}{ ANNUAL SAVINGS } \\
\hline $\begin{array}{l}\text { Energy Metrics } \\
\text { Total primary energy } \\
\text { displaced (trillion Btu) }\end{array}$ & 35.74 & 109.55 & 192.31 & 720.66 & 1525.82 & 2336.52 & 2086.07 & 1321.85 & 933.49 \\
\hline $\begin{array}{l}\text { Direct electricity displaced } \\
\text { (billion kWh) }\end{array}$ & 0.92 & 2.83 & 5.71 & 22.84 & 44.04 & 54.78 & 50.70 & 51.17 & 48.04 \\
\hline $\begin{array}{l}\text { Direct natural gas } \\
\text { displaced (bcf) }\end{array}$ & 19.14 & 51.66 & 93.96 & 369.63 & 809.49 & 1383.68 & 1171.59 & 572.27 & 341.46 \\
\hline $\begin{array}{l}\text { Direct petroleum displaced } \\
\text { (million barrels) }\end{array}$ & 0.43 & 0.98 & 1.71 & 7.21 & 14.67 & 13.80 & 8.06 & 6.21 & 4.98 \\
\hline $\begin{array}{l}\text { Direct coal displaced } \\
\text { (million short tons) }\end{array}$ & 0.13 & 0.85 & 1.26 & 3.31 & 6.01 & 10.01 & 13.46 & 8.18 & 3.15 \\
\hline $\begin{array}{c}\text { Feedstock energy } \\
\text { displaced (trillion BTU) }\end{array}$ & 1.48 & 2.48 & 4.55 & 30.75 & 109.36 & 135.32 & 77.91 & 56.49 & 67.49 \\
\hline $\begin{array}{l}\text { Biomass energy displaced } \\
\text { (trillion BTU) }\end{array}$ & 0.00 & 0.00 & 0.51 & 1.46 & 3.95 & 11.83 & 21.74 & 25.50 & 21.73 \\
\hline $\begin{array}{l}\text { Waste energy displaced } \\
\text { (trillion BTU) }\end{array}$ & 0.00 & 0.12 & 0.19 & 1.50 & 6.21 & 5.95 & 1.49 & 0.03 & 0.00 \\
\hline $\begin{array}{c}\text { Other energy displaced } \\
\text { (trillion Btu) }\end{array}$ & 0.25 & 0.53 & 1.05 & 4.89 & 12.35 & 18.19 & 20.72 & 21.50 & 12.76 \\
\hline
\end{tabular}

Table H-6: Summary of 55 Technology Impact Projections Model Runs for GPRA08

\begin{tabular}{|l|l|c|c|c|c|}
\hline \multicolumn{1}{|c|}{\begin{tabular}{|}
\multicolumn{1}{|c|}{ Impact } \\
Target
\end{tabular}} & \multicolumn{1}{|c|}{ Project } & $\begin{array}{c}\text { Energy } \\
\text { Savings } \\
\mathbf{( T b t u )} \\
\mathbf{2 0 1 0}\end{array}$ & $\begin{array}{c}\text { Energy } \\
\text { Savings } \\
\text { (TBtu) } \\
\mathbf{2 0 2 0}\end{array}$ & $\begin{array}{c}\text { Energy } \\
\text { Savings } \\
\text { (TBtu) } \\
\mathbf{2 0 3 0}\end{array}$ & $\begin{array}{c}\text { Year of } \\
\text { Intro / Market } \\
\text { Selector / } \\
\text { Acceleration Period }\end{array}$ \\
\hline $\begin{array}{l}\text { Efficient } \\
\text { Aluminum } \\
\text { Melting } \\
\text { Technologies }\end{array}$ & $\begin{array}{l}\text { Energy Efficient Melting and Direct Delivery } \\
\text { of High Quality Molten Aluminum (Energy } \\
\text { Efficient Isothermal Melting of Aluminum) } \\
\text { CPS Agreement \#13128 }\end{array}$ & 0.4 & 12.7 & 11.0 & $2008 / \mathrm{b} / 12$ \\
\hline $\begin{array}{l}\text { Aluminum } \\
\text { Forming } \\
\text { Technologies }\end{array}$ & $\begin{array}{l}\text { Hot Rolling Scrap Reduction through Edge } \\
\text { Cracking and Surface Defects Control }\end{array}$ & 0.01 & 0.5 & 1.1 & $2010 / \mathrm{b} / 20$ \\
\hline CPS Agreement \#13134 & Aluminum Subtotal & $\mathbf{0 . 4}$ & $\mathbf{1 3 . 2}$ & $\mathbf{1 2 . 2}$ & \\
\hline Chemicals & Olefins by High Intensity Oxidation & 2.9 & 43.8 & 2.6 & $2008 / \mathrm{b} / 3$ \\
\hline
\end{tabular}




\begin{tabular}{|c|c|c|c|c|c|}
\hline $\begin{array}{l}\text { Impact } \\
\text { Target }\end{array}$ & Project & $\begin{array}{c}\text { Energy } \\
\text { Savings } \\
\text { (Tbtu) } \\
\mathbf{2 0 1 0}\end{array}$ & $\begin{array}{l}\text { Energy } \\
\text { Savings } \\
\text { (TBtu) } \\
\mathbf{2 0 2 0}\end{array}$ & $\begin{array}{l}\text { Energy } \\
\text { Savings } \\
\text { (TBtu) } \\
2030\end{array}$ & $\begin{array}{c}\text { Year of } \\
\text { Intro / Market } \\
\text { Selector / } \\
\text { Acceleration Period }\end{array}$ \\
\hline \multirow[t]{14}{*}{$\begin{array}{l}\text { Processing } \\
\text { Technologies }\end{array}$} & $\begin{array}{l}\text { Advances in Process Intensification Through } \\
\text { Multifunctional reactor Engineering }\end{array}$ & 0.3 & 2.5 & 17.2 & $2010 / \mathrm{c} / 5$ \\
\hline & $\begin{array}{l}\text { Using Ionic Liquids in Selective Hydrocarbon } \\
\text { Conversion Processes }\end{array}$ & 0.0 & 1.7 & 16.3 & $2012 / \mathrm{c} / 3$ \\
\hline & Purification Process for PTA & 0.1 & 2.7 & 1.6 & $2008 / b / 10$ \\
\hline & $\begin{array}{l}\text { Production and Separation of Fermentation } \\
\text { Derived Acetic Acid }\end{array}$ & 0.0 & 13.8 & 7.3 & $2011 / b / 5$ \\
\hline & Millisecond Oxidation of Alkenes & 0.7 & 35.3 & 16.3 & $2009 / b / 7$ \\
\hline & $\begin{array}{l}\text { Oxidative Dehydrogenation of Ethane Present } \\
\text { in Natural Gas to Ethylene }\end{array}$ & 0.0 & 34.8 & 26.9 & $2012 / b / 4$ \\
\hline & $\begin{array}{l}\text { Development of Highly Selective Oxidation } \\
\text { Catalysts by Atomic Layer Deposition }\end{array}$ & 0.0 & 24.3 & 62.6 & $2014 / b / 4$ \\
\hline & $\begin{array}{l}\text { Microchannel Reactor System for Catalytic } \\
\text { Hydrogenation }\end{array}$ & 0.3 & 27.1 & 19.3 & $2011 / b / 6$ \\
\hline & Microchannel Reactor System for $\mathrm{H}_{2} \mathrm{O}_{2}$ & 0.7 & 36.0 & 14.2 & $2010 / \mathrm{b} / 5$ \\
\hline & $\begin{array}{l}\text { Enhanced Productivity of Chemical Processes } \\
\text { Using Dense Fluidized Beds }\end{array}$ & 1.0 & 6.1 & 28.9 & $2010 / \mathrm{c} / 5$ \\
\hline & $\begin{array}{l}\text { Low Cost Chemical Feedstocks Using an } \\
\text { Improved Energy Efficient NGL Removal } \\
\text { Process }\end{array}$ & 1.3 & 17.3 & 0.9 & $2008 / b / 3$ \\
\hline & $\begin{array}{l}\text { Development of Advanced membrane } \\
\text { Technology Platforms for Hydrocarbon } \\
\text { Separations }\end{array}$ & 0.4 & 3.3 & 23.9 & $2008 / \mathrm{c} / 5$ \\
\hline & $\begin{array}{l}\text { Heat Integrated Distillation Through the Use } \\
\text { of Microchannel Technology }\end{array}$ & 0.5 & 32.6 & 23.2 & $2010 / b / 7$ \\
\hline & Chemicals Subtotal & 8.1 & 281.2 & 260.9 & \\
\hline $\begin{array}{l}\text { Paper Pulp } \\
\text { Fiber } \\
\text { Recycling }\end{array}$ & $\begin{array}{l}\text { Development of Screenable Wax Coating \& } \\
\text { Water-Based Pressure Sensitive Adhesives } \\
\text { (PSAs) }\end{array}$ & 0.1 & 3.7 & 7.4 & $2010 / b / 10$ \\
\hline \multirow[t]{6}{*}{$\begin{array}{l}\text { High } \\
\text { Efficiency } \\
\text { Pulping }\end{array}$} & $\begin{array}{l}\text { Increasing Yield and Quality of Low- } \\
\text { Temperature, Low-Alkali Kraft Cooks with } \\
\text { Microwave Pretreatment }\end{array}$ & 0.5 & 2.7 & 11.6 & $2010 / \mathrm{c} / 5$ \\
\hline & $\begin{array}{l}\text { Integration of MSS-AQ Pulping and BL } \\
\text { Gasification }\end{array}$ & 0.4 & 0.7 & 1.9 & $2010 / \mathrm{d} / 10$ \\
\hline & $\begin{array}{l}\text { Improved Wood Properties through Genetic } \\
\text { Manipulation: Syringyl-type lignin }\end{array}$ & 0.0 & 1.4 & 3.2 & $2015 / \mathrm{d} / 10$ \\
\hline & $\begin{array}{l}\text { Directed Causticizing for BLG in Circulating } \\
\text { Fluidized Bed }\end{array}$ & 0.2 & 0.3 & 0.9 & $2010 / \mathrm{d} / 10$ \\
\hline & $\begin{array}{l}\text { Hemicellulose Extraction and Its Integration } \\
\text { in Pulp Production }\end{array}$ & 0.0 & 0.5 & 3.0 & $2015 / \mathrm{c} / 10$ \\
\hline & Highly Efficient D-GLU Pulping & 0.0 & 4.2 & 39.9 & $2015 / b / 10$ \\
\hline \multirow{4}{*}{$\begin{array}{l}\text { Innovative } \\
\text { Wood Drying } \\
\text { and Curing }\end{array}$} & Biological Air Emissions Control & 0.0 & 0.7 & 6.9 & $2015 / b / 10$ \\
\hline & HAPs Reduction from Drying \& Pressing & 0.4 & 34.1 & 4.7 & $2010 / \mathrm{a} / 5$ \\
\hline & $\begin{array}{l}\text { Development of Renewable Microbial } \\
\text { Polyesters for Wood-Plastic Composites }\end{array}$ & 0.3 & 2.3 & 11.4 & $2010 / \mathrm{c} / 10$ \\
\hline & Forest Products Subtotal & 1.8 & 50.4 & 90.8 & \\
\hline
\end{tabular}




\begin{tabular}{|c|c|c|c|c|c|}
\hline $\begin{array}{l}\text { Impact } \\
\text { Target }\end{array}$ & Project & $\begin{array}{c}\text { Energy } \\
\text { Savings } \\
\text { (Tbtu) } \\
\mathbf{2 0 1 0} \\
\end{array}$ & $\begin{array}{l}\text { Energy } \\
\text { Savings } \\
\text { (TBtu) } \\
\mathbf{2 0 2 0}\end{array}$ & $\begin{array}{l}\text { Energy } \\
\text { Savings } \\
\text { (TBtu) } \\
\mathbf{2 0 3 0} \\
\end{array}$ & $\begin{array}{c}\text { Year of } \\
\text { Intro / Market } \\
\text { Selector / } \\
\text { Acceleration Period }\end{array}$ \\
\hline $\begin{array}{l}\text { Advanced } \\
\text { Melting / } \\
\text { Innovative } \\
\text { Casting } \\
\text { Processes }\end{array}$ & $\begin{array}{l}\text { Energy Saving Melting and Revert Reduction } \\
\text { Technology (E-SMARRT) }\end{array}$ & 0.0 & 37.6 & 80.3 & $2014 / b / 20$ \\
\hline \multirow[t]{2}{*}{$\begin{array}{l}\text { Innovative } \\
\text { Casting } \\
\text { Processes }\end{array}$} & $\begin{array}{l}\text { In-Situ Real Time Monitoring and Control of } \\
\text { Mold Making and Filling Processes }\end{array}$ & 0.0 & 1.9 & 7.1 & $2011 / b / 20$ \\
\hline & Metal Casting Total & 0.0 & 39.5 & 87.4 & \\
\hline \multirow[t]{2}{*}{$\begin{array}{l}\text { Cokeless } \\
\text { Ironmaking }\end{array}$} & $\begin{array}{l}\text { Mesabi Nugget Research Project (future } \\
\text { efforts) }\end{array}$ & 14.6 & 74.8 & 252.2 & $2009 / \mathrm{c} / 5$ \\
\hline & $\begin{array}{l}\text { Next Gen Metallic Iron Nodule Technology } \\
\text { for EAFs }\end{array}$ & 0.0 & 7.0 & 28.4 & $2010 / \mathrm{c} / 6$ \\
\hline $\begin{array}{l}\text { Next- } \\
\text { Generation } \\
\text { Steelmaking }\end{array}$ & $\begin{array}{l}\text { Process to Continuous Melt, Refine, and Cast } \\
\text { Steel }\end{array}$ & 0.4 & 2.6 & 14.6 & $2010 / \mathrm{c} / 8$ \\
\hline \multirow{10}{*}{$\begin{array}{l}\text { Advanced } \\
\text { Steel Process } \\
\text { Development }\end{array}$} & $\begin{array}{l}\text { Automated Steel Cleanliness Analysis Tool } \\
\text { (ASCAT) }\end{array}$ & 0.1 & 2.2 & 0.0 & 2009/a/7 \\
\hline & $\begin{array}{l}\text { Development of Submerged Entry Nozzles } \\
\text { that Resist Clogging }\end{array}$ & 0.3 & 9.4 & 2.1 & $2009 / \mathrm{b} / 6$ \\
\hline & $\begin{array}{l}\text { Inclusion Optimization for Next Generation } \\
\text { Steel Products }\end{array}$ & 0.1 & 4.0 & 2.0 & 2009/b/9 \\
\hline & Validation of Hot Strip Mill Model & 0.1 & 1.2 & 0.2 & $2009 / b / 5$ \\
\hline & $\begin{array}{l}\text { Enrichment of By-products from Pickling } \\
\text { Acid Regeneration Plants }\end{array}$ & 0.0 & 0.2 & 0.0 & $2009 / b / 5$ \\
\hline & $\begin{array}{l}\text { Characterization of Fatigue and High Strain } \\
\text { Rate Deformation }\end{array}$ & 0.1 & 1.4 & 0.5 & $2009 / b / 8$ \\
\hline & Direct Flame Impingement & 0.2 & 1.1 & 3.8 & $2009 / \mathrm{c} / 4$ \\
\hline & Elimination of Oscillation Marks & 0.0 & 1.4 & 2.2 & $2013 / \mathrm{b} / 5$ \\
\hline & $\begin{array}{l}\text { Criteria of Yield Point Elongation of Surface- } \\
\text { Critical Steels }\end{array}$ & 0.0 & 0.5 & 0.1 & $2009 / b / 5$ \\
\hline & Steel Subtotal & 15.8 & 98.8 & 277.5 & \\
\hline \multirow{8}{*}{$\begin{array}{l}\text { Advanced } \\
\text { Industrial } \\
\text { Materials }\end{array}$} & $\begin{array}{l}\text { Novel Refractories for High Alkaline } \\
\text { Environments - ORNL }\end{array}$ & 0.0 & 9.6 & 64.7 & $2014 / b / 11$ \\
\hline & $\begin{array}{l}\text { Advanced Membrane Separation } \\
\text { Technologies for Energy Reduction from } \\
\text { Industrial Process Streams - ORNL }\end{array}$ & 0.0 & 16.2 & 123.8 & $2014 / b / 16$ \\
\hline & $\begin{array}{l}\text { Advanced Wear-Resistant Nanocomposites } \\
\text { for Increased Energy Efficiency -Ames }\end{array}$ & 0.0 & 8.9 & 29.0 & $2012 / b / 13$ \\
\hline & $\begin{array}{l}\text { Nanocoatings for High-Efficiency Industrial } \\
\text { Hydraulic and Tooling Systems - Eaton }\end{array}$ & 0.04 & 1.7 & 1.1 & $2010 / b / 8$ \\
\hline & $\begin{array}{l}\text { Hydrogen Transport Membrane Material for } \\
\text { Green Ethylene Production - Innovene }\end{array}$ & 0.0 & 5.9 & 46.6 & $2012 / \mathrm{c} / 38$ \\
\hline & $\begin{array}{l}\text { Aerogel-Based Insulation for Industrial } \\
\text { Steam Distribution Systems - Aspen }\end{array}$ & 0.0 & 48.3 & 19.1 & $2011 / b / 5$ \\
\hline & $\begin{array}{l}\text { Heirarchical Nanoceramics for Industrial } \\
\text { Process Sensors - GE }\end{array}$ & 0.0 & 3.2 & 24.5 & $2012 / \mathrm{c} / 4$ \\
\hline & Industrial Materials Subtotal & 0.04 & 93.7 & 308.7 & \\
\hline
\end{tabular}

Projected Benefits of Federal Energy Efficiency and Renewable Energy Programs (FY 2008-FY 2050) Appendix H-Industrial Technologies Program - Page H-22 


\begin{tabular}{|c|c|c|c|c|c|}
\hline $\begin{array}{l}\text { Impact } \\
\text { Target }\end{array}$ & Project & $\begin{array}{l}\text { Energy } \\
\text { Savings } \\
\text { (Tbtu) } \\
2010\end{array}$ & $\begin{array}{l}\text { Energy } \\
\text { Savings } \\
\text { (TBtu) } \\
\mathbf{2 0 2 0}\end{array}$ & $\begin{array}{l}\text { Energy } \\
\text { Savings } \\
\text { (TBtu) } \\
\mathbf{2 0 3 0}\end{array}$ & $\begin{array}{c}\text { Year of } \\
\text { Intro / Market } \\
\text { Selector / } \\
\text { Acceleration Period }\end{array}$ \\
\hline \multirow{2}{*}{$\begin{array}{l}\text { Advanced } \\
\text { Sensors }\end{array}$} & Surface Quality Assured Steel Bar & 1.5 & 37.0 & 4.1 & $2009 / \mathrm{b} / 4$ \\
\hline & $\begin{array}{l}\text { Honeywell PHASED Gas Composition } \\
\text { Microanalytics }\end{array}$ & 0.6 & 6.5 & 4.8 & $2009 / \mathrm{c} / 3$ \\
\hline \multirow{4}{*}{$\begin{array}{l}\text { Affordable } \\
\text { Wireless } \\
\text { Technologies }\end{array}$} & Eaton Wireless Sensor Network & 2.1 & 42.4 & 4.2 & $2009 / \mathrm{b} / 4$ \\
\hline & $\begin{array}{l}\text { GE Distributed Wireless Multi-sensor } \\
\text { Technologies }\end{array}$ & 1.9 & 30.6 & 2.2 & $2009 / b / 3$ \\
\hline & Honeywell Wireless & 1.3 & 22.5 & 1.7 & $2009 / b / 3$ \\
\hline & Sensors and Automation Subtotal & 7.3 & 138.9 & 17.0 & na \\
\hline \multirow[t]{6}{*}{$\begin{array}{l}\text { Combustion } \\
\text { Technologies }\end{array}$} & $\begin{array}{l}\text { Super Boiler PM/TM Boiler Development } \\
\text { and Demonstration }\end{array}$ & 2.0 & 54.7 & 27.0 & $2009 / b / 10$ \\
\hline & $\begin{array}{l}\text { Super Boiler 2nd Generation Technology for } \\
\text { Watertube Boilers }\end{array}$ & 0.0 & 122.6 & 238.4 & $2012 / b / 8$ \\
\hline & $\begin{array}{l}\text { Modular, High Efficiency, Low Emissions } \\
\text { Package Boiler }\end{array}$ & 0.0 & 73.3 & 142.6 & $2012 / b / 8$ \\
\hline & $\begin{array}{l}\text { Multi-Staged Printed Circuit Boiler for } \\
\text { Industrial Applications }\end{array}$ & 0.0 & 44.1 & 164.4 & $2012 / b / 8$ \\
\hline & Advanced Combustion Subtotal & 2.0 & 294.7 & 572.4 & \\
\hline & Grand Total for 55 R\&D Projects & 35.4 & 1010.4 & 1626.9 & \\
\hline
\end{tabular}


Table H-7: IAC Program - QM Estimation and Summary

\begin{tabular}{|c|c|c|c|c|c|c|c|}
\hline Item & & 2008 & 2010 & 2015 & 2020 & 2025 & 2030 \\
\hline & Assessments & & & & & & \\
\hline 1 & New plants affected & 300 & 300 & 300 & 300 & 300 & 300 \\
\hline 2 & Cumulative plants affected & 300 & 900 & 2400 & 3900 & 5400 & 6900 \\
\hline 3 & Plants retired from count each year & & & 300 & 300 & 300 & 300 \\
\hline 4 & Cumulative plants retired from counting & & & 300 & 1800 & 3300 & 4800 \\
\hline 5 & Net plants still affected & 300 & 900 & 2100 & 2100 & 2100 & 2100 \\
\hline 6 & Average MMBtu savings per plant assessment & 5900 & 5900 & 5900 & 5900 & 5900 & 5900 \\
\hline 7 & $\begin{array}{l}\text { Delayed, replicated and spin-off MMBtu savings } \\
\text { generated per plant }\end{array}$ & & 1475 & 1475 & 1475 & 1475 & 1475 \\
\hline \multirow[t]{2}{*}{8} & Total TBtu savings from assessments & 1.77 & 6.20 & 15.49 & 15.49 & 15.49 & 15.49 \\
\hline & Alumni & & & & & & \\
\hline 9 & Number of students graduated in each year & & 70 & 70 & 70 & 70 & 70 \\
\hline 10 & Cumulative number of alumni & & 70 & 420 & 770 & 1120 & 1470 \\
\hline 11 & Percent of alumni staying in energy efficiency & & $50 \%$ & $50 \%$ & $50 \%$ & $50 \%$ & $50 \%$ \\
\hline 12 & Cumulative number of alumni staying in energy efficiency & & 35 & 210 & 385 & 560 & 735 \\
\hline 13 & Alumni retired from count each year & & 0 & 0 & 0 & 35 & 35 \\
\hline 14 & Cumulative alumni retired from counting & & 0 & 0 & 0 & 175 & 350 \\
\hline 15 & Net alumni still counted & & 35 & 210 & 385 & 385 & 385 \\
\hline 16 & Number of assessments conducted per alumnus & & 4 & 4 & 4 & 4 & 4 \\
\hline 17 & Number of alumni assessments annual total & & 140 & 840 & 1540 & 1540 & 1540 \\
\hline 18 & Cumulative alumni conducted assessments & & 140 & 2940 & 9240 & 16940 & 24640 \\
\hline 19 & Alumni assessments retired from count each year & & & & 560 & 1260 & 1540 \\
\hline 20 & Cumulative retired alumni assessments & & & & 1400 & 6300 & 13860 \\
\hline 21 & Net alumni assessments still counted & & 140 & 2940 & 7840 & 10640 & 10780 \\
\hline 22 & Average MMBtu savings per alumni assessment & & 5900 & 5900 & 5900 & 5900 & 5900 \\
\hline 23 & $\begin{array}{l}\text { Delayed, replicated and spin-off MMBtu savings } \\
\text { generated per alumni assessment }\end{array}$ & & & 1475 & 1475 & 1475 & 1475 \\
\hline \multirow[t]{2}{*}{24} & Total TBtu savings from alumni & & 0.83 & 20.44 & 56.37 & 78.06 & 79.50 \\
\hline & Web Users & & & & & & \\
\hline 25 & Annual number of unique visitors (initial reach) & 30,000 & 30,000 & 30,000 & 30,000 & 30,000 & 30,000 \\
\hline 26 & Number of unique plants using the database & 394 & 394 & 394 & 394 & 394 & 394 \\
\hline 27 & Number of unique plants that implement projects & 78 & 78 & 78 & 78 & 78 & 78 \\
\hline 28 & $\begin{array}{l}\text { Cumulative number of unique plants that } \\
\text { implement projects }\end{array}$ & 78 & 234 & 624 & 1014 & 1404 & 1794 \\
\hline 29 & Number of unique plants retiring projects each year & & 0 & 78 & 78 & 78 & 78 \\
\hline 30 & Cumulative number of unique plants retiring projects & & 0 & 78 & 468 & 858 & 1248 \\
\hline 31 & Net number of unique plants with implemented projects & 78 & 234 & 546 & 546 & 546 & 546 \\
\hline 32 & $\begin{array}{l}\text { Average MMBtu savings per unique plant } \\
\text { implementing measures }\end{array}$ & 5900 & 5900 & 5900 & 5900 & 5900 & 5900 \\
\hline 33 & $\begin{array}{l}\text { Total TBtu savings from web users (unique plants } \\
\text { implementing measures) }\end{array}$ & 0.46 & 1.38 & 3.22 & 3.22 & 3.22 & 3.22 \\
\hline 34 & $\begin{array}{l}\text { IAC PROGRAM } \\
\text { Total Energy Savings (TBtu) }\end{array}$ & 2.23 & 8.40 & 39.15 & 75.08 & 96.77 & 98.21 \\
\hline
\end{tabular}

Projected Benefits of Federal Energy Efficiency and Renewable Energy Programs (FY 2008-FY 2050) Appendix H - Industrial Technologies Program - Page H-24 
Table H-8: BestPractices Program - QM Estimation and Summary

\begin{tabular}{|c|c|c|c|c|c|c|c|}
\hline & & 2008 & 2010 & 2015 & 2020 & 2025 & 2030 \\
\hline Item & Energy Saving Assessments for Large Plants & & & & & & \\
\hline 1 & New Original Plants Implementing Each Year & 200 & 200 & 200 & 200 & 200 & 200 \\
\hline 2 & New Replicating Plants Implementing Each Year & 550 & 550 & 550 & 550 & 550 & 550 \\
\hline 3 & Cumulative Original Plants Affected & 200 & 600 & 1600 & 2600 & 3600 & 4600 \\
\hline 4 & Cumulative Replicating Plants Affected & 550 & 1650 & 4400 & 7150 & 9900 & 12650 \\
\hline 5 & Cumulative Total Plants Affected & 750 & 2250 & 6000 & 9750 & 13500 & 17250 \\
\hline 6 & Average Original Identified TBtus Savings per Plant & 0.120 & 0.120 & 0.120 & 0.120 & 0.120 & 0.120 \\
\hline 7 & Average Identified TBtus Savings per Replicating Plant & 0.120 & 0.120 & 0.120 & 0.120 & 0.120 & 0.120 \\
\hline 8 & Original Implemented TBtus Savings & 4.32 & 12.96 & 12.96 & 12.96 & 12.96 & 12.96 \\
\hline 9 & Replicated Implemented TBtus Savings & 11.88 & 35.64 & 35.64 & 35.64 & 35.64 & 35.64 \\
\hline 10 & Total New Implemented Energy Savings (TBtu) & 16.20 & 48.60 & 48.60 & 48.60 & 48.60 & 48.60 \\
\hline 11 & Persisted Energy Savings (from up to 7 years previous, TBtu) & 0.00 & 48.60 & 275.40 & 291.60 & 291.60 & 291.60 \\
\hline \multirow[t]{2}{*}{12} & Total Energy Savings from Energy Saving Assessments & 16.20 & 97.20 & 324.00 & 340.20 & 340.20 & 340.20 \\
\hline & Training Medium Plants & & & & & & \\
\hline 13 & Number of Medium Plants Represented in Initial Reach & 1,061 & 1,061 & 1,061 & 1,061 & 1,061 & 1,061 \\
\hline 14 & Number of Medium Unique Plants Taking Action & 531 & 531 & 531 & 531 & 531 & 531 \\
\hline 15 & Cumulative Number of Medium Unique Plants Taking Action & 531 & 1,592 & 4,244 & 6,897 & 9,549 & 12,202 \\
\hline 16 & Unique Medium Plants Retired from Count Each Year & & & 531 & 531 & 531 & 531 \\
\hline 17 & Cumulative Number of Medium Plants Retired from Counting & & & 531 & 3,183 & 5,836 & 8,488 \\
\hline 18 & Net Medium Unique Plants Implementing Savings & 531 & 1,592 & 3,714 & 3,714 & 3,714 & 3,714 \\
\hline 19 & Average TBtu Savings per Medium Plant & 0.002 & 0.002 & 0.002 & 0.002 & 0.002 & 0.002 \\
\hline \multirow[t]{2}{*}{20} & Total Energy Savings from Training with Medium Plants (TBtu) & 0.98 & 2.95 & 6.87 & 6.87 & 6.87 & 6.87 \\
\hline & Training Large Plants & & & & & & \\
\hline 21 & Number of Large Plants Represented in Initial Reach & 136 & 136 & 136 & 136 & 136 & 136 \\
\hline 22 & Number of Large Unique Plants Taking Action & 68 & 68 & 68 & 68 & 68 & 68 \\
\hline 23 & Cumulative Number of Large Unique Plants Taking Action & 68 & 204 & 544 & 884 & 1,224 & 1,564 \\
\hline 24 & Large Unique Plants Retired from Count Each Year & & & 68 & 68 & 68 & 68 \\
\hline 25 & Cumulative Large Plants Retired from Counting & & & 68 & 408 & 748 & 1,088 \\
\hline 26 & Net Large Unique Plants Implementing Savings & 68 & 204 & 476 & 476 & 476 & 476 \\
\hline 27 & Average TBtu Savings per Large Plant & 0.061 & 0.061 & 0.061 & 0.061 & 0.061 & 0.061 \\
\hline \multirow[t]{2}{*}{28} & Total Energy Savings from Training with Large Plants (TBtu) & 4.17 & 12.52 & 29.20 & 29.20 & 29.20 & 29.20 \\
\hline & Software Medium Plants & & & & & & \\
\hline 29 & Number of Medium U.S. Plants Represented in Initial Research & 2,705 & 2,705 & 2,705 & 2,705 & 2,705 & 2,705 \\
\hline 30 & Number of Medium U.S. Plants Taking Action Each Year & 541 & 541 & 541 & 541 & 541 & 541 \\
\hline 31 & Cumulative Medium U.S. Plants Taking Action & 541 & 1,623 & 4,328 & 7,033 & 9,738 & 12,443 \\
\hline 32 & Medium U.S. Plants Retired from Count Each Year & & & 541 & 541 & 541 & 541 \\
\hline 33 & Cumulative Medium U.S. Plants Retired from Count & & & 541 & 3,246 & 5,951 & 8,656 \\
\hline 34 & Net Medium Unique Plants Implementing Savings & 541 & 1,623 & 3,787 & 3,787 & 3,787 & 3,787 \\
\hline 35 & Average Energy Savings per Medium U.S. Plant & 0.002 & 0.002 & 0.002 & 0.002 & 0.002 & 0.002 \\
\hline \multirow[t]{2}{*}{36} & Total Savings from Software Use by Medium U.S. Plants (TBtu) & 1.07 & 3.21 & 7.48 & 7.48 & 7.48 & 7.48 \\
\hline & Software Large Plants & & & & & & \\
\hline 37 & Number of Large U.S. Plants Represented in Initial Research & 383 & 383 & 383 & 383 & 383 & 383 \\
\hline 38 & Number of Large U.S. Plants Taking Action Each Year & 77 & 77 & 77 & 77 & 77 & 77 \\
\hline 39 & Cumulative Large U.S. Plants Taking Action & 77 & 230 & 613 & 996 & 1,379 & 1,762 \\
\hline 40 & Large U.S. Plants Retired from Count Each Year & & & 77 & 77 & 77 & 77 \\
\hline 41 & Cumulative Large U.S. Plants Retired from Count & & & 77 & 460 & 843 & 1,226 \\
\hline 42 & Net Large Unique Plants Implementing Savings & 77 & 230 & 536 & 536 & 536 & 536 \\
\hline 43 & Average Energy Savings per Large U.S. Plant (TBtu) & 0.064 & 0.064 & 0.064 & 0.064 & 0.064 & 0.064 \\
\hline \multirow[t]{2}{*}{44} & Total Savings from Software Use by Large U.S. Plants (TBtu) & 4.90 & 14.70 & 34.30 & 34.30 & 34.30 & 34.30 \\
\hline & Qualified Specialists Medium Plants & & & & & & \\
\hline 45 & Unique Plants Affected in Each Year & 540 & 540 & 540 & 540 & 540 & 540 \\
\hline 46 & Number of Unique Plants Taking Action & 270 & 270 & 270 & 270 & 270 & 270 \\
\hline 47 & Cumulative Number of Unique Plants Taking Action & 270 & 810 & 2,160 & 3,510 & 4,860 & 6,210 \\
\hline 48 & Unique Plants Retired From Count Each Year & & & 270 & 270 & 270 & 270 \\
\hline 49 & Cumulative Plants Retired from Counting & & & 270 & 1,620 & 2,970 & 4,320 \\
\hline 50 & Net Unique Medium Plants Implementing Savings & 270 & 810 & 1,890 & 1,890 & 1,890 & 1,890 \\
\hline 51 & Average TBtu Savings per Plant & 0.001 & 0.001 & 0.001 & 0.001 & 0.001 & 0.001 \\
\hline \multirow[t]{2}{*}{52} & Total Savings from Qualified Specialists (TBtu) & 0.37 & 1.12 & 2.61 & 2.61 & 2.61 & 2.61 \\
\hline & Qualified Specialists Large Plants & & & & & & \\
\hline 53 & Unique Plants Affected in Each Year & 127 & 127 & 127 & 127 & 127 & 127 \\
\hline 54 & Number of Unique Plants Taking Action & 64 & 64 & 64 & 64 & 64 & 64 \\
\hline 55 & Cumulative Number of Unique Plants Taking Action & 64 & 191 & 508 & 826 & 1,143 & 1,461 \\
\hline 56 & Unique Plants Retired from Count Each Year & & & 64 & 64 & 64 & 64 \\
\hline 57 & Cumulative Plants Retired from Counting & & & 64 & 381 & 699 & 1,016 \\
\hline 58 & Net Unique Large Plants Implementing Savings & 64 & 191 & 445 & 445 & 445 & 445 \\
\hline 59 & Average TBtu Savings per Plant & 0.079 & 0.079 & 0.079 & 0.079 & 0.079 & 0.079 \\
\hline 60 & Total Savings from Qualified Specialists (TBtu) & 5.03 & 15.10 & 35.23 & 35.23 & 35.23 & 35.23 \\
\hline 61 & ENERGY TOTAL FOR ALL DELIVERY CHANNELS (TBtu) & 327 & 147 & 440 & 456 & 456 & 456 \\
\hline
\end{tabular}

Projected Benefits of Federal Energy Efficiency and Renewable Energy Programs (FY 2008-FY 2050) Appendix H - Industrial Technologies Program - Page H-25 


\section{Bibliography}

DOE/EIA, Annual Energy Outlook 2006.

DOE/EERE, Industrial Technologies Program Multiyear Program Plan, August 2006.

DOE Office of the Chief Financial Officer, Department of Energy Five-Year Plan FY 2007-FY 2011 Volume I. March 15, 2006. See http://www.science.doe.gov/Budget and Planning/FiveYear\%20Plan/FYP\%20Vol\%20I\%20-\%20final\%20version.pdf.

Energetics Incorporated, "GPRA08 Quality Metrics - Methodology and Results," draft, June 2006.

ITP Technology Impact Projections Model (GPRA 2008 shell v8.1 - 3/8/06), Energetics Incorporated. 


\section{APPENDIX I - FEDERAL ENERGY MANAGEMENT PROGRAM (FEMP) INPUTS FOR FY 2008 BENEFITS ESTIMATES}

Table of contents

Program Summary …….............................................................................................................. I-2

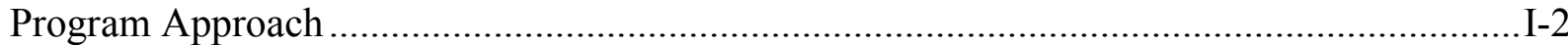

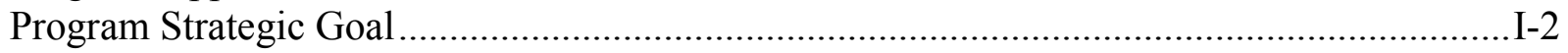

Significant Changes from Previous Analysis..................................................................................... I-3

The Baseline ("without DOE RD3" case) ........................................................................................ I-3

Target Market Description.............................................................................................

Baseline Adjustments to the AEO2006 Reference Case.........................................................

Representation of Program-Relevant Technologies in the AEO Reference Case ..................... I-4

Removing Effects of Program Activities ............................................................................. I-4

Other Program-Relevant Adjustments to AEO Reference Case................................................ -4

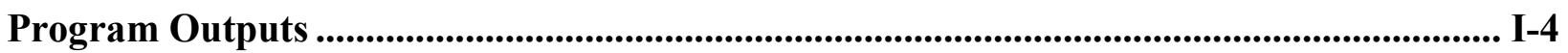

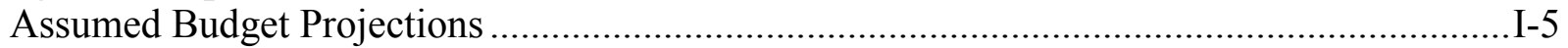

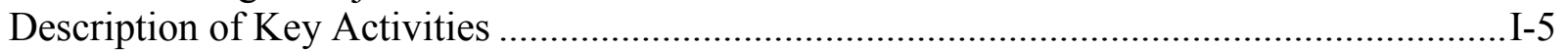

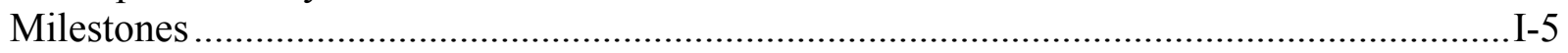

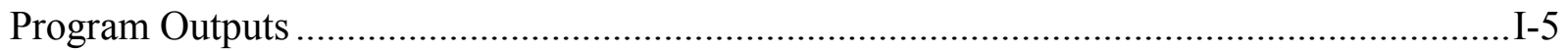

Translating Program Outputs to Market Outcomes...................................................................... I-6

Key Factors in Shaping Market Adoption of EERE technologies........................................... I-7

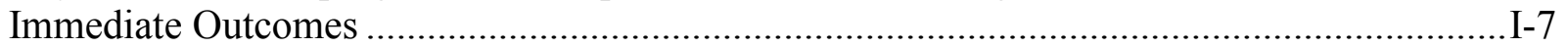

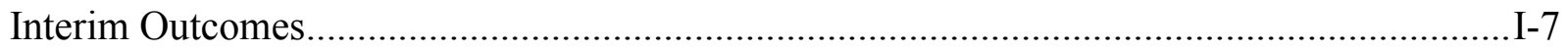

Final Outcomes (Benefits) …………………………….................................................

Summary of Inputs ............................................................................................................................. I-14

Bibliography ................................................................................................................................. I-14 


\section{Program Summary}

The Federal Energy Management Program (FEMP) strives to enhance energy security, environmental stewardship, and cost reduction within the Federal Government by advancing energy efficiency and water conservation; promoting the use of renewable energy, alternative fuels in Federal vehicle fleets, sustainable building design, and distributed energy resources; and improving utility management decisions at Federal facilities.

FEMP supports the mission of the Office of Energy Efficiency and Renewable Energy (EERE) by improving the energy efficiency and productivity of Federal Government buildings and by bringing clean, innovative, energy-efficient, and renewable technologies to Federal facilities. FEMP supports DOE's goal of improving energy security by promoting a diverse supply and delivery of reliable, affordable, and environmentally sound energy to Federal facilities. These activities fulfill several national energy and environmental priorities as outlined in the President's National Energy Policy (NEP) as well as the statutory requirements of the National Energy Conservation Policy Act (NECPA); Energy Policy Act of 1992 (EPACT 1992); Energy Policy Act of 2005 (EPAct 2005); and provisions of Executive Order 13123 (Efficient Energy Management) and Executive 13149 (Federal Fleet). These policy measures call upon Federal agencies to reduce the energy intensity of their operations, accelerate the protection and improvement of the environment, and increase our Nation's energy security.

\section{Program Approach}

FEMP assists Federal agencies in increasing their use of energy efficiency and renewable energy through alternative financing contract support and technical assistance and reporting and evaluating agency progress each year. Success occurs when FEMP and its agency and privatesector partners enable Federal energy managers to make better energy management choices that result in a more efficient, effective, and energy-secure government.

\section{Program Strategic Goal}

FEMP's goal is to provide assistance with project financing and technical assistance to Federal agencies to further the use of cost-effective energy efficiency and renewable energy. FEMP's activities enhance energy security, environmental stewardship, and cost reduction within the Federal Government.

These energy savings will help agencies reach the goals set by executive orders and legislation. In addition to these FEMP-assisted efforts, agencies make additional energy-savings investments without direct FEMP assistance and are expected to continue to do so. Federal agencies will need to make significant investments beyond the projects assisted by FEMP to meet the goals set forth by Executive Order 13123 and EPAct 2005 as summarized below:

- Executive Order 13123 establishes that the goal for all Federal agencies is to reduce energy intensity in Federal buildings by $35 \%$ by 2010 (relative to the 1985 baseline level of 139,480 Btu per gross square foot).

- EPAct 2005 sets forth the following goals for Federal agencies (including DOE):

○ Reduce energy consumption per square foot by $20 \%$ by 2015 , compared to the baseline year of FY 2003, at a rate of $2 \%$ per year. 
- Ensure that at least 3\% of Federal electricity consumption be generated by renewables in the years FY 2007 through FY 2009; 5\% in the years FY 2010 through FY 2012; and $7.5 \%$ in FY 2013 and each fiscal year thereafter.

DOE has already achieved the Executive Order 13123 goal for 2010 to reduce the energy intensity in its standard ${ }^{1}$ buildings. The baseline (1985) energy intensity in standard buildings was 473,126 Btu per square foot, whereas the energy intensity in 2005 was 224,043 Btu per square foot, showing a 53\% reduction in energy intensity in that time period. Contributing factors to this reduction in intensity include actions that were related to FEMP program activities such as retrofit projects receiving technical assistance from FEMP or projects financed through Energy Savings Performance Contracts. Other factors independent of FEMP that have contributed to this reduction include decommissioning of old buildings, changes in mission at facilities, and construction of new facilities (which are generally more energy efficient than older building stock).

In FY 2005, renewable energy accounted for 4.7\% of Federal facility electricity consumption, thereby exceeding the Executive Order 13123 requirement to use renewable energy for $2.5 \%$ of electricity consumption in FY 2005.

\section{Significant Changes from Previous Analysis}

In previous years, FEMP utilized a "top-down" modeling approach, in that it first estimated the total energy intensity reduction expected in the Federal sector, and then estimated the share of those savings that would be due to FEMP activities. For FY08, FEMP employed a "bottom-up" approach, in that energy savings from specific historic FEMP activities are estimated and then total future FEMP benefits are estimated from aggregating across all FEMP activities. This new modeling approach is used to better align FEMP's program activities and outputs with its estimated benefits. Also, because funding for the Departmental Energy Management Program is discontinued in FY 2008, it is no longer modeled.

\section{The Baseline ("without DOE RD3" case)}

FEMP assumed that the Annual Energy Outlook (AEO) 2006 Reference Case adequately captured the technological improvements that would occur in the absence of the program. In the AEO2006 Commercial Reference Case, shell improvements for new buildings can range up to $22 \%$ more efficient than the 1999 building stock; and through 2030, new building shells are assumed to improve by $8 \%$, while existing building stock efficiency is assumed to improve $6 \%$ over the 1999 stock efficiency (EIA 2006).

\section{Target Market Description.}

The target market is the Federal sector, the Nation's 3.0 billion square feet of standard Federal buildings (e.g., military bases, post offices, hospitals, courthouses) and the Nation's 300 million square feet of Federal energy-intensive operations (e.g., laboratories, check-processing facilities, and linear accelerators). The Federal Government's actions - via leadership, awards, influence,

\footnotetext{
${ }^{1}$ The Federal sector's buildings are grouped into two general categories: standard buildings and energy-intensive operations buildings. Standard buildings include military bases, post offices, and hospitals; and energy-intensive operations buildings include laboratories, check-processing facilities, and linear accelerators.
} 
and raw purchasing power - may well influence private-sector and state and local government decisions with respect to energy-related decisions, but any such "spillover" impact is not estimated in this GPRA process. Therefore, FEMP's impact on future energy savings may be understated.

\section{Baseline Adjustments to the $A E O 2006$ Reference Case} FEMP is not modeled endogenously within NEMS-GPRA08; however, the base energy use in the commercial module is modified to reflect the impact of the FEMP programs before the other DOE programs are modeled. The baseline for the energy efficiency goal for Federal facilities of EPAct 2005 is the FY 2003 energy intensity of standard and energy-intensive Federal buildings approximately 115,000 Btu per square foot (this baseline will be updated in FY 2006 when revised FY 2003 data are available). The baseline for Executive Order 13123 for standard buildings is the 1985 energy intensity of 139,480 Btu/square foot.

\section{Representation of Program-Relevant Technologies in the AEO Reference Case}

As Federal floor space is neither specifically tracked nor projected within the AEO, and as FEMP is a deployment program for currently available technologies, FEMP assumed that the AEO Reference Case adequately represents a "no DOE RD3" baseline. ${ }^{2}$ The AEO2006 Commercial Reference Case includes impacts of energy efficiency programs through behavior rules. Additionally, the commercial module assumes that the shell efficiency of new and existing buildings will increase by $8 \%$ and $6 \%$ over their respective 1999 baselines (EIA 2006). The commercial module also includes the minimum efficiency standards that were passed as part of EPAct 2005; however, there is no indication in the EIA NEMS documentation that the EPAct provisions for Federal agencies were specifically included in the reference case; as Federal buildings are not specifically broken out, it is unlikely that the AEO Reference Case reflects these projections because they are specific to Federal buildings.

\section{Removing Effects of Program Activities}

As discussed in the previous paragraph, FEMP assumed that no program-related impacts are included in the $A E O 2006$ Reference Case; therefore, nothing was removed from the Reference Case to establish the "non-program" baseline.

\section{Other Program-Relevant Adjustments to AEO Reference Case}

No other corrections or adjustments were made to the AEO2006 Reference Case.

\section{Program Outputs}

FEMP assists Federal agencies in providing benefits to the Nation by increasing their use of energy efficiency and renewable energy through alternative financing contract support, technical assistance, guidance on Federal fleet activities, and reporting and evaluating agency progress each year. The program facilitates the award of alternative financing contracts between agencies and the private sector to fund energy efficiency improvements through the use of savings to the Treasury on Federal energy bills. While alternative financing activities do not save energy per se, as savings come from project selection and execution, alternative financing activities do allow cost-effective projects to be implemented when funding is not otherwise available through the

\footnotetext{
${ }^{2}$ A "no DOE RD3" baseline reflects the expectations of a future without FEMP. 
appropriations process. FEMP provides technical assistance to Federal energy managers so they can identify, design, and implement energy efficient and renewable energy technologies and practices. In addition, FEMP reports to Congress on Federal energy efficiency, renewable electric power, and agency compliance with executive order requirements to reduce dependence on foreign sources of oil.

\section{Assumed Budget Projections}

FEMP assumed level funding of \$16,791,000 throughout the analysis period (2008 through 2030).

\section{Description of Key Activities}

FEMP developed its alternative financing effort to help Federal agencies access private-sector financing to fund needed energy improvements. It provides guidance, documentation, and individual project assistance to agencies that utilize Energy Savings Performance Contracts (ESPCs), public benefit funds, and Utility Energy Service Contracts (UESCs) to finance energy saving improvements. This financing pays for energy improvements at Federal facilities that are in need of significant energy system retrofits. Projects include energy improvements of all types, such as lighting upgrades, new heating and ventilation systems, and improved control systems. EPAct 2005 extended the authority for implementing ESPCs through 2016.

Technical Guidance and Assistance helps agencies take advantage of innovative technologies, tools, and best practices. FEMP assists Federal energy managers in their efforts to identify, design, and implement new construction and facility improvement projects. FEMP provides unbiased, expert technical assistance in areas such as audits for buildings and new technology deployment, including combined heat and power and distributed energy technologies. FEMP also provides analytic software tools to help agencies choose the most effective energy and water project investments. In addition, FEMP helps agencies acquire the most energy-efficient and water-conserving products by continuing to update its specifications for highly energy efficient products and providing them to the General Services Administration (GSA) and Defense Logistics Agency (DLA) as required by the "federal purchase requirement" set forth in EPAct 2005.

\section{Milestones}

Each year, FEMP will complete ESPC and UESC contract awards and provide technical assistance that will result in 15-year life-cycle energy savings of 20.2 trillion Btu.

\section{Program Outputs}

FEMP pursues its mission through integrated activities to improve the energy efficiency of, and renewable energy use by, the Federal Government. We expect these improvements to reduce the energy intensity at Federal facilities, lower their energy bills, and provide environmental benefits. Additionally, energy efficiency technologies for buildings provide less easily quantifiable benefits, such as improved lighting quality and building-occupant productivity. The benefits estimates reported exclude any expected acceleration in the deployment of the technologies that may result from "spillover" to state or local office buildings. 
In addition to the benefits quantified, improved energy management increases the ability of the Federal Government to manage its energy loads during emergencies, and facilitates coordination of energy use with local authorities in the event of local energy supply constraints or emergencies.

Table I-1. Program Outputs, Activities and Milestones

\begin{tabular}{|c|c|c|}
\hline Outputs & Associated Activities & Associated Milestones \\
\hline $\begin{array}{l}\text { Project Financing Activities } \\
\text { (Annual) }\end{array}$ & $\begin{aligned} & \text { Key activities } \\
& \text { 1. Energy Savings } \\
& \\
& \text { Performance Contracts } \\
& \text { (ESPC) } \\
& \text { 2. Utility Energy Savings } \\
& \text { 3. } \\
& \text { Enentracts (UESC) } \\
& \text { Energy Markets/Shared } \\
&\end{aligned}$ & $\begin{array}{l}\text { Complete project financing } \\
\text { activities that will result in } \\
\text { lifecycle Btu savings of } 14.9 \\
\text { trillion annually. }\end{array}$ \\
\hline $\begin{array}{l}\text { Technical Assistance Activities } \\
\text { (Annual) }\end{array}$ & $\begin{aligned} \text { Key activities } \\
\text { 1. } \\
\text { Technical Assistance } \\
\text { Projects (TA) } \\
\text { 2. } \\
\begin{array}{l}\text { Renewable Energy } \\
\text { Purchases }\end{array}\end{aligned}$ & $\begin{array}{l}\text { Complete technical assistance } \\
\text { activities that will result in } \\
\text { lifecycle Btu savings of } 4.7 \text { trillion } \\
\text { and support renewable energy } \\
\text { purchases of } 0.6 \text { trillion Btu } \\
\text { annually. }\end{array}$ \\
\hline
\end{tabular}

\section{Translating Program Outputs to Market Outcomes}

As of 2005 (the year with the latest available data), FEMP has assisted agencies in reducing energy intensity in Federal buildings by $29.6 \%$, using 1985 as a baseline. While there is a trend in reducing energy intensity over time, many factors combine to affect Federal energy consumption in any one year. Throughout its history, FEMP has had a significant effect on reducing Federal energy intensity. Other factors such as new Federal building construction, military base closures and greater use of the existing building stock have contributed to this reduction as well.

Table I-2. Linkage of Outputs with Outcomes

\begin{tabular}{llll}
\hline Outputs & $\begin{array}{l}\text { Associated Immediate } \\
\text { Outcomes }\end{array}$ & $\begin{array}{l}\text { Associated Interim } \\
\text { Outcomes }\end{array}$ & $\begin{array}{l}\text { Associated Ultimate } \\
\text { Outcomes }\end{array}$ \\
\hline Project Financing & - Energy Savings & Complete project \\
Activities & Performance & Linancing activities \\
& Contracts & Utility Energy & 14.9 trillion annually. \\
& Savings Contracts & & \\
& - Energy & & \\
& Markets/Shared & & \\
& Energy Savings & & \\
& Support & & \\
& - Technical Assistance & Complete technical & \\
& Projects & assistance activities & Lifecycle Btu savings of \\
Technical Assistance & Renewable Energy & & $\begin{array}{l}\text { renewable energy } \\
\text { purchases of 0.6 trillion } \\
\text { Activities }\end{array}$ \\
& Purchases & & Btu annually. \\
\hline
\end{tabular}


Key Factors in Shaping Market Adoption of EERE technologies

The following factors were considered in developing benefits estimates for the impact of FEMP:

- Price: FEMP is a deployment program that provides energy-related project financing and technical assistance support to Federal agencies. The technologies and practices promoted by FEMP are commercially available. As such, FEMP does not have a direct impact on the price of these technologies.

- Non-price factors

○ Policy factors: FEMP's mission is to assist the 32 Federal agencies in attaining the energy goals set by executive order and other legislation for the Federal Government. Strictly speaking, these are not goals for FEMP but goals for each individual agency, and their involvement is essential. Executive Order 13123 establishes that the goal for all Federal agencies is to reduce energy intensity in "standard" Federal buildings by $35 \%$ by 2010 (relative to the 1985 statutory baseline level of 139,480 Btu per gross square foot). Additionally, Executive Order 13123 contains a goal for energyintensive operations, which is to reduce energy per square foot by $25 \%$ in 2010 relative to a 1990 baseline.

EPAct 2005 establishes the following goals: to reduce energy consumption per square foot by $20 \%$ by 2015 compared to the baseline year of FY 2004 at a rate of $2 \%$ per year; and to ensure that at least $3 \%$ of Federal electricity consumption is generated by renewables in the years FY 2007 through FY 2009, by 5\% in the years FY 2010 through FY 2012, and by 7.5\% in FY 2013 and each fiscal year thereafter.

\section{Immediate Outcomes}

The immediate outcomes of FEMP's activities include: established Energy Savings Performance Contracts and Utility Energy Savings Contracts, Energy Markets/Shared Energy Savings Support, technical assistance activities, and renewable energy purchases.

\section{Interim Outcomes}

Interim outcomes include completed project financing activities and technical assistance projects.

\section{Final Outcomes (Benefits)}

FEMP maintains a database with information on all of the projects it assists - through both its technical assistance and project financing efforts. The database includes information regarding engineering estimates of energy and cost savings for individual projects. FEMP relied on this database, as well as written contracts, to develop annual energy savings estimates for projects it assisted in FY 2001, FY 2002, FY 2003, FY 2004, and FY 2005. These engineering estimates were used to develop a savings projection for FY 2008-FY 2030.

Annual energy savings projections attributable to quantifiable FEMP activities were calculated for five FEMP subprograms using the following sources and assumptions. Life-cycle energy savings were estimated by multiplying the annual savings by 15 years, the average life span of installed energy efficient equipment. 
The five FEMP subprograms are categorized into two groups: Project Financing activities and Technical Assistance activities. The next section of this appendix will discuss how benefits estimates for these activities are developed.

Project Financing (PF) Activities:

(1) Energy Savings Performance Contracts (ESPC)

An ESPC is a contracting vehicle that allows agencies to accomplish energy projects for their facilities without upfront capital costs and without special Congressional appropriations to pay for the improvements. An ESPC project is a partnership between the customer and an energy services company (ESCO). The ESCO conducts a comprehensive energy audit and identifies improvements that will save energy at the facility. In consultation with the agency customer, the ESCO designs and constructs a project that meets the agency's needs and arranges financing to pay for it. The ESCO guarantees that the improvements will generate savings sufficient to pay for the project over the term of the contract. After the contract ends, all additional cost savings accrue to the agency. Contract terms up to 25 years are allowed. Estimates of annual savings from these contracts were obtained directly from Super ESPC 3 Delivery Order schedules. Savings are assumed to begin accruing in the year of the delivery order award. In instances where annual savings data were not available for a particular delivery order, the average savings per dollar of project investment (9,000 Btu/dollar) was used to estimate annual savings. Savings in this category only apply to ESPCs in which agencies receive assistance from FEMP in developing and negotiating the award.

(2) Utility Energy Savings Contracts (UESC)

With a UESC, the utility typically arranges financing to cover the capital costs of the project. Then the utility is repaid over the contract term from the cost savings generated by the energy efficiency measures. With this arrangement, agencies can implement energy improvements with no initial capital investment; the net cost to the Federal agency is minimal, and the agency saves time and resources by using the one-stop shopping provided by the utility. Savings in this category apply only to UESCs awarded with direct assistance from FEMP.

(3) Energy Markets/Shared Energy Savings Support

These estimates apply to projects in which FEMP directly assisted agencies in successfully applying for public benefit funds or other energy efficiency funds.

Technical Assistance (TA) Activities:

(4) Technical Assistance Projects

These estimates reflect the savings potential from projects for which FEMP provided technical assistance, including both energy efficiency and renewable energy support. In the case of renewable energy projects, nonrenewable energy savings are presumed to equal the amount of energy generated from the on-site renewable project and used by the Federal facility.

(5) Renewable Energy Purchases

Renewable energy purchases were credited as one-year, nonrecurring savings when measuring progress toward the Federal reduction goals. "Savings" in this category apply to

\footnotetext{
${ }^{3}$ Super ESPCs are indefinite-delivery, indefinite-quantity (IDIQ) contracts that are competitively awarded to energy service companies (ESCOs), with several ESCOs representing each region. A Super ESPC covers all facilities in a geographic region, allowing agencies to skip time-consuming competitive awards of contract and go directly to developing a project and delivery order.
} 
renewable energy purchase contracts that were entered into with FEMP's assistance using contract arrangements and negotiations.

FEMP Project Financing - Estimated Savings. Project financing benefits estimates were derived from the average annual energy savings (in billion Btu) for projects signed in fiscal years 2002 through 2005. Table I-3 details the annual FEMP-facilitated savings for the three project financing programs - Super ESPCs, UESCs, and Energy Markets - including support for the Postal Service's shared energy-savings projects.

Table I-3. Annual Savings for Project Financing Programs (Billion Btu)

\begin{tabular}{lrrrrr}
\hline & $\mathbf{2 0 0 2}$ & $\mathbf{2 0 0 3}$ & $\mathbf{2 0 0 4}$ & $\mathbf{2 0 0 5}$ & $\begin{array}{r}\text { Average 2002- } \\
\mathbf{2 0 0 5}\end{array}$ \\
\hline Super ESPC & 517 & 2,634 & 215 & 559 & 981 \\
\hline UESC & 204 & 163 & 140 & $140^{*}$ & 162 \\
\hline Energy Markets & 0 & 66 & 142 & $142^{*}$ & 88 \\
\hline Project Financing Total & 720 & 2,863 & 498 & 841 & 1,231 \\
\hline * 2005 data were not available; therefore 2004 data were used as a proxy. & & &
\end{tabular}

Some further explanation of the ESPC numbers for 2003 and 2004 is warranted. Authorization for ESPC contracts, established as part of the National Energy Conservation Policy Act of 1978, included a sunset requirement of October 1, 2003. Because of this sunset requirement, a number of agencies signed ESPCs during 2003 in anticipation of the sunset clause. During FY 2004, there was a lapse in authority for ESPC contracts, so no new contracts were signed; however, modifications to existing contracts were allowed and the 2004 numbers presented in Table I-3 reflect energy savings from those contract modifications. The National Defense Authorization Act reauthorized the ESPC program and extended the ESPC sunset date to October 1, 2006; and then EPAct 2005 further extended ESPC authorization to 2016. FEMP used a simple average of 2002 through 2005 because FEMP assumed that many ESPC contracts signed in 2003 would otherwise have been signed in 2004 if the sunset clause had not been in effect, causing the 2003 and 2004 numbers to "average out."

FEMP divided the average annual energy savings by the total project financing annual budgets (Table I-4) for the four years to determine "Annual Energy Savings per FEMP Dollar of Funding" shown in Table I-5.

Table 1-4. Project Financing Dollars (Thousand \$)

\begin{tabular}{rrrrr}
\hline $\mathbf{2 0 0 2}$ & $\mathbf{2 0 0 3}$ & $\mathbf{2 0 0 4}$ & $\mathbf{2 0 0 5}$ & $\mathbf{2 0 0 2 - 2 0 0 5}$ \\
\hline$\$ 8,700$ & $\$ 7,839$ & $\$ 7,830$ & $\$ 7,133$ & $\$ 31,502$ \\
\hline
\end{tabular}

Table I-5. Annual Energy Savings per FEMP Dollar of PF Funding (Site-Delivered Btu/\$)

\begin{tabular}{rrrrr}
\hline 2002 & 2003 & 2004 & $\mathbf{2 0 0 5}$ & $\begin{array}{r}\text { Average } \\
\mathbf{2 0 0 2 - 2 0 0 5}\end{array}$ \\
\hline 82,813 & 365,224 & 63,550 & 117,951 & 156,257 \\
\hline
\end{tabular}

The “Annual Energy Savings per FEMP Dollar of Funding” for 2002-2005 (156.3 kBtu) was multiplied by the draft project financing budget request for FY 2008 to estimate annual savings from the project financing activity for that year, yielding an estimate of 1,240 billion Btu. 
FEMP's benefits estimate for project financing in 2008 is $80 \%$ of the annual estimate for FY 2008 (or 992 billion Btu) based on the average performance of the fiscal years 2002 through 2005. FEMP used the $80 \%$ multiplier to ensure that the projected savings estimates are conservative and attainable.

FEMP calculated life-cycle energy savings by taking the estimated annual savings and multiplying by 15 to reflect an average project life of 15 years, for a total life-cycle energy savings of 14,880 billion site-delivered Btu.

FEMP Technical Assistance - Estimated Savings. Program benefits estimates for these activities were derived first from the estimated recommended annual energy savings from all TA projects facilitated by FEMP (Table I-6), whether or not those projects are ultimately implemented by the agency. Data for FY 2001 - FY 2004 were used, as FY 2005 data were not available at the time of the analysis.

Table I-6. Estimates of Recommended Annual Energy Savings for Technical Assistance Programs (Billion Btu)

\begin{tabular}{lrrrrr}
\hline & $\mathbf{2 0 0 1}$ & $\mathbf{2 0 0 2}$ & $\mathbf{2 0 0 3}$ & $\mathbf{2 0 0 4}$ & $\begin{array}{r}\text { Average } \\
\mathbf{2 0 0 1 - 2 0 0 4}\end{array}$ \\
\hline Energy Efficiency & 720.2 & 817.4 & $3,673.1$ & 762.2 & $1,493.2$ \\
\hline Renewable Energy & 103.8 & 48.2 & 22.8 & 14.4 & 47.3 \\
\hline TOTAL & 824.0 & 865.6 & $3,695.9$ & 776.7 & $1,540.5$ \\
\hline
\end{tabular}

The estimated annual energy savings for fiscal years 2001 through 2004 were divided by the total TA budget for those years (Table I-7) to arrive at "Recommended Annual Energy Savings per FEMP TA Dollar of Funding" (Table I-8).

Table I-7. Technical Assistance Dollars (Thousand \$)

\begin{tabular}{rrrrr}
\hline 2001 & 2002 & 2003 & $\mathbf{2 0 0 4}$ & $\mathbf{2 0 0 1 - 2 0 0 4}$ \\
\hline$\$ 7,896$ & $\$ 7,000$ & $\$ 7,825$ & $\$ 8,140$ & $\$ 30,861$ \\
\hline
\end{tabular}

Table I-8. Recommended Annual Energy Savings per FEMP Dollar of TA Funding (Site-Delivered Btu/\$)

\begin{tabular}{rrrrr}
\hline $\mathbf{2 0 0 1}$ & $\mathbf{2 0 0 2}$ & $\mathbf{2 0 0 3}$ & $\mathbf{2 0 0 4}$ & $\begin{array}{r}\text { Average } \\
\mathbf{2 0 0 1 - 2 0 0 4}\end{array}$ \\
\hline 104,359 & 123,656 & 472,315 & 95,414 & 199,674 \\
\hline
\end{tabular}

FEMP multiplied the average annual energy savings per dollar (199.7 thousand Btu from Table I-8) by the draft budget request for FY 2008 to estimate potential annual savings identified by all TA projects for FY 2008. FEMP estimated that $30 \%$ of the potential savings $(1,301.7$ billion Btus) would be implemented, yielding a realized annual savings of 391 billion Btu. FEMP used the 30\% multiplier to reflect that not all projects for which FEMP provides technical assistance are actually implemented. Based on the estimated savings from recommendations vs. estimated savings for implemented projects for 2001-2004, FEMP determined the $30 \%$ figure to be a reasonable estimate of how many projects would be implemented in the future. 
FEMP calculated the 2008 TA benefits estimates by taking $80 \%$ of estimated implemented savings from TA facilitated projects, yielding 312 billion Btu. FEMP used the $80 \%$ multiplier to ensure that the projected savings estimates were conservative and attainable.

FEMP calculated life-cycle energy savings by taking the estimated annual savings and multiplying by 15 to reflect an average project life of 15 years, for a total life-cycle energy savings of 4,680 billion site-delivered Btus.

Renewable purchases are also covered under the TA budget. For the analysis period, FEMP assumed that renewable purchases would be essentially level with FY 2004, the last year for which data was available (see Table I-9).

Table I-9. Renewable Purchase Energy Savings (Billion Btu)

\begin{tabular}{lccrrr}
\hline & 2001 & 2002 & 2003 & 2004 & $\begin{array}{r}\text { Annual } \\
\text { Projected } \\
\text { Purchases } \\
\text { 2008-2030 }\end{array}$ \\
\hline Renewable Purchases & 491 & 181 & 590 & 808 & 800 \\
\hline
\end{tabular}

FEMP calculated the 2008 Renewable Purchase benefits estimates by taking $80 \%$ of the projected renewable purchases, yielding 640 billion Btu. FEMP used the $80 \%$ multiplier to ensure that the projected savings estimates were conservative and attainable.

Forecast of Benefits for the Analysis Period. The annual benefits estimated using the procedures described in the preceding sections were assumed to represent the realized savings that would be associated with each year's funding. With the exception of renewable purchases, which will be discussed shortly, FEMP assumed that the savings associated with each year's funding would be in effect through the life cycle of the equipment (e.g., a project implemented in 2008 will continue to save energy for the life cycle of the equipment, or 15 years, so it is assumed to realize the savings level in each year). 
Table I-10 illustrates this by presenting the "in-year" savings, which are the savings associated with the PF and TA activities; and the "annual savings," which are the savings that are accruing to the program due to program activities that began in FY 2008. As can be seen in the annual savings column, the savings level off after 15 years, when projects implemented in the early years are no longer assumed to save energy because the life of the project has been exhausted.

With respect to renewable purchases, the above discussion does not apply. Renewable purchases displace fossil energy with renewable energy that is used in that year; renewable energy purchases do not have savings that can be carried over from year to year and therefore count for only one year of savings. Therefore, the annual savings for 2010 are equal to the PF and nonrenewable purchase TA activities that were implemented in 2008, 2009, and 2010, plus the renewable purchases that occurred within 2010. 
Table I-10. Calculation of Annual Site Savings (Billion Btu)

\begin{tabular}{lrrrrr}
\hline Year & $\begin{array}{r}\text { In-Year } \\
\text { PF Site } \\
\text { Savings }\end{array}$ & $\begin{array}{r}\text { In-Year } \\
\text { TA Site } \\
\text { Savings }\end{array}$ & $\begin{array}{r}\text { Total } \\
\text { In-Year } \\
\text { Site } \\
\text { Savings }\end{array}$ & $\begin{array}{r}\text { In-Year } \\
\text { Renewable } \\
\text { Purchases }\end{array}$ & $\begin{array}{r}\text { Annual } \\
\text { Site } \\
\text { Savings }\end{array}$ \\
\hline 2008 & 992 & 312 & 1,304 & 640 & 1,944 \\
\hline 2009 & 992 & 312 & 1,304 & 640 & 3,249 \\
\hline 2010 & 992 & 312 & 1,304 & 640 & 4,553 \\
\hline 2011 & 992 & 312 & 1,304 & 640 & 5,857 \\
\hline 2012 & 992 & 312 & 1,304 & 640 & 7,162 \\
\hline 2013 & 992 & 312 & 1,304 & 640 & 8,466 \\
\hline 2014 & 992 & 312 & 1,304 & 640 & 9,770 \\
\hline 2015 & 992 & 312 & 1,304 & 640 & 11,075 \\
\hline 2016 & 992 & 312 & 1,304 & 640 & 12,379 \\
\hline 2017 & 992 & 312 & 1,304 & 640 & 13,683 \\
\hline 2018 & 992 & 312 & 1,304 & 640 & 14,988 \\
\hline 2019 & 992 & 312 & 1,304 & 640 & 16,292 \\
\hline 2020 & 992 & 312 & 1,304 & 640 & 17,596 \\
\hline 2021 & 992 & 312 & 1,304 & 640 & 18,901 \\
\hline 2022 & 992 & 312 & 1,304 & 640 & 20,205 \\
\hline 2023 & 992 & 312 & 1,304 & 640 & 20,205 \\
\hline 2024 & 992 & 312 & 1,304 & 640 & 20,205 \\
\hline 2025 & 992 & 312 & 1,304 & 640 & 20,205 \\
\hline 2026 & 992 & 312 & 1,304 & 640 & 20,205 \\
\hline 2027 & 992 & 312 & 1,304 & 640 & 20,205 \\
\hline 2028 & 992 & 312 & 1,304 & 640 & 20,205 \\
\hline 2029 & 992 & 312 & 1,304 & 640 & 20,205 \\
\hline 2030 & 992 & 312 & 1,304 & 640 & 20,205 \\
\hline & & & & &
\end{tabular}

FEMP allocated the energy savings into savings by fuel type using historical fuel-mix data from the Federal sector (Annual Reports, see Figure I-1). FEMP assumed that the FY 2004 Federal fuel mix would apply throughout the analysis period (i.e., year 2030).

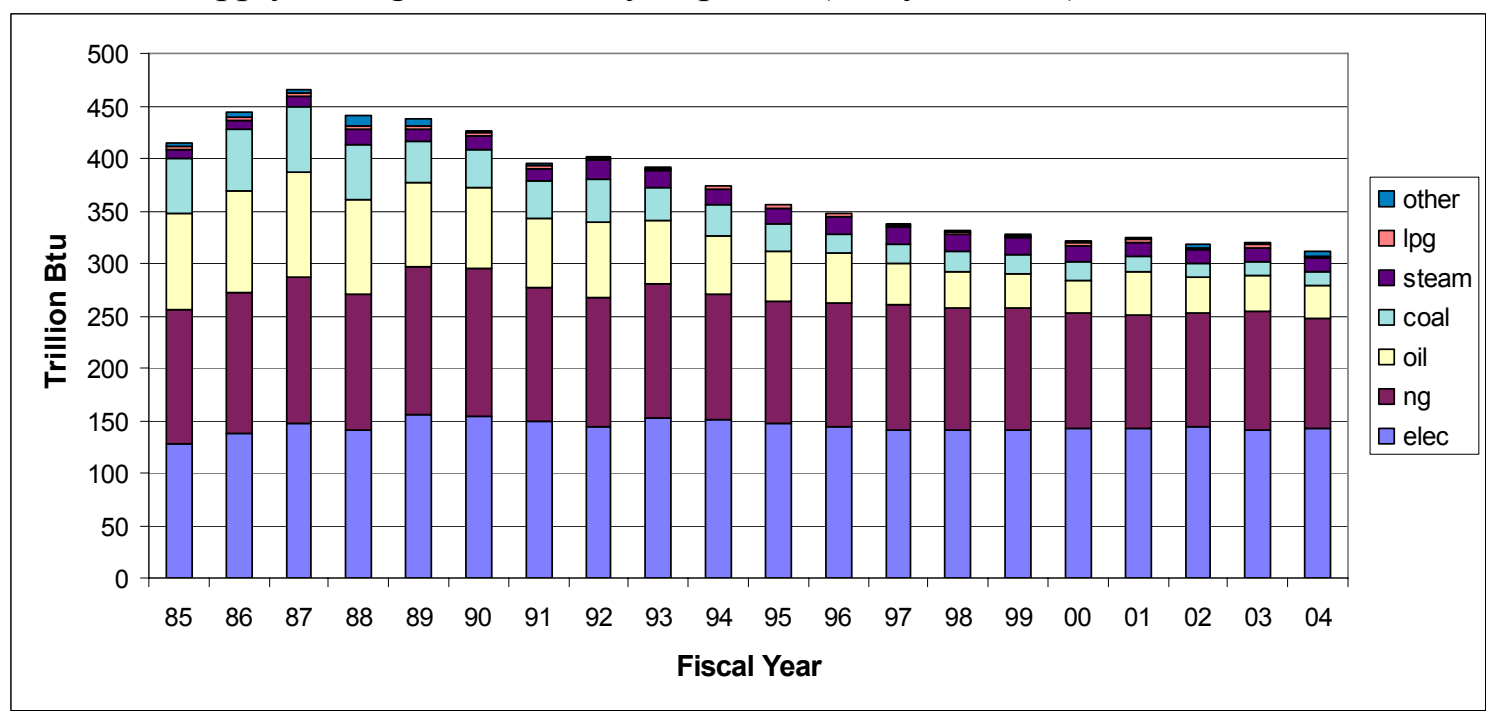

Figure I-1. Historical Energy Use in Standard Federal Buildings 


\section{Summary of Inputs}

FEMP provided the calculated benefits, shown in Table I-11, for inclusion in the integrated modeling effort.

Table I-11. Summary of Benefits Inputs to Models (Billion Btu)

\begin{tabular}{|c|c|c|c|c|c|c|c|c|c|c|}
\hline Year & $\begin{array}{r}\text { In-Year } \\
\text { Site } \\
\text { Savings }\end{array}$ & $\begin{array}{r}\text { In-Year } \\
\text { Renewable } \\
\text { Purchases }\end{array}$ & $\begin{array}{r}\text { Annual } \\
\text { Site } \\
\text { Savings }\end{array}$ & $\begin{array}{r}\text { Annual } \\
\text { Site } \\
\text { Electricity } \\
\text { Savings }\end{array}$ & $\begin{array}{r}\text { Annual } \\
\text { Site } \\
\text { Natural } \\
\text { Gas } \\
\text { Savings }\end{array}$ & $\begin{array}{r}\text { Annual } \\
\text { Site } \\
\text { Fuel Oil } \\
\text { Savings }\end{array}$ & $\begin{array}{r}\text { Annual } \\
\text { Site } \\
\text { Coal } \\
\text { Savings }\end{array}$ & $\begin{array}{r}\text { Annual } \\
\text { Site } \\
\text { Purchased } \\
\text { Steam } \\
\text { Savings } \\
\end{array}$ & $\begin{array}{r}\text { Annual } \\
\text { Site } \\
\text { LPG } \\
\text { Savings }\end{array}$ & $\begin{array}{r}\text { Annual } \\
\text { Site } \\
\text { Other } \\
\text { Savings }\end{array}$ \\
\hline 2008 & 1,304 & 640 & 1,944 & 1,235 & 442 & 131 & 54 & 56 & 11 & 16 \\
\hline 2009 & 1,304 & 640 & 3,249 & 1,830 & 884 & 261 & 107 & 111 & 23 & 32 \\
\hline 2010 & 1,304 & 640 & 4,553 & 2,424 & 1,326 & 392 & 161 & 167 & 34 & 48 \\
\hline 2011 & 1,304 & 640 & 5,857 & 3,019 & 1,768 & 523 & 214 & 223 & 46 & 64 \\
\hline 2012 & 1,304 & 640 & 7,162 & 3,614 & 2,210 & 653 & 268 & 279 & 57 & 80 \\
\hline 2013 & 1,304 & 640 & 8,466 & 4,209 & 2,652 & 784 & 322 & 334 & 69 & 96 \\
\hline 2014 & 1,304 & 640 & 9,770 & 4,804 & 3,094 & 915 & 375 & 390 & 80 & 112 \\
\hline 2015 & 1,304 & 640 & 11,075 & 5,399 & 3,536 & 1,046 & 429 & 446 & 92 & 128 \\
\hline 2016 & 1,304 & 640 & 12,379 & 5,993 & 3,978 & 1,176 & 482 & 502 & 103 & 144 \\
\hline 2017 & 1,304 & 640 & 13,683 & 6,588 & 4,420 & 1,307 & 536 & 557 & 115 & 160 \\
\hline 2018 & 1,304 & 640 & 14,988 & 7,183 & 4,862 & 1,438 & 590 & 613 & 126 & 176 \\
\hline 2019 & 1,304 & 640 & 16,292 & 7,778 & 5,304 & 1,568 & 643 & 669 & 138 & 193 \\
\hline 2020 & 1,304 & 640 & 17,596 & 8,373 & 5,746 & 1,699 & 697 & 725 & 149 & 209 \\
\hline 2021 & 1,304 & 640 & 18,901 & 8,967 & 6,188 & 1,830 & 750 & 780 & 161 & 225 \\
\hline 2022 & 1,304 & 640 & 20,205 & 9,562 & 6,629 & 1,960 & 804 & 836 & 172 & 241 \\
\hline 2023 & 1,304 & 640 & 20,205 & 9,562 & 6,629 & 1,960 & 804 & 836 & 172 & 241 \\
\hline 2024 & 1,304 & 640 & 20,205 & 9,562 & 6,629 & 1,960 & 804 & 836 & 172 & 241 \\
\hline 2025 & 1,304 & 640 & 20,205 & 9,562 & 6,629 & 1,960 & 804 & 836 & 172 & 241 \\
\hline 2026 & 1,304 & 640 & 20,205 & 9,562 & 6,629 & 1,960 & 804 & 836 & 172 & 241 \\
\hline 2027 & 1,304 & 640 & 20,205 & 9,562 & 6,629 & 1,960 & 804 & 836 & 172 & 241 \\
\hline 2028 & 1,304 & 640 & 20,205 & 9,562 & 6,629 & 1,960 & 804 & 836 & 172 & 241 \\
\hline 2029 & 1,304 & 640 & 20,205 & 9,562 & 6,629 & 1,960 & 804 & 836 & 172 & 241 \\
\hline 2030 & 1,304 & 640 & 20,205 & 9,562 & 6,629 & 1,960 & 804 & 836 & 172 & 241 \\
\hline
\end{tabular}

\section{Bibliography}

Annual Report to Congress on Federal Government Energy Management and Conservation Programs for each fiscal year (available online through http://www.eere.energy.gov/femp)

Energy Information Administration, March 2006 (EIA 2006). Assumptions to the Annual Energy Outlook 2006. DOE/EIA-0554(2006).

Federal Energy Management Program FY 2008 Budget Request 


\section{APPENDIX J - WEATHERIZATION AND INTERGOVERNMENTAL PROGRAM (WIP) INPUTS FOR FY 2008 BENEFITS ESTIMATES}

Table of contents

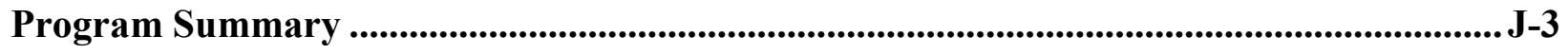

Significant Changes from Previous Analysis................................................................................. J-3

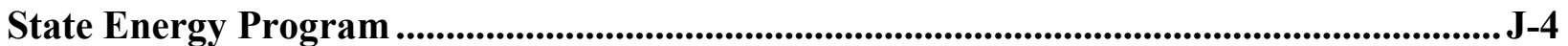

The Baseline ("without DOE RD3" case) ……………...................................................... J-5

Target Market Description............................................................................................... J-5

Baseline Adjustments to the AEO2006 Reference Case ………………................................ J-5

Removing Effects of Program Activities .......................................................................... J-5

Other Program-Relevant Adjustments to AEO Reference Case................................................ J-5

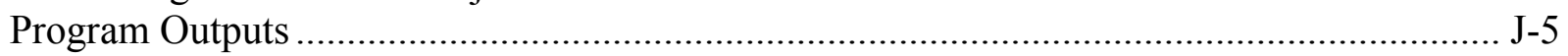

Assumed Budget Projections ………………………………………………………..... J-5

Description of Key Activities …………………………............................................... J-6

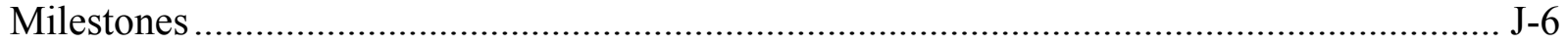

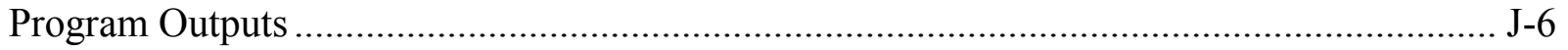

Translating Program Outputs to Market Outcomes .............................................................. J-7

Key Factors in Shaping Market Adoption of EERE technologies........................................... J-7

Final Outcomes (Benefits) …………………………................................................. J-8

Summary of Inputs................................................................................................... J-19

Weatherization Assistance Program Grants ............................................................................ J-21

The Baseline ("without DOE RD3" case) ………............................................................. J-21

Target Market Description.............................................................................................. J-21

Baseline Adjustments to the AEO2006 Reference Case ...................................................... J-21

Removing Effects of Program Activities ........................................................................ J-22

Other Program-Relevant Adjustments to AEO Reference Case............................................ J-22

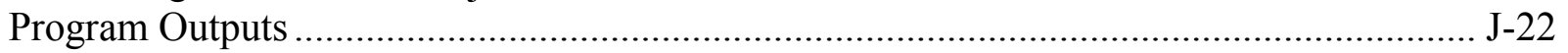

Assumed Budget Projections ………………………...................................................... J-22

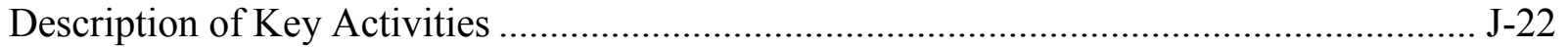

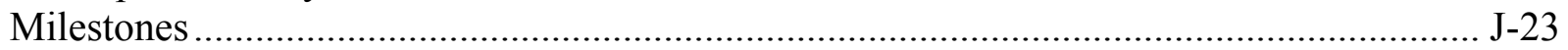

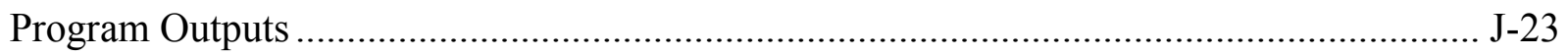

Translating Program Outputs to Market Outcomes ........................................................... J-24

Key Factors in Shaping Market Adoption of EERE technologies......................................... J-24

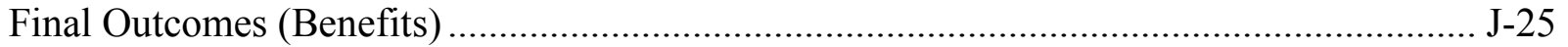

Summary of Inputs ..................................................................................................... J-27

Tribal Energy Program (TEP) .............................................................................................................. J-28

The Baseline ("without DOE RD3" case) ………………................................................ J-28 


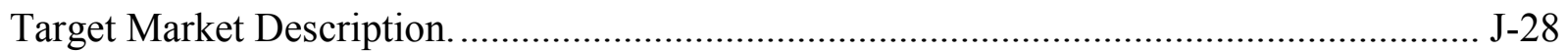

Baseline Adjustments to the AEO2006 Reference Case ................................................... J-29

Representation of Program-Relevant Technologies in the AEO Reference Case ................. J-29

Removing Effects of Program Activities .......................................................................... J-29

Other Program-Relevant Adjustments to AEO Reference Case............................................ J-29

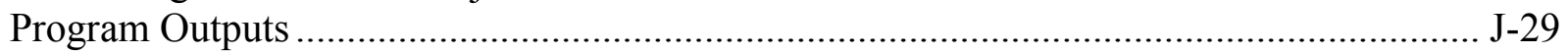

Assumed Budget Projections ……………………….....................................................

Description of Key Activities .......................................................................................

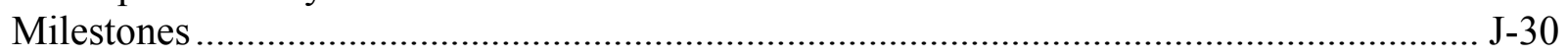

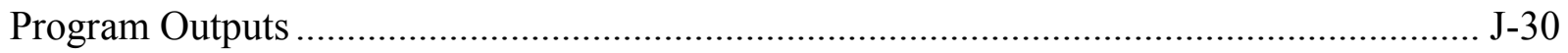

Translating Program Outputs to Market Outcomes ........................................................... J-31

Key Factors in Shaping Market Adoption of EERE technologies......................................... J-31

Final Outcomes (Benefits) …………….......................................................................... J-32

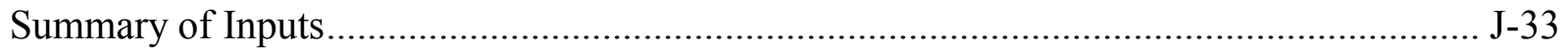

Renewable Energy Production Incentive........................................................................................ J-34

The Baseline ("without DOE RD3" case) ……………................................................... J-35

Target Market Description................................................................................................ J

Baseline Adjustments to the AEO2006 Reference Case .................................................... J-35

Representation of Program-Relevant Technologies in the AEO Reference Case ................. J-35

Removing Effects of Program Activities ............................................................................ J-35

Other Program-Relevant Adjustments to AEO Reference Case............................................. J-35

Program Outputs ……………………………………............................................. J-35

Assumed Budget Projections …………………………............................................. J-38

Description of Key Activities ………………………….............................................. J-38

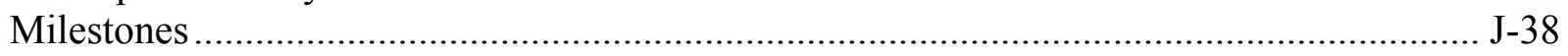

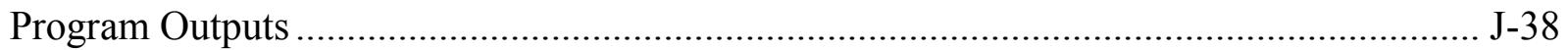

Translating Program Outputs to Market Outcomes ............................................................ J-38

Key Factors in Shaping Market Adoption of EERE technologies........................................ J-39

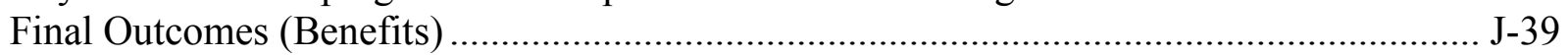

Summary of Inputs ................................................................................................. J-39

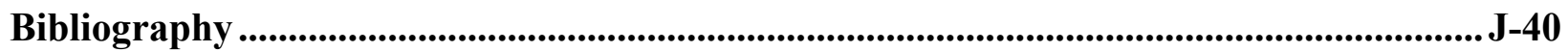




\section{Program Summary}

The Weatherization and Intergovernmental Program (WIP) provides funding and technical assistance to its partners in state and local governments, American Indian tribes, and international agencies to facilitate the adoption of renewable energy and energy efficiency technologies. WIP activities speed the adoption of new technologies and help transfer technologies that are developed by Department of Energy (DOE)-funded research to the private sector.

WIP activities are different from those of most DOE research and development programs that focus on basic science and hardware development. WIP projects are more likely to focus on issues such as economic development in rural areas or how renewable energy and energy efficiency projects can improve air quality. For this reason, it is difficult to characterize the benefits resulting from WIP activities by measuring their energy impact.

In general, WIP activities are characterized by:

- Multiple Technologies

$\circ$ WIP facilitates adoption of a range of technologies that are developed by the DOE Office of Energy Efficiency and Renewable Energy (EERE).

- Work Across All Energy Market Sectors

$\circ$ WIP sponsors activities in the major energy market sectors - buildings, electric power, industry, and transportation - and works to educate the public, teachers, and students about the benefits of renewable energy and energy efficiency technologies. WIP also helps state and local agencies improve their energy efficiencies by upgrading public facilities.

- Partnerships

- WIP is involved with a broad range of energy stakeholders that cover the breadth of the U.S. economy. WIP staff members consult regularly with the National Governors' Association, the National Association of State Energy Officials, the National Council of State Legislatures, the National Association of Counties, the U.S. Conference of Mayors, the National Association of State and Community Service Programs, and many others.

- Leverage of Federal Resources

○ Almost every WIP project involves substantial participation and investment by state and local agencies, Indian tribes, and the private sector.

\section{Significant Changes from Previous Analysis}

Table J-1 outlines the activities characterized for WIP's FY08 Government Performance and Results Act (GPRA) and identifies any changes from the FY07 GPRA effort. WIP provided characterizations and inputs for these activities to EERE's integrated modeling effort. 
Table J-1: Weatherization and Intergovernmental Program Activities

\begin{tabular}{|c|c|c|c|}
\hline Subprogram & Activity & $\begin{array}{l}\text { Inputs } \\
\text { changed } \\
\text { from } \\
\text { FY07? }\end{array}$ & Reason for Change \\
\hline State Energy Program & $\begin{array}{l}\text { Codes and Standards } \\
\text { Energy Audits } \\
\text { Rating and Labeling } \\
\text { Workshops/Training } \\
\text { Incentives } \\
\text { Retrofits } \\
\text { Loans and Grants } \\
\text { Technical Assistance } \\
\text { Traffic Signals } \\
\text { Procurement } \\
\text { Tax Credits } \\
\text { Renewable Energy } \\
\text { Special Projects: Competitive } \\
\quad \text { Grants } \\
\end{array}$ & Yes & Change in direction \\
\hline $\begin{array}{l}\text { Weatherization Assistance } \\
\text { Program Grants }\end{array}$ & Weatherization Assistance & Yes & Decrease in funding \\
\hline \multirow{3}{*}{ Intergovernmental Activities } & Tribal Energy Activities & Yes & Decrease in funding \\
\hline & $\begin{array}{l}\text { International Renewable } \\
\text { Energy Program }\end{array}$ & Dropped & Decrease in funding \\
\hline & $\begin{array}{l}\text { Renewable Energy } \\
\text { Production Incentive }\end{array}$ & Yes & Change in research \\
\hline
\end{tabular}

For FY08, the SEP program added three new grant areas to the analysis: Tax Credits, Procurement, and Renewable Energy. Additionally, SEP plans to revamp its Special Projects to focus on competitive grants that promote market transformation. In 2008, the State Energy Program will allocate approximately $78 \%$ of its funding to the traditional grant programs, and $22 \%$ of its funding to competitive grants. With a projected budget of $\$ 45$ million, the traditional SEP grants will receive \$35 million and the new SEP Market Transformation program will receive $\$ 10$ million. The SEP Special Projects: Competitive Grants program was developed to strategically realign the SEP program by transforming energy markets at the state level, to promote an integrated portfolio of energy efficiency and renewable energy options, and to strengthen the traditional state energy grant programs.

The GPRA08 inputs for each activity are described in the following sections.

\section{State Energy Program}

The State Energy Program provides financial assistance to states, enabling state governments to target their own high-priority energy needs and expand clean energy choices for their citizens and businesses. With these funds and the resources leveraged by them, the State and Territory Energy Offices develop and manage a variety of programs geared to increase energy efficiency, reduce energy use and costs, develop alternative energy and renewable energy sources, promote environmentally conscious economic development, and reduce reliance on imported oil. 


\section{The Baseline ("without DOE RD3" case)}

SEP provides grants and promotes energy-efficient technologies. Therefore, WIP assumes that no technological improvements beyond those that are in the baseline would occur in the absence of the subprogram.

Target Market Description.

SEP provides grants to the states for them to design and carry out their renewable energy and energy efficiency programs in a way that makes the most sense for their resources and economies. Activities promote technology policies and projects that increase building, transportation, and industrial efficiency, reduce dependence on foreign oil, and increase use of renewable energy.

\section{Baseline Adjustments to the AEO2006 Reference Case}

WIP assumed that the $A E O 2006$ Reference Case adequately captured the technological improvements that would occur in the absence of the program. In the AEO2006 Commercial Reference Case, shell improvements for new buildings can range up to $22 \%$ more efficient than the 1999 building stock; and through 2030, new building shells are assumed to improve by 8\%, while existing building stock efficiency is assumed to improve 6\% over the 1999 stock efficiency (EIA 2006).

Within the AEO2006 Residential Reference Case, one of the implicit assumptions is that there will be no radical changes in technology or consumer behavior through 2030. Additional assumptions for the residential reference case include: 1) no new efficiency regulations, beyond what is already in law, nor new government efficiency programs; 2) technologies that have not achieved widespread acceptance already will not achieve significant penetration by 2030;3) currently available technologies will evolve in both cost and efficiency; and 4) consumers in the future will behave similarly to current consumer behavior (EIA 2006).

\section{Removing Effects of Program Activities}

As discussed in the previous paragraphs, WIP assumed that no program-related impacts are included in the AEO2006 Reference Case; therefore, nothing was removed from the Reference Case to establish the "non-program" baseline.

Other Program-Relevant Adjustments to AEO Reference Case

No other corrections were made to the AEO2006 Reference Case.

\section{Program Outputs}

The State Energy Program (SEP) mission is to provide financial assistance through formula grants to states, enabling state governments to target their own high-priority energy needs and expand clean energy choices for their citizens and businesses.

\section{Assumed Budget Projections}

WIP assumed level funding of $\$ 45$ million throughout the analysis period (2008-2030). Of this, \$35 million was assumed to fund formula grants, and \$10 million to special projects, which will be geared toward competitive market transformation activities in FY 2008. 


\section{Description of Key Activities}

The SEP is the only Federally funded, state-based program administered by DOE that provides resources directly to the states. With these funds and the resources leveraged by them, the State and Territory Energy Offices develop and manage a variety of programs designed to increase energy efficiency, reduce energy use and costs, develop alternative energy and renewable energy sources, promote environmentally conscious economic development and reduce reliance on oil produced outside the United States. State energy offices are also instrumental in administering public benefits funds and energy emergency preparedness.

\section{Formula Grants}

SEP will provide formula grants to 50 states, the District of Columbia, and territories for energy efficiency/renewable energy programs. These grants will:

- Support implementation of the 2006 SEP Strategic Plan, addressing key goals of market transformation and collaboration with environmental and economic development interests,

- Assist states in strategic planning and analysis,

- Provide technical assistance and training to develop state-level capabilities to form collaborative partnerships and conduct evaluation of the impact of state energy efficiency and renewable energy programs nationwide,

- Provide technical assistance to address emerging regional energy and environmental issues such as transportation and air quality, and

- Support information technology systems for program evaluation and reporting in compliance with E-Gov initiative.

\section{Special Projects: Competitive Grants}

Special Projects will focus on market transformation and crosscutting solutions targeted at individual market sectors. They will not be technology-specific independent solicitations. The SEP competitive special project grants will enable states to initiate innovative financially selfsustaining energy planning and program activities. DOE would seek proposals that establish policies that increase available capital for energy efficiency and renewable energy projects and implement strategies that would create a self-sustaining resource base for state programs over the long term, e.g., revolving loan funds, financing risk reduction, performance contracting, etc. SEP will provide tailored technical assistance to states to support state and local actions that further national energy priorities and transform markets for EERE technologies and practices.

\section{Milestones}

Award grants to states and territories.

\section{Program Outputs}

The State Energy Program will enable state energy offices to tailor energy efficiency programs to state and local needs and to leverage non-Federal resources to supplement Federal assistance. SEP supports state partners in areas such as utility restructuring, implementing newly developed energy efficiency technologies, and urban/regional planning for sustainability. Utilizing a corporate crosscutting approach, EERE will assess the research and development program priorities and provide tailored technical assistance to states to support state and local actions that further national energy priorities. 
Table J-2: WAP Outputs, Activities, and Milestones

\begin{tabular}{lll}
\hline Outputs & Associated Activities & Associated Milestones \\
\hline Enable state energy offices to & Key activities & $\begin{array}{l}\text { Award grants to states and } \\
\text { territories }\end{array}$ \\
$\begin{array}{l}\text { tailor energy efficiency programs } \\
\text { to state and local needs and to }\end{array}$ & 1. Formula Grants & \\
$\begin{array}{l}\text { leverage non-Federal resources } \\
\begin{array}{l}\text { to supplement Federal } \\
\text { assistance }\end{array}\end{array}$ & Compecial Projects & \\
\hline
\end{tabular}

Translating Program Outputs to Market Outcomes

Table J-3: Linkage of Outputs with Outcomes

\begin{tabular}{|c|c|}
\hline Outputs & $\begin{array}{l}\text { Associated Ultimate } \\
\text { Outcomes }\end{array}$ \\
\hline $\begin{array}{l}\text { Enable state energy } \\
\text { offices to tailor energy } \\
\text { efficiency programs to } \\
\text { state and local needs } \\
\text { and to leverage non- } \\
\text { Federal resources to } \\
\text { supplement Federal } \\
\text { assistance }\end{array}$ & $\begin{array}{l}\text { Achieve an average } \\
\text { annual energy savings } \\
\text { of } 10-12 \text { trillion source } \\
\text { Btus (an estimated } \$ 60 \\
\text { million- } \$ 70 \text { million in } \\
\text { annual energy cost } \\
\text { savings) with DOE } \\
\text { funds. }\end{array}$ \\
\hline
\end{tabular}

Key Factors in Shaping Market Adoption of EERE technologies

- Price: The program developed incremental cost data using available cost information for similar projects. Where specific costs were not available, simple payback calculations were used to generate incremental private investment based on on-site fuel costs (EIA 2006) and representative payback periods associated with individual program areas.

\section{Formula Grants}

- Codes and Standards: WIP assumed a five-year payback period on investment to develop incremental investment costs, based on previous benefit-cost studies of energy codes ${ }^{1}$ (i.e., an annual energy cost savings of \$1 implies an initial investment of \$5).

- Energy Audits, Workshops/Training, Retrofits, and Technical Assistance: For residential sector prices, WIP used the average cost for Energy Star: Home Performance projects as a guide. For FY05, pilot Home Performance projects were spending between $\$ 4,000$ and $\$ 6,000$ in retrofits, so WIP assumed an average of $\$ 5,000$ of cost to yield $20 \%$ energy savings (Energy Design Guide 2003). Commercial-sector prices were based on estimated project costs for the Building Technologies Rebuild America activity, which assumed a cost of $\$ 3$ per square foot to reduce energy use by $25 \%$.

- Rating and Labeling, Traffic Signals, Procurement, and Tax Credits: WIP assumed a three-year payback period on investment to develop incremental investment costs. The three-year payback comes from a comparative analysis of energy efficiency retrofit payback options. Of the 5,263 buildings sampled, 91\% of the implemented energy

\footnotetext{
${ }^{1}$ See case studies presented on Building Energy Codes Web site for more information: http://www.energycodes.gov/implement/tech_assist_reports.stm. 
conservation measures fell below the three-year payback threshold (Anderson and Newell 2002).

- Loans, Grants, and Incentives: For the SEP Loans/Grants activity, WIP assumed that the total amount of funding (DOE plus leveraged) would equal the incremental private investment expenditures. For the SEP Incentives activity, the incremental private investment was assumed by WIP to equal the value of the rebates generated by incentive payments.

- Renewable Energy: A 10-year payback was applied to the Renewable Energy program area, based on a study titled The Economics of Wind Energy, which outlines the average payback of a $50 \mathrm{MW}$ wind farm at approximately 10 years (AWEA 2002). Because large wind farms make up the lion's share of the renewable market to date, this metric was chosen as an appropriate metric for the entire renewable energy program.

\section{Special Projects: Competitive Grants}

- The building- and industrial-sector payback periods for the market transformation program were set at three years (Anderson and Newell 2002).

- A five-year payback was applied to the transportation-sector analysis, based on the fact that most of the transportation programs are funded by state and local governments, whose investment is less risky and can handle somewhat longer payback.

- A 10-year payback was applied to the clean energy sector, based on a study titled The Economics of Wind Energy, which outlines the average payback of a $50 \mathrm{MW}$ wind farm at approximately 10 years (AWEA 2002). Because large wind farms make up the majority of the clean energy sector to date, this metric was chosen as an appropriate metric for the entire clean energy sector.

\section{Final Outcomes (Benefits)}

For the FY08 GPRA metrics, the State Energy Program (SEP) was characterized based on the FY08 budget request and the associated leveraged funding. The metrics were derived from $A n$ Evaluation of State Energy Program Accomplishments: 2002 Program Year (ORNL 2005), where 12 activities (referred to in the report as "project areas") supported by SEP were selected to represent the traditional grant programs. The following activities: Codes and Standards, Energy Audits, Rating and Labeling, Workshops/Training, Incentives, Retrofits, Loans and Grants, Technical Assistance, Traffic Signals, Tax Credits, Procurement, and Renewable Energy account for approximately $94.8 \%$ of the total estimated energy savings within ORNL 2005.

For the Special Projects activity, the energy savings metrics were developed for each sector, based on the technical potential calculations developed in Arent et al. (2006). ${ }^{2}$ For the FY08 inputs, WIP assumed that the metric for "energy savings per dollar invested" is valid for the SEP inputs using the FY08 funding level expected for the SEP Special Projects program.

More detail about the development of the benefits for each of these activities follows.

\footnotetext{
${ }^{2}$ Distribution of the full report is limited by DOE. The following report, based on the full report, is publicly available: Arent, D.; Benioff, R.; Mosey, G.; Bird, L.; Brown, J.; Brown, E.; Vimmerstedt, L.; Aabakken, J.; Parks, K.; Lapsa, M.; Davis, S.; Olszewski, M.; Cox, D.; McElhaney, K.; Hadley, S.; Hostick, D.; Nicholls, A.; McDonald, S.; Holloman, B. (2006). Energy Sector Market Analysis. NREL Report No. TP-620-40541
} 


\section{Formula Grants}

Codes and Standards. The purpose of the SEP Codes and Standards activity is to encourage the adoption of building codes and standards through training and implementation activities. In ORNL 2005, data were collected on three separate metrics related to building codes: name of new energy-efficiency building code adopted, name of old energy-efficiency building code replaced, and percentage of new construction in state covered by the new code (ORNL 2005). The information provided by each state, on all three metrics combined, was used to calculate energy savings achieved by code activity (ORNL 2005). For consistency, WIP based the estimated savings of the Codes and Standards activities funded by the SEP on the savings estimates produced for the Residential and Commercial Energy Codes projects within the Office of Building Technologies (BT). The program assumed that $50 \%$ of the energy savings due to the deployment of codes would result from SEP's Codes and Standards training and implementation activities. A full explanation of the development of these figures can be found in Appendix $G$ of this document.

Energy Audits. The SEP Energy Audits activity provides recipients with specific information needed to improve the energy efficiency of their facility/building through on-site energy audits. Energy-audit savings calculations were based on three indicators: number of audits, square feet retrofit, and reported savings (ORNL 2005). For this effort, WIP converted these three indicators into number of households and square footage of commercial floor space impacted by this activity.

The program assumed a savings per audit of 21.7 MMBtu per household and 0.0167 MMBtu per square foot of commercial floor space (ORNL 2005). The per-unit energy savings estimate for residential retrofits (43.3 million source BTU per project) provides the base for the estimate of savings associated with energy audits in the residential sector (ORNL 2005). An adjustment factor of 0.50 was applied to the retrofit number, based on the conservative assumption that only half of the recommended measures would be installed (ORNL 2005). Based on Tables 1.2.3 and 1.2.4 of the Buildings Energy Data Book, approximately $84 \mathrm{MMBtu} / \mathrm{HH} / \mathrm{yr}$ are used by residential space heating and space cooling, yielding a load reduction attributable to the audits of $26 \%$ for residential space heating and cooling. Based on Tables 1.3.3 and 1.3.4 of the Buildings Energy Data Book, approximately $121 \mathrm{kBtu} / \mathrm{SF} / \mathrm{yr}$ are used by commercial space heating, space cooling, and lighting, yielding a load reduction attributable to the audits of $14 \%$ for commercial space heating, space cooling, and lighting.

States reported to WIP a total of 581 residential audits, 1,878,809 residential square feet retrofit, and 139,851 MMBtu projected residential source savings. To convert the residential indicators into an estimated number of households, the program assumed that each residential audit represented one household, divided the total residential square feet retrofit by 1,707 (which is the average heated square footage for all residential units in the United States from the 2001 Residential Energy Consumption Survey), and divided the estimated reported annual savings by the 21.7 MMBtu/HH figure (ORNL 2005). This yields an estimate of approximately 8,100 households impacted by energy audits in any given year.

In the categories of commercial, industrial, and institutional, states reported to the WIP program a total of 35 audits performed, 67,976,934 square feet retrofit, and 17,551,878 MMBtu projected 
source savings. To convert the commercial/industrial/institutional indicators into an estimated commercial square footage, the WIP program assumed that each commercial audit represented one building multiplied by 14,500 square feet (which is the average building size taken from the 1999 Commercial Building Energy Consumption Survey), used the square footage reported, and divided the estimated annual savings by the $0.0167 \mathrm{MMBtu} / \mathrm{SF}$ figure (ORNL 2005). This yields an estimate of approximately 1.1 billion square feet impacted by energy audits in any given year, or $1.6 \%$ of existing commercial floor space each year.

The WIP program assumed that the number of energy audits performed would be in direct proportion to the funds available for energy audits. The ORNL 2005 figures were based on SEP funding of $\$ 46.2$ million. Therefore, the figures above were adjusted downward to reflect the $\$ 35$ million budget request.

Rating and Labeling. The purpose of the Rating and Labeling activity is to establish and promote energy efficiency ratings and equipment labeling. Energy savings in this project area were captured through the energy saved statewide as a result of a state's endorsement of rating and labeling systems for up to 15 different types of energy consuming devices (ORNL 2005). Because the Energy Star program is the largest successful rating and labeling program, and many states use SEP funds to encourage participation in the Energy Star program, savings associated with the program were used to represent the savings achieved by all state rating and labeling efforts (ORNL 2005). Although there are 40 different Energy Star devices, the top 15 were profiled in the ORNL 2005 report. Thus, savings for 25 devices was not included in this analysis. The top 15 Energy Star devices were profiled by capturing the nationwide sales for each device. The energy savings metric was then applied to each device, using the unit savings per device, compared to the energy consumed by an Energy Star device (ORNL 2005). The national savings for each type of energy-consuming device was adjusted downward by multiplying by an "attribution factor" of 0.10, which approximates the proportion of Energy Star purchases made as a result of state encouragement (Feldman and Tannenbaum 2000). Table J-4 contains the estimated energy savings from rating and labeling. 
Table J-4: Estimated Energy Savings from Rating and Labeling (ORNL 2005)

\begin{tabular}{lrrrr}
\hline Device & $\begin{array}{l}\text { Energy } \\
\text { Star } \\
\text { savings } \\
\text { per unit } \\
\text { (MMBtu } \\
\text { source) }\end{array}$ & $\begin{array}{l}\text { Number of } \\
\text { Energy Star } \\
\text { units sold in } \\
\text { U.S., 2002 }\end{array}$ & $\begin{array}{l}\text { National } \\
\text { Savings, } \\
\text { 2002 } \\
\text { (MMBtu } \\
\text { source) }\end{array}$ & $\begin{array}{l}\text { Adjusted } \\
\text { national } \\
\text { savings (using } \\
\text { 0.10 } \\
\text { "attribution } \\
\text { factors" } \\
\text { (MMBtu source) }\end{array}$ \\
\hline Office Computer/Monitor & 2.938 & $22,941,000$ & $67,400,658$ & $6,740,066$ \\
\hline Home Computer/Monitor & 0.853 & $11,402,000$ & $9,725,906$ & 972,591 \\
\hline Fax Machine & 1.801 & $2,271,000$ & $4,090,071$ & 409,007 \\
\hline Copier & 3.033 & 209,000 & 633,897 & 63,390 \\
\hline Multi-function Device & 6.540 & $1,338,000$ & $8,750,520$ & 875,052 \\
\hline Scanner & 2.654 & $6,810,000$ & $18,073,740$ & $1,807,374$ \\
\hline Printer & 2.085 & $7,369,000$ & $15,364,365$ & $1,536,437$ \\
\hline TV & 0.360 & $10,446,000$ & $3,760,560$ & 376,056 \\
\hline VCR & 0.171 & $12,028,000$ & $2,056,788$ & 205,679 \\
\hline TV/VCR & 0.332 & $4,643,000$ & $1,541,476$ & 154,148 \\
\hline Audio Equipment & 0.171 & $3,687,000$ & 630,477 & 63,048 \\
\hline Room AC & 0.663 & $2,195,000$ & $1,455,285$ & 145,529 \\
\hline Dishwasher & 0.569 & $2,262,000$ & $1,287,078$ & 128,708 \\
\hline Refrigerator & 1.137 & $1,956,000$ & $2,223,972$ & 222,397 \\
\hline Clothes Washer & 2.464 & $1,224,000$ & $3,015,936$ & 301,594 \\
\hline Total & & $90,781,000$ & $140,010,729$ & $14,001,076$ \\
\hline
\end{tabular}

The WIP program assumed that the savings would be effective for 10 years, and that they were attributable to electricity, based on the conservative life expectancies of major appliances (Demesne 2006).

Workshops/Training. The purpose of this SEP activity is to promote energy efficiency measures through targeted workshops and training sessions. The first item to address in workshops and training is the residential building sector. A residential energy-savings multiplier was developed through the selection of four common energy-conservation measures that could easily be taught in workshops and training sessions (ORNL 2005). Consequently, the WIP program modeled the residential training measures as air infiltration sealing, resetting water heater thermostats, attic insulation, and compact fluorescent lightbulbs (CFLs); and assumed that the average annual savings per household for these four measures was 28.7 source MMBtu, which was derived from the impacts of these measures in four representative cities (Schenectady, New York; Birmingham, Alabama; Moline, Illinois; and Eureka, California) using the Home Energy Saver System, ${ }^{3}$ a Web-based energy audit system that is driven by the DOE-2 building simulation program (ORNL 2005). The WIP program assumed that 3.4 MMBtu of those savings resulted from CFLs; 5.5 MMBtu resulted from resetting water heater thermostats; and that the rest was attributable to space conditioning (Schweitzer and Eisenberg 2002). Based on the Building Energy Data Book, Tables 1.2.4 and 1.2.3, total primary household consumption for 2005 is 191.4 MMBtu/HH: $44.1 \%$ (or 84.4 MMBtu) is space conditioning, $12.7 \%$ (or 24.3 MMBtu) is water heating, and $11.8 \%$ (or $22.6 \mathrm{MMBtu}$ ) is lighting. Therefore, the estimated savings resulting from residential workshops and training are $23.4 \%$ space conditioning savings, $22.6 \%$ water

${ }^{3}$ Accessible at http://hes.lbl.gov/

Projected Benefits of Federal Energy Efficiency and Renewable Energy Programs (FY 2008-FY 2050) Appendix J-Weatherization and Intergovernmental Program - Page J-11 
heating savings, and $15 \%$ lighting savings. WIP assumed that $20 \%$ of attendees would implement the measures based on the findings from three recent studies (Reed et al. 1999; Peters and McRae 2001; Tools of Change 2004) and that the average attendee would influence 1.75 homes based on U.S Census Bureau residential construction numbers and conservative estimates formulated in the ONRL 2005 report. There were approximately 49,000 residential workshop attendees in 2002 (ORNL 2005), so the program assumed that this number would continue, resulting in residential workshops/training impacting approximately 17,150 existing residential households, or $0.02 \%$ of existing residential homes per year.

ORNL 2005 provided an estimate for both commercial and institutional buildings. Because the savings coefficients reported for commercial (156.8 MMBtu/attendee) and institutional (151 MMBtu/attendee) were within 5\% of each other, the two were modeled together by the WIP program. The WIP program assumed estimated commercial savings of $5.25 \%$ for heating, ventilating, and air conditioning (HVAC) measures and 3.2\% for lighting measures based on two reports (McClain et al. 1994; Abraham and MacDonald 1995) that identified the percent energy savings possible from HVAC and lighting retrofits in large and small office buildings (ORNL 2005). The program assumed that HVAC savings equate to both space heating and space cooling. The report used a weighted median number of buildings influenced by each trainee as four buildings per trainee. WIP assumed that $20 \%$ of attendees would implement the measures (ORNL 2005). The total number of commercial buildings training attendees in 2002 was 19,000 and institutional building attendees was 25,000 (ORNL 2005). This is equivalent to 176,000 buildings impacted. The program assumed the average square feet per commercial building is 14,500 (CBECS 1999), so commercial and institutional workshops/training impacts about 0.51 billion square feet of existing commercial floor space, or $0.74 \%$ of existing commercial floor space per year.

The ORNL 2005 figures were based on SEP funding of $\$ 46.2$ million. Therefore, the figures above were adjusted downward to reflect the $\$ 35$ million budget request.

Technical Assistance. The purpose of the Technical Assistance activity is to promote energy efficiency measures by providing technical assistance to building owners. WIP assumed that technical assistance is credited with half the implementation of workshops, and half the savings achieved by workshop attendees (see discussion above for derivation of savings estimates). Because the program assumed that technical assistance savings were half the savings of workshops (ORNL 2005), the estimated savings resulting from residential technical assistance are $11.7 \%$ space conditioning savings, $11.3 \%$ water heating savings, and $7.5 \%$ lighting savings. The program assumed that $10 \%$ of attendees would implement the measures (ORNL 2005). This implementation rate is half that of the rate used for workshops and training, based on the assumption that the implementation rate would be substantially lower than workshops and training sessions because technical assistance is less intensive and personal interaction is more limited, providing less detailed instruction, and would therefore be expected to be less motivational. There were approximately 297,350 contacts for residential technical assistance in 2002 (ORNL 2005), so residential technical assistance impacts approximately 29,735 existing residential households, or $0.04 \%$ of existing residential homes per year. 
WIP assumed that technical assistance commercial building savings would be half the savings of workshops (ORNL 2005), yielding an estimated savings of $2.63 \%$ in space conditioning and $1.6 \%$ in lighting. The program assumed that HVAC savings equate to both space heating and space cooling. WIP assumed that $10 \%$ of attendees would implement the measures (ORNL 2005). The total number of technical assistance contacts in 2002 for commercial buildings was 67,000 (ORNL 2005). The program assumed the average square feet per commercial building is 14,500, from the 1999 Commercial Buildings Energy Consumption Survey, so commercial and institutional workshops/training impacts about 0.19 billion square feet of existing commercial floorspace, or $0.28 \%$ of existing commercial floorspace per year.

WIP assumed that the amount of technical assistance provided would be in direct proportion to the funds available for technical assistance. The ORNL 2005 figures were based on SEP funding of $\$ 46.2$ million. Therefore, the figures above were adjusted downward to reflect the $\$ 35$ million budget request.

Retrofits. The purpose of this SEP activity is to provide building owners with retrofit assistance. Energy-savings estimates for retrofits were reported in residential structures, commercial structures, schools, health-care facilities, government buildings, and industrial applications (ORNL 2005). Retrofit calculations were based on two indicators: number of retrofits and square feet retrofit (ORNL 2005). For this effort, WIP converted these two indicators to number of households and square feet of commercial floor space impacted.

The program assumed a savings per retrofit of 43.4 MMBtu per household based on an unweighted, nationwide average energy savings for the residential sector. This number was based on primary energy savings per house from residential retrofits for four regions of the country, as developed for the Weatherization Assistance Program (Schweitzer and Eisenberg 2002). Based on Tables 1.2.3 and 1.2.4 of the Buildings Energy Data Book, approximately $84 \mathrm{MMBtu} / \mathrm{HH} / \mathrm{yr}$ are used by residential space heating and space cooling, yielding a load reduction of $54 \%$ for residential space heating and cooling.

States reported to WIP a total of 683 residential building retrofits and 49.7 million square feet of residential floorspace retrofit. To convert the residential indicators into an estimated number of households, the WIP program assumed that each residential retrofit represented one household and divided the total residential square feet retrofit by the average square feet per household $(1,707$, which is the average heated square footage for all residential units in the United States from the 2001 Residential Energy Consumption Survey). This yielded an estimate of approximately 29,800 households impacted by retrofits in any given year, or $0.037 \%$ of existing residential single-family buildings in each year.

The program assumed a savings per retrofit of $18.8 \%$ per square foot of commercial floor space. This number was based on the average savings in retrofits in commercial buildings reported in two studies (Greely et al. 1990, Coates 1995).

States reported to WIP a total of 18 commercial building retrofits and 119.5 million square feet of commercial floor space retrofit. To convert the indicators into an estimated commercial square footage, the WIP program assumed that each commercial retrofit represented one building 
multiplied by the average building size (14,500 square feet, from the 1999 Commercial Buildings Energy Consumption Survey) and used the square footage reported. This yielded an estimate of approximately 0.119 billion square feet impacted by retrofits in any given year, or $0.18 \%$ of existing commercial floor space in each year.

WIP assumed a savings per retrofit of 0.016 MMBtu per square foot of educational floor space (Greely et al. 1990). Based on Tables 1.3.3 and 1.3.7 of the Buildings Energy Data Book, approximately $67 \mathrm{kBtu} / \mathrm{SF} / \mathrm{yr}$ are used by education space heating, space cooling, and lighting, yielding a load reduction of $24 \%$ for education building space heating, space cooling, and lighting.

States reported to the program a total of 73 education building retrofits and 68.6 million square feet of education floor space retrofit. To convert the indicators into an estimated commercial square footage, WIP assumed that each education retrofit represented one building multiplied by the average building size (26,400 square feet, from the 1999 Commercial Buildings Energy Consumption Survey) and used the square footage reported. This yielded an estimate of approximately 0.07 billion square feet impacted by retrofits in any given year, or $0.68 \%$ of existing commercial floor space in each year.

WIP assumed a savings per retrofit of 0.041 MMBtu per square foot of health-care floor space (Lew and Wang 1998). Based on Tables 1.3.3 and 1.3.7 of the Buildings Energy Data Book, approximately $168 \mathrm{kBtu} / \mathrm{SF} / \mathrm{yr}$ are used by health-care space heating, space cooling, and lighting, yielding a load reduction of $24 \%$ for health-care space heating, space cooling, and lighting.

States reported to WIP a total of one health-care building retrofit and 18.7 million square feet of health-care floor space retrofit. To convert the indicators into an estimated commercial square footage, the WIP program assumed that each health-care retrofit represented one building multiplied by the average building size (23,000 square feet, from the 1999 Commercial Buildings Energy Consumption Survey) and used the square footage reported. This yielded an estimate of approximately 0.02 billion square feet impacted by retrofits in any given year, or $0.92 \%$ of existing commercial floor space in each year.

The ORNL 2005 figures were based on SEP funding of \$46.2 million. Therefore, the figures above were adjusted downward to reflect the $\$ 35$ million budget request.

Loans and Grants. The purpose of this SEP activity is to facilitate energy efficiency loans and grants. WIP found defensible study results on the amount of loans provided and estimated energy savings associated with those loans for the following three programs: Oregon Low-Interest Loan Program, Texas LoanStar Program, and Nebraska Dollar and Energy Savings Loan Program (ORNL 2005). The program also found defensible study results on the amount of grants provided and energy savings associated with those grants for the following five programs: Illinois Energy Efficient Affordable Housing Program, California Grants, Louisiana Institutional Conservation Program, Wisconsin Farm Save Energy Project, and New York State Variable Speed Drive Program (ORNL 2005). The program assumed the estimates of savings per loan/grant by sector as reported in Table $\mathbf{J}-\mathbf{5}$. Loan/grant funding as a percent of total SEP funding reported for all project areas was $16.2 \%$ in 2002 (ORNL 2005). The program assumed that this percentage 
would apply to FY08. In 2002, leveraged dollars per SEP dollar for loans/grants was $\$ 10.65$ (ORNL 2005). Based on the FY 2008 request, WIP assumed that approximately \$66.1 million (from both SEP and leveraged funds) would be spent on loan/grant activities. Using the dollar amounts from ORNL 2005's underlying calculations, the percentage of the total rebate package per sector was calculated (see Table J-5) to determine the proportion of each sector's savings, yielding a total annual savings of about $1.1 \mathrm{TBtu}[(22.9 \% \times$ x $\$ 66.1 \mathrm{M} \times 0.0148)+(9.1 \% \times \$ 66.1 \mathrm{M}$ x 0.0148$)+(3.4 \%$ x $\$ 66.1 \mathrm{M}$ x 0.0178) $+(63.3 \%$ x $\$ 66.1 \mathrm{M}$ x 0.0178) $+(1.2 \%$ x $\$ 66.1 \mathrm{M} x$ $0.0161)]$. The program assumed that the savings would be in effect for 15 years.

Table J-5: Percentage of Total Loan/Grant Amount and Savings per Loan/Grant Dollar by Sector (ORNL 2005)

\begin{tabular}{lrrrrr}
\hline & Residential & Commercial & Industrial & Institutional & Agriculture \\
\hline \% of loan & $22.9 \%$ & $9.1 \%$ & $3.4 \%$ & $63.3 \%$ & $1.2 \%$ \\
\hline MMBtu/\$ loan & 0.0148 & 0.0148 & 0.0178 & 0.0178 & 0.0161 \\
\hline
\end{tabular}

Financial Incentives. The purpose of this SEP activity is to provide financial incentives (or rebates) to encourage the installation of energy-efficient equipment. Defensible study results were cited on rebate payments and the associated energy savings for four programs: Anaheim Public Utilities Energy Efficiency Incentives Program, Pacific Gas and Electric Single Family Homes Energy Efficiency Rebate Program, Pacific Gas and Electric Multifamily Energy Efficiency Rebate Program, and Pacific Gas and Electric Express Efficiency Program (ORNL 2005). These program results provide the basis for assumptions made by sector. WIP assumed the estimates of savings per rebate dollar by sector as reported in Table J-6. In 2002, incentive funding of \$34.7 million provided for \$21.5 million worth of rebates (ORNL 2005). The program, therefore, assumed that each program dollar of funding provides $\$ 0.62$ in rebates. Incentive funding as a percent of total SEP funding reported for all project areas was $1.3 \%$ in 2002 (ORNL 2005). WIP assumed that this percentage would apply to FY08. The program assumed that leveraged dollars per SEP dollar for incentives was \$60.87 (ORNL 2005). Based on the FY 2008 request, the WIP program assumed that approximately \$28.2 million dollars (from both SEP and leveraged funds) would be spent on incentive activities, equating to about $\$ 17.5$ million in rebates. Using the dollar amounts from ORNL 2005's underlying calculations, the percentage of the total rebate package per sector was calculated (see Table J-6) to determine the proportion of each sector's savings, yielding a total annual savings of about $0.96 \mathrm{TBtu}[(78.6 \% \mathrm{x}$ $\$ 17.5 \mathrm{M} \times 0.0281)+(14.9 \% \times \$ 17.5 \mathrm{M} \times 0.1558)+(3.1 \%$ x $\$ 17.5 \mathrm{M} \times 0.1558)+(2.8 \% \times \$ 17.5 \mathrm{M}$ $\mathrm{x} 0.1558)+(0.5 \% \mathrm{x} \$ 17.5 \mathrm{M} \times 0.1455)]$. The program assumed that the savings would be in effect for 15 years.

Table J-6: Percentage of Total Rebate Amount and Savings per Rebate Dollar by Sector (ORNL 2005)

\begin{tabular}{lrrrrr}
\hline & Residential & Commercial & Industrial & Institutional & Agriculture \\
\hline$\%$ of rebate & $78.6 \%$ & $14.9 \%$ & $3.1 \%$ & $2.8 \%$ & $0.5 \%$ \\
\hline $\begin{array}{l}\text { MMBtu/\$ } \\
\text { rebate }\end{array}$ & 0.0281 & 0.1558 & 0.1558 & 0.1558 & 0.1455 \\
\hline
\end{tabular}


Traffic Signals. WIP assumed that incandescent bulbs used in traffic signals would be replaced with light-emitting diodes (LEDs) (ORNL 2005). The average traffic light serviced would save $793.9 \mathrm{kWh}$ or 8.64 million source Btu per year, and the total number of traffic signals replaced in 2002 was 94,824 (ORNL 2005). The program calculated the number of replaced traffic signals by developing a number of replaced traffic signals per funding level, and multiplied this by the projected FY08 funding allocation. The program also assumed that the savings would be in effect for 11 years, based on the average life of an LED bulb, which is 100,000 hours (LEDTRONICS).

The ORNL 2005 figures were based on SEP funding of $\$ 46.2$ million. Therefore, the figures above were adjusted downward to reflect the $\$ 35$ million budget request.

Tax Credits. The purpose of this SEP activity is to promote the implementation of tax credits within a state. WIP found defensible study results provided by the Oregon Office of Energy (2000), which reported the number of tax credits issued in 2000 (ORNL 2005). The Oregon Office of Energy reported the total monetary value of tax credits given to the following categories: renewable resources, appliances, alternative fuel vehicles, and energy-efficient ducts issued in 2000 . They also provided the correlating energy savings reported in electricity, natural gas, and fuel oil savings.

WIP assumed the appliance savings are attributable to electricity, and the alternative fuel vehicles savings are attributable to fuel oil. The energy-efficient ducts allocation came from the Buildings Energy Data Book, Table1.1, where 28.6\% of the savings was attributed to electricity and $71.4 \%$ was attributed to natural gas. For the renewable resources, the WIP program assumed $86.53 \%$ of the savings was attributable to electricity and $13.24 \%$ of the savings was attributable to natural gas, which correlates to the generic distribution provided by ORNL 2005.

Renewable Energy. WIP developed the renewable energy metric with information provided on six different submetrics within the SEP Alternative Energy program. The first three relate to the number of conventional vehicles converted to alternative fuel vehicles and hybrid vehicle purchases made by state and local governments (ORNL 2005). One of the submetrics was developed through the states' impact on the private sector and relates to the number of refueling stations for alternative fuel vehicles. The last two submetrics relate to the total wind- and solarpowered generation capacity installed as a result of the state energy program (ORNL 2005).

Procurement. WIP developed metrics on the procurement of energy-efficient products made by the SEP, based on information provided in ORNL 2005. ORNL 2005 gathered information on the number of energy-efficient vehicles, office equipment, HVAC equipment, street lights, and "exit" signs purchased by the various state energy programs.

The energy-efficient vehicles metric was developed based on the consumption and use of midsize automobiles and standard pickup trucks vs. the fuel consumption of their energyefficient counterparts (ORNL 2005). The metric for energy-efficient office products is calculated from the number of Energy Star office products purchased by the state (ORNL 2005). The HVAC metric was developed based on the impact to the commercial sector through the government procurement programs (ORNL 2005). For street lights, the number of high-pressure 
sodium (HPS) fixtures that were retrofit in place of the old mercury vapor lamps was calculated (ORNL 2005). The exit signs metric used information on the number of incandescent exit signs that were replaced by compact fluorescent exit signs (ORNL 2005).

WIP assumed the office equipment, street lamps, and exits signs purchases would all reduce electric energy consumption. The HVAC purchase allocations came from the Buildings Energy Data Book, Table1.1, where $28.6 \%$ of the savings was attributed to electricity and $71.4 \%$ was attributed to natural gas. The alternative-fuel vehicles purchases were assumed to offset fuel oil consumption.

\section{Special Projects: Competitive Grants}

The Special Projects activity has been modified to accelerate the transformation of energy markets, based on the technical potential of the competitive grants issued in four sectors: Buildings, Clean Energy, Industry, and Transportation. The market penetration and rates for energy savings per dollar invested were developed initially in Arent et al. 2006, and scaled back to represent the proposed FY08 funding level of $\$ 10$ million. The buildings, clean energy, and transportation sectors were assumed to each receive $\$ 2.8$ million, with the remaining $\$ 1.8$ million going to the industrial sector. The aggregate funding level allocations were assumed to be equivalent to those developed in Arent et al. 2006, with small changes to a few individual subprograms, based on recent market trends. A five-year market acceleration rate has been applied to each of the competitive grant programs to reflect the fact that this activity will accelerate the penetration of policies, financing mechanisms, and competitive loan programs, all used to introduce renewable and energy efficiency technologies into the U.S. market at an accelerated rate.

Buildings. Buildings-sector savings were based on estimated impacts for seven potential deployment activities (Arent et al. 2006): Whole Building Retrofit, Building America Deployment (zero net energy homes), 30\% Above Code in New Commercial Construction, High Performance Building Deployment (Ultra Low Energy Commercial Building Designs), Increase CFL penetration in homes, Advanced Residential Water Heating, and Commercial Lighting High Efficacy Options. Benefits were estimated using Pacific Northwest National Laboratory's BEAMS tool (PNNL 2004). Penetration rates used in BEAMS were based on generic diffusion curves developed from historic energy-efficient building technology market diffusion (PNNL 2004). Generic scalable curves were developed representing an incremental $1 \%$ penetration impact. WIP assumed that it would be responsible for approximately $3 \%$ of the incremental change in market penetration, accelerating the practice in the marketplace by one to five years, depending on current efforts by others.

WIP assumed the following performance parameters for each of the potential buildings-related activities:

- Whole-building retrofits (consumer, corporation, institution): 20\% load reduction in space conditioning, lighting, and water heating

- Building America deployment: 18\% whole-building reduction, increasing to 36\% wholebuilding reduction by 2020 (reaches $50 \%$ by 2030); additional $10 \%$ of building load met by renewables in 2007, increasing to $30 \%$ by 2020 and after (applied to subset of buildings) 
- $30 \%$ above code: $40 \%$ reduction in lighting load, $25 \%$ reduction in space conditioning loads

- High Performance Building deployment: $8 \%$ whole-building reduction, increasing to $36 \%$ whole-building reduction by 2025 (reaches $50 \%$ by 2035 ); additional $10 \%$ of building load met by renewables in 2007, increasing to $30 \%$ by 2025 on (applied to subset of buildings)

- Increase CFL Penetration in Homes: CFLs at 51 lumens/watt; recessed can CFLs at 37 lumens/watt

- Advanced Residential Water Heating: Electric Heat Pump Water Heater with 2.0 Energy Factor (EF), and Gas Condensing Water Heater with $0.80 \mathrm{EF}$

- Commercial High-Efficacy Lighting: Super T-8s at 100 lumens/watt.

Clean Energy. The clean energy-sector analysis addressed SEP's impact on renewable technologies in the electric sector, and the potential market acceleration of SEP's actions regarding the following activities: Renewable Portfolio Standards Assistance, Integrated Resource Planning, Renewable Energy Certificates (REC)/Voluntary Markets, and the Utility Voluntary Energy Program. In the Renewable Portfolio Standards Assistance activity, 10\% of the savings were attributed to SEP, based on the SEP program providing assistance in meeting RPS targets, and adopting new RPS policies based on the levering capabilities of SEP (Arent et al. 2006). In the Integrated Resource Planning (IRP) activity, the SEP program provides assistance to utilities and public utility commissions by implementing IRP. This would include the facilitation of information sharing and technical assistance by the SEP program. Based on SEP's leveraging actions, $10 \%$ of the savings were attributed to SEP (Arent et al. 2006). SEP was assumed to contribute to the REC/Voluntary Markets activity by addressing unresolved issues and barriers, and serving as an information sharing/coordination mechanism for individual states. Again, based on the levering capabilities of SEP, $10 \%$ of the savings were attributed to SEP (Arent et al. 2005). Finally, under the Utility Voluntary Renewable Energy Program, the SEP program was assumed to serve as an educator and information facilitator, which could lead to a greater number of voluntary utility renewable energy commitments. Based on SEP's leveraging capabilities, $10 \%$ of the savings were attributed to SEP (Arent et al. 2006). A fiveyear acceleration was then applied to each activity, which assumes the involvement of the SEP would accelerate the acceptance of the technology or practice within the market by five years.

Industry. WIP developed metrics for the industrial sector based on SEP actions relating to large manufacturing plants, medium-sized manufacturing plants, water/wastewater plants, industrial buildings, and establishing an academic cooperative (Arent et al. 2006). The SEP program would provide assistance to large manufacturing plants with best-practices training, plant-wide assessments, and helping companies match projects with appropriate funding partners. SEP would provide assistance to the water/wastewater industry through education and assessment programs centered on improving pumping efficiency. The medium-sized plants would receive assistance from SEP to implement the Industrial Assessment Center activities and investigate manufacturer-financed modifications. SEP would provide assistance to industrial buildings through best-practices training and efficiency assessments. Finally, the academic cooperative would consist of training new engineers on techniques of implementing best practices and energy efficiency assessments. A five-year acceleration was then applied to each activity, which 
assumes the involvement of the SEP would accelerate the acceptance of the technology or practice by five years.

Transportation. The transportation-sector analysis focused on the impact of the consumer, corporate, and state/local government impacts on reducing petroleum use in the transportation sector (Arent et al. 2006). Within the consumer program, the savings were aggregated to consumer-focused Energy Star transportation programs, a fuel economy guide program, and a $1 \mathrm{MPG}$ increase in personal vehicle market program. The fuel economy guide program focuses on tools and educational services provided to consumers; and the $1 \mathrm{MPG}$ increase in personal vehicle market is based on the reduction in fuel use associated with the U.S. transportation fleet turnover ratio, and a $1 \%$ increase in U.S. fleet fuel economy. The corporate program savings were developed based on aggregate savings associated with the Energy Star voluntary program referenced above, the fleet analysis building from Clean Cities work, and the fleet analysis variation with $15 \%$ savings growth (Arent et al. 2006). The fleet analysis building from Clean Cities work savings was developed from data presented at the 2004 Clean Cities Conference, and the efficiency improvements in the transportation sector associated with this program (Arent et al. 2006). The fleet analysis variation with $15 \%$ savings growth comes from a second initiative issued within the Clean Cities program to increase petroleum savings by $15 \%$ annually at constant funding (Arent et al. 2006). The state and local government program savings were aggregated to the voluntary state adoption of petroleum savings mandates, and an ethanol oxygenation proposed Clean Cities component. The voluntary state adoption of petroleum savings mandates is based on an assumption that one state per year for 25 years will implement a mandate to reduce petroleum use (Arent et al. 2006). The ethanol oxygenation proposed Clean Cities component develops savings based on a Clean Cities analysis regarding a project to encourage states to use ethanol instead of other oxygenates (Arent et al. 2006). The savings for each of these programs was scaled back to the 2008 funding level. A five-year acceleration was then applied to each activity, which assumes the involvement of the SEP would accelerate the acceptance of the technology or practice by five years.

\section{Summary of Inputs}

Table J-7 contains the summary of benefits developed for this activity. 
Table J-7: State Energy Program (SEP) - Summary of Inputs to Models

\begin{tabular}{|c|c|c|c|c|c|c|c|c|c|}
\hline & 2008 & 2009 & 2010 & 2011 & 2012 & 2015 & 2020 & 2025 & 2030 \\
\hline \multicolumn{10}{|l|}{ Site Electric } \\
\hline SEP: Codes & 0.7 & 2.2 & 4.2 & 6.6 & 9.3 & 18.6 & 34.6 & 49.1 & 62.8 \\
\hline SEP: Energy Audits & 3.2 & 6.3 & 9.2 & 12.1 & 14.8 & 22.3 & 32.9 & 35.4 & 32.7 \\
\hline SEP: Rating \& Labeling & 3.7 & 7.7 & 12.0 & 16.3 & 20.8 & 35.0 & 45.9 & 45.9 & 45.9 \\
\hline SEP: Workshops/Training & 0.4 & 0.8 & 1.2 & 1.5 & 1.9 & 2.8 & 4.2 & 4.6 & 4.3 \\
\hline $\begin{array}{l}\text { SEP: Loans, Grants, \& } \\
\text { Incentives }\end{array}$ & 0.7 & 1.4 & 2.1 & 2.9 & 3.6 & 6.2 & 10.5 & 12.1 & 12.1 \\
\hline SEP: Retrofits & 1.0 & 2.0 & 3.0 & 3.9 & 4.8 & 7.2 & 10.7 & 11.6 & 10.9 \\
\hline $\begin{array}{l}\text { SEP: Technical } \\
\text { Assistance }\end{array}$ & 0.1 & 0.2 & 0.3 & 0.5 & 0.6 & 0.9 & 1.3 & 1.4 & 1.3 \\
\hline SEP: Traffic Signals & 0.2 & 0.5 & 0.7 & 1.0 & 1.2 & 2.0 & 3.2 & 3.2 & 3.2 \\
\hline SEP: Tax Credits & 0.0 & 0.0 & 0.0 & 0.0 & 0.0 & 0.0 & 0.1 & 0.1 & 0.1 \\
\hline SEP: Procurement & 0.3 & 0.7 & 1.0 & 1.3 & 1.6 & 2.6 & 4.2 & 4.9 & 4.9 \\
\hline SEP: Renewable Energy & 0.2 & 0.3 & 0.5 & 0.6 & 0.8 & 1.2 & 2.0 & 2.8 & 3.6 \\
\hline SEP: Competitive Grants & 4.1 & 9.4 & 15.4 & 21.9 & 26.0 & 18.7 & 12.8 & 9.4 & 4.8 \\
\hline Total & 14.6 & 31.5 & 49.6 & 68.6 & 85.4 & 117.5 & 162.4 & 180.5 & 186.6 \\
\hline \multicolumn{10}{|l|}{ Natural Gas } \\
\hline SEP: Codes & 0.3 & 0.8 & 1.0 & 1.3 & 1.8 & 3.7 & 6.0 & 8.3 & 11.0 \\
\hline SEP: Energy Audits & 2.4 & 4.7 & 7.1 & 9.4 & 11.7 & 18.4 & 29.2 & 32.7 & 31.5 \\
\hline SEP: Rating \& Labeling & 0.0 & 0.0 & 0.0 & 0.0 & 0.0 & 0.0 & 0.0 & 0.0 & 0.0 \\
\hline SEP: Workshops/Training & 0.4 & 0.8 & 1.2 & 1.7 & 2.1 & 3.3 & 5.2 & 5.9 & 5.7 \\
\hline $\begin{array}{l}\text { SEP: Loans, Grants, \& } \\
\text { Incentives }\end{array}$ & 0.2 & 0.4 & 0.5 & 0.7 & 0.9 & 1.4 & 2.3 & 2.7 & 2.7 \\
\hline SEP: Retrofits & 0.9 & 1.9 & 2.8 & 3.8 & 4.7 & 7.5 & 11.9 & 13.5 & 13.3 \\
\hline $\begin{array}{l}\text { SEP: Technical } \\
\text { Assistance }\end{array}$ & 0.1 & 0.3 & 0.4 & 0.6 & 0.7 & 1.1 & 1.8 & 2.0 & 2.0 \\
\hline SEP: Traffic Signals & 0.0 & 0.0 & 0.0 & 0.0 & 0.0 & 0.0 & 0.0 & 0.0 & 0.0 \\
\hline SEP: Tax Credits & 0.0 & 0.0 & 0.0 & 0.0 & 0.0 & 0.0 & 0.0 & 0.0 & 0.0 \\
\hline SEP: Procurement & 0.1 & 0.2 & 0.3 & 0.4 & 0.5 & 0.8 & 1.3 & 1.4 & 1.4 \\
\hline SEP: Renewable Energy & 0.0 & 0.0 & 0.0 & 0.0 & 0.0 & 0.0 & 0.0 & 0.0 & 0.0 \\
\hline SEP: Competitive Grants & 0.1 & 1.5 & 3.0 & 4.5 & 6.1 & 8.4 & 9.0 & 8.2 & 8.2 \\
\hline Total & 4.5 & 10.6 & 16.3 & 22.4 & 28.5 & 44.6 & 66.7 & 74.7 & 75.8 \\
\hline \multicolumn{10}{|l|}{ Fuel Oil } \\
\hline SEP: Codes & 0.1 & 0.3 & 0.4 & 0.6 & 0.8 & 1.5 & 2.4 & 3.3 & 4.2 \\
\hline SEP: Energy Audits & 0.1 & 0.3 & 0.4 & 0.6 & 0.8 & 1.2 & 1.9 & 2.0 & 1.9 \\
\hline SEP: Rating \& Labeling & 0.0 & 0.0 & 0.0 & 0.0 & 0.0 & 0.0 & 0.0 & 0.0 & 0.0 \\
\hline SEP: Workshops/Training & 0.0 & 0.1 & 0.1 & 0.1 & 0.1 & 0.2 & 0.4 & 0.4 & 0.4 \\
\hline $\begin{array}{l}\text { SEP: Loans, Grants, \& } \\
\text { Incentives }\end{array}$ & 0.0 & 0.1 & 0.1 & 0.1 & 0.2 & 0.3 & 0.4 & 0.5 & 0.5 \\
\hline SEP: Retrofits & 0.1 & 0.2 & 0.3 & 0.3 & 0.4 & 0.6 & 1.0 & 1.0 & 1.0 \\
\hline $\begin{array}{l}\text { SEP: Technical } \\
\text { Assistance }\end{array}$ & 0.0 & 0.0 & 0.0 & 0.1 & 0.1 & 0.1 & 0.1 & 0.2 & 0.2 \\
\hline SEP: Traffic Signals & 0.0 & 0.0 & 0.0 & 0.0 & 0.0 & 0.0 & 0.0 & 0.0 & 0.0 \\
\hline SEP: Tax Credits & 0.0 & 0.0 & 0.0 & 0.0 & 0.0 & 0.0 & 0.0 & 0.0 & 0.0 \\
\hline
\end{tabular}




\begin{tabular}{lrrrrrrrrr}
\hline SEP: Procurement & 0.0 & 0.1 & 0.1 & 0.2 & 0.2 & 0.4 & 0.6 & 0.6 & 0.6 \\
\hline SEP: Renewable Energy & 0.1 & 0.2 & 0.2 & 0.3 & 0.4 & 0.6 & 1.1 & 1.5 & 1.9 \\
\hline SEP: Competitive Grants & 3.8 & 6.0 & 8.9 & 12.0 & 15.4 & 19.4 & 36.9 & 48.9 & 32.0 \\
\hline Total & 4.2 & 7.3 & 10.5 & 14.3 & 18.4 & 24.3 & 44.8 & 58.4 & 42.7 \\
\hline
\end{tabular}

\section{Weatherization Assistance Program Grants}

The U.S. Department of Energy (DOE) Weatherization Assistance Program (WAP) reduces energy costs for low-income households by increasing the energy efficiency of their homes while ensuring their health and safety. DOE provides funding to states, which manage the day-to-day details of the program. Low-income families receive services from a network of more than 900 local weatherization service providers.

The Baseline ("without DOE RD3" case)

WAP provides cost-effective energy efficiency services to low-income households who otherwise could not afford the investment but who would benefit significantly from the cost savings of energy efficiency technologies. Therefore, WIP assumes that no technological improvements would occur in these households in absence of the subprogram.

Target Market Description.

The market includes households that are eligible for Federal assistance, or about 33.8 million households (RECS 2001). Households are categorized as eligible for Federal assistance if the household income is below the Federal maximum standard of $150 \%$ of the poverty line or $60 \%$ of statewide median income, whichever is higher. Individual states can also set the standard at a lower level than the Federal maximum. ${ }^{4}$ Target measures include air sealing; caulking and weather stripping; furnace and boiler tune-up, repair, and replacement; cooling system tune-up and repair; replacement of windows and doors; addition of storm windows and doors; insulation of building shells; and replacement of air conditioners, whole-house fans, evaporative coolers, screening, and window films (Berry et al. 1997). Weatherization Plus expands this strategy to include water heating, refrigeration, lighting, and cooling (Weatherization Plus 1999).

\section{Baseline Adjustments to the AEO2006 Reference Case}

WIP assumed that the $A E O 2006$ Reference Case adequately captured the technological improvements that would occur in the absence of the program. Within the AEO2006 Residential Reference Case, one of the implicit assumptions is that there will be no radical changes in technology or consumer behavior through 2030. Additional assumptions for the residential reference case include: 1) no new efficiency regulations, beyond what is already in law, nor new government efficiency programs; 2) technologies that have not achieved widespread acceptance already will not achieve significant penetration by $2030 ; 3$ ) currently available technologies will evolve in both cost and efficiency; and 4) consumers in the future will behave similarly to current consumer behavior (EIA 2006).

\footnotetext{
${ }^{4}$ Eligibility requirements for Weatherization Assistance can be found at http://www.eere.energy.gov/weatherization/apply.html 


\section{Removing Effects of Program Activities}

As discussed in the previous paragraph, WIP assumed that no program-related impacts are included in the AEO2006 Reference Case; therefore, nothing was removed from the Reference Case to establish the "non-program" baseline.

\section{Other Program-Relevant Adjustments to AEO Reference Case}

No other corrections were made to the AEO2006 Reference Case.

\section{Program Outputs}

In WAP, weatherization services are cost-effective energy efficiency measures for existing residential and multifamily housing with low-income residents. In the early years, WAP focused on low-cost improvements like adding weather stripping to doors and windows to save energy. These measures made up the services provided by weatherization, and are likely responsible for the program's name. For example, DOE's Office of Energy Efficiency and Renewable Energy (EERE) publishes a series of fact sheets about these measures on its Web pages for consumers

Today, WAP includes a wide variety of energy efficiency measures that encompass the building envelope, its heating and cooling systems, its electrical system, and electricity-consuming appliances. In other words, the full range of energy efficiency measures in buildings that apply to all homes and apartment buildings is also included in weatherization technologies.

WAP serves low-income families free of charge and limits according to Federal rules the amount of money that can be spent on any single residence. As a result, only the most cost-effective measures are included in the upgrade of a particular home. This constant pressure for low-cost energy savings has become the trademark of weatherization and distinguishes it from the larger home retrofit industry.

Another distinguishing feature of weatherization is attention to all-around safety check. Many buildings receiving attention are old and need repairs. Weatherization service providers check major energy systems to ensure occupant safety.

Increasingly, weatherization service providers look at the house as a system under the concept of "whole-house weatherization." In recent years, weatherization providers in many states have begun to combine resources from other programs to address other needs of their clients. In recognition that weatherization serves many vital roles in low-income communities, the current multifaceted program is called Weatherization Plus.

\section{Assumed Budget Projections}

WIP assumed level funding of \$144 million throughout the analysis period (2008-2030).

\section{Description of Key Activities}

Weatherization Assistance provides technical assistance and formula grants to state and local weatherization agencies throughout the United States. A network of approximately 970 local agencies provide trained crews to perform weatherization services for eligible low-income households in single-family homes, multifamily dwellings, and mobile homes. All homes receive a comprehensive energy audit, which is a computerized assessment of a home's energy use and 
an analysis of which energy conservation measures are best for the home and a combination of those energy-saving measures are installed.

\section{Weatherization Assistance}

This activity will provide formula grants to states to weatherize low-income homes. Ninety percent of the total WAP funding will be allocated to the states as operating funds for this purpose, i.e., for labor, materials, equipment, administrative systems, etc. Ten percent of the total program funding will be allocated for training and technical assistance, to maintain a high standard of technology application, effectiveness, and results. Most training and technical assistance will be performed at state and local levels.

\section{Training and Technical Assistance}

DOE will fund training and technical assistance activities that can be more cost-effectively performed at national/regional levels, to support effective program operations by the network of state and local weatherization agencies. DOE will conduct analysis, measure and document program performance, and promote (e.g., through pilot programs, publications, training programs, workshops, and peer exchange) the application of advanced techniques and collaborative strategies to continually improve program effectiveness.

\section{Milestones}

From 2001 to 2011 , complete weatherization upgrades for 1.25 million low-income households.

\section{Program Outputs}

The overall WAP goal is to reduce the burden of energy prices on the disadvantaged. For FY 2008, WAP will weatherize 55,000 homes with DOE funds, and support the weatherization of approximately 100,000 additional homes with leveraged funds. While the energy impacts of this program can be measured, the additional benefits accruing to low-income families are not adequately represented by an energy-savings metric alone. For example, low-income families pay a higher percentage of their income on energy expenditures and are more likely to be renters with less control over their energy-expenditure options. The net benefits of making more disposable income available for more productive uses is not included in the WAP benefits assessment. 
Table J-8: WAP Outputs, Activities, and Milestones

\begin{tabular}{|c|c|c|}
\hline Outputs & Associated Activities & Associated Milestones \\
\hline $\begin{array}{l}\text { Reduce the burden of energy } \\
\text { prices for low-income families }\end{array}$ & $\begin{array}{ll}\text { Key activities } \\
\text { 1. Weatherization } \\
\text { Assistance } \\
\text { 2. Training and Technical } \\
\text { Assistance }\end{array}$ & $\begin{array}{l}\text { Weatherize } 54,599 \text { homes } \\
\text { annually with DOE funds and } \\
\text { support the weatherization of } \\
50,000 \text { additional homes with } \\
\text { leveraged funds }\end{array}$ \\
\hline
\end{tabular}

Translating Program Outputs to Market Outcomes

Low-income households spend much more of their income on energy bills than do families with median incomes. This percentage of income spent on energy is called the "energy burden," and it is substantial for some weatherization recipients. For example, some elderly recipients who lived on fixed incomes pay as much as $35 \%$ of their annual incomes for energy bills.

Many weatherization clients are senior citizens, single parents, or disabled people. DOE guidelines for eligibility give preference to homes where one or more family member has a disability. Some statistics about recipients follow:

- $49 \%$ of households receiving weatherization services have one or more family members who have disabilities or are elderly and with special needs.

- $90 \%$ of weatherization clients have incomes less than $\$ 15,000$, and two-thirds earn less than $\$ 8,000$ per year.

Table J-9: Linkage of Outputs with Outcomes

\begin{tabular}{ll}
\hline Outputs & $\begin{array}{l}\text { Associated Ultimate } \\
\text { Outcomes }\end{array}$ \\
\hline Reduce the burden of & $\begin{array}{l}\text { Site Btu savings of 15- } \\
\text { energy prices for low- }\end{array}$ \\
$\begin{array}{l}35 \%, \text { depending on } \\
\text { income families }\end{array}$ & $\begin{array}{l}\text { region and energy } \\
\text { usage }\end{array}$ \\
\hline
\end{tabular}

Key Factors in Shaping Market Adoption of EERE technologies

- Price: WIP employed the average household weatherization cost of \$1,890 (Eisenberg 2001); this estimate does not include training, technical assistance, and administrative costs. Incremental investment beyond this amount for Weatherization Plus homes was estimated at an average of $\$ 1,400$ by the Weatherization Project (Eisenberg 2001). Average costs are based on legislative caps and historical costs for each region. WIP assumed that this amount will be provided by leveraging funds from other organizations.

Table J-10 shows the estimated total costs by region for Plus homes.

Table J-10: Estimated Regional Costs for Weatherization Plus Homes

\begin{tabular}{ll}
\hline Region & $\begin{array}{l}\text { Cost per "Plus" } \\
\text { Household }\end{array}$ \\
\hline South & $\$ 2,861$ \\
\hline Northeast & $\$ 3,674$ \\
\hline West & $\$ 1,814$ \\
\hline Midwest & $\$ 3,429$ \\
\hline
\end{tabular}




\section{Final Outcomes (Benefits)}

WAP was characterized based on an estimated level of savings per household, cost to weatherize each household, budget request, leveraged funds, and an assumed life expectancy of 15 years for weatherization measures. The basic assumptions were derived from a spreadsheet provided by the Weatherization Project in September 2001 (Eisenberg 2001). The EERE-integrated models calculate effects such as reductions in carbon emissions and energy intensity.

Table $\mathbf{J}-11$ shows the savings per household used for each region.

\section{Table J-11: Savings Per Household for the Weatherization Assistance Project (Regular and "Plus" Programs)}

\begin{tabular}{lrr}
\hline Region & $\begin{array}{r}\text { Regular Household } \\
\text { Savings (MMBtu/yr) }\end{array}$ & $\begin{array}{r}\text { "Plus" Household } \\
\text { Savings (MMBtu/yr) }\end{array}$ \\
\hline South & 22.25 & 24.23 \\
\hline Northeast & 31.20 & 46.04 \\
\hline West & 19.04 & 20.31 \\
\hline Midwest & 31.20 & 49.21 \\
\hline
\end{tabular}

The figures in the table were calculated based on the 1997 ORNL meta-evaluation report (Berry et al. 1997), the ORNL Meeting the Challenge report (Schweitzer and Eisenberg 2000), and special tabulations from the 1997 "Residential Energy Consumption Survey" (Eisenberg 2001b). The regional differences in savings between regular and Plus households are due largely to the greater savings potential within colder climate housing. Because WAP measures require a savings-to-investment ratio of 1 or greater, the higher cost of energy combined with the higher energy intensity per household in the Northeast and Midwest provide more cost-effective savings opportunities for additional dollar investments. This tends not to be the case in the Western and Southern regions.

Of the units estimated to be weatherized in FY 2008, WIP assumed that 50\% would have the higher savings rates associated with Weatherization Plus (Schweitzer and Eisenberg 2000). In Schweitzer and Eisenberg 2003, these savings rates were calculated on a regional basis and multiplied by the expected number of Plus households in each region.

To develop energy savings by building type, WIP evaluated historical Weatherization Project data (Berry et al. 1997) concerning the types of households weatherized (see Table J-12). 
Table J-12: Percent of Weatherized Households by Type

\begin{tabular}{ll}
\hline Household Type & $\begin{array}{l}\text { \% of Weatherized } \\
\text { Households }\end{array}$ \\
\hline Single-Family & $64 \%$ \\
\hline Mobile Home & $20 \%$ \\
\hline Multifamily & $16 \%$ \\
\hline
\end{tabular}

To develop energy savings by fuel type, WIP used historical data regarding the primary fuels used in households weatherized, as reported in the 1996 meta-evaluation (Berry et al 1997). Because the GPRA metrics are reported for electricity, natural gas, and fuel oil (but not for LPG and kerosene), other fuels were allocated within those types based on similarities of emissions. Table $\mathbf{J}-13$ shows the allocation approaches used.

Table J-13: Percent of Weatherized Households by Fuel Type

\begin{tabular}{lll}
\hline Primary Heating Fuel & $\begin{array}{l}\text { \% of Weatherized } \\
\text { Households }\end{array}$ & Categorized as \\
\hline Natural Gas & $50.6 \%$ & Natural Gas \\
Liquid Propane Gas & $13.2 \%$ & \\
\hline Fuel Oil & $16.0 \%$ & Fuel Oil \\
Kerosene & $3.2 \%$ & \\
Other (includes wood and coal) & $7.5 \%$ & \\
\hline Electricity & $9.5 \%$ & Electricity \\
\hline
\end{tabular}

The DOE budget and historical data on regional splits and leveraged funding were used to determine the number of households weatherized in each category (regular or Plus) for each of the four regions (South, Northeast, West, and Midwest). The target for FY 2008 funding is to weatherize nearly 55,000 households with DOE funds. This target was segregated into regions based on historical regional splits contained in Eisenberg 2001, which divided the total as shown in Table J-14.

Table J-14: Average projection of households by category

\begin{tabular}{lr}
\hline Category and Region & $\begin{array}{r}\text { \% of Total } \\
\text { Households }\end{array}$ \\
\hline Regular South & $10.2 \%$ \\
\hline Regular Northeast & $12.1 \%$ \\
\hline Regular West & $12.1 \%$ \\
\hline Regular Midwest & $15.6 \%$ \\
\hline Plus South & $10.2 \%$ \\
\hline Plus Northeast & $12.1 \%$ \\
\hline Plus West & $12.1 \%$ \\
\hline Plus Midwest & $15.6 \%$ \\
\hline
\end{tabular}

Previous benefits estimates for WAP have included benefits that resulted from leveraged funding. For the FY 2008 GPRA analysis, only a portion of leverage-funded household savings was included in the analysis. To calculate an appropriate proportion of leveraged households to which savings should be attributed to DOE, WIP only included savings to leveraged households 
where the states indicated that "blended" funding was used in FY 2003 to weatherize

households. Blended funding means that funds from other sources are pooled with DOE funds to produce a completely weatherized home (as opposed to "unduplicated," meaning that the state can track production to a specific funding source). Using blended vs. unduplicated data, the number of leveraged households reported in "blended" states represented approximately $30 \%$ of the implied total number of households weatherized using leveraged funds, ${ }^{5}$ approximately 26,000 out of 89,000 households (U.S. DOE 2004). WIP assumed that 26,000 additional households would be weatherized each year with leveraged funds that could be attributed to DOE

Table J-15 shows the projection for regular and Plus households to be weatherized. WIP assumed that the number of households weatherized for each category would be constant from 2012 through 2030.

Table J-15: Projected Regular and Plus Households to be Weatherized

\begin{tabular}{lrrrrr}
\hline & $\mathbf{2 0 0 8}$ & $\mathbf{2 0 0 9}$ & $\mathbf{2 0 1 0}$ & $\mathbf{2 0 1 1}$ & $\mathbf{2 0 1 2 - 2 0 3 0}$ \\
\hline Total Households & 81,000 & 81,000 & 81,000 & 81,000 & 81,000 \\
\hline Regular South & 8,281 & 8,281 & 8,281 & 8,281 & 8,281 \\
\hline Regular Northeast & 9,778 & 9,778 & 9,778 & 9,778 & 9,778 \\
\hline Regular West & 9,827 & 9,827 & 9,827 & 9,827 & 9,827 \\
\hline Regular Midwest & 12,614 & 12,614 & 12,614 & 12,614 & 12,614 \\
\hline Plus South & 8,281 & 8,281 & 8,281 & 8,281 & 8,281 \\
\hline Plus Northeast & 9,778 & 9,778 & 9,778 & 9,778 & 9,778 \\
\hline Plus West & 9,827 & 9,827 & 9,827 & 9,827 & 9,827 \\
\hline Plus Midwest & 12,614 & 12,614 & 12,614 & 12,614 & 12,614 \\
\hline
\end{tabular}

The number of households in each category was multiplied by the estimated savings level for each category. The estimated savings level for each household category was further divided by household type and then by fuel type. WIP assumed that savings from each household weatherized would last for 15 years; i.e., savings from households weatherized in 2008 were included in the annual total savings estimates for 2008 through 2022.

\section{Summary of Inputs}

Table J-16 contains the summary of benefits developed for this activity. The chapters on midterm and long-term benefits analysis describe how these inputs are utilized within the NEMS-GPRA08 and MARKAL-GPRA08 models.

\footnotetext{
${ }^{5}$ Total weatherized households and total DOE weatherized households were reported in the survey; WIP assumed that the difference equaled the number of leveraged households.
} 
Table J-16: Weatherization Assistance Program (WAP) - Summary of Inputs to Models

\begin{tabular}{lrrrrrrr}
\hline Year & $\begin{array}{r}\text { Average } \\
\text { Cost per } \\
\text { Household }\end{array}$ & $\begin{array}{r}\text { Annual No. } \\
\text { Households } \\
\text { Weatherized }\end{array}$ & $\begin{array}{r}\text { Households } \\
\text { Saving } \\
\text { Energy in } \\
\text { Year }\end{array}$ & $\begin{array}{r}\text { Energy } \\
\text { Savings } \\
\text { (site } \\
\text { TBtu) }\end{array}$ & $\begin{array}{r}\text { Single } \\
\text { Family } \\
\text { Household } \\
\text { Savings } \\
\text { (site TBtu) }\end{array}$ & $\begin{array}{r}\text { Mobile } \\
\text { Home } \\
\text { Household } \\
\text { Savings } \\
\text { (site TBtu) }\end{array}$ & $\begin{array}{r}\text { Multi } \\
\text { Fousehold } \\
\text { Savings } \\
\text { (site TBtu) }\end{array}$ \\
\hline 2008 & $\$ 2,433$ & 81,000 & 81,000 & 2.56 & 1.64 & 0.51 & 0.41 \\
\hline 2009 & $\$ 2,447$ & 81,000 & 162,000 & 5.12 & 3.28 & 1.02 & 0.82 \\
\hline 2010 & $\$ 2,462$ & 81,000 & 243,000 & 7.69 & 4.92 & 1.54 & 1.23 \\
\hline 2011 & $\$ 2,476$ & 81,000 & 324,000 & 10.25 & 6.56 & 2.05 & 1.64 \\
\hline 2012 & $\$ 2,476$ & 81,000 & 405,000 & 12.81 & 8.20 & 2.56 & 2.05 \\
\hline 2013 & $\$ 2,476$ & 81,000 & 486,000 & 15.37 & 9.84 & 3.07 & 2.46 \\
\hline 2014 & $\$ 2,476$ & 81,000 & 567,000 & 17.94 & 11.48 & 3.59 & 2.87 \\
\hline 2015 & $\$ 2,476$ & 81,000 & 648,000 & 20.50 & 13.12 & 4.10 & 3.28 \\
\hline 2016 & $\$ 2,476$ & 81,000 & 729,000 & 23.06 & 14.76 & 4.61 & 3.69 \\
\hline 2017 & $\$ 2,476$ & 81,000 & 810,000 & 25.62 & 16.40 & 5.12 & 4.10 \\
\hline 2018 & $\$ 2,476$ & 81,000 & 891,000 & 28.18 & 18.04 & 5.64 & 4.51 \\
\hline 2019 & $\$ 2,476$ & 81,000 & 972,000 & 30.75 & 19.68 & 6.15 & 4.92 \\
\hline 2020 & $\$ 2,476$ & 81,000 & $1,053,000$ & 33.31 & 21.32 & 6.66 & 5.33 \\
\hline 2021 & $\$ 2,476$ & 81,000 & $1,134,000$ & 35.87 & 22.96 & 7.17 & 5.74 \\
\hline 2022 & $\$ 2,476$ & 81,000 & $1,215,000$ & 38.43 & 24.60 & 7.69 & 6.15 \\
\hline 2023 & $\$ 2,476$ & 81,000 & $1,215,000$ & 38.43 & 24.60 & 7.69 & 6.15 \\
\hline 2024 & $\$ 2,476$ & 81,000 & $1,215,000$ & 38.43 & 24.60 & 7.69 & 6.15 \\
\hline 2025 & $\$ 2,476$ & 81,000 & $1,215,000$ & 38.43 & 24.60 & 7.69 & 6.15 \\
\hline 2026 & $\$ 2,476$ & 81,000 & $1,215,000$ & 38.43 & 24.60 & 7.69 & 6.15 \\
\hline 2027 & $\$ 2,476$ & 81,000 & $1,215,000$ & 38.43 & 24.60 & 7.69 & 6.15 \\
\hline 2028 & $\$ 2,476$ & 81,000 & $1,215,000$ & 38.43 & 24.60 & 7.69 & 6.15 \\
\hline 2029 & $\$ 2,476$ & 81,000 & $1,215,000$ & 38.43 & 24.60 & 7.69 & 6.15 \\
\hline 2030 & $\$ 2,476$ & 81,000 & $1,215,000$ & 38.43 & 24.60 & 7.69 & 6.15 \\
\hline
\end{tabular}

\section{Tribal Energy Program (TEP)}

The Tribal Energy Program offers financial and technical assistance to American Indian tribes to help them create sustainable renewable energy installations on their lands. This program promotes tribal energy self-sufficiency and fosters employment and economic development on America's tribal lands.

The Baseline ("without DOE RD3" case)

The Tribal Energy Program builds partnerships with tribal governments to help assess American Indian energy needs for residential, commercial, and industrial uses. Additionally, it provides technical and financial assistance in energy efficiency and renewable energy project development. Energy projects are competitively awarded on a cost-shared basis for Indian tribes to implement comprehensive energy plans. Therefore, WIP assumes that no technological improvements would occur on tribal lands in absence of the program.

Target Market Description.

In May 2000, the department issued a report, "Energy Consumption and Renewable Energy Development Potential on Indian Lands," which determined that, "Household energy availability 
and use on Tribal Lands is significantly below that of non-Indian households. In fact, sizable tribal populations have no access to electricity at all." From FY 1996 through FY 2001, the Renewable Tribal Energy Resources Program funding had been earmarked solely for the benefit of Alaska natives. The TEP attempts to address the needs of those American Indians residing in the lower 48 states, as well as Alaska natives, as reflected in the joint DOE/ Bureau of Land Management's assessment of the renewable resource potential of public lands (DOE/DOI 2003).

\section{Baseline Adjustments to the AE02006 Reference Case}

The AEO2006 Reference Case includes renewable energy generation and consumption by sector and source; however, the basis for these improvements is not specified by the EIA. For FY08 GPRA, WIP did not suggest the removal of any program-related impacts that might be included in the AEO2006 Reference Case.

\section{Representation of Program-Relevant Technologies in the AEO Reference Case}

There is no documented evidence that the Tribal Energy Program has any measurable effect on the renewable energy portion of the AEO2006 reference case.

\section{Removing Effects of Program Activities}

The AEO2006 Reference Case includes renewable energy generation and consumption by sector and source; however, the basis for these improvements is not specified by the EIA. For FY08 GPRA, WIP did not suggest the removal of any program-related impacts that might be included in the $A E O 2006$ Reference Case.

\section{Other Program-Relevant Adjustments to AEO Reference Case}

No other changes were made to the AEO2006 Reference Case.

\section{Program Outputs}

The stated goal of the program is to promote tribal energy sufficiency, economic development, and employment on tribal lands through the use of renewable energy and energy efficiency technologies. As such, a measurement of the energy impacts of the TEP does not adequately represent the full scope of the benefits of this program.

The TEP offers financial and technical assistance to tribes through government-to-government partnerships that:

1) Allow tribal leaders to make informed decisions;

2) Bring renewable energy and energy efficiency options to Indian lands;

3) Enhance human capacity through education and training;

4) Improve local tribal economies and the environment; and

5) Make a difference in the quality of life of American Indians.

The program seeks to increase development of renewable energy supply. The assessment of renewable resource potential (DOE/DOI 2003) informed the planning of the Tribal Energy Program. The program will proceed with central-station development of wind resources, followed by biomass resources. Biomass was found to show the most potential for central-station development on tribal lands. Therefore, biomass power would reach parity with wind in terms of capacity additions by 2012 and exceeds wind capacity after 2012 . 


\section{Assumed Budget Projections}

WIP assumed level funding of $\$ 2,957,000$ throughout the analysis period.

\section{Description of Key Activities}

The Tribal Energy Program supports cooperative agreements and builds partnerships with tribal governments to foster information exchange, and technical and financial assistance projects.

These activities are intended to promote understanding and acceptance of energy efficiency and renewable energy technologies and to foster stronger public-private partnerships to expand domestic and overseas markets for U.S. manufacturers to these technologies.

The Tribal Energy Program provides financial and technical assistance to tribes for strategic planning, energy options analysis, organizational development, capacity building, feasibility studies, and cost-shared development of sustainable renewable energy on tribal lands. These activities promote tribal energy self-sufficiency and foster employment and economic development on tribal lands.

The DOE policy related to American Indian and Alaska Native tribal governments is designed to ensure an effective implementation of a government-to-government relationship with American Indian and Alaska Native tribal governments. Through the authorities set forth in the Energy Policy Act (EPAct) and subsequent executive orders, DOE is seeking to foster energy selfsufficiency on tribal lands and be responsive to the aforementioned policy.

The Tribal Energy Program supports the development of capacity within the 565-plus Federally recognized Native American tribes and Alaskan Native corporations to meet their energy needs for residential and productive uses; provides, where appropriate, new power supplies for export; and advances the Department's technology performance and integration efforts. Tribal leaders are provided resource assessment services, workshops, training, and energy-plan development assistance toward making decisions regarding the tribes' energy future. Through competitively selected projects, tribes will begin implementing energy plans to assist tribal members in using renewable energy technologies and resources.

\section{Milestones}

The Tribal Energy Program goal is to develop $100 \mathrm{MW}$ of renewable electrical capacity on tribal lands by 2012 and electrification of 10,000 currently nonelectrified tribal households (TEP 2004, 2005, 2006).

\section{Program Outputs}

The Tribal Energy Program offers assistance for renewable energy feasibility studies and shares the cost of renewable energy projects on tribal lands. The program also offers assistance to tribes for the initial steps toward developing renewable energy and energy efficiency projects, including strategic planning, energy options analysis, human capacity building, and organizational development planning. 
Table J-17: Program Outputs, Activities, and Milestones

\begin{tabular}{|c|c|c|}
\hline Outputs & Associated Activities & Associated Milestones \\
\hline \multirow{2}{*}{$\begin{array}{l}\text { Assistance to tribes for feasibility } \\
\text { studies, strategic planning, } \\
\text { energy options analysis, human } \\
\text { capacity building, and } \\
\text { organizational development }\end{array}$} & \multirow[t]{2}{*}{$\begin{array}{ll}\text { Key activities } \\
\text { 1. } & \text { Feasibility studies } \\
\text { 2. } & \text { Strategic planning } \\
\text { 3. } & \text { Energy options analysis }\end{array}$} & $\begin{array}{l}\text { Complete sufficient number of } \\
\text { key activities by } 2012 \text { to achieve } \\
\text { the outcome of } 100 \mathrm{MW} \text { of new } \\
\text { renewable electric capacity }\end{array}$ \\
\hline & & $\begin{array}{l}\text { Complete sufficient number of } \\
\text { key activities by } 2012 \text { to achieve } \\
\text { the outcome of electrifying } \\
10,000 \text { households }\end{array}$ \\
\hline
\end{tabular}

\section{Translating Program Outputs to Market Outcomes}

In many cases, the DOE funds are leveraged with other sources such as tribal, state, other Federal, and local grants. The basis for this attribution is that, were DOE not leading this activity, these development projects would never occur. WIP did not analyze whether success of this program would eventually lead to the private-sector involvement in developing the new renewables capacity on tribal lands in later years, but such an outcome would be possible under the right pricing conditions.

Table J-18: Linkage of Outputs with Outcomes

\begin{tabular}{ll}
\hline Outputs & $\begin{array}{l}\text { Associated Ultimate } \\
\text { Outcomes }\end{array}$ \\
\hline $\begin{array}{ll}\text { Assistance to tribes for } \\
\text { feasibility studies, }\end{array}$ & $\begin{array}{l}\text { Reduction in carbon } \\
\text { emissions and oil }\end{array}$ \\
$\begin{array}{l}\text { strategic planning, } \\
\text { energy options analysis, } \\
\text { human capacity building, }\end{array}$ & $\begin{array}{l}\text { Impreased comfort of } \\
\text { and organizational members } \\
\text { development }\end{array}$ \\
\end{tabular}

\section{Key Factors in Shaping Market Adoption of EERE technologies}

- Price: WIP assumed the cost of leased solar arrays and battery storage of electricity to be less than the consumer costs of extending electrical transmission from the nearest electrical utility. For central-station development, WIP assumed the electricity resource produced from renewable resources would cost less than utility-supplied electricity provided to the immediate tribal land with jurisdiction.

- Non-price factors (only those that might affect what gets bought)

○ Key consumer preferences/values: This program seeks to establish electrical service for households currently without electricity on tribal lands. This is not a comparison of alternative electrical services or of using renewable fuels to provide electrical service, but rather a characterization of providing electrical service where none currently exists, using fuels and facilities that are within the control of tribal organizations.

- Manufacturing factors: Based on program materials and TEP Web site documents (TEP 2004, 2005, 2006), most current activities are focused on development of wind resources. EIA (2000) suggests that biopower provides the greatest potential 
for central-station power at competitive prices on tribal lands; therefore, WIP assumed that an even mix of technology will develop, eventually shifting to a majority of biopower development by 2028 .

- Community factors: Community development would include electrification strategies for the reservation. Central-station facilities on tribal lands utilizing renewable fuels may generate value streams from off-reservation utility interests.

\section{Final Outcomes (Benefits)}

To permit analysis of program success, WIP made several enabling assumptions in consultation with the Tribal Energy Program:

- Achieving the program goal of $100 \mathrm{MW}$ in new electric capacity from renewable energy on tribal lands by 2012 would represent approximately $20 \%$ of the total potential capacity, or $500 \mathrm{MW}$.

- Current development efforts are almost all wind projects. The EIA report suggests that biopower provides the greatest potential for central-station power at competitive prices (EIA 2000). Therefore, we assume that an even mix of technology will develop by 2012, and eventually biopower capacity will exceed wind.

- New biopower plants would operate at a capacity factor of $83 \%$, and wind would operate at a capacity factor of $37 \%$, on average (EIA 2006).

- For solar electrification, materials (EIA 2000) indicate that approximately 25,000 reservation households are without electricity access. The Navajo reservation accounts for the largest percentage of these households, and the EIA report indicates that photovoltaic (PV) rooftop modules may be a feasible way to provide electricity to these and other tribal households in the Southwest. For this analysis, the assumed target was electrification of 10,000 households by 2028 .

- WIP assumed a capacity factor of $20 \%$ for new PV systems deployed in the Southwest, and the default system was assumed to be $0.6 \mathrm{~kW}$ based on an average of currently installed PV units on tribal lands (TEP 2006).

These interim outcomes were provided to the EERE-integrating models for their calculation of final outcomes such as reductions in carbon emissions and energy intensity. The chapters on midterm and long-term benefits analysis describe how these inputs are utilized within the NEMS-GPRA08 and MARKAL-GPRA08 models. 


\section{Summary of Inputs}

Table J-19: Development of Tribal Renewable Energy Capacity Resulting from FY 2008 Budget Assumptions

\begin{tabular}{|c|c|c|c|c|c|c|c|c|c|c|c|c|c|c|c|}
\hline \multirow[b]{2}{*}{ Year } & \multirow{2}{*}{$\begin{array}{c}\text { Fraction of } \\
\text { Potential }\end{array}$} & \multirow{2}{*}{\begin{tabular}{|c|} 
MW \\
capacity \\
(cummulative)
\end{tabular}} & \multirow{2}{*}{$\begin{array}{l}\text { Added } \\
\text { MW }\end{array}$} & \multicolumn{2}{|c|}{ Share Assumptions } & \multicolumn{3}{|c|}{ Added MW } & \multicolumn{2}{|c|}{ Cummulative MW } & \multicolumn{2}{|c|}{ Capacity factor } & \multirow{2}{*}{$\begin{array}{c}\text { Wind } \\
\text { MWh }\end{array}$} & \multirow{2}{*}{$\begin{array}{c}\text { Biomass } \\
\mathrm{MWh}\end{array}$} & \multirow{2}{*}{\begin{tabular}{|c|} 
Total Service \\
$\mathrm{MWh}$ \\
\end{tabular}} \\
\hline & & & & \begin{tabular}{c|} 
Wind \\
Fraction
\end{tabular} & $\begin{array}{l}\text { Biomass } \\
\text { Fraction }\end{array}$ & Wind & Biomass & Total & Wind & Biomass & Wind & Biomass & & & \\
\hline 2008 & 0.020 & \begin{tabular}{|r|}
10 \\
\end{tabular} & 4 & 1.00 & 0.00 & 4 & 0 & 4 & 10 & 0 & 0.370 & 0.830 & 32,412 & 0 & 32,412 \\
\hline 2009 & 0.037 & 19 & 9 & 0.95 & 0.05 & 9 & 0 & 9 & 19 & 0 & 0.370 & 0.830 & 60,124 & 3,272 & 63,396 \\
\hline 2010 & 0.067 & 34 & 15 & 0.95 & 0.05 & 14 & 1 & 15 & 33 & 1 & 0.440 & 0.830 & 126,424 & 8,725 & 135,149 \\
\hline 2011 & 0.118 & 59 & 25 & 0.95 & 0.05 & 24 & 1 & 25 & 57 & 2 & 0.440 & 0.830 & 217,966 & 17,813 & 235,780 \\
\hline 2012 & 0.200 & 100 & 41 & 0.50 & 0.50 & 21 & 21 & 41 & 77 & 23 & 0.440 & 0.830 & 296,982 & 166,865 & 463,846 \\
\hline 2013 & 0.319 & 160 & 60 & 0.50 & 0.50 & 30 & 30 & 60 & 107 & 53 & 0.440 & 0.830 & 412,614 & 384,989 & 797,602 \\
\hline 2014 & 0.468 & 234 & 74 & 0.50 & 0.50 & 37 & 37 & 74 & 144 & 90 & 0.440 & 0.830 & 555,226 & 654,008 & $1,209,235$ \\
\hline 2015 & 0.622 & 311 & 77 & 0.50 & 0.50 & 39 & 39 & 77 & 183 & 128 & 0.440 & 0.830 & 703,621 & 933,934 & $1,637,555$ \\
\hline 2016 & 0.755 & 378 & 67 & 0.50 & 0.50 & 34 & 34 & 67 & 216 & 162 & 0.440 & 0.830 & 832,743 & $1,177,506$ & $2,010,249$ \\
\hline 2017 & 0.852 & 426 & 48 & 0.50 & 0.50 & 24 & 24 & 48 & 240 & 186 & 0.440 & 0.830 & 925,249 & $1,352,005$ & $2,277,254$ \\
\hline 2018 & 0.900 & 450 & 24 & 0.25 & 0.75 & 6 & 18 & 24 & 246 & 204 & 0.440 & 0.830 & 948,375 & $1,482,880$ & $2,431,255$ \\
\hline 2019 & 0.911 & 456 & 6 & 0.25 & 0.75 & 2 & 5 & 6 & 248 & 208 & 0.440 & 0.830 & 954,157 & $1,515,598$ & $2,469,755$ \\
\hline 2020 & 0.922 & 461 & 5 & 0.25 & 0.75 & 1 & 4 & 5 & 249 & 212 & 0.460 & 0.830 & $1,002,564$ & $1,542,864$ & $2,545,428$ \\
\hline 2021 & 0.933 & 467 & 6 & 0.25 & 0.75 & 2 & 5 & 6 & 250 & 217 & 0.460 & 0.830 & $1,008,609$ & $1,575,582$ & $2,584,191$ \\
\hline 2022 & 0.944 & 472 & 5 & 0.25 & 0.75 & 1 & 4 & 5 & 252 & 220 & 0.460 & 0.830 & $1,013,646$ & $1,602,848$ & $2,616,494$ \\
\hline 2023 & 0.956 & 478 & 6 & 0.25 & 0.75 & 2 & 5 & 6 & 253 & 225 & 0.460 & 0.830 & $1,019,690$ & $1,635,566$ & $2,655,257$ \\
\hline 2024 & 0.967 & 483 & 5 & 0.25 & 0.75 & 1 & 4 & 5 & 254 & 229 & 0.460 & 0.830 & $1,024,727$ & $1,662,832$ & $2,687,559$ \\
\hline 2025 & 0.978 & 489 & 6 & 0.25 & 0.75 & 2 & 5 & 6 & 256 & 233 & 0.460 & 0.830 & $1,030,772$ & $1,695,551$ & $2,726,322$ \\
\hline 2026 & 0.989 & 494 & 5 & 0.25 & 0.75 & 1 & 4 & 5 & 257 & 237 & 0.460 & 0.830 & $1,035,809$ & $1,722,816$ & $2,758,625$ \\
\hline 2027 & 1.000 & 500 & 6 & 0.25 & 0.75 & 2 & 5 & 6 & 259 & 241 & 0.460 & 0.830 & $1,041,853$ & $1,755,535$ & $2,797,388$ \\
\hline
\end{tabular}


Table J-20: Development of Off-Grid Solar PV Capacity Resulting from FY2008 Budget Assumptions

\begin{tabular}{lrrr}
\hline Year & $\begin{array}{l}\text { Cumulative } \\
\text { Households }\end{array}$ & \multicolumn{1}{l}{ MW } \\
Capacity & \multicolumn{1}{l}{ MWH } \\
\hline 2008 & 110 & 0.07 & 125 \\
\hline 2009 & 200 & 0.13 & 228 \\
\hline 2010 & 370 & 0.24 & 421 \\
\hline 2011 & 670 & 0.44 & 763 \\
\hline 2021 & 1,180 & 0.77 & 1,344 \\
\hline 2013 & 2,000 & 1.30 & 2,278 \\
\hline 2014 & 3,190 & 2.07 & 3,633 \\
\hline 2015 & 4,680 & 3.04 & 5,330 \\
\hline 2016 & 6,220 & 4.04 & 7,083 \\
\hline 2017 & 7,550 & 4.91 & 8,598 \\
\hline 2018 & 8,520 & 5.54 & 9,703 \\
\hline 2019 & 9,000 & 5.85 & 10,249 \\
\hline 2020 & 9,111 & 5.92 & 10,376 \\
\hline 2021 & 9,222 & 5.99 & 10,502 \\
\hline 2022 & 9,333 & 6.07 & 10,629 \\
\hline 2023 & 9,444 & 6.14 & 10,755 \\
\hline 2024 & 9,556 & 6.21 & 10,882 \\
\hline 2025 & 9,667 & 6.28 & 11,008 \\
\hline 2026 & 9,778 & 6.36 & 11,135 \\
\hline 2027 & 9,889 & 6.43 & 11,261 \\
\hline 2028 & 10,000 & 6.50 & 11,388 \\
\hline & & & \\
\hline
\end{tabular}

\section{Renewable Energy Production Incentive}

The Renewable Energy Production Incentive (REPI) is part of an integrated strategy in the Energy Policy Act of 1992 to promote increases in the generation and utilization of electricity from renewable energy sources and to further the advances of renewable energy technologies. This program, authorized under section 1212 of the Energy Policy Act of 1992, provides financial incentive payments for electricity produced and sold by new qualifying renewable energy-generation facilities. Eligible electric production facilities are those owned by state and local government entities (such as municipal utilities) and not-for-profit electric cooperatives that started operations between October 1, 1993, and September 30, 2003. Qualifying facilities are eligible for annual incentive payments of 1.5 cents per kilowatt-hour (1993 dollars and indexed for inflation) for the first 10-year period of their operation, subject to the availability of annual appropriations in each Federal fiscal year of operation. Criteria for qualifying facilities and application procedures are contained in the rulemaking for this program. Qualifying facilities must use solar, wind, geothermal (with certain restrictions as contained in the rulemaking), or biomass (except for municipal solid waste combustion) generation technologies.

The Baseline ("without DOE RD3" case)

The Renewable Energy Production Incentive (REPI) Subprogram provides incentive payments to qualified renewable energy facilities. These incentive payments are subject to availability of appropriations and are determined by the type and total quantity of electric energy that is 
generated and sold from facilities that apply for the incentive. Therefore, WIP assumes that renewable energy production would neither increase nor decrease in the absence of the program.

\section{Target Market Description.}

The market includes qualified renewable energy facilities. A qualified renewable energy facility is a facility that is owned by a not-for-profit electric cooperative, a public utility, a state, commonwealth, territory, or possession of the United States, or District of Columbia, or a political subdivision thereof, an Indian tribal government or a subdivision thereof, ${ }^{6}$ or a Native Corporation, ${ }^{7}$ and which generates electric energy for sale in, or affecting, interstate commerce using solar, wind, biomass, landfill gas, livestock methane, ocean, ${ }^{8}$ or geothermal.

Sixty percent of the funds appropriated for the fiscal year are paid to facilities that use solar, wind, ocean, geothermal, or closed-loop biomass technologies to generate electricity, while $40 \%$ of the funds are appropriated to the remaining project types of landfill, livestock methane, and open loop biomass (REPI 2005).

\section{Baseline Adjustments to the AEO2006 Reference Case}

The AEO2006 Reference Case includes renewable energy generation and consumption by sector and source; however, the basis for these improvements is not specified by the EIA. For GPRA08, WIP did not suggest the removal of any program-related impacts that might be included in the AEO2006 Reference Case.

\section{Representation of Program-Relevant Technologies in the AEO Reference Case}

It is observed that REPI has no measurable effect on the renewable energy portion of the AEO2006 reference case.

\section{Removing Effects of Program Activities}

It is observed that REPI has no measurable effect on the renewable energy portion of the AEO2006 reference case.

\section{Other Program-Relevant Adjustments to AEO Reference Case}

No other corrections were made to the AEO2006 Reference Case.

\section{Program Outputs}

REPI was reauthorized by the Energy Policy Act of 2005 until the end of FY2026. A qualified renewable energy facility may receive payments under this section for a 10 -year period. Such a period shall begin with the fiscal year in which electricity generated from the facility is first eligible for such payments, or in which the Secretary of Energy determines that all necessary Federal and state authorizations have been obtained for the construction of the facility.

In general, incentive payments made by the secretary under this section to the owner or operator of any qualified renewable energy facility shall be based on the number of kilowatt hours of electricity generated by the facility through the use of solar, wind, biomass, landfill gas, livestock methane, ocean (including tidal, wave, current, and thermal), or geothermal energy during the

\footnotetext{
${ }^{6}$ New qualified renewable energy facility generator, EPAct 2005.

${ }^{7}$ New qualified renewable energy facility generator, EPAct 2005.

${ }^{8}$ New qualified technology, EPAct 2005. Ocean technologies include production from tidal, wave, current, and thermal energies. 
payment period. REPI payments are based on an annual 1.5 cents per kilowatt-hour $(\mathrm{kWh})$ rate (1993 dollars and indexed for inflation).

In past years, not all of the energy generation from qualified facilities received an incentive. They receive a portion of what they are qualified to receive. Table $\mathbf{J - 2 1}$ identifies the historical electric production and reimbursement for production.

Table J-21: REPI Appropriations Summary

\begin{tabular}{|c|c|c|c|c|c|c|c|c|}
\hline $\begin{array}{l}\text { Year of } \\
\text { Production } \\
\text { (FY) }\end{array}$ & $\begin{array}{l}\text { Year of } \\
\text { Payment } \\
\text { (FY) }\end{array}$ & $\begin{array}{l}\text { Appropriated } \\
\text { Funds }\end{array}$ & $\begin{array}{l}\text { Tier } 1 \\
\text { Paid }^{(9)}\end{array}$ & $\begin{array}{l}\text { Tier } 1 \\
\text { Unpaid }\end{array}$ & $\begin{array}{l}\% \\
\text { Tier } \\
1 \\
\text { Paid }\end{array}$ & $\begin{array}{l}\text { Tier } 2 \\
\text { Paid }^{(10)}\end{array}$ & $\begin{array}{l}\text { Tier } 2 \\
\text { Unpaid }\end{array}$ & $\begin{array}{l}\% \\
\text { Tier } \\
2 \\
\text { Paid }\end{array}$ \\
\hline 1994 & 1995 & $\$ 693,120$ & $\$ 100,725$ & - & $100 \%$ & $\$ 592,395$ & - & $100 \%$ \\
\hline 1995 & 1996 & $\$ 2,398,472$ & $\$ 218,604$ & - & $100 \%$ & $\$ 2,178,217$ & - & $100 \%$ \\
\hline 1996 & 1997 & $\$ 2,490,893$ & $\$ 195,902$ & - & $100 \%$ & $\$ 2,294,991$ & $\$ 347,038$ & $87 \%$ \\
\hline 1997 & 1998 & $\$ 2,853,997$ & $\$ 154,504$ & - & $100 \%$ & $\$ 2,699,493$ & $\$ 6,519,682$ & $29 \%$ \\
\hline 1998 & 1999 & $\$ 4,000,000$ & $\$ 122,167$ & - & $100 \%$ & $\$ 3,877,833$ & $\$ 9,747,420$ & $28 \%$ \\
\hline 1999 & 2000 & $\$ 1,500,000$ & $\$ 603,182$ & - & $100 \%$ & $\$ 896,818$ & $\$ 15,664,879$ & $5 \%$ \\
\hline 2000 & 2001 & $\$ 3,991,000$ & $\$ 1,339,377$ & - & $100 \%$ & $\$ 2,651,625$ & $\$ 24,755,332$ & $10 \%$ \\
\hline 2001 & 2002 & $\$ 3,787,000$ & $\$ 1,365,846$ & - & $100 \%$ & $\$ 2,421,154$ & $\$ 33,679,732$ & $7 \%$ \\
\hline 2002 & 2003 & $\$ 4,815,033$ & $\$ 1,810,911$ & - & $100 \%$ & $\$ 3,004,122$ & $\$ 40,211,074$ & $7 \%$ \\
\hline 2003 & 2004 & $\$ 3,714,911$ & $\$ 3,714,911$ & $\$ 1,091,206$ & $77 \%$ & - & $\$ 58,145,027$ & $0 \%$ \\
\hline 2004 & 2005 & $\$ 4,960,000$ & $\$ 4,960,000$ & $\$ 2,205,009$ & $69 \%$ & - & $\$ 43,393,560$ & $0 \%$ \\
\hline
\end{tabular}

Table J-22 identifies the reimbursed and projected reimbursable amounts of electric energy production from REPI qualified facilities (REPI 2006).

\footnotetext{
${ }^{9}$ Sixty percent of the funds appropriated for the fiscal year are paid to facilities that use solar, wind, ocean, geothermal, or closedloop biomass technologies to generate electricity (Tier 1).

${ }^{10}$ Forty percent of the funds are appropriated to the project types of landfill, livestock methane, and open loop biomass (Tier 2).
} 
Table J-22: Historical and Calculated REPI Reimbursed Energy (kWh)

\begin{tabular}{|c|c|c|c|}
\hline Year & $\begin{array}{l}\text { Appropriated } \\
\text { Funds }\end{array}$ & $\begin{array}{l}\text { Incentive } \\
\text { per kWh }\end{array}$ & $\begin{array}{l}\text { Calculated Electric } \\
\text { Production Net kWh }\end{array}$ \\
\hline 1993 & & $\$ 0.015$ & \\
\hline 1994 & $\$ 693,120$ & $\$ 0.015$ & $45,246,571$ \\
\hline 1995 & $\$ 2,398,472$ & $\$ 0.016$ & $153,419,858$ \\
\hline 1996 & $\$ 2,490,893$ & $\$ 0.016$ & $156,362,717$ \\
\hline 1997 & $\$ 2,853,997$ & $\$ 0.016$ & $176,232,769$ \\
\hline 1998 & $\$ 4,000,000$ & $\$ 0.016$ & $244,296,795$ \\
\hline 1999 & $\$ 1,500,000$ & $\$ 0.017$ & $90,306,430$ \\
\hline 2000 & $\$ 3,991,000$ & $\$ 0.017$ & $235,155,041$ \\
\hline 2001 & $\$ 3,787,000$ & $\$ 0.017$ & $217,973,477$ \\
\hline 2002 & $\$ 4,815,033$ & $\$ 0.018$ & $272,974,795$ \\
\hline 2003 & $\$ 3,714,911$ & $\$ 0.018$ & $207,140,568$ \\
\hline 2004 & $\$ 4,960,000$ & $\$ 0.018$ & $272,085,553$ \\
\hline 2005 & $\$ 4,856,000$ & $\$ 0.019$ & $262,134,103$ \\
\hline 2006 & $\$ 4,946,000$ & $\$ 0.019$ & $262,803,036$ \\
\hline 2007 & $\$ 4,960,000$ & $\$ 0.019$ & $259,475,467$ \\
\hline 2008 & $\$ 4,960,000$ & $\$ 0.019$ & $255,527,899$ \\
\hline 2009 & $\$ 4,960,000$ & $\$ 0.020$ & $251,698,645$ \\
\hline 2010 & $\$ 4,960,000$ & $\$ 0.020$ & $247,982,464$ \\
\hline 2011 & $\$ 4,960,000$ & $\$ 0.020$ & $244,374,421$ \\
\hline 2012 & $\$ 4,960,000$ & $\$ 0.021$ & $240,869,863$ \\
\hline 2013 & $\$ 4,960,000$ & $\$ 0.021$ & $237,464,401$ \\
\hline 2014 & $\$ 4,960,000$ & $\$ 0.021$ & $234,153,891$ \\
\hline 2015 & $\$ 4,960,000$ & $\$ 0.023$ & $218,377,141$ \\
\hline 2016 & $\$ 4,960,000$ & $\$ 0.023$ & $213,443,498$ \\
\hline 2017 & $\$ 4,960,000$ & $\$ 0.023$ & $215,670,928$ \\
\hline 2018 & $\$ 4,960,000$ & $\$ 0.024$ & $203,087,254$ \\
\hline 2019 & $\$ 4,960,000$ & $\$ 0.025$ & $197,980,282$ \\
\hline 2020 & $\$ 4,960,000$ & $\$ 0.026$ & $193,011,129$ \\
\hline 2021 & $\$ 4,960,000$ & $\$ 0.026$ & $188,285,313$ \\
\hline 2022 & $\$ 4,960,000$ & $\$ 0.027$ & $183,683,294$ \\
\hline 2023 & $\$ 4,960,000$ & $\$ 0.028$ & $179,203,700$ \\
\hline 2024 & $\$ 4,960,000$ & $\$ 0.028$ & $175,029,995$ \\
\hline 2025 & $\$ 4,960,000$ & $\$ 0.029$ & $170,957,846$ \\
\hline 2026 & $\$ 4,960,000$ & $\$ 0.030$ & $167,070,870$ \\
\hline
\end{tabular}

The REPI goal has been met each year as shown by Table J-22. Assuming a constant funding level and a steady GDP estimated inflation rates (OMB), the amount of electricity that is paid as an incentive will decrease. However, the subprogram assumes electricity generation continues to increase based on historical data and other market factors.

\section{Assumed Budget Projections}

WIP assumed level funding of $\$ 4,960,000$ throughout the analysis period.

\section{Description of Key Activities}

The REPI Subprogram provides monetary incentives to qualified renewable energy facilities. 


\section{Milestones}

From 2008 to 2026, applications for the incentive must be received between October 1 and December 31 for production credit for the previous fiscal year.

\section{Program Outputs}

The REPI program offers a production incentive. REPI strives to promote increases in generation and utilization of electricity from renewable energy sources and further advances of renewable energy technologies through a production incentive that pays an appropriated amount of money for electricity generated in the previous fiscal year. Because of the goals to diversify the energy market and spur renewable energy, it is difficult to quantify the benefits of this subprogram based on energy savings alone.

Table J-23: Program Outputs, Activities, and Milestones

\begin{tabular}{|c|c|c|}
\hline Outputs & Associated Activities & Associated Milestones \\
\hline $\begin{array}{l}\text { Incentive payments for } \\
\text { renewable electricity generated } \\
\text { in prior fiscal year. }\end{array}$ & $\begin{array}{l}\text { Key activities } \\
\text { 1. Process applications and } \\
\text { conduct other activities } \\
\text { needed to provide } \\
\text { incentive payments. }\end{array}$ & $\begin{array}{l}\text { Incentive payments annually } \\
\text { through } 2026 \text {, the end of the } \\
\text { reauthorization period }\end{array}$ \\
\hline
\end{tabular}

Translating Program Outputs to Market Outcomes

There was no direct outcome identified that removed REPI from marketplace growth and technology advancement.

Table J-24: Linkage of Outputs with Outcomes

\begin{tabular}{llll}
\hline Outputs & $\begin{array}{l}\text { Associated Immediate } \\
\text { Outcomes and Dates }\end{array}$ & $\begin{array}{l}\text { Associated Interim } \\
\text { Outcomes }\end{array}$ & $\begin{array}{l}\text { Associated Ultimate } \\
\text { Outcomes }\end{array}$ \\
\hline Incentive payments for & None & Increases in the & Environmental and \\
renewable electricity & & $\begin{array}{l}\text { generation and } \\
\text { utilization of electricity } \\
\text { generated in prior fiscal }\end{array}$ & $\begin{array}{l}\text { economic benefits and } \\
\text { other effects. }\end{array}$ \\
year & & $\begin{array}{l}\text { sources and further } \\
\text { advances of renewable }\end{array}$ & \\
& & energy technologies. & \\
& &
\end{tabular}

Key Factors in Shaping Market Adoption of EERE technologies

- Price: The REPI Subprogram is not cost-sensitive to the renewable energy technologies for which incentives are provided. Because of the constant dollar fund appropriation coupled with the inflation index, fewer projects will be funded in the future. Competition for available funds must be a factor in the future.

- There are no non-price factors identified.

Final Outcomes (Benefits)

Four studies were evaluated to asses the relationship between renewable energy trends and the REPI program. WIP evaluated the observable market applicability, geographical mix of generation resources, economic growth, and green pricing in order to identify increases in the generation and utilization of electricity from renewable energy sources based solely on REPI. 
Market applicability research attempted to identify studies, reports, or literature that specifically explained the relationship between decisions to build and operate qualified renewable energy facilities and REPI. While utilities acknowledge REPI as a possible vehicle to decrease costs, their more overwhelming concern is that the uncertainty of REPI's funding and appropriations may reduce its value.

The geographic generation study compared the total electricity generation applied for REPI and EIA's estimate of total U.S. renewable energy generation by region and type of generation (EIA 2005).

The growth and green pricing study attempted to identify any growth and green pricing trends that may be attributable to REPI, resulting in new renewable energy generation. An NREL study was reviewed for a relationship between green pricing and application for REPI, with little correlation found (APPA 2005). Although public utilities' renewable energy production has increased in the past few years, there was no observable evidence that REPI was responsible for this.

After completing the four studies to assess the casual relationship between renewable energy trends and the REPI program, WIP could not attribute an incremental market transformation benefit above and beyond the actual REPI project benefits.

\section{Summary of Inputs}

WIP did not provide to the integrated benefits models any energy benefit input resulting from REPI. 


\section{Bibliography}

Abraham, M. and J. MacDonald, 1995. Energy and Conservation Opportunities in Small Commercial Buildings, ORNL/CON-414, Oak Ridge National Laboratory, Oak Ridge, Tenn., August.

American Public Power Association (APPA). Fall 2005. Public Power: Generating Greener Communities. Accessed at http://www.appanet.org/files/PDFs/GenGreenComm.pdf American Wind Energy Association, The Economics of Wind Energy, March 2002 Accessed at http://www.awea.org/pubs/factsheets/EconomicsofWind-March2002.pdf

Anderson, S. and N. Richard, 2002. Information Programs for Technology Adoption: The Case of Energy Efficiency Audits, Recourses of the Future, Discussion Paper 02-58

Arent, D.; Benioff, R.; Mosey, G.; Bird, L.; Brown, J.; Brown, E.; Vimmerstedt, L.; Aabakken, J.; Parks, K.; Lapsa, M.; Davis, S.; Olszewski, M.; Cox, D.; McElhaney, K.; Hadley, S.; Hostick, D.; Nicholls, A.; McDonald, S.; Holloman, B. 2006. (Arent et al. 2006). Energy Sector Market Analysis. NREL Report No. TP-620-40541.

Berry, L.G., M.A. Brown, and L.F. Kinney. 1997. Progress Report of the National Weatherization Assistance Program, ORNL/CON-450, Oak Ridge National Laboratory, Oak Ridge, Tenn.

Brown, M.A., L.G. Bery, R.A. Balzer, and E. Faby. 1993. National Impacts of the Weatherization Assistance Program in Single-Family and Small Multifamily Dwellings. ORNL/CON-326, Oak Ridge National Laboratory, Oak Ridge, Tennessee.

Coates, B., 1995. "Persistence of Energy Savings in Commercial Buildings," 1995 Energy Program Evaluation Conference, 649-655, Chicago, Ill.

Commercial Buildings Energy Consumption Survey (CBECS). 1999. U.S. Department of Energy, Energy Information Administration.

Demesne. 2006. Appliance Life Expectancy, How Long Should an Appliance Last? Accessed at http://www.demesne.info/Home-Maintenance/Appliance-Life-Expectancy.htm

DOE/DOI (2003). Assessing the Potential for Renewable Energy on Public Lands, joint report from the Bureau of Land Management and the National Renewable Energy Laboratory, DOE/GO-102003-1704, February 2003.

DOE's Office of Energy Efficiency and Renewable Energy: Weatherization \& Intergovernmental Program. 2006. Renewable Energy Production Incentive (REPI). Accessed at http://www.eere.energy.gov/wip/program/repi.html 
Eisenberg, J.F., Oak Ridge National Laboratory. 2001. (Eisenberg 2001). Projections for the Weatherization Assistance Program, provided to the WIP program in file

"Projections02d230.xls."

Eisenberg, J.F., Oak Ridge National Laboratory. 2001. (Eisenberg 2001b). Special tabulations for the Weatherization Population derived from the 1997 Residential Energy Consumption Survey.

Elliott, D.B.; D.M. Anderson; D.B. Belzer; K.A. Cort; J.A. Dirks; D.J. Hostick. June 2004 (PNNL 2004). Methodological Framework for Analysis of Buildings-Related Programs: The GPRA Metrics Effort. PNNL-14697. Pacific Northwest National Laboratory, Richland, Wash.

Energy Design Update (Energy Design Update 2003). "Energy Star Tackles Existing Homes," Energy Design Update, Volume 23, No. 8, August 2003.

Energy Information Administration (EIA). 2000. Energy Consumption and Renewable Energy Development Potential on Indian Lands, SR/CNEAF/2000-01, available online at: http://www.eia.doe.gov/cneaf/solar.renewables/ilands/ilands_sum.html

Energy Information Administration (EIA). August 2005. Renewable Energy Trends 2004. Tables 15 and 18. Renewable Electric Power Sector Net Generation by Energy Source and State, 2002 and 2003. Accessed at http://www.eia.doe.gov/cneaf/solar.renewables/page/trends/table 15.xls and http://www.eia.doe.gov/cneaf/solar.renewables/page/trends/table_18.xls

Energy Information Administration (EIA). March 2006. Assumptions to the Annual Energy Outlook 2006. DOE/EIA-0554(2006).

Energy Information Administration (EIA). December 2006. Energy Prices by Sector and Source. DOE/EIA- 0383(2007)

Feldman, S. and B. Tannenbaum, 2000. "Swoosh!? Awareness and Effects of the Energy Star Brand in Wisconsin Appliance Efficiency Programs," ACEEE Summer Study 2000, 6.107-119, American Council for an Energy-Efficient Economy, Washington, D.C.

Greely, K., J. Harris, and A. Hatcher, 1990. "Measured Energy Savings and Cost-Effectiveness of Conservation Retrofits in Commercial Buildings," ACEEE 1990 Summer Study on Energy Efficiency in Buildings, American Council for an Energy-Efficient Economy, Washington, D.C.

LEDTRONICS, INC, Type-1 LED Traffic Light Bulbs. Accessed at http://www.ledtronics.com/ds/136d/default.asp

Lew, V. and J. Wang, 1998. "Do Completed Projects Result in Energy Savings?" ACEEE Summer Study 1998, 4.237-248. American Council for an Energy Efficient Economy, Washington, D.C. 
McClain, H., S. Leigh, and J. McDonald, 1994. Analysis of Savings Due to Multiple Energy Retrofits in a Large Office Building, ORNL/CON-363, Oak Ridge National Laboratory, Oak Ridge, Tenn, May.

Office of Management and Budget (OMB). Table 10.1-Gross Domestic Product and Deflators Used in the Historical Tables. Provided by Dan Beckley 4/28/2006.

http://www.whitehouse.gov/omb/budget/fy2007/sheets/hist10z1.xls

Peters, J.S. and M.R. McRae, 2001. Market Progress Evaluation Report, Architecture + Energy Program, Final Report, Report \#E01-084, Northwest Energy Efficiency Allowance, Portland, Oregon, June.

Reed, J.M., M. O’Drain, and J. Chace, 1999. "Transforming Markets Through Educational Information: A Study of the Pacific Energy Center," 1999 International Energy Program Evaluation Conference, Denver, CO, August 18-20.

REPI. 42 USCS $\S 13317$ (2005). Renewable energy production incentive. Accessed at http://www.eere.energy.gov/wip/pdfs/repi2005code.pdf

Residential Energy Consumption Survey (RECS). 2001. U.S. Department of Energy, Energy Information Administration.

Schweitzer, M. and J.F. Eisenberg. 2000. Meeting The Challenge: The Prospect of Achieving 30 Percent Energy Savings Through the Weatherization Assistance Program. ORNL/CON 479, Oak Ridge National Laboratory, Oak Ridge, Tennessee.

Schweitzer, M. and B. Tonn. 2005. (ORNL 2005). An Evaluation of State Energy Program Accomplishments: 2002 Program Year, prepared by Oak Ridge National Laboratory for the U.S. Department of Energy, Office of the Weatherization and Intergovernmental Program, ORNL/CON-492

Sachs, H., S. Nadel, J. Thorne Amann, M. Tuazon, E. Mendelsohn, L. Rainer, G. Todesco, D. Shipley, and M. Adelaar. Emerging Energy Saving Technologies and Practices for the Buildings Sector as of 2004. October 2004. ACEEE, Report Number A042.

Tools of Change, 2004. Whitney Public School Case Study, www.toolsofchange.com

Tribal Energy Program. FY 2004 Peer Review Meeting, Roadmap and Metrics presentation, available online at http://www.eere.energy.gov/tribalenergy/pdfs/7_road_map_metrics.pdf

Tribal Energy Program. DOE's Tribal Energy Program, Program Review, October 17, 2005. Available at http://www.eere.energy.gov/tribalenergy/pdfs/0510review tep.pdf

Tribal Energy Program. Personal communication (5/15/2006) with Thom Sacco, Native American and International Programs, Office of Weatherization and Intergovernmental Programs. 
U.S. Department of Energy, Weatherization Assistance Program. 2004 (U.S. DOE 2004). Funding Survey for Program Year 2003. Prepared by National Association for State Community Services Programs, Washington, D.C.

Weatherization Plus: Opportunities for the $21^{\text {st }}$ Century. April 1999. Millennium Committee Strategy Report accessed at http://www.eere.energy.gov/weatherization/pdfs/mcsr.pdf 


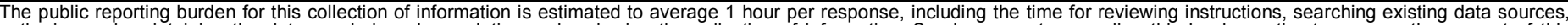

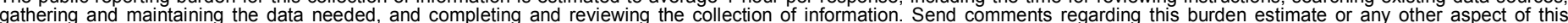

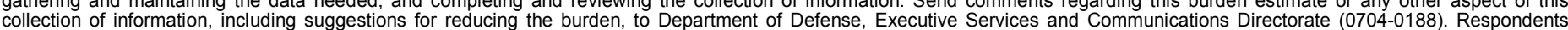

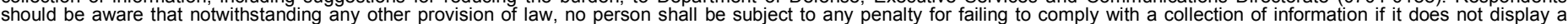

should be aware that notwithstanding

PLEASE DO NOT RETURN YOUR FORM TO THE ABOVE ORGANIZATION.

\begin{tabular}{l|l|l|l} 
1. REPORT DATE $(D D-M M-Y Y Y Y)$ & 2. REPORT TYPE & 3. DATES COVERED (FrOm - TO)
\end{tabular}

March 2007

Technical Report

4. TITLE AND SUBTITLE

Projected Benefits of Federal Energy Efficiency and Renewable

Energy Programs - FY 2008 Budget Request

5a. CONTRACT NUMBER

DE-AC36-99-G010337

5b. GRANT NUMBER

5c. PROGRAM ELEMENT NUMBER

6. AUTHOR(S)

John Sheehan, Compiler

5d. PROJECT NUMBER

NREL/TP-640-41347

5e. TASK NUMBER

SA07.2300

5f. WORK UNIT NUMBER
7. PERFORMING ORGANIZATION NAME(S) AND ADDRESS(ES)

National Renewable Energy Laboratory

1617 Cole Blvd.

Golden, CO 80401-3393
8. PERFORMING ORGANIZATION REPORT NUMBER

NREL/TP-640-41347

9. SPONSORING/MONITORING AGENCY NAME(S) AND ADDRESS(ES)

10. SPONSOR/MONITOR'S ACRONYM(S)

NREL

11. SPONSORING/MONITORING AGENCY REPORT NUMBER

12. DISTRIBUTION AVAILABILITY STATEMENT

National Technical Information Service

U.S. Department of Commerce

5285 Port Royal Road

Springfield, VA 22161

13. SUPPLEMENTARY NOTES

14. ABSTRACT (Maximum 200 Words)

This document summarizes the results of the benefits analysis of EERE's programs, as described in the FY 2008

Budget Request. EERE estimates benefits for its overall portfolio and for each of its nine Research, Development, Demonstration, and Deployment (RD3) programs. Benefits for the FY 2008 budget request are estimated for the midterm (2008-2030) and long term (2030-2050).

15. SUBJECT TERMS

Government Performance and Results Act; GPRA 08; benefits estimates; portfolio benefits; program benefits; benefits analysis; biomass program; building technologies program; distributed energy resources program; federal energy management program; hydrogen, fuel cells, and infrastructure technologies program; industrial technologies program; solar energy technologies program; vehicle technologies program; weatherization and intergovernmental program; wind and hydropower technologies program.

\begin{tabular}{|c|c|c|c|c|}
\hline \multicolumn{3}{|c|}{ 16. SECURITY CLASSIFICATION OF: } & \multirow{2}{*}{$\begin{array}{l}\text { 17. LIMITATION } \\
\text { OF ABSTRACT } \\
\text { UL }\end{array}$} & \multirow{2}{*}{$\begin{array}{ll}\text { 18. } & \text { NUMBER } \\
\text { OF PAGES }\end{array}$} \\
\hline $\begin{array}{l}\text { a. REPORT } \\
\text { Unclassified }\end{array}$ & $\begin{array}{l}\text { b. ABSTRACT } \\
\text { Unclassified }\end{array}$ & $\begin{array}{l}\text { c. THIS PAGE } \\
\text { Unclassified }\end{array}$ & & \\
\hline
\end{tabular}

19a. NAME OF RESPONSIBLE PERSON

19b. TELEPHONE NUMBER (Include area code) 


\section{A Strong Energy Portfolio for a Strong America}

Energy efficiency and clean, renewable energy will mean a stronger economy, a cleaner environment, and greater energy independence for America. Working with a wide array of state, community, industry, and university partners, the U.S. Department of Energy's Office of Energy Efficiency and Renewable Energy invests in a diverse portfolio of energy technologies.

For more information or to order additional copies contact EERE Information Center 1-877-EERE-INF (1-877-337-3463) eereic@ee.doe.gov 